$140+120+79$ FASTREACTOR

ANL-7583

$-12-69$

$1 / 26$

ANL-7583

unclass

thahe 1217169

Argonne Rational Laboratom

A CONCEPTUAL DESIGN STUDY OF A

FLUORIDE-VOLATILITY PLANT

FOR REPROCESSING LMFBR FUELS 


\section{DISCLAIMER}

This report was prepared as an account of work sponsored by an agency of the United States Government. Neither the United States Government nor any agency Thereof, nor any of their employees, makes any warranty, express or implied, or assumes any legal liability or responsibility for the accuracy, completeness, or usefulness of any information, apparatus, product, or process disclosed, or represents that its use would not infringe privately owned rights. Reference herein to any specific commercial product, process, or service by trade name, trademark, manufacturer, or otherwise does not necessarily constitute or imply its endorsement, recommendation, or favoring by the United States Government or any agency thereof. The views and opinions of authors expressed herein do not necessarily state or reflect those of the United States Government or any agency thereof. 


\section{DISCLAIMER}

Portions of this document may be illegible in electronic image products. Images are produced from the best available original document. 
The facilities of Argonne National Laboratory are owned by the United States Government. Under the terms of a contract (W-31-109-Eng-38) between the U. S. Atomic Energy Commission, Argonne Universities Association and The University of Chicago, the University employs the staff and operates the Laboratory in accordance with policies and programs formulated, approved and reviewed by the Association.

\section{MEMBERS OF ARGONNE UNIVERSITIES ASSOCIATION}

The University of Arizona Carnegie-Mellon University Case Western Reserve University The University of Chicago University of Cincinnati Illinois Institute of Technology University of Illinois Indiana University Iowa State University The University of Iowa
Kansas State University The University of Kansas Loyola University Marquette University Michigan State University The University of Michigan University of Minnesota University of Missouri Northwestern University University of Notre Dame
The Ohio State University

Ohio University

The Pennsylvania State University

Purdue University

Saint Louis University

Southern Illinois University

University of Texas

Washington University

Wayne State University

The University of Wisconsin

\section{LEGAL NOTICE}

This report was prepared as an account of Government sponsored work. Neither the United States, nor the Commission, nor any person acting on behalf of the Commission:

A. Makes any warranty or representation, expressed or implied, with respect to the accuracy, completeness, or usefulness of the information contained in this report, or that the use of any information, apparatus, method, or process disclosed in this report may not infringe privately owned rights; or

B. Assumes any liabilities with respect to the use of, or for damages resulting from the use of any information, apparatus, method, or process disclosed in this report.

As used in the above, "person acting on behalf of the Commission" includes any employee or contractor of the Commission, or employee of such contractor, to the extent that such employee or contractor of the Commission, or employee of such contractor prepares, disseminates, or provides access to, any information pursuant to his employment or contract with the Commission, or his employment with such contractor.

Printed in the United States of America Available from

Clearinghouse for Federal Scientific and Technical Information

National Bureau of Standards, U. S. Department of Commerce

Springfield, Virginia 22151

Price: Printed Copy $\$ 3.00 ;$ Microfiche $\$ 0.65$ 


\section{ARGONNE NATIONAL LABORATORY}

9700 South Cass Avenue

Argonne, Illinois 60439

\section{A CONCEPTUAL DESIGN STUDY OF A \\ FLUORIDE-VOLATILITY PLANT FOR REPROCESSING LMFBR FUELS}

\section{Fluoride Volatility Section Staff}

Norman M. Levitz, Study Coordinator

\section{Contributors}

Louis J. Anastasia

Erwin L. Carls

Albert A. Chilenskas

Johan A. E. Graae

Albert A. Jonke

Robert W. Kessie
Robert P. Larsen

William J. Mecham

Devabhaktuni Ramaswami

Martin J. Steindler

G. John Vogel

Chemical Engineering Division 


\section{THIS PAGE}

\section{WAS INTENTIONALLY \\ LEFT BLANK}


TABLE OF CONTENTS

Pa:ge

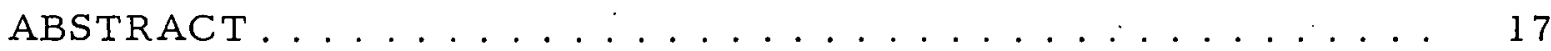

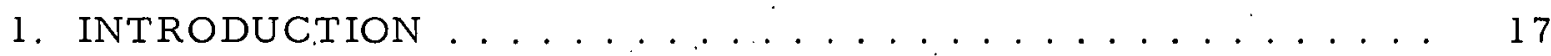

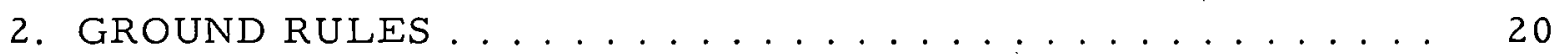

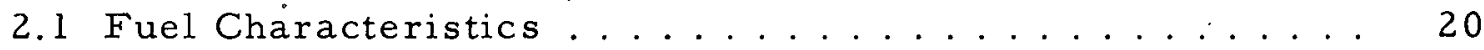

2.2 Conceptual Process . . . . . . . . . . . . . . 20

2.3 Reference Fuel Elements ................. 21

2.4 Reference Fuel Load ................... 23

2.5 Isotopic Distribution of Heavy Elements in FBR Fuel. . . . 25

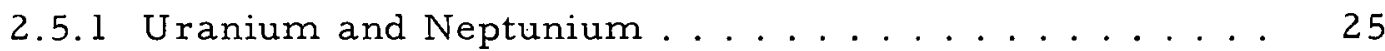

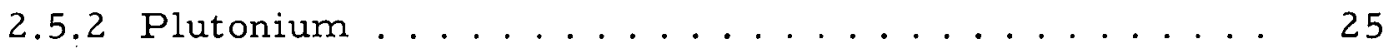

3. DESCRIPTION OF REFERENCE PROCESS. . . . . . . . . 27

3.1 Mechanical Head-end .................. 27

3.2 Storage and Pneumatic Conveying of Fuel Powder . . . . . 30

3.3 Recovery of Uranium--Operation of Reactor A . . . . . . . 32

3.4 Recovery of Plutonium--Operation of Reactor B . . . . . . 37

3.5 Plutonium Purification and Separation from $\mathrm{UF}_{6} \ldots \ldots 38$

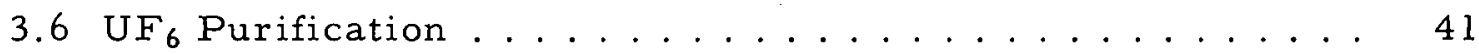

3.7 Conversion of Hexafluorides to Oxides. . . . . . . . . . . 43

3.8 Off-gas Treatment...................... 44

4. DESIGN BASIS AND ANALYSIS OF REFERENCE PROCESS. . . 47

4.1 General Considerations. . . . . . . . . . . . . 47

4.1 .1 Continuous and Batch Operation. ......... 47

4.1 .2 Design of Processing Vessels ........... 48

4.1.2.1 Fluorinator Design............. 48

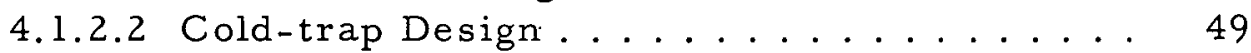

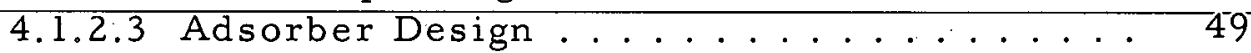

4.1 .3 Process Instrumentation. . . . ......... 50 
TABLE OF CONTENTS

Page

4.2 Head-end Process ....................... 51

4.2.1 Chief Features of Head-end Process......... 51

4.2.2 Engineering Design of Equipment in Head-end

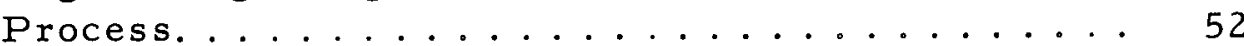

4.2.2.1 General Design Considerations and State of the Art................... 52

4.2.2.2 Ball Mill for Mechanical Decladding ..... 53

4.2.2.3 Alternative Concept for Mechanical

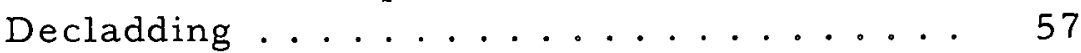

4.2.2.4 Fuel-powder Storage System ......... 59

4.2.3 Instrumentation for Head-end Process ........66 61

4.2.4 Physical and Chemical Bases of Head-end Process. . 61

4.2.4.1 Separation of Oxide Fuel from Cladding.... 61

4.2.4.2 Sizing of Fuel Particles in Head-end Process ................ 63

4.2.4.3 Release of Fission-product Gases....... 63

4.2.4.4 Transport and Monitoring of Fuel and Solids Flow ................... 63

4.2.4.5 Handling Sodium-logged Fuel ........ 64

4.2 .5 Head-end Process Wastes............ 65

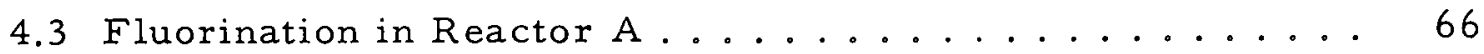

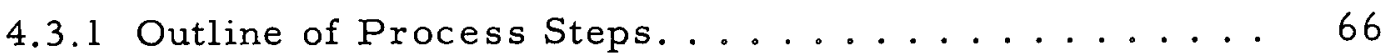

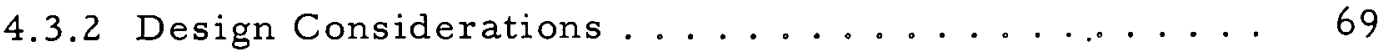

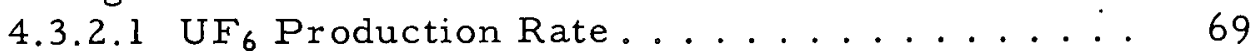

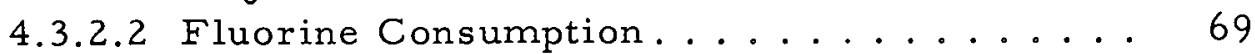

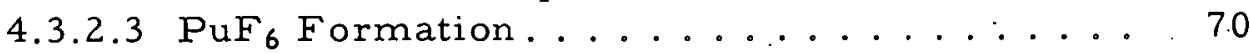

4.3.2.4 Heat Load................... 70

4.3.3 Description and Mechanical Features of Reactor A . . 70

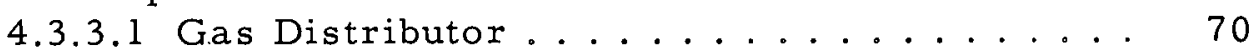

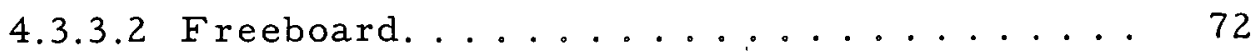

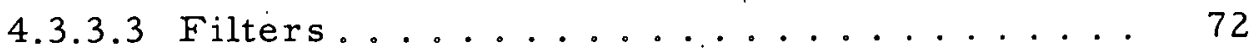

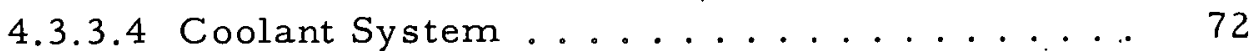

4.3.3.5 Design of Reactor Wall ............ 73

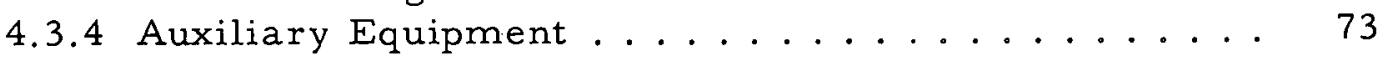

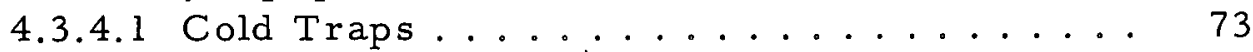

4.3.4.2 Gas-circulating Compressors........ 75

4.3.4.3 Pneumatic Conveyors ........... 75

4.3.4.4 Conveyor for Oxide Fuel and Alumina .... 75

4.3 .5 Process Instrumentation. .............. 76

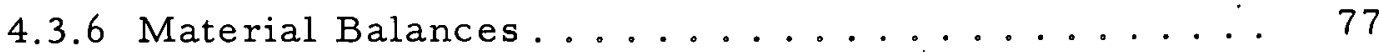

4.3.7 Normal and Abnormal Operations.......... 78 
TABLE OF CONTENTS

Page

4.3.8 Description of Physical and Chemical Processes in

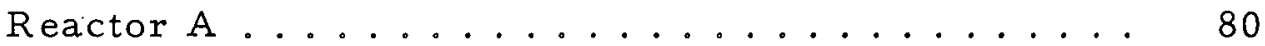

4.3.8.1 Fluorination Reactions .......... 82

4.3.8.2 Removal of Fission Products from $\mathrm{UF}_{6}$ Stream in FP-1............... 85

4.3.8.3 Condensation of Fluorides in CT-1 .... 89

4.3 .9 Solid Waste Streams ................ 92

4.4 . Fluorination of Plutonium in Reactor B . . . . . . . . 96

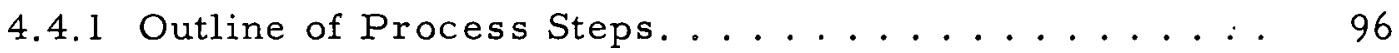

4.4.2 Design Considerations for Reactor $B$ and Associated

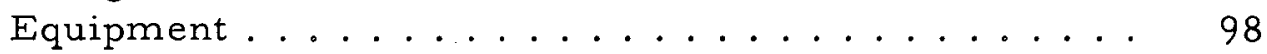

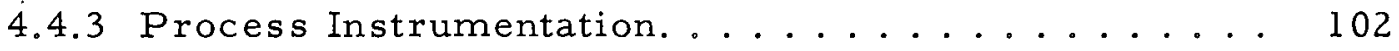

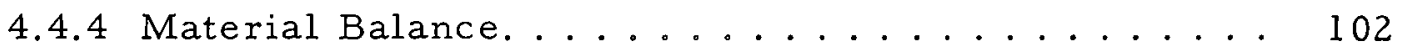

4.4.5 Description of Physical and Chemical Processes in

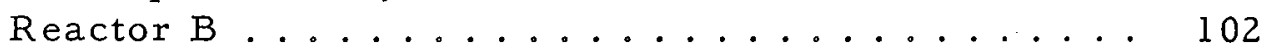

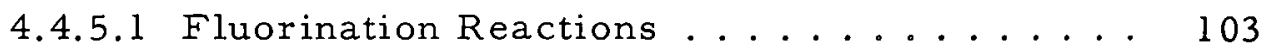

4.4.5.2 Removal of Fission Products in FP-2 .... 105

4.4.5.3 Condensation of Actinides and Fission

Products in CT-2.............. 107

4.4.5.4 Recovery of Plutonium from Miscellaneous

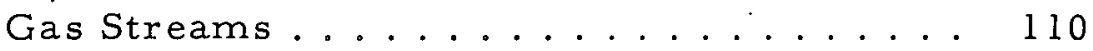

4.4.6 Solid Waste Streams ................ 111

4.5 Plutonium Purification and Separation from $\mathrm{UF}_{6} \ldots \ldots 11$

4.5.1 Outline of Process Steps............... 111

4.5.2 Design of Equipment for $\mathrm{PuF}_{6}$ Purification. ...... 114

4.5.2.1 Feed Vessel ................ 114

4.5.2.2 Thermal Decomposer-Refluorinators..... 115

4.5 .2 .3 Cold $\operatorname{Trap} \mathrm{CT}-3 \ldots \ldots \ldots 116$

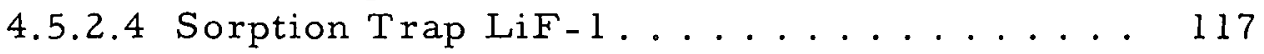

4.5 .3 Process Instrumentation. ................ 118

4.5.4 Material Balance..................... 118

4.5.5 Physical and Chemical Processes in Purification of $\mathrm{PuF}_{6} \ldots \ldots \ldots \ldots \ldots \ldots \ldots$

4.5.5.1 Transfer of Condensate from CT-1 and CT-2 to Feed Vessel............ 118

4.5.5.2 Fission-product Behavior and Radiation D.ecomposition-in_E-e.ed_Vess.el

4.5.5.3 Thermal Decomposition of $\mathrm{PuF}_{6}$ in TD-1 . . 122

4.5.5.4 Recovery of Plutonium from Thermal

Decomposer Effluents............ 124

4.5.5.5 Production of Purified $\mathrm{PuF}_{6} \ldots \ldots \ldots 125$

4.5 .6 Solid Waste Handling ............... 126 
TABLE OF CONTENTS

$\underline{\text { Page }}$

$4.6 \mathrm{UF}_{6}$ Purification $\ldots \ldots \ldots \ldots \ldots \ldots \ldots \ldots \ldots \ldots \ldots$

4.6.1 Outline of Process Steps.............. 126

4.6.2 Design of Equipment for $\mathrm{UF}_{6}$ Purification ....... 128

4.6.2.1 The Distillation Units . . . . . . . . . 128

4.6.2.2 The $\mathrm{MgF}_{2}$ Trap ............. 134

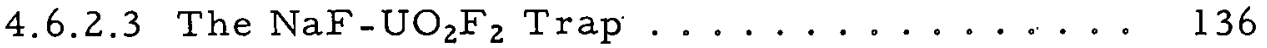

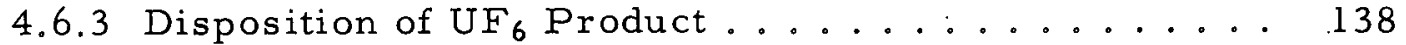

4.6.4 Composition of $\mathrm{UF}_{6}$ Product . ............ 138

4.7 Conversion of Mixed Hexafluorides to Oxides . . . . . . . . 139

4.7.1 Outline of.Process Steps............... 139

4.7.2 Engineering and Instrumentation ........... 141

4.7.3 Chemistry of Conversion Reactions . . . . . . . 145

4.7.4 $\mathrm{PuO}_{2}-\mathrm{UO}_{2}$ Product Packaging. . . . . . . ... 148

4.8 Gaseous Waste Handling System . . . . . . . . . . . . 149

4.8 .1 Outline of Process System . . . . . . . . . . 149

4.8.2 Engineering Aspects and Equipment Design ...... 149

4.8.2.1 The $\mathrm{NaF}-\mathrm{MgF}_{2}$ Bed. . . . . . . . . 150

4.8.2.2 The High-temperature Activated-alumina

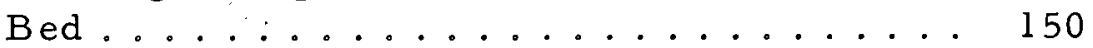

4.8.2.3 The Soda-lime Bed.............. 151

4.8.2.4 The Low-temperature Activated-alumina

Bed ...................... 151

4.8.2.5 Molecular.Sieve Dryer ............ 151

4.8.2.6 Oxygen-Hydrogen Reactor ........... 151

4.8.2.7 Xenon-Krypton Compression and Storage ... 151

4.8 .3 Instrumentation. . . . . . . . . . . . . 152

4.8 .4 Material Balance. . . . . . . . . . . . . 152

4.8.5 Chemistry of Gaseous Waste Disposal. . . . . . . 152

4.8.5.1 Fission-product and Uranium Retention by $\mathrm{NaF}-\mathrm{MgF}_{2} \ldots \ldots \ldots \ldots \ldots \ldots$

4.8.5.2 Reaction of Fluorides with Heated Activated Alumina .................... 154

4.8.5.3 Reaction of Fluorides with Soda Lime and Low-temperature Activated Alumina ...... 154

4.8.6 Solid Waste from Gaseous Waste Handling System. . . 155

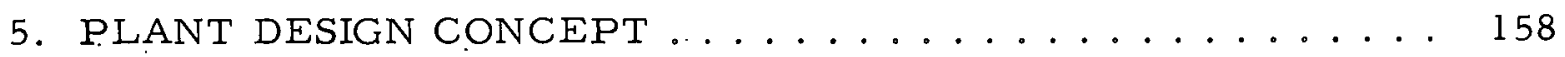

5.1 Cell Design. . . . . . . . . . . . . . . 158 
TABLE OF CONTENTS

$\underline{\text { Page }}$

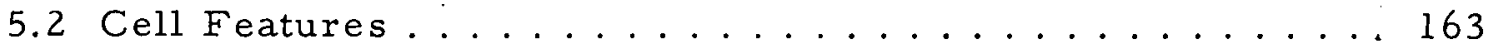

5.2.1 Cell Height. .................. 163

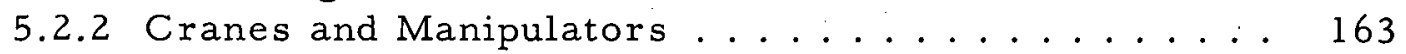

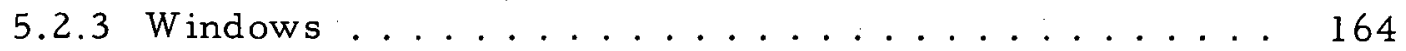

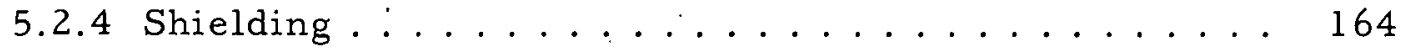

5.2.5 Equipment Transfer................ 164

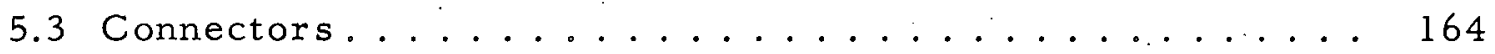

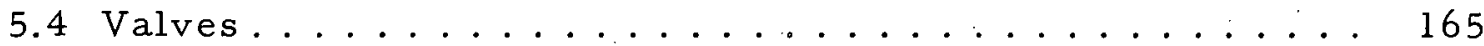

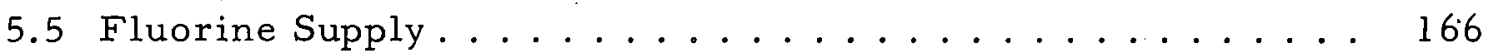

6. ANCILLARY CONSIDERATIONS ............... 167

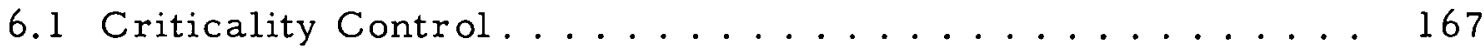

6.1.1 General Considerations of Reference Designs. . . . . 170

6.1.1.1 Continuous Fluorination.......... 170

6.1 .1 .2 Batch Units.................. 170

6.1.2 Source of Data for Criticality Analysis ........ 171

6.1.3 Nuclear-safety Analysis of the Reference Process . . 176

6.1.3.1 Fluorinator A ............. 177

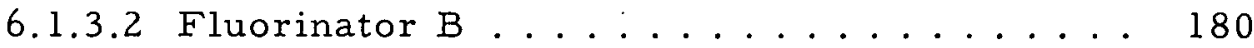

6.1 .3 .3 Cold Traps ................. 180

6.1 .3 .4 Feed Vessel ............... 180

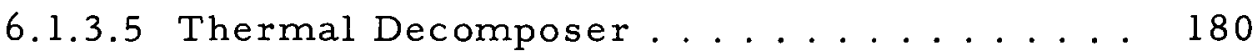

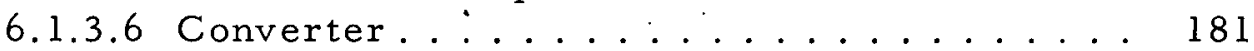

6.1.3.7 Ball Mill (Head-end)............ 181

6.1.3.8 Slab-geometry Storage Vessels......... 182

6.1.4 Nuclear Safety Analysis of the Ventilation System... 182

6.1.4.1 Disposition of Fissile Material in

Ventilation System ............ 182

6.1.4.2 Criticality in Air Space of Process Cells

and Ducts Leading to Scrubber........ 184

$6.1 .4 .3^{\circ}$ Criticality in Scrubber Unit ........ 185

6.1.4.4 Criticality in Filter System......... 185

6.1.5 Critique of Reference Concept for Criticality

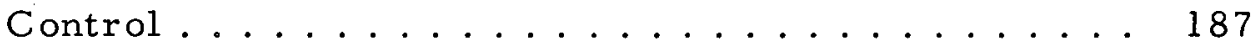

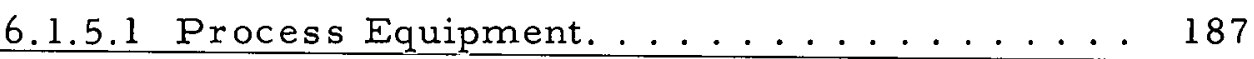

6.1 .5 .2 Ventilation System .......... 188 
TABLE OF CONTENTS

$\underline{\text { Page }}$

6.2 Ventilation System Safety Analysis: Introduction and System Design Concept................. 188

6.2.1 Safety Analysis: $\mathrm{PuF}_{6}$ Release ............ 190

6.2.2 Safety Analysis: Fission-product Release....... 193

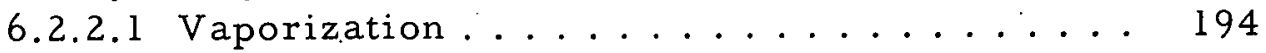

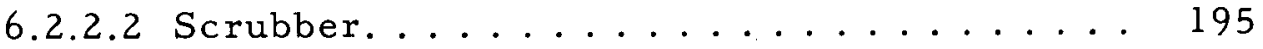

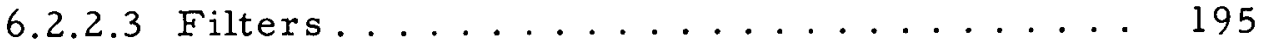

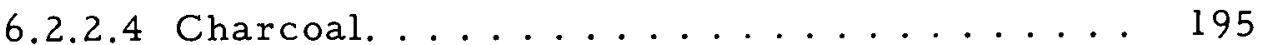

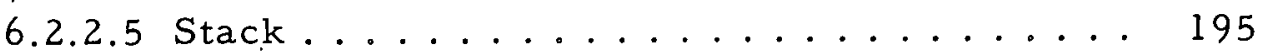

$6.2 .2 .6 \mathrm{MPC} \ldots \ldots \ldots \ldots 19 \ldots \ldots \ldots$

6.2.2.7 Exposure and Conclusions ......... 196

6.2.3. Comments on the Safety Analysis of the Ventilation

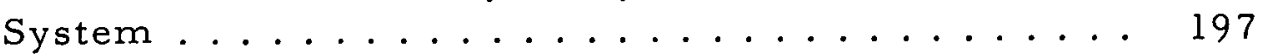

6.3 Maintenance . . . . . . . . . . . . . . . 197

6.4 Corrosion of Materials of Construction . . . . . . . . 198

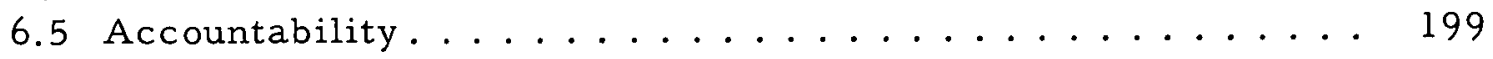

6.5.1 Chemical Analyses: Determination of Uranium and

Plutonium in Feed and Products. ......... 200

6.5.2 Determination of Plutonium in Aluminum Oxide

Waste Stream................................. 201

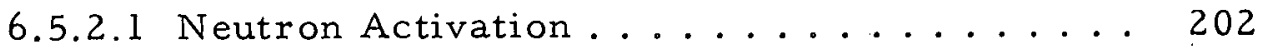

6.5 .2 .2 X-ray Spectrometry ............. 204

6.5.2.3 Discontinuous Radiochemical Determination

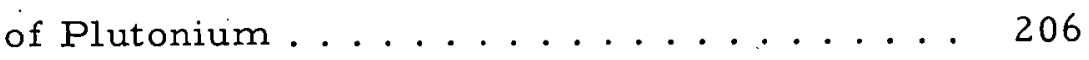

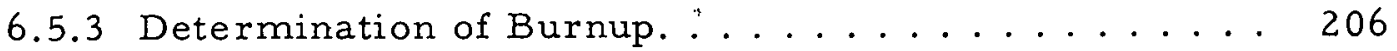

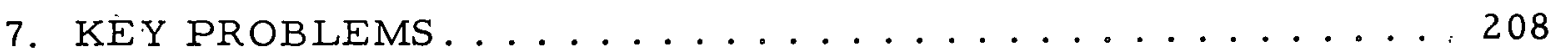

7.1 Mechanical Separation of Fuel from Cladding . . . . . . 208

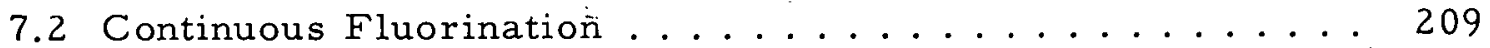

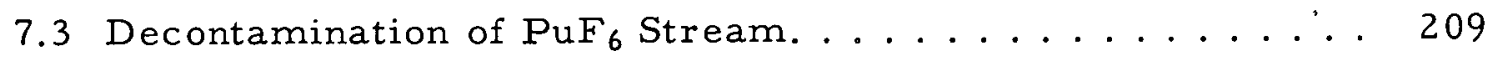

7.4 Preparing an Acceptable $\mathrm{PuO}_{2}-\mathrm{UO}_{2}$ Product . . . . . . . . 209

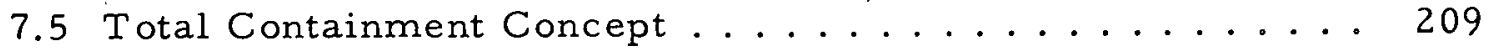

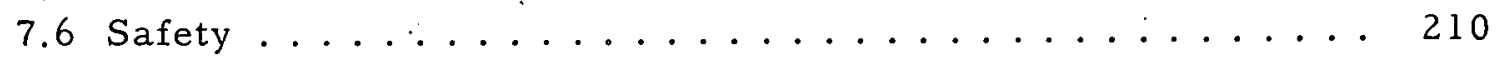

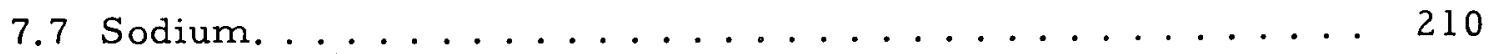


TABLE OF CONTENTS

$\underline{\text { Page }}$

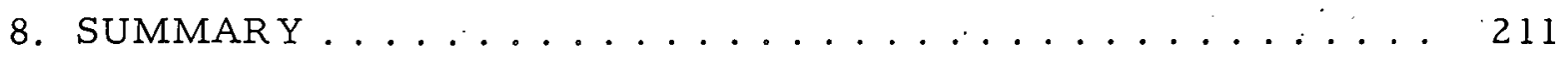

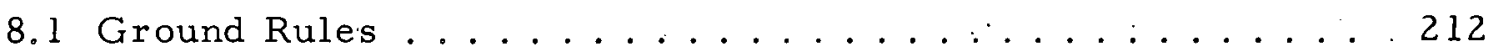

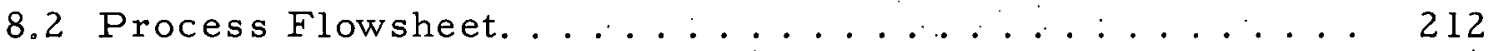

8.3 Process Analysis and Plant Design............ 215

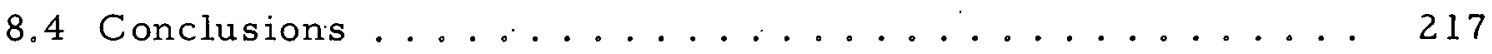

APPENDIX A: Possible Methods for Monitoring Plutonium Buildup ...................... 220

1. Noise Measurements ................... 220

2. Coincidence Correlation with Fission Neutrons . . ..... 221

3. Spatial Dependence of the Fundamental Mode . . . . . . . 222

4. Threshold Detectors................... 224

APPENDIX B: Process-gas Circulation. ........... 237

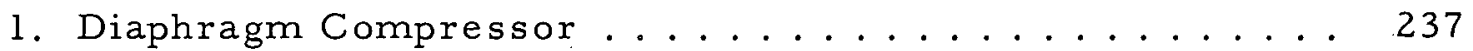

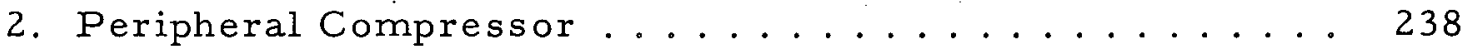

3. Piston Compressor .................... 238

4. Centrifugal Compressor . . . . . . . . . . 240

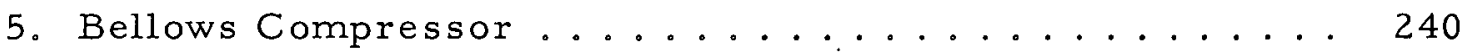

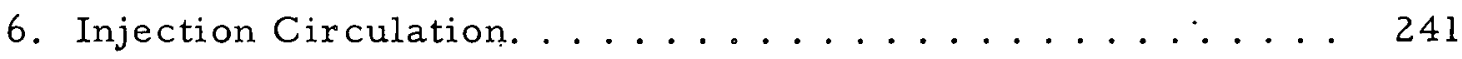

APPENDIX C: Properties of Oxides and Fluorides of Actinide

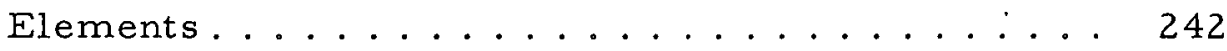

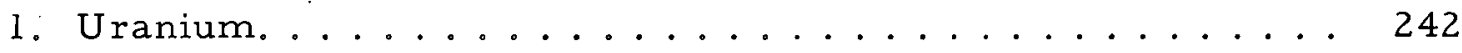

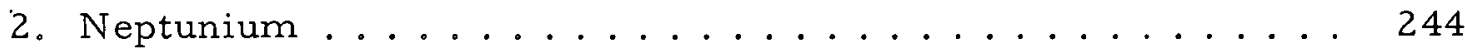

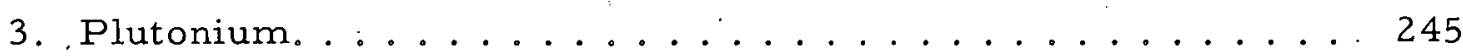

A-PPEN-DIX-D:-V-apor-P-re-s-sures-of_V-olatile_Fluorides_.._._._.. . . 249

APPENDIX E: Calculation of Centerline Temperatures in

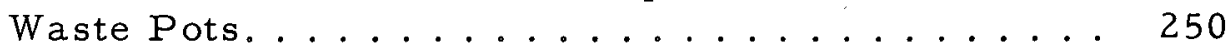


$\underline{\text { Page }}$

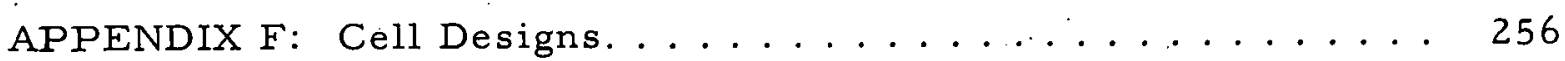

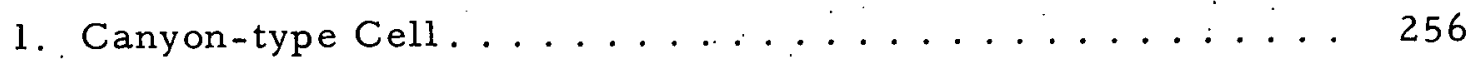

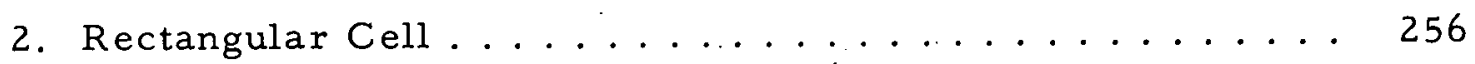

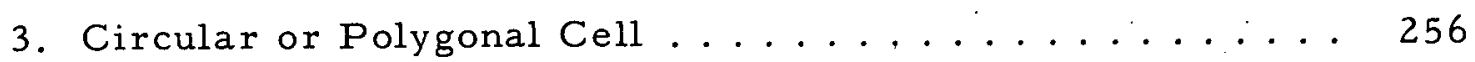

4. Vertical or "Silo"-type Cell............... 258

APPENDIX G: Manipulators and Cranes ............. 259

1. Argon-designed General Mills-fabricated Manipulator . . . 259

2. PaR Electromechanical Manipulator........... 259

3. ANL Model E-4 Electric Master-Slave Manipulator...... 259

APPENDIX H: Connectors for Radioactive Plants ......... 261

1. New Remote Connectors at Fontenay-aux-Roses, France . . 261

2. Other Connectors and Experience............. 265

ACKNOWLEDGMENTS $\ldots \ldots \ldots \ldots \ldots$

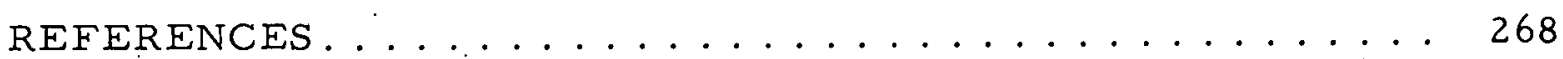




\section{LIST OF FIGURES}

No.

Title

$\underline{\text { Page }}$

3.1. Conceptual Fluoride-volatility Process for LMFBR Fuels. .

3.2. Mechanical Head-end Process .............. 28

3.3. Conceptual Pneumatic Conveying System........... 31

3.4. Fluorination of Actinides and Fission Products . . . . . . 32

3.5. Vapor Pressures of $\mathrm{UF}_{6}, \mathrm{PuF}_{6}, \mathrm{NbF}_{5}$, and $\mathrm{RuF}_{5} \ldots \ldots 35$

3.6. Plutonium Purification and Separation from $U F_{6} \ldots . . . .39$

3.7. $\mathrm{UF}_{6}$ Purification System .................. 42

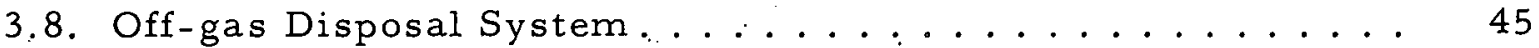

4.1. Conceptual Continuous Ball Mill . . . . . . . . . . . 54

4.2. Conceptual Continuous Ball Mill: Section A-A . . . . . . 55

4.3. A Roller-Crusher-Splitter Concept for Mechanical Decladding of Fuel Pins ................. 58

4.4. Fluorination Reactor A and Associated Equipment...... 67

4.5. Schematic Diagram of Uranium Fluorinator (Reactor A) . . . 71

4:6. Externally Cooled Cold Trap . . . . . . . . . . . 74

4.7. Transient Temperature Distribution in Static Bed for

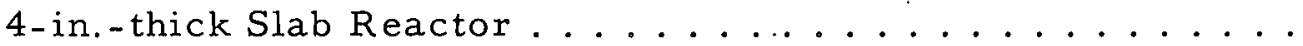

4.8. Decrease in Heat Generation Rate with Time for NaF Loaded with Ruthenium and Niobium (from FP-1 or FP-2) . . 95

4.9. Fluorination Reactor B and Associated Equipment...... 98

4.10. Equilibrium Production Rates for $\mathrm{PuF}_{6}$ in Reactor B . . . . 100

4.11. Schematic Diagram of Plutonium Fluorinator (Reactor B) . . 101

4.12. Decrease in Heat-generation Rate with Time for Fluorinator

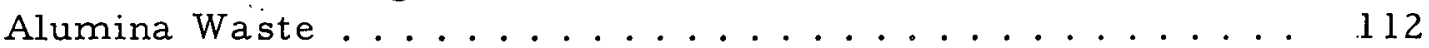

4.13. Thermal Decomposer-Plutonium Refluorination System . . . 113

4.14. Typical Operating Schedule for PuF 6 Purification System . . 114

4.15. Schematic Diagram of $\mathrm{UF}_{6}$ Purification System . . . . . . 127

4.16. Phase Equilibria in Condensed System UF $6-\mathrm{MoF}_{6} \ldots \ldots \ldots$

4.17. Removal of $\mathrm{NpF}_{6}$ from $\mathrm{UF}_{6}-\mathrm{NpF}_{6}$ Gas Mixtures by Reaction with $\mathrm{NaF} \ldots \ldots \ldots \ldots \ldots \ldots$ 


\section{LIST OF FIGURES}

No.

Title

$\underline{\text { Page }}$

4.18. Schematic Diagram of Equipment for Conversion of Mixed Hexafluorides to Oxide Products ............. 140

4.19. Schematic Diagram of Fluid-bed Converter . . . . . . . 142

4.20. Moving-bed Adsorber for Removing Hydrogen Fluoride from Converter Off-gas ................. 144

4:21. Schematic Diagram of Gaseous Waste Handling System . . . 149

4.22. Schematic Diagram of Gaseous Waste Handling System . . . 153

4.23. Composite of Figs. 4.4,4.9, and 4.13 .......... 156

4.24. Composite of Figs. 4.15,4.18, and 4.22 ......... 157

5.1. Conceptual Layout of LMFBR Fuel-reprocessing Plant . . . 159

5.2. Elevation View of Conceptual LMFBR Fuel-reprocessing

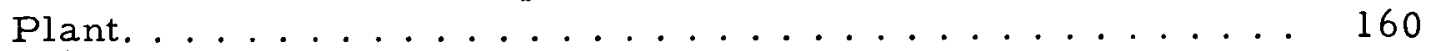

5.3. Process Cell Equipment Layout............... 162

6.1. Source Data for Criticality Analysis for 4-in.-thick Slabs. . 173

6.2. Reference Cases for Criticality Analysis for 4-in.-thick

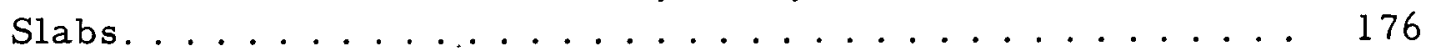

6.3. Components of Reference Ventilation System ........ 182

6.4. Response of Delayed-neutron Monitor to ${ }^{235} \mathrm{U}$ in Leached

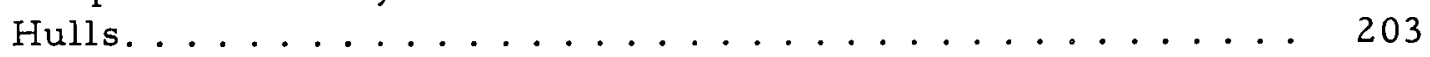

A. 1. Differential Cross Section for ${ }^{24} \mathrm{Mg}(\mathrm{n}, \mathrm{p}){ }^{24} \mathrm{Na}$ Reaction. . . . 226

A.2. Differential Cross Section for ${ }^{27} \mathrm{Al}(\mathrm{n}, \alpha)^{24} \mathrm{Na}$ Reaction . . . . 227

A.3. Differential Cross Section for ${ }^{27} \mathrm{Al}(\mathrm{n}, \mathrm{p}){ }^{27} \mathrm{Mg}$ Reaction. . . . 228

A.4. Differential Cross Section for ${ }^{28} \mathrm{Si}(\mathrm{n}, \mathrm{p})^{28} \mathrm{Al}$ Reaction. . . . . 229

A.5. Differential Cross Section for ${ }^{31} \mathrm{P}(\mathrm{n}, \mathrm{p})^{31} \mathrm{Si}$ Reaction . . . . . 230

A.6. Differential Cross Section for ${ }^{32} \mathrm{~S}(\mathrm{n}, \mathrm{p})^{32} \mathrm{P}$ Reaction. ..... 231

A. 7. Differential Cross Section for ${ }^{56} \mathrm{Fe}(\mathrm{n}, \mathrm{p}){ }^{56} \mathrm{Mn}$ Reaction. . . . 232

A.8. Differential Cross Section for ${ }^{115} \operatorname{In}\left(n, n^{1}\right)^{115 m} \operatorname{In}$ Reaction . . . 233

A.9. Differential Cross Section fór ${ }^{232}$ Thi(n,f)FP Rejaction . . . . 234

A. 10. Differential Cross Section for ${ }^{238} \mathrm{U}(\mathrm{n}, \mathrm{f}) \mathrm{FP}$ Reaction . . . . . 235

B.1. Fluorine Circulation by Injection ............ 241 


\section{LIST ÖF FIGURES}

No... Title

$\underline{\text { Page }}$

E.1. Centerline Temperatures for Cylinders and Slabs Filled with Activated Alumina: $\mathrm{q}$ vs $\mathrm{T}_{\mathrm{c}} \ldots \ldots \ldots \ldots . \ldots . \ldots . \ldots 252$

E.2. Centerline Temperatures for Cylinders and Slabs Filled with Activated Alumina: $\mathrm{d}$ or $\mathrm{W}$ vs $\mathrm{T}_{\mathrm{c}} \ldots \ldots . \ldots 253$

E.3. Centerline Temperatures for Cylinders and Slabs Filled with $40 \%$ Aluminum-60\% Alumina: $q$ vs $\mathrm{T}_{\mathrm{c}} \ldots \ldots . \ldots 254$

E.4. Centerline Temperatures for Cylinders and Slabs Filled with $40 \%$ Aluminum-60\%.Alumina: $\mathrm{d}$ or $\mathrm{W}$ vs $\mathrm{T}_{\mathrm{C}} \ldots \ldots . \ldots 255$

H.1. Angular Pipe Connector Used at Fontenay-aux-Roses ...... 261

H.2. "LèChaton" Connector. . . . . . . . . . . . . . . . . 262

H.3. Motorized Capstan Drive for LeChaton Conne/ctor. . . . . . . 263

H.4. Flanged Joint Used at Fontenay-aux-Roses . . . . . . . . . 264

H.5. Motorized Bolt Torquer Used at Fontenay-aux-Roses . . . . 264

H.6. TRU Disconnect Clamp and Ferrules . . . . . . . . . 265 


\section{LIST OF TABLES}

No.

Title

Page

2.1. Reference Core Fuel Elements .............. 22

2.2. Reference Radial-blanket Fuel Elements . . . . . . . . 22

2.3. Reference Daily Processing Load. . . . . . . . . . . . 23

2.4. Fission-product Content of Reference Load . . . . . . . . . 24

2.5. Isotopic Composition of Plutonium in AI Reference Fuel

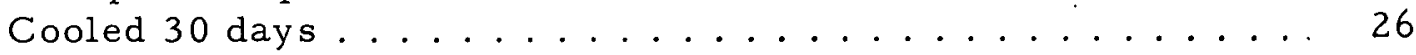

3.1. Distribution of Fission-product Fluorides and Their Associated Radioactivity. ................

3.2. Decontamination Achieved by Single-stage Evaporation from Feed Vessel with Greater than $99 \%$ of $\mathrm{UF}_{6}$ and $\mathrm{PuF}_{6}$ Taken

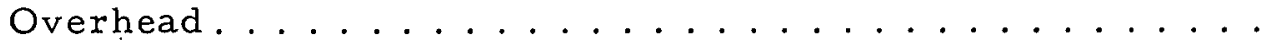

3.3. Decontamination Achieved by Single-stage Evaporation of $90 \%$ of $\mathrm{PuF}_{6}$ from Cold Trap CT $-3 \ldots \ldots \ldots$

3.4. Vapor Pressures for Volatile Compounds in $\mathrm{UF}_{6}$ Purification System .................... 43

3.5. Sources of Gaseous Wastes for Disposal .......... 45

4.1. Material Balance: Fluorination Loop A. ..........66

4.1A. Applications, Number, and Heat Loads of Cold Traps.... 75

4.2. Partitioning of Actinide and Fission-product Elements According to Volatility of Their Fluoride Compounds......

4.3. Partitioning of the Actinide Fluorides and Volatile Fission

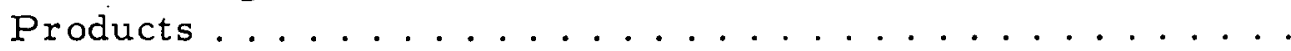

4.4. Solid Solubilities and Crystal Structures of Selected

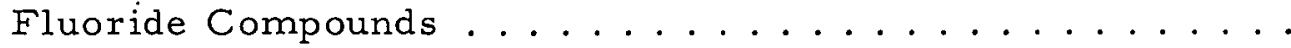

4.5. Retention of Fission Products in FP-1 and CT-1...... 89

4.6. Energy Evolution from Fission Products in FP- 1 and CT-1 . 91

4.7. Alternative Methods for Storing Alumina Waste . . . . . . . 94

4.8. Quantities of Fission Products in Process Waste Streams. . 97

4.9. Cylinder Requirements for Long-term Waste Storage . . . . 97

4.10. Material Balance: Fluorination Loop B. . . . . . . . 103

4.11. Volatilization of Actinides and Fission Products from

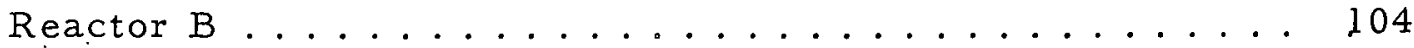




\section{LIST OF TABLES}

No

Title

Page

4.12. Retention of Fission Products in FP-2 and CT-2 ..... 108

4.13. Energy Evolution from Fission Products in CT-2 ..... 109

4..14. Gas Residence Times Required to Achieve Equilibrium during Thermal Decomposition of $\mathrm{PuF}_{6}$ to $\mathrm{PuF}_{4} \ldots \ldots \ldots 115$

4.15. Specifications for $\operatorname{Trap} \operatorname{LiF}-1 \ldots \ldots \ldots 18$

4.16. Material Balance for $\mathrm{PuF}_{6}$. Purification Equipment. . . . . . 119

4.17. Material Inventories in $\mathrm{PuF}_{6}$ Purification Equipment . . . . 119

4.18. Material Charged to Feed Vessel .............. 119

4.19. Separations Effected by Single-stage Distillation from Feed

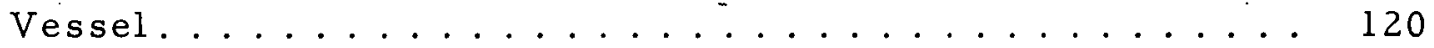

4.20. Energy Evolution from Fission Products in Feed Vessel. . . 121

4.21. Estimated Thermodynamic Stability Constants for Fissionproduct Fluorides ...................... 124

4.22. Purification of $\mathrm{PuF}_{6}$ by Vaporization from CT-3 at $80^{\circ} \mathrm{C} \ldots 126$

4.23. Quantity and Relative Volatility of Constituents in Feed to Still $s_{-1}^{\prime} \ldots \ldots \ldots \ldots$. . . . . . . . . . . . . . . . . . . .

4.24. Relative Volatilities of Selected Fission-product Compounds . 130

4.25. Size and Design Specifications for Stills S-1 and S-2 . . . 132

4.26. Quantity and Relative Volatility of Constituents in Feed to

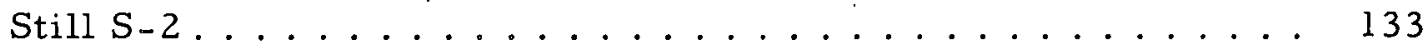

4.27. Vapor Pressures of Uranium Hexafluoride and Selected

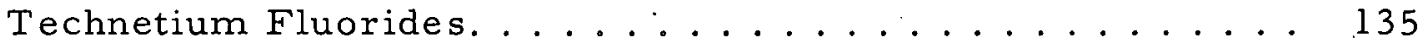

4.28. Specifications for $\mathrm{MgF}_{2} \mathrm{Trap} \ldots \ldots \ldots \ldots$

4.29. Removal of $\mathrm{NpF}_{6}$ from $\mathrm{UF}_{6}-\mathrm{NpF}_{6}$ Gas Mixtures by Multistage Contacting with $\mathrm{NaF}$ at $409^{\circ} \mathrm{C} \ldots \ldots \ldots 137$

4.30. Specifications for Multistage $\mathrm{NaF}-\mathrm{UO}_{2} \mathrm{~F}_{2}$ Trap . . . . . 138

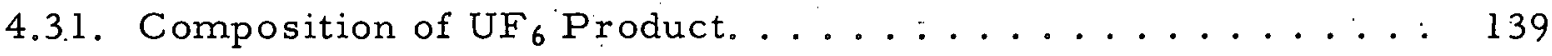

4.32. Reactant and Product Flowrates for Converter System.... . 141

4.33. Material Balance for: the Conversion of $\mathrm{PuF}_{6}-\mathrm{UF}_{6}$ to

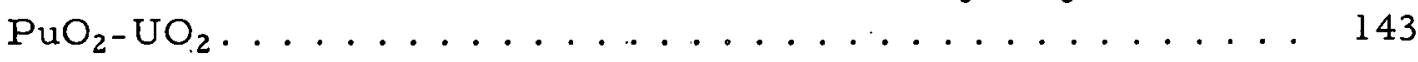

4.34. Material Balance for the Hydrogen Fluoride Adsorber . . . . 145 
LIST OF TABLES

No.

Title

Page

4.35. Fission-product Activities Associated with the Converter Feed and Product Streams and Overall DF.......... 148

4.36. Material Balance for Gaseous Waste Handling System . . . . 152

4.37. Solid Wastes from Gaseous Waste Handling System . . . . 155

5.1. Key to Equipment Layout of Fig. 5.3 ............ 161

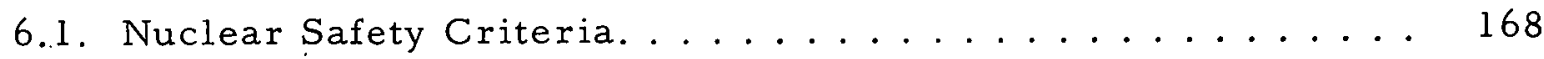

6.2. Reference Data on Fissile Content of Major Process

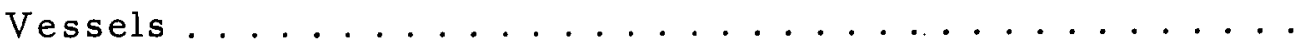

6.3. Reference Data on Fissile Content of Miscellaneous Process

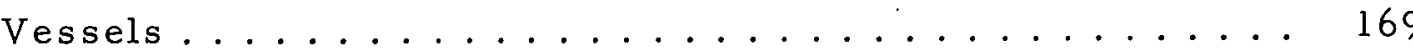

6.4. Criticality Source Data................. 172

6.5. Reference Criticality Model Estimated from Source Data . . 175

6.6. Reference Operation and Design Conditions for Fluorinator A. 178

6.7. Estimated Filter Loading Capacity for $\mathrm{PuF}_{6}$ Release . . . . 185

6.8. Estimated Critical Thicknesses of Infinite Slabs of Homogeneous Water-moderated Plutonium $\left({ }^{239} \mathrm{Pu}\right) \ldots \ldots 186$

6.9. Plutonium Inventory Limits as Used in Ventilation System

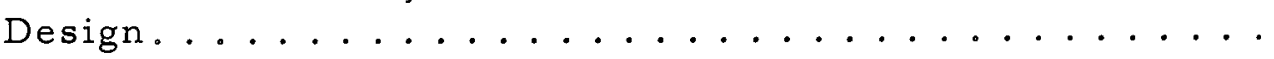

6.10. Air-temperature Effect on Scrubber Design for Air That Is Saturated with Hexafluorides at Selected Constant

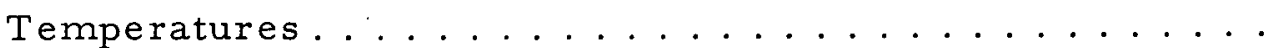

6.1. Factors in Calculating Exposure of the Public as a Result of a Maximum Credible Release of $\mathrm{PuF}_{6} \ldots \ldots \ldots$

6.12. Estimated Separation Factors and Calculated Exposures in Unrestricted Areas ....................

6.13. Maximum Permissible Concentrations of Volatile Fissionproduct Fluorides in Unrestricted Areas ...........

6.14. Anticipated Corrosion Rates for Selected Process Components Made of Nickel. . . . . . . . . . . . .

A. 1. Spontaneous Fission and Alpha Emitters for a 500-kg Spent Core Section.

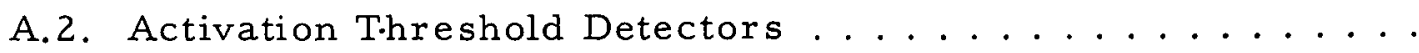




\title{
A CONCEPTUAL DESIGN STUDY OF A \\ FLUORIDE-VOLATILITY PLANT \\ FOR REPROCESSING LMFBR FUELS
}

\begin{abstract}
The potential of reprocessing fast-breeder-reactor fuels by fluoride-volatility methods is evaluated in this plant design concept study. A reference flowsheet designed on the basis of knowledge developed in earlier fluoride-volatility work on lightwater-reactor. (LWR) fuels includes innovative features, such as continuous processing in slab-shaped fluid-bed reactors for criticality safety and total containment of radioactive and noxious waste gases.

The process comprises the following steps: (1) separation of cladding from the fuel by mechanical means, (2) fluorination of the fuel to selectively remove $U_{6}$, (3) fluorination of the residue in a second fluid-bed reactor to recover $\mathrm{PuF}_{6}$, (4) separation and purification of plutonium by thermal decomposition of $\mathrm{PuF}_{6}$ to nonvolatile $\mathrm{PuF}_{4}$, (5) purification of $\mathrm{UF}_{6}$ by distillation and sorption techniques, and (6) mixing of $U_{F_{6}}$ and $\mathrm{PuF}_{6}$ in the desired proportions for conversion to homogeneous $\mathrm{UO}_{2}-\mathrm{PuO}_{2}$ material by simultaneous reaction of the $\mathrm{UF}_{6}-\mathrm{PuF}_{6}$ mixture with steam and hydrogen.

A preliminary design and plant layout are presented. A preliminary nuclear criticality analysis of key process vessels and a safety analysis of the plant are included. Key problems that would serve as the basis for a fluoride-volatility R\&D program are outlined.
\end{abstract}

\section{INTRODUCTION}

A major goal in the nuclear-energy field is the development of a Liquid Metal Fast Breeder Reactor (LMFBR) industry capable of fulfilling the country's energy requirements in an economic manner. Current projections ${ }^{1}$ indicate that such an industry should be viable in the late 1980 's. Among the major tasks in the LMFBR fuel cycle is the development of an economical-method-of-fuel-repreces-sing.-The-de-velopment_of_rec.overy processes for LMFBR fuels is expected to require 6 to 10 years, and the translation of technology into physical capability an estimated 6 years. An extensive $R \& D$ program appears necessary because of the characteristics of LMFBR fuel and its nuclear history. 
The reference fuel is $\mathrm{UO}_{2}-\mathrm{PuO}_{2}$ clad in stainless steel. The specific power of the nuclear-reactor core fuel is expected to be about $200 \mathrm{MWt} /$ metric ton, and the burnup $100 \mathrm{GWd} /$ metric ton. Discharged core fuel will contain about $20 \% \mathrm{PuO}_{2}$. Short out-of-reactor time for the fuel will be necessary because of the high interest charges on the inventory of fissile material. Therefore, short cooling prior to reprocessing is highly desirable. The high fission-product content, high plutonium content, and high radioactivedecay heat load represent a unique challenge to candidate methods of processing--both the aqueous methods and the nonaqueous methods. The current state of the art in fuel reprocessing is such that no method has yet demonstrated a capability for economical reprocessing of short-cooled LMF BR fuels.

The most effective $R \& D$ program for the development of technically and economically feasible reprocessing schemes requires a sustained program of evaluation parallel to the experimental effort. An in-depth analysis and evaluation of each candidate process, as well as potential hybrid schemes, appear to be a logical first step.

This document represents an analysis and evaluation of the applicability of the fluoride-volatility method to the reprocessing of LMFBR fuels. Application of this technique would represent an extension of technology established over the last 15 to 20 years in related areas of the nuclear fuel cycle. The refining of uranium by fluoride-volatility methods is a commercial process (5000-10,000 tons/yr uranium) in operation at the Allied Chemical Corporation ${ }^{2}$ plant at Metropolis, Illinois. The first plant-scale application for reprocessing of irradiated light-water-reactor (LWR) fuels by fluoride-volatility methods is planned by General Electric ${ }^{3}$ in their Midwest Fuel Recovery Plant (MFRP) for the uranium portion of the recovery process. The technical and economic feasibility of the volatility process for reprocessing irradiated, fully enriched uranium fuels has been established in work in the U.S. and abroad. ${ }^{4}$ Work on engineering details needed for plant design is yet to be completed.

The ability to produce'and handle kilogram quantities of $\mathrm{PuF}_{6}$, an important feature of an all-volatility process, has been confirmed by work at $\mathrm{ANL}^{5}$ with engineering-scale equipment and by work at the Dow Rocky Flats Plant ${ }^{6}$ on plutonium scrap recovery. A prototype facility for plutonium scrap recovery, with a capacity of about $12 \mathrm{~kg} / \mathrm{day}$ of plutonium, is being designed by Dow and is scheduled for 1969 installation.

Extensive plant-scale experience at the Idaho Chemical Processing Plant? on the fluid-bed calcination of radioactive-waste solutions has also contributed valuable, pertinent knowledge toward the successful handling of tonnage quantities of.radioactive solids in fluid-bed systems.

The scope of the study contained in this report is embodied in the following statement of purpose: to provide guidance in at least two 
areas--(1) the technical and engineering feasibility of applying volatility techniques to the recycle of FBR fuels, along with an indication of a preferred approach if one should emerge from the study, and (2) definition of key problem areas or areas of uncertainty, their magnitude, an estimate of the effort required to resolve them, and an order of priority in approaching the problems as an aid to program planning.

Two cases were selected for study: (1) a large central reprocessing plant serving a regional area (15,000 MWe of installed FBR nuclear capacity) and providing a highly decontaminated product (decontamination factor in the range $10^{6}-10^{7}$ ) and (2) a small on-site plant serving a reactor park (3000 MWe) and providing an overall decontamination factor of about $10^{3}$. This second case implies either remote refabrication of the fuel or further decontamination in a large central plant facility. The present report develops only the case for the large plant. The remainder of this report is divided into the following. sections:

Section 2. Ground Rules and assumptions, including scope and input.

Section 3. Description of Reference Process.

Section 4. Design Basis and Analysis of Reference Process, which includes the basis for process selection, process alternatives, process equipment design information, material balance and heat-load information, discussion of problems, and uncertainties.

Section 5. Plant Design Concept, including the physical layout of the process cells and other plant areas, as well as the description of mechanical equipment.

Section 6. Ancillary Considerations, such as nuclear criticality, ventilation system safety analysis, maintenance, corrosion, and accountability.

Section 7. Key Problems.

Section 8. Summary.

Appendixes, which contain background and support information.

Acknowledgments.

References.

A reference process was selected by combining those steps that have reasonably sound technical bases according to present technology. Optimization, such as that represented by parametric studies, was not attempted, although in numerous instances alternative schemes, which were potential improvements, were considdered-Because-of-the-limited-time-fer-eompletionof the study, most of these alternatives were not included in the basic plant concept study. Decisions on a particular step were made at an arbitrary cutoff date in the midst of conflicting judgments so that calculations and the design study might proceed. Although the flowsheet chosen for this study is considered acceptable for the evaluation of process feasibility, this flowsheet would probably not be selected for intensive development without modification. 


\section{GROUND RULES}

The design basis for this conceptual plant uses the following ground rules and assumptions.

\subsection{Fuel Characteristics}

a. Core specific power:

b. Average core burnup:

c. Average blanket burnup:

d. Composition of discharged fuel:

e. Design:

f. Cooling time:
$200 \mathrm{MWt} /$ metric ton

$100 \mathrm{GWd} /$ metric ton

$5 \mathrm{GWd} /$ metric ton

Core: $20 \% \mathrm{PuO}_{2}-\mathrm{UO}_{2}$ Blanket: $2 \% \mathrm{PuO}_{2}-\mathrm{UO}_{2}$ Cladding: Stainless steel Bonding: Gas, but $1 \%$ of the fuel is assumed to be sodium-logged

Axial blanket integral with core 30 days

\subsection{Conceptual Process}

The scope of this study includes the arrival of fuel elements at the reprocessing site, but does not include shipping, preshipment fuel handling, or mechanical disassembly of neutron-shield sections. Some end hardware attached to the fuel elements when they are received must be removed by sawing, as described. later.

The reference process uses a mechanical head-end process to provide, from stainless steel-clad $\mathrm{UO}_{2}-\mathrm{PuO}_{2}$ fuel consisting of the combined core and blankets, a fluidizable oxide feed for continuous, fluid-bed fluorinators. With appropriate temperature and reagent concentration. in the fluorinators, first the uranium and then the plutonium are converted to hexafluoride and separated from those fission products that remain with the alumina bed as nonvolatile fluorides. A continuous stream of granular alumina serves as a vehicle for moving these nonvolatile fission products through the fluorinators to waste receivers. The overhead $U F_{6}$ and $\mathrm{PuF}_{6}$ streams are purified, using cold traps and selective sorption, thermal decomposition, and fractional distillation. The purified $\mathrm{UF}_{6}$ and $\mathrm{PuF}_{6}$ are recombined and converted to a mixed particulate oxide product.

A mechanical head-end was selected for the reference flowsheet. Fluorine gas was selected as the fluorinating agent for the reference fuel. A single reagent is. inherently, simpler than the interhalogen-fluorine combinations used in recent studies on low-plutonium-content fuels.*

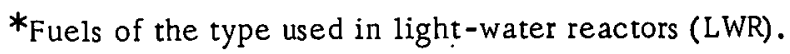


The core and blanket materials are assumed to be blended and processed together. Alternatively, the plant could process a load of core fuel, then a load of blanket fuel.

The process is designed to give highly decontaminated (decontamination factor of $10^{6}-10^{7}$ ) products in the form of (1) $23 \mathrm{wt} \% \mathrm{PuO}_{2}-\mathrm{UO}_{2}$. suitable for refabrication of core fuel and (2) pure $U F_{6}$ for shipment offsite and subsequent conversion to the desired fuel compound. The conceptual plant will have the capability of producing separate $\mathrm{UO}_{2}$ and $\mathrm{PuO}_{2}$ products as well.

High-level wastes are stored in solid form onsite for the life of the plant, followed by shipment offsite, possibly to a salt cavern. Intermediateand low-level solid wastes are converted to a form suitable for long-term storage onsite. Intermediate - and low-level liquid wastes are treated to the degree necessary so that all effluent discharged.is within the applicable limits. Waste concentrates are solidified and handled as outlined above. Total containment of gaseous wastes. is planned. In the reference process, off-gas and vent streams are so treated that the gases are converted.to stable solid waste forms or compressed to relatively small volumes for storage. Gaseous waste discharges are held within the applicable limits set by regulations.

In general, this case study was developed on the basis of known technology and is well referenced.' Yet considerable extrapolation of existing information was required in several areas. Key problem areas and areas of uncertainty are defined (in Section. 7) and will serve as the basis for future R\&D programs.

\subsection{Reference Fuel Elements}

Reference fuel elements were designated based on discussions with ANL project engineers. involved with LMFBR design studies. ${ }^{8}$ The fuel elements are of the nonvented type. A fuel element consists of a hexagonal, shrouded array, of fuel pins. The fuel pins in a core fuel element have axial blanket sections. with no separators between core and blanket sections. Each core pin consists of a 4 -ft core section with a $\mathrm{l}-\mathrm{ft}$ section of blanket fuel at each end. Each pin has a 6-ft-long plenum section where fission gases collect. The core fuel elements and radial blanket fuel elements are described in Tables 2.1 and 2.2, respectively. The design of an Atomics International fuel element typical of those under consideration. in the LMFBR program has been described recently. ${ }^{9}$

The fuel element is so constructed-a's-to permit-ready-removal-of individual fuel pins. The tapered (solid plug) ends of the fuel pins fit into grid end plates, which hold the fuel pins in place. The end plates are welded to the shroud, but the pins are not welded to the end plates or the shroud. A spiral-wound wire, wrapped on each pin, separates the pins from each 
other along the fuel-element length and provides a path for sodium coolant during nuclear-reactor service and later a path for gas coolant during mechanical disassembly operations.

TABLE 2.1. Reference Core Fuel Elements

\begin{tabular}{ll}
\hline Fuel-pin diameter & $0.25 \mathrm{in.}$ \\
Cladding thickness & $0.015-\mathrm{in} . \mathrm{SS}$ \\
Core active height & $4.0 \mathrm{ft}$ \\
Axial blanket length & $1.0 \mathrm{ft}$ at each end \\
No. of fuel pins per fuel element & 217 \\
Spacing between pins & $0.05 \mathrm{in.}$ \\
Fuel density & $80 \% \mathrm{TD}^{\mathrm{a}}$ (core) \\
& $93 \% \mathrm{TD}^{\mathrm{a}}$ (axial blanket) \\
Fission-gas handling & Nonvented \\
Fuel-element shape & Hexagonal, 5.4 in. across flats \\
Shroud thickness & 0.17 -in. SS \\
Cladding length & 144 in. (includes fission-gas plenum)
\end{tabular}

$\mathrm{a}_{\mathrm{TD}}=$ theoretical density.

TAB LE 2.2. Reference Radial-blanket Fuel Elements

\begin{tabular}{lccc}
\hline & & \multicolumn{2}{c}{ Outer Ring } \\
\cline { 3 - 4 } & Inner Ring & Type I Element Type II Element \\
\hline Fuel-pin diameter, in. & 0.35 & 0.35 & 0.51 \\
No. of pins per fuel element & 169 & 169 & 91 \\
Cladding thickness, in. of SS & 0.015 & 0.015 & 0.015 \\
Spacing between pins, in. & 0.05 & 0.05 & 0.05 \\
Fuel length, in. & 60 & 48 & 48 \\
Fuel density, \% of TD & 93 & 93 & 93 \\
Cladding length, in. & 84 & 72 & 72 \\
\hline
\end{tabular}

$a_{T D}=$ theoretical density.

At the time this report is being written, fuel-element designs are still evolving; intermediate holding grids, springs, and other appurtenances are still under consideration. Nevertheless, it is assumed that the ultimate designs will be basically simple and will lend themselves to the handling and processing procedures described here. 


\subsection{Reference Fuel Load}

An average daily processing load has been based on the fuel discharge rate from a 15,000-MWe network. Fuel reloading (per reactor) occurs about twice a year. Approximately one-third of the core section is replaced at that time, giving average irradiation times of about $l \frac{1}{2} \mathrm{yr}$. Radial blanket elements are irradiated for 2 to $4 \mathrm{yr}$, with refueling increments of $1 / 8$ or $1 / 4$, depending on location. The plant processes core, axial blanket, and radial blanket material and operates 300 days per year.

Table 2.3 summarizes the daily average actinide and fissionproduct (F.P.) loads from the core, axial blanket, and radial-blanket sections for 30-day-cooled fuel. An average of six core fuel elements (includes axial blanket) and 4.1 radial blanket elements are processed daily. The total average daily load is about 1 ton, distributed as follows: $875 \mathrm{~kg}$ of uranium, $83.5 \mathrm{~kg}$ of plutonium, and about $39 \mathrm{~kg}$ of fission products. Neptunium content is about $186 \mathrm{~g}$.

TABLE 2.3. Reference Daily Processing Load

\begin{tabular}{cccccr}
\hline & \multicolumn{5}{c}{ Daily Discharge Rate, kg } \\
\cline { 2 - 6 } Fuel Component & Core & Blanket & Blanket & Blanket & Total \\
\hline U & $223^{\mathrm{a}}$ & 178 & 401 & 474 & 875 \\
Pu & $72.3^{\mathrm{a}}$ & 1.6 & 73.9 & 9.6 & 83.5 \\
U + Pu & 295.3 & 179.6 & 474.9 & 483.6 & 958.5 \\
F.P. & 35.06 & 1.08 & 36.14 & 2.84 & 38.98 \\
Np & $85^{\mathrm{b}}$ & $20.5 \mathrm{~b}$ & $105.5 \mathrm{~b}$ & 80.8 & $186.3 \mathrm{~b}$
\end{tabular}

Fuel Elements Processed per Day

Core plus axial blanket: 6

Radial Blanket

Inner ring: 2.6

Outer ring: 1.5

aThese values, representing $22 \% \mathrm{PuO}_{2}-\mathrm{UO}_{2}$ core fuel, were used for all calculations made in this study. This plutonium-to-uranium ratio is higher than the $20 \% \mathrm{PuO}_{2}-\mathrm{UO}_{2}$ ratio specified in the ground rules, but does not affect the overall conclusions-drawn in this study.

bNeptunium values are gram amounts. 
The fission-product content of the input fuel is shown on Table 2.4. The fission-product content was estimated using a computer program developed by Varteressian. ${ }^{10}$ The calculations as ume that the fission products are produced by a constant rate of fission of ${ }^{239} \mathrm{Pu}$ by $2-\mathrm{MeV}$ neutrons

TABLE 2.4 Fission-product Content of Reference Load

$$
\text { Basis: } \begin{aligned}
& 38.98 \mathrm{~kg} \text { of }{ }^{239} \mathrm{Pu} \text { fissioned } \\
& 500 \text {-day irradiated in } 2-\mathrm{MeV} \text { flux } \\
& 30 \text {-day cooled }
\end{aligned}
$$

\begin{tabular}{|c|c|c|c|c|}
\hline Element & Gramsa & $\begin{array}{c}\text { Radioactive } \\
\text { Is otope }\end{array}$ & $\begin{array}{c}\text { Beta } \\
\text { Curies }\end{array}$ & Watts ${ }^{b}$ \\
\hline $\mathrm{H}$ & 0.213 & ${ }^{3} \mathrm{H}$ & $2.06 \times 10^{3}$ & c \\
\hline $\mathrm{Kr}$ & 132 & 85 & $3.67 \times 10^{3}$ & 5 \\
\hline $\mathrm{Rb}$ & 142 & 86 & 42 & $c$ \\
\hline \multirow[t]{2}{*}{$\mathrm{Sr}$} & 398 & 89 & $5.964 \times 10^{5}$ & 1789 \\
\hline & & 90 & $3.271 \times 10^{4}$ & $180^{d}$ \\
\hline \multirow[t]{2}{*}{$\mathrm{Y}$} & 223 & 90 & $3.271 \times 10^{4}$ & - \\
\hline & & 91 & $1.174 \times 10^{6}$ & 3756 \\
\hline $\mathrm{Zr}$ & $2.95 \times 10^{3}$ & 95 & $2.279 \times 10^{6}$ & $1.162 \times 10^{4}$ \\
\hline $\mathrm{Nb}$ & 76 & 95 & $2.956 \times 10^{6}$ & $1.389 \times 10^{4}$ \\
\hline Mo & $3.78 \times 10^{3}$ & 99 & $2.100 \times 10^{3}$ & c \\
\hline $\mathrm{Tc}$ & 928 & 99 & 16 & c \\
\hline \multirow[t]{2}{*}{$\mathrm{Ru}$} & $3.94 \times 10^{3}$ & 103 & $2.243 \times 10^{6}$ & 8301 \\
\hline & & 106 & $2.181 \times 10^{6}$ & $1.810 \times 10^{4} \mathrm{e}$ \\
\hline $\mathrm{Rh}$ & $1.01 \times 10^{3}$ & 106 & $2.181 \times 10^{6}$ & - \\
\hline $\mathrm{Pd}$ & $2.77 \times 10^{3}$ & 107 & 0.4 & c \\
\hline $\mathrm{Ag}$ & 518 & 111 & $3.368 \times 10^{4}$ & 84 \\
\hline $\mathrm{Cd}$ & 294 & $115 \mathrm{~m}$ & $5.178 \times 10^{3}$ & 21 \\
\hline In & 16 & $115 \mathrm{~m}$ & 7 & c \\
\hline Sn & 213 & 125 & $1.535 \times 10^{4}$ & 78 \\
\hline $\mathrm{Sb}$ & 141 & 125 & $8.318 \times 10^{4}$ & 299 \\
\hline $\mathrm{Te}$ & 870 & $\mathrm{f}$ & $\mathrm{g}$ & g \\
\hline I & 511 & 131 & $2.396^{6} \times 10^{5}$ & 839 \\
\hline $\mathrm{Xe}$ & $4.68 \times 10^{3}$ & 133 & $8.607 \times 10^{4}$ & 103 \\
\hline \multirow[t]{2}{*}{$\mathrm{Cs}$} & $3.65 \times 10^{3}$ & 134 & 317 & c \\
\hline & & 137 & $8.422 \times 10^{4}$ & $446^{h}$ \\
\hline $\mathrm{Ba}$ & 922 & 140 & $5.742 \times 10^{5}$ & 1780 \\
\hline $\mathrm{La}$ & 903 & 140 & $6.657 \times 10^{5}$ & 1112 \\
\hline \multirow{2}{*}{$\mathrm{Ce}$} & $2.62 \times 10^{3}$ & 141 & $1.469 \times 10^{6}$ & 2203 \\
\hline & & 144 & $1.453 \times 10^{6}$ & $1.002 \times 10^{4^{i}}$ \\
\hline \multirow[t]{2}{*}{$\mathrm{Pr}$} & $1.03 \times 10^{3}$ & 143 & $7.025 \times 10^{5}$ & 1335 \\
\hline & & 144 & $1.453 \times 10^{6}$ & - \\
\hline $\mathrm{Nd}$ & $2.63 \times 10^{3}$ & 147 & $1.839 \times 10^{5}$ & 515 \\
\hline $\mathrm{Pm}$ & 397 & 147 & $3.723 \times 10^{5}$ & 186 \\
\hline $\mathrm{Sm}$ & 475 & 151 & $6.647 \times 10^{3}$ & 1 \\
\hline \multirow[t]{2}{*}{$\mathrm{Eu}$} & 69 & 155 & $1.110 \times 10^{4}$ & 8 \\
\hline & & 156 & $6.240 \times 10^{3}$ & 44 \\
\hline Total & $\overline{36.3 \times 10^{3}}$ & & $\overline{21.13 \times 10^{6}}$ & $\overline{76.72 \times 10^{3}}$ \\
\hline
\end{tabular}

ancludes all stable and radioactive isotopes of the element.

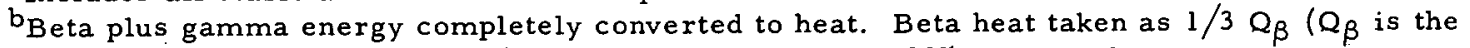
maximum beta-particle energy). Gamma heat taken as $100 \%$ gamma photon energy.

c Negligibly small.

$\mathrm{d}_{\text {Includes }}{ }^{90} \mathrm{Y}$ decay.

Includes ${ }^{106} \mathrm{Rh}$ decay.

$\mathrm{f}_{\text {Mainly }}{ }^{125 \mathrm{~m}} \mathrm{Te},{ }^{127} \mathrm{Te},{ }^{127 \mathrm{~m}} \mathrm{Te},{ }^{129} \mathrm{Te}$, and ${ }^{129 \mathrm{~m}} \mathrm{Te}$.

$\mathrm{g}_{\text {Not calculated, small value. }}$

$\mathrm{h}_{\text {Includes }}{ }^{137 \mathrm{~m}_{\mathrm{Ba}} \text { decay. }}$

${ }^{\mathrm{i}}$ Includes ${ }^{144} \operatorname{Pr}$ decay. 
for 500 days followed by a.30-day cooling period. The conversion of decay energy to heat.was calculated assuming total conversion of all beta.particles and gamma photons to heat. The totals are $2.11 \times 10^{7}$ beta curies and $7.67 \mathrm{x}$ $10^{4} \cdot \mathrm{W}$ per average daily."load of fuel, or $80 \mathrm{~W} / \mathrm{kg}(\mathrm{U}+\mathrm{Pu})$.

\subsection{Is otopic Distribution of Heavy Elements in FBR Fuel}

Data. on the isotopic content of discharged FBR fuel at equilibrium are available from the AI study on a large LMFBR. ${ }^{11}$ No data are readily available for fuel that precisely match the ground rules (e.g., $100 \mathrm{GWd}$ ) metric ton burnup), nor do the ground rules specify the neutronic characteristics of the reactors from which the fuel is obtained. Although information on isotopic distribution of heavy elements in the fuel is not precise, it should be adequate to illustrate the magnitude of effects.

\subsubsection{Uranium and Neptunium}

Depleted uranium is used throughout the FBR and, for ease of estimation, only little ${ }^{235} \mathrm{U}$ is assumed to be discharged from the reactor. Minor amounts. of other isotopes of uranium such as ${ }^{237} \mathrm{U},{ }^{232} \mathrm{U}$, and ${ }^{236} \mathrm{U}$ are formed by $(n, 2 n), \alpha$ decay, and $(n, \gamma)$ reactions. The most abundant of the minor isotopes, ${ }^{237} \mathrm{U}$, represents only $\sim 100$ parts per billion parts of uranium in 30-day-cooled fuel averaged over the entire reactor. Core fuel and radial blanket fuel, which show slightly greater concentrations of ${ }^{237} \mathrm{U}$, contain. less than $200 \mathrm{ppb}$.

The only isotope of neptunium present in significant quantity after 30 -day cooling of the fuel is ${ }^{237} \mathrm{~Np}$. The fuel mixture from all parts of the reactor (core, axial blanket, and radial blanket) will contain approximately 1.70 parts neptunium per million parts of $\mathrm{U}+\mathrm{Np}+\mathrm{Pu}$. Neptunium concentration in the core can be expected to reach $\sim 300$ ppm since the harder neutron flux at that site increases the rate of the $(n, 2 n)$ reaction with ${ }^{238} \mathrm{U}$.

\subsubsection{Plutonium}

The isotopic distribution of discharged.plutonium depends, in part, on the "quality" of the plutonium used as feed.in the core. The AI study" assumes an input of equilibrium makeup plutanium composed of $66 \%{ }^{239} \mathrm{Pu}$, $27 \%{ }^{240} \mathrm{Pu}, 5 \%{ }^{241} \mathrm{Pu}$, and $2 \%{ }^{242} \mathrm{Pu}$, and this composition is used to calculate the discharge composition. Further, we assumed that after 30-day cooling, one-half of the ${ }^{236} \mathrm{~Np}$ discharged has converted to ${ }^{236} \mathrm{Pu}$, all of the ${ }^{239} \mathrm{~Np}$ has decayed to ${ }^{239} \mathrm{Pu}$, and all ${ }^{243} \mathrm{Pu}$ has decayed to ${ }^{243} \mathrm{Am}$. Also, the decay of

${ }^{24.1} \mathrm{P}$ u during the cooting period-has-been-ignored. T-able-2.5-show-s-theresulting composition of plutonium in.30-day-cooled fuel. 
TABLE 2.5. Isotopic Composition of Plutonium in AI Reference Fuel Cooled 30 days

\begin{tabular}{lccccc}
\hline \multicolumn{5}{c}{ Fraction of Total Plutonium } \\
\cline { 2 - 6 } & Core & $\begin{array}{c}\text { Axial } \\
\text { Blanket }\end{array}$ & $\begin{array}{c}\text { Core plus Axial } \\
\text { Blanket }\end{array}$ & $\begin{array}{c}\text { Radial } \\
\text { Blanket }\end{array}$ & $\begin{array}{c}\text { Total } \\
\text { Reactor }\end{array}$ \\
\hline${ }^{236} \mathrm{Pu}$ & $3.27 \times 10^{-8}$ & $2.29 \times 10^{-10}$ & $2.89 \times 10^{-8}$ & $4.59 \times 10^{-8}$ & $3.15 \times 10^{-8}$ \\
${ }^{238} \mathrm{Pu}$ & $2.07 \times 10^{-4}$ & $1.38 \times 10^{-5}$ & $1.85 \times 10^{-4}$ & $3.38 \times 10^{-4}$ & $2.08 \times 10^{-4}$ \\
${ }^{239} \mathrm{Pu}$ & 0.622 & 0.9738 & 0.663 & 0.9568 & 0.7071 \\
${ }^{240} \mathrm{Pu}$ & 0.307 & 0.0256 & 0.275 & 0.0416 & 0.2397 \\
${ }^{241} \mathrm{Pu}$ & 0.047 & $4.48 \times 10^{-4}$ & 0.0415 & $1.16 \times 10^{-3}$ & 0.0355 \\
${ }^{242} \mathrm{Pu}$ & 0.023 & $5.13 \times 10^{-6}$ & 0.0206 & $.14 \times 10^{-5}$ & 0.0175 \\
\hline
\end{tabular}

The composition of plutonium from the core and axial blanket approximates that assumed in the AI study for equilibrium feed to the core. The effects of ${ }^{238} \mathrm{Pu}$ and ${ }^{236} \mathrm{Pu}$ and their decay products on the properties of plutonium related to refabrication are not part of this or the AI study, but will need to be considered in a study of expanded scope. Effects of alpha radiation from plutonium and gamma radiations from fission products on the decomposition of $\mathrm{PuF}_{6}$ are discussed separately in Section 4.3.8.3. 


\section{DESCRIPTION OF. REFERENCE PROCESS}

This section of the report comprises a descriptive account of the reference process. The process, shown schematically in the simplified flowsheet in Fig. 3.1, includes a mechanical head-end (which separates the fuel from the cladding), continuous fluid-bed fluorination (in which the uranium and plutonium are converted to their respective hexafluorides in separate reactors), separate purification methods for the $\mathrm{UF}_{6}$ and $\mathrm{PuF}_{6}$, and reconversion of the hexafluorides to a particulate oxide product suitable for refabrication into nuclear fuel. A combination of continuous units (the fluorinators, stills, and converter) and batch units is used. Duplicate or triplicate batch units allow one unit to be on stream at all times, thereby obtaining overall continuous operation of the plant.

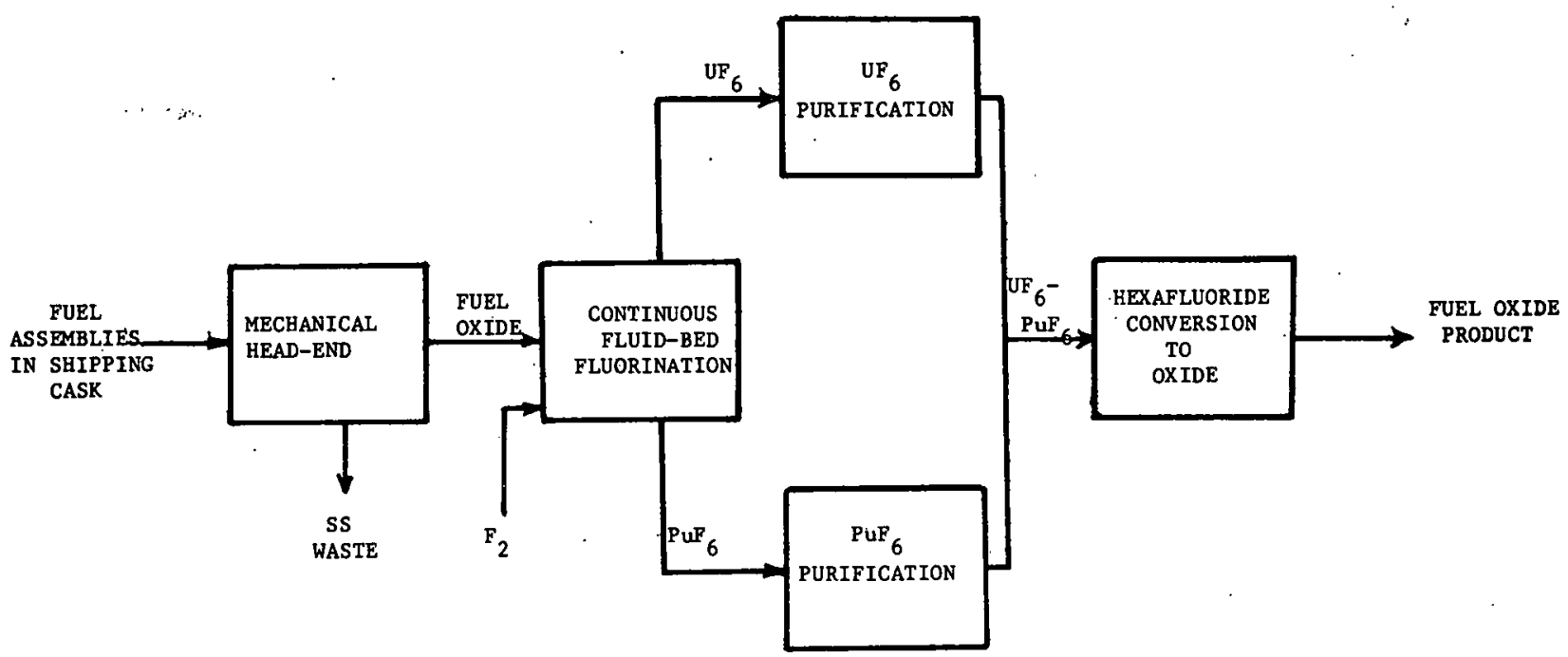

Fig. 3.1. Conceptual Fluoride-volatility Process for LMFBR Fuels.

Reference fuel: $\mathrm{PuO}_{2}-\mathrm{UO}_{2}$ clad in stainless steel.

Each main step following receipt of fuel at the plant is described in a separate section (Sections 3.1-3.7), and Section 3.8 describes the treatment of the off-gas. Process systems description, design criteria, and analysis (critique) of each main step are found in corresponding numbered parts of Section 4, which is fully referenced.

\subsection{Mechanical Head-end}

In the reference process, the mechanical head-end (shown schematically in Fig. 3.2) involves a sequence of mechanical operations performed on the fuel elements to separate the stainless steel cladding from the fuel and to provide fuel in a form suitable for the fluorination step which follows. The sequence of head-end operations is: 
a. Unloading of fuel elements from shipping containers.

b. Removal of sodium from external surfaces of the fuel elements in a cleaning vessel.

c. Transfer of fuel elements into the storage pool.

d. Mechanical disassembly of fuel elements into individual fuel pins.

e. Assay of fuel pins to identify sodium-logged pins (sodium logging of $1 \%$ of the fuel pins is a ground rule).

f. Rebundling of intact fuel pins for feeding to the pin chopper.

g. Chopping of the fuel pins into short $(\sim 1 / 2-$ in. $)$ lengths.

h. Continuous ball-milling of the fuel to separate powdered fuel from the hulls.

i. Examination of separated stainless steel hulls to identify those containing residual fuel.

j. Pneumatic conveyance of the fuel powder to interim storage facilities preparatory to chemical processing.

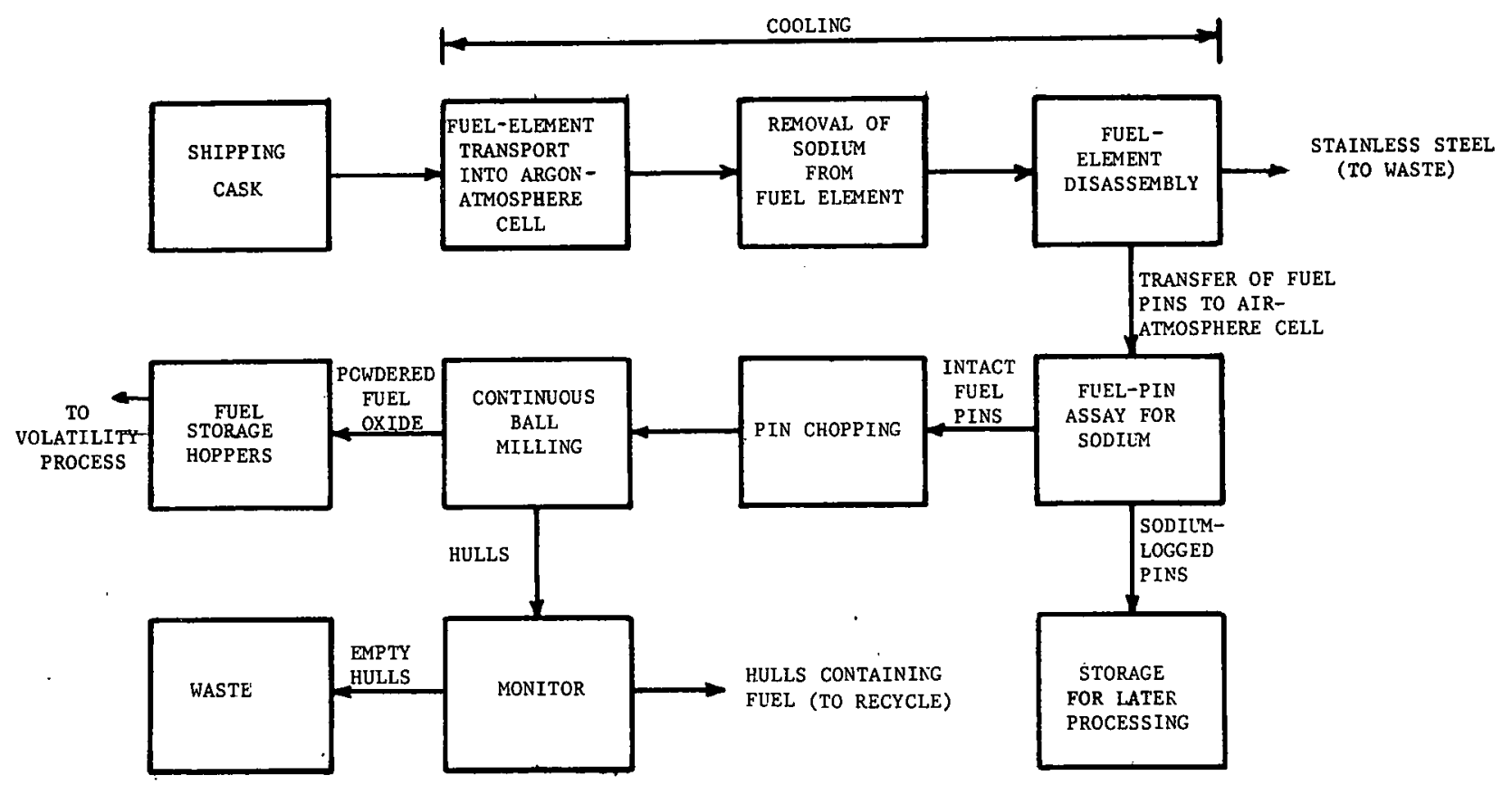

Fig. 3.2. Mechanical Head-end Process

The fuel elements shipped to the process plant do not have attached to them inactive (neutron shield) ends, which are removed before shipping. The fuel is received at the process plant in shipping casks containing sodium as a heat-transfer medium. Each fuel element is sealed in a can filled with sodium, and each can is located in a sodium-filled.hole in the cask. Upon arrival at the process plant, a cask is lowered onto a transfer cart in an 
underground passageway. The cart transports the cask to a position under the fuel-unloading cell. The cask is lifted and sealed against a transfer hatch in the floor of the fuel-unloading cell, which contains an inert-gas atmosphere. After purging of the space between the cask and the hatch, the cell hatch cover is removed and the cask cover is unbolted and lifted aside. One by one, the cans are opened and the fuel elements lifted out, using a grapple. During transfer, part of the cooled cell gas is circulated through the fuel element to stabilize its temperature at a safe level.

Each fuel element is transferred into a cleaning vessel for the removal of exterior sodium. Sodium is removed by reacting it with dry air (forming sodium oxide) and then washing the fuel element with water; this method avoids the formation of hydrogen. The fuel element is next transferred to a storage pool preparatory to underwater disassembly.

Succeeding fuel elements are then processed in the same manner until all have been unloaded from the cask, cleaned, and stored. The cans are resealed and returned to the shipping cask. The cask cover is replaced and secured, and the cask is returned to a reactor site for reuse.

The fuel elements in storage are next moved to the underwater disassembly station. An abrasive circular saw crops the top and bottom parts of each fuel element without cutting into the fuel-containing sections of the pins. (The pins contain fission-product gases under considerable pressure, perhaps 500-1000 psi.) Cutting through the shroud of the fuel element allows the fuel-pin end plate to be removed. The fuel pins are then pulled out, removed from the water, and allowed to dry.

The fuel pins are each assayed for sodium logging (i.e., for sodium that has leaked into the fuel pin as a result of cladding failure) in an airatmosphere cell. For this purpose, an eddy-current device is used similar to one developed for detecting sodium bond defects in EBR-II fuel pins. The fuel pins are passed through the assay coil one by one, running on rollers (as in a rolling mill) at a speed of several feet per second. Logged pins are automatically deflected from the main line and conveyed to a separate storage rack for later processing (described in Section 4.2.4.5). Intact pins are automatically conveyed to a machine for grouping into 25-pin bundles, which are then fed to the pin chopper.

The chopper and the next machine (the ball mill) are operated inside an enclosure to confine the fission-product gases. Each bundle of 25 pins is fed into the chopper through a lock to maintain a controlled atmosphere in the enclosure. The fuel pins are chopped-into-1-/2-in-pie-ees.-E-is.sion-gas_es contained in the fuel pins and released during chopping are fed with a small amount of oxygen (purge gas) into the main off-gas treatment system. The chopped sections of the fuel pins drop into a continuous multicompartment 
ball mill, which is provided with perforations so that as soon as the fuel oxide is dislodged from the stainless steel hulls it falls through the inner shell of the ball mill. With oxygen as the purge gas in the ball mill, pulverization of the fuel is enhanced. A close-fitting screen surrounding the inner shell of the ball mill allows material to fall into a hopper when it reaches the size range selected as suitable for conveying and processing (e.g., less than 40 mesh). Coarser material is retained in the mill for further comminution. The empty hulls are discharged at the far end of the mill; the balls are returned to the front end of the mill. Partitions in the mill separate the compartments and form a dam over which excess hulls spill from the first compartment into the second. Gas is recirculated through the mill and through a cooler to control the temperature of the mill and fuel.

The separated oxide is conveyed, pneumatically, to interim storage hoppers. The hulls are monitored for retained fuel oxide by a method that detects delayed neutrons from fission (induced by irradiation from an external neutron source). This method detects fissile material directly, even in high beta-gamma radiation fields. Suspect hulls are automatically returned to the ball mill. The fuel-free hulls are compressed and sealed in waste cans for disposition in the waste storage facilities (pool or burial ground).

\subsection{Storage and Pneumatic Conveying of Fuel Powder}

The fuel-storage hoppers are weighed continuously, using a system that has automatic readout. The hopper weight is noted while the hoppers are filling and also while they are being emptied (i.e., when the fuel is being fed to the first fluorination reactor). During filling of the hoppers, the change in weight serves as a check on the flow of material through the ball mill. The full hopper is weighed for fuel accountability: as fuel is withdrawn from the hopper, process feed-rate information is obtained. This information is thus used for both monitoring and process control.

The fuel is fed by gravity out of the bottom of the hopper and is conveyed by a circulating oxygen system to the first fluid-bed fluorination reactor (reactor A). Figure 3.3 shows the conceptual pneumatic conveying system. Fuel samples for accountability and burnup analyses are taken directly out of the pneumatic conveyor line.

Downstream from the fuel-sampling point, a sintered grade of granular alumina is injected into the feed stream so that the weight ratio of fuel to alumina in the feed to the fluorinator is 5 to.l. Alumina is the major constituent of all beds used in the fluorination reactions. 


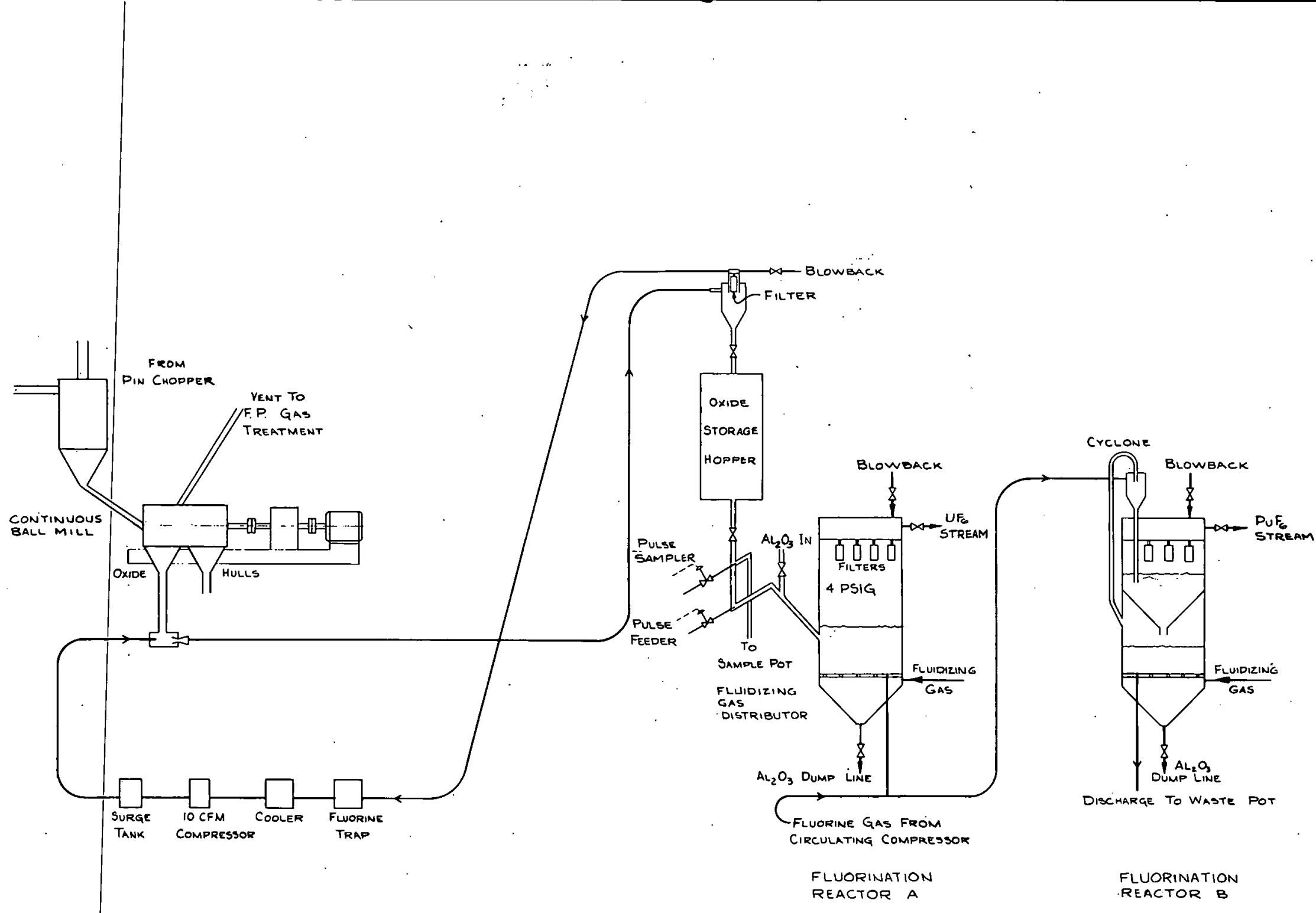

308-1736 Rev. 2

Fig. 3.3. Conceptual Pneumatic Conveying System 
In this conveyor system, as in the conveyor systems used for transporting the powder to the hoppers and from reactor $A$ to reactor $B$, only reactive process gases (fluorine or oxygen) are used, allowing adherence to the philosophy outlined earlier of total containment of waste gases. Oxygen is used between the ball mill and the storage hopper; fluorine is used to convey the solids to reactor $B$. Backleakage of process gas into the conveyor loops is prevented by maintaining a higher pressure in the loop than in the downstream system.

\subsection{Recovery of Uranium--Operation of Reactor A}

Uranium and plutonium are fluorinated to volatile hexafluorides in fluid-bed fluorinators, which are operated continuously. Granular alumina, an inert fluidizable material, serves as solid diluent for fuel and fission products. Continuous fluorination of uranium in a fluid-bed reactor has industrial precedents, the principal example being the Allied Chemical uranium-refining plant at Metropolis, Ill.

Figure 3.4 is a process schematic diagram of uranium and plutonium fluorination in the present reference LMFBR plant. Two fluorinators are used in series. The first (reactor A described in this section) yields virtually all the $\mathrm{UF}_{6}$ for the process, and the second (reactor $\mathrm{B}$ described in Section 3.4) yields $\mathrm{PuF}_{6}$. Associated with each fluorinator are two cold traps (desublimators) in series, the first being fission-product trap FP-1 or FP-2 (principally to condense solid $\mathrm{NbF}_{5}$ and $\mathrm{RuF}_{5}$ ), and the second being product trap CT-1 or CT-2 (condenser) to collect solid hexafluorides.

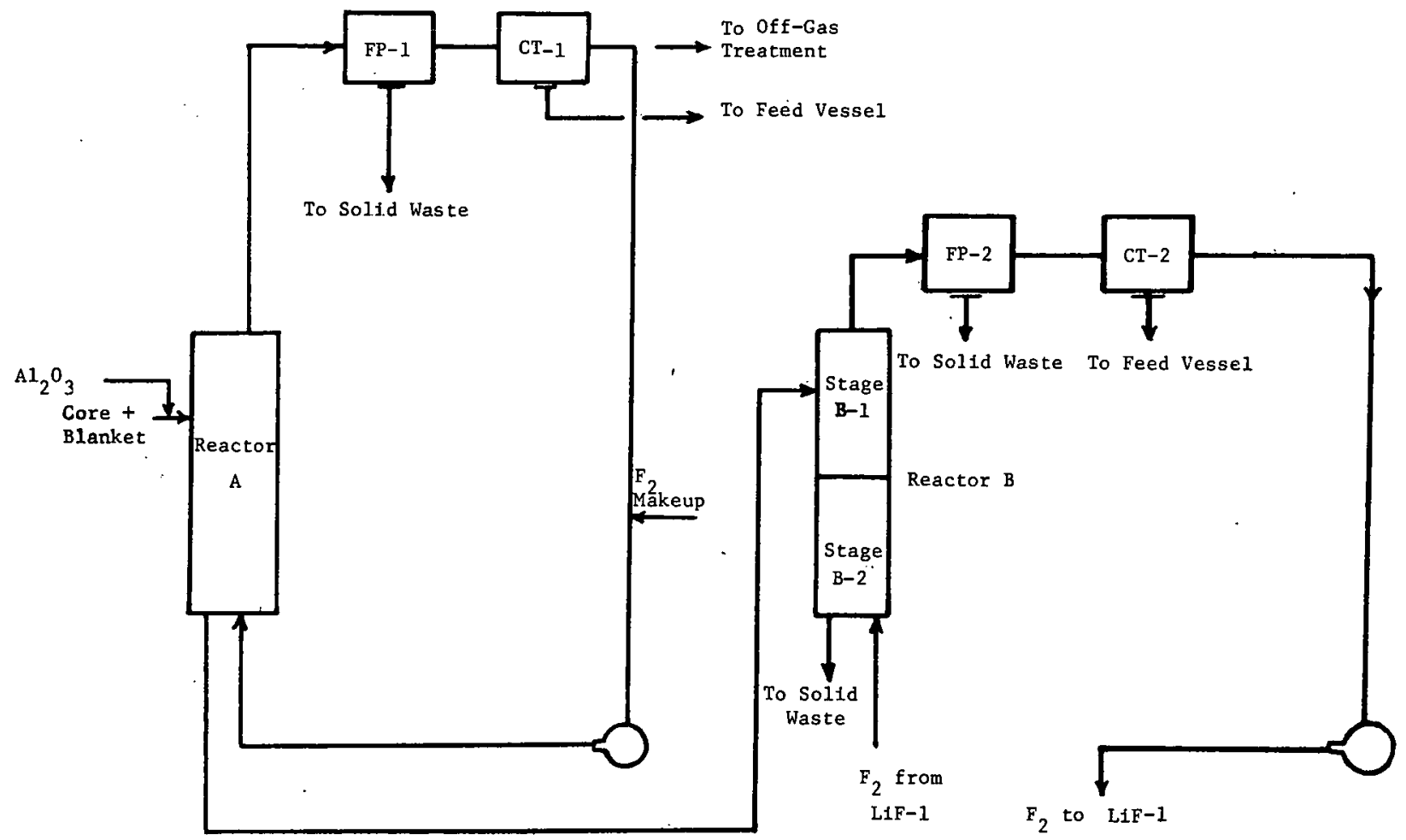

Fig. 3.4. Fluorination of Actinides and Fission Products 
The fluorinators and the condensers are of slab geometry to promote nuclear safety and temperature control by providing a high surfaceto-mass ratio. Also, fluidization promotes solids mixing and heat transfer in the reaction zone of the fluorinators. External forced-air cooling of the fluorinators removes the heat generated by the chemical reaction and by fission-product decay in the fluorinator. Solids are transported pneumatically into and out of the fluid-bed reactors and between reactors, as described in Section 3.2.

Fluorination of uranium with dilute fluorine is the first chemical reaction in the process. In this step, the powdered oxide fuel from the head-end operations and granular alumina are fed continuously into a fluid-bed fluorination reactor. Continuous fluorination under steady-state conditions promises a higher degree of control than would be practical for batch operation. In the reference process, fuel from the core and blanket are blended. In reactor $A, 99 \%$ of the entering uranium is fluorinated to $\mathrm{UF}_{6}$, which exits from the reactor in the gas effluent; the remaining $1 \%$ of the uranium leaves as $\mathrm{UF}_{4}$ in the solid effluent, which is the feed for the following fluid-bed fluorinator. Only a small fraction (4\% maximum) of the plutonium entering reactor $A$ leaves as $\mathrm{PuF}_{6}$ with the $\mathrm{UF}_{6}$ product; the major fraction of the plutonium leaves as $\mathrm{PuF}_{4}$ in the solid effluent from the uranium fluorinator. A substantial portion of the fission products form volatile fluorides and leave with the vapor products of this fluorination; the remainder of the fission products leave with the solid effluent stream, which contains alumina as the major constituent.

This selective fluorination step separates nearly all the uranium as $\mathrm{UF}_{6}$ product. In addition to uranium separation, most of the volatile fission products are separated from the plutonium. Fluorination reference condi-. tions are as follows: temperature of $350^{\circ} \mathrm{C}$, fluidizing gas composition of $23 \%$ fluorine (balance oxygen), and gas flowrate of $1 \mathrm{ft} / \mathrm{sec}$ (at reactor conditions). Under process conditions, a fluorination rate of $100 \mathrm{lb} \mathrm{UF}_{6} /$ $(\mathrm{hr})$ (sq ft of reactor cross-sectional.area) and a fluorine utilization of $75 \%$ are estimated. The reference conditions were chosen to effect UF 6 production at a low temperature. Removal of uranium at a relatively low temperature $\left(350^{\circ} \mathrm{C}\right)$ in reactor $A$ is believed to enhance the efficiency of subsequent removal of plutonium from alumina by fluorination. The maximum $\mathrm{PuF}_{6}$ concentration in the gaseous effluent is expected to be that in equilibrium with the excess fluorine ( $25 \%$ of inlet fluorine) in the effluent. In actual. plant operation, it might be desirable to optimize the fluorinator performance at conditions somewhat different from these reference values.

The combined oxide feed to this fluorination ${ }^{-}$step-in-the-reference plant is 41.4 and $4.0 \mathrm{~kg} / \mathrm{hr}$ of $\mathrm{UO}_{2}$ and $\mathrm{PuO}_{2}$, respectively. The inert alumina flow through the reactor is $10 \mathrm{~kg} / \mathrm{hr}$. The solid effluent rates are as follows: for the alumina, the same rate as the feed rate; for the plutonium, 
virtually the same rate as the feed rate; and for the uranium, about $1 \%$ of the feed rate. It is assumed that solids mixing in fluorinator $A$ is complete and that the overall average fluid-bed composition is the same as the solid effluent composition, which is $27 \mathrm{wt} \% \mathrm{PuF}_{4}, 2.4 \mathrm{wt} \% \mathrm{UF}_{4}$, and $62 \mathrm{wt} \%$ $\mathrm{Al}_{2} \mathrm{O}_{3}$ along with the residual fission-product fluorides. The high degree of uranium removal is achieved with a nominal $12-\mathrm{hr}$ residence time for solids in the reactor, which holds about $222 \mathrm{~kg}$ of total solids. Under the reference steady-state conditions, the plutonium inventory of the fluorinator is $45 \mathrm{~kg}$.

Uranium fluorination to produce the desired chemical separation can be carried out under a wide range of temperatures and compositions, although uranium, plutonium, and fission-product separations are not completely independent of one another.

The distribution of each fission product during fluorination depends on the volatility of its fluoride compounds. Table 3.1 summarizes the fis sion products, indicating which elements form volatile and which nonvolatile fluorides; noble gases are also included since they are released during fluorination. The bulk of the fission products $(21 \mathrm{~kg} / \mathrm{day}) \mathrm{remain}$ in the fluid bed, and these are effectively separated from the actinide hexafluoride products. The other fission products $(9.7 \mathrm{~kg} /$ day) form volatile fluorides and leave the fluorinators with the $\mathrm{UF}_{6}$ and $\mathrm{PuF}_{6} ;$ we have assumed that $90 \%$ of the volatile activity leaves with the uranium hexafluoride product of reactor $A$, and that the remaining $10 \%$ leaves with the plutonium hexafluoride product of reactor $B$.

TABLE 3.1. Distribution of Fission-product Fluorides and Their Associated Radioactivity

\begin{tabular}{lll}
\hline & $\begin{array}{c}\text { Elements } \\
\text { Nonvolatile Fluorides }\end{array}$ & $\begin{array}{c}\text { Elements }{ }^{\mathrm{b}} \text { Forming } \\
\text { Volatile Fluorides }\end{array}$ \\
\hline & $\mathrm{Rb}, \mathrm{Ag}, \mathrm{Cs}$ & ${ }^{3} \mathrm{H}$ \\
& $\mathrm{Sr}, \mathrm{Cd}, \mathrm{Ba}$ & $\mathrm{Nb}, \mathrm{Sb}$ \\
& Y, In, La & $\mathrm{Mo}, \mathrm{Te}$ \\
& $\mathrm{Ce}, \mathrm{Pr}, \mathrm{Nd}, \mathrm{Pm}, \mathrm{Sm}, \mathrm{Eu}$ & $\mathrm{Tc}, \mathrm{I}$ \\
& $\mathrm{Zr}, \mathrm{Sn}$ & $\mathrm{Ru}, \mathrm{Kr}, \mathrm{Xe}$ \\
& $\mathrm{Rh}, \mathrm{Pd}$ & 9.7 \\
Total weight, kg/day & $21 \mathrm{~K}$ & $1.0 \times 10^{7}$ \\
Total activity, Ci/day & $1.1 \times 10^{7}$ & 42 \\
Total heat, $\mathrm{kW} /$ day & 35 & \\
\hline
\end{tabular}

$\mathrm{a}_{\text {These elements remain in the fluid bed. }}$

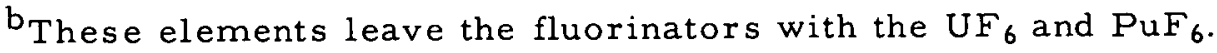

No fluoride formation by krypton.

The niobium and ruthenium represent $96 \%$ of the activity and heat associated with the volatile fission-product fluorides. Therefore, the bulk of the $\mathrm{NbF}_{5}$ and $\mathrm{RuF}_{5}$ are removed in a fission-product trap at $15^{\circ} \mathrm{C}, \mathrm{FP}-1$, 
before the $\mathrm{UF}_{6}$ product is collected in CT-1. Similarly, a fission-product trap, FP-2, downstream from the plutonium fluorinator collects niobium and ruthenium. The fission products are collected by holding these traps at a temperature low enough to condense $\mathrm{NbF}_{5}$ and $\mathrm{RuF}_{5}$ but not low enough to cause appreciable condensation of $\mathrm{UF}_{6}$ and $\mathrm{PuF}_{6}$. Figure 3.5 shows the

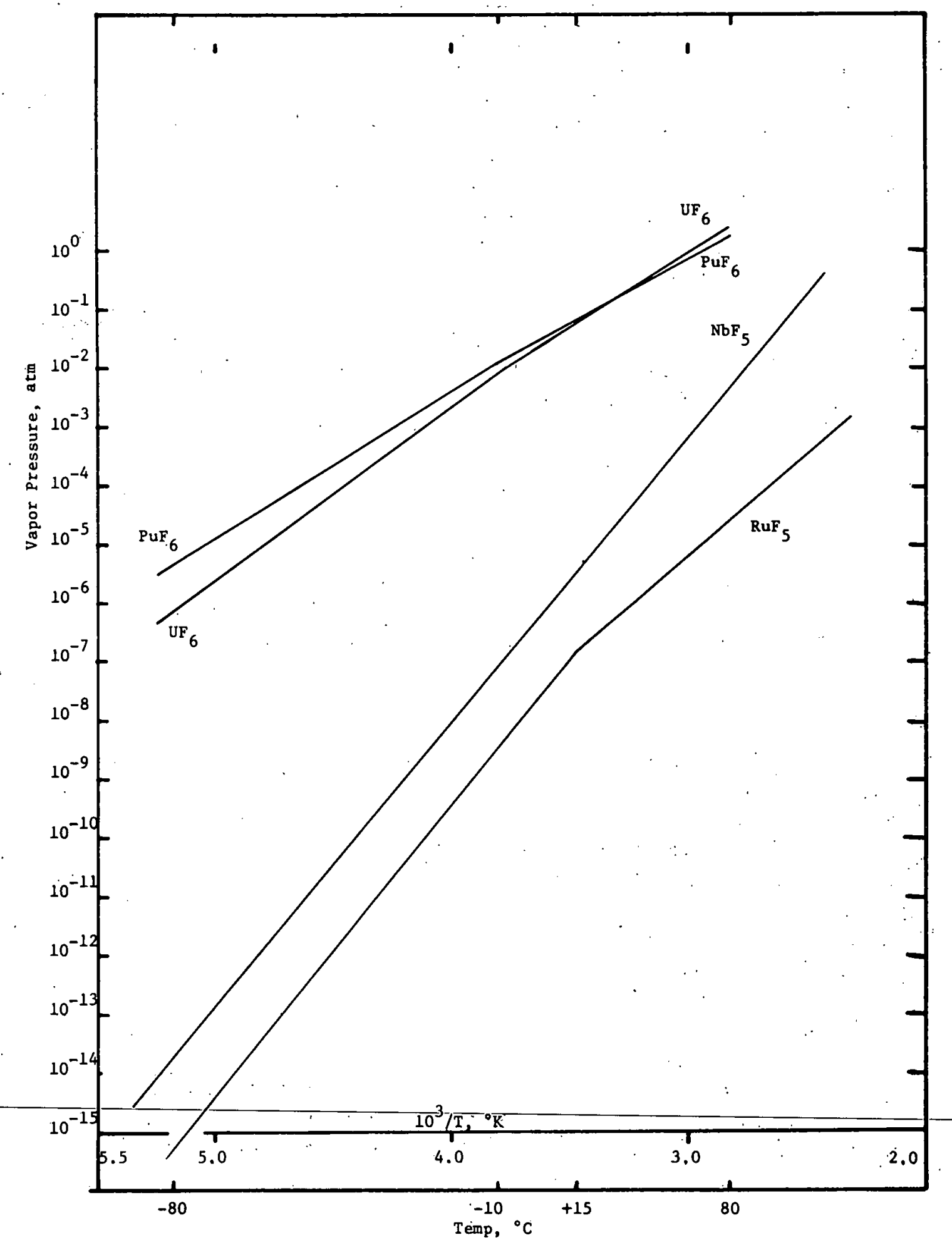

Fig. 3.5. Vapor Pressures of $\mathrm{UF}_{6}, \mathrm{PuF}_{6}, \mathrm{NbF}_{5}$, and $\mathrm{RuF}_{5}$ 
vapor pressures of $\mathrm{NbF}_{5}, \mathrm{RuF}_{5}, \mathrm{UF}_{6}$, and $\mathrm{PuF}$. The hexafluoride decontamination factors obtained in FP-1, based on (1) the inlet concentrations for the reference flow and (2) the exit concentrations as given by vapor pressures at $15^{\circ} \mathrm{C}$, are 4 for $\mathrm{NbF}_{5}$ and 3300 for $\mathrm{RuF}_{5}$.

Each fission-product trap is operated semicontinuously; one of two FP-1 units (i.e., FP-1A or FP-1B) is on-streamwhile the other is on a trap-emptying cycle. The traps are emptied by heating the trap to about $200^{\circ} \mathrm{C}$ in a purge of oxygen. This purged waste gas, containing the volatile fission products, is passed through beds of sodium fluoride. The volatile fission products are absorbed on the solid beds, which are periodically removed and packaged for storage as solid waste. The oxygen and any nonabsorbed material in the gas effluent from the absorbers enter the wastegas treatment system for volume reduction and further handling. The details of these operations are described later.

Process gas passing through the fission-product trap enters the product-collection trap (CT-1), where solid hexafluoride product is condensed at about $-80^{\circ} \mathrm{C}$. At this temperature, virtually all actinides and volatile fission products including $\mathrm{XeF}_{4}$ are deposited as solids: krypton remains a gas along with oxygen and unused fluorine. Such product traps for $\mathrm{UF}_{6}$ have been extensively used in large production facilities at AEC gaseous diffusion plants and at the Allied Chemical Plant for UF 6 refining at Metropolis, Ill., and will be used at the l-ton/day reprocessing plant to be built by General Electric at Morris, Ill... About. $650 \mathrm{~kg}$ of.condensed product is collected in CT-l during each cycle. Of the hexafluoride entering the trap, only about $0.001 \%$ remains in the vapor passing through the condenser at reference conditions. The equivalent value in concentration is about 4 ppm in the exit-gas stream.

The hexafluoride contents of product trap CT-1 are removed by heating the trap and draining the contents as liquid into the feed vessel for the thermal decomposition step (described in Section 3.5). A batch of material transferred from the trap contains about $650 \mathrm{~kg}$ of $U F_{6}$ and $2.5 \mathrm{~kg}$ of $\mathrm{PuF}_{6}$ (max), as well as the volatile fission-product activity, which has been separated from the nonvolatile fission products krypton, niobium, and ruthenium. The total uranium decontamination factor achieved by the above fission-product separations is about 40 .

Gas passing through product trap CT-l contains oxygen, krypton, residual fluorine, and a small amount of uncondensed actinides and fission products. This gas is recycled to fluorinator A by means of a pump. Fluorine recycle provides a higher overall fluorine-utilization efficiency than the nominal fluorine utilization of $75 \%$ for once-through operation. 
Part of the gas $(2.2 \mathrm{scfm})$ is bled out of the recirculating system at a rate sufficient to remove oxygen released from the oxides in the fluorination step. This gas contains about $6 \%$ fluorine. The gas bled out is passed through alumina and soda lime absorber beds, which are periodically discharged as waste. The gas passing through the absorber beds is sent to the waste-gas system for volume reduction and packaging. Off-gas treatment is described in more detail in Section 3:8.

\subsection{Recovery of Plutonium--Operation of Reactor B}

Fluorination of plutonium to yield $\mathrm{PuF}_{6}$ is accomplished in a continuous fluid-bed fluorinator with concentrated fluorine at $500-550^{\circ} \mathrm{C}$. Figure 3.4 is a schematic diagram of this operation. Equipment associated with the vapor product includes a volatile fission-product collection trap, FP-2, and a hexafluoride product collection trap, CT -2 , in addition to the fluorinator (reactor $B$ ). Fluorination of the plutonium is carried out on feed material, which is the solid effluent of the uranium fluorinator (reactor A) described in Section 3.3. The basic design features of the fluorinators are similar, but conditions are somewhat different owing to different process requirements.

Plutonium fluorination is carried out continuously in a two-stage fluid-bed reactor. The two stages ( $B-1$ and $B-2$ in reactor $B$ ) provide flow of solids countercurrent to concentrated fluorine to enhance the removal of plutonium from the solids. The solids feed (from reactor $A$ ) enters the upper stage of reactor $B$ and has a reference composition of 27 wt $\% \mathrm{PuF}_{4}$, 2.4 wt $\% \mathrm{UF}_{4}, 62$ wt $\% \mathrm{Al}_{2} \mathrm{O}_{3}$, and fission-product fluorides. Fluorination in the upper stage (B-1) is conducted at $500^{\circ} \mathrm{C}$; the gas for fluorination and fluidization enters at the bottom of the lower stage. The gas leaving the upper stage is the product gas effluent and contains $\mathrm{PuF}_{6}$ product, which passes through a fission-product cold trap (FP-2) and a product-collection cold trap $(C T-2)$ as shown in Fig. 3.4. The fluorination gas is recycled by means of a pump.

Fluorination in the lower stage is carried out at $550^{\circ} \mathrm{C}$ on the solids received from the upper stage. The fluorination and fluidization gas entering the reactor at the lower stage is principally $(\sim 90$ vol \%) fluorine. Fluorine is added as makeup to the residual gas.in the recirculating-gas system as needed. A portion of this recirculating-gas stream serves as the motive gas in the pneumatic transport of solids from reactor A to reactor $B$.

The sizes of the fluid beds in both stages of the plutonium fluorinator (reactor B) are such that the average solids residence-time-i-s-a-bout $9 \mathrm{hr}$ in each stage. We assumed that solids mixing is complete and that the average solids compositions in the two stages at reference conditions are the same as the respective effluent compositions for each stage: for the 
upper stage, 4 wt $\% \mathrm{PuF}_{4}, 82$ wt $\% \mathrm{Al}_{2} \mathrm{O}_{3}, 0.02$ wt $\% \mathrm{UF}_{4}$, and $\sim 14$ wt $\%$ fissionproduct fluorides; for the lower stage, 85 wt $\% \mathrm{Al}_{2} \mathrm{O}_{3}, 15$ wt $\%$ fission-product fluorides, and $0.07 \mathrm{wt} \% \mathrm{PuF}_{4}$. The total solids inventories of the upper and lower stages are about $106 \mathrm{~kg}$ each. The plutonium inventories are $4 \mathrm{~kg}$ of $\mathrm{PuF}_{4}$ in the upper stage and $0.07 \mathrm{~kg}$ of $\mathrm{PuF}_{4}$ in the lower stage. The overall average $\mathrm{PuF}_{6}$ production rate (both stages) is $\sim 13 \mathrm{lb}$ of $\mathrm{PuF}_{6}$ per (hr)(sq ft of reactor cross-sectional area). Based on the $P u F_{6} / F_{2}$ equilibrium, the once-through fluorine efficiency is $90 \%$ in the reference fluorinator.

The solids leaving the plutonium fluorinator in the reference process contain less than 0.2 wt $\%$ of the original plutonium input to the process. This waste contains about 50 wt $\%$ of the total input fission-product activity. The cooling requirement is nearly all due to fission products: $16 \mathrm{~kW}$ for each stage. Solids waste is transported to waste containers and sent to interim storage. The details of waste handling and the waste storage system are described later in the report.

The fission-product trap, FP-2, in the recirculating process-gas loop of the plutonium fluorinator operates at $-10^{\circ} \mathrm{C}$. This temperature, which is lower than that for the trap FP-l in the uranium fluorinator, is appropriate for the removal of fission product $\mathrm{NbF}_{5}$ and $R u F_{5}$ from product gas having a lower concentration of actinide hexafluorides. The mode of operation of the fission-product trap in this step is the same as for the fission-product trap in the uranium fluorination step (described in Section 3.3).

The product hexafluoride collection traps, CT-2A and CT-2B, and the waste-gas handling system for plutonium fluorination are similar to those for uranium fluorination (described in Section 3.3 ). About $60 \mathrm{~kg}$ of condenser product is collected in each cycle; of the plutonium hexafluoride entering the product trap, only about $0.05 \%$ remains in the vapor that passes through the trap at reference conditions. This quantity is represented by an exit concentration of about $5 \mathrm{ppm}$. The gas bleed from this process step is recycled to reactor A to minimize plutonium losses. The $\mathrm{PuF}_{6}$ is removed from the product cold trap by heating and draining into the feed vessel for the thermal-decomposition step.

Total decontamination of plutonium to this point, based on the calculated removal of nonvolatile fission products, of noble gases, and of niobium and ruthenium in the fission-product trap, is about 400 .

\subsection{Plutonium Purification and Separation from $\mathrm{UF}_{6}$}

In the next sequence of operations in the reference process, (a) the $\mathrm{UF}_{6}$ and $\mathrm{PuF}_{6}$ are partially decontaminated, (b) the $\mathrm{PuF}_{6}$ is separated from the $\mathrm{UF}_{6}$, and (c) $\mathrm{PuF}_{6}$ decontamination is essentially completed. Figure 3.6 shows this portion of the flowsheet schematically. Steps a and $c$ are simple 
one-stage batch-distillation (evaporation) operations in which further use is made of the fact that volatilities of the fission-product fluorides differ from those of $\mathrm{UF}_{6}$ and $\mathrm{PuF}_{6}$ to effect some decontamination. Step $\mathrm{b}$ is a fluid-bed thermal-decomposition step in which the Pu.F 6 decomposes to solid $\mathrm{PuF}_{4}$, separating it from the $\mathrm{UF}_{6}-\mathrm{PuF}_{6}$ feed; some decontamination of the plutonium is also effected here. In each step, slab-shaped vessels are used--the same design as is used in the fluorinators and cold traps. Operations are conducted basically on alternating 12-hr cycles; to maintain continuity of operations, dual units are provided for each step. The feed vessels and cold traps, used as evaporators, are mounted on scales to monitor and allow control of transfer and distillation.

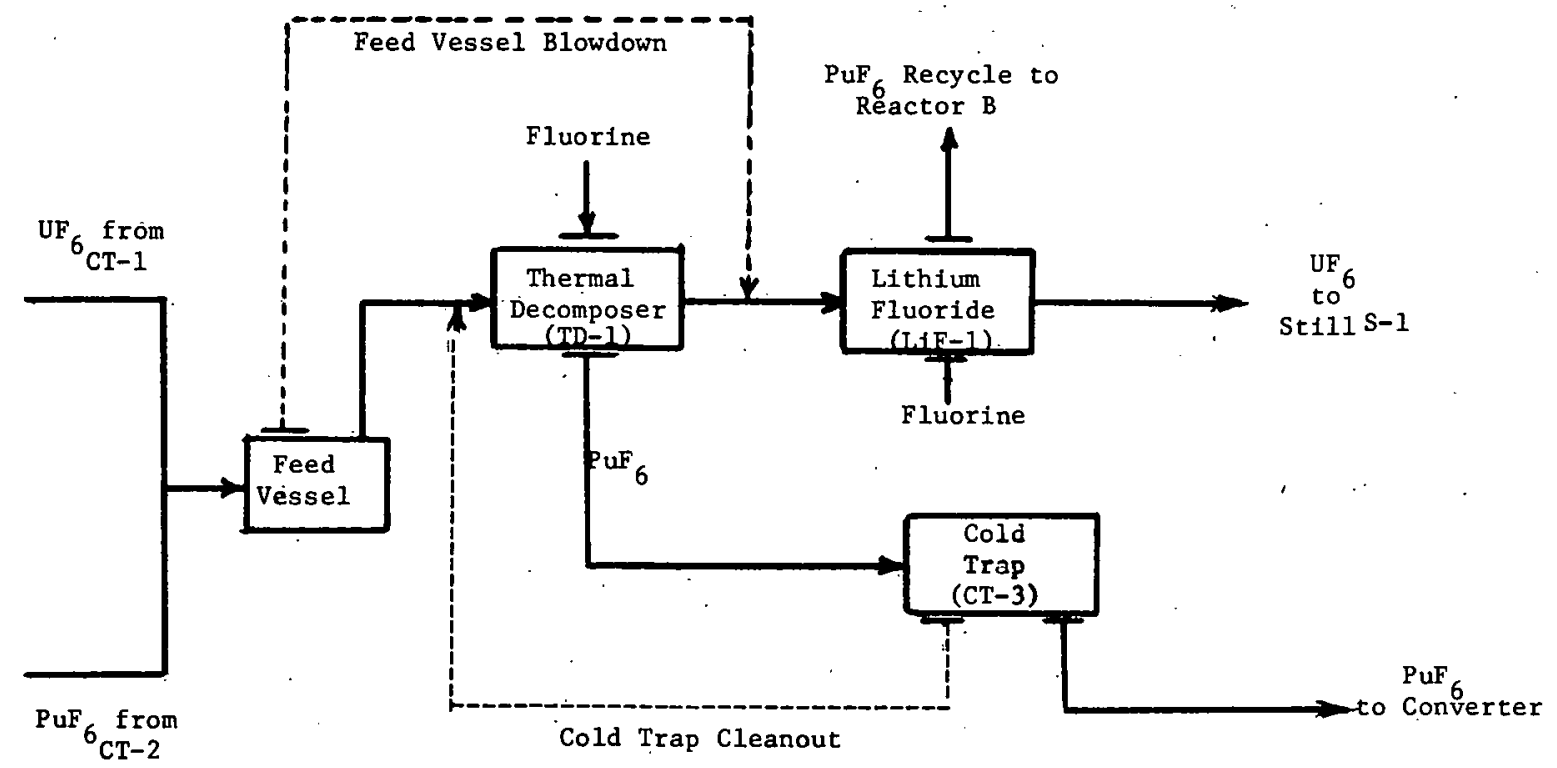

Fig. 3.6. Plutonium Purification and Separation from $\mathrm{UF}_{6}$

At the start of this sequence, the $\mathrm{UF}_{6}$ and $\mathrm{PuF}_{6}$ are combined in one of the feed vessels to the thermal decomposer. A batch, consisting of about $645 \mathrm{~kg}$ of $\mathrm{UF}_{6}$ and $61 \mathrm{~kg}$ of $\mathrm{PuF}_{6}$, is dis -

TABLE 3.2. Decontamination Achieved by Single-stage Evaporation from Feed Vessel with Greater than $99 \%$ of $\mathrm{UF}_{6}$ and $\mathrm{PuF}_{6}$ Taken Overhead

\begin{tabular}{lcc}
\hline Compound & Volatilized, \% & $\begin{array}{c}\text { Decontamination } \\
\text { Factor }\end{array}$ \\
\hline $\mathrm{UF}_{6}$ & 99.9 & - \\
$\mathrm{NpF}_{6}$ & 99.8 & - \\
$\mathrm{PuF}_{6}$ & 99.3 & - \\
$\mathrm{NbF}_{5}$ & 0.08 & 1250 \\
$\mathrm{RuF}_{5}$ & 1.24 & 80.5 \\
$\mathrm{SbF}_{5}$ & 24.4 & 4.1 \\
$\mathrm{XeF}_{4}$ & 34.8 & 2.9 \\
$\mathrm{IF}_{5}$ & 73.3 & 1.36 \\
\hline
\end{tabular}
tilled at $80^{\circ} \mathrm{C}$ and about 34 psia pressure. Distillation from the feed vessel is continued until there is a significant drop in production rate, signifying a marked buildup of higher boiling materials in the bottoms. Calculations of decontamination factors, for $99.9 \%$ removal of $\mathrm{UF}_{6}$ at the conditions indicated, using simple binary relationships, show a $\mathrm{DF}$ of about $10^{3}$ for $\mathrm{NbF}_{5}$, about 80 for $\mathrm{RuF}_{5}$, and less for compounds boiling at lower temperatures such as $\mathrm{SbF}_{5}$ and IF $_{5}$ (as shown in Table 3.2). 
The residue in the feed vessel is flashed to the $\mathrm{UF}_{6}$ purification system, passing enroute through a $\operatorname{LiF}$ trap $(\mathrm{LiF}-\mathrm{l})$ at $300^{\circ} \mathrm{C}$, which retains the $\mathrm{PuF}_{6}$ fraction by formation of a complex. The feed vessel is now ready for the next cycle.

Thermal decomposition of $\mathrm{PuF}_{6}$ is conducted at $350^{\circ} \mathrm{C}$ as a fluid-bed operation; the $\mathrm{UF}_{6}-\mathrm{PuF}_{6}$ distillate from the feed vessel is the fluidizing gas. One batch of hexafluorides in the feed vessel is processed through the thermal decomposer in about $12 \mathrm{hr}$. Granular alumina is present as the starting bed material, on which the $\mathrm{PuF}_{4}$ deposits. A relatively fine alumina is used, permitting a low fluidizing velocity and thereby extending gas residence time. With about a $10-\mathrm{sec}$ residence time in the bed, it is calculated on the basis of equilibrium considerations that $99.6 \%$ of the $\mathrm{PuF}_{6}$ in the feed decomposes to $\mathrm{PuF}_{4}$.

In the stream leaving the decomposer is $\mathrm{UF}_{6}$, undecomposed $\mathrm{PuF}_{6}$, fluorine produced during decomposition, and the bulk of the volatile fission products (a DF of 1000 is assumed across the thermal decomposer). This stream passes first through the LiF-l trap, which retains the undecomposed $\mathrm{PuF}_{6}$, then to the $\mathrm{UF}_{6}$ purification stills.

The $\mathrm{PuF}_{6}$ sorbed on the $\mathrm{LiF}$ is recovered by refluorinating at $450^{\circ} \mathrm{C}$, using the reactor $B$ fluorine stream, and recycling the plutonium to the B loop. Dual LiF traps are used so that the sorbed $P u F_{6}$ on one trap can be recovered while the second trap is on-stream during decomposition. The LiF is reused for a number of cycles and discarded to waste only when the buildup of fission-product activity represents an excessive. heat load. Then, the trap and contents are removed as a unit.

The bed in the thermal decomposer contains about $60 \mathrm{~kg}$ of $\mathrm{PuF}_{4}$ in about $1: 1$ weight ratio with alumina. It is fluorinated with concentrated fluorine at $500^{\circ} \mathrm{C}$ to recover the plutonium as $\mathrm{PuF}_{6}$. As is characteristic of batch operations, there is.a high rate period followed by a low rate period as the bed becomes depleted in $\mathrm{PuF}_{4}$. The reaction is monitored by observing the weight change of the $\mathrm{PuF}_{6}$ collection cold trap (CT-3) and is stopped at the end of the high rate period, i.e., after about $8 \mathrm{hr}$ of fluorination. By this time, about $95 \%$ of the plutonium has been recovered from the thermal decomposer. The remaining $\mathrm{PuF}_{4}$ in the thermal decomposer represents holdup (not loss) since the bed is reused for the next decomposition cycle. The alumina is reused a number of times and is given an exhaustive fluorination onlý before it is discarded to waste.

The $\mathrm{PuF}_{6}$ recovered in the refluorination operation is cold-trapped in CT-3 at $-80^{\circ} \mathrm{C}$. The cold trap serves both as a collector and as an evaporator. After a batch of $\mathrm{PuF}_{6}$ has been collected, the trap is taken offstream by valving and is heated to $80^{\circ} \mathrm{C}$, liquefying the $\mathrm{PuF}_{6}$ for the partial 
TABLE 3.3. Decontamination Achieved.by Single-stage Evaporation of $90 \%$ of $\mathrm{PuF}_{6}$ from Cold Trap CT -3

\begin{tabular}{lcr}
\hline Compound & Volatilized, \% & $\begin{array}{c}\text { Decontamination } \\
\text { Factor }\end{array}$ \\
\hline $\mathrm{NbF}_{5}$ & 0.04 & 2500 \\
$\mathrm{RuF}_{5}$ & 0.58 & 170 \\
$\mathrm{SbF}_{5}$ & 12.2 & 8 \\
$\mathrm{IF}_{5}$ & 45.9 & 2 \\
\hline
\end{tabular}

evaporation step. About $90 \%$ of the $\mathrm{PuF}_{6}$ is taken overhead in this step; the distillate represents the purified plutonium fraction of the feed stream to the converter. The heel in cold trap CT-3 is recycled as vapor to the thermal decomposer next on line.

Table 3.3 summarizes the decontamination achieved by this single-stage evaporation (calculated

for $90 \%$ removal of the $\mathrm{PuF}_{6}$ ). Although the quantities of key fission products $\mathrm{NbF}_{5}$ and $\mathrm{RuF}_{5}$ are small, the DF's are substantial, more than 1000 and 100 , respectively. At this point, the overall DF required for $\mathrm{PuF}_{6}\left(10^{6}-10^{7}\right)$ has been achieved.

The products of this overall sequence of operations are: (1) $\mathrm{PuF}_{6}$ suitable for feed to the conversion step, (2) $U F_{6}$, still contaminated, for feed to the continuous $\mathrm{UF}_{6}$ distillation (purification) columns, and (3) some $\mathrm{PuF}_{6}$ ( $1 \%$ of the input) from trap LiF-l for recycle to reactor B. Over an extended period of operation, some alumina and LiF waste solids will be produced.

\section{$3.6 \mathrm{UF}_{6}$ Purification}

Well-developed methods incorporating continuous fractional distillation and sorption are used to purify the $\mathrm{UF}_{6}$ stream; Fig. 3.7 outlines the purification system. $\mathrm{UF}_{6}$ in the overhead product from the thermal decomposer feeds continuously as saturated vapor to the first still (S-1). Still-pot conditions are $90^{\circ} \mathrm{C}$ and about $33 \mathrm{psia}$. The stream contains, in addition to $\mathrm{UF}_{6}$, volatile fission-product fluorides and fluorine from the thermal decomposition step. The vapor pressures for these volatile compounds are listed and compared with $\mathrm{UF}_{6}$ in Table 3.4. The two compounds with volatilities closest to $\mathrm{UF}_{6}$ (namely, $\mathrm{TcF}_{6}$ and $\mathrm{NpF}_{6}$ ) are not readily separable by distillation, but are selectively sorbed from the UF 6 distillation product stream on $\mathrm{MgF}_{2}$ and $\mathrm{NaF}$, respectively.

In the first still, $\mathrm{UF}_{6}$ is separated from constituents that boil at high temperatures, the key separation being that of $\mathrm{UF}_{6}$ from $\mathrm{IF}_{5}$. The IF 5 and compounds of lower volatility concentrate in the still pot as still bottoms that are periodically discharged as waste. These fission products and the $\mathrm{UF}_{6}$ in the bottoms (equivalent to about a $1 \%$ loss of uranium) are flashed-to-activated-al-umina-and_soda_lime sorption traps. Residual waste gas is vented to the off-gas treatment system. When a waste solids trap becomes exhausted, it is removed as a unit and sent to the storage pool. 


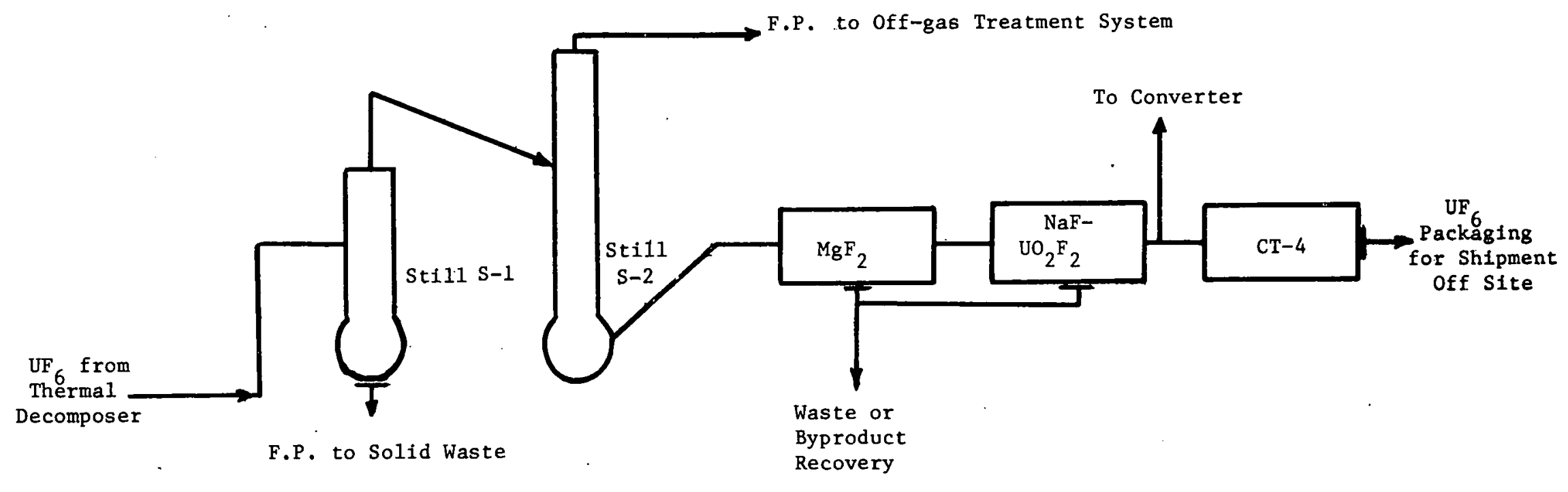

Fig. 3.7. $\mathrm{UF}_{6}$ Purification System 
TABLE 3.4. Vapor Pressures for Volatile Compounds in UF 6 Purification System

\begin{tabular}{lcc|ccc}
\hline Component & $\begin{array}{c}\text { Vapor } \\
\text { Pressure, } \\
\mathrm{mm} \mathrm{Hg} \text { at } 80^{\circ} \mathrm{C}\end{array}$ & $\begin{array}{c}\text { Volatility } \\
\text { Relative } \\
\text { to } \mathrm{UF}_{6}\end{array}$ & Component & $\begin{array}{c}\text { Vapor } \\
\text { Pressure, } \\
\mathrm{mm} \mathrm{Hg} \text { at } 80^{\circ} \mathrm{C}\end{array}$ & $\begin{array}{c}\text { Volatility } \\
\text { Relative } \\
\text { to UF }\end{array}$ \\
\hline $\mathrm{TeF}_{6}$ & 19,650 & 10.70 & $\mathrm{IF}_{5}$ & 351 & 0.19 \\
${ }^{3} \mathrm{HF}$ & 4,651 & 2.53 & $\mathrm{XeF}_{4}$ & 114.8 & 0.0617 \\
$\mathrm{MoF}_{6}$ & 3,303 & 1.80 & $\mathrm{SbF}_{5}$ & 74.6 & 0.040 \\
$\mathrm{UF}_{6}$ & 1,840 & 1.00 & $\mathrm{NbF}_{5}$ & 3.3 & 0.0018 \\
$\mathrm{NpF}_{6}$ & 1,652 & 0.90 & $\mathrm{RuF}_{5}$ & 0.21 & 0.00011 \\
$\mathrm{TcF}_{6}$ & 1,628 & 0.88 & & & \\
\hline
\end{tabular}

The bulk of the $\mathrm{UF}_{6}$, the more volatile fission products, and the fluorine move up still S-1 to the overhead condenser. A partial condenser provides liquid reflux to still S-1; the fluorine and saturated vapor leaving the condenser are fed to still S-2.

In still S-2, where operating conditions are similar to those in still $\mathrm{S}-1$, the key separation is between $\mathrm{UF}_{6}$ and the more volatile $\mathrm{MoF}_{6}$. The distillate, a waste containing some $\mathrm{UF}_{6}$ (equivalent to about a $1 \%$ los s of uranium) and fluorine, is treated in the off-gas treatment system. The bottoms, $\mathrm{UF}_{6}$ containing trace amounts of $\mathrm{NpF}_{6}, \mathrm{TcF}_{6}$, and $\mathrm{MoF}_{6}$ as impurities, represent the distillation product.

The $\mathrm{UF}_{6}$ product stream receives a final polishing treatment in $\mathrm{MgF}_{2}$ and $\mathrm{NaF}$ traps. The $\mathrm{MgF}_{2}$ trap, operated at $125^{\circ} \mathrm{C}$, removes about $97 \%$ of the $\mathrm{TCF}_{6}$ and about $90 \%$ of the $\mathrm{MoF}_{6}$. The $\mathrm{TCF}_{6}$ may be recovered from the $\mathrm{MgF}_{2}$ if interest warrants; otherwise this material represents a waste. The $\mathrm{NpF}_{6}$ is reduced to an acceptable level in the $\mathrm{UF}_{6}$ stream by using a staged $\mathrm{NaF}-\mathrm{UO}_{2} \mathrm{~F}_{2}$ trap operated at $\sim 400^{\circ} \mathrm{C}$. The $\mathrm{NaF}$ complexes with the neptunium fluoride as $\mathrm{NpF}_{5} \cdot \mathrm{NaF}$, releasing fluorine. Fluorine is removed from the gas stream by reaction with $\mathrm{UO}_{2} F_{2}$. Four stages of $\mathrm{NaF}-\mathrm{UO}_{2} \mathrm{~F}_{2}$ are used to achieve an $88 \% \mathrm{NpF}_{6}$ removal. At the operating temperature, negligible amounts of $\mathrm{UF}_{6}$ are retained by the $\mathrm{NaF}$. Any $\mathrm{UF}_{6}$ formed by the $\mathrm{F}_{2}-\mathrm{UO}_{2} \mathrm{~F}_{2}$ reaction merely adds to the main $\mathrm{UF}_{6}$ flow.

The $\mathrm{UF}_{6}$ has now been sufficiently decontaminated (DF of $\sim 10^{7}$ ) for use in the conversion process for the preparation of $23 \mathrm{wt} \% \mathrm{PuO}_{2}-\mathrm{UO}_{2}$ product. The quantity of $\mathrm{UF}_{6}$ in excess of that required for the preparation of the $\mathrm{PuO}_{2}-\mathrm{UO}_{2}$ product is bled from the main hexafluoride stream, coldtrapped in trap $\mathrm{CT}-4$, and subsequently transferred to large $\mathrm{UF}_{6}$ receivers for shipment off-site.

\subsection{Conversion of Hexafluorides to Oxides}

The final step in the reference process is conversion of decontaminated $\mathrm{PuF}_{6}$ and $\mathrm{UF}_{6}$ to a sinterable oxide product suitable for remanufacture into FBR fuel. The product of the reference process is 23 wt $\% \mathrm{PuO}_{2}-\mathrm{UO}_{2}$. 
The conversion process is an adaptation of a process developed for the preparation of $\mathrm{UO}_{2}$ and involves the simultaneous reaction of $\mathrm{UF}_{6}$ and $\mathrm{PuF}_{6}$ with a mixture of steam and hydrogen at $650^{\circ} \mathrm{C}$ in a fluidized bed of the oxide product. The process is semicontinuous in that a cyclic method of operation is used. In the first half of the cycle, hexafluorides, steam, and hydrogen are fed to the reactor to yield the expected products $\mathrm{PuO}_{2}-\mathrm{UO}_{2}$ and $\mathrm{HF} . \mathrm{PuO}_{2}-\mathrm{UF}_{4}$ and $\mathrm{PuO}_{2}-\mathrm{U}_{3} \mathrm{O}_{8}$ may also form; consequently, for the second half of the conversion cycle, only steam and hydrogen are fed to the converter to reduce fluoride content and to densify the product. Excess reagents are used throughout the conversion cycle to ensure a high-density product with a minimum amount of residual fluoride. The design basis for the converter allows the withdrawal of $34.1 \mathrm{~kg}$ of $\mathrm{PuO}_{2}-\mathrm{UO}_{2}$ after each $2-\mathrm{hr}$ cycle.

The HF produced, together with the excess steam and hydrogen, is fed to a moving-bed limestone tower where the $H F$ is chemically removed from the gas stream. The steam is condensed, and excess hydrogen is burned to water and collected. The spent limestone is a solid waste of low activity level and is stored as such. Waste gas from the limestone tower vents to the plant ventilation system; however, if its residual activity is above specified limits, the waste gas would pass through special equipment (not considered in this design study) for $\mathrm{CO}_{2}$ removal, then vented to the off-gas treatment system.

Most of the fission products associated with the hexafluorides fed to the converter remain as trace oxide contaminants in the product; however, the overall $\mathrm{DF}$ at this point in the process is $7.5 \times 10^{6}$. The product is routinely sampled for accountability and quality checks and is then stored in product receivers that are critically safe by geometry. Product characteristics such as particle size, density, and residual fluoride content can be controlled by variation of the converter parameters (e.g., operation cycle, temperature, and reactant ratios). Typically, a spheroidal product can be produced with a high density (e.g., $85 \%$ of theoretical) or a low density $(65 \%$ of theoretical) as desired.

\subsection{Off-gas Treatment}

- All gases bled from the process gas streams and vent gases are treated in the off-gas treatment plant shown schematically in Fig. 3.8. Four sources of gaseous materials requiring treatment are indicated in the figure: fission-product gases, volatile F.P. fluorides (compounds with boiling points near $100^{\circ} \mathrm{C}$ ), highly volatile F.P. fluorides (compounds with boiling points below $50^{\circ} \mathrm{C}$ ), and process gases. Table 3.5 lists the gaseous materials requiring treatment and their origins. This listing is not comprehensive but rather representative of streams in the reference process. 


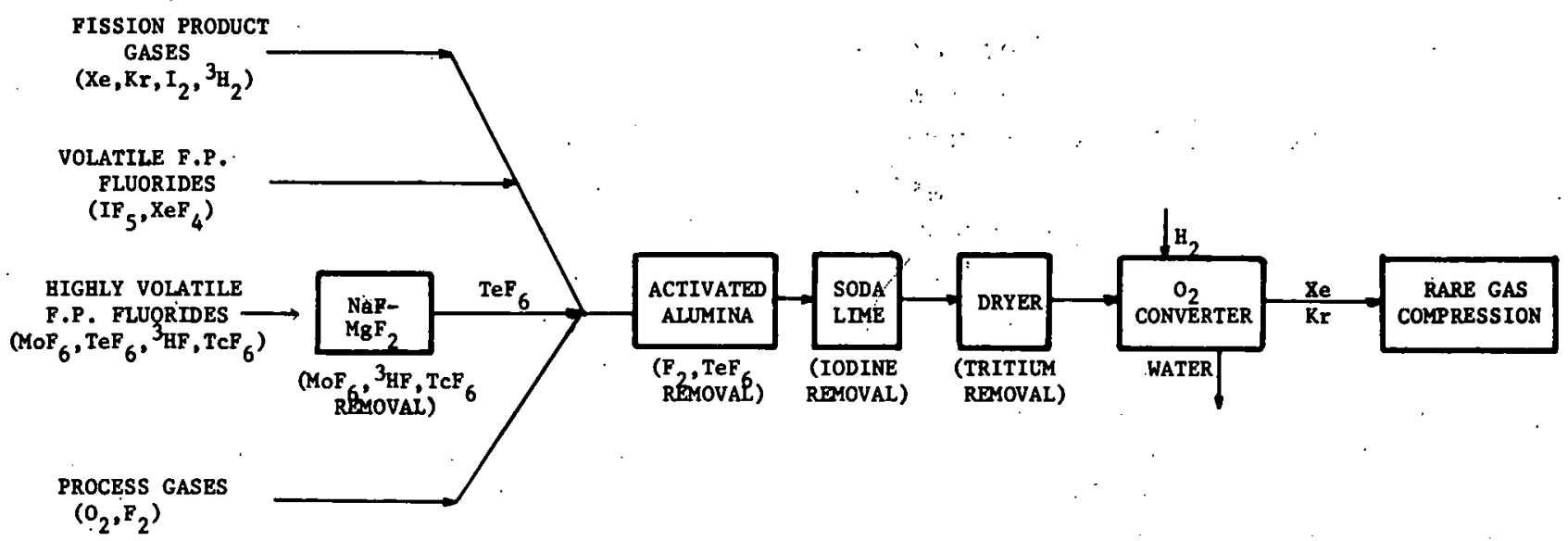

Fig. 3.8. Off-gas Disposal System

TABLE 3.5. Sources of Gaseous Wastes for Disposal

\begin{tabular}{|c|c|c|c|c|c|}
\hline . & Head End & $\begin{array}{l}\text { CT - } 1 \\
\text { Bleed }\end{array}$ & $\begin{array}{l}\text { FP- } 1 \text { and } \\
\text { FP-2 Vent }\end{array}$ & $\begin{array}{c}\text { S-1 Bottoms } \\
\text { Vent }\end{array}$ & $\begin{array}{c}\text { S-2 } \\
\text { Overhead }\end{array}$ \\
\hline$U F_{6}$ & & $\frac{X}{x}$ & & & $\mathrm{X}$ \\
\hline $\mathrm{PuF}_{6}$ & & $\begin{array}{l}\mathrm{X} \\
\mathrm{x}\end{array}$ & & & \\
\hline $\begin{array}{l}\mathrm{NpF}_{6} \\
\mathrm{NbF}_{5}\end{array}$ & & $\begin{array}{l}x \\
x\end{array}$ & & & $X$ \\
\hline $\begin{array}{l}\mathrm{NbF}_{5} \\
\mathrm{MoF}_{6}\end{array}$ & & $\mathrm{X}$ & & & $\mathrm{X}$ \\
\hline$T \subset F_{6}$ & & $\mathrm{X}$ & & & $\mathrm{x}$ \\
\hline $\mathrm{RuF}_{5}$ & & $\mathrm{X}$ & & & \\
\hline $\mathrm{SbF}_{5}$ & & $\mathrm{X}$ & & & . \\
\hline $\mathrm{TeF}_{6}$ & & $\mathrm{x}$ & & & $\mathrm{X}$ \\
\hline $\mathrm{I}_{2}$ or $\mathrm{IF}_{5}$ & $\mathrm{X}$ & $\mathrm{X}$ & & $\mathrm{X}$ & . \\
\hline${ }^{3} \mathrm{HF}$ & & & & & $\mathrm{x}$ \\
\hline $\mathrm{Xe}$ or $\mathrm{XeF}_{4}$ & $\mathrm{X}$ & $\mathrm{X}$ & & $\mathrm{X}$ & \\
\hline $\mathrm{Kr}$ & $\mathrm{X}$ & $\mathrm{X}$ & & & \\
\hline $\mathrm{O}_{2}$ & $\mathrm{X}$ & $\mathrm{X}$ & $\mathrm{X}$ & $\mathrm{X}$ & \\
\hline$F_{2}$ & & $\mathrm{X}$ & $\mathrm{X}$ & $\mathrm{X}$ & \\
\hline
\end{tabular}

The off-gas treatment plant consists mainly of (1) a series of traps containing active solid materials (e.g.; activated alumina, soda lime), which will either react with or sorb the bulk of the noxious components, (2) a reactor for converting oxygen to water (basically a hydrogen burner), and (3) a gas compressor and cylinder storage system for the rare gases. Small enough quantities of inert gases enter the off-gas treatment plant so that confinement with the rare gases is feasible. The quantities of gaseous wastes and details of the plant are described in Section 4.8.

The three waste form's (solids,-liquids, and-gases-)-a-re-rep-res-ented in the products of the off-gas treatment plant. Waste solids are generated from both fluid-bed systems and fixed-bed traps, and their quantity depends on the quantity and reactivity of the materials being disposed of. For example, fluorine-containing streams are treated first in a fluidized bed of 
activated alumina. When the alumina is spent, it is discharged to waste receivers for ultimate storage in the waste storage pool. The fixed-bed traps are disposable and are removed as units $r$ ather than being emptied and refilled with fresh reagent. Water generated in the oxygen converter is treated according to its activity level. If the activity level of the water necessitates further treatment, the water can be converted to a solid waste such as concrete. Finally, xenon and krypton are compressed and stored for 30 days to allow sufficient decay of radioactivity before release to the atmosphere. In the context of this study, the total containment concept is not violated in this release of gaseous wastes, since the level of radioactivity of these gases will decay to an acceptable level before they are released. 


\section{DESIGN BASIS AND ANALYSIS OF REFERENCE PROCESS}

This section, in its discussion of each fuel-handling operation and process step, presents an analysis of the total plant concept and the process design. Selected background information from the literature, together with the underlying assumptions involved in the process design, are presented and discussed. The design of particular equipment to perform the specific processing steps has not been optimized. Instead equipment design has been based as much as possible on known technology to ensure that the technical feasibility of the processing steps can be demonstrated and to demonstrate that the required equipment is workable and has a practical size. Each main subsection includes a schematic drawing of the equipment pertinent to that part of the flowsheet. For convenience, the six separatedrawings are presented again in two composite figures (Figs.4.23 and 4.24) at the end of Section 4.

Discussion of ancillary considerations, which include accountability, criticality, maintenance, and safety of the ventilation system, is deferred to Section 6 of this report. Key problem areas are summarized and discussed in Section 7.

\subsection{General Considerations}

General considerations, which influenced equipment design and mode of operation, are presented first as an introduction to the more detailed discussion (critique) of the process steps and related equipment which follows in Sections 4.2 to 4.8 . Included in the introductory remarks is a brief review of the process instrumentation requirements.

\subsubsection{Continuous and Batch Operation:}

Generally, a chemical reaction is carried out either as a batch process or as a continuous process. In a batch process, all reactants are added to the reactor before chemical reaction is allowed to proceed. Reactant concentrations change with time so that time is an important variable in this type of process. Time is consumed in charging the reactor, heating to reaction temperature, carrying out the reaction, cooling the reactor, and discharging the products. In a continuous process, reactants are charged continuously at one end of the reactor and products are removed continuously at the other end. Normally, a steady state exists so that reactant concentrations do not change with time but rather with position in the reactor. If thorough mixing is provided, uniform reactant concentrations will exist throughout the reactor and the effluent-solid-stream-will-have-the same composition as the reactor bed. This is the ideal situation, which is only closely approached in practice. In modern industry, which emphasizes mass production, a continuous process is highly favored over a batch process because of a clear-cut economic superiority for high material throughputs 
and unvarying product quality. ${ }^{12}$ In certain instances, for a particular application, a batch process may be superior to a continuous process.

In the reference plant, both continuous-processing equipment and batch-processing equipment have been specified. In particular, for fluidbed and distillation operations much industrial experience is available and continuous processing equipment can be specified for these operations. On the other hand, relatively little or no information is available for continuouscold-trapping devices; therefore, a reliable design for the reference plant requires that batch-processing equipment be specified for the cold traps. For other operations (e.g., sorption), either batch- or continuous-processing equipment can be designed satisfactorily. When high heat removal, relatively high material throughput, and a narrow range of sorption temperatures are required, continuously operated fluid-bed equipment has been specified; in the absence of these requirements, batch-processing equipment is specified for sorption operations.

\subsubsection{Design of Processing Vessels}

In the handling and processing of LMFBR fuels, two major problem areas require scrutiny under all conceivable operating conditions and circumstances. These are nuclear criticality and heat removal.

To provide positive control over any and all criticality hazards, geometric criticality control has been imposed on the design of each processing vessel which handles significant quantities of plutonium. Thus, the major processing vessels (i.e., the fuel-powder storage vessels, the uranium and plutonium fluorinators, and the hexafluoride converter) have been designed in the form of slabs rather than cylinders. For a required reactor volume, the slab reactor has a higher surface-area-to-volume ratio than a cylindrical reactor, and the higher surface area aids in heat removal. Even with a static or packed bed of solids, tolerable centerline temperatures (below the solids melting point) can be maintained in a slab reactor because the reactor thickness is small (up to $4 \mathrm{in.}$ ) in the reference plant.

Although the slab design has been adopted for the reference plant, it is not claimed that cylindrical or annular designs could not be used or that a final optimum slab design has been established. Gas and solids mixing in a fluid-bed slab reactor is expected to be as good as that experienced in a cylindrical reactor; however, actual experience with slab reactors under practical conditions is needed to provide confidence in this design. The slab reactor appears to satisfy the needs for the reference plant. A similar slabdesign philosophy was selected by Euratom ${ }^{13}$ in their conceptual studies involved with reprocessing fast-breeder fuel elements by fluoride-volatility methods.

4.1.2.1 Eluorinator Design. To give the reference plant the required high capacity, continuous fluid-bed reactors have been specified for the 
separation of uranium and plutonium by fluorination. Continuous fluorination offers additional advantages: The steady-state plutonium content in the various processing vessels and dissipation of chemical and fission product heat loads appear to be more favorable than in batch operations. The assumptions made for the reactor design include: (1) Instantaneous and complete mixing of feed with bed solids occurs, (2) solids leaving the reactor have the same composition as the bed, and (3) the average residence time of solids will be sufficient to achieve the requisite separation of uranium and plutonium from the bed material. (That is, the concentrations of actinides in the discharged waste alumina will be within set limits.) These assumptions represent ideality. In the actual case, axial and horizontal concentration gradients may exist, ${ }^{14}$ and in the course of the proposed development program, their consequences must be evaluated in terms of effects on the process.

4.1.2.2 Cold-trap Design. In general, batch-processing equipment

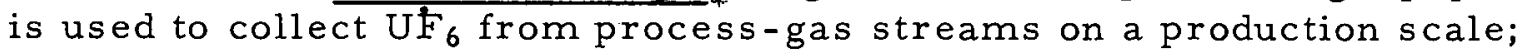
thus, the availability of design information has favored the use of batch operation for the cold traps in the reference process. The reliability of the design and operation of the units specified is exemplified by ORGDP, which currently uses an internally cooled, finned trap and an externally cooled, "egg-crate" $\operatorname{trap}^{15}$ in its $\mathrm{UF}_{6}$ production and $\mathrm{UF}_{6}$ diffusion-cascade plants. Similar cold traps were selected by Allied Chemical Company for their Metropolis, Illinois, plant ${ }^{2}$ where $\mathrm{UF}_{6}$ is produced from uranium ore concentrates and by General Electric Company for their Morris, Illinois, plant ${ }^{3}$ where spent nuclear fuel will be processed. A theoretical approach to the design of batch cold traps was described recently by Dunthorn. ${ }^{16}$

Continuous cold-trapping designs were considered for possible use in the reference flowsheet. One design which may have application for continuous operation is a scraped-wall cold trap ${ }^{17,18}$ patented by Standard Oil of New Jersey. The British have also developed a scraped-wall cold trap; ${ }^{19}$ additionally, a fluid-bed unit which shows promise for continuous operation has been tested. ${ }^{20,21}$ Both the scraped-wall and fluid-bed designs have higher heat-transfer coefficients than either the finned or the "egg-crate" cold traps; however, these designs have not been tested on a large scale or have other problems associated with their use.

4.1.2.3 Adsorber Design. A variety of adsorption units are used in the reference flowsheet to fix fission products for disposal and to remove chemically active reagents (e.g., fluorine and HF) from waste-gas streams. Three types of adsorption units have been specified to fit particular applications in the process; these-are-(-1-)-fluid--bed-(-2-)-packed--bed, and-(3-)-movin-gbed units. The fluid-bed and moving-bed units are operated continuously; the packed-bed units are used in batch operations.

Fluid-bed units have been specified in situations where high heat loads are encountered (e.g., from fission-product decay or chemical heat of reaction) 
and where the temperature must be kept within specified limits for efficient adsorption. Packed-bed adsorption units are used for low heat-load and small-throughput applications. A moving-bed adsorber is used for HF removal from the converter off-gas because the design has been proven and demonstrated on a pilot-plant scale for HF removal (see Section 4:7.2).

\subsubsection{Process Instrumentation}

The use of continuous process steps with inherent steady-state concentrations, flowrates, and operating temperatures enhances automatic control of the process by instrumentation and computer. Instruments to measure, record, and control the process parameters are readily available as off-theshelf items from commercial suppliers. A computer of sufficient size and versatility to handle all the required information from the plant in either open- or closed-loop control* is also available for short-term delivery from manufacturers.

There are, however, several measurement and detection areas in the reference plant which will require highly specialized instruments that currently are not commercially manufactured. These areas include instruments to detect (1) whether spent fuel has been completely separated from cladding hulls after shearing and ball milling; (2) whether sodium is present inside fuel pins as a result of inleakage through pinholes in the cladding, and (3) whether the movement and/or accumulation of plutonium in the process equipment take place as planned. Prototype devices similar to those required have been built and tested at government installations.

An instrument for measuring residual oxide in hulls has been tested, and two prototype models have been built. ${ }^{22}$ The principle of operation is the counting of delayed neutrons emitted by fission products after ${ }^{235} \mathrm{U}$ or other fissionable material has been bombarded with slow neutrons. Approximately $10 \mathrm{mg}$ of ${ }^{235} \mathrm{U}$ can be detected in the presence of a gamma-radiation field of $10^{5} \mathrm{R} / \mathrm{hr}$. Test results on a prototype designed for semicontinuous operation indicate that the unit is adaptable for completely automatic operation.

FBR fuel pins could be monitored for sodium inleakage with an instrument similar to that used routinely to detect sodium-bond defects in EBR-II fuel pins. ${ }^{23}$ The instrument performs a nondestructive test by using an eddy current to detect any gas-filled or shrinkage voids in the sodium bonding between the metallic fuel pin and the cladding.

Instruments or instrument systems for monitoring the movement and accumulation (above steady-state values) of plutonium in process vessels will require a thorough research program for development. ${ }^{24}$ Existing instruments which measure neutron activity might be applicable if the neutron

*Open-loop control provides for manual and automatic control; closed-loop is completely automatic. 
flux from the $(\alpha, n)$ reaction on fluorine can be related to the quantity of plutonium. Correlation of data and testing of an instrument in a high gamma field would be required.

From the criticality standpoint, a safe geometry is used throughout the reference plant, and instrumentation is considered only a secondary control system having a capability of monitoring significant increases in nuclear multiplication. A redundancy of detection methods is desirable to monitor the state of criticality. Techniques now in use or under consideration in critical assembly work and which have potential application in the reference plant include: (1) noise-measurement techniques, (2) coincidence correlation with fission neutrons, (3) neutron intensity distribution (fundamental mode shape) peculiar to the vessel shape, and (4) threshold detectors. These are discussed in some detail in Appendix A. Development and evaluation of working systems for use with high gamma, high neutron background situations will be required. This problem is considered a moderately difficult one, but of secondary importance since primary control is not by instrumentation but by safe geometry.

\subsection{Head-end Process}

\subsubsection{Chief Features of Head-end Process}

The head-end-process steps in the reference plant include all fuelhandling operations from the receipt of fuel elements in shipping casks to the supply of feed material to fluorinator A. The input to the head-end process is thus the fuel received, and the output is the oxide fuel fed to fluorinator A. The composition of fuel elements is described in the Ground: Rules (Section 2), and the features of feed pertinent to fluorinator operation are discussed in Sections 4.3 .2 and 4.3.8. The other major effluents of the head-end process are waste streams, namely, the separated segments of cladding (i.e., cladding hulls empty of fuel), the sodium-containing material from the washing step (which removes sodium from fuel and cladding), and the purge gas which contains fission products vented during the fuel-pin chopping and ball-milling operations. The cladding hulls are packaged and stored as described in Section 4.2.5, the gas waste is sent to the waste-gas treatment system described in Section 4.8, and the aqueous waste from washing of the fuel is handled as described in Section 4.2.5.

An alternative to mechanical decladding, a chemical-decladding scheme involving reaction of stainless steel with 50-50 HF-oxygen mixtures at $550^{\circ} \mathrm{C}$, was also considered. However, because of the close-packed design of the fuel elements, the spacing between fuel pins does not permit free movement of fluid-bed material in the fuel-element voids. Therefore, chemical decladding might result in overheating and uncontrolled reaction in the main fluorination reactor. 
Process requirements for head-end operations depend on: (1) allowable fuel losses to the cladding waste stream in the separation of fuel from cladding, (2) allowable sodium content of the fuel fed to the fluorinators, (3) allowable size distributions of particles for pneumatic conveying and for feeding to fluorinator A, and (4) containment of fission-product gases. These topics are discussed in this section, and the basis for the head-end requirements is reinforced in other sections of the report.

The sequence of major process steps in the head-end process is outlined in Section 3.1. The fuel-conveying system for transferring fuel from the head-end step to the subsequent process steps is described in Section 3.2. Further details concerning the engineering design, process separations, and waste handling for the head-end operations are presented below.

\subsubsection{Engineering Design of Equipment in Head-end Process.}

\subsubsection{General Design Considerations and State of the Art. The} head-end process is defined as the sequence of operations that provides fuel in a form suitable for feeding to the first major chemical-processing step (uranium fluorination). In the present reference design, the reference fuel, $\mathrm{UO}_{2}-\mathrm{PuO}_{2}$ (in the form of multitube fuel elements or subassemblies) is separated from the cladding (stainless steel) and transformed into a powdered form for processing in a fluid-bed reactor.

The head-end process involves a number of steps common to both aqueous and nonaqueous processing schemes. Because a head-end concept had been under development as part of the aqueous-process studies being conducted at ORNL, the major features of their design ${ }^{25}$ were adopted at the start of this fluoride-volatility concept study. As for our study, the ORNL head-end design represents a reference design and is considered consistent with the overall ground rules set forth for these studies in discussions with AEC-DRDT personnel. Deviations from the ORNL design are noted in the discussion below.

Briefly, the head-end process involves removing fuel elements from sodium-filled shipping casks, deactivating the sodium clinging to external parts of the fuel elements, mechanically disassembling the elements into individual fuel pins, detecting and separating sodium-logged fuel pins for separate processing, and processing the main stream of fuel pins through a chopper and continuous ball mill, ultimately separating powdered fuel from a stainless steel waste which is free of fuel and ready for disposal by burial.

For this volatility-process plant study, a mechanical head-end (decladding) process has been selected, primarily because chemical methods appear to have deficiencies. (For example, the behavior of stainless steel in the catalytic oxidation of stainless steel with $\mathrm{HF}-\mathrm{O}_{2}$ remains a large uncertainty.) Disposal of compacted stainless steel waste from the mechanical head-end process is relatively easy compared to waste disposal for other procedures. 
On the basis of encouraging results from exploratory studies and the current state of development, ${ }^{26}$ pin chopping followed by ball milling has been selected as a technique for decladding the fuel and separating the fuel oxide from the cladding for the reference plant concept study. An alternative method, the use of rollers to crush and split the fuel pins appears possible and could prove to be preferable or supplemental to the above method, but the crushing-splitting procedure needs considerable development work (see Section 4.2.2.3) and therefore was not included in the reference case. Work on pin chopping and ball milling has been done in both the USA and Europe. ${ }^{26}$ For example, at Fontenay-aux-Roses in France, a new continuous ball mill is under construction.

Only the designs of the ball mill, the fuel storage system, and the pneumatic conveying system are discussed in detail here since the bulk of the remaining components required for the head-end step are common to all fuel processes and are not considered a design problem for this study. Considerable effort on the design of these other components is being spent at ORNL.

4.2.2.2 Ball Mill for Mechanical Decladding. In the reference process, the ball mill operates continuously, accepting short, clad fuel sections and through its action separating the fuel from the cladding and milling the fuel to a powder suitable for use in the continuous fluid-bed fluorination reactors. The mill, in tandem with the pin chopper, is operated in an enclosure so that fission gases released during chopping and ball milling can be contained and directed to the off-gas treatment system. Oxygen is to be used as a purge gas. The ball mill must automatically provide separate discharge of fuel and cladding hulls and return of balls. Figures 4.1 and 4.2 show design features of a conceptual mill. To resist wear, the mill shell will be fairly heavy (about $1 / 4$ in. thick). The compartment at the feed end of the shell will be perforated with holes of $1 / 8$ - to $3 / 16-i n$, diameter to allow fuel oxide to pass through but retain the hulls. To achieve further discrimination in sizing the fuel, a 40 -mesh screen will enclose the shell, so that only material smaller than 40 mesh will be conveyed to the next process vessel. Coarser material is expected to fall back into the milling region for further processing. The behavior of the oxide during milling is unknown, but vanes are provided on the inside of the shell to lift the balls and perhaps. provide more effective crushing of the powder. The mill has one or more compartments separated by partitions, each having a central hole through which the accumulated hulls pass.

Other general features are sealed and shielded bearings and the use of radiation-resistant lubricants. A lead shield at the drive end protects the motor and gear reducer. Means will be provided for emptying the mill.

4.2.2.2.1 Size of Mill. The mill size was chosen on the basis of processing an average daily load of fuel in about $16 \mathrm{hr}$, allowing $8 \mathrm{hr}$ (on the average) for downtime and maintenance. The daily load of six core assemblies 


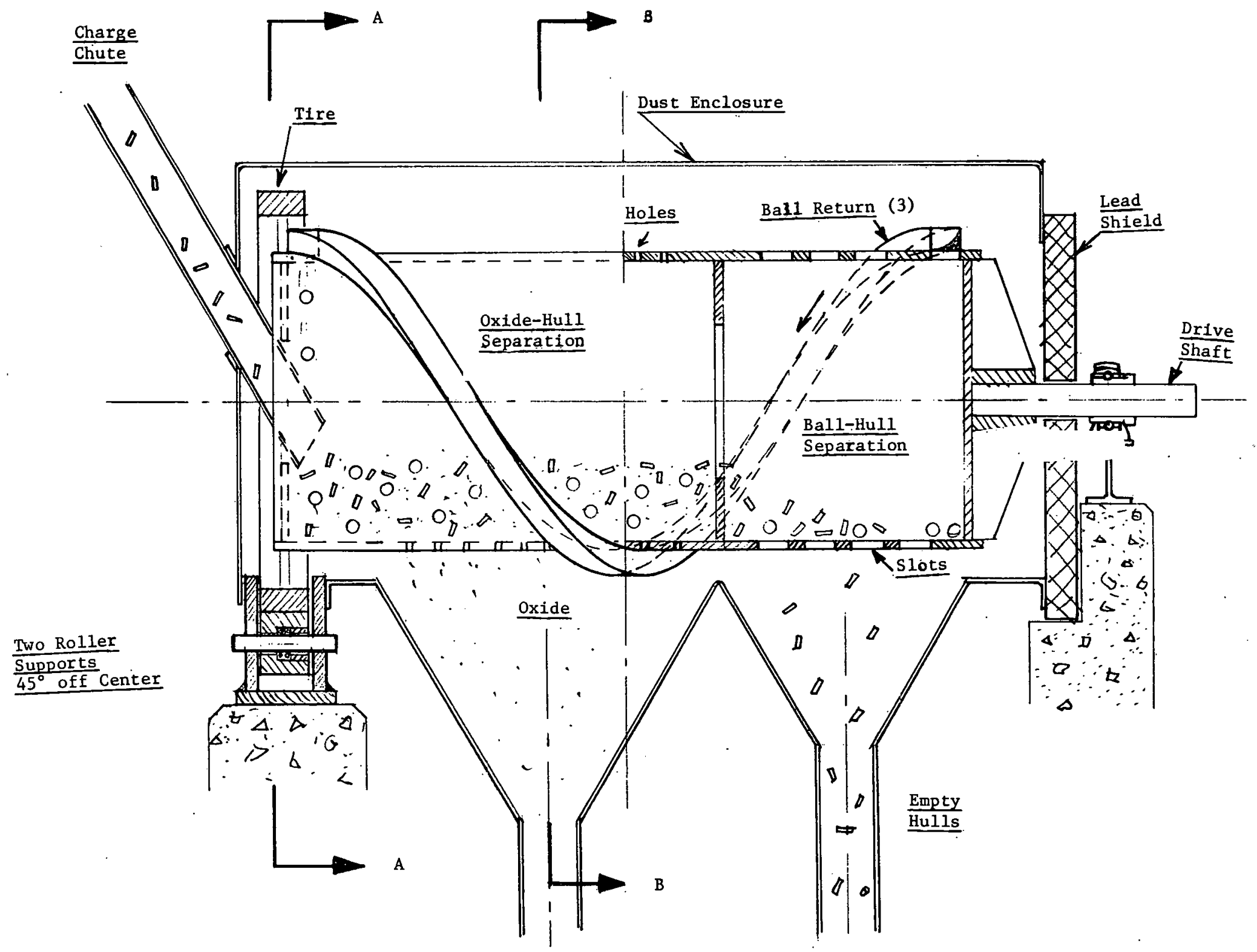

Fig. 4.1. Conceptual Continuous Ball Mill 


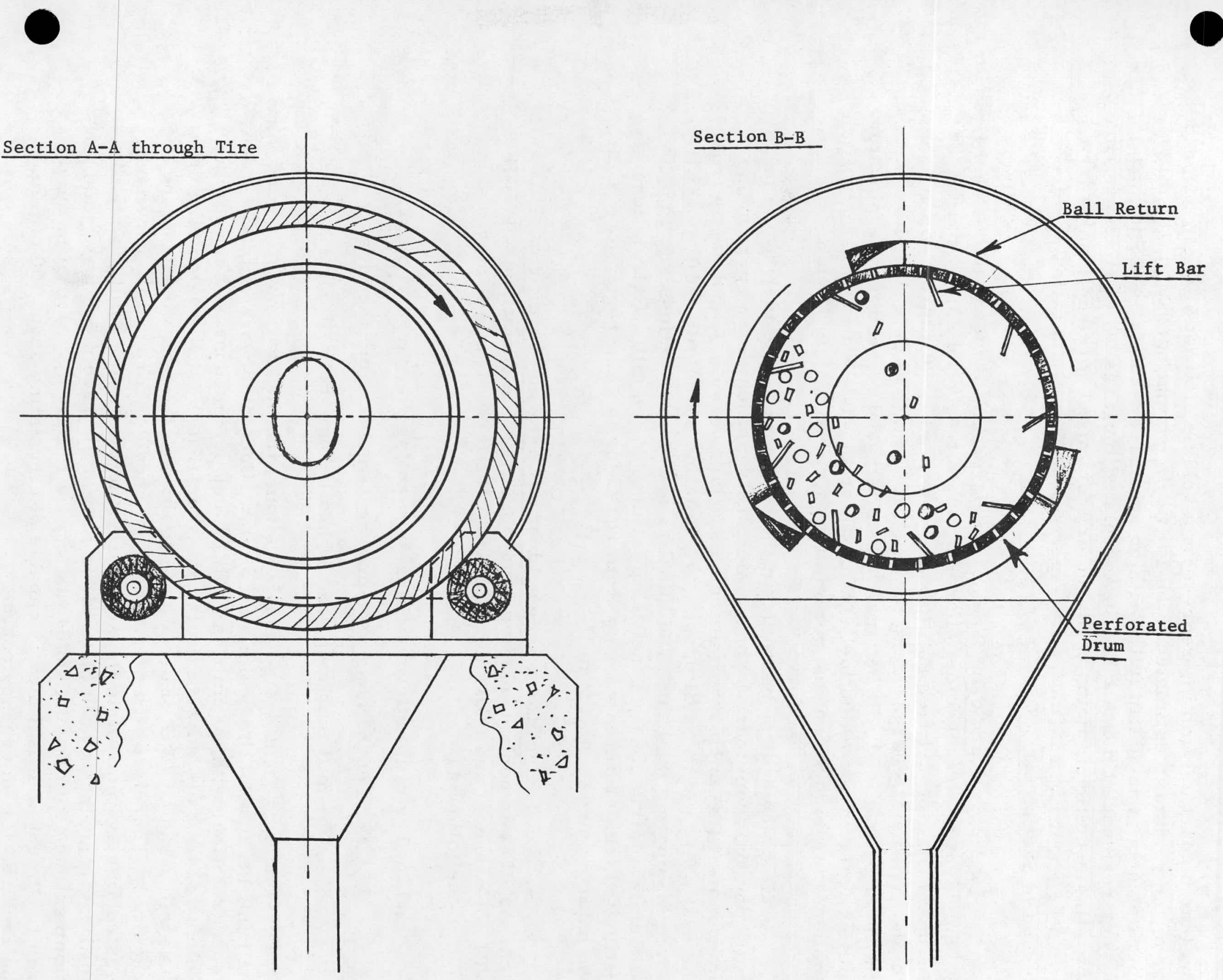

Fig. 4.2. Conceptual Continuous Ball Mill: Section A-A 
and four blanket assemblies represents a volume of about $5 \mathrm{ft}^{3}$. In chopped form, the volume is estimated to be $10 \mathrm{ft}^{3}$. In normal operation, the mill operates about one-fourth full. With an arbitrary diameter of 18 in. and a powder residence time of $2 \mathrm{hr}$, the calculated length is $40 \mathrm{in}$. Under normal operating conditions, plutonium inventory for mixed core and blanket feed would be about $12 \mathrm{~kg}$. Criticality aspects of ball-mill operation are discussed in Section 6.1.3.7.

4.2.2.2.2 Heat Load. The normal inventory of fuel in the ball mill is equivalent to about 1.5 fuel elements. With a value of $45,000 \mathrm{Btu} / \mathrm{hr}$ for the heat load of a fuel element, the total input is $67,500 \mathrm{Btu} / \mathrm{hr}$. Since powder will be discharged along the length of the mill as it is sized (to 40 mesh), the average heat load will be small. This is based on results of exploratory milling tests on simulated fuel sections (porcelain-filled stainless steel tube sections) in which $97 \%$ of the porcelain was discharged in 15 min.

Heat flow will be partly from the heat source (the fuel) to the ballmill body and from there by convection and radiation to the surrounding environment (the enclosure wall and enclosure purge gas) and partly from the heat source to the mill purge gas. Rotation of the mill ( $50 \mathrm{rpm}$ ) will aid in dissipating the heat. The tumbling and milling actions are expected to maintain fairly constant fuel temperatures in the mill. Calculations give estimated temperatures ranging from $162^{\circ} \mathrm{C}$ for the fuel region to $72^{\circ} \mathrm{C}$ at the exterior surface of the mill.

4.2.2.2.3 Heat Load under Adverse Operating Conditions. For safety reasons, it is important that even under unfavorable conditions, the ball mill will not overheat and cause a meltdown of the fuel. The mill may malfunction in the following ways:

1. The mill outlet may plug, preventing discharge of pins.

2. None of the fuel oxide may be removed from the pins.

3. The mill may stop after it has become half-filled with hulls.

Under present design considerations, the mill will not fill more than half full because of the design of the inlet. Under the worst situation, that is, no rotation, with the mill half full of fuel (no discount is taken for the volume of the mill balls), calculations show that the fuel-region temperature will reach $1179^{\circ} \mathrm{C}$. Forced cooling through the mill would then be required. Therefore, the original design should incorporate a recyclinggas cooling system within the secondary enclosure of the mill. Only the mill environment gas can be used for cooling, in keeping with the total containment concept of using gases that can be readily disposed of in the offgas treatment plant. A blower capable of circulating about $500 \mathrm{cfm}$ may be required for emergency cooling. 
4.2.2.3 Alternative Concept for Mechanical Decladding. A possible alternative ${ }^{26}$ to ball milling as a decladding method uses heavy rollers for crushing and splitting the oxide fuel pins. The method treats pins singly and lends itself to continuous processing. Attractive features are: (1) positive mechanical separations applied to each fuel pin individually, (2) virtual freedom from heat transfer and criticality limits because individual fuel pins are handled, (3) high speed of operation.

In preliminary testing of the basic principle, porcelain-filled stainless steel pins of dimensions identical to FBR fuel pins were found to split when compressed to half their original diameter. ${ }^{26}$ The compression was done in a hydraulic press and in a set of laboratory rollers. The splitting of the cladding was uneven, however. In a subsequent test, the pins were scored axially at diametrically opposite sides. Subsequent compression or rolling produced complete and straight splitting of the pins.

Figure 4.3 shows a decladding scheme using these principles. The apparatus will have the following parts:

discs.

1. A pair of feed rollers for pushing the fuel pin into the cutting

2. A set of cutting discs, perhaps 8 in. in diameter, for cutting two diametrically opposite grooves in the pin.

3. A set of straight, hardened rollers that compress and crush the fuel pin, causing. it to split in two.

4. A splitting wedge to open the split cladding and facilitate its separation.from the oxide.

The machine will be enclosed to contain fuel-oxide dust and fissionproduct gases. Removal of the enclosure will be possible, allowing the rollers and cutters to be exposed to facilitate maintenance and verify proper operation. Rollers and cutters can be replaced so that fuel pins of different diameters can be processed. Because of the much less severe action to be experienced by the large, circular cutting discs than, for example, cutting heads on pin choppers, the cutting discs should have longer service lives than cutting heads. Rollers should also have long service lives.

All bearings and gears are enclosed and shielded, and radiationresistant grease and oil are used. Suitable guides are provided to ensure that the fuel pins will enter the rollers and cutters where intended. Scrapers will prevent oxide from building up on the crushing rollers.

For adequate throughput, a 6 -ft-long fuel pin must be processed in seconds. If a fast processing rate can be achieved, the daily load of the reference plant can be declad in less than $8 \mathrm{hr}$. 


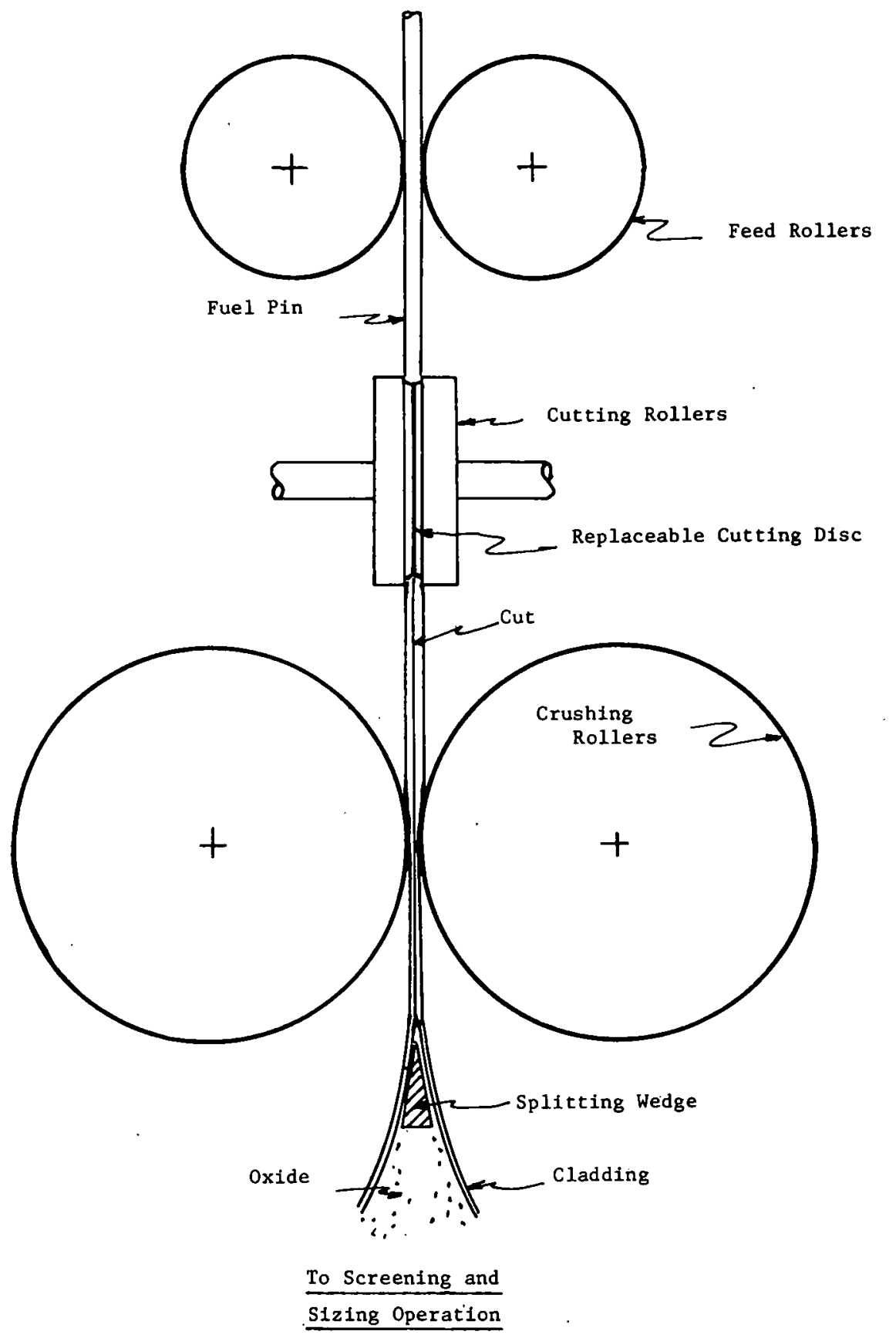

Fig. 4.3. A Roller-Crusher-Splitter Concept for Mechanical Decladding of Fuel Pins

The roller-crusher-splitter method has the obvious advantage of exposing the inside surface of the cladding so that after the bulk of the oxide presumably falls away, any fuel oxide adhering to the cladding can be removed by a scraping device. The cladding would be disçarded after monitoring for any residual oxide. Alternatively, after splitting, the cladding can be chopped and the pieces of split cladding tumbled in a perforated rotating. drum for escape of the loosened oxide. If this drum is part of a ball mill such as that described above, the roller method would be an adjunct to the 
ball-milling concept. The criticality and heat load considerations for this combined scheme would be similar to those for the ball mill alone, although mill operation would probably be less troublesome since a large bulk of fuel. would require only sizing.

Mechanical decladding is also being investigated at Karlsruhe Kernforschungszentrum in Germany. ${ }^{26}$ A decladding machine is being developed there using feed rollers, rotating-saw cutters, and splitters that deflect the cladding after it is split into three sections. The German concept differs in that a special, hollow-core drill is used to recover the fuel. The fuel is sucked through the drill to storage. Disadvantages of this machine are that it is very slow ( 1 to 2 in. per second) and that it has several parts (circular saws, cutting knives, drill) subject to frequent maintenance.

4.2.2.4 Fuel-powder Storage System. Storage space is provided for the fuel powder produced in the head-end operations. This interim holdup of the fuel, preparatory to its being fed into the first fluorinator, facilitates obtaining weight data and samples required for accountability. The amount of hopper space to be allotted depends upon the degree of flexibility considered necessary for the overall plant operation. Holdup equivalent to a one-day throughput is considered a baseline case in which it is assumed that any discontinuity in the head-end operation will be corrected in one day. The problems associated with the storage containers concern criticality, monitoring of inventory, ability to get material into and out of the vessels, and control of temperature (to prevent sintering).

The volume réquirements have been calculated for a one-day holdup. A slab design has been selected for the individual storage hoppers. This is consistent with the basic design of the other process equipment. The slabs provide nuclear criticality safety and are desirable from the heat-transfer standpoint.

Assumptions regarding fuel-powder properties are as follows:

Daily fuel load: $\quad 1130 \mathrm{~kg}$ of core and blanket oxide

Density of fuel powder: $5.0 \mathrm{~g} / \mathrm{cc}$

Effective thermal con-

ductivity of fuel powder: $0.25 \mathrm{Btu} /(\mathrm{hr})\left({ }^{\circ} \mathrm{F}\right)(\mathrm{ft})$

Heat load:

$340 \mathrm{Btu} / \mathrm{kg}(\mathrm{U}+\mathrm{Pu}$ blend)

Powder density was taken as $50 \%$ of the pellet density; the latter was assumed to be $90 \%$ of the theoretical value $(10.97 \mathrm{~g} / \mathrm{cc})$ for $\mathrm{UO}_{2}$. The effective thermal conductivity was assumed to be about equivalent to the value, $0.25 \mathrm{Btu} /(\mathrm{hr})\left({ }^{\circ} \mathrm{F}\right)(\mathrm{ft})$, selected for alumina, although values for the effective thermal conductivity of $\mathrm{UO}_{2}$ powders have been reported $d^{27-30}$ as ranging 
from. 0.05 to $0.95 \mathrm{Btu} /(\mathrm{hr})\left({ }^{\circ} \mathrm{F}\right)(\mathrm{ft})$, depending on particle size, temperature, and cover gas (air, nitrogen, helium, or argon). The heat load is $95.5 \mathrm{~kW} / \mathrm{day}$ (4.5 and $91 \mathrm{~kW} /$ day for radial blanket and core plus axial blanket fuel, respectively), but this load was assumed to be reduced by $22.5 \%$ because of the gamma radiation escaping from the thin slab vessels.

Centerline temperatures were calculated for several slab thicknesses and a range of wall temperatures. These calculations were based on heat transfer in a packed-bed slab configuration using the equation

$$
T_{\text {axial }}=\frac{Q L^{2}}{2 k}+T_{w}
$$

where

$$
\begin{aligned}
\mathrm{Q} & =\text { heat load, } \mathrm{Btu} / \mathrm{ft}^{3} ; \\
\mathrm{L} & =\text { half thickness of slab }=1,1.5, \text { or } 2 \mathrm{in} . ; \\
\mathrm{k} & =\text { effective thermal conductivity, Btu } /(\mathrm{hr})\left({ }^{\circ} \mathrm{F}\right)(\mathrm{ft}) ; \\
\mathrm{T}_{\text {axial }} & =\text { centerline temperature, }{ }^{\circ} \mathrm{F} ;
\end{aligned}
$$

and

$$
T_{w}=\text { wall temperature, } 300,500 \text {, or } 700^{\circ} \mathrm{F}\left(149,260 \text {, or } 371^{\circ} \mathrm{C}\right)
$$

Centerline temperatures range from 395 to $618^{\circ} \mathrm{C}$ for a 2 -in.-thick slab, and from 700 to $923^{\circ} \mathrm{C}$ for a 3 -in.-thick slab. If $700^{\circ} \mathrm{C}$ is the limit, three hoppers (each 2 in. thick by $3 \mathrm{ft}$ wide with a $5 . \mathrm{ft}$ depth of powder) will be required for the storage of one day's fuel load. These will be connected in parallel, but the individual storage vessels will be weighed continuously (automatically) for accountability purposes. A 2 in. thickness provides a critically safe system.

The storage vessels are expected to be fabricated of stainless steel, perhaps $1 / 4$ in. thick. If design temperatures are exceeded in heat-transfer tests, additional heat-transfer area can be provided by incorporating fins on the exterior wall of each vessel. The overall height of the vessels can be increased by $1 \mathrm{ft}$ or more to provide additional disengaging space in the event that beds are pulsed from time to time to keep them "fluid." Sinteredmetal filters might be required if beds are sometimes pulsed.

Although many details of design have not been presented, the fuelpowder storage facility will apparently have no major problems associated with it on the basis of experience obtained at the Idaho Waste Calcining Facility. ${ }^{31}$ The major uncertainty is the behavior of fuel powder on standing, 
that is, whether vibration or pulsing will be needed to keep the solids mobile. This would be determined in a test program, and the design of the system would be modified as necessary.

\subsubsection{Instrumentation for Head-end Process}

Only devices used in the fluoride-volatility head-end process are discussed here. The fuel pins must be assayed for sodium logging (1\% of the pins are assumed to be sodium-logged, as specified in the ground rules of this study). For assay of fuel pins, we propose a device that measures eddy current. The device uses a wire coil connected to an electronic analyzer. The fuel. pins are passed through the coil one by one, running on rollers (like on a rolling mill). A speed of several feet per second is required to achieve the specified production rate. The presence of sodium metal in a fuel pin causes a signal, which is used to deflect the fuel pin to a separate storage area for later processing (mainly removal of the sodium by washing and drying of the oxide). The capability of this device in this application is an uncertainty of some magnitude and requires full evaluation.

The delayed-neutron monitor ${ }^{22}$ for detecting fuel-oxide remnants is another special instrument that requires further testing for complete evaluation. Refinement of this instrument may be required. A possible complication in its use is the presence of a neutron background ( $\alpha, n$ reaction and spontaneous fission) from transplutonium elements in the fuel pin, which would lessen the sensitivity of this method. Alternatively, it might be possible to simply use the high neutron flux from elements such as curium as an indication of the presence of fuel oxide. In that case, only a shielded, total-neutron detector will be required. The feasibility of using this instrument will have to be determined in further investigations.

In the event of buildup of plutonium in the ball mill, neutron detectors or other devices might be required as monitors. Devices that may be useful for this purpose are discussed in Appendix A. These devices were mainly considered for fluorinators $A$ and $B$, but have possible application in other parts of the process.

\subsubsection{Physical and Chemical Bases of Head-end Process}

Although the head-end processes can be considered essentially mechanical, the operations involved are based on definite physical and chemical behavior of the fuel material and its constituents. The related state of the art includes several process steps which have been developed for similar or analogous purposes.

4.2.4.1 Separation of Oxide Fuel from Cladding: When the stainless steel cladding is broached, the oxide fuel tends to fall out of the cladding under the influence of gravity and mechanical vibration. Oxide fuel as 
discharged from the reactor is highly cracked and fragmented. Not much of a fuel-cladding bond is found, because the absence of a tendency to bond is a condition for selection of the cladding. Due to neutron irradiation, the stainless steel cladding of the discharged fuel has a greatly reduced ductility. Therefore, fractures rather than deformations should be produced, and breaking-open of the cladding should be facilitated.

Several techniques have been described for separating fuel from cladding. A vibratory decompaction technique for LWR oxide fuel has been under development at Hanford Laboratories. ${ }^{32}$ In this method, a fuel pin has the end (or ends) cut off and is subjected to vibratory hammering of the outside of the cladding while the fuel is in a vertical position. The hammering is applied at a narrow zone which is moved up and down the fuel pin. The fragmented oxide falls out of the cladding. Clean, rapid separations have been achieved. Testing of $\mathrm{PuO}_{2}-\mathrm{UO}_{2}$ fuel of the small diameter typical of LMFBR fuel has not been done.

Atomics International has developed a low-decontamination scheme for reconstitution of oxide fuel, termed the Airox ${ }^{33}$ process. In this technique, oxidation-reduction of oxides was used to loosen and break up the fuel matrix, with the assistance of vibration to promote falling-away of the oxide powder. Vertical mounting or grinding of the cut fuel elements was used in various tests. The method appeared to be feasible.

Oxidative pulverization of $\mathrm{UO}_{2}$ fuel pellets in a fluid bed was studied at Argonne National Laboratory. ${ }^{34}$ Unirradiated $\mathrm{UO}_{2}$ pellets were rapidly pulverized to $\mathrm{U}_{3} \mathrm{O}_{8}$ at temperatures of $400^{\circ} \mathrm{C}$ and above with air. The reaction was strongly exothermic. The application of this method to $20 \% \mathrm{PuO}_{2}-$ $\mathrm{UO}_{2}$ should result in pulverization of the $\mathrm{UO}_{2}$ matrix and would be expected to enhance the operation of a mechanical separation method. For example, oxygen would be provided as the sweep gas in the ball mill (which would be operated at an appropriate temperature). Partial oxidation would then lead to particle breakup of $\mathrm{UO}_{2}$, as described in a patent obtained by Knudsen and Levitz. ${ }^{35}$

The amount of fuel oxide clinging to separated cladding segments can be reduced by the physical means of vibration, brushing, air-blasting, or scrubbing in a fluid bed. However, since plutonium is the only element of concern, preferential recovery of plutonium as $\mathrm{PuF}_{6}$ could be done by circulating fluorine through a bed of the cladding segments at about $500^{\circ} \mathrm{C}$. Although fluidization of the bed would probably not be necessaryor desirable, mechanical vibration might result in rapid exposure of the residual oxide on cladding. Some chromium from the stainless steel might be volatilized with the $\mathrm{PuF}_{6}$ in this plutonium recovery step; the chromium could be separated by thermal decomposition of the $\mathrm{PuF}_{6}$ to $\mathrm{PuF}_{4}$ or by other methods. 
The above techniques are cited because of their relevance in the supporting state of the art to the type of mechanical separations concept adopted as the reference process in this study. The existence of these techniques promises a high probability of success. in developing a feasible head-end operation.

4.2.4:2 Sizing of Fuel Particles in Head-end Process. A requirement of the mechanical separation from the cladding is that fuel particles of the desired size range be provided. To separate fuel from the cladding, it is only necessary that the particles be substantially smaller than the $1 / 2$-in.-long cladding pieces. However, particle size requirements are relatively strict for the operations of (a) pneumatic conveying and (b) fluidbed fluorination. For conveying, sizes smaller than about 20 mesh are desired. Fines (i.e., particles smaller than 200 mesh) probably can be accommodated readily.

For fluid-bed fluorination, the particle sizedistribution is notcritical; some large particles (e.g., 14 mesh) and some fines (e.g., 325 mesh) can be tolerated. However, optimum behavior would probably be obtained with particles in the range of 40 to 200 mesh. Powders finer than 200 mesh could be handled in the reference case since the bulk of the bed is composed of alumina of selected size, presenting a very stable system for fluidization.

\subsubsection{Release of Fission-product Gases. The rate of release of} fission-product gases in the head-end operations is believed to vary widely, depending on the state of the fuel, the temperature history and conditions in the head-end, the state of subdivision of the fuel, and the chemical reactions (such as oxidation) that might occur. In all parts of the head-end, some gases (principally xenon, krypton, iodine, and ${ }^{3} \mathrm{H}$ ) are expected to be released. The first major release of gases would occur when the cladding is first chopped. After that, more gases would be expected to be released in the ball mill. Higher temperatures and oxidizing conditions favor release. The off-gas system is designed to handle the fission product gases.

\subsubsection{Transport and Monitoring of Fuel and Solids Flow. Solids} will be transported from the ball mill to the storage vessels, then to the first fluorinator, and between fluorinators by a pneumatic conveying system. A standpipe-gas pulse technique is considered applicable, but will need testing.

Solids flow from the storage vessels to the fluorinator may be monitored in several ways. Direct weighing of individual vessels is possible, using strain-gauge systems. A weighing sensitivity of $0.1^{-} \%$ on a typical-load (estimated to consist of a $800-1 \mathrm{~b}$ vessel plus $800 \mathrm{lb}$ of fuel) would involve a total differential of $1.6 \mathrm{lb}$. Since the average feed rate is about $103.5 \mathrm{lb} / \mathrm{hr}$, such sensitivity is considered adequate to monitor the solids flow. 
A second possible monitoring system is a solids-level gauge, for example, the X-ray type (basically a density meter). The feed provides the source radiation. A suitable detector of a collimated beam could readily determine the bed level as solids are withdrawn at the bottom of a process vessel.

Thermocouples attached at given elevations on external wall surfaces should provide still another simple but perhaps less accurate means of monitoring solids movement out of the vessel. This method would be used in conjunction with one of the other more accurate systems.

Still other concepts might be developed which would provide a means of monitoring solids feed. For example, injection of tracers is widely used as a means of monitoring liquid and gas flow. Similarly, the injection of solids which would mix with the feed and form detectable chemical reaction products, preferably at the outlet of the plutonium fluorination reactor, might be possible. A fission product already in the feed may serve this purpose. A careful study of fission-product reactions should indicate the feasibility of this scheme.

4.2.4.5 Handling Sodium-logged Fuel. In the event of fuel-pin failure during the reactor cycle or during subsequent storage of fuel elements in sodium, sodium could leak into the fuel pins. The ground rules for this study state that an average of $1 \%$ of the pins will be sodium-logged. The sodium might be confined locally in a pellet void and be of negligible quantity, or it might completely fill the plenum included in the presently designed fuel pins for the collection of fission-product gases.

Introduction of sodium into the process is undesirable since sodium has been found to be an excellent "getter" for $\mathrm{PuF}_{6}$ when in the form of $\mathrm{NaF}$. If introduced as oxide, the sodium would quickly convert to the fluoride upon exposure to fluorine. A second reason to avoid having $\mathrm{NaF}$ in the fluorinator is that it may promote sintering (the formation of low-melting salts), although its exact behavior in $\mathrm{Al}_{2} \mathrm{O}_{3}-\mathrm{AlF}_{3}-\mathrm{F} . \mathrm{P}$. mixtures is not established. For these reasons, special consideration of the processing of sodium-logged fuel. is necessary.

The problem involves certain assumptions and has several aspects. First, it is assumed that all the sodium in a sodium-logged pin has not been completely converted to the oxide. A fraction remains as metal and can be detected in the pin, presumably by the eddy-current method. ${ }^{23,36}$ The eddycurrent detection method is sensitive, perhaps to a milligram of sodium,* but a satisfactory rate of fuel monitoring remains to be demonstrated. Tests

\footnotetext{
* Assuming a NaF:PuF 4 complex, $1 \mathrm{mg}$ of sodium will be associated with about $13.7 \mathrm{mg}$ of $\mathrm{PuF}_{4}$; sodium $(\sim 7.5 \mathrm{~g})$ in a 1-ft length of $0.25-i n$. -OD fuel pin could be associated with $102 \mathrm{~g}$ of PuF 4 .
} 
in which individual pins were fed through a coil were made at speeds of only $2 \mathrm{in./sec.} \mathrm{A} \mathrm{rate} \mathrm{tenfold} \mathrm{higher} \mathrm{is} \mathrm{desirable} \mathrm{for} \mathrm{the} \mathrm{present} \mathrm{applica-}$ tion and appears feasible on a go/no-go basis. ${ }^{37}$ Another aspect that must be tested is the instrument's ability to function reliably in high-radiation fields. Here again, experience suggests that this is no problem. Tests at elevated temperatures $\left(\sim 250^{\circ} \mathrm{C}\right)$ were satisfactory.

The logged pins are separated from the nonlogged pins and then treated to remove sodium. A special treatment for sodium removal needs to be developed. Methods of removing sodium from fuel include direct vaporization (b.p. of sodium is $880^{\circ} \mathrm{C}$ ) and washing. Vaporization requires broaching of the cladding with the fuel in an inert atmosphere, heating of the pins (self-heating may be possible), and controlled flow of the off-gas to avoid deposition of sodium on equipment surfaces. The volatilized sodium might be trapped on solid sorbents.

Washing to remove sodium, although undesirable from the moderation and criticality standpoints, can readily be done in critically safe equipment. Such a procedure does not appear particularly disadvantageous since the quantity of sodium-logged fuel to be processed separately is small. The fuel pins can be bundled for the chopping operation; any sodium present will probably oxidize in the chopper atmosphere and remain inocuous until removed by washing. The washing will be done batchwise on the chopped sections in a circulating-water tower. After thorough rinsing, the fuel can be dried simply by self-heating and then fed to the ball mill. After the water is filtered to recover any contained fuel, it represents a small but highly active liquid-waste stream, which can either be evaporated to reduce the waste volume or be absorbed directly on solids for storage.

Alternatively, the fuel powder might be washed after it has been separated from the cladding. The total volume of material to be treated would then be somewhat smaller, and a greater degree of sodium removal would be achieved. This powder would then be blended with the main stream of oxide fuel.

Such procedures do not appear to offer problems, although admittedly many details of this operation have not been examined in depth. The problem of handling sodium-logged fuel pins changes magnitude if vented fuel elements are used and relatively large amounts of sodium are present. The boiling off of sodium might then be reviewed. Further study and evaluation of this problem (namely, the role of sodium) are needed.

\section{2 .5 Head-end Process Wastes}

Solid metal, liquid, and gaseous wastes are produced in the head-end process. Solid wastes result from (a) removing, by cutting, the end fittings from the fuel assemblies, (b) disassembling the pins from the shroud and 
other parts of the assembly, and (c) the accumulation of empty hulls from the ball-mill operation. These wastes are combined, compressed, and sealed in stainless steel cylinders for ground burial. The volume of waste from these sources is not expected to exceed $4 \mathrm{ft}^{3} / \mathrm{day}$.

Aqueous waste results from washing the fuel-element surfaces (before disassembly of the element) to remove the sodium in which it is immersed during shipping. Another aqueous waste results from separate washing of the oxide from sodium-logged pins. The former waste will probably contain little activity but must be monitored before it can be discharged to a lagoon. If active, it will be stored in tanks and ultimately converted to a solid form (perhaps to concrete after an evaporation step). The volume of water used for sodium removal is relatively unimportant since this water is further diluted and then discharged from the plant site. Water used for washing the oxide powder (to remove the sodium from logged pins) will probably contain radioactive elements, but in unknown quantities. Storage tanks will be provided. Analysis of this solution will be required to determine the quantity and types of fission products in solution.

Fission-product gases (xenon, krypton, iodine, and ${ }^{3} \mathrm{H}$ ) contained in the fuel pins are released during chopping and probably to some extent during ball-milling. Both the pin chopper and ball mill operate within a secondary enclosure so that these gases and oxygen (or another purge gas) are contained and can be fed to the off-gas treatment plant. The quantities of gases involved have not been estimated.

\subsection{Fluorination in Reactor A}

\subsubsection{Outline of Process Steps}

The portion of the process included in this section uses the equipment shown in $\mathrm{Fig}$. 4.4. The input to this process step is pulverized $\mathrm{UO}_{2}-\mathrm{PuO}_{2}$ fuel (stream 1) and alumina (stream 2), which are mixed before introduction into fluorinator A (as described in Section 3.1). The input gas stream is 23 vol \% fluorine-oxygen.

For ease of discussion, the output streams from this process step have been arbitrarily designated product stream, intermediate product stream, and waste stream. Figure 4.4 gives the compositions of these streams, and Table 4.1 shows a complete material balance. The values used here ignore the release of fission-product gases during the mechanical head-end operations.

The product from trap CT-1 (stream 5) is the major product stream and consists of volatile fluorides. Processing of this stream after it leaves $\mathrm{CT}-1$ is discussed in Section 4.4 . 


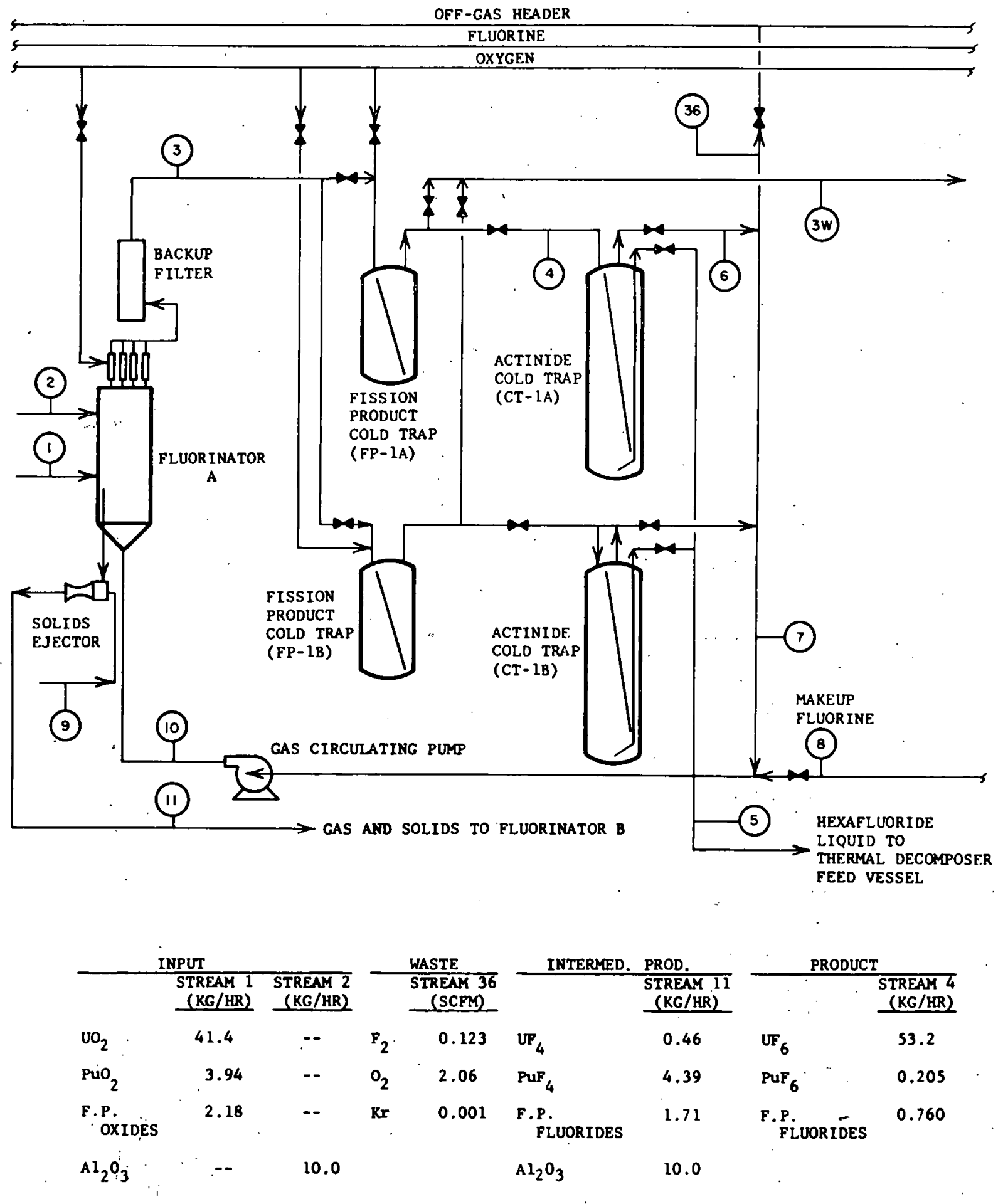

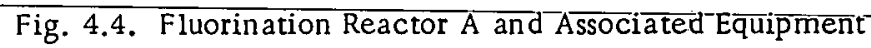


TABLE 4.1. Material Balance: Fluorination Loop A

\begin{tabular}{|c|c|c|c|c|c|c|c|c|c|c|c|c|c|}
\hline & & \multicolumn{12}{|c|}{ Stream No. } \\
\hline & & 1 & 3 & $3 W$ & 4 & .5 & 6 & 36 & 7 & 8 & 10 & 11 & 9 \\
\hline \multicolumn{2}{|l|}{$\mathrm{U}, \mathrm{kg} / \mathrm{day}$} & 875 & 866 & & 866 & 866 & 0.01 & $<0.001$ & 0.01 & & 0.01 & 8.8 & \\
\hline \multicolumn{2}{|l|}{$\mathrm{Pu}, \mathrm{kg} / \mathrm{day}$} & 83.5 & 3.3 & & 3.3 & 3.3 & $<0.001$ & $<0.001$ & $<0.001$ & & $<0.001$ & 80.2 & \\
\hline \multicolumn{2}{|c|}{ F.P. oxides, $\mathrm{kg} / \mathrm{day}$} & 52.3 & & & & & & & & & & $41.0^{9}$ & \\
\hline \multicolumn{2}{|l|}{$\mathrm{Al}_{2} \mathrm{O}_{3}, \mathrm{~kg} / \mathrm{day}$} & 240 & $\cdot$ & & & & & & & & & 240 & \\
\hline \multicolumn{14}{|c|}{$\underline{\text { Actinide Compounds, g/day }}$} \\
\hline \multicolumn{2}{|l|}{$\mathrm{PuF}_{6}$} & $123 \times 10^{3}$ & 4920 & 0 & 4920 & 4919.5 & 0.5 & 0.03 & 0.47 & & 0.47 & $118.0 \times 10^{3}$ & \\
\hline \multicolumn{2}{|l|}{$\mathrm{UF}_{6}$} & $1290 \times 10^{3}$ & $1277 \times 10^{3}$ & 0 & $1277 \times 10^{3}$ & $1277 \times 10^{3}$ & 18 & 1 & 17 & & 17 & $12.9 \times 10^{3}$ & \\
\hline \multicolumn{2}{|l|}{$\mathrm{NpF}_{6}$} & 242 & 121 & 0 & 121 & 121 & 0.04 & 0.003 & 0.037 & & 0.037 & 121 & \\
\hline \multicolumn{14}{|c|}{$\begin{array}{l}\text { Volatile Fission- } \\
\text { product Elements or } \\
\text { Compounds, g/day }\end{array}$} \\
\hline \multicolumn{2}{|l|}{$\mathrm{NbF}_{5}$} & 152 & 137 & 103 & 34 & 34 & $8.0 \times 10^{-14}$ & $7.8 \times 10^{-13}$ & $1.0 \times 10^{-11}$ & & $1.0 \times 10^{-11}$ & 15 & \\
\hline \multicolumn{2}{|l|}{$\mathrm{MOF}_{6}$} & 8120 & 7308 & 0 & 7308 & 7290 & 18 & 1 & 17 & & 17 & 829 & \\
\hline \multicolumn{2}{|l|}{$\mathrm{TcF}_{6}$} & 1990 & 1791 & 0 & 1791 & 1791 & 0.46 & 0.03 & 0.43 & & 0.43 & 199 & \\
\hline \multicolumn{2}{|l|}{$\mathrm{RuF}_{5}$} & 7470 & 6723 & 6721 & 2 & 2 & $1.3 \times 10^{-16}$ & $9.4 \times 10^{-18}$ & $1.2 \times 10^{-16}$ & & $1.2 \times 10^{-16}$ & 747 & \\
\hline \multicolumn{2}{|l|}{$\mathrm{SbF}_{5}$} & 248 & 223 & 0 & 223 & 223 & 0.094 & 0.007 & 0.087 & & 0.087 & 25 & \\
\hline \multicolumn{2}{|l|}{$\mathrm{TeF}_{6}$} & 1620 & - & 0 & - & 1365 & - & 93 & - & & - & 162 & \\
\hline \multicolumn{2}{|l|}{$\mathrm{IF}_{5}$} & 882 & 794 & 0 & 794 & 794 & 0.025 & 0.003 & 0.023 & & 0.023 & .88 & \\
\hline \multicolumn{2}{|l|}{$\mathrm{Kr}$} & 132 & 132 & 0 & - & 0 & - & 132 & - & & - & - & \\
\hline \multicolumn{2}{|l|}{$\mathrm{Xe}$} & 4680 & 75480 & 0 & - & - & - & 4680 & $\cdot$ & & - & - & \\
\hline \multicolumn{14}{|c|}{ Gas Flowrates, scim } \\
\hline \multicolumn{2}{|l|}{$U F_{6}$} & & 1.99 & & & & & & & & & & \\
\hline \multicolumn{2}{|l|}{$\mathrm{PuF}_{6}$} & & 0.008 & & & & & & & & & & \\
\hline \multicolumn{2}{|l|}{$\mathrm{F}_{2}$} & & 1.8 & & & & 1.8 & 0.123 & 1.7 & 6.8 & 8.5 & & 5.4 \\
\hline \multicolumn{2}{|c|}{$\mathrm{O}_{2}$ (Reaction product) } & 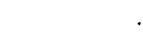 & 2.1 & & & & & & & & & & \\
\hline $\mathrm{O}_{2}$ (Diluent) & & & 27.9 & & & & 30.0 & 2.06 & 27.9 & & 27.9 & & 0.6 \\
\hline$x_{e}$ & & & 0.316 & & . & & 0.316 & 0.02 & 0.30 & & 0.30 & & \\
\hline $\mathrm{Kr}$ & & & 0.014 & & & & 0.014 & $\underline{0.001}$ & 0.013 & & 0.013 & & \\
\hline Total Gas F & wrate & & 34.1 & & & & 32.1 & 2.2 & 29.9 & 6.8 & 36.7 & & 6.0 \\
\hline & $\frac{\text { Fluorin }}{\text { Inven }}$ & $\frac{\text { lator A }}{\text { itory }}$ & & & & & & & & & & & \\
\hline & $\underline{\mathrm{kg}}$ & $\underline{w t} \%$ & & & & & & & & & & & \\
\hline $\mathrm{U}$ & (4.9) & $(2.2)$ & & & & & & & & & & & \\
\hline $\mathrm{UF}_{4}$ & 6.6 & 2.9 & & & & & & . & & & & & \\
\hline $\mathrm{Pu}$ & $(44.6)$ & $(20.1)$ & & & & & & & & & & & \\
\hline PuF $_{4}$ & 60.2 & 27.1 & & & & & & & & & & & \\
\hline F.P. fluorides & 18.1 & 8.1 & & & · & & & & . & & & & \\
\hline $\mathrm{Al}_{2} \mathrm{O}_{3}$ & 137.0 & 61.8 & & & & & & & & & & & \\
\hline
\end{tabular}

as F.P. fluorides.

The intermediate product stream (stream ll) consists of bed solids continuously removed from fluorinator A and transferred to fluorinator B. This section of the process description is concerned with solids processing in fluorinator A. Table 4.1 gives the composition of stream 11 .

The waste streams in this section of the process are represented by the gaseous bleed from the fluorination loop (stream 36) and gaseous fission products from trap FP-l (stream $3 \mathrm{~W}$ ). The composition of waste stream 36 and the system designed to handle gaseous wastes are described in Section 4.8. Section 4.3.9 discusses the formation, composition, and disposal of stream $3 \mathrm{~W}$ (the contents of FP-1). 


\subsubsection{Design Considerations}

The process equipment for uranium fluorination was designed from experience gained in (1).reprocessing studies on LWR fuels and (2) the production of feed materials for the gaseous-diffusion plant. The fluorinator, cold traps, gas-circulating pump, and the solids conveyor system are described separately.

The chemical and physical processes relevant to the design of the fluorinator are discussed first, followed by a description of the fluorinator (Section 4.3.3) and the mechanical design considerations that influenced the final design.

4.3.2.1 $\mathrm{UF}_{6}$ Production Rate. High $\mathrm{UF}_{6}$ production rates can be expected, since the system of finely divided oxide feed is highly reactive and since excellent gas-solids contact will be achieved in the fluid bed. The design production rate for $\mathrm{UF}_{6}$ with an input of $47.5 \mathrm{~kg} / \mathrm{hr}$ of mixed core and blanket fuel is $100 \mathrm{lb} /(\mathrm{hr})\left(\mathrm{ft}^{2}\right)$. This projected rate is based on laboratory and pilot-plant data ${ }^{34,38,39}$ wherein $\mathrm{U}_{3} \mathrm{O}_{8}-\mathrm{PuO}_{2}$ fines were fluorinated at high rates with fluorine. A survey ${ }^{40}$ of reaction rates for the fluorination of $\mathrm{U}_{3} \mathrm{O}_{8}$ and of $\mathrm{UO}_{2}$ with fluorine indicates no significant difference in rate constants under similar reaction conditions. Thus, UF 6 production rates of $100 \mathrm{lb} /(\mathrm{hr})\left(\mathrm{ft}^{2}\right)$ will probably be realized unless the irradiated $\mathrm{UO}_{2}-\mathrm{PuO}_{2}$ fast-reactor fuel is particularly unreactive. With a reactorcrosssectional area of $1.33 \mathrm{ft}^{2}$, the design basis of $100 \mathrm{lb} /(\mathrm{hr})\left(\mathrm{ft}^{2}\right)$ is about $13 \%$ higher than the actual rate required, $88 \mathrm{lb} /(\mathrm{hr})\left(\mathrm{ft}^{2}\right)$, for $100 \%$ conversion of the uranium feed.

The reaction rate constant $t^{38}$ of $6.5 \times 10^{-3} \mathrm{~min}^{-1}$ for the reaction of $\mathrm{U}_{3} \mathrm{O}_{8}$ with fluorine indicates that the residence time to effect $99 \%$ conversion of $\mathrm{U}_{3} \mathrm{O}_{8}$ to $\mathrm{UF}_{6}$ is approximately $2 \mathrm{hr}$. Based on a total solids inventory of $222 \mathrm{~kg}$ for the uranium fluorinator and the rate of solids removal from the reactor shown in Fig. 4.4 (stream 11 ), the average particle residence time is $13.4 \mathrm{hr}$. Therefore, the average particle residence time is about 6.7 times that required to effect the design conversion of $99 \%$ of the uranium charge to $\mathrm{UF}_{6}$.

\subsubsection{Fluorine Consumption. Almost complete consumption of} fluorine has been achieved in a variety of reaction systems. Hence, a value of $75 \%$ fluorine consumption is considered conservative. It may actually prove desirable to limit fluorine utilization to ensure excess fluorine in the fluorinator effluent and to avoid the formation of undesirable uranium intermediates through the reaction of ${ }^{-U F_{6}}$ with-unreacted-oxide-feed-U-rani-um intermediates apparently were responsible for agglomeration of bed material noted in some development studies on LWR fuel. The mode of operation that will give an appropriate fluorination utilization will have to be determined during a future development effort. 
4.3.2.3 $\mathrm{PuF}_{6}$ Formation. In the present flowsheet, the quantity of $\mathrm{PuF}_{6}$ formed during the uranium fluorination step is unimportant since the $\mathrm{UF}_{6}$ (product of the $\mathrm{A}$ loop) and $\mathrm{PuF}_{6}$ (product of the $\mathrm{B}$ loop) are combined, then later separated in the thermal-decomposition step. Equilibrium calculations indicate that a maximum of $4 \%$ of the input plutonium is converted to $\mathrm{PuF}_{6}$ at the selected fluorine flowrates and fluorine utilization. The steadystate inventory of plutonium in the uranium fluorinator corresponds to 20.1 wt $\%$ plutonium or a total of $44.6 \mathrm{~kg}$ of plutonium and is the subject of a nuclear criticality analysis (see Section 6.1.3.1).

4.3.2.4 Heat Load. The daily heat load from fission-product decay totals $76.7 \mathrm{~kW} *$ in the following proportions: core fuel, $109.4 \mathrm{~W} / \mathrm{lb}(\mathrm{U}+\mathrm{Pu}$ ): axial blanket fuel, $3.2 \mathrm{~W} / \mathrm{lb}(\mathrm{U}+\mathrm{Pu})$; and radial blanket fuel, $5.5 \mathrm{~W} / \mathrm{lb}(\mathrm{U}+\mathrm{Pu})$. Thus, fission products fed to fluorinator A will contribute $5.5 \mathrm{~kW} / \mathrm{hr}$ to the heat load for this reactor. Of this amount, $43.5 \%(1.4 \mathrm{~kW} / \mathrm{hr})$ leaves the fluorinator as volatile fission-productfluorides, and the remainder, $1.8 \mathrm{~kW} / \mathrm{hr}$, leaves with the solids feed stream and passes into stage B-l (see Fig. 3.4) of the plutonium fluorinator.

The chemical heat load for $\mathrm{UF}_{6}$ production at a rate of $100 \mathrm{lb} /(\mathrm{hr})\left(\mathrm{ft}^{2}\right)$ is $51.9 \mathrm{~kW}(177,000 \mathrm{Btu} / \mathrm{hr})$. Approximately $1.8 \mathrm{~kW}$ is expended in heating the alumina, spent fuel, and fluidizing gas to reaction temperature, leaving a net chemical heat load of $50.1 \mathrm{~kW}$. The steady-state fission-product heat load in the uranium fluorinator has been calculated on the basis of $3 \mathrm{ft}$ of static bed and gives an additional heat load of $28.4 \mathrm{~kW}(97,000 \mathrm{Btu} / \mathrm{hr})$. Assuming a static bed height of $3 \mathrm{ft}$ and reactor dimensions of $4 \mathrm{in}$. thickness by $4 \mathrm{ft}$ width, the net heat flux from the uranium reactor is $11,200 \mathrm{Btu} /$ $(\mathrm{hr})\left(\mathrm{ft}^{2}\right)$. With bed expansion upon fluidization to a height of $4 \mathrm{ft}$, the net heat flux is reduced to $8400 \mathrm{Btu} /(\mathrm{hr})\left(\mathrm{ft}^{2}\right)$.

\subsubsection{Description and Mechanical Features of Reactor A}

The uranium fluorinator is a rectangular parallelepiped with inside dimensions of $4 \mathrm{in.} \mathrm{thick,} 4 \mathrm{ft}$ wide, and $10 \mathrm{ft}$ high (see Fig. 4.5). The fluidized bed is $4 \mathrm{ft} \mathrm{high,} \mathrm{and} \mathrm{the} \mathrm{upper} 6 \mathrm{ft}$ of reactor provides freeboard and space for the exit gas filters. The fluorinator is forced-air cooled and has external fins for transferring process heat to the cooling air. The process-gas distributor has a bubble cap design.

4.3.3.1 Gas Distributor. Cylindrical industrial-scale fluid-bed reactors use a jet or perforated-plate gas distributor. ${ }^{41}$ Methods have been developed for the design of such distributors. ${ }^{42}$ Slab reactors (thin "twodimensional" columns of $3 / 8$ to 1 in. thickness) have been used in fundamental fluidization studies; however, there appears to be no information concerning the practical design and operation of slab reactors 4 in. thick. ${ }^{43}$

\footnotetext{
*A preliminary estimate of the fission-product heat load. A refined estimate is given in Section 2.4 .
} 
Pyramid and saw-toothed shaped distributors in small-scale noncircular units were tested, and it was observed that spouting and areas of nonfluidization can be avoided by using specially constructed inserts to correct the stagnant areas. ${ }^{43}$

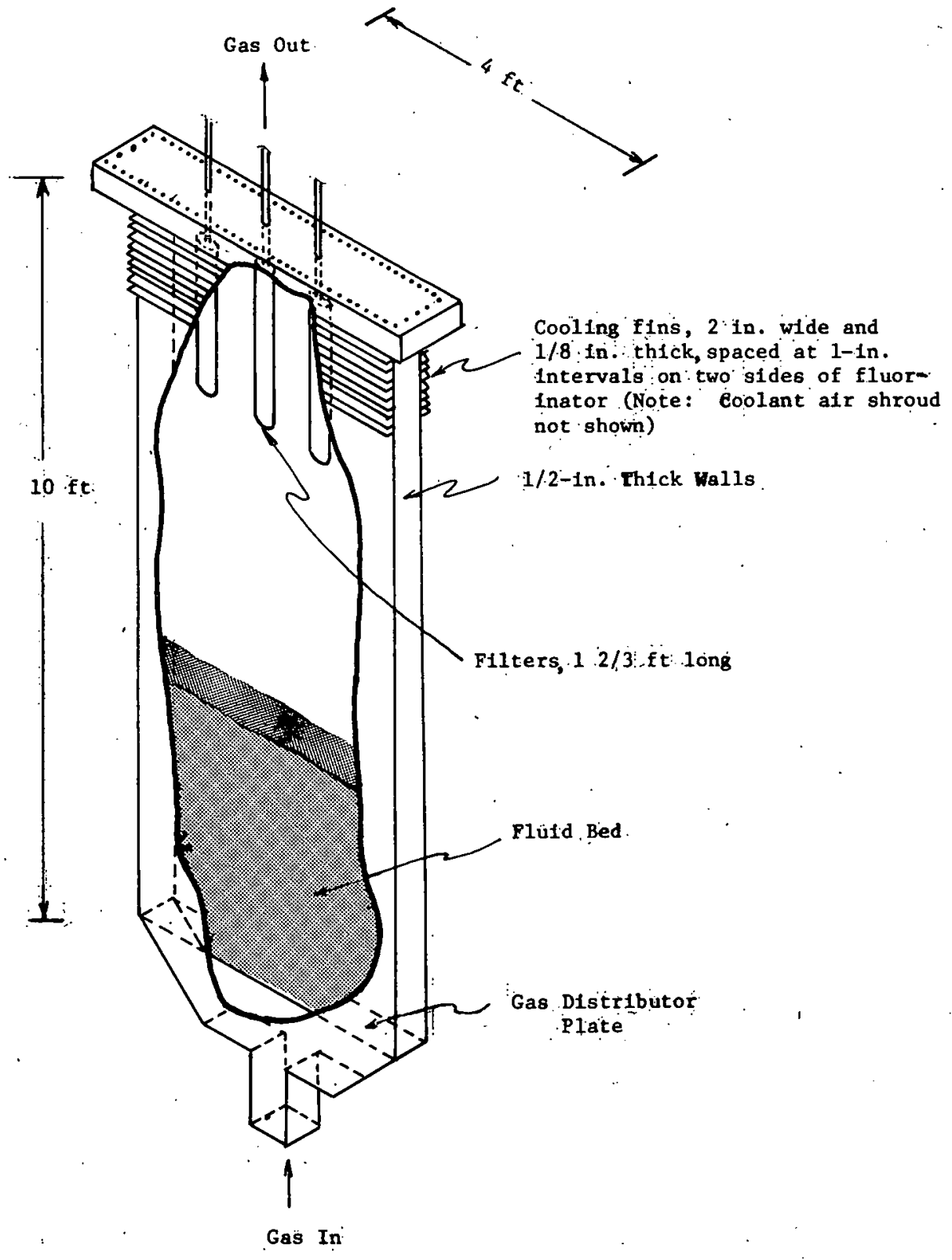

Fig. 4.5. Schematic Diagram of Uranium Fluorinator (Reactor A)

Petrie and $\mathrm{Black}^{44}$ discussed factors affecting distributor design; they propose a bubble-cap design which avoids nonfluidized-regions-a-bove the distributor caps, prevents seepage of fluid-bed material below the distributor plate when fluidization stops, and reduces the chance of serious erosion of the plate and caps. This design was developed after prolonged operation and tests of a gas distributor in the Waste Calciner Facility at ICPP. ${ }^{45}$ 
These fluidization tests, carried out with calcined alumina particles, clearly identified the problem areas for the original gas distributor. The bubble cap design developed by Petrie and Black will probably serve as the basis for an adequate gas distributor for the uranium fluorinator.

4.3.3.2 Freeboard. Although an enlarged-diameter section is provided in some fluid-bed reactors for gas-solids disengaging, reactor $A$ has the same cross-sectional area from top to bottom of the vessel. This will probably simplify construction. On the basis of the results of several studies, ${ }^{46-48}$ a solids disengaging height of about $2.7 \mathrm{ft}$ should be sufficient.

4.3.3.3 Filters. Solids entrained in the fluidizing gas are removed by sintered-metal filters placed in the top of the reactor. Empirical design parameters described by Carls and Levitz ${ }^{49}$ suggest that $6.8 \mathrm{ft}^{2}$ of filter surface would be sufficient to allow operation at the recommended value of 0.8 for the ratio of blowback-gas flowrate to forward-gas flowrate through the filters. An arrangement that conservatively satisfies this design parameter would be 12 bayonet-type primary filters, each 2.75 in. wide, 20 in. 1 ong, and 1 in. thick, having a total filter area of $9 \mathrm{ft}^{2}$. The filters would be arranged in three banks of four filters each. Accumulated solids on the filters would be returned to the reactor bed by intermittent blowback of each filter with oxygen at 80 psig.

4.3.3.4 Coolant System. The large number of fins required for increasing the mechanical strength of the reactor walls (see Section 4.3.3.5) adds necessary heat-transfer area to cool the reactor. Because of criticality considerations (see Section 6.1), no tubing or piping should be added to carry liquid coolants to the reactor walls since these in effect increase the wall thickness and affect the nuclear $k_{\text {eff }}$ values. Therefore, we propose that the reactor be cooled by forced-air convection, the air being blown through rectangular channels formed by the reactor walls, the fins, and the supporting plates (i.e., the shroud).

The lower $6 \mathrm{ft}$ of fluorinator A will provide heat exchange with the cooling air. Ambient air will be blown through the rectangular channels (Fig. 4.5) at $6000 \mathrm{scfm}$, and the velocity past the reactor will be $50 \mathrm{ft} / \mathrm{sec}$. Pressure drop past the reactor ${ }^{50}$ will be about 1.2 in. $\mathrm{H}_{2} \mathrm{O}$. Commercial, off-the-shelf gas blowers are readily available for this purpose.

A conservative approach to the heat-removal calculation has been taken by assuming that the heat-transfer area is limited to the fluid-bed height of $4 \mathrm{ft}$. A widely used heat-transfer correlation ${ }^{51}$ and an equivalent diameter for the rectangular ducts ${ }^{52}$ have been used to calculate a heattransfer coefficient of $8.1 \mathrm{Btu} /(\mathrm{hr})\left(\mathrm{ft}^{2}\right)\left({ }^{\circ} \mathrm{F}\right)$ for the conditions existing in the uranium fluorinator. The temperature rise for the cooling air will be $206^{\circ} \mathrm{F}\left(115^{\circ} \mathrm{C}\right)$. 
It will also be desirable to maintain the temperature of the sinteredmetal filters at $200^{\circ} \mathrm{C}$. For this purpose, the top $2 \mathrm{ft}$ of the reactor will also be cooled. If there is no accumulation of radioactive fission products on the filter, the heat flux will be small, $<100 \mathrm{Btu} /(\mathrm{hr})\left(\mathrm{ft}^{2}\right)$, and a maximum of $1000 \mathrm{cfm}$ cooling air will be more than adequate to maintain the filter temperatures at $200^{\circ} \mathrm{C}$.

\subsubsection{Design of Reactor Wall. The reactor-wall thickness (shown} in Fig. 4.5) is 0.5 in., and, because of the corrosive reagents used, the material of construction is low-carbon nickel (nickel 201) throughout. Questions regarding the mechanical strength of the nickel walls under the proposed operating conditions prompted a mechanical-engineering stress analysis, ${ }^{53}$ which was performed for an assumed internal pressure of 15 psig. and a temperature of $350^{\circ} \mathrm{C}$. For this analysis, the reactor walls were assumed to be flat plates under uniform loading with fixed edges. The calculated stress is 17,300 psi with no allowance made for corrosion of the walls; the ASME pressure-vessel code allows a maximum stress of $7400 \mathrm{psi}$ for low-carbon nickel. At the higher temperature of $550^{\circ} \mathrm{C}$ used in fluorinator B, the ASME code allows a stress of only 3000 psi. Therefore, the walls of the reactor need support and are to be strengthened by a waffle-type construction formed by (1) the reactor wall, (2) $1 / 8$-in.-thick, 2 -in.-wide fins spaced at 1 in. intervals horizontally along the reactor walls $(10 \mathrm{ft})$, and (3) an outer plate made of suitable metal (e.g., stainless steel) for structural strength and mechanical support of the reactor. Alternative fabrication methods may include bonding techniques with, for example, Inconel, in order to strengthen selected vessel sections.

\subsubsection{Auxiliary Equipment}

4.3.4.1 Cold Traps. The fluorinator A loop has two sets of cold traps, one set to remove ruthenium-niobium fluorides: from the process-gas stream and the other to remove actinide fluorides. Two types of commercial batch cold traps are available for this application--an internally finned design and an "egg-crate" design. A digital-computer program for design of these traps is available. ${ }^{16}$

The internally cooled, finned cold trap consists of a trapping surface made of parallel-plane fins brazed to U tubes. The heat-transfer medium passes through the $U$ tubes, which are inside the trap. Mixing of the coolant with the process gas in the event of coolant-tube failure is considered perhaps the most serious hazard of this design.

In the "egg-crate" design, the refrigeration-or-cooling-tubes-are attached to the outside of the shell. Consequently, both the tube and the shell would have to rupture at the same point before coolant and process gas could mix. Therefore, this design has been selected for the plant. The heattransfer area is composed of egg-crate fins held in circumferential rings 
bonded to the shell, as shown in Fig. 4.6. It has been stated ${ }^{17}$ that this trap has an overall heat-transfer coefficient ranging from 0.5 to $1.5 \mathrm{Btu} /$ $(\mathrm{hr})\left(\mathrm{ft}^{2}\right)\left({ }^{\circ} \mathrm{F}\right)$ and that the capacity ranges from about 10 to $40 \%$ of the void volume.
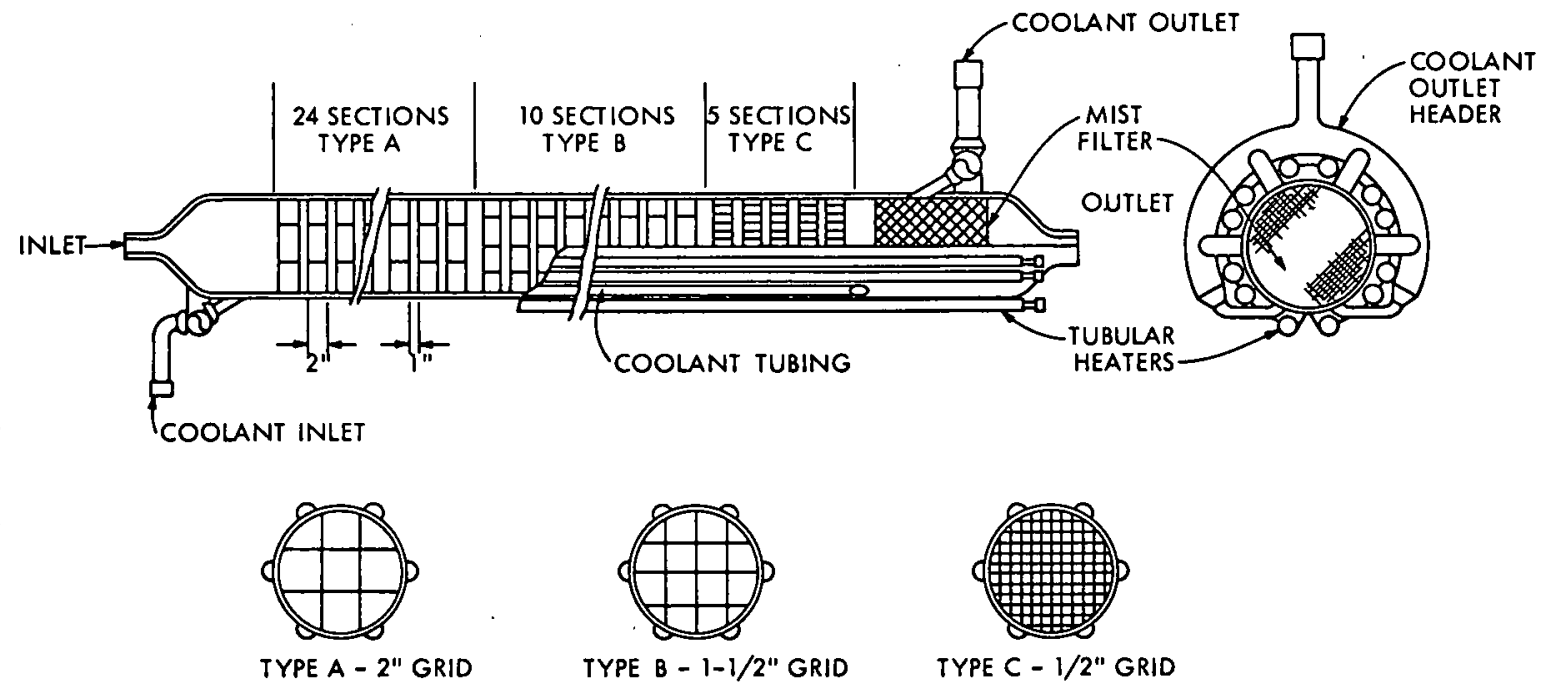

Fig. 4.6. Externally Cooled Cold Trap*

For all traps except one (trap CT-4, Fig. 4.15, in which only $\mathrm{UF}_{6}$ is collected), criticality considerations limit the cross section of the cold traps. Therefore, traps are slabs $4 \mathrm{in.}$ thick, $4 \mathrm{ft}$ wide, and of various heights.** Coolant for the traps will be a pressurized liquid-nitrogen system such as that being used successfully at the Dow Rocky Flats plant in plutonium fluorination work. ${ }^{54}$

The design criteria and assumptions selected for these traps are as follows:

1. An overall heat-transfer coefficient of $1.0 \mathrm{Btu} /(\mathrm{hr})\left(\mathrm{ft}^{2}\right)\left({ }^{\circ} \mathrm{F}\right)$ and a maximum loading of $20 \%$ of void volume were used in the calculations; these values are about in the middle of the range for the egg-crate design.

2. The inside surface area of the slab-shaped egg-crate trap was assumed to average $10 \mathrm{ft}^{2} / \mathrm{ft}$ of trap length. Since the solids loading will be very low (less than $1 \%$ of the void volume) for the two traps (FP-1 and FP-2) associated with the removal of ruthenium and niobium, the heat-transfer surface area was doubled to $20 \mathrm{ft}^{2} / \mathrm{ft}$ length of trap to halve its length.

3. Heating or cooling of the traps is assumed to require at least $4 \mathrm{hr}$; discharge of the cold trap contents to another container, about $2 \mathrm{hr}$.

4. Slab-shaped and cylindrical units operate equally well.

\footnotetext{
*From D. I. Dunthorn, The Design of Batch Desublimers, K-L-6220 (Sept 1968).

**Cold trap CT -4 is of slab design for convenience only.
} 
Table 4.1A shows the size, number of traps required, heat loads, and the batch processing cycle for FP-1 and CT-1. Table $4.1 \mathrm{~A}$ also contains data on traps FP-2 and CT-2, which are discussed in Sections 4.4.1, 4.4.5.2, and 4.4 .5 .3 of this report.

TA8LE 4.1A. Applications, Number, and Heat Loads of Cold Traps

\begin{tabular}{|c|c|c|c|c|c|c|c|c|c|c|c|c|c|}
\hline \multirow{3}{*}{$\begin{array}{c}\text { Trap } \\
\text { Designation }\end{array}$} & \multirow[b]{3}{*}{ Trap Use } & \multirow{2}{*}{\multicolumn{2}{|c|}{$\begin{array}{l}\text { Slab-type Trap } \\
4 \text { in. Thick }\end{array}$}} & \multirow{3}{*}{$\begin{array}{c}\text { Number of } \\
\text { Traps } \\
\text { Required }\end{array}$} & \multirow{2}{*}{\multicolumn{5}{|c|}{ Batch Processing Cycle, hr }} & \multicolumn{4}{|c|}{ Heat Load, Btu/hr } \\
\hline & & & & & & & & & & \multirow{2}{*}{$\begin{array}{l}\text { In } \\
\text { Cooling }\end{array}$} & \multirow{2}{*}{$\begin{array}{c}\text { In } \\
\text { Condensing } \\
\text { Fluorides }\end{array}$} & \multirow{2}{*}{$\begin{array}{l}\text { Fission- } \\
\text { product } \\
\text { Heat }\end{array}$} & \multirow[b]{2}{*}{ Total } \\
\hline & & Length, it & Width, in. & & Cool & Collect & Heat & $\begin{array}{l}\text { Discharge } \\
\text { Contents }\end{array}$ & Total & & & & \\
\hline FP-1 & $\begin{array}{l}\text { Remove } \mathrm{RuF}_{5}, \mathrm{NbF}_{5} \text { from } \\
\text { fluorinator } \AA \text { off-gas }\end{array}$ & 10 & 48 & 2 & 6 & 12 & 4 & 2 & 24 & 5,620 & 60 & $56.750^{3}$ & 62,430 \\
\hline CT-1 & $\begin{array}{l}\text { Remove } \mathrm{UF}_{6}, \mathrm{PuF}_{6} \text { from } \\
\text { fluorinator } \mathrm{A} \text { off-gas }\end{array}$ & 17 & 48 & 2 & 6 & 12 & 4 & 2 & 24 & 6,750 & 7,690 & 5,860 & 20,300 \\
\hline FP-2 & $\begin{array}{l}\text { Remove } \mathrm{RuF}_{5}, \mathrm{NbF}_{5} \text { from } \\
\text { fluorinator } \mathrm{B} \text { off-gas }\end{array}$ & 4 & 24 & 2 & 6 & 12 & 4 & 2 & 24 & 3,430 & Small & $6,830^{\mathrm{a}}$ & 10,260 \\
\hline CT-2 & $\begin{array}{l}\text { Remove } \mathrm{PuF}_{6} \text { from } \\
\text { fluorinator } \mathrm{B} \text { off-gas }\end{array}$ & 7 & 24 & 2 & 6 & 12 . & 4 & $\cdot 2$ & 24 & 4,220 & 720 & Small & 4,940 \\
\hline
\end{tabular}

${ }^{a}$ Heat load from condensed fission products after 12 hr.

4.3.4.2 Gas-circulating Compressors. The fluorination process gas circulated consists of fluorine-oxygen mixtures with traces of actinide and fission-product fluorides or oxyfluorides. The compressor systems considered for the application were a diaphragm compressor, a piston compressor, a peripheral compressor, a bellows compressor, a centrifugal compressor, and a compression system based on injection circulation. The types of compressors commercially available and their advantages and disadvantages from a process standpoint are discussed in Appendix B. For the above system, the diaphragm compressor is the most suitable from the standpoint of availability and reliability.

4.3.4.3 Pneumatic Conveyors. Pneumatic conveying is an important feature of the continuous fluorination process. Oxide fuel and alumina are fed to fluorinator $A$, and plutonium-rich alumina overflowing from fluorinator $A$ is transported to fluorinator $B$. The solids are fed directly into the fluid bed rather than into the gas space above the bed in order to minimize elutriation of fines contained in the feed. Two types of pneumatic conveyors that might be used are depicted in the conceptual pneumatic solids feed system shown in Fig. 3.3.

Pneumatic systems of the types described are in continuous service, ${ }^{31}$ and the only unique aspect of the present application is the large radiation heat load. Pneumatic conveyors depend on the solids being thermally stable (noncaking), and since alumina, oxides, and fluorides in the mixture to be conveyed have relatively high melting points, they should convey well. However, because of the possibility of overheating and subsequent plugging, the system-mus-t-be-designed-s.o-that_i.tcan_be_rodded._Design and testing of pneumatic systems are suggested as part of an overall R\&D program.

4.3.4.4 Conveyor for Oxide Fuel and Alumina. In the pulse conveyor used to deliver oxide and alumina feed to fluorinator A (shown in Fig. 3.3), 
the solids in the standpipe are fluidized by a gas pulse, and expansion of the bed causes solids to drop by gravity into fluorinator A. The pulsing gas is oxygen, and thus no extraneous gas is introduced into the fluorination system. The volume of oxygen used is expected to be less than $0.6 \mathrm{scfm}$.

Solids take off from reactor A (shown in Fig.4.4) is through an internal leg rather than an overflow. This arrangement maintains a seal between reactors $A$ and $B$. (A seal is needed to keep gaseous uranium and fission-product species out of the $\mathrm{PuF}_{6}$ stream.) The solids feed $\mathrm{rate}$ from reactor $A$ to reactor $B$ is controlled by adjusting the flowrate of the conveying gas. This method of control has been in use in the Waste Calcining Facility at Idaho. ${ }^{31}$ Heat dissipation from solids in the static leg is considered a relatively minor problem. A relatively small pipe $(\sim 1$ in.) will be. used, with air cooling of the outside if necessary. An extended-surface pipe could be provided if needed.

The pneumatic system would probably be constructed of stainless steel Types 304 and 347, which have exhibited combined corrosion-erosion rates of $<1.0 \mathrm{mil} /$ month in the Waste Calciner Facility at ICPP. ${ }^{55}$ The actual transport velocities required are a function of the particle characteristics, the gas properties, and the geometry of the system. Velocities ${ }^{56}$ are generally greater than $7 \mathrm{ft} / \mathrm{sec}$, and usually design velocities range from 15 to $40 \mathrm{ft} / \mathrm{sec}$. At a design velocity of $20 \mathrm{ft} / \mathrm{sec}$, a 1 -in.-diam solidstransport pipe requires a gas rate of $6.6 \mathrm{scfm}$ and a 2 -in.-diam pipe requires $26 \mathrm{scfm}$. If recycled gas is used for conveying, no increase in gaseous waste results.

\subsubsection{Process Instrumentation}

The two fluorination systems ( $A$ and $B$ ) have similar instrumentation. The instruments on fluid-bed units such as the fluorinators measure the following: pressure in the fluorinator, differential pressure across the alumina fluidized bed and across the filter banks, internal temperature (bed, cooling, and filter zones), skin temperature, coolant air volume and inlet and outlet temperatures, and volume of gas being recirculated to the fluorinator. All interior-bed-temperature control points have high-temperature-level alarms, which notify the operator of a temperature problem. Depending on the mode of operation, controls can be designed to automatically shut down any bed-heating circuits and increase the flow of coolant air to the maximum. In extreme situations, automatic stoppage of the flow of reactants can be programmed, or the bed can be dumped into the storage cylinders provided for handling the alumina wastes from reactor B. High pressure in the system will also activate an alarm and require special procedures after the operator analyzes the situation. Work conducted preliminary to plant startup would dictate which procedures to follow in each situation.

The bed level in the fluorinators is monitored and controlled by the pneumatic conveying system, which controls the solids input and withdrawal 
rates. Fresh alumina, kept in a weighed hopper, is injected either continuously or intermittently with the fuel to fluorinator $A$, and represents the main flow of solids through the reactors. Withdrawal from reactor $A$ is from a standpipe, which serves as a gas-seal device between reactors. Temperatures in the powder transfer system are monitored, and gas flow and/or pressure are monitored to indicate whether the system is operational.

The fission-product trap (FP-1), in which the temperature must be controlled within a narrow range for effective fission-product removal, has upper- and lower-temperature-level alarms to alert the operator to out-ofrange operations. Since out-of-range temperatures for trap FP-1 could cause a major process upset, automated responses to deviations of the temperature from the set point are available. These responses take the form of bypassing the trap, increasing coolant flow, adding heat to the trap, etc. During the condensing cycle, the trap is cooled by nitrogen gas under pressure, which is metered automatically to the cooling zone as required. A central pressurized liquid-nitrogen refrigeration system is proposed for the entire plant. During the trap-emptying cycle, the fission products in the traps are heated (or allowed to self-heat) to an automatically controlled temperature, then transferred to a fluid-bed NaF sorption unit in a stream of oxygen. Temperature-, pressure-, and flow-measurement instruments for. the fluid-bed sorber are similar to those for the fluorinator fluidized bed.

The temperature of the uranium hexafluoride product cold trap (CT-1) is controlled automatically during the collecting cycle and during the discharge cycle, when the liquid hexafluoride is transferred to the feed vessel for the thermal-decomposer unit. System pressure during liquid transfer is monitored, and if it is too high the heat automatically shuts off. The cold traps (and feed vessel) have remote automatic weighing systems, so that filling and dumping progress can be observed.

\subsubsection{Material Balances}

A process equipment flowsheet with numbered process streams is shown in Fig. 4.4, and the compositions of the numbered streams are given in Table 4.1. Material-balance calculations were made on the basis that instantaneous mixing occurs in the fluorinator so that the composition of the stream of solids leaving the fluorinator is identical to the composition of the fluidized bed in the reactor. The rate of solids input to the fluorinator is $57.5 \mathrm{~kg} / \mathrm{hr}$ and includes $47.5 \mathrm{~kg} / \mathrm{hr}$ of mixed core and blanket fuel and $10 \mathrm{~kg} / \mathrm{hr}$ of fresh, granular alumina. The solids stream, which leaves fluorinator A at $16.6 \mathrm{~kg} / \mathrm{hr}(3.3 \mathrm{~kg} / \mathrm{hr}$ of plutonium), is fed to the plutonium fluorinator.

The uranium fluorinator is operated at $350^{\circ} \mathrm{C}$ with a fluidizing gas velocity of $1 \mathrm{ft} / \mathrm{sec}$ at $350^{\circ} \mathrm{C}$ and 1 atm. About $75 \%$ of the fluorine in the inlet gas (23.1 vol \% fluorine and 76 vol \% oxygen) is reacted in passing 
through the reactor. Most of the fluorine is consumed by formation of the main reaction product, $U F_{6}$, which is produced at a nominal rate of $100 \mathrm{lb} /(\mathrm{hr})\left(\mathrm{ft}^{2}\right)$; fluorine is also consumed in the formation of volatile and solid fission-product fluorides, $\mathrm{PuF}_{4}$, and some $\mathrm{PuF}_{6}$. Plutonium leaving the uranium fluorinator as $\mathrm{PuF}_{6}$ is estimated to be a maximum of about $4 \%$ of the plutonium charged by assuming that the unreacted excess fluorine $\left(1.8 \mathrm{scfm}\right.$ ) in stream 3 (Fig. 4.4) is in equilibrium with $\mathrm{PuF}_{6}$ at $350^{\circ} \mathrm{C}$. The volatile fission-product fluorides (mainly $\mathrm{RuF}_{5}$ and $\mathrm{NbF}_{5}$ ) in the gas leaving fluorinator $A$ are removed in cold trap FP-1. Hexafluoride products are subsequently removed from the gas stream in cold trap CT-1. Most of the gas leaving CT-1 is recycled to the reactor to increase overall fluorine utilization. Because the gas is recycled, $98.0 \%$ of the total fluorine added is used to form fluoride products: $86.6 \%$ of the fluorine is used to form $\mathrm{UF}_{6}$. Recycle reduces the volume of high-radiation-level gaseous waste from the fluorinator. As shown in Table 4.1,29.9 scfm is recycled and $2.2 \mathrm{scfm}$ is withdrawn from the system to the off-gas treatment system. Since fluorine is consumed in the reaction, $6.8 \mathrm{scfm}$ (stream 8 ) must be added to the recycle loop. The steady-state concentrations of xenon have been calculated on the basis that no $\mathrm{XeF}_{4}$ is formed in the fluorinator. However, based on a 1963 publication, ${ }^{57}$ reaction conditions in fluorinator A may be favorable for the formation of $\mathrm{XeF}_{4}$. The $\mathrm{XeF}_{4}$ formed would be deposited in CT -1 .

Two gas flows not included in the material-balance data are the oxygen required for filter blowback and for the pulse feeder systems. Both gas volumetric rates should be relatively small, the exact requirements being uncertain. For the plutonium calculations, it was assumed that no $\mathrm{PuF}_{6}$ decomposed.

The steady-state inventories of plutonium, uranium, and fissionproduct fluorides in fluorinator A are $44.6,4.9$, and $18.1 \mathrm{~kg}$, respectively. The maximum quantities of hexafluorides collected in cold trap CT-1, which is operated on 12 -hr cycles, are:

$$
\begin{aligned}
& 637 \mathrm{~kg} \text { of } \mathrm{UF}_{6} \\
& 2.5 \mathrm{~kg} \text { of } \mathrm{PuF}_{6}
\end{aligned}
$$

\subsubsection{Normal and Abnormal Operations}

Normal operation of fluid-bed reactors is characterized by normal values of temperature, pressure, flow, etc., generally measured with conventional control and monitoring instrumentation. The key to successful plant operation, however, is the capability of detecting off-specification operations that are indicative of potential problems. Off-specification operations, i.e., deviations from the norm (unusual pressure fluctuations, nonuniform bed temperatures, etc。), are quickly identified by means of automatic data logging combined with an on-line computer system, allowing operating 
personnel to be quickly alerted. Corrective operations in the event of a temperature excursion in the uranium fluorinator include, for example; cutting off reactant flow and increasing the gas velocity. Heat transfer in a fluid-bed system normally provides stable operation, and so as quickly as temperature upsets are detected, corrective action can be initiated. Since the chemical-reaction heat load is almost twice that of the fissionproduct heat load (discussed in Section 4.3.2.4), quick reduction in heat generation is possible by cutting off reactant flow. Furthermore, in continuous fluorination systems, the inventory of chemically active species at any given time is relatively small. Reactant cutoff (or other control features) would be planned to be automatic rather than to depend on manual control, although manual overrides would be included for flexible operation.

The fluid-bed process steps described are predicated on normal behavior of the gas-solids system, namely, that good gas distribution and solids movement will be maintained. In the event of abnormal functioning and bed overheating, which could result in serious caking, normal processing will be suspended, cooling will be maintained at the walls, and the cake will be broken up by mechanical and chemical means. After rodding of the bed, the solids may be slowly fluorinated in place in a packed-bed operation. In more extreme cases, the bed might be removed and the solids returned to the ball mill for final breakup. These solids would then be returned to the fluorinator for processing.

Success of the fluorination operations will also depend on the reliability of the air coolant system for the fluid-bed reactors, both during normal periods and during off-periods when the bed is not fluidized. The design of the present system appears to have adequate heat-removal capability, but high reliability is also required. Blowers must be kept on standby for safety. A standby liquid nitrogen system might be included also to provide additional safety in the event of mechanical breakdown of the forcedair system.

If the fluidized bed suddenly becomes static because of an inter ruption in the fluidizing gas flow or other circumstances, chemical reaction will stop and the total heat load of the reactor. will be due to radioactive decay of the accumulated fission products. Under these conditions, the internal heatgeneration rate in the uranium fluorinator becomes $25,000 \mathrm{Btu} /(\mathrm{hr})\left(\mathrm{ft}^{3}\right)$ or $\sim 260 \mathrm{~W} /$ liter, and the centerline temperature in the static bed increases until heat losses out of the reactor are equal to the heat-generation rates.

The equation to calculate the centerline temperature in the static bed, unde-r-the-cond-iti-on-that-ful-1-reactor-cooling-is maintained,ais_given by $\mathrm{Jakob},{ }^{58}$ is

$$
\frac{T_{L}-T_{0}}{2}=\left[\left(T_{0}-T_{e}\right)-\frac{q^{\prime \prime \prime}}{k^{2}}\right]\left(\sinh \frac{m L}{2}\right)^{2}
$$


where

$$
\begin{aligned}
\mathrm{T}_{\mathrm{L}} & =\text { centerline temperature, }{ }^{\circ} \mathrm{F} ; \\
\mathrm{T}_{0} & =\text { wall temperature, }{ }^{\circ} \mathrm{F} ; \\
\mathrm{T}_{\mathrm{e}} & =\text { average coolant gas temperature, }{ }^{\circ} \mathrm{F} ; \\
\mathrm{q}^{\prime \prime \prime} & =\text { internal heat-generation rate, } \mathrm{Btu} /(\mathrm{hr})\left(\mathrm{ft}^{3}\right) ; \\
\mathrm{m} & =(\mathrm{hc} / \mathrm{kA})^{1 / 2} ; \\
\mathrm{k} & =\text { settled bed thermal conductivity, } \mathrm{Btu} /(\mathrm{lb})(\mathrm{ft})\left({ }^{\circ} \mathrm{F}\right) ; \\
\mathrm{h} & =\text { surface coefficient of heat transfer, } \mathrm{Btu} /(\mathrm{hr})\left(\mathrm{ft}^{2}\right)\left({ }^{\circ} \mathrm{F}\right) ; \\
\mathrm{c} & =\text { perimeter of heat-transfer area, } \mathrm{ft} ; \\
\mathrm{A} & =\text { area for heat transfer, } \mathrm{ft}{ }^{2} ;
\end{aligned}
$$

and

$$
L=\text { distance from centerline to outer wall, } \mathrm{ft} \text {. }
$$

For calculation of the centerline temperature, it is assumed that the effective thermal conductivity of the static bed is $0.22 \mathrm{Btu} /(\mathrm{hr})(\mathrm{ft})\left({ }^{\circ} \mathrm{F}\right)$ and that the heat-transfer coefficient from the wall to the cooling gas remains at $8 \mathrm{Btu} /(\mathrm{hr})\left(\mathrm{ft}^{2}\right)\left({ }^{\circ} \mathrm{F}\right)$. If the outside wall of the reactor remains at $350^{\circ} \mathrm{C}$, then, according to Eq. 1, the maximum centerline temperature for the static bed will be $800^{\circ} \mathrm{C}$. With the reactor cooling system in operation and with heat transfer from the center of the bed to the wall more difficult because of the static conditions, the wall temperature will decrease. If the wall temperature is $200^{\circ} \mathrm{C}$, the maximum centerline temperature predicted by Eq. 1 is $710^{\circ} \mathrm{C}$.

Temperature distribution in a 4 -in.-thick static bed with time is shown in Fig. 4.7. These temperature distributions were calculated using the general numerical method of Dusinber $e^{59}$ for transient one-dimensional heat transfer with internal heat generation and forced convection on the outside wall. For these calculations, a value of 2 was used for the parameter $\dot{M} . \quad\left[M=(\Delta x)^{2} / \alpha \Delta \theta\right.$, where $\Delta x$ is a finite thickness of a slab slice, $\Delta \theta$ is a finite time increment, and $\alpha$ is the thermal diffusivity.] With an $M$ of 2 , the calculations predict that a centerline temperature of $800^{\circ} \mathrm{C}$ will be reached in about $50 \mathrm{~min}$; with an $\mathrm{M}$ of 5 , the required time is predicted to be $70 \mathrm{~min}$. Thus, if fluidization can be restarted about an hour after the bed goes static, the maximum centerline temperature will not be reached.

\subsubsection{Description of Physical and Chemical Processes in Reactor A}

This section describes the physical and chemical processes that contribute to the functioning of each piece of equipment in this part of the process. The description includes background information and data that 
are needed not only in Section 4.3, but also for a more comprehensive description of processes taking place elsewhere in the plant. Physical properties of actinide materials are given in Appendix C, and vapor pressures of volatile fluorides at key temperatures in Appendix D. Radiation effects on reactions other than decomposition of actinides have been ignored, but this will require study.

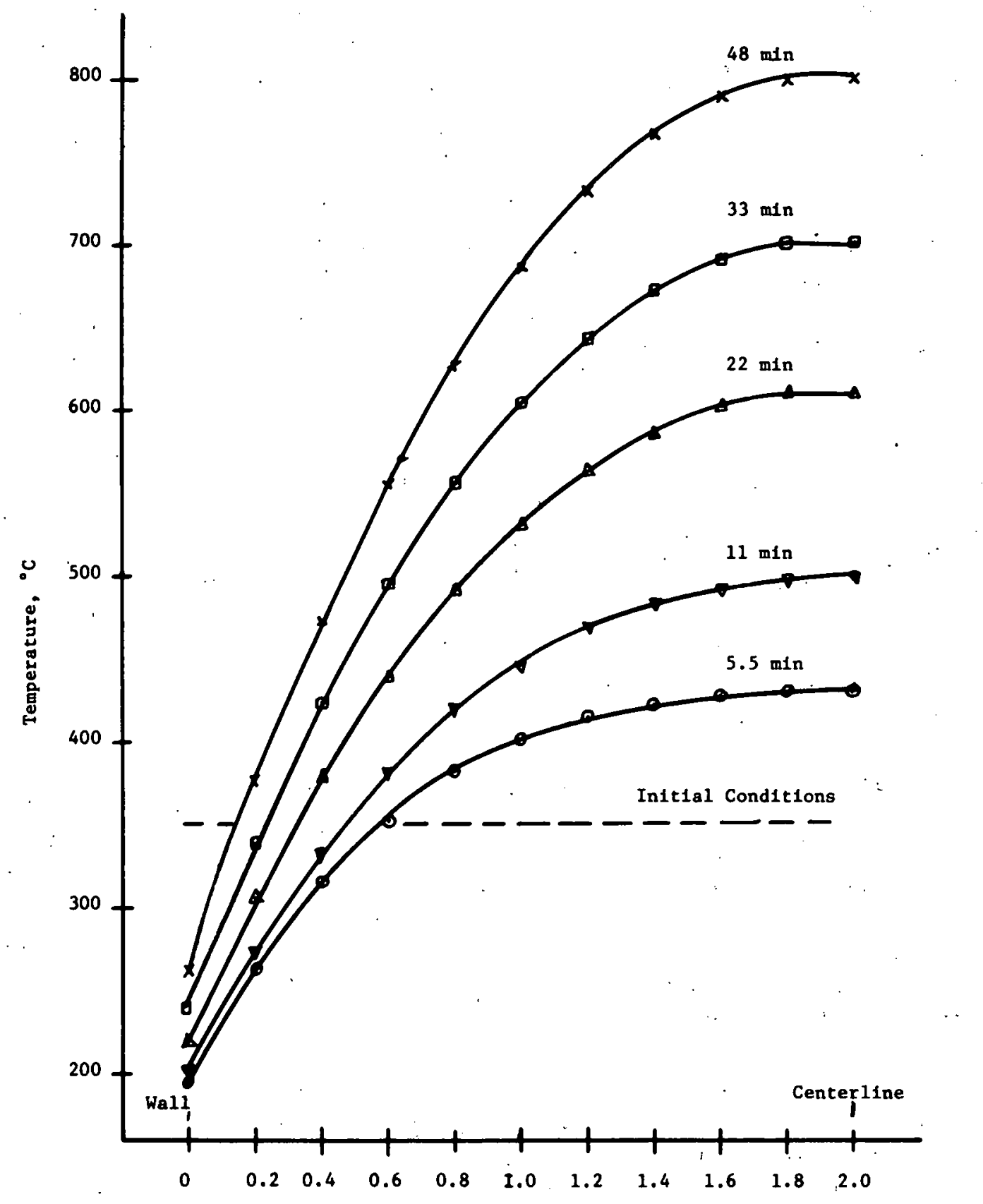

Distance from Outside Wall, In.

Fig. 4.7. Transient Temperature Distribution in Static Bed for 4-in.-thick Slab Reactor 
4.3.8.1 Fluorination Reactions. The feed to reactor $A$ is the powdered-oxide fuel material (from the ball mill) mixed with alumina: The feed may contain small amounts of stainless steel chips formed in the cropping and milling operations. The primary reactions taking place in reactor A are:

$\mathrm{UO}_{2}(\mathrm{~s})+3 \mathrm{~F}_{2}(\mathrm{~g}) \rightarrow \mathrm{UF}_{6}(\mathrm{~g})+\mathrm{O}_{2}(\mathrm{~g}), . \Delta \mathrm{H}_{600 \mathrm{~K}}=-253.4 \mathrm{kcal} / \mathrm{mole} \mathrm{U}_{;}^{60}$ $\mathrm{U}_{3} \mathrm{O}_{8}(\mathrm{~s})+9 \mathrm{~F}_{2}(\mathrm{~g}) \rightarrow 3 \mathrm{UF}_{6}(\mathrm{~g})+4 \mathrm{O}_{2}(\mathrm{~g}), \Delta \mathrm{H}_{600 \mathrm{~K}}=-227.4 \mathrm{kcal} / \mathrm{mole} \mathrm{U}_{i}^{60}$ $\mathrm{PuO}_{2}(\mathrm{~s})+2 \mathrm{~F}_{2}(\mathrm{~g}) \rightarrow \mathrm{PuF}_{4}(\mathrm{~s})+\mathrm{O}_{2}(\mathrm{~g}), \Delta \mathrm{H}_{600 \mathrm{~K}}=-160.7 \mathrm{kcal} / \mathrm{mole} \mathrm{Pu}_{\circ}{ }^{61}$

Since operating conditions have been chosen to ensure a significant fluorine concentration in the effluent from fluorinator $A$, some of the $\mathrm{PuF}_{4}$ dispersed in $\mathrm{Al}_{2} \mathrm{O}_{3}$ will be converted to $\mathrm{PuF}_{6}$ and volatilized together with the $\mathrm{UF}_{6}$ and some fission-product fluorides. Calculations on the formation of $\mathrm{PuF}_{6}$ are based on the equilibrium ${ }^{62}$

$$
\mathrm{PuF}_{4}+\mathrm{F}_{2} \rightleftharpoons \mathrm{PuF}_{6}
$$

and the assumption that at $350^{\circ} \mathrm{C}$ the effluent $\mathrm{PuF}_{6}$ is in equilibrium with the effluent fluorine. These calculations indicate that $4 \%$ of the plutonium charged to the fluorinator will be converted to $\mathrm{PuF}_{6}$. Recent experimental results ${ }^{63}$ on the fluorination of oxidized, simulated FBR core fuel indicate that the initial conversion of uranium oxide to $\mathrm{UF}_{6}$ is accompanied by conversion of only a very small amount of plutonium oxide to $\mathrm{PuF}_{6}$ and that conditions may be found that could limit $\mathrm{PuF}_{6}$ formation in fluorinator $A$ to significantly less than the $4 \%$ as sumed in the flowsheet.

Neptunium in the fuel will also be converted to some extent to the hexafluoride by the reaction

$$
\mathrm{NpO}_{2}(\mathrm{~s})+3 \mathrm{~F}_{2}(\mathrm{~g}) \rightarrow \mathrm{NpF}_{6}(\mathrm{~g})+\mathrm{O}_{2}(\mathrm{~g}), \Delta \mathrm{H}_{600 \mathrm{~K}}=-215^{*} \mathrm{kcal} / \mathrm{mole} \mathrm{Np} .
$$

Transplutonium elements present in the fuel such as americium and curium do not form hexafluorides, but are probably converted to the nonvolatile tetrafluorides $\mathrm{AmF}_{4}$ and $\mathrm{CmF}_{4}$.

A limited number of fission products form volatile compounds under the process conditions in fluorinator A (see Table 3.1). These fission products include tritium, niobium, molybdenum, technetium, ruthenium, antimony, tellurium, iodine, and xenon. The anticipated behavior of these fission products is outlined below.

Tritium in the fuel charged to fluorinator $A$ is expected to be completely converted to ${ }^{3} \mathrm{HF}$ and volatilized from the fluorinator. Niobium and

\footnotetext{
* Estimated.
} 
antimony are converted by fluorine into $\mathrm{NbF}_{5}$ and $\mathrm{SbF}_{5}$, and tellurium is fluorinated to $\mathrm{TeF}_{6}$, all of which are also volatile.

Molybdenum, technetium, ruthenium, and iodine may form one or more compounds, some of which contain oxygen. Since each of these compounds is volatile at the operating temperature of fluorinator $A$, they are expected to distill out of the fluorinator with the $U_{6}$. Xenon, liberated during the reaction of solid oxide fuel and fluorine, may react with fluorine to form the tetrafluoride $\mathrm{XeF}_{4}{ }^{57}$ and minor quantities of the intermediate $\mathrm{XeF}_{2}{ }^{64}$ Both of these xenon fluorides are volatile and should distill from the reactor. Krypton does not form a fluoride that is stable at the operating conditions of fluorinator A.

The anticipated behavior of stainless steel constituents is of interest, since some cladding chips will accompany the fuel. Considerable work has been done on the fluoride-promoted oxidation of stainless steel. Most of the emphasis has been on the use of $\mathrm{HF}-\mathrm{O}_{2}$ mixtures to pulverize fuel cladding prior to treatment with fluorine for the volatilization of uranium and plutonium values in the fuel. Work at Argonne National Laboratory ${ }^{65}$ with $\mathrm{UO}_{2}$ stainless steel cermet and an $\mathrm{HF}-\mathrm{O}_{2}-\mathrm{N}_{2}$ mixture showed that the stainless steel was converted to an oxide, with no chromium found to volatilize. A subsequent step with $F_{2}-\mathrm{N}_{2}$ mixtures at temperatures ranging from 250 to $550^{\circ} \mathrm{C}$ showed $45 \%$ of the chromium volatilizing. In similar work with stainless steel tubing, Bartlett et al. at Brookhaven ${ }^{66}$ showed about $51 \%$ chromium volatilization during fluorination. The volatile chromium species was isolated and identified as $\mathrm{CrO}_{2} \mathrm{~F}_{2}$ by X-ray diffraction analysis. Workers at Oak Ridge National Laboratory ${ }^{67}$ also noted the volatilization of a chromium compound during the fluorination step. However, this compound had only a moderate volatility and was largely condensed in process lines held at about $100^{\circ} \mathrm{C}$. Other work by Jarry and co-workers ${ }^{68}$ showed about $60 \%$ of the chromium content of decladding $\left(\mathrm{HF}-\mathrm{O}_{2}\right)$ reaction products volatilized during fluorination of $(\mathrm{U}, \mathrm{Pu}) \mathrm{O}_{2}$. The volatile compound was tentatively identified as $\mathrm{CrO}_{2} \mathrm{~F}_{2}$ by its cinnamon-red color and volatility. In one test by Chilenskas, ${ }^{69}$ the exposure of a specimen of Type 316 stainless steel in a fluidized bed of alumina to a mixture of $\mathrm{F}_{2}-\mathrm{O}_{2}-\mathrm{N}_{2}$ at $550^{\circ} \mathrm{C}$ for $2 \mathrm{hr}$ resulted in the formation of a tightly adherent pale-green film on the specimen. The specimen showed a $6.5 \%$ weight gain.

The application of these results to the present flowsheet suggests that only a small amount, if any, of the volatile chromium compounds will be formed since the expected contamination of the oxide feed with stainless steel is very low and since the work of Chilenskas ${ }^{69}$ shows that a low rate of reaction of stainless steel with flưorine-is-possible-in-the-a-bs-ence-of-a-p-e-treatment with $\mathrm{HF}-\mathrm{O}_{2}$. Assuming, however, that small amounts of $\mathrm{CrF}_{4}$, $\mathrm{CrF}_{5}$, and $\mathrm{CrO}_{2} \mathrm{~F}_{2}$ form, these compounds would distill from fluorinator $\mathrm{A}_{\text {. }}$ Their behavior is discussed further in Section 4.3.8.2. 
The remaining fission products and constituents of the cladding form fluorides of low volatility at the operating conditions of fluorinator $A$ and hence would be expected to remain in the bed of alumina together with most of the plutonium. The partitioning of the actinide and fission-product elements, according to the volatilities of their fluoride compounds, is shown in Table 4.2, which includes data on the total weight of each element in one day's charge, the beta curies, and the total energy evolution rate for each fission-product element. Data (for example, Ref. 70) indicate that complete removal of a fission product by volatilization from the bed of fluorinator $\mathrm{A}$ is unlikely.

TABLE 4.2. Partitioning of Actinide and Fission-product Elements According to Volatility of Their Fluoride Compounds

\begin{tabular}{|c|c|c|c|c|c|c|c|}
\hline \multicolumn{4}{|c|}{ Nonvolatile } & \multicolumn{4}{|c|}{ Volatile } \\
\hline Element & Grams ${ }^{a}$ & $\beta$ Curies $^{b}$ & Watts $^{c}$ & Element & Grams & $\beta$ Curies $^{b}$ & Watts ${ }^{c}$ \\
\hline $\mathrm{Rb}$ & 142 & 42 & d & $\mathrm{U}$ & $8.75 \times 10^{5}$ & - & $\mathrm{d}$ \\
\hline $\mathrm{Sr}$ & 398 & $6.291 \times 10^{5}$ & $1969^{e}$ & $\mathrm{~Np}$ & 164 & - & $\mathrm{d}$ \\
\hline $\mathrm{Y}$ & 223 & $1.177 \times 10^{6}$ & 3756 & $\mathrm{Pu}$ & $8.35 \times 10^{4}$ & - & $\mathrm{d}$ \\
\hline $\mathrm{Zr}$ & 2950 & $2.279 \times 10^{6}$ & $1.162 \times 10^{4}$ & ${ }^{3} \mathrm{H}$ & 0.21 & 2060 & $\mathrm{~d}$ \\
\hline $\mathrm{Rh}$ & 1010 & $f$ & $f$ & $\mathrm{Kr}$ & 132 & 3670 & $5^{\circ}$ \\
\hline $\mathrm{Pd}$ & 2770 & 0.4 & $\mathrm{~d}$ & $\mathrm{Nb}$ & 76 & $2.956 \times 10^{6}$ & $1.389 \times 10^{4}$ \\
\hline $\mathrm{Ag}$ & 518 & $3.37 \times 10^{4}$ & 84 & Mo & 3780 & 2100 & $\mathrm{~d}$ \\
\hline $\mathrm{Cd}$ & 294 & 5178 & 21 & $\mathrm{Tc}$ & 928 & 16 & $\mathrm{~d}$ \\
\hline In & 16 & 7 & d & $\mathrm{Ru}$ & 3940 & $6.605 \times 10^{6}$ & $2.640 \times 10^{4}$ \\
\hline $\mathrm{Cs}$ & 3650 & $8.454 \times 10^{4}$ & $446 \mathrm{~g}$ & $\mathrm{Sn}$ & 213 & $1.535 \times 10^{4}$ & 78 \\
\hline $\mathrm{Ba}^{\circ}$ & 922 & $5.742 \times 10^{5}$ & 1780 & $\mathrm{Sb}$ & 141 & $8.318 \times 10^{4}$ & 299 \\
\hline $\mathrm{La}$ & 903 & $6.657 \times 10^{5}$ & 1112 & $\mathrm{Te}$ & 870 & $9.3 \times 10^{3}$ & $73^{\circ}$ \\
\hline $\mathrm{Ce}$ & 2620 & $2.921 \times 10^{6}$ & $1.222 \times 10^{4^{\mathrm{h}}}$ & I & 511 & $2.396 \times 10^{5}$ & 839 \\
\hline $\operatorname{Pr}$ & 1030 & $2.156 \times 10^{6}$ & 1335 & $\mathrm{Xe}$ & 4680 & $8.607 \times 10^{4}$ & 103 \\
\hline $\mathrm{Nd}$ & 2630 & $1.839 \times 10^{5}$ & 515 & Total & $\overline{9.739 \times 10^{5}}$ & $\overline{9.993 \times 10^{6}}$ & 41610 \\
\hline Pm & 397 & $3.723 \times 10^{5}$ & 186 & & & & \\
\hline $\mathrm{Sm}$ & 475 & 6647 & 1 & & & & \\
\hline $\mathbf{E} \dot{u}$ & 69 & $1.734 \times 10^{4}$ & 52 & & & & \\
\hline Total & 21020 & $11.106 \times 10^{6}$ & 35100 & & & & \\
\hline
\end{tabular}

a The quantity of all stable and radioactive isotopes of the element in a daily charge.

$b_{\text {Beta curies only. }}$

${ }^{c}$ Beta plus gamma energy, assumed to be completely converted to heat. Beta heat taken as $1 / 3 Q_{\mathrm{B}(\max )}$ (maximum beta particle energy); gamma heat taken as 100\% gamma photon energy.

$\mathrm{d}_{\text {Negligibly small. }}$.

encludes ${ }^{90} \mathrm{Y}$ decay.

$f_{103} \mathrm{Rh}$ and ${ }^{106} \mathrm{Rh}$ included with $\mathrm{Ru}$.

Includes ${ }^{137 m} \mathrm{Ba}$ decay.

$\mathrm{h}_{\text {Includes }}{ }^{144} \mathrm{Pr}$ decay. 
Flowsheet calculations for the reference process are based on the probable distribution of fission-product compounds (as listed in Table 4.3). The alumina bed material, transferred to reactor $B$, is assumed to contain all the actinides and fission products not volatilized from reactor $A$.

TABLE 4.3: 'Partitioning of the Actinide Fluorides and Volatile Fission Products

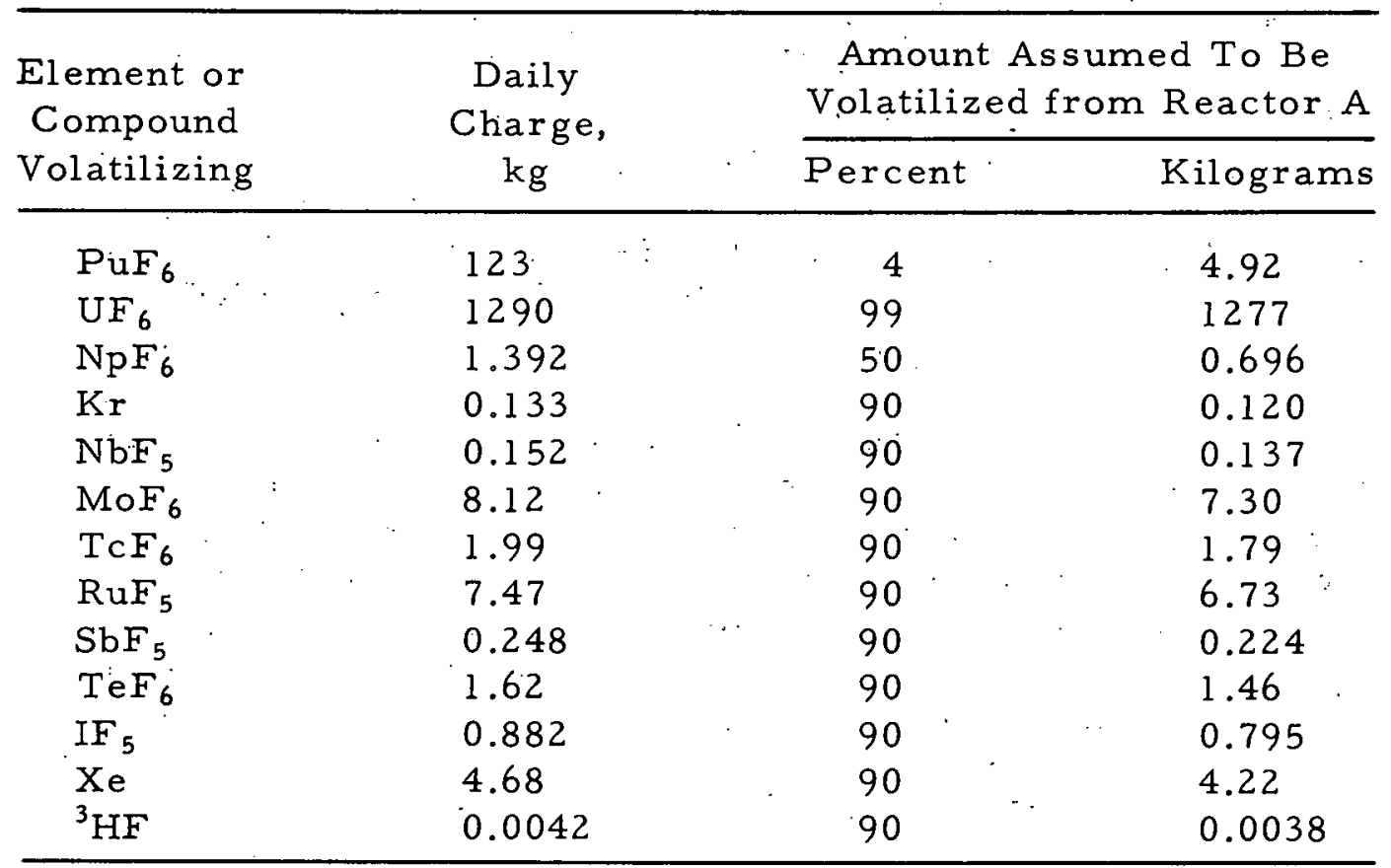

4.3.8.2 Removal of Fission Products from UF.6 Stream in FP-1. The off-gases from fluorinator $A$ are passed through a cold trap, FP-l, which is held at $15^{\circ} \mathrm{C}$ and is designed to remove a large fraction of the ruthenium and niobium pentafluorides. The vapor pressures at $15^{\circ} \mathrm{C}$ of the actinide fluorides formed in fluorinator $A$ are greater than the average total pressure of the actinides. in the effluent gas stream; hence no $\mathrm{UF}_{6}, \mathrm{NpF}_{6}$ or $\mathrm{PuF}_{6}$ is expected to condense in FP-1. Fluorine, oxygen, and fission-product krypton also pass through the trap unaffected. The pertinent vapor-pressure data for all components of the stream passed into FP-1 are given in Appendix D.

Tritium fluoride is not expected to condense at $15^{\circ} \mathrm{C}$, because of its low concentration (partial pressure) and high vapor pressure at $15^{\circ} \mathrm{C}$. Niobium pentafluoride is expected to partially condense at $15^{\circ} \mathrm{C}$, since its vapor pressure is $2 \times 10^{-3} \mathrm{~mm} \mathrm{Hg}$.

Flows-heet-c-al-cul-ation-s-ha-ve-been-ba-sed-on-the-as.s.umption_that_Mo.F-6 is the product of fluorination of the fuel. The literature on oxyfluorides of molybdenum indicates, however, that $\mathrm{MoOF}_{4}$ may be present, together with $\mathrm{MoF}_{6}$, in the off-gas from fluorinator $A$. The oxyfluoride exhibits a vapor pressure of $0.2 \mathrm{~mm} \mathrm{Hg}$ at $15^{\circ} \mathrm{C}$, and if molybdenum is mainly present as the 
oxyfluoride the bulk of $\mathrm{MoOF}_{4}$ should condense in FP-1. Little $\mathrm{MoF}_{6}$ is expected to condense from the gas stream at $15^{\circ} \mathrm{C}$. Regardless of the partition of molybdenum between $\mathrm{MoF}_{6}$ and $\mathrm{MoOF}_{4}$, the conservative flowsheet calculations provide adequate product decontamination, even if all the molybdenum condenses with the actinide hexafluoride product.

A similar uncertainty about the species present applies to technetium, except that two oxyfluorides (rather than one) are possible products of fluorination. The flowsheet calculations have been made on the assumption that $\mathrm{TcF}_{6}$ is the fluoride formed. By analogy to molybdenum, we can assume that $\mathrm{TcOF}_{4}$ may form, together with $\mathrm{TcO}_{3} \mathrm{~F}$, which, however, is not likely to be present. $\mathrm{TcO}_{3} \mathrm{~F}$ has a vapor pressure of $16 \mathrm{~mm} \mathrm{Hg}$ at $15^{\circ} \mathrm{C}$; $\mathrm{TcOF}_{4}$ is likely to be less volatile than $\mathrm{MoOF}_{4}$. Separation of $\mathrm{TcOF}_{4}$ from $\mathrm{UF}_{6}$ should occur by condensation of $\mathrm{TcOF}_{4}$ in FP-I; $\mathrm{TcF}_{6}$ and any $\mathrm{TcO}_{3} \mathrm{~F}$ should pass through the condenser with the actinides.

Flowsheet calculations on the decontamination of the actinides from ruthenium fission product were based on the assumption that the volatile ruthenium compound formed was $\mathrm{RuF}_{5}$. This is supported by work of Jarry et al., ${ }^{71}$ who reacted inactive ruthenium metal and $\mathrm{RuO}_{2}$ with fluorine and fluorine-oxygen mixtures at temperatures of process interest and showed that $\mathrm{RuF}_{5}$ was the only species formed. A recent review of the literature by Rudzitis ${ }^{72}$ regarding the formation of oxyfluorides of various fission elements suggests that ruthenium will probably exist only as the pentafluoride. On the other hand, work by Chilenskas, ${ }^{70}$ in which irradiated oxide fuel was fluorinated with various reagents, suggested the possible formation of ruthenium compounds more volatile than $\mathrm{RuF}_{5}$. The data from several runs in which $\mathrm{BrF}_{5}$ followed by fluorine were used as fluorinating agents suggested that ruthenium was present as a mixture of $\mathrm{RuF}_{5}$ with one or more compounds, possibly $\mathrm{RuOF}_{4}$ and $\mathrm{RuF}_{6}$. Therefore, no firm conclusion can be drawn regarding the ruthenium species formed under the anticipated process conditions, except that the bulk (if not all) of the ruthenium will be present as $\mathrm{RuF}_{5}$. The effect of the presence of ruthenium compounds other than $\mathrm{RuF}_{5}$ on the decontamination of uranium and plutonium is examined below.

Separation of ruthenium from uranium in the present flowsheet is accomplished primarily in three operations: the preferential condensation of $\mathrm{RuF}_{5}$ from $\mathrm{UF}_{6}$ in trap FP-1, the separation effected by single-stage distillation from the feed vessel for the thermal-decomposition step, and the multistage distillation in still S-1. Since it appears quite certain that the bulk of the ruthenium will be converted by fluorination to $\mathrm{RuF}_{5}$, the efficacy of trap FP-l for the bulk removal of ruthenium as $R F_{5}$ will not be impaired by the presence of the compounds $\mathrm{RuOF}_{4}$ and $\mathrm{RuF}_{6} \cdot \mathrm{Bec}$ ause these latter two compounds have significantly higher vapor pressure than $\mathrm{RuF}_{5}$, little or no $\mathrm{RuOF}_{4}$ or $\mathrm{RuF}_{6}$ can be expected to condense in FP-1. 
Antimony is expected to form only $\mathrm{SbF}_{5}$ during fluorination of the fuel. This compound will pass through the trap with the actinides, since its vapor pressure $(2.3 \mathrm{~mm} \mathrm{Hg})$ is greater than the anticipated partial pressure $(\sim 0.1 \mathrm{~mm} \mathrm{Hg})$. For the same reasons, $\mathrm{TeF}_{6}$ is not expected to condense at $15^{\circ} \mathrm{C}$. Flowsheet calculations are based on the assumption that iodine is converted to $I F_{5}$, although the presence of $I O F_{5}$ and $I F_{7}$ is possible. None of these iodine fluorides should condense at $15^{\circ} \mathrm{C}$, based on the vapor pressures of the pure compounds. Finally, the kinetic and equilibrium data for the $\mathrm{Xe}-\mathrm{F}_{2}$ system indicate that conditions in fluorinator A are favorable for the formation of $\mathrm{XeF}_{4}$ and possibly $\mathrm{XeF}_{2}$. Neither of these compounds (vapor pressures at $15^{\circ} \mathrm{C}$ of 1.09 and $2.09 \mathrm{~mm} \mathrm{Hg}$, respectively) should condense in FP-1.

Chromium from stainless steel may be fluorinated to $\mathrm{CrF}_{4}$ or $\mathrm{CrF}_{5}$, both of which would partially condense in FP. 1 . If $\mathrm{CrO}_{2} \mathrm{~F}_{2}$ is present in the gas stream, this species would pass through FP-l with the actinide hexafluorides.

The formation of solid solutions involving actinide hexafluorides and fission-product fluorides would affect the purification and recovery of actinides. Specifically, solid-solution formation during the condensation operations carried out in vessel FP-1 (or in FP-2, CT-1, or CT-2) requires comment. Formation of solid solutions in any of these operations would decrease the partial pressure of actinide hexafluorides and fission-product fluorides involved. In the absence of experimental data on solid solutions involving fission-product fluorides and actinide hexafluorides, the physical properties of the individual compounds must be used to make qualitative predictions. The likelihood that solid solutions of two compounds will form is greater when their crystal symmetries are identical and their lattice constants approach equality than when the structure parameters are dissimilar. 'As an example, the crystal symmetries for the actinide hexafluorides are the same and their lattice constants are similar (as shown in Table 4.4); accordingly, in the binary systems $\mathrm{NpF}_{6}-\mathrm{UF}_{6}$ and $\mathrm{PuF}_{6}-\mathrm{UF}_{6}$, the solids are miscible in all proportions as shown by experiment. ${ }^{73}$ Also, the solid solubility of $\mathrm{UF}_{6}$ having an orthorhombic structure has been shown experimentally to be greater in the orthorhombic modification of $\mathrm{MoF}_{6}$ than in the cubic modification of $\mathrm{MoF}_{6} \cdot{ }^{74}$ Additional examples are the binary condensed phase diagrams of $\mathrm{UF}_{6}$ with each of the four compounds, $\mathrm{HF}$, $\mathrm{ClF}_{3}, \mathrm{BrF}_{3}$, and $\mathrm{BrF}_{5}$, whose lattice parameters differ considerably from those of $\mathrm{UF}_{6}$. The phase diagrams indicate that these are simple eutectic systems, implying mutual immiscibility in the solid phase. ${ }^{74}$ Regardless of a mismatch of crystal parameters, however, binary systems nominally exhibiting_a_simple_eutectic_(implying_mutual_insolubility_of_solids_)mus_t show areas of solid solubility at very high ( $(>99 \%)$ values of composition, i.e., at the extreme ends of the phase diagram. Using these considerations, we can make qualitative statements about the effect of solid-solution formation in the condensation operations. 
TABLE 4.4. Solid Solubilities and Crystal Structures of Selected Fluoride Compounds

\begin{tabular}{|c|c|c|c|c|c|c|}
\hline Compound & Crystal Form & $a_{0}, \AA$ & $b_{0}, \AA$ & $c_{0}, \AA$ & $\mathrm{V},{\stackrel{\circ}{\mathrm{A}^{3}}}^{-}$ & Solid Solubility with $\mathrm{UF}_{6}$ \\
\hline $\mathrm{UF}_{6}$ & Orthorhombic & 9.916 & 8.960 & 5.245 & 466.0 & - \\
\hline $\mathrm{NpF}_{6}$ & Orthorhombic & 9.909 & 8.997 & 5.202 & 463.8 & Completely miscible \\
\hline $\mathrm{PuF}_{6}$ & Orthorhombic & 9.912 & 8.942 & 5.206 & 461.4 & Completely miscible \\
\hline \multirow[t]{2}{*}{$\begin{array}{l}\mathrm{MoF}_{6} \\
\mathrm{MoF}_{6}\end{array}$} & $\begin{array}{l}\text { Orthorhombic } \\
\text { Body-centered }\end{array}$ & 9.65 & 8.68 & 5.05 & 423 & Maximum 12 to $18 \mathrm{~mol} \% \mathrm{UF}_{6}$ \\
\hline & Cubic & 6.23 & - & - & 241.8 & Less than 12 to $18 \mathrm{~mol} \% \mathrm{UF}_{6}$ \\
\hline $\mathrm{RuF}_{5}{ }^{\mathrm{a}}$ & Monoclinic & 12.47 & 10.01 & 5.42 & 667 & b \\
\hline $\mathrm{NbF}_{5} \mathrm{c}$ & Monoclinic & 9.62 & 14.43 & 5.12 & 706 & b \\
\hline $\mathrm{HF}^{\mathrm{d}}$ & Orthorhombic & 3.42 & 4.32 & 5.41 & 79.9 & Not soluble \\
\hline $\mathrm{ClF}_{3} \mathrm{e}$ & Or thorhombic & 8.825 & 6.09 & 4.52 & 243 & Not soluble \\
\hline $\mathrm{BrF}_{3} \mathrm{e}$ & Or thorhombic & 5.34 & 7.35 & 6.61 & 259 & Not soluble \\
\hline $\mathrm{BrF}_{5} \mathrm{e}$ & Orthorhombic & 6.422 & 7.245 & 7.846 & 365 & Not soluble \\
\hline
\end{tabular}

$a_{\beta}=99^{\circ} 50^{\prime}$, J. H. Holloway et al., J. Chem. Soc. 1964, 644 .

bo data.

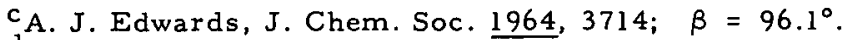

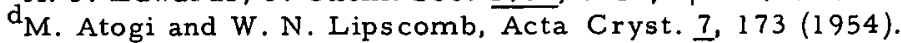

$e_{R}$. W. G. Wycoff, Crystal Structures, Vol. 2, Interscience, New York, data for BrF ${ }_{3}$ and $\mathrm{BrF}_{5}$ at $-120^{\circ} \mathrm{C}$, for $\mathrm{UF}_{3}$ at $-82.5^{\circ} \mathrm{C}$.

The purpose of the operations in vessels FP-1 (and FP-2) is elimination of $\mathrm{RuF}_{5}$ and $\mathrm{NbF}_{5}$ from the product streams. The temperature of these vessels is to be above the dew point of the actinide hexafluorides but below the dew point of $\mathrm{RuF}_{5}$ or $\mathrm{NbF}_{5}$. Thus the major condensed phases in these vessels will be $\mathrm{RuF}_{5}$ and $\mathrm{NbF}_{5}$, which could serve as solvents for actinide hexafluorides. On the basis of the argument given above that solution may occur in the presence of very high solvent/solute ratios regardless of crystal parameters, the occurrence of solid solutions is possible. Association of fission-product fluorides in solid solution with each other or with actinide hexafluorides would increase actinide retention in the traps.

Pilot-plant studies ${ }^{75}$ with a graphite-base nuclear fuel containing $\mathrm{NbC}$ have been made which have demonstrated an efficient separation of $\mathrm{UF}_{6}$ from $\mathrm{NbF}_{5}$ using a gas cooler at $25^{\circ} \mathrm{C}$. The average uranium concentration in the $\mathrm{NbF}_{5}$ collected was reported to be $0.33 \%$. The mechanism associated with uranium deposition is not discussed. If the value $0.33 \%$ is applied to the amounts of $\mathrm{NbF}_{5}$ and $\mathrm{RuF}_{5}$ to be deposited in FP-1 and FP-2, the uranium deposition under our process conditions would be less than $4 \mathrm{~g} /$ day.

Uranium losses in FP-1 by solid-solution formation are believed to be negligible.

In summary, FP-l is designed to remove the bulk of the fissionproduct ruthenium and niobium from the actinide hexafluoride stream by partial desublimation. Table 4.5 summarizes the pertinent data applicable to this process step. Any formation of $\mathrm{MoOF}_{4}$ and $\mathrm{TcOF}_{4}$ would decrease the molybdenum and technetium concentrations in the product-stream effluent from FP-1. The presence of significant concentrations of $\mathrm{RuF}_{6}$ and $\mathrm{RuOF}_{4}$ would decrease the efficiency of removal of ruthenium from the 
product stream and would result in greater heat loads in CT-1 and greater DF requirements for subsequent process steps. Calculations were made which showed that even a 90:5:5 distribution of ruthenium among $\mathrm{RuF}_{5}$, $\mathrm{RuOF}_{4}$, and $\mathrm{RuF}_{6}$ in the stream entering FP-1 would result in an overall product DF from ruthenium of greater than $10^{7}$ for both uranium and plutonium.

TABLE 4.5. Retention of Fission Products in FP-1 and CT-1

\begin{tabular}{|c|c|c|c|c|}
\hline Compound & $\begin{array}{l}\text { Fraction } \\
\text { Retained }^{a} \\
\text { in FP- } 1\end{array}$ & $\begin{array}{l}\text { Vapor Pressure } \\
\text { at } 15^{\circ} \mathrm{C}, \mathrm{mm} \mathrm{Hg}\end{array}$ & $\begin{array}{c}\text { Fraction } \\
\text { Retained } \\
\text { in CT-1 }\end{array}$ & $\begin{array}{l}\text { Vapor Pressure } \\
\text { at }-80^{\circ} \mathrm{C}, \mathrm{mm} \mathrm{Hg}\end{array}$ \\
\hline $\mathrm{UF}_{6}$ & Nil & 55.6 & $\sim 1.0$ & $4.6 \times 10^{-4}$ \\
\hline $\mathrm{NpF}_{6}$ & $\mathrm{Nil}$ & 75.9 & $\sim 1.0$ & $2.6 \times 10^{-3}$ \\
\hline $\mathrm{PuF}_{6}$ & Nil & 53.2 & $\sim 1.0$ & $3.5 \times 10^{-3}$ \\
\hline${ }^{3} \mathrm{HF}$ & $\mathrm{Nil}$ & 637 & $\sim 1.0$ & 3.6 \\
\hline $\mathrm{NbF}_{5}$ & 0.75 & $2.5 \times 10^{-3}$ & $\sim 1.0$ & $10^{-11}$ \\
\hline $\mathrm{MoF}_{6}$ & $\mathrm{Nil}$ & 358 & $\cdot 0.997$ & 0.1 \\
\hline $\mathrm{MoOF}_{4}$ & $\mathrm{~b}$ & 0.2 & $\sim 1.0$ & $<10^{-5}$ \\
\hline $\mathrm{TcF}_{6}$ & Nil & 135 & $\sim 1.0$ & $10^{-2}$ \\
\hline $\mathrm{TcOF}_{4}$ & $\mathrm{~b}$ & $<0.2$ & $\sim 1.0$ & $<10^{-5}$ \\
\hline $\mathrm{TcO}_{3} \mathrm{~F}$ & $\mathrm{~b}$ & 16 & $\sim 1.0$ & $<10^{-4}$ \\
\hline $\mathrm{RuF}_{5}$ & 0.9997 & $1.2 \times 10^{-4}$ & $\sim 1.0$ & $3 \times 10^{-13}$ \\
\hline $\mathrm{RuOF}_{4}$ & $\mathrm{~b}$ & 0.2 & $\sim 1.0$ & $2.6 \times 10^{-6}$ \\
\hline $\mathrm{RuF}_{6}$ & $\mathrm{Nil}$ & 57 & $\sim 1.0$ & $0.08^{\mathrm{C}}$ \\
\hline $\mathrm{SbF}_{5}$ & $\mathrm{Nil}$ & 2.3 & $\sim 1.0$ & NA \\
\hline $\mathrm{TeF}_{6}$ & Nil & 4596 & 0.96 & $44 \vdots 3$ \\
\hline $\mathrm{IF}_{5}$ & Nil & 14.7 & $\sim 1.0$ & $1.1 \times 10^{-4}$ \\
\hline $\mathrm{IF}_{7}$ & Nil & 1104 & - & 2.3 \\
\hline $\mathrm{IOF}_{5}$ & $\mathrm{Nil}$ & 1693 & - & $\mathrm{NA}$ \\
\hline $\mathrm{XeF}_{4}$ & Nil & 1.09 & $\sim 1.0$ & $2.2 \times 10^{-6}$ \\
\hline $\mathrm{XeF}_{2}$ & $\mathrm{Nil}$ & 2.09 & $\sim 1.0$ & $<5 \times 10^{-4}$ \\
\hline
\end{tabular}

${ }^{a}$ Fraction of material entering vessel.

$\mathrm{b}$ Dependent on the partial pressure of the compound in the gas stream entering FP-1.

cEstimated value.

4.3.8.3 Condensation of Fluorides in CT-1. The final operation in this part of the process is the condensation of actinide hexafluorides and contaminants in a cold trap $(\mathrm{CT}-1)$ held at $-80^{\circ} \mathrm{C}$. The vapor pressures of $\mathrm{UF}_{6}, \mathrm{~N} \overline{\mathrm{pF}} \overline{6}$, and $-\mathrm{PuF}_{6}$ are-such-that-all-but-an-in-signifi-eant-f-ra-tion-of-the hexafluorides is retained in $\mathrm{CT}-1$. Whether ${ }^{3} \mathrm{HF}$ condenses in the cold traps depends on whether it forms, solid solutions with product hexafluorides or with other condensible fission-product compounds present in the off-gas from FP-1 (or FP-2). Although the literature (see Section 4.3.8.2) indicates 
no solid solubility with $\mathrm{UF}_{6}$ process calculations assumed that the bulk of the ${ }^{3} \mathrm{HF}$ would condense in the cold traps with only a trace $(\sim 1 \%)$ remaining in the off-gas. This was assumed because of the very small amount of ${ }^{3} \mathrm{HF}$ present in a large amount of condensing $\mathrm{UF}_{6}-\mathrm{PuF}_{6}$ in the cold traps. The actual partitioning obtained is not important, however, since all the ${ }^{3} \mathrm{HF}$ containing waste streams are later combined and treated for ${ }^{3} \mathrm{HF}$ removal.

Flowsheet calculations assume that almost all the $\mathrm{MoF}_{6}$ will be condensed in CT-1. If, however, all molybdenum is present as $\mathrm{MoOF}_{4}$, the bulk of this compound will condense in FP-l and about $1 \mathrm{~kg}$ (of the approximately $7 \mathrm{~kg}$ ) will be trapped at $-80^{\circ} \mathrm{C}$ in $\mathrm{CT}-1$. If significant quantities of $\mathrm{TcO}_{3} \mathrm{~F}$ are formed in fluorinator $\mathrm{A}$, this material together with any $\mathrm{TcF}_{6}$ will be condensed at $-80^{\circ} \mathrm{C}$. All ruthenium compounds $\left(R_{u F}, R_{u O F}\right.$, and traces of $\mathrm{RuF}_{5}$ ) entering $\mathrm{CT}-\mathrm{l}$ will also condense at $-80^{\circ} \mathrm{C}$. No vaporpressure data for solid $\mathrm{SbF}_{5}$ exist, but existing data on the liquid (v.p. at $10^{\circ} \mathrm{C}=1.65 \mathrm{~mm} \mathrm{Hg}$ ) indicate that this material would condense at $-80^{\circ} \mathrm{C}$. All but about $4 \%$ of the $\mathrm{TeF}_{6}$ is expected to condense at $-80^{\circ} \mathrm{C}$, the $4 \%$ being removed in the gaseous waste stream.

If $\mathrm{IOF}_{5}$ and $\mathrm{IF}_{7}$ form solid solutions with the condensing hexafluorides in the cold traps ( $\mathrm{CT}-1$ and $\mathrm{CT}-2$ ), removal of these compounds from the gas streams may occur. If solid solutions are not formed in the cold traps, a large fraction of the $\mathrm{IOF}_{5}$ and $\mathrm{IF}_{3}$ will be present in the off-gas leaving CT-1. All gaseous effluents are handled in the off-gas disposal system (Section 4.8), which has the capability of retaining all the iodine contained in the fuel. Xenon fluorides are condensed at $-80^{\circ} \mathrm{C}$, but elemental xenon, present because of radiolytic decomposition of the fluorides or because of incomplete reaction of xenon and fluorine, passes through the condenser. Chromium fluorides passing through FP-l (including $\mathrm{CrO}_{2} \mathrm{~F}_{2}$, which has a vapor pressure at $-80^{\circ} \mathrm{C}$ of $9 \times 10^{-5} \mathrm{~mm} \mathrm{Hg}$ ) all condense in $\mathrm{CT}-1$.

The fission-product inventory in CT-1 represents an appreciable source of energy due to the beta and gamma decay of fission products. It is of interest, therefore, to briefly discuss the effects of radiation on the contents of CT-1. Emphasis on the behavior of $\mathrm{PuF}_{6}$ is warranted, since decomposition of $\mathrm{PuF}_{6}$ by radiation is well documented.62,76-78 As can be calculated from data in Tables 2.5 and A.l, the isotopic composition of FBR plutonium is such that an alpha activity about twice that observed for ${ }^{239} \mathrm{Pu}$ can be anticipated. Thus, on the basis of a decomposition rate for ${ }^{239} \mathrm{PuF}_{6}$ of about $1.5 \%$ day in the condensed phase, the decomposition of $\mathrm{FBR}$ $\mathrm{PuF}_{6}$ in $\mathrm{CT}-1$ should be about $3 \% /$ day. The daily throughput of $\mathrm{PuF}_{6}$ in $\mathrm{CT}-1$ is $4920 \mathrm{~g}$, resulting in an estimated deposition of $1 / 2 \times 3 \% \times 4920$ or $\sim 66 \mathrm{~g}$ of $\mathrm{PuF}_{4}$ per day. This quantity of $\mathrm{PuF}_{4}$ is insignificant, and the presence of $\mathrm{UF}_{6}$ may reduce the decomposition somewhat below this figure.

A more important source of radiation decomposition of fluorides is the fission-product activity. Table 4.6 is based on the fission products in the 
streams fed to $\mathrm{CT}-1$ and FP-1, according to the flowsheet calculations. The specific activities needed for the calculations were obtained from the calculated isotopic content of the listed fission-product elements after the irradiation and cooling times prescribed for the reference FBR fuel (see Section 2.4). Energy emission for the beta decay was based on $1 / 3 \mathrm{E}_{\beta}(\max )$; data were taken from standard sources. ${ }^{79}$ Decay schemes in the literature $\mathrm{e}^{80}$ were used to obtain gamma-decay energies, and the as sumption that $10 \%$ of the gamma energy is absorbed in the fluorides is reflected in Table 4.6. The G value (molecules decomposed per $100 \mathrm{eV}$ absorbed) for decomposition of $\mathrm{PuF}_{6}$ is $\sim 7$; data for $\mathrm{UF}_{6}$ give an estimated $G$ value of about 2 .

TABLE 4.6. Energy Evolution from Fission Products in $\mathrm{FP}-1$ and $\mathrm{CT}-1$ (in $\left.10^{19} \mathrm{eV} / \mathrm{sec}\right)$

\begin{tabular}{|c|c|c|c|c|c|c|}
\hline & \multicolumn{3}{|c|}{ Stream $4^{a}$} & \multicolumn{3}{|c|}{ Stream $3^{b}$} \\
\hline & $\beta^{c}$ & $10 \% \gamma$ & Total ${ }^{d}$ & $\beta$ & $10 \% \gamma$ & Total ${ }^{d}$ \\
\hline${ }^{3} \mathrm{HF}$ & 4.71 & - & 4.71 & 4.71 & - & 4.71 \\
\hline $\mathrm{NbF}_{5}$ & 121 & 175 & 296 & 487 & 705 & 1192 \\
\hline $\mathrm{MoF}_{6}$ & 1.13 & 0.07 & 1.20 & 1.13 & 0.07 & 1.20 \\
\hline $\mathrm{TcF}_{6}$ & $5.9 \times 10^{-3}$ & $1.7 \times 10^{-3}$ & $7.6 \times 10^{-3}$ & $5.9 \times 10^{-3}$ & $1.7 \times 10^{-3}$ & $7.6 \times 10^{-3}$ \\
\hline $\mathrm{RuF}_{5}$ & 4.12 & 0.13 & 4.25 & 13800 & 446 & 14250 \\
\hline $\mathrm{SbF}_{5}$ & $32: 9$ & 14.8 & 47.7 & 32.9 & 14.8 & 47.7 \\
\hline $\mathrm{TeF}_{6}$ & 0.36 & 3.80 & 4.16 & 0.36 & 3.80 & 4.16 \\
\hline$I F_{5}$ & 149 & 29.6 & 178.6 & 149 & 29.6 & 178.6 \\
\hline $\mathrm{XeF}_{4}$ & 25.5 & 1.43 & 26.9 & 25.5 & 1.43 & 26.9 \\
\hline Total & & & 563.5 & & & 15700 \\
\hline \multicolumn{3}{|c|}{$\mathrm{PuF}_{6}$ decomposed, ${ }^{e} \mathrm{~kg} / \mathrm{day}$} & 10.0 & & & 278 \\
\hline
\end{tabular}

${ }^{a}$ Feed stream for $C T-1$, based on flowsheet quantities (Table 4.1) of fission products.

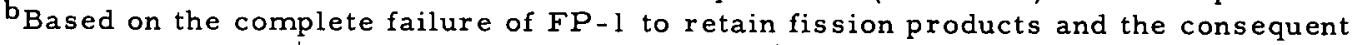
transfer of all ruthenium and niobium into $\mathrm{CT}-1$, together with the existing $\mathrm{CT}-1$ fission-product inventory.

${ }^{c_{B}}$ Based on $1 / 3 E_{\beta(\max )}$.

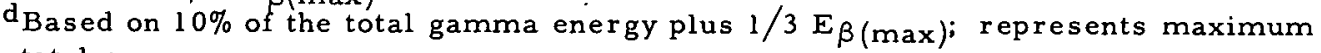
total energy.

e Decomposed $\mathrm{PuF}_{6}$ calculated on the assumptions of $\mathrm{GPuF}_{6}=7$, that half the total energy (averaged over a day) was available, and that all the available energy was absorbed in $\mathrm{PuF}_{6}$.

If, as assumed in Table 4.6, the decomposition of $\mathrm{PuF}_{6}$ by fissionproduct $\beta-\gamma$ radiation proceeds with a $\mathrm{G}$ of 7 , most if not all $\mathrm{PuF}_{6}$ entering $\mathrm{CT}-1$ will be converted to $\mathrm{PuF}_{4}$ and remain in $\mathrm{CT}-1$ when the liquid is transferred from the heated cold trap. However, part of the $\mathrm{PuF}_{4}$ might be transferred as a slurry to the feed vessel (for thermal decomposition). Neutron monitoring of $\mathrm{CT}-1$ would be desirable to ensure that the fissile content of the vessel does not exceed specified limits before refluorination of the trap contents is achieved.

It is instructive to examine the consequence of excessive fissionproduct activity in $\mathrm{CT}-1$. If the activity level in $\mathrm{CT}-1$ is such that all the $\mathrm{PuF}_{6}$ decomposes to $\mathrm{PuF}_{4}$, direct vapor transfer of $\mathrm{UF}_{6}$ could be made to 
the distillation columns (although analysis for plutonium might be required as a precaution).* This would constitute an early separation of uranium from plutonium. Furthermore, deposition of significant quantities of lower uranium fluorides can be anticipated under these abnormal conditions, and cleanout of the cold trap by fluorination is indicated. The frequency of refluorination may be determined by criticality considerations and should be once or twice per week.

Alpha decomposition of $\mathrm{PuF}_{6}$ in $\mathrm{CT}-1$ therefore appears to be negligible compared to the decomposition anticipated due to beta and gamma radiation from fission products. Because CT -1 contains only a small part of the plutonium, the deposited $\mathrm{PuF}_{4}$, if retained in $\mathrm{CT}-1$, can be periodically refluorinated and, if desired, transferred to CT-2. Some of the uranium will probably also be subject to radiation decomposition and contaminate the deposited $\mathrm{PuF}_{4}$. Because of uncertainties in the calculation of $\mathrm{PuF}_{6}$ decomposition (e.g., the effect of energy absorption in $\mathrm{UF}_{6}$ and the reformation of $\mathrm{PuF}_{6}$ by irradiation of $\mathrm{PuF}_{4}-\mathrm{F}_{2}$ to produce a steady-state $\mathrm{PuF} \mathrm{F}_{6}$ content), reference flowsheet calculations are based on transfer of the entire contents of $\mathrm{CT}-1$ to the feed vessel for thermal decomposition.

\subsubsection{Solid Waste Streams}

The only waste stream in solid form from this part of the process is generated by disposal of the fission products collected in FP-1. The $\mathrm{RuF}_{5}-\mathrm{NbF}_{5}$ fission products are condensed from the fluorinator $\mathrm{A}$ off-gas stream in FP-1 before the remaining condensibles (mainly $U_{6}$ ) are collected in CT-1. After a batch (half of a daily load) of ruthenium and niobium fluorides has been collected, the fission-product trap is taken offstream and the temperature of the trap is allowed to increase while oxygen is passed through the trap. The oxygen and vaporized fission-product fluorides from the trap pass into a fluidized bed** of $\mathrm{NaF}$ at $350^{\circ} \mathrm{C}$ where the fission-product fluorides are sorbed on $\mathrm{NaF}$. The sorber bed is 6 in. in diameter and $6 \mathrm{ft}$ tall. Oxygen leaving the sorber joins the oxygen-rich off-gas stream from the fluorinator and is handled as a gaseous waste stream (see Section 4.8).

Because of the low thermal conductivity of wastes [for example, the thermal conductivity of alumina is about $\left.0.25 \mathrm{Btu} /(\mathrm{hr})(\mathrm{ft})\left({ }^{\circ} \mathrm{F}\right)\right]$ and the stipulation that centerline temperatures in the storage cylinder cannot exceed $1000^{\circ} \mathrm{C}\left(750^{\circ} \mathrm{C}\right.$ for ruthenium-containing waste); the calculated diameter of cylinders used for storage of undiluted wastes is generally small. For example, fluorinator B alumina, FP-1 waste, and FP-2 waste would have to be stored in 5-,2-, and 2-in.-diam cylinders, respectively, if no additive was introduced. This would result in the handling of many cylinders each

\footnotetext{
* It has been shown that $\mathrm{PuF}_{4}$ and fluorine will combine under gamma radiation to form $\mathrm{PuF}_{6}$ at a pressure greater than that anticipated on the basis of the thermodynamic equilibrium constant. 70

** The fluid-bed waste-handling reactor is indicated in Fig. 4.4.
} 
day, and a larger storage area would be needed than if the cylinders were of greater diameter. Appendix $E$ gives a method of calculating centerline temperatures in waste pots. Various additives--metals that melt, metals that do not melt; and heat-transfer salts--have been proposed to aid the transfer of heat from the storage cylinder centerline to the walls where heat can be removed. Of these, aluminum (which melts at $660^{\circ} \mathrm{C}$ and has a conductivity about 600 times that of alumina) appears to be the best and would allow the cylinder diameters for all wastes cited to be increased to $2 \mathrm{ft}$.

The calculated centerline temperatures with aluminum added would be less than the $660^{\circ} \mathrm{C}$ melting point of aluminum. As an example, the following is assumed to happen when aluminum shot is added to the mixture of fission products and alumina from fluorinator B: Since the thermal conductivity of the mixture is low, the temperature will increase in the mixture until the aluminum melts. Good conductivity will then be established between the solids and the cooled wall of the cylinder. The heat will be efficiently removed, lowering the temperature below the melting point of aluminum, solidifying the aluminum, and trapping alumina and fission-product particles in the aluminum matrix.

Whether the alumina and fission-product particles would be embedded in the metal matrix has not been determined experimentally. Preliminary experiments have shown that 48-100 mesh alumina will not mix with molten aluminum but will float on the aluminum surface. ${ }^{81}$ Wetting agents (sodium, lithium, or magnesium) as well as substitute metals (zinc, lead, or magnesium) need to be investigated. Of the metals under consideration, aluminum has the lowest volumetric cost. If the alumina and fission-product particles do not wet and fail to become embedded in the aluminum, it may be possible to physically restrain them from floating to the surface by using screens that would be positioned in the storage pot at intervals.

Besides the lower handling cost and the smaller storage-space requirements, there is a fabrication cost advantage to using large- instead of small-diameter storage cylinders, even when the cost of metal additives is included. For example, for the alumina waste from the fluorinator, waste with aluminum additive could be stored in one 24-in.-diam cylinder per week; without additive, twenty-three 5-in.-diam cylinders would be needed. Fabrication cost for the 24-in.-diam cylinder plus the cost of the added aluminum is estimated at $\$ 1800$; the cost of twenty-three 5-in.-diamcylinders is $\$ 3230$. The estimated cost advantage from using the larger cylinders is $\$ 1.430$.

Othe-r-add-i-ti-ves-f-er-a-idi-n-g-heat-tran-fer hav-e-been-consider-ed

A high-melting-point metal in powder form, e.g., iron, could be mixed with alumina and fission products and would probably not segregate. However, the heat conductivity of the powder mixture would not be significantly greater than that of the alumina and fission-product mixture. The use of salts for 
heat transfer also has no great economic advantage since again the heat conductivity of the salt is only a little higher than that of alumina. In addition, stability of the salt under high-level radiation may be a problem.

Not completely defined is the chemical stability of the waste solidmetal system; since aluminum and other metals form stable fluorides and could reduce the fission-product fluorides. Since good heat transfer requires a stable system and maintenance of a functional metal phase, the absence of excessive reaction must be demonstrated.

Although the chosen on-site method of waste storage is in cylinders in a canal, many alternative methods are possible. Relatively low-level wastes have been stored in bins, a method claimed to be cheaper than canal storage of cylinders. ${ }^{82}$ Table 4.7 gives preliminary data on sizes of storage units, cooling requirements for bins, and other methods for the storage of alumina from fluorination reactors. The cost of each method would have to be evaluated before a final selection could be made.

TABLE 4.7. Alternative Methods for Storing Alumina Waste

Storage Method

1. Cylinder storage. Cylinder stored in water. Aluminum added to alumina to aid heat transfer from centerline to cylinder wall. (This is the storage method selected in this report.)

2. Cylinder storage in water. No aluminum diluent.

3. Bin storage. Forced-air cooling. No aluminum diluent.

4. Bin storage. Forced-air cooling over fins. Aluminum diluent.

5. Fluid-bed stor age.
Comments

40224 -in.-diam cylinders would be required at storage equilibrium. Centerline temperature would be $210^{\circ} \mathrm{C}$. Wastes could be stored in cylinders with up to $6 \mathrm{ft}$ diameter if desired, and centerline temperatures would not exceed $1000^{\circ} \mathrm{C}$.

With a centerline temperature limitation of $1000^{\circ} \mathrm{C}$, a total of 90385 -in.-diam cylinders would be required at storage equilibrium.

Eight bins would be required, each $20 \mathrm{ft}$ high. The bins are made in concentric circles. Alumina would be stored in $2 \frac{1}{2}$-in. annular bins with a 2 in. space between adjacent bins for air cooling. The diameter of the outermost ring would be $24 \mathrm{ft}$.

The concentric bins in which the alumina is stored could be $4 \mathrm{ft}$ thick.

Eight storage units would be required. Each would have a $10 \mathrm{ft}$ diameter, and the bed would be $16.2 \mathrm{ft}$ tall. The bed temperature would initially be $520^{\circ} \mathrm{C}$.

Flowsheet calculations were based on the use of aluminum as a heat-transfer agent in the waste-stream containers. Hence, the NaF bed loaded with ruthenium and niobium from FP-1 or FP-2 (5\% metal loading was assumed) is discharged, mixed with aluminum, and stored in 2 -ft-diam cylinders. With the anticipated heat loads, each cylinder must be stored for 7.1 yr before heat generation decreases to $2 \mathrm{~W} /$ liter. Figure 4.8 shows change of the heat-generation $r$ ate with time. A total of 220 cylinders (198 and 22 for FP-1 and FP-2 wastes, respectively) are required at storage equilibrium. 
$-129-$

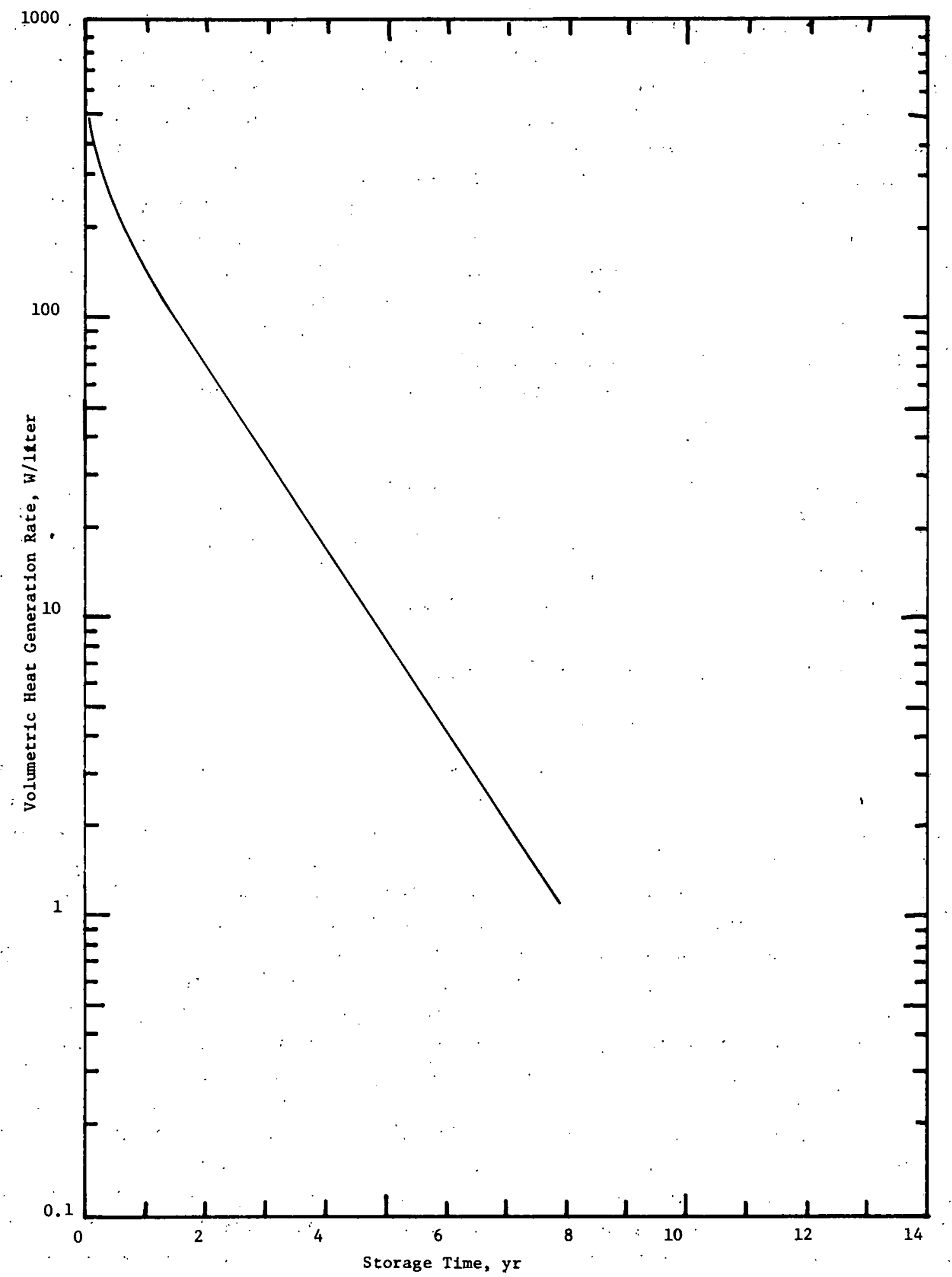

Fig. 4.8. Decrease in Heat Generation Rate with Time for NaF Loaded with Ruthenium and Niobium (from FP-1 or FP-2) 
A fluid bed of NaF was selected for traps FP-l and FP -2 becäuse the high heat-removal rate required to keep the sorbent bed below $350^{\circ} \mathrm{C}$ would require packed beds with very small diameters. Heat-removal rates for fluid beds are about 50 times those for packed beds, allowing the use of larger-diameter equipment. The diameter of a static bed would have to be 1 in. to keep the bed temperature between 300 and $350^{\circ} \mathrm{C}$. To handle one batch (half the daily requirement) of $\mathrm{RuF}_{5}-\mathrm{NpF}_{5}$ from FP-1, about $200 \mathrm{ft}$ of 1 -in.-diam tubes would be required for a static bed. Unloading the NaF from the tubes to the 2 -ft-diam storage cylinders would pose a problem; the alternative, storage in 1 -in.-diam tubes, would require considerable handling labor and storage space. Providing the oxygen required to keep a bed fluidized would present no problem, since it could be furnished by gaseous water-handling equipment, although equipment size would have to be increased.

Quantities and heat loads are summarized for all solids waste streams in Table 4.8, and the cylinder requirements for long-term storage of waste are summarized in Table 4.9. The emphasis in this discussion has been on stream $3 \mathrm{~W}$ from FP-1; however, other data in Tables 4.8 and 4.9 are discussed in subsequent report sections.

\subsection{Fluorination of Plutonium in Reactor $B_{*}$}

\subsubsection{Outline of Process Steps}

This portion of the process has been described in outline form in Section 3.3 and concerns primarily the fluorination, partial decontamination, and trapping of plutonium. Figure 4.9 is a schematic representation of the part of the process discussed in this section. The input to this process section is the solids pneumatically transferred from reactor $A$ and consists of alumina, fission products, a small fraction of the uranium fed to reactor $A$, and most of the process throughput of plutonium. The solids are, except for alumina, in the form of nonvolatile fluorides. The fluidizing gas is $\sim 100 \%$ fluorine. The output from this part of the process is the mixture of condensed actinides and fission-product fluorides trapped in CT-2. The bed from fluorination reactor $B$ is dumped (stream $20 \mathrm{~W}$ ) into waste cylinders and constitutes the solid waste stream discussed in this section. Fission products retained in FP-2 are transferred in an oxygen stream (stream $12 \mathrm{~W}$ ) to the fluid-bed waste-disposal system and there are sorbed on heated NaF. The present section includes a description of the composition and characteristics of stream $12 \mathrm{~W}$, but fluid-bed disposal of these fission-product wastes is discussed in Section 4.3.9. Gaseous wastes in the gas circulation loop are bled periodically to the gas loop of fluorinator A through stream 17, as described in Section 4.4.5.4. Disposal of the gaseous waste is described in detail in Section 4.8 .

Other operations discussed in this section include (1) the fluorination of plutonium deposited in $\mathrm{CT}-2$ by radiation decomposition of $\mathrm{PuF}_{6}$ (Section 4.4.5.3) and (2) the introduction of a small amount of $\mathrm{PuF}_{6}$ into 
reactor B from fluorination of the sorber bed LiF-1 (Section 4.4.5.4): The composition of the $\mathrm{PuF}_{6}$-containing gas stream from LiF-1 is defined in this section, but the principal discussion of the fluorination of LiF-1 is given in Section 4.5.2.4.

TABL,E 4.8. Quantities of Fission Products in Process Waste Streams

(in $\mathrm{g} /$ day)

\begin{tabular}{|c|c|c|c|c|c|c|c|c|c|c|c|c|c|}
\hline Waste Stream & Source of Waste & $\begin{array}{l}\text { Nonvolatile } \\
\text { Fluorides }\end{array}$ & $\mathrm{NbF}_{5}$ & $\mathrm{RuF}_{5}$ & $\mathrm{SbF}_{5}$ & $\mathrm{MoF}_{6}$ & $\mathrm{TeF}_{6}$ & $\mathrm{IF}_{5}$ & $\mathrm{TcF}_{6}$ & $\mathrm{Kr}$ & $\mathrm{XeF}_{4}$ & ${ }^{3} \mathrm{H}$ & $\mathrm{Np}$ \\
\hline $20 W$ & $\begin{array}{l}\text { Discharged } \mathrm{Al}_{2} \mathrm{O}_{3} \text { from } \\
\text { fluorinator } \mathrm{B}\end{array}$ & $\begin{array}{l}21300 \\
\text { (as elements) }\end{array}$ & 1 & 2 & 1 & 16 & 3 & 2 & 1 & & & & 2 \\
\hline $3 W$ & $\begin{array}{l}\text { Low-boiling waste col- } \\
\text { lected in FP-l }\end{array}$ & & 103 & 6721 & & & & & & & & & \\
\hline $12 W$ & $\begin{array}{l}\text { Low-boiling waste col- } \\
\text { lected in FP-2 }\end{array}$ & . & 13.4 & 745 & & & & & & & & & \\
\hline $32 W$ & Still S-1 bottoms & & 31.1 & 1.8 & 220 & 82 & & 511 & 20 & & 7360 & & 2.4 \\
\hline $33 W$ & Still S-2 overhead & & & & & 7935 & 1522 & & 20 & & & & 2.4 \\
\hline $34 \mathrm{~W}$ & $\begin{array}{l}\text { Fission-product fluorides } \\
\text { and } \mathrm{NpF}_{6} \text { sorbed from } \\
\text { distillation product } \mathrm{UF}_{6}\end{array}$ & & & & & 69 & & & 1889 & & & & 211.3 \\
\hline \multirow[t]{4}{*}{36} & $\begin{array}{l}\text { Gàs from fluorinator } \\
\text { recycle loop }\end{array}$ & & 1 & 93 & & & 132 & & 0.044 & \\
\hline & Total grams & 21300 & 149 & 7470 & 221 & 8103 & 1618 & 513 & 1930 & 132 & 7360 & 0.044 & 218 \\
\hline & Heat load, W/day & 45200 & 13700 & 26400 & 290 & Negligible & 62 & 839 & Negligible & 4.3 & 103 & - & $\cdot$ \\
\hline & $\begin{array}{l}\text { W/g of compound } \\
\text { or element }\end{array}$ & 2.1 . & 92 & 3.5 & 1.3 & Negligible & 0.04 & 1.64 & Negligible & 0.03 & 0.01 & & \\
\hline
\end{tabular}

TABLE 4.9. Cylinder Requirements for Long-term Waste Storage

\begin{tabular}{|c|c|c|c|c|c|c|c|c|c|c|}
\hline $\begin{array}{l}\text { Waste } \\
\text { Stream } \\
\text { No. }\end{array}$ & $\begin{array}{l}\text { Description of } \\
\text { Waste Source }\end{array}$ & Method of Handling & $\begin{array}{l}\text { Daily } \\
\text { Volume } \\
\text { of Waste, } \\
\mathrm{ft}^{3}\end{array}$ & $\begin{array}{l}\text { Cylinder } \\
\text { Diameter, } \\
\text { it }\end{array}$ & $\begin{array}{l}\text { Cylinder } \\
\text { Length, } \\
\mathrm{ft}\end{array}$ & $\begin{array}{l}\text { Approximate } \\
\text { Number of } \\
\text { Cylinders } \\
\text { Required } \\
\text { per Year }\end{array}$ & $\begin{array}{l}\text { Temporary } \\
\text { Storage } \\
\text { Time, yr }\end{array}$ & $\begin{array}{l}\text { Number of } \\
\text { Cylinders } \\
\text { at Storage } \\
\text { Equilibrium }\end{array}$ & $\begin{array}{l}\text { Centerline } \\
\text { Temp, }{ }^{\circ} \mathrm{C}\end{array}$ & $\begin{array}{l}\text { Initial } \\
\text { Heat Content } \\
\text { of Waste, } \\
\text { Btu/(hr)(it }\end{array}$ \\
\hline $20 \mathrm{~W}$ & $\begin{array}{l}48-100 \text { mesh } \mathrm{Al}_{2} \mathrm{O}_{3} \text { plus } \\
\text { fission products discharged } \\
\text { from fluorinator B }\end{array}$ & $\begin{array}{l}\text { Mix with aluminum and } \\
\text { stored in cylinders }\end{array}$ & 4.24 & 2 & 9 & . 50 & 8 & 402 & 210 & 36,600 \\
\hline $3 W$ & $\begin{array}{l}\text { RuF5 and } \mathrm{NbF}_{5} \text { condensed } \\
\text { from fluorinator } \mathrm{A} \\
\text { overhead }\end{array}$ & $\begin{array}{l}\text { Transfer in oxygen to a } \\
\text { fluidized bed of } \mathrm{NaF} \text { at } \\
-350^{\circ} \mathrm{C} \text {. NaF mixed with } \\
\text { aluminum and stored in } \\
\text { cylinders }\end{array}$ & 2.36 & 2 & 9 & 28 & 7.1 & 198 & 236 & 47,720 \\
\hline $12 W$ & $\begin{array}{l}\text { RuF5 and NbFs condensed } \\
\text { from fluorinator B } \\
\text { overhead }\end{array}$ & Same as $3 W$ & 0.26 & 2 & 9 & 3 & 7.1 & - 22 & 236 & 47,720. \\
\hline $32 W$ & $\begin{array}{l}\text { S-1 still bottoms contain- } \\
\text { ing UF6. IF5. XeF4, SbF5. } \\
\text { RuF5. MoF } 6 \text {, and TeF6 }\end{array}$ & Transferred to $\mathrm{Al}_{2} \mathrm{O}_{3}$ & 1.45 & 2 & 9 & 17 & 0.26 & 6 & 240 & 206 \\
\hline $33 W$ & $\begin{array}{l}\text { 5-2 overhead containing } \\
\mathrm{UF}_{6}, \mathrm{MoF}_{6} . \mathrm{TeF}_{6}, \mathrm{TCF}_{6} \text {, and } \\
3_{\mathrm{HF}}\end{array}$ & $\begin{array}{l}\text { Transferred to NaF-MgF2 } \\
\text { bed, and stored in cylin- } \\
\text { ders without aluminum } \\
\text { addition }\end{array}$ & 3.74 & 2 & 9 & 44 & 0 & 0 & Room & Negligible \\
\hline $34 W$ & $\begin{array}{l}\text { (a) } \mathrm{TCF}_{6} \text { and } \mathrm{MOF}_{6} \text { sorbed } \\
\text { from } \mathrm{UF}_{6} \text { product } \\
\text { stream of distillation }\end{array}$ & $\begin{array}{l}\mathrm{MgF}_{2} \text { stored without } \\
\text { aluminum addition }\end{array}$ & 3.26 & 2 & 9 & 39 & 0 & 0 & Room & Negligible \\
\hline & (b) Np sorber & $\mathrm{NaF}$ stored as is & 0.6 & 2 & 9 & $<1$ & 0 & 0 & Room & Negligible \\
\hline
\end{tabular}



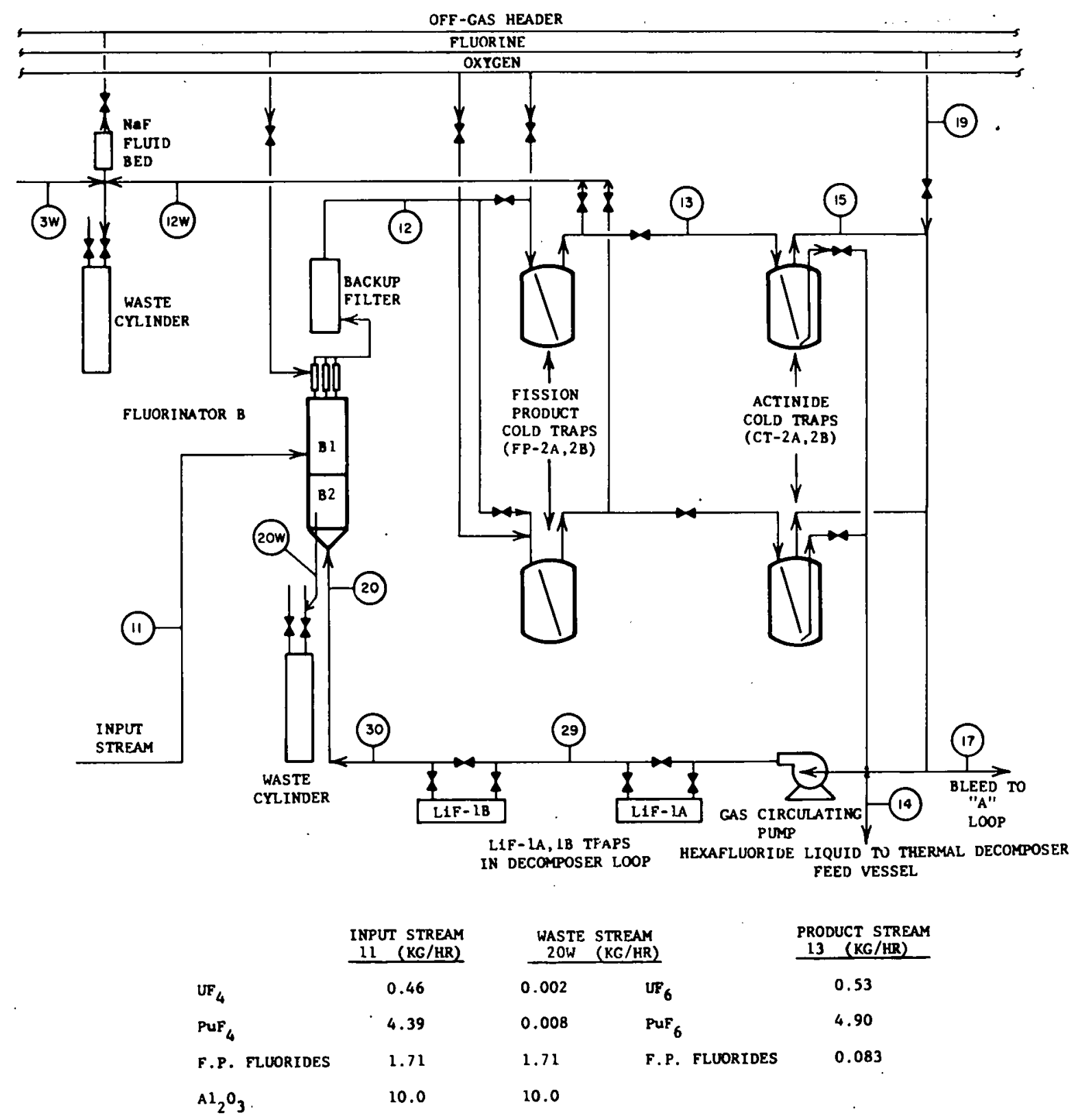

Fig. 4.9. Fluorination Reactor B and. Associated Equipment

\subsubsection{Design Considerations for Reactor B and Associated Equipment}

Solids containing the bulk of the plutonium fed to the process, a small amount of uranium, and a partially fluorinated fission-product mixture are fed continuously from fluorinator A to the upper stage of the twostage fluid-bed reactor, fluorinator $B$. Here most of the plutonium is fluorinated and removed from the solids at $500^{\circ} \mathrm{C}$; the solids continuously move from the upper stage to the lower stage, where the remainder of the plutonium is removed at $550^{\circ} \mathrm{C}$. Almost all the uranium and some of the fission products are also reacted and volatilized. Two fluorination stages (rather than one) provide a margin of safety by ensuring adequate residence 
time for the removal of the plutonium from the solids before the solids are discharged from the fluorinator to waste.

The $\mathrm{PuF}_{6}$ production rate in the fluorinator is a function of (1) the fluorine throughput (i.e., the gas velocity for the given reactor area and the percentage of fluorine in the gas), (2) the reaction temperature (since plutonium fluorination is an equilibrium reaction), and (3) the degree to which equilibrium is approached. The higher the temperature, the greater is the $\mathrm{PuF}_{6}$ content of the fluorine in equilibrium with $\mathrm{PuF}_{4}$. Based on the assumption that equilibrium is achieved, production rates for three temperatures $\left(450,500\right.$, and $\left.550^{\circ} \mathrm{C}\right)$ with $90 \%$ fluorine in the fluidizing gas and different gas velocities are given in Fig. 4.10. At the selected design conditions, not all the plutonium entering the upper bed is fluorinated. The remainder is fluorinated in the lower bed. The desired $r$ ate of production for $\mathrm{PuF}_{6}$ is about $4.9 \mathrm{~kg} / \mathrm{hr}$.

The selected design gas velocity of $\sim 1.4 \mathrm{ft} / \mathrm{sec}$ is satisfactory from an operational standpoint and is adequate to achieve the required plutonium removal. The $90 \%$ approach to equilibrium is thought to be realistic since campaign-type experiments ${ }^{5}$ involving fluorination of $\mathrm{PuF}_{4}$ from alumina (without uranium or fission products present) showed that equilibrium was nearly achieved by maintaining the plutonium inventory in the bed above 3 wt \%. This is the design value for the upper stage of the plutonium fluorinator.

Bed temperatures of $500^{\circ} \mathrm{C}$ for the upper stage and $550^{\circ} \mathrm{C}$ for the lower stage were also selected on the basis of plutonium removal results obtained in previous fluorination process studies. The beds were sized to give average particle residence times of $9 \mathrm{hr}$ in each stage, based on results of earlier batch studies which showed that good removal was achieved in $10 \mathrm{hr}$ in a single stage. Fluorination of the uranium entering reactor $\mathrm{B}$ is not expected to interfere with recovery of the plutonium. The quantity of uranium represents $2 \%$ of the feed to reactor $B$.

In the lower stage, the plutonium concentration is reduced from 2.94 to $0.05 \mathrm{wt} \%$ by fluorinating the solids at $550^{\circ} \mathrm{C}$ with 90 vol $\%$ fluorine at a gas velocity of $1.4 \mathrm{ft} / \mathrm{sec}$. The gas leaving this stage and entering the upper stage contains $\sim 7 \%$ of the equilibrium amount of $\mathrm{PuF}_{6}$.

The plutonium fluorinator is a rectangular parallelepiped similar to the uranium fluorinator, but its inside dimensions are 4 in. thick, $2.5 \mathrm{ft}$ wide, and $10 \mathrm{ft}$ high. The plutonium fluorinator (shown schematically in Fig. 4.11)

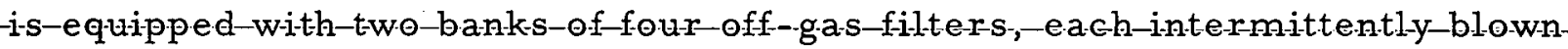
back to return accumulated solids to the bed.

Heat loads and nuclear-criticality problems are considerably less severe in the plutonium fluorinator than in the uranium fluorinator; nevertheless, the waffle design for the wall construction of the plutonium fluorinator 


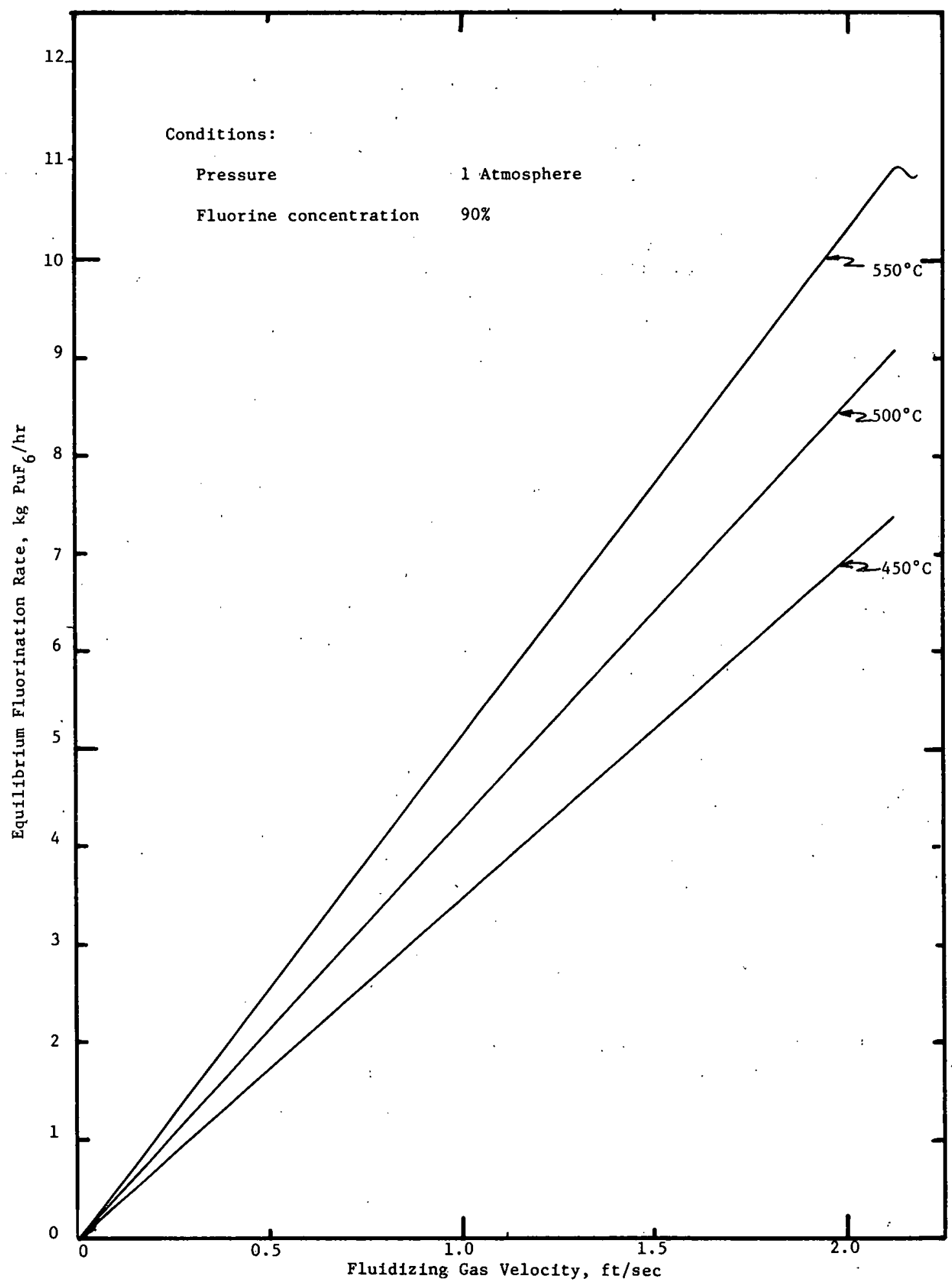

Fig. 4.10. Equilibrium Production Rates for $\mathrm{PuF}_{6}$ in Reactór $\mathrm{B}$ 


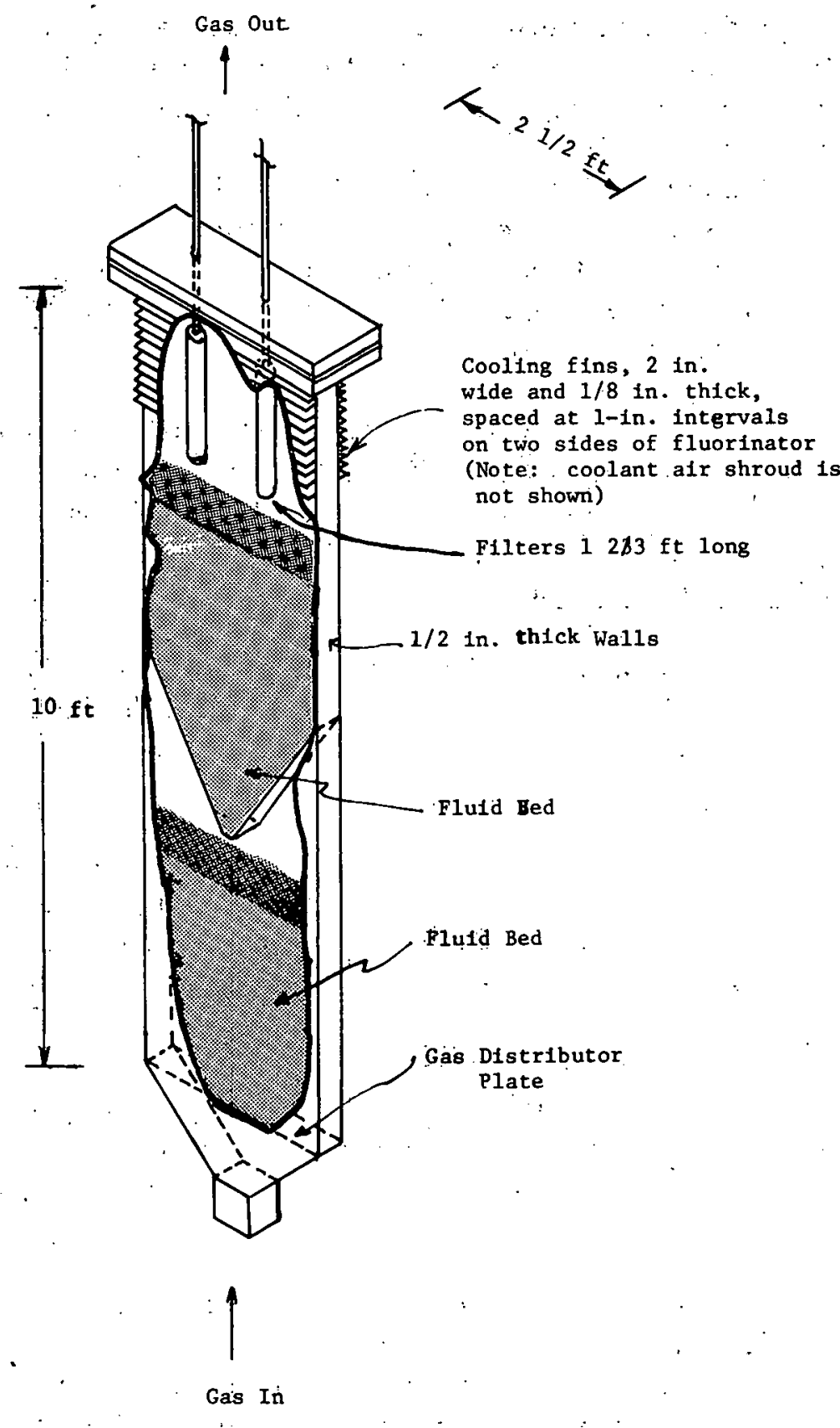

Fig. 4.11. Schematic Diagram of Plutonium Fluorinator (Reactor B)

is the same as that of the uranium fluorinator to ensure adequate mechanical strength. Heat loads will be less than one-half those for the uranium fluorinator. Therefore, for the plutonium fluorinator, coolant air at a rate of $3000 \mathrm{scfm}$ for the lower $6 \mathrm{ft}$ of the reactor and $1000 \mathrm{scfm}$ for the reactor wall-in the filter-area-wil-suffice. The-heat-ioad-i-dure-mainly-to-the-accumulation of fission products in the fluidized bed. While the bed is fluidized, the bed height in each stage of the reactor will be $3 \mathrm{ft}$, giving a total heat flux of about $3800 \mathrm{Btu} /(\mathrm{hr})\left(\mathrm{ft}^{2}\right)$. If fluidization stops, the lower $4.5 \mathrm{ft}$ of reactor will contain the static bed, and the heat flux will be $5100 \mathrm{Btu} /(\mathrm{hr})\left(\mathrm{ft}^{2}\right)$. 
The main difference between the two fluorination vessels is that the uranium fluorinator is a one-stage vessel operated at $350^{\circ} \mathrm{C}$ and the plutonium fluorinator is a two-stage vessel with the stages operating at 500 and $550^{\circ} \mathrm{C}$. Staging is effected by the use of a baffle arrangement, as exemplified in the work of Overcashier et al ${ }^{83}$ The baffle allows countercurrent flow of solids and gases in the reactor. Since the design and installation of baffles are specific to a particular application, some ANL work ${ }^{84}$ is being done on mocked-up.systems applicable to the slab-reactor design. Early studies yielded promising results.

The cold traps and gas circulating pumps differ only in size from those used in the loop of reactor A. Size, fission-product loading, and operating cycles for the cold traps are given in Tables $4.1 \mathrm{~A}$ and 4.8 .

\subsubsection{Process Instrumentation}

All instrumentation is similar to that specified in the other fluorination loop (reactor A) and is described in Section 4.3.5.

\subsubsection{Material Balance}

The stream numbers and the compositions of the process streams are given in the equipment flowsheet (Fig. 4.9) and Table 4.10, respectively. The solids stream leaving the uranium fluorinator is fed to the two-stage plutonium fluorinator at $16.6 \mathrm{~kg} / \mathrm{hr}$, the contained plutonium being fed at $4.39 \mathrm{~kg} / \mathrm{hr}$ as $\mathrm{PuF}_{4}$.

Solids are removed from the plutonium fluorinator at $11.7 \mathrm{~kg} / \mathrm{hr}$; these solids represent the main solids waste stream from the process and contain $51 \%$ of the radioactivity and $0.2 \%$ of the plutonium charged to the process.

Gaseous reagents are recycled in the plutonium fluorination step as in the uranium fluorination step. Here recycle of the gas is desirable mainly to conserve fluorine. Fluorine makeup to this system is required at $0.2 \mathrm{scfm}$ to replace fluorine consumed by reaction. System pressure will be relieved intermittently by venting the gas to the uranium fluorination system. Not included in the material-balance flow data are the volumes of gas required for blowback of the fluorinator filters and for movement of solids from fluorinator A to fluorinator B.

\subsubsection{Description of Physical and Chemical Processes in Reactor B}

This section contains a description of the physical and chemical reactions pertinent to fluorination in reactor $B$, trapping of fission products in FP-2, and condensation of contaminated actinides in $\mathrm{CT}-2$. 
TABLE 4.10. Material Balance: Fluorination Loop B

\begin{tabular}{|c|c|c|c|c|c|c|c|c|c|c|c|c|}
\hline \multirow[t]{2}{*}{ 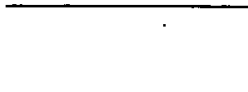 } & \multicolumn{12}{|c|}{ Stream } \\
\hline & $20 \mathrm{~W}$ & 11 & 12 & $12 W$ & 13 & 15 & 20 & 29 & 30 & 19 & 14 & 17 \\
\hline $\begin{array}{l}\mathrm{U}, \mathrm{kg} / \mathrm{day} \\
\mathrm{Pu}, \mathrm{kg} / \mathrm{day} \\
\mathrm{F} . \mathrm{P} . \text { fluorides, } \mathrm{kg} / \text { day } \\
\mathrm{Al}_{2} \mathrm{O}_{3}, \mathrm{~kg} / \mathrm{day}\end{array}$ & $\begin{array}{r}0.09 \\
0.17 \\
41.0 \\
240.0\end{array}$ & $\begin{array}{r}8.7 \\
79.9 \\
41.0 \\
240.0\end{array}$ & & $\begin{array}{l}0 \\
0\end{array}$ & & & & & 0.5 & & $\begin{array}{r}8.6 \\
79.8\end{array}$ & \\
\hline \multicolumn{13}{|c|}{ Actinide Compounds, g/day } \\
\hline $\begin{array}{l}\mathrm{PuF}_{6} \\
\mathrm{UF}_{6} \\
\mathrm{NpF}_{6}\end{array}$ & $\begin{array}{r}250 \\
130 \\
2\end{array}$ & $\begin{array}{c}118.0 \times 10^{3} \\
.12 .9 \times 10^{3} \\
121\end{array}$ & $\begin{array}{l}117.8 \times 10^{3} \\
12.8 \times-10^{3} \\
119\end{array}$ & $\begin{array}{l}0 \\
0 \\
0\end{array}$ & $\begin{array}{l}117.8 \times 10^{3} \\
12.8 \times 10^{3} \\
119\end{array}$ & $\begin{array}{l}76 \\
1 \\
0.3\end{array}$ & & & & & $\begin{array}{c}117.8 \times 10^{3} \\
12.8 \times 10^{3} \\
118.7\end{array}$ & \\
\hline \multicolumn{13}{|c|}{$\frac{\text { Volatile Fission Product Elements }}{\text { or Compounds, g/day }}$} \\
\hline $\begin{array}{l}\mathrm{NbF}_{5} \\
\mathrm{MoF}_{6} \\
\mathrm{TcF}_{6} \\
\mathrm{RuF}_{5} \\
\mathrm{SbF}_{5} \\
\mathrm{TeF}_{6} \\
\mathrm{IF}_{5} \\
\mathrm{Kr} \\
\mathrm{Xe}\end{array}$ & $\begin{array}{r}1 \\
16 \\
1 \\
2 \\
1 \\
3 \\
2 \\
0 \\
0\end{array}$ & $\begin{array}{r}15 \\
829 \\
199 \\
747 \\
25 \\
162 \\
88 \\
-\end{array}$ & $\begin{array}{r}14 \\
813 \\
198 \\
745 \\
24 \\
159 \\
86 \\
- \\
-\end{array}$ & $\begin{array}{c}13.4 \\
0 \\
0 \\
744.97 \\
0 \\
0 \\
0 \\
0 \\
.0\end{array}$ & $\begin{array}{c}0.6 \\
813 \\
198 \\
0.03 \\
24 \\
- \\
86 \\
- \\
-\end{array}$ & $\begin{array}{c}2.9 \times 10^{-11} \\
14 \\
0.32 \\
3.9 \times 10^{-11} \\
7.2 \times 10^{-4} \\
- \\
1.8^{*} \times 10^{-3} \\
-\end{array}$ & & & & & $\begin{array}{c}0.6 \\
813 \\
197.7 \\
0.03 \\
24 \\
159 \\
86 \\
0 \\
0\end{array}$ & \\
\hline \multicolumn{13}{|l|}{ Gas Flowrates, scfm } \\
\hline $\begin{array}{l}\mathrm{UF}_{6} \\
\mathrm{PuF}_{6} \\
\mathrm{~F}_{2} \\
\mathrm{O}_{2} \text { (diluent) }\end{array}$ & & - & $\begin{array}{c}0.018 \\
0.185 \\
20.5 \\
2.3 \\
230\end{array}$ & & & $\begin{array}{r}20.5 \\
2.3 \\
22.8\end{array}$ & $\begin{array}{r}20.7 \\
2.3 \\
230\end{array}$ & $\begin{array}{r}20.7 \\
2.3 \\
230\end{array}$ & $\begin{array}{c}\text { Negligible } \\
20.7 \\
2.3 \\
230\end{array}$ & $\frac{0.2}{0.2}$ & & $\begin{array}{l}\text { Negligible } \\
\text { Negligible }\end{array}$ \\
\hline
\end{tabular}

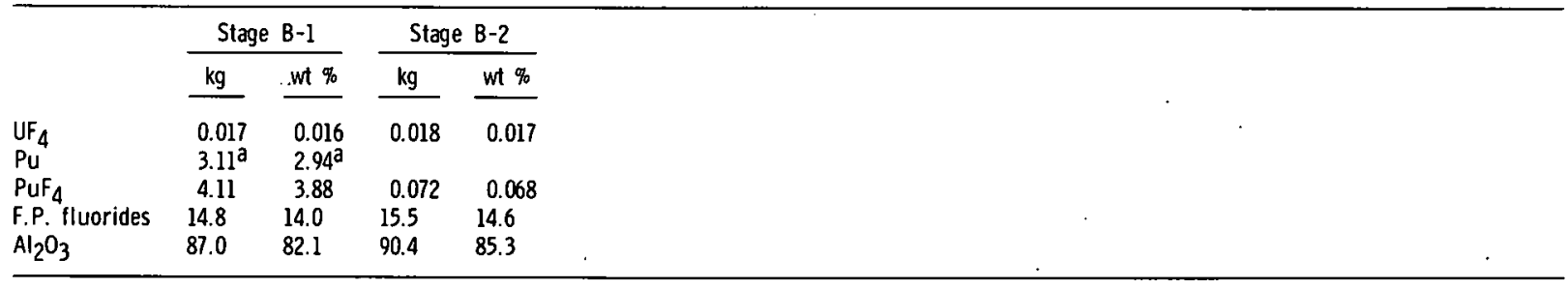

aEstimated value.

4.4.5.1 Fluorination Reactions. The primary chemical reaction in fluorination reactor $\mathrm{B}$ is the conversion of $\mathrm{PuF}_{4}$ to $\mathrm{PuF}_{6}$ by elemental fluorine, carried out at $500^{\circ} \mathrm{C}$ in reactor stage $\mathrm{B}-1$ and at $550^{\circ} \mathrm{C}$ in reactor stage $\mathrm{B}-2$. The reaction is

$$
\mathrm{PuF}_{4}+\mathrm{F}_{2} \rightarrow \mathrm{PuF}_{6}, \Delta \mathrm{H}_{800 \mathrm{~K}}=+4.9 \mathrm{kcal} / \mathrm{mole} \mathrm{Pu} .{ }^{61}
$$

The equilibrium between $\mathrm{PuF}_{4}$, fluorine, and $\mathrm{PuF}_{6}$, which limits the $\mathrm{PuF}_{6}$ produced in reactor $\mathrm{A}$ at $350^{\circ} \mathrm{C}$ (Section 4.3.6) also limits the concentration of $\mathrm{PuF}_{6}$ in fluorine attainable at 500 or $550^{\circ} \mathrm{C}$ (see Appendix $\mathrm{C}$ ). Flowsheet calculations have been based on the assumption that $90 \%$ of the equilibrium concentration of $\mathrm{PuF}_{6}$ in fluorine is reached in the gaseous effluent from the $500^{\circ} \mathrm{C}$ section of fluorinator $B$. This as sumption is supported by data ${ }^{5}$ on the fluorination of $\mathrm{Pu}_{4}$ in $\mathrm{Al}_{2} \mathrm{O}_{3}$ : Fluorine efficiencies near $100 \%$ (based on the thermodynamic equilibrium) were obtained at $450^{\circ} \mathrm{C}$ when significant concentrations $\left(>3.9\right.$ wt $\% \mathrm{PuF}_{4}$ ) of $\mathrm{PuF}_{4}$ were in the $\mathrm{Al}_{2} \mathrm{O}_{3}$ bed. The steady-state concentration of $\mathrm{PuF}_{4}$ in the bed of fluorinator $\mathrm{B}-1$ is estimated to be 3.9 wt \% $\mathrm{PuF}_{4}$. Fluorination of $\mathrm{PuF}_{4}$ in stage $\mathrm{B}-2$ at $550^{\circ} \mathrm{C}$ 
is assumed to reach a $\mathrm{PuF}_{6}$ effluent concentration equal to $\sim 7 \%$ of the equilibrium value at the $550^{\circ} \mathrm{C}$ operating temperature. By adjustment of the residence times in $B-1$ and $B-2$, it is estimated that all but $0.2 \%$ of the original plutonium fed to reactor $A$ will be converted to $\mathrm{PuF}_{6}$.

The partition of fission products between fluorinator $A$ and fluorinator $B$ has been outlined previously (Section 4.3.8). Flowsheet calculations for fluorinator $B$ have been based on the conservative assumption that all the fission products transported to fluorinator B (stream ll) whose fluorides are volatile are removed from fluorinator $B$ with the actinides and unreacted fluorine. Table 4.11 shows the quantities of volatile actinides and fission products in the fluorinator B off-gas stream.

TABLE 4.11. Volatilization of Actinides and Fission Products from Reactor B

\begin{tabular}{cccccc}
\hline $\begin{array}{c}\text { Element } \\
\text { or Compound } \\
\text { Volatilized }\end{array}$ & $\begin{array}{c}\text { Assumed } \\
\text { Percentage } \\
\text { Volatilizeda }\end{array}$ & $\begin{array}{c}\text { Kilograms } \\
\text { Volatilized } \\
\text { (Stream 12) }\end{array}$ & $\begin{array}{c}\text { Element } \\
\text { or Compound } \\
\text { Volatilized }\end{array}$ & $\begin{array}{c}\text { Assumed } \\
\text { Percentage } \\
\text { Volatilized }\end{array}$ & $\begin{array}{c}\text { Kilograms } \\
\text { Volatilized } \\
\text { (Stream 12) }\end{array}$ \\
\hline $\mathrm{PuF}_{6}$ & 96 & 117.8 & $\mathrm{RuF}_{5}$ & 10 & 0.745 \\
$\mathrm{UF}_{6}$ & 1 & 12.8 & $\mathrm{SbF}_{5}$ & 10 & 0.024 \\
$\mathrm{NpF}_{6}$ & 50 & 0.119 & $\mathrm{TeF}_{6}$ & 10 & 0.159 \\
$\mathrm{Kr}$ & 10 & 0.01 & $\mathrm{IF}_{5}$ & 10 & 0.086 \\
$\mathrm{NbF}_{5}$ & 10 & 0.014 & $\mathrm{XeF}_{4}$ & 10 & 0.736 \\
$\mathrm{MoF} 6$ & 10 & 0.813 & ${ }^{3} \mathrm{HF}$ & 10 & 0.0004 \\
$\mathrm{TCF} 6$ & 10 & 0.198 & & & \\
\hline
\end{tabular}

as a percentage of initial charge to fluorinator A (see Table 4.1).

The species of the fission products carried in the alumina- $\mathrm{PuF}_{4}$ stream (11) fed to reactor $B$ is generally assumed to be a lower nonvolatile fluoride where applicable or otherwise the unreacted fission-product element or oxide. Unlike the gas recycled through fluorinator $A$, the steady-state gaseous reagent in loop $B$ is nearly pure fluorine. Consequently, formation of oxyfluorides is likely to be minimized in fluorination reactor B. "The formation of oxyfluorides is discussed in Section 4.3.8.1, where it is indicated that molybdenum, technetium, ruthenium, and iodine are the only fission products that would form oxyfluorides under the conditions in fluorination reactor A. No data exist that permit reliable estimates of the nature of the fluoride species. formed in fluorination reactor $B$. Therefore, the bases for flowsheet calculations used in the description of the chemical reactions in fluorination reactor $A$ are used in the corresponding description for reactor B, although formation of a high fraction of fully fluorinated compounds is probable.

Tritium, as ${ }^{3} \mathrm{HF}$, is volatilized from fluorinator $B$, together with $\mathrm{NbF}_{5}, \mathrm{SbF}_{5}$, and $\mathrm{TeF}_{6}$. Fiuorides or oxyfluorides of molybdenum, technetium, ruthenium, and iodine are all volatile at 500 or $550^{\circ} \mathrm{C}$ and distill from the reactor with the actinide hexafluorides. Xenon not liberated from the solid fuel in reactor $A$ is expected to be evolved as $\mathrm{XeF}_{4}$ or elemental xenon, the former compound being assumed for flowsheet calculations. Krypton is expected to be evolved as the element. 
Fragments of stainless steel and products of the reaction of stainless steel with $\mathrm{O}_{2}-\mathrm{F}_{2}$ in reactor $A$ would be transported to reactor $B$ and be expected to react to some extent with fluorine at 500 or $550^{\circ} \mathrm{C}$. Metallic stainless steel, although relatively inert to elemental fluorine in the absence of significant concentrations of oxygen, would react to form $\mathrm{CrF}_{4}$ or $\mathrm{CrF}_{5}$, which are volatile and would distill from reactor B. Chromium oxides formed in reactor $A$ would be expected to form volatile $\mathrm{CrO}_{2} \mathrm{~F}_{2}$. Other constituents of stainless steel are expected to remain with the alumina bed as nonvolatile fluorides or unreacted metal. All the remaining fission products form nonvolatile fluorides, which, together with the transplutonium elements, remain in the alumina bed of fluorination reactor $B$.

Alumina used as the bed material in the fluorination reactors is relatively: inert to fluorination. However, a small fraction of the alumina can be expected to react to form aluminum fluoride according to the reaction

$$
\mathrm{Al}_{2} \mathrm{O}_{3}(\mathrm{~s})+6 \mathrm{~F}_{2}(\mathrm{~g}) \rightarrow 2 \mathrm{AlF}_{3}(\mathrm{~s})+3 / 2 \mathrm{O}_{2}(\mathrm{~g}), \Delta \mathrm{H}_{800 \mathrm{~K}}=-156.1 \mathrm{kcal} / \mathrm{mole} \mathrm{AlF} 3 .
$$

The extent of conversion of aluminum oxide to aluminum fluoride is likely to be small ${ }^{38}$ and is estimated at $\sim 3 \%$ of the alumina. Thus, the $10 \mathrm{~kg}$ of $\mathrm{Al}_{2} \mathrm{O}_{3}$ discharged from reactor $\mathrm{B}$ each hour would contain $300 \mathrm{~g}$ of $\mathrm{AlF}_{3}$. The $\mathrm{AlF}_{3}$ is nonvolatile and remains with the bed of solids.

Fluorination of the nickel fluorinator walls, even at $550^{\circ} \mathrm{C}$ in elemental fluorine, proceeds at a low rate ${ }^{85}$ according to the reaction

$$
\mathrm{Ni}(\mathrm{s})+\mathrm{F}_{2}(\mathrm{~g}) \rightarrow-\mathrm{NiF}_{2}(\mathrm{~s}), \Delta \mathrm{H}_{800 \mathrm{~K}}=-156.4 \mathrm{kcal} / \mathrm{mole} .^{86}
$$

Corrosion of materials of construction is discussed in Section 6.4. The nickel fluoride formed by the corrosion reaction is expected to become part of the alumina bed and to be discharged from reactor $B$ in the waste stream.

In summary, fluorination reactions in fluorinator $B$ result in the volatilization of $\mathrm{PuF}_{6}, \mathrm{UF}_{6}, \mathrm{NpF}_{6}$, fluorides of the fission-product elements ${ }^{3} \mathrm{H}, \mathrm{Nb}, \mathrm{Sb}, \mathrm{Te}, \mathrm{Mo}, \mathrm{Ru}, \mathrm{Tc}, \mathrm{Xe}$, and I, krypton in elemental form, and possibly chromium fluorides originating from stainless steel introduced with the fuel fed to reactor $A$. Nonvolatile fluorides of the remaining fission products and transplutonium elements, together with $\mathrm{AlF}_{3}$ and $\mathrm{NiF}_{2}$, are retained in the alumina bed, which is discharged as a solids waste stream from reactor $B$.

4..4.5-2_-Removal_of_F_is.s.ion_P_r_oduc.ts_in_FP_2-_-The_function_of_FP_2 is to remove fission-product ruthenium and niobium by condensation from the gas stream effluent from fluorination reactor $B$ without loss of product hexafluorides. The temperature of FP-2. is held at $-10^{\circ} \mathrm{C}$, chosen as a functional temperature which will allow condensation of $\mathrm{RuF}_{5}$ and $\mathrm{NbF}_{5}$. The 
production rate of $\mathrm{PuF}_{6}$ from reactor $\mathrm{B}$ is low enough so that the average partial pressure of $\mathrm{PuF}_{6}$ in the fluorine stream $(\sim 4.8 \mathrm{~mm} \mathrm{Hg})$ is 1 ess than the vapor pressure of $\mathrm{PuF}_{6}$ at $-10^{\circ} \mathrm{C}(7.9 \mathrm{~mm} \mathrm{Hg})$.

No ${ }^{3} \mathrm{HF}$ is expected to condense at $-10^{\circ} \mathrm{C}$, because of the high vapor pressure of this fluoride and the low partial pressure of ${ }^{3} \mathrm{HF}$ in the gas stream. No molybdenum is expected to condense at $-10^{\circ} \mathrm{C}$ if $\mathrm{MoF}_{6}$ is the only species formed. If $\mathrm{MoOF}_{4}$ is the predominant species, however, some condensation of molybdenum can be expected at $-10^{\circ} \mathrm{C}$, since the vapor pressure of $\mathrm{MoOF}_{4}$ at this temperature is $\sim 0.02 \mathrm{~mm} \mathrm{Hg}$, whereas the average partial pressure of $\mathrm{MoOF}_{4}$ could be more than twice this value $(\sim 0.056 \mathrm{~mm} \mathrm{Hg})$. If molybdenum were present as $\mathrm{MoOF}_{4}$, as much as $0.65 \mathrm{~kg}$ (of the approximately $0.8 \mathrm{~kg}$ ) of this compound could condense in FP-2. In the absence of experimental data, the flowsheet calculations are based on the conservative assumption that all molybdenum follows the actinide product stream through FP-2. A similar argument is valid for the behavior of technetium, except that the vapor pressure of $\mathrm{TcOF}_{4}$, while likely to be less than that of $\mathrm{MoOF}_{4}$, is not known and the quantity of technetium fed to fluorination reactor $B$ is less than that of molybdenum. The oxyfluoride $\mathrm{TcO}_{3} \mathrm{~F}$, if formed, would accompany $\mathrm{TcF}_{6}$ through the $-10^{\circ} \mathrm{C}$ trap. Flowsheet calculations are based on no technetium being retained in FP-2.

Ruthenium pentafluoride has an estimated vapor pressure at $-10^{\circ} \mathrm{C}$ of $3 \times 10^{-6} \mathrm{~mm} \mathrm{Hg}$, which is low enough to ensure almost complete condensation of $\mathrm{RuF}_{5}$ in FP-2. Flowsheet calculations have been carried out on the basis that $\mathrm{RuF}_{5}$ is the only species formed. This assumption results in a $D F$ for ruthenium across the FP-2 trap of $\sim 2.5 \times 10^{4}$. If ruthenium is converted to $\mathrm{RuF}_{6}$ in fluorination reactor $B$, no condensation of ruthenium can be expected in FP-2. If $\mathrm{RuOF}_{4}$ is formed in significant concentrations, a part of this compound could be expected to remain in FP-2, since the estimated vapor pressure of $\mathrm{RuOF}_{4}$ at $-10^{\circ} \mathrm{C}\left(2.3 \times 10^{-2} \mathrm{~mm} \mathrm{Hg}\right)$ is less than one-half the maximum average partial pressure of this species in the gasstream effluent from fluorination reactor B. Discussion of the decontamination of plutonium from ruthenium at the end of this section will treat the extremes in the assumptions regarding the effectiveness of FP-2 (i.e., almost complete removal of ruthenium by condensation of $R F_{5}$, or no removal of ruthenium in FP-2)..

Niobium pentafluoride is the only niobium species anticipated in the effluent from fluorination reactor $\mathrm{B}$. About $96 \%$ of the $\mathrm{NbF}_{5}$ entering FP-2 is expected to be retained at $-10^{\circ} \mathrm{C}$, since the vapor pressure of $\mathrm{NbF}_{5}$ at that temperature is estimated to be $6 \times 10^{-5} \mathrm{~mm} \mathrm{Hg}$. Neither iodine in any of the fluoride forms anticipated. $\left(\mathrm{IF}_{5}, \mathrm{IF}_{7}\right.$, or $\left.\mathrm{IOF}_{5}\right)$ nor $\mathrm{TeF} 6$ will condense at $-10^{\circ} \mathrm{C}$. Xenon or $\mathrm{XeF}_{4}$ will also pass into $\mathrm{CT}-2$ with the actinide hexafluoride stream. Chromium fluorides $\left(\mathrm{CrF}_{4}, \mathrm{CrF}_{5}\right)$ formed in the fluorination of stainless steel would condense to some extent at $-10^{\circ} \mathrm{C}$, but $\mathrm{CrO}_{2} \mathrm{~F}_{2}$ would pass through FP-2. 
Formation of solid solutions of fission-product fluorides and plutonium hexafluoride are a potential source of loss of plutonium in this part of the process. Solid-solution formation is discussed in Section 4.3.8.2, where it is concluded that this source of loss is highly unlikely because of the differences in the crystal structures of actinide hexafluorides and the condensed fission-product fluorides. Both solid $\mathrm{MoOF}_{4}$ (Ref. 87) and solid $\mathrm{TcOF}_{4}$ (Ref. 88) (which may condense in FP-1) are monoclinic and have a crystal structure differing from that of $\mathrm{PuF}_{6}$, which is orthorhombic. The remaining fluorides for which data are available have been described in Table 4.4. The most important consequence of solid-solution formation would be the loss of $\mathrm{PuF}_{6}$ in the process of discharging waste from FP-2. However, the amount of $\mathrm{PuF}_{6}$ associated in solid solution is expected to be negligible since (a) the total amount of fission-product fluorides (solvent) is small and (b) the solubility limit is expected to be low, owing to the differences in crystal parameters.

If the hypothesis that the amount of $\mathrm{PuF}_{6}$ as sociated in solid solution in FP-2 (and FP-1) will be nil is not upheld by experiment, additional techniques might be used to decrease the retention of $\mathrm{PuF}_{6}$ in FP-2. Two examples are: (a) operation of FP-2 with temperature and residence times such that gas-solid equilibrium is not reached, resulting in less than the solubility limit of $\mathrm{PuF}_{6}$ being retained by the solid phase in the trap; and (b) coating the solid surfaces of the trap with an inert solid phase of monoclinic crystal structure, favoring condensation of monoclinic solids ( $\mathrm{RuF}_{5}$ and $\mathrm{NbF}_{5}$ ) and discriminating against condensation of solids of other crystal structure (actinide hexafluorides).

Retention of $\mathrm{PuF}_{6}$ in FP-1 and FP- 2 might be caused by at least one mechanism other than solid solubility (i.e., physical entrapment). This mechanism could be offset by using an additional sublimation-condensation stage.

In summary, flowsheet calculations for the fluorinator $B$ loop are based on the effective retention in FP-2 $\left(-10^{\circ} \mathrm{C}\right)$ of almost all the ruthenium as $\mathrm{RuF}_{5}$ and most of the niobium as $\mathrm{NbF}_{5}$. Formation of oxyfluorides of molybdenum and technetium would increase decontamination of the actinide stream from these fission products, compared to the calculated values. Ruthenium hexafluoride would be expected to pass through FP-2 and contaminate the condensate in $\mathrm{CT}-2$. Other fission products $\left(\mathrm{Xe}, \mathrm{I}_{8}{ }^{3} \mathrm{H}\right)$ are expected to pass into $\mathrm{CT}-2$. No loss of actinide hexafluorides by condensation or solid-solution formation at $-10^{\circ} \mathrm{C}(\mathrm{FP}-2)$ is anticipated. Retention of fluorides in FP-2 is summarized in Table 4.12.

4.4.5.3 Condensation of Actinides and Fission Products in CT -2 . Cold trap CT-2, operated at $\approx-80^{\circ} \mathrm{C}$, is designed to condense the actinide hexafluorides. Most of the fission-product compounds formed in fluorinator $B$ and passed through FP-2 at $-10^{\circ} \mathrm{C}$ will also be condensed. The 
vapor pressures of $\mathrm{UF}_{6}, \mathrm{NpF}_{6}$, and $\mathrm{PuF}_{6}$ at $-80^{\circ} \mathrm{C}$ are such that all but an insignificant fraction of these compounds will be retained in CT.-2. A very high fractional retention (shown in Table 4.12) is also expected for most of the fission-product fluorides, based on the vapor pressures of the pure components at $-80^{\circ} \mathrm{C}$. Small amounts of $\mathrm{MoF}_{6}, \mathrm{TeF}_{6}$, and $\mathrm{TcF}_{6}$ are expected to pass through CT-2 and be recycled, together with all of the unreacted fluorine, elemental krypton, and some elemental xenon, * to fluorinator B.

TABLE 4.12. Retention of Fission Products in FP-2 and CT-2

\begin{tabular}{lccc}
\hline & $\begin{array}{c}\text { Fraction Retained } \\
\text { in FP-2 }\end{array}$ & $\begin{array}{c}\text { V.P. at }-10^{\circ} \mathrm{C}, \\
\mathrm{mm} \mathrm{Hg}\end{array}$ & $\begin{array}{c}\text { Fraction } \\
\text { in } \mathrm{CT} \text { Retained }\end{array}$ \\
\hline $\mathrm{UF}_{6}$ & $\mathrm{Nil}$ & 7.44 & $\sim 1.0$ \\
$\mathrm{NpF}_{6}$ & $\mathrm{Nil}$ & 10.77 & $\sim 1.0$ \\
$\mathrm{PuF}_{6}$ & $\mathrm{Nil}$ & 7.90 & $\sim 1.0$ \\
${ }^{3} \mathrm{HF}$ & $\mathrm{Nil}$ & 234 & $\sim 1.0$ \\
$\mathrm{NbF}_{5}$ & 0.96 & $6 \times 10^{-5}$ & $\sim 1.0$ \\
$\mathrm{MOF}_{6}$ & $\mathrm{Nil}$ & 96.2 & 0.983 \\
$\mathrm{MOOF}_{4}$ & $\mathrm{c}$ & 0.02 & $\sim 1.0$ \\
$\mathrm{TcF}_{6}$ & $\mathrm{Nil}$ & 29.7 & 0.998 \\
$\mathrm{TcOF}_{4}$ & $\mathrm{c}$ & $<0.02^{\mathrm{d}}$ & $\sim 1.0$ \\
$\mathrm{TcO}_{3} \mathrm{~F}$ & $\mathrm{Nil}$ & 0.02 & $\sim 1.0$ \\
$\mathrm{RuF}_{5}$ & $0.999+$ & $2.6 \times 10^{-6}$ & $\sim 1.0$ \\
$\mathrm{RuOF}_{4}$ & $\mathrm{Nil}$ & $2.3 \times 10^{-2}$ & $\sim 1.0$ \\
$\mathrm{RuF}_{6}$ & $\mathrm{Nil}$ & $12^{\mathrm{d}}$ & $\sim 1.0$ \\
$\mathrm{SbF}_{5}$ & $\mathrm{Nil}$ & $0.38^{\mathrm{d}}$ & $\sim 1.0$ \\
$\mathrm{TeF}_{6}$ & $\mathrm{Nil}$ & 2171 & 0.96 \\
$\mathrm{IF}_{5}$ & $\mathrm{Nil}$ & 1.7 & $\sim 1.0$ \\
$\mathrm{IF}_{7}$ & $\mathrm{Nil}$ & 372 & - \\
$\mathrm{IOF}_{5}$ & $\mathrm{Nil}$ & $470^{\mathrm{d}}$ & - \\
$\mathrm{XeF}_{4}$ & $\mathrm{Nil}$ & 0.10 & $\sim 1.0$ \\
$\mathrm{XeF}_{2}$ & $\mathrm{Nil}$ & 0.23 & $\sim 1.0$ \\
\hline $\mathrm{F}_{2}$ & & &
\end{tabular}

${ }^{a}$ Fraction of material entering vessel.

${ }^{b}$ Vapor pressures of the fluorides at $-80^{\circ} \mathrm{C}$ are shown in Table 4.5 and

Appendix D.

c Dependent on the partial pressure of the compound in the gas stream.

dEstimated.

Condensed $\mathrm{PuF}_{6}$ in $\mathrm{CT}-2$ is subject to decomposition due to absorption of energy from alpha decay of plutonium and beta-gamma decay of fission products (see Section 4.3.8.3). The daily charge of $\mathrm{PuF}_{6}(117.8 \mathrm{~kg})$ can be expected to decompose by alpha radiation at an average rate of $3 \%$ per day. This rate, reduced by one-half,** yields approximately $1.76 \mathrm{~kg}$ $\mathrm{PuF}_{6}(1.19 \mathrm{~kg} \mathrm{Pu})$ decomposed per day in $\mathrm{CT}-2$. Decomposition in the vapor phase is neglected. Frequency of removal of this deposited plutonium will be governed primarily by criticality limitations in the slab-shaped cold traps and is estimated at one cleanout every operating week.

Additional decomposition of $\mathrm{PuF}_{6}$ is expected because of absorption of beta-gamma energy from the decay of fission products. Calculations

* Elemental xenon is produced by the radiation decomposition of $\mathrm{XeF}_{4}$. Refluorination of xenon by fluorine would proceed at modest temperatures such as may be found in process pipes close to reactor $B$, but would be very slow at the temperatures of FP-2 and CT -2 .

** The value one-half is used based on the average residence time of a batch being one-half the time period during which the batch is collected. 
based on normal and abnormal process operations are summarized in Table 4.13, where the energy emission rate from fission products retained in CT-2 is estimated. Under normal operation conditions, the composition of stream 13 is indicative of the fission-product inventory of CT-2, which would result in decomposition of $0.57 \mathrm{~kg}$ of $\mathrm{PuF}_{6}(0.386 \mathrm{~kg}$ of plutonium).. per day. The assumptions used in this calculation, listed in footnote e of Table 4.13, are the same as those used previously in a similar calculation for decomposition of $\mathrm{PuF}_{6}$ in $\mathrm{CT}_{-1}$ (Section 4.3.8.3.).

TABLE 4.13. Energy Evolution from Fission Products in CT-2

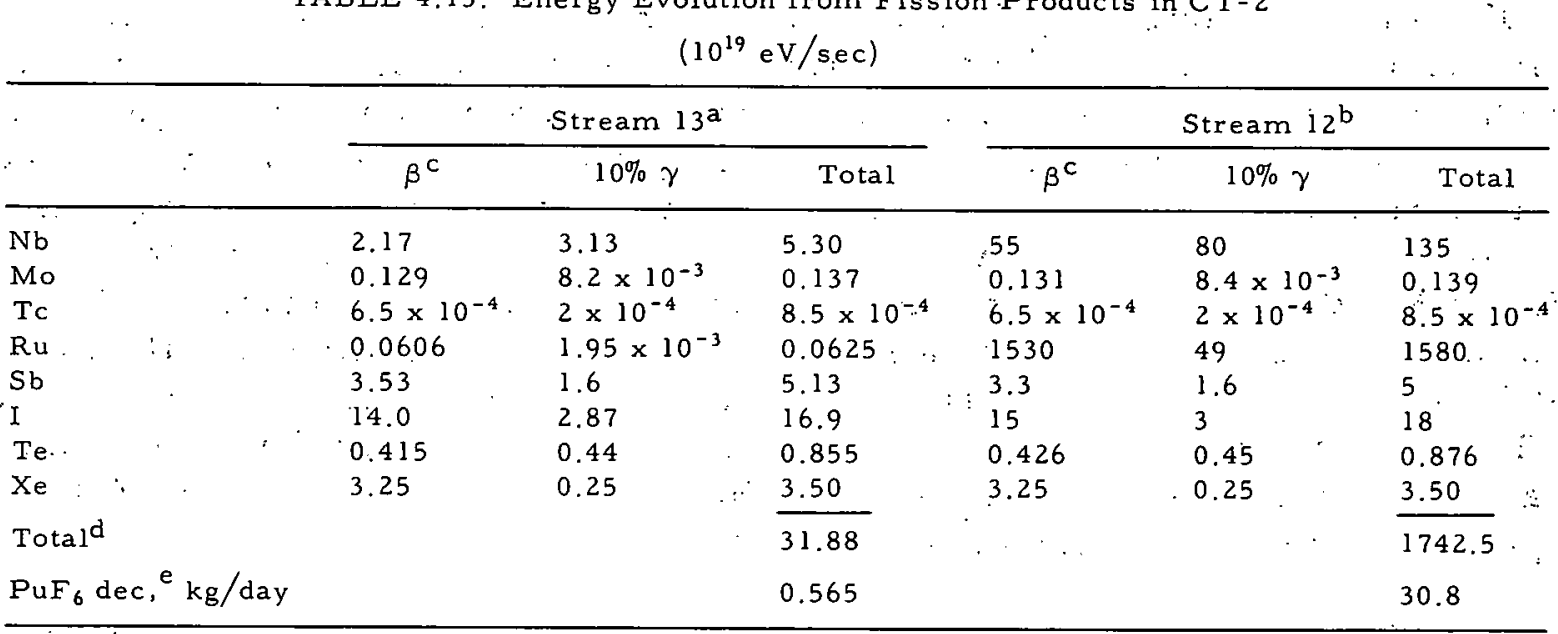

${ }^{a}$ Feed stream to CT-2 from FP-2, based on flowsheet quantities (Table 4.10) of fission products.

Feed stream to FP-2; indicative of the fission-product content of CT- 2 if trap FP- 2 failed to retain any fission products.

$c_{\text {Based on } 1 / 3 E_{\beta}(\max ) \text {. }}$

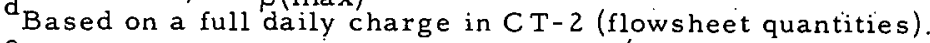

${ }^{e} \mathrm{PuF}_{6}$ decomposed based on $\mathrm{G}=7 \mathrm{~mol} / 100 \mathrm{eV}, 86,400 \mathrm{sec} / \mathrm{d}$, that the re was no recombination of $\mathrm{PuF}_{4}$ and fluorine, that half the total available energy, averaged over a day, is absorbed, and that all energy is absorbed only in $\mathrm{PuF}_{6}$.

The effect of one type of abnormal process operation is illustrated by data in Table 4.13, which shows the result of FP-2 failing to retain fission products, particularly ruthenium and niobium. Decay energy available for decomposition of $\mathrm{PuF}_{6}$ would increase because of the presence of increased amounts of ruthenium and niobium in CT-2 and resulting in an increase in the decomposition rate of $\mathrm{PuF}_{6}$ to $30.8 \mathrm{~kg}(20.8 \mathrm{~kg}$ of plutonium) per day. If only criticality limits are considered; daily refluorination of the deposited. $\mathrm{PuF}_{4}$ appears to be needed.

It should be emphasized that calculations of the decomposition rate of $\mathrm{PuF}_{6}$ are imprecise, being only. estimates. No consideration has been given in these estimates to the formation of lower uranium fluorides by decomposition of $U_{6}$, nor has absorption of decay energy in $U_{6} F_{6}$ been considered. Both $\mathrm{PuF}_{4}$ and fluorine are likely to be present in adequate concentrations so that recombination may occur, reducing the net $\mathrm{PuF}_{6}$ decomposition, but this recombination has been neglected. The decomposition data, believed to be adequately conservative for flowsheet planning, 
must be verified by experimental results under process conditions. Finally, during removal of condensed hexafluorides from CT-2 by liquid transfer to the feed vessel (see Section 4.5.5.1), solid decomposition products could be entrained, resulting in a smaller plutonium residue in CT- 2 than calculated and a greater plutonium inventory in the feed vessel than anticipated.

Solids deposited in CT -2 will be refluorinated at $350^{\circ} \mathrm{C}$ with concentrated $(>90 \%)$ fluorine. It may be desirable to increase the fluorination temperature to as high as $500^{\circ} \mathrm{C}$ to shorten the time required to convert all the $\mathrm{PuF}_{4}$ to $\mathrm{PuF}_{6}$. Competing factors, such as reduction in fluorination time at high temperature compared to the time required to bring the vessel to the high temperature and the design of a vessel for operation at the higher temperatures, would need evaluation in developing an optimum operating scheme. Furthermore, no quantitative consideration has been given to the deposition of fission products by decomposition of volatile fluorides to nonvolatile forms,* although some deposition of nonvolatile fission products can be anticipated. Flowsheet calculations are based on conversion of $\mathrm{PuF}_{4}$ to $\mathrm{PuF}_{6}$ at $350^{\circ} \mathrm{C}$ in $\mathrm{CT}-2$ and transfer of the volatile product(s) to the onstream $\mathrm{CT}-2$ cooled to $-80^{\circ} \mathrm{C}$. Little difficulty has been encountered in the fluorination of $\mathrm{PuF}_{4}$ by elemental fluorine. Hence no further discussion of this operation appears warranted at this time.

4.4.5.4 Recovery of Plutonium from Miscellaneous Gas Streams. Recovery of plutonium from sorbent trap LiF-l requires that the full filuorine stream from CT-2 (stream 15) be routed through the sorbent trap heated to $\sim 450^{\circ} \mathrm{C}$. Calculations indicate that the $\mathrm{PuF}_{6}$ content of the effluent gas stream from LiF-l is no greater than $106 \mathrm{ppm}$ (see Section 4.5). The effluent gas stream, composed primarily of elemental fluorine, is pumped into stage B-2 of fluorination reactor $\mathrm{B}$ held at $550^{\circ} \mathrm{C}$. Since the equilibrium between $\mathrm{PuF}_{4}$, fluorine, and $\mathrm{PuF}_{6}$ at $550^{\circ} \mathrm{C}$ and 1 atm fluorine results in a $\mathrm{PuF}_{6}$ concentration of $1.28 \times 10^{4} \mathrm{ppm}$, no decomposition of the incoming $\mathrm{PuF}_{6}$ in fluorinator $B$ is expected.

Flowsheet calculations call for periodic removal of accumulated fission products from FP-2 by vapor-phase transfer to the fluid-bed NaF sorber in an oxygen stream (stream $12 \mathrm{~W}$ ). No data are available on the reaction of $\mathrm{RuF}_{5}$ or $\mathrm{NbF}_{5}$ with elemental oxygen, and reaction leading to a nonvolatile product is not anticipated.

A small portion of the circulating fluorine stream is to be bled to the gas loop of fluorinator A (stream 17). Except for xenon and krypton, this stream contains only fluorine in significant concentrations. Hence, no reactions important to process operations are expected.

\footnotetext{
* With one exception $\left(\mathrm{XeF}_{4}\right)$, the radiation decomposition of fission-product fluorides has not been documented in the literature.
} 


\subsubsection{Solid Waste Streams}

Two solid wastes are generated in the plutonium fluorination step: the alumina waste from the plutonium fluorinator and the fission-product ruthenium-niobium waste from FP-2. Processing of the latter waste is similar to processing of the $\mathrm{FP}-1$ stream described in Section 4.3.9. The cold trap (FP-2) is warmed, and the fission products are transferred in oxygen to a fluidized bed of $\mathrm{NaF}$ and sorbed. Data on change of heatgeneration rate with time and quantities of fission products in the waste stream are summarized in Fig. 4.8 and Table 4.8.

The alumina, which contains nonvolatile fission products, is discharged from plutonium fluorinator $B$ to waste-storage cylinders. About $1 \mathrm{~kg}$ of fission-product fluorides of the rare-earth elements cerium, cesium, barium, lanthanum, zirconium, and others, plus $10 \mathrm{~kg}$ of alumina are discharged each hour. The fission-product decay heat released by this waste stream is about one-half of all heat released by the fission products in the fuel charge.

Aluminum shot is added to the waste as it is transferred to the storage cylinder to promote the transfer of heat from the center of the cylinder to the walls and thus lower the centerline temperature. This permits the use of 2 -ft-diam cylinders instead of the 5 -in.-diam cylinders required if no aluminum metal is added.

The heat generated by fission-product decay in the fluorinator alumina waste decreases yearly, as shown in Fig. 4.12, until after $8 \mathrm{yr}$ the volumetric heat release has dropped to $2 \mathrm{~W} /$ liter, an allowable value for permanent storage ${ }^{89}$ At storage equilibrium, 402 cylinders are stored in the canal. Data are summarized in Table 4.9 .

\subsection{Plutonium Purification and Separation from $U_{6}$}

\subsubsection{Outline of Process Steps}

This part of the process involves the preparation of $\mathrm{PuF}_{6}$, its separation from $U_{6}$, and its decontamination to the required level (DF of $10^{6}-10^{7}$ ). The inputs (feed streams) to this purification process are (1) the contents of cold traps $\mathrm{CT}-1$ and $\mathrm{CT}-2\left(\mathrm{UF}_{6}\right.$ and $\mathrm{PuF}_{6}$ fluorination products, respectively), which are recombined in one of the feed vessels preparatory to the evaporation and thermal-decomposition steps, and (2) fluorine for converting the $\mathrm{PuF}_{4}$ to $\mathrm{PuF}_{6}$ in thermal decomposer TD- 1 and in LiF sorption trap LiF-1.

The products of this process are purified $\mathrm{PuF}_{6}$, suitable as feed to the converter (see Section 4.7), and contaminated $U F_{6}$; which is fed to still S-1 (see Section 4.6).. The fluorine produced in the thermai decomposition of $\mathrm{PuF}_{6}$ accompanies the $\mathrm{UF}_{6}$ and fission products to the still. The $\mathrm{PuF}_{6}$ recovered from the LiF trap is recycled to the reactor $\mathrm{B}$ loop 
(see Section 4.4.5.4). All the fluorine used in the conversion of $\mathrm{PuF}_{4}$ to $\mathrm{PuF}_{6}$ is recycled, and no waste fluorine is produced. Solids used in the process (e.g., alumina bed material in the thermal decomposer and LiF in sorption trap LiF-1) are reused several times before discharge as waste products.

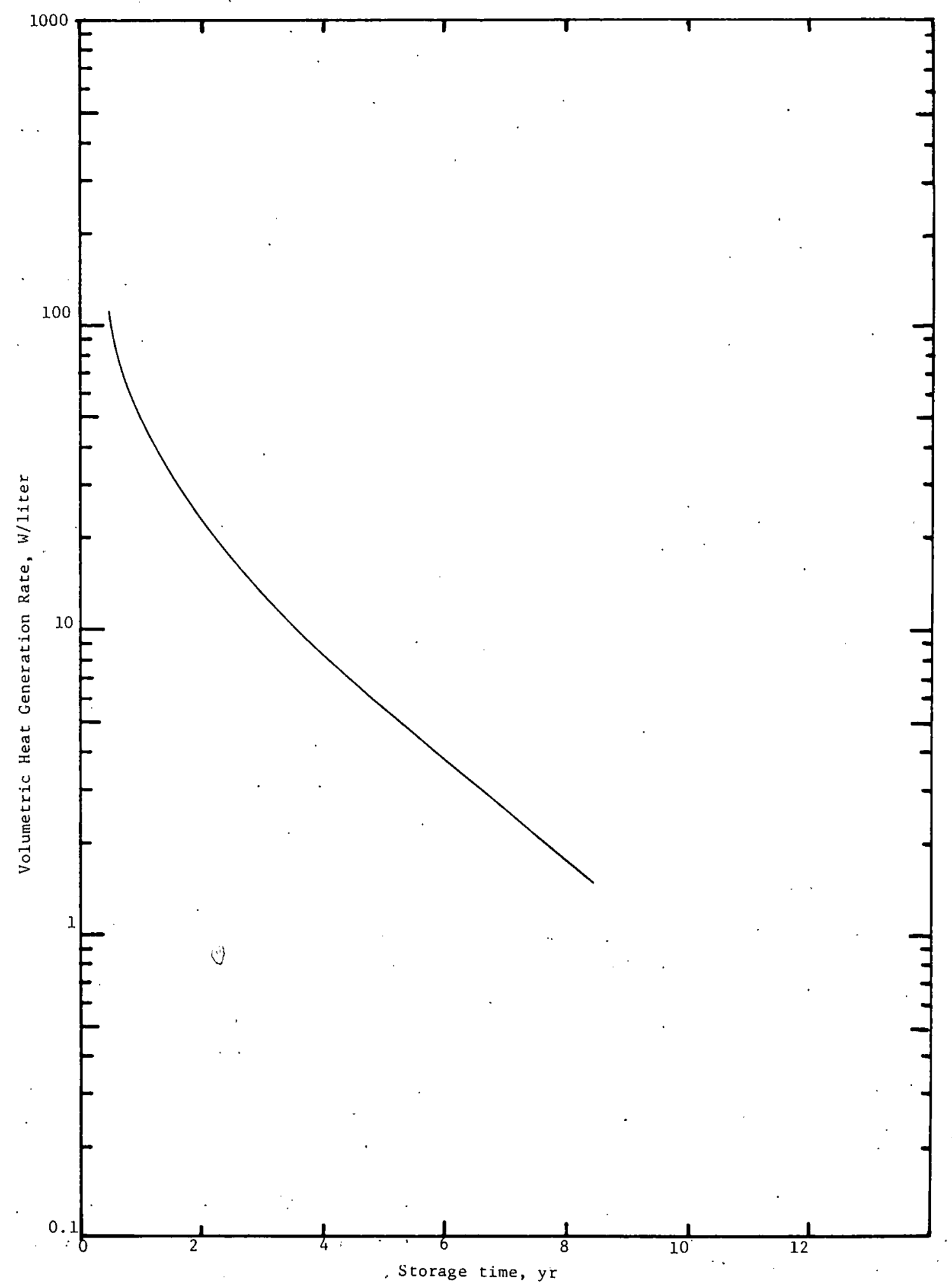

Fig. 4.12. Decrease in Heat-generation Rate with Time for Fluorinator Alumina Waste 
Figure 4.13 shows the major equipment items. Streams are numbered for later reference. To allow continuity of operations, dual units are used as indicated, and sometimes even a third unit is provided as for cold trap CT-3. The entire system operates on a nominal 24-hr cycle, as shown in Fig. 4.14. Cleanup-fluorinations to recover deposits of plutonium resulting from radiation decomposition of the $\mathrm{PuF}_{6}$ to $\mathrm{PuF}_{4}$ are incorporated into the schedule as needed.

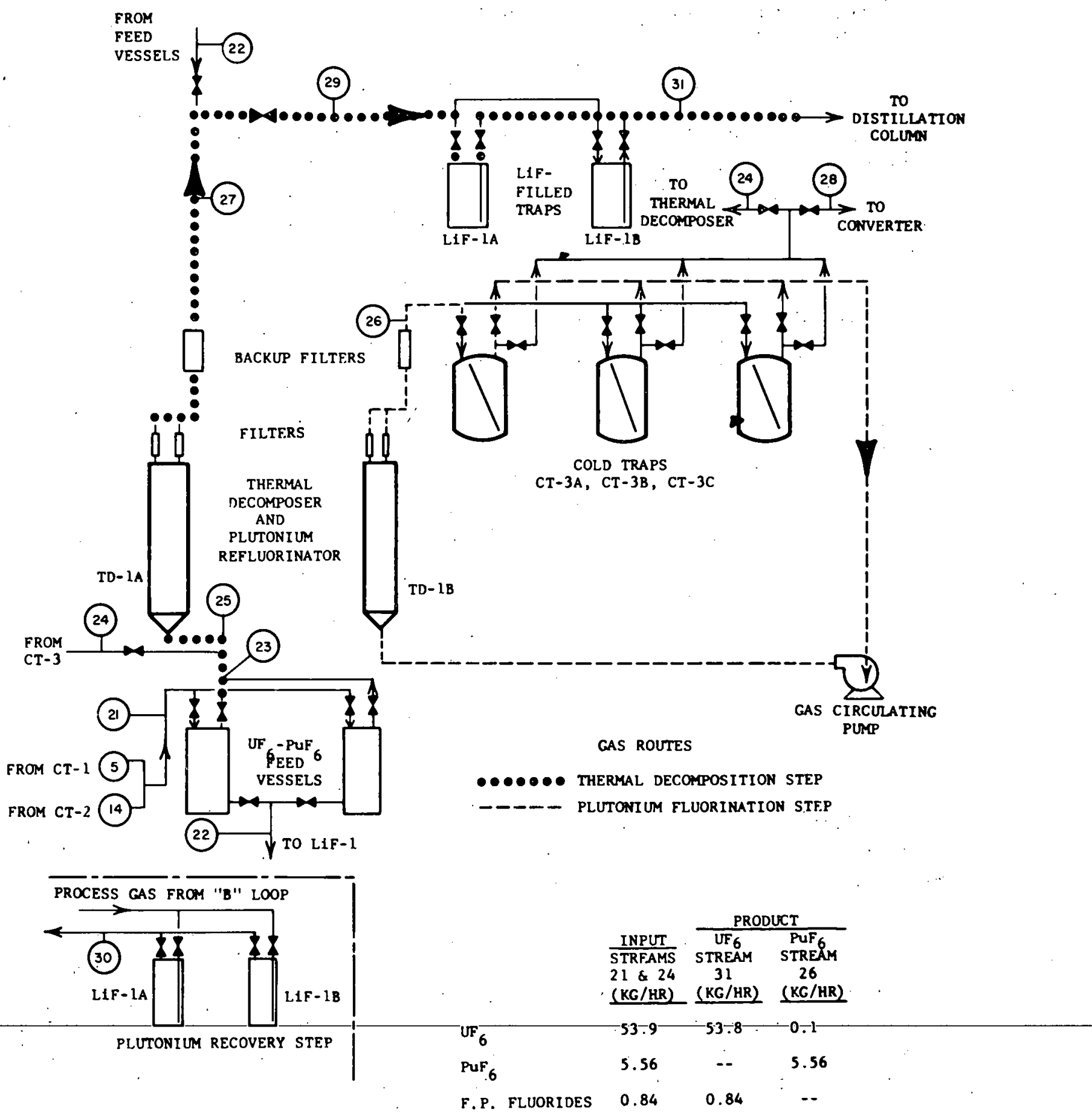

Fig. 4.13. Thermal Decomposer-Plutonium Refluorination System 


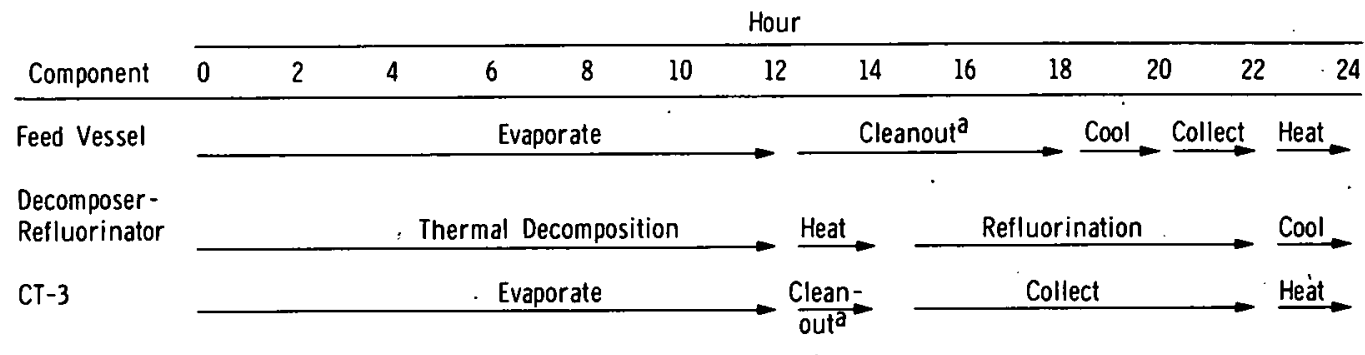

aRefers to removal of heel material idistinct from cleanup-fluorinations, which are scheduled at intervals of several days or several weeks).

Fig. 4.14. Typical Operating Schedule for PuF6 Purification System

Slab shapes are used for all vessels except the LiF traps, because of the criticality limitations with large plutonium inventories. Heat loads, both from chemical reactions and from fission products, are small in these process steps, and heat removal is not a critical design parameter. All. process units are made of nickel.

\subsubsection{Design of Equipment for $\mathrm{PuF}_{6}$ Purification}

4.5.2.1 Feed Vessel. The hexafluorides are transferred from CT-1 and CT -2 to a feed vessel as liquids. The feed vessel serves as a boiler for the $\mathrm{UF}_{6}-\mathrm{PuF}_{6}$ feed to a thermal decomposer; some decontamination of the combined $\mathrm{UF}_{6}-\mathrm{PuF}_{6}$ from high-boiling fission products is provided during this evaporation (single-stage distillation). The feed vessel is required to evaporate a batch of about $711 \mathrm{~kg}$ of $\mathrm{UF}_{6}$ and $P \mathrm{PF}_{6}$ in about $12 \mathrm{hr}$ or at a rate of about $59 \mathrm{~kg} / \mathrm{hr}$. Evaporation is carried out at a temperature $\left(\sim 80^{\circ} \mathrm{C}\right)$ low enough to minimize the thermal decomposition of $\mathrm{PuF}_{6}$ and at about 35 psia.

The decontamination factors ( $D F^{\prime}$ 's) for this evaporation step were calculated using the relationship

$$
\log \left(\mathrm{A} / \mathrm{A}_{0}\right)=\alpha \log \left(\mathrm{B} / \mathrm{B}_{0}\right) \text {, }
$$

where $\alpha$ is the relative volatility of components $A$ and $B$ at the temperature of the distillation, and $A / A_{0}$ and $B / B_{0}$ are the mole ratios of the components related to a base time. The $\mathrm{DF}^{\prime} \mathrm{s}$ are about 100 and 1000 for $\mathrm{NbF}_{5}$ and $\mathrm{RuF}_{5}$, respectively, when $99.9 \%$ of the $\mathrm{UF}_{6}$ is volatilized at $80^{\circ} \mathrm{C}$ (see Section 4.5 .5 .2 ).

The feed vessel is made ready to receive a new batch of hexafluorides by allowing any heel material to flash first through LiF sorption trap LiF-1 to recover volatilized $\mathrm{PuF}_{6}$ and then to $\mathrm{UF}_{6}$ still S-1. After recovery of the heel, residual solids $\left(\mathrm{PuF}_{4}\right.$ and other fluorides) in the feed vessel are recovered and recycled to the fluorinator $B$ loop in a cleanupfluorination operation conducted during an off-period of the cycle. 
The feed vessels are $4 \mathrm{in}$. thick, $4 \mathrm{ft}$ wide, and $5.6 \mathrm{ft}$ tall and are each sized to hold a $12-\mathrm{hr}$ batch of hexafluorides $(\sim 711 \mathrm{~kg})$ when $90 \%$ full. Each vessel is fitted with a reflux condenser, which upgrades its operation as a simple distillation column and provides some purification of the $\mathrm{UF}_{6}$ and $\mathrm{PuF}_{6}$ from higher boiling compounds. Sufficient heaters are provided to heat the units to $500^{\circ} \mathrm{C}$ for the cleanup-fluorination operations. Some means of chilling the vessel appears desirable, even though all normal operations will be performed at temperatures above the triple points of the $\mathrm{UF}_{6}$ and $\mathrm{PuF}_{6}$. As a safety feature, only up-legs are provided.

The vessels will be mounted on scales so that the transfer and evaporation operations can be monitored. Weight data can also be used for control purposes. Weighing will be automatic. Other instrumentation will be conventional.

\subsubsection{Thermal Decomposer-Refluorinators. The thermal} decomposer-refluorinators (TD-1A and - 1B) are fluid-bed units used alternately, first for the thermal decomposition to separate the plutonium as $\mathrm{PuF}_{4}$ from the $\mathrm{PuF}_{6}-\mathrm{UF}_{6}$ feed, and then as a refluorination vessel to recover the plutonium as $\mathrm{PuF}_{6}$. The maximum percentage of the $\mathrm{PuF}_{6}$ that can be decomposed to $\mathrm{PuF}_{4}$ in a single stage is limited by equilibrium considerations. Primarily because earlier work was carried out at $350^{\circ} \mathrm{C}$, this temperature was selected for the reference case. At equilibrium, this temperature gives a separation of $99.6 \%$ (see Section 4.5.5.3).

A rate equation developed by Trevorrow and Steindler ${ }^{90}$ gives the residence times* (Table 4.14) needed to achieve equilibrium at $300-450^{\circ} \mathrm{C}$ for the approximate present feed composition. For the reference tempera-

TABLE 4.14. Gas Residence Times Required to Achieve Equilibrium during Thermal Decomposition of $\mathrm{PuF}_{6}$ to $\mathrm{PuF}_{4}$

Feed: $\sim 9 \mathrm{~mol} \mathrm{\%} \mathrm{PuF}_{6}$ in $\mathrm{UF}_{6}$

\begin{tabular}{cc}
\hline Temp, ${ }^{\circ} \mathrm{C}$ & $\begin{array}{c}\text { Residence Time, } \\
\text { sec }\end{array}$ \\
\hline 300 & 30 \\
350 & 9 \\
400 & 3.4 \\
450 & 1 \\
\hline
\end{tabular}
ture of $350^{\circ} \mathrm{C}$, the thermal decomposer would have to provide a minimum gas residence time of $9 \mathrm{sec}$, and the bed height was chosen accordingly. A relatively fine ( minus 100 mesh) alumina is used as the bed material so that a relatively low gas velocity can be used for fluidization, thereby maximizing gas residence time. For a superficial.gas velocity of $0.1 \mathrm{ft} / \mathrm{sec}$, similar to that used in pilot-plant studies, ${ }^{91}$ the minimum staticbed height should be about i ft.

A quantity $(60 \mathrm{~kg})$ of alumina was used such that the weight ratio of alumina to $\mathrm{PuF}_{4}$ at the end of the $12-\mathrm{hr}$ decomposition period would be $1: 1$. This bed gives a static-bed height of about 15 in.

${ }^{*}$ Residence time $=\frac{\text { static-bed height }}{\text { superficial fluidizing-gas velocity }}$. 
Decontamination factors of 1000 are assumed for all fission products entering with the feed. Decontamination factors of this magnitude were achieved in LWR fuel studies ${ }^{92}$ for ruthenium and molybdenum (presumed present as $\mathrm{RuF}_{5}$ and $\mathrm{MoF}_{6}$ ).

The design of the step involving refluorination of the $\mathrm{PuF}_{4}$ in the thermal decomposer is modeled after the $\mathrm{PuF}_{4}$ fluorination operation in stage $\mathrm{B}-\mathrm{l}$ of reactor $\mathrm{B}$. A temperature of $500^{\circ} \mathrm{C}$ is used with concentrated fluorine which is recycled. A higher pressure than in reactor $B$ is used, $1.9 \mathrm{~atm}$ absolute. A gas velocity of $1 \mathrm{ft} / \mathrm{sec}$ meets the fluorine throughput requirements, which are based on achieving $90 \%$ of equilibrium. The major difference in the two operations is that the fluorination in reactor $B$ is continuous, but this refluorination step is a batch operation.

Pilot-plant results ${ }^{5}$ for the fluorination of $\mathrm{PuF}_{4}$ from an alumina bed showed that fluorine efficiencies remain high as long as the plutonium inventory is large (above 3 wt \%): therefore, the present step was designed accordingly. The bed, with a starting inventory of about $60 \mathrm{~kg}$ of $\mathrm{PuF}_{4}$, is fluorinated until about $2 \mathrm{~kg}$ of $\mathrm{PuF}_{4}$. remain, equivalent to about $3 \mathrm{wt} \%$ of the final bed. Fluorination time is $8 \mathrm{hr}$, the production rate being about $8.1 \mathrm{~kg}$ of $\mathrm{PuF}_{6} / \mathrm{hr}$ [21 lb of $\mathrm{PuF}_{6} /(\mathrm{hr})(\mathrm{sq} \mathrm{ft})$ ]. Removal of $\mathrm{PuF}_{4}$ in each cycle is only $97 \%$, but the quantity remaining with the alumina represents holdup, not loss, since the bed is reused for repeated thermal decomposition-refluorination cycles. If there are indications that plutonium buildup in the bed has occurred with repeated use, an exhaustive (cleanup) fluorination would be scheduled.

The thermal decomposer-refluorinator vessels are slab-shaped fluid-bed reactors, $4 \mathrm{in.} \mathrm{thick,} 31 \mathrm{in.} \mathrm{wide,} \mathrm{and} \mathrm{about} 7 \mathrm{ft}$ tall. Design features such as general mechanical construction and details such as gas distributors, filter requirements, and monitoring and control instrumentation are similar to those selected for the uranium and plutonium fluorination reactors (see Sections 4.3.3, 4.3.5, and 4.4.2). Heaters are required for operations at 350 and $500^{\circ} \mathrm{C}$ (thermal decomposition and refluorination steps, respectively). A chilled-air cooling system will be provided to expedite the shift in operation from the higher to the lower temperature. Associated piping manifolds and valving will provide automatic admission of hexafluorides from the feed vessel during decomposition or admission of fluorine for the refluorination step. Fluorine will be used as the filter blowback gas.

4.5.2.3 Cold Trap CT-3. Several cold traps are required for collection of the $\mathrm{PuF}_{6}$ produced by refluorination of the $\mathrm{PuF}_{4}$ in $\mathrm{TD}-1$. These traps (designated CT-3 in Fig. 4.13) serve a dual function: as evaporators, providing feed to the converter, and at the same time effecting additional decontamination of the $\mathrm{PuF}_{6}$ from high boiling fission products. These units have the same general design basis as those used in conjunction with fluorinator $B$, except that heat generation in these units is lower because of negligible residual fission-product activity. 
Nominal operating conditions are $-80^{\circ} \mathrm{C}$ and about 30 psia during collection periods, and $80^{\circ} \mathrm{C}$ and about $35 \mathrm{psia}$ when the units are used as evaporators. The units must also be capable of being heated to $500^{\circ} \mathrm{C}$ for cleanup-fluorination operations.

The cold traps operate semicontinuously, one being on-stream for a given operation at a given time (i.e., one receiving $\mathrm{PuF}_{6}$ from $\mathrm{TD}-\mathrm{l}$ ) while a second cold trap feeds $\mathrm{PuF}_{6}$ to the converter, and so on. Three units are used in all. Cycle time requires $8 \mathrm{hr}$ for collection of $\mathrm{PuF}_{6}, 2 \mathrm{hr}$ for heatup to the evaporation temperature, $12 \mathrm{hr}$ for the evaporation step, and a period for heel cleanout. Cleanup-fluorinations have to be fitted into the schedule from time to time.

The evaporation step, being part of the converter operation, is conducted in a cyclic fashion, $1 \mathrm{hr}$ of evaporating $\mathrm{PuF}_{6}$ overhead, followed by $\mathrm{l} \mathrm{hr}$ with the cold trap in a stand-by state. The $\mathrm{PuF}_{6}$ evaporation rate is about $6.2 \mathrm{~kg} / \mathrm{hr}$ during the on-period. The procedure is automatic and represents no particular control problem. The $\mathrm{PuF}_{6}$ is decontaminated during the evaporation step by volatilizing only $90 \%$ of the trap contents. The $10 \%$ heel is flashed out of the cold trap and recycled to the on-line TD-1.

Cold traps CT-3 are slabs which have the nominal dimensions $4 \mathrm{in.} \mathrm{by} 24 \mathrm{in.} \mathrm{by} 3 \mathrm{ft}$. Three units in parallel are required to accommodate the collecting and discharging sequence of operations.

4.5.2.4 Sorption Trap LiF-1. Sorption of $\mathrm{PuF}_{6}$ on $\mathrm{LiF}_{\mathrm{F}}$ is used to recover (a) undecomposed $\mathrm{PuF}_{6}$ from the overhead $\mathrm{UF}_{6}$ stream from the thermal decomposer and (b) residual $\mathrm{PuF}_{6}$ in the heel of the thermaldecomposer feed vessel. With a bed of low-surface-area LiF, 95\% or more of the $\mathrm{PuF}_{6}$ fed is recovered. Sorption is at $300^{\circ} \mathrm{C}$; recovery with concentrated fluorine is at $450^{\circ} \mathrm{C}$. Some ruthenium remains fixed on the LiF after treatment with fluorine, and replacement of trap LiF-l as a unit would be required occasionally.

If the reaction $\mathrm{PuF}_{6}+4 \mathrm{LiF} \rightleftharpoons(4 \mathrm{LiF}) \cdot \mathrm{PuF}_{4}+\mathrm{F}_{2}$ is assumed to be the basis for complexing of. $\mathrm{PuF}_{6}$, the fluorine requirement will be about equivalent to that normally used in the reactor $\mathrm{B}\left(\mathrm{PuF}_{6}\right.$ fluorinator) loop, assuming that $90 \%$ of equilibrium is achieved. Approximately $30 \mathrm{scfm}$ of fluorine (the same feed rate as in reactor $B$ loop) will be used in the regeneration step, and the recovered $\mathrm{PuF}_{6}$ will be recycled to reactor $\mathrm{B}$. Trap cycle time is shown in Table 4.15. Dual traps are used, as shown in Fig. 4.13, one being on-stream with the thermal decomposer, while plutonium is being removed from the other.

The LiF sorption traps are packed-bed units, 10 in. in diameter and $3.5 \mathrm{ft}$ tall, and are of nickel construction. They are of relatively simple construction because in the referençe design concept a trap will be discarded as a unit as waste, albeit after repeated cycles. 
TABLE 4.15. Specifications for Trap LiF-1

Size: $\quad 10-$ in. diameter by $3.5 \mathrm{ft}$

LiF sorbent: Low-surface-area material, $\sim 2 \mathrm{~m}^{2} / \mathrm{g} ; 45 \mathrm{~kg}$

\begin{tabular}{llll}
\hline \multicolumn{2}{c}{ Loading Step } & \multicolumn{2}{c}{ Regeneration Step } \\
\hline Operating temp: & $300^{\circ} \mathrm{C}$ & Operating temp: & $450^{\circ} \mathrm{C}$ \\
PuF 6 load: & $2.8 \mathrm{~kg}$ & Fluorine rate: & $\sim 30 \mathrm{scfm}$ \\
Loading time: & $2 \mathrm{days}$ & Regeneration time: $\sim 1.6$ days \\
Gas flowrate: & $2 \mathrm{scfm}$ & & \\
Gas residence time: & $4 \mathrm{sec}$ & & \\
\hline
\end{tabular}

\subsubsection{Process Instrumentation}

Instrumentation for the fluid-bed units and the cold traps is similar to that described in Section 4.3.5. The packed-bed units (LiF traps) require differential pressure monitoring to indicate any tendency toward plugging. Temperature control is automated. Alarm levels will be established to alert operators to an off-specification situation wherein switching to a parallel unit may be carried out. The evaporation operations present no unique problems.

Monitors to indicate residual levels of plutonium may be desirable; neutron survey meters may find application here. As indicated earlier, weighing will be used both for monitoring and for control purposes. Weighing systems using load cells are commercially available, but may require adaptation because of the radiation environments.

\subsubsection{Material Balance}

Stream compositions and inventories pertinent to the $\mathrm{PuF}_{6}$ purification process are summarized in Tables 4.16 and 4.17 .

4.5.5 Physical and Chemical Processes in Purification of $\mathrm{PuF}_{6}$

Different types of operations are carried out to purify $\mathrm{PuF}_{6}$, each requiring satisfactory completion of a chemical or physical process. The bases for the various operations are discussed in the order in which process streams are treated.

4.5.5.1 Transfer of Condensate from CT-1 and CT-2 to Feed Vessel. Solid fluorides retained in CT-l and CT-2 at $-80^{\circ} \mathrm{C}$ are warmed until they become liquid and are drained from the cold traps into a common receiver, which serves as the feed vessel for the thermal-decomposition step. The bulk of the contents of $\mathrm{CT}-1$ is $\mathrm{UF}_{6}$, and the triple point of $\mathrm{UF}_{6}\left(64^{\circ} \mathrm{C}\right)$ may not need to be significantly exceeded to effect complete removal of the 
fluorides. Molten uranium hexafluoride should serve as an excellent solvent for the other hexafluorides such as $\mathrm{PuF}_{6}, \mathrm{NpF}_{6}, \mathrm{MoF}_{6}, \mathrm{~T} . \mathrm{F}_{6}$, and $\mathrm{TeF} \mathrm{F}_{6}$. These hexafluorides are volatile covalent compounds and are present in CT-l in low concentrations (less than 1 wt $\%$ ). The other volatile fission-product fluorides $\left(\mathrm{NbF}_{5}, \mathrm{RuF}_{5}, \mathrm{SbF}_{5}, \mathrm{IF}_{5}, \mathrm{XeF}_{4}\right.$, and $\left.{ }^{3} \mathrm{HF}\right)$ are also covalent compounds present in very low concentrations: less than 0.2 wt \%, except for $\mathrm{XeF}_{4}$ $(\sim 0.7$ wt \%). Few solubility data exist for any pertinent solutes in liquid $\mathrm{UF}_{6}{ }^{*}$ * hence complete solubility of all volatile fluorides in $\mathrm{UF}_{6}$ is assumed. A similar assumption, but for the solvent $\mathrm{PuF}_{6}$, is made concerning the contents of $\mathrm{CT}-2$. The presence of fluoride species other than those listed is not expected to change the bases of the assumptions. Table 4.18 shows. the daily charge to the feed vessel.

TABLE 4.16. Material Balance for Puf6 Purification Equipment (see Fig. 4.13)

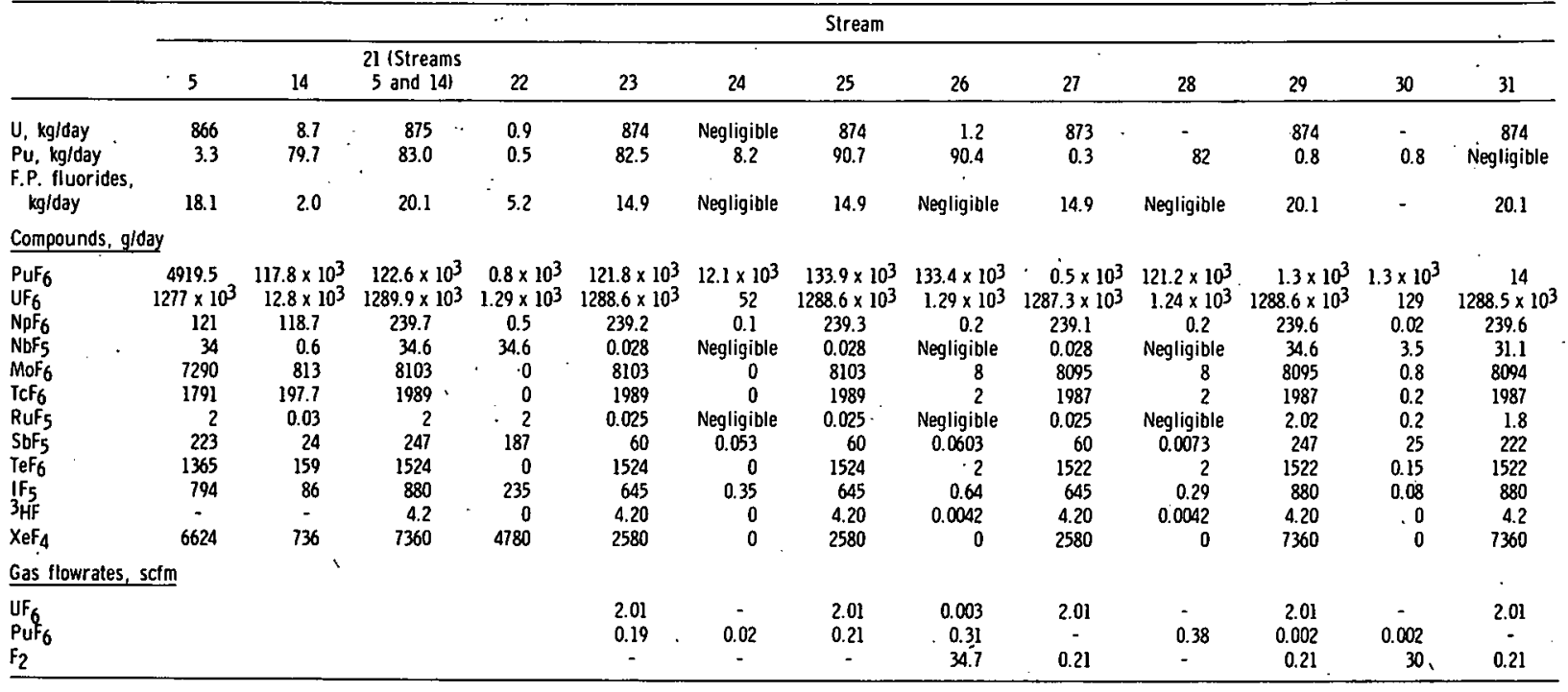

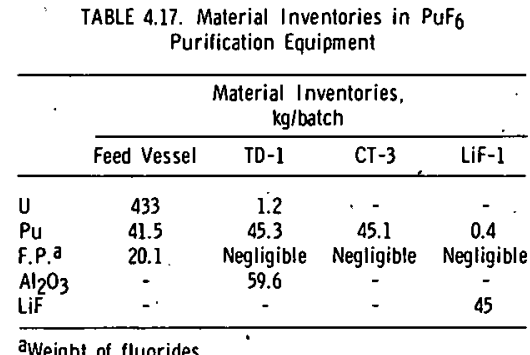

\begin{tabular}{|c|c|c|c|c|c|c|c|}
\hline & \multicolumn{3}{|c|}{$\begin{array}{c}\text { Material Charged, } \\
\text { kg/day }\end{array}$} & & \multicolumn{3}{|c|}{$\begin{array}{c}\text { Material Charged, } \\
\text { kg/day }\end{array}$} \\
\hline & $\begin{array}{l}\text { From CT-1, } \\
\text { Stream } 5\end{array}$ & $\begin{array}{l}\text { From CI-2, } \\
\text { Stream } 14\end{array}$ & $\begin{array}{c}\text { Total. } \\
\text { Stream } 21\end{array}$ & & $\begin{array}{l}\text { From CT-1, } \\
\text { Stream } 5\end{array}$ & $\begin{array}{l}\text { From CT-2, } \\
\text { Stream } 14\end{array}$ & $\begin{array}{l}\text { Total, } \\
\text { Stream } 21\end{array}$ \\
\hline $\begin{array}{l}\mathrm{UF}_{6} \\
\mathrm{PuF}_{6} \\
\mathrm{NpF}_{6} \\
\mathrm{NbF}_{5} \\
\mathrm{MoF}_{6} \\
\cdot \mathrm{IcF}_{6}\end{array}$ & $\begin{array}{l}1277 \\
4.9195 \\
0.121 \\
0.034 \\
7.290 \\
1.791\end{array}$ & $\begin{array}{l}12.8 \\
117.8 \\
0.1187 \\
0.0006 \\
0.813 \\
0.1977\end{array}$ & $\begin{array}{l}1289.8 \\
122.7 \\
0.2397 \\
0.0346 \\
8.103 \\
1.9887\end{array}$ & $\begin{array}{l}\mathrm{RuF}_{5} \\
\mathrm{SbF}_{5} \\
\mathrm{TeF}_{6} \\
\mathrm{IF}_{5} \\
\mathrm{XeF}_{4} \\
{ }^{3} \mathrm{HF}\end{array}$ & $\begin{array}{l}0.002 \\
0.223 \\
1.365 \\
0.794 \\
6.624 \\
0.004\end{array}$ & $\begin{array}{l}0.00003 \\
0.024 \\
0.159 \\
0.086 \\
0.736 \\
.\end{array}$ & $\begin{array}{l}0.00203 \\
0.247 \\
1.524 \\
0.880 \\
7.360 \\
0.004\end{array}$ \\
\hline
\end{tabular}

Products of the radiolytic decomposition of fluorides in $\mathrm{CT}-\mathrm{l}$ and CT-2 are likely to be nonvolatile lower fluorides of plutonium (e.g., PuF 4 ), uranium $\left(\mathrm{UF}_{4}, \mathrm{U}_{2} \mathrm{~F}_{9}, \mathrm{U}_{4} \mathrm{~F}_{17}\right.$, and $\left.\mathrm{UF}_{5}\right)$, neptunium $\left(\mathrm{NpF}_{4}\right)$, and fission products . No products of radiolytic-decomposition-othe-r-than-Pu-F-and-the-lower_fluorides of uranium have been identified. However, nonvolatile lower fluorides,

${ }^{*}$ Molybdenum hexafluoride is completely miscible with $\mathrm{UF}_{6}$ at $80^{\circ} \mathrm{C}, 93$ and $\mathrm{HF}$ is miscible with $\mathrm{UF}_{6}$ up to $\approx 2.5 \mathrm{wt} \% \mathrm{HF}$ at $80^{\circ} \mathrm{C} .94$ 
which are likely to be ionic compounds, are expected to be rather insoluble in $\mathrm{UF}_{6}$ or $\mathrm{PuF}_{6} \cdot{ }^{95 *}$ It is likely, therefore, that $\mathrm{CT}-1$ (and $\mathrm{CT}-2$ ) will contain a solid phase consisting of insoluble fluorides as well as a liquid $\mathrm{UF}_{6}$ (or $\mathrm{PuF}_{6}$ ) phase containing dissolved fluorides. Liquid transfer of hexafluoride from CT-1 or CT-2 may, therefore, result in the entrainment of finely divided solids, which will constitute a solid phase in the feed vessel.

Although partition of solids between $\mathrm{CT}-\mathrm{l}$ and the feed vessel appears likely, the exact distribution will largely be determined by as-yet-undefined engineering design features of the plant equipment. No reduction in either fission product or actinide content due to radiolytic decomposition is assumed in flowsheet calculations, although such decomposition is recognized in preceding discussions of $\mathrm{PuF}_{4}$ deposition rates and clean-out schedules.

\subsubsection{Fission-product Behavior and Radiation Decomposition in}

Feed Vessel. Fluorides collected in the feed vessel are transferred to the thermal decomposer in a single-stage distillation step at $80^{\circ} \mathrm{C}$, which produces a heel containing $\sim 1.3 \mathrm{~kg}$ of $\mathrm{UF}_{6}$. The separation (decontamination) effected in this distillation was calculated using the relation

$$
\log \left(A / A_{0}\right)=\alpha \log \left(B / B_{0}\right)
$$

(These symbols are defined in Section 4.5.2.1.) The data in Table 4.19 represent the fission-product species potentially present in the feed-vessel mixture and indicate that distillation of $99.9 \%$ of the U.F 6 would result in significant decontamination of the hexafluorides from niobium and ruthenium (as $\mathrm{NbF}_{5}$ and $\mathrm{RuF}_{5}$ ). On the other hand, no decontamination can be expected from ${ }^{3} \mathrm{H}$, molybdenum (as $\mathrm{MoF}_{6}$ ), technetium (as $\mathrm{T} c \mathrm{~F}_{6}$ ), tellurium, and iodine (as $\mathrm{IF}_{7}$ or $\mathrm{IOF}_{5}$ ). If ruthenium is present as $\mathrm{RuF}_{6}$, most of that species will accompany the actinide hexafluoride stream.

TABLE 4.19. Separations Effected by Single-stage Distillation from Feed Vessel

\begin{tabular}{|c|c|c|c|c|c|c|c|c|c|c|c|}
\hline & $\begin{array}{l}\text { Vapor Pressure } \\
\text { at } 80^{\circ} \mathrm{C} \text {, } \\
\mathrm{mm} \mathrm{Hg}\end{array}$ & $a^{a}$ & $A / A_{0}$ & $\begin{array}{c}\text { Percent } \\
\text { Volatilized }\end{array}$ & $\begin{array}{l}\text { Decontamination } \\
\text { Factorb }\end{array}$ & & $\begin{array}{c}\text { Vapor Pressure } \\
\text { at } 80^{\circ} \mathrm{C} \text {. } \\
\mathrm{mm} \mathrm{Hg}\end{array}$ & $a^{a}$ & $A / A_{0}$ & $\begin{array}{l}\text { Percent } \\
\text { Volatilized }\end{array}$ & $\begin{array}{c}\text { Decontamination } \\
\text { Factor }^{b}\end{array}$ \\
\hline $\mathrm{UF}_{6}$ & 1840 & 1.40 & 0.001 & 99.9 & -1 & RuF5 & 0.21 & 0.00016 & 0.9993 & 0.07 & 1430 \\
\hline $\mathrm{PuF}_{6}$ & 1315 & 1.00 & 0.007 & 99.3 & $\sim 1$ & $\mathrm{RuOF}_{4}$ & 13.8 & 0.010 & 0.9516 & 4.84 & 20.7 \\
\hline $\mathrm{NpF}_{6}$ & 1652 & 1.26 & 0.002 & 99.8 & $\sim 1$ & $\mathrm{RuF}_{6}$ & $1000 \mathrm{C}$ & 0.76 & 0.0230 & 97.7 & $\sim 1$ \\
\hline $3 \mathrm{HF}$ & 4600 & 3.5 & $\sim 0$ & -100 & $\sim 1$ & $\mathrm{SbF}_{5}$ & 74.6 & 0.057 & 0.7536 & 24.6 & 4.1 \\
\hline $\mathrm{NbF}_{5}$ & 3.33 & 0.0025 & 0.9876 & 1.24 & 80.6 & TeF $_{6}$ & $1.96 \times 10^{4}$ & 14.9 & $\sim 0$ & 100 & $\sim 1$ \\
\hline $\mathrm{MoF}_{6}$ & 3303 & 2.51 & $\sim 0$ & $\sim 100$ & $\sim 1$ & $\mathrm{IF}_{5}$ & 351.3 & 0.27 & 0.262 & 73.8 & 1.35 \\
\hline $\mathrm{MoOF}_{4}$ & 13.44 & 0.010 & 0.9516 & 4.84 & 20.7 & $\mathrm{IF}_{7}$ & 6900 & 5.25 & $\sim 0$ & 100 & -1 \\
\hline $\mathrm{TcF}_{6}$ & 1628 & 1.24 & 0.0021 & $\sim 100$ & $\sim 1$ & $10 F_{5}$ & $1.9 \times 10^{4}$ & 14.4 & $\sim 0$ & 100 & $\sim 1$ \\
\hline $\mathrm{TCOF}_{4}$ & $<136$ & $<0.01$ & $<0.95$ & $<4.8$ & $>21$ & $\mathrm{XeF}_{4}$ & 114.7 & 0.087 & 0.6494 & 35.1 & 2.85 \\
\hline $\mathrm{TCO}_{3} \mathrm{~F}$ & 370 & 0.28 & 0.249 & 75.1 & 1.3 & $\mathrm{XeF}_{2}$ & 145.9 & 0.11 & 0.5794 & 42.1 & 2.37 \\
\hline
\end{tabular}

aRelative volatility at $80^{\circ} \mathrm{C}$, compared to volatility of $\mathrm{PuF}_{6}$ at $80^{\circ} \mathrm{C}$.

bDecontamination factor $=100 / p e r c e n t$ volatilized.

CEstimated.

${ }^{*}$ Calculations were made using Hildebrand's equations on the ideal solubility of $\mathrm{UF}_{4}$ and $\mathrm{ThF}_{4}$ in $\mathrm{UF}_{6}$, since pertinent data for $\mathrm{PuF}_{4}$ (heat of melting) were not available. Results varied from 100 to $10^{-2} \mathrm{ppm}$.

W. R. Golliher of Union Carbide Nuclear Company, Paducah, Kentucky, indicated (in a private communication) that on the basis of preliminary data, the solubility of $\mathrm{PuF}_{4}$ in $\mathrm{UF}_{6}$ at $100^{\circ} \mathrm{C}$ is $<3 \mathrm{ppm}$. 
The liquid contents of the feed vessel include a significant amount of $\beta .-\gamma$ active fission products as well as $\dot{\alpha}$-active plutonium.* On the basis of previously discussed decomposition rates of $\mathrm{PuF}_{6}$ due to alpha particle radiolysis (see Sections 4.3.8.3 and 4.4.9.3), approximately $3.6 \mathrm{~kg}$ of $\mathrm{PuF}_{6}$ $(\sim 3 \%)$ will decompose in the feed vessels per day, or $\sim 1.8 \mathrm{~kg}$ of $\mathrm{PuF}_{6}$ will decompose in each of two feed vessels. Cleanout rates of the deposited $\mathrm{PuF}_{4}$ will be governed by criticality limitations, and cleanup can be expected to be necessary about. once every operating week.

The fission products in the input streams to the feed vessel include fission products which, by $\beta-\gamma$ decay, cause decomposition of $\mathrm{PuF}_{6}$ and other fluorides. On the basis of the assumptions listed in footnote $c$ of Table 4.20, approximately $15 \mathrm{~kg}$ of $\mathrm{PuF}_{6}$ will decompose daily to $\mathrm{PuF}_{4}$ in the feed vessel. The $\mathrm{PuF}_{4}$, which is insoluble in the liquid hexafluorides, will remain in the feed vessel after flash evaporation of the feed vessel heel and will require periodic fluorination to avoid exceeding the criticality limi-

I tations for the feed vessel. No deposition of uranium or fission-product compounds has been assumed, even though small quantities of these elements will probably be part of the solid,residue in the feed vessel.

TABLE 4.20. Energy Evolution from Fission Products in Feed Vessela

\begin{tabular}{lccc}
\hline & \multicolumn{3}{c}{ Energy, $10^{19} \mathrm{eV} / \mathrm{sec}$} \\
\cline { 2 - 4 } & $\beta^{\mathrm{b}}$ & $10 \% \gamma$ & Total \\
\hline${ }^{3} \mathrm{HF}$ & 4.7 & - & 4.7 \\
$\mathrm{NbF}_{5}$ & 120 & 17.9 & 13.7 .9 \\
$\mathrm{MoF}_{6}$ & 1.27 & 0.0813 & 1.35 \\
$\mathrm{TcF}_{6}$ & $6.6 \times 10^{-3}$ & $1.9 \times 10^{-3}$ & $8.5 \times 10^{-3}$ \\
$\mathrm{RuF}_{5}$ & 4.1 & 0.13 & 4.23 \\
$\mathrm{SbF}_{5}$ & 36.3 & 16.3 & 52.6 \\
$\mathrm{TeF}_{6}$ & 4.0 & 4.3 & 8.3 \\
$\mathrm{IF}_{5}$ & 160. & 32 & 192 \\
$\mathrm{XeF}_{4}$ & 32.5 & 2.5 & 35.0 \\
$\mathrm{Total}$ & & & 436.1 \\
PuF & decomposed, ${ }^{\mathrm{c}} \mathrm{kg} / \mathrm{day}$ & & 15.4 \\
\hline
\end{tabular}

a Based on the sum of streams 5 and 14 to the feed vessel, using the flowsheet quantities of fission products.

$\mathrm{b}_{\text {Based on } 1 / 3 \mathrm{E}_{\beta} \text { (max). }}$.

${ }^{c}$ Plutonium decomposed based on $\mathrm{G}=7 \mathrm{~mol} / 100 \mathrm{eV}$, $86,400 \mathrm{sec} / \mathrm{day}$; assumes that all energy is dissipated in ' $\mathrm{PuF}_{6}$ and that $100 \%$ of the' energy is available over a day, since collection time in the feed is short ( $2 \mathrm{hr}$ ).

* The alpha activity of ${ }^{237} \mathrm{~Np}$ is neglected. 
4 4.5.5.3 Thermal Decomposition of $\mathrm{PuF}_{6}$ in $\mathrm{TD}-1$. The primary process in $\mathrm{TD}-1$ is the decomposition of $\mathrm{PuF}_{6}$ according to the equation

$$
\mathrm{PuF}_{6}(\mathrm{~g}) \rightarrow \mathrm{PuF}_{4}(\mathrm{~s})+\mathrm{F}_{2}(\mathrm{~g}), \Delta \mathrm{H}_{600 \mathrm{~K}}=-5.78 \mathrm{kcal} / \mathrm{mole}
$$

The equilibrium for the above reaction is such that at $350^{\circ} \mathrm{C}$, $\mathrm{K}_{\mathrm{eq}}=\mathrm{PuF}_{6} / \mathrm{F}_{2}=0.0039$. The decomposition temperature of $350^{\circ} \mathrm{C}$ was chosen on the basis of experience and not on the basis of optimum process operations. Decomposition of $\mathrm{PuF}_{6}$ at $500^{\circ} \mathrm{C} \mathrm{r}$ ather than at $350^{\circ} \mathrm{C}$ would, for example, allow rapid establishment of equilibrium and would reduce the heat-up and cooling times required for TD-1 (see Section 4.5.1). On the other hand, larger quantities of $\mathrm{PuF}_{6}$ would accumulate in and need to be removed from the LiF-l trap because of the less favorable equilibrium at $500^{\circ} \mathrm{C}$.

The input to the thermal decomposer contains little or no elemental fluorine, while the effluent from TD-l (assumed to be at equilibrium at $350^{\circ} \mathrm{C}$ ) will contain small amounts of $\mathrm{PuF}_{6}$, unreacted $\mathrm{UF}_{6}$ and fission products, and elemental fluorine from the decomposition. A rate equation has been empirically developed ${ }^{90}$ which relates the rate of decomposition of $\mathrm{PuF}_{6}$ to the ratio of $\mathrm{PuF}_{6}$ to fluorine as a function of time.

In addition, experimental data are available on the decomposition of $\mathrm{PuF}_{6}$ in mixtures with $\mathrm{UF}_{6}$. These data indicate that a separation of $99.6 \%$ of the plutonium could be obtained at $350^{\circ} \mathrm{C}$ and that adequate rates of decomposition should be obtained. The rate of decomposition is enhanced by the presence of $\mathrm{PuF}_{4}$ in the fluid-bed decomposer, since the reaction appears to proceed by both a homogeneous (gas phase) mechanism and a heterogeneous mechanism. ${ }^{62}$.

Uranium hexafluoride is thermodynamically stable to thermal decomposition at $350^{\circ} \mathrm{C}$. Experimental results indicate, ${ }^{96}$ however, that small amounts of uranium are found in the deposited $\mathrm{PuF}_{4}$, and the flowsheet calculations are made on the assumption that $0.1 \%$ of the $\mathrm{UF}_{6}$ remains in $\mathrm{TD}-1$. The presence of small ( 1 wt \%) amounts of uranium in the plutonium that is used to refabricate mixed oxide fuel material is of no process concern, since additional $\mathrm{UF}_{6}$ is eventually added. More extensive purification of $\mathrm{PuF}_{6}$ is possible by staging the decomposition-refluorination process. Neptunium hexafluoride also appears to be stable (based on results of experiments in which a mixture of $\mathrm{PuF}_{6}$ with $\mathrm{NpF}_{6}$ was thermally decomposed). ${ }^{97}$

Few of the fission-product fluorides anticipated in the feed stream to the thermal decomposer are expected to decompose to nonvolatile species. The stability of the volatile form of fission-product fluorides is expected to be enhanced because of the presence of elemental fluorine formed by decomposition of $\mathrm{PuF}_{6}$. Decomposition of xenon fluorides to elemental xenon in 
the presence of fluorine is unlikely...Elemental iodine formed by the decomposition of iodine fluorides. should distill from the thermal decomposer and remain in the $\mathrm{UF}_{6}$ stream.

Information regarding the thermodynamic stability of $\mathrm{IOF}_{5}$ and $\mathrm{IF}_{7}$ is lacking, but several generalizations can be made. Thermal decomposition of $\mathrm{IF}_{7}$ to $\mathrm{IF}_{5}$ and $\mathrm{F}_{2}$ results in no significant reduction in the volatility of iodine; hence contamination of $\mathrm{PuF}_{4}$ by iodine is not expected to increase, because of the thermal decomposition of $\mathrm{IF}_{7}$. The presence of added elemental fluorine from the decomposition of $\mathrm{IF}_{7}$ is not expected to alter the efficiency of the thermal decomposition of $\mathrm{PuF}_{6}$ by a significant amount. The fluorination of $\mathrm{PuF}_{4}$ to $\mathrm{PuF}_{6}$ by $\mathrm{IF}_{7}$ is thermodynamically unfavorable $\left(\triangle \mathrm{G}_{600 \mathrm{~K}}^{\circ}=\sim 7 \mathrm{kcal} / \mathrm{mole}\right)$ * $^{*}$ Decomposition of $\mathrm{IOF}_{5}$ to $\mathrm{IF}_{5}$ and oxygen is similar to the $\mathrm{IF}_{7} \rightarrow \mathrm{IF}_{5}$ decomposition, and no change in decontamination of $\mathrm{PuF}_{6}$ is expected. Iodine oxides, although potential products of the decomposition of $\mathrm{IOF}_{5}$ (viz., IOF $\mathrm{IO}_{5} \rightarrow \mathrm{I}_{2} \mathrm{O}_{4}, \mathrm{I}_{2} \mathrm{O}_{5}, \mathrm{I}_{4} \mathrm{O}_{9}+[\mathrm{F}]$ ) are all unstable at the temperature of $\mathrm{TD}-1 .{ }^{97 \mathrm{a}}$ Other iodine oxyfluorides (e.g., $\mathrm{IO}_{2} \mathrm{~F}$ and $\mathrm{IO}_{3} \mathrm{~F}$ ) which may be considered as possible decomposition products of $I_{0} F_{5}$ are also not stable at the temperature of TD-l and produce oxygen and iodine.

No thermodynamic data on $\mathrm{NbF}_{3}$ are available, but $\mathrm{NbF}_{5}$ appears to be a stable species at $350^{\circ} \mathrm{C}$. The thermal decomposition of $\mathrm{RuF}_{5}$ to $\mathrm{RuF}_{3}$ is estimated to have a high; positive free-energy change and is not expected to proceed. Ruthenium hexafluoride is unstable at $200^{\circ} \mathrm{C}$ and decomposes to $\mathrm{RuF}_{5}$ and fluorine. Other fluorides such as $\mathrm{MoF}_{6}, \mathrm{TcF}_{6}, \mathrm{SbF}_{5}$, and $\mathrm{TeF}_{6}$ all appear to be stable at $350^{\circ} \mathrm{C}$, based on estimates of the free energies of formation of the parent compound and the most stable.lower fluoride. No data are available on fission product oxyfluorides, and all such compounds are assumed to be stable at $350^{\circ} \mathrm{C}$ in the $\mathrm{UF}_{6}-\mathrm{F}_{2}$ stream effluent from $\mathrm{TD}-1$. Chromium fluorides, present in the feed stream, are also assumed stable at $350^{\circ} \mathrm{C}$. Stability data are summarized in Table 4.21.. The magnitude of the stability constants would indicate that very high decontamination factors should be obtainable in the thermal-decomposition step. Deposition of fission products on $\mathrm{PuF}_{4}$ by mechanisms other than thermal decomposition (e.g., corrosion reactions and surface effects) is possible; hence, decontamination factors less than theoretical are likely and have been assumed.

Few experimental data on the purification of $\mathrm{PuF}_{6}$ by thermal decomposition exist. Workers at $\mathrm{ANL}^{92}$ processed $\sim 52 \mathrm{~g}$ of $\mathrm{PuF}_{6}$ in $20 \mathrm{~kg}$ of $\mathrm{UF}_{6}-\mathrm{PuF}_{6}$ through an alumina-filled fluid-bed thermal decomposer at $300 .-350^{\circ} \mathrm{C}$ and observed a D.E for ruthenium of $10^{3}$ to $10^{4}$. In work ${ }^{30}$ with long-cooled irradiated $\mathrm{UO}_{2}$, in which $\mathrm{PuF}_{6}$ containing ruthenium was sublimed-from-a-col-d-trap-a.t-0G-th-rough-al-umin-a-at $3.00^{\circ} \mathrm{G}$,-the-decontamination factors obtained varied from 1 to 4 . The reasons for the difference in these

*Estimated from data in F. L. Oetting, Chem。 Rev. 67,261 (1967) and recalculated data for $\mathrm{IF}_{5}$ and $\mathrm{IF}_{7}$. based on recent calorimetry experiments (J. Settle, Argonne National Labọatory, private communication 1968). 
results have not been clarified. Laboratory data ${ }^{99}$. on the decomposition of $\mathrm{PuF}_{6}$ mixed with $\mathrm{UF}_{6}$ and $\mathrm{MoF}_{6}$ (work carried out with hollow. nickel spheres at $300^{\circ} \mathrm{C}$ ) indicated that very small quantities of molybdenum and uranium. were present in the final product. A DF of 100 for molybdenum was estimated because. the molybdenum concentration was below the analytical limits of detection. The DF for uranium was $>1000$. Pilot-plant studies ${ }^{100}$ also indicated a DF of $>100$ for molybdenum in the thermal-decomposition step.

TABLE 4.21. Estimated Thermodynamic Stability

Constants for Fission-product Fluorides

\begin{tabular}{llll}
\hline Compound & Decomposition Products & $\log \mathrm{K}^{\mathrm{a}}$ & $\mathrm{T},{ }^{\circ} \mathrm{K}$ \\
\hline $\mathrm{HF}$ & $\mathrm{H}_{2}, \mathrm{~F}_{2}$ & $-24 \mathrm{~b}$ & 600 \\
$\mathrm{NbF}_{5}$ & $\mathrm{NbF}_{3}, \mathrm{~F}_{2}$ & $-60^{\mathrm{c}}$ & 600 \\
$\mathrm{MoF}_{6}$ & $\mathrm{MoF}_{5}, \mathrm{~d}^{\mathrm{e}} \mathrm{F}_{2}$ & -27 & 298 \\
$\mathrm{TcF}_{6}$ & $\mathrm{TcF}_{5}, \mathrm{~d}_{2}$ & -18 & 298 \\
$\mathrm{RuF}_{5}$ & $\mathrm{RuF}_{3}, \mathrm{~F}_{2}$ & $-39^{\mathrm{f}}$ & 623 \\
$\mathrm{SbF}_{5}$ & $\mathrm{SbF}_{3}, \mathrm{~d}_{2}$ & $-57^{101}$ & 298 \\
$\mathrm{TeF}$ & $\mathrm{Te}_{2} \mathrm{~F}_{10}, \mathrm{~d}_{2}$ & $-12^{102}$ & 600 \\
$\mathrm{IF}_{5}$ & $\mathrm{I}_{2}, \mathrm{~d}_{2} \mathrm{~F}_{2}$ & $-60^{103}$ & 600 \\
$\mathrm{XeF}_{4}$ & $\mathrm{XeF}_{2}, \mathrm{~d}_{2}$ & -11 & 298 \\
\hline
\end{tabular}

$a_{K}=$ (decomposition product $) /($ compound $)$.

b JANAF tables.

CEstimated, M. J. Steindler, Argonne National Laboratory.

dProduct volatile at $350^{\circ} \mathrm{C}$.

eikely to decompose further to $\mathrm{MoF}_{4}$.

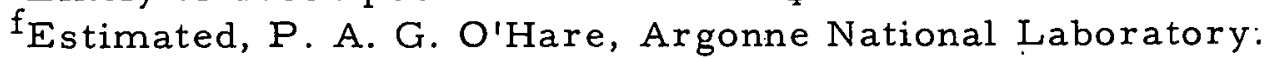

In summary, the decomposition of $\mathrm{PuF}_{6}$ in a fluid bed of alumina at $350^{\circ} \mathrm{C}$ is expected to produce $\mathrm{PuF}_{4}$ rapidly and in high yield, limited only by the thermodynamic equilibrium in the $\mathrm{PuF}_{6}-\mathrm{PuF}_{4}-\mathrm{F}_{2}$ system. Decontamination factors of plutonium from fission products ruthenium, molybdenum, technetium, and iodine have been assumed to be 1000 . This magnitude of the DF is believed to be a reasonable process objective, although, as noted above, little experimental data can be called on to substantiate the assumption.

4.5.5.4 Recovery of Plutonium from Thermal Decomposer Effluents. The efficiency of the thermal decomposer is expected to be high. Accordingly, the stream effluent from TD-1 will only contain approximately $0.5 \mathrm{~kg}$ of $\mathrm{PuF}_{6}$ per.day, together with substantially all of the $\mathrm{UF}_{6}$ and fissionproduct fluorides. In addition, the heel from the feed vessel will contain $\sim 1 \mathrm{~kg}$ of $\mathrm{PuF}_{6}$. The effluent stream and the volatilized heel will be passed through a bed of $\mathrm{LiF}_{\text {to }}$ remove the $\mathrm{PuF}_{6}$ before the remaining $\mathrm{UF}_{6}$-fissionproduct mixture is fed to the first distillation tower. 
Katz and Cathers ${ }^{104}$ have examined the use of LiF for the sorption and desorption of $\mathrm{PuF}_{6}$ under a wide range of conditions. According to their results, a bed of low-surface-area LiF operating as a sorber at $300^{\circ} \mathrm{C}$ and as a desorber at $450^{\circ} \mathrm{C}$ would provide recovery of about 95 to $99 \%$ of the $\mathrm{PuF}_{6}$ fed to the LiF-1 trap. Further, work by Trevorrow and Riha ${ }^{105}$ with $\mathrm{RuF}_{5}$ and $4 \mathrm{LiF} \cdot \mathrm{PuF}_{4}$ at $400^{\circ} \mathrm{C}$ showed that ruthenium is fixed in the solid phase, even after treatment with fluorine removed the plutonium. Similar results were obtained by $\mathrm{Jarry}^{106}$ in a study of the reaction of LiF with mixtures of $\mathrm{UF}_{6}$ and $\mathrm{RuF}_{5}$. These results suggest that a buildup of ruthenium in the LiF sorbent may occur and that occasional replacement of the bed with fresh LiF would be required to reduce residual activity. Uranium hexafluoride does nōt react with LiF under the process conditions. Neptunium hexafluoride is poorly sorbed on $\mathrm{LiF}^{107}$ and is expected to pass through the sorbent without loss. No other data on the reaction of LiF with components of the process stream appear to be available. Therefore, no fission product other than ruthenium is assumed to be retained. Only $10 \%$ of the ruthenium in the feed to $L i F-1$ is assumed to be retained in the trap.

Plutonium is removed from the LiF trap by elemental fluorine under the conditions listed in Table 4.15. Work by Trevorrow and Riha ${ }^{105}$ showed that $4 \mathrm{LiF} \cdot \mathrm{PuF}_{4}$ at $450^{\circ} \mathrm{C}$ can be fluorinated at rates such that $>90 \%$ of the $\mathrm{PuF}_{4}$ is converted to $\mathrm{PuF}_{6}$ in less than $4 \mathrm{hr}$. The equilibrium constant for the reaction

$$
4 \mathrm{LiF} \cdot \mathrm{PuF}_{4}+\mathrm{F}_{2} \rightleftharpoons \mathrm{PuF}_{6}+4 \mathrm{LiF}, \quad \log \mathrm{K}=2047 / \mathrm{T}(\mathrm{K})+0.827,
$$

rather than the kinetics, will be the limiting factor in the fluorination of the complex. The gas stream containing $\mathrm{PuF}_{6}$ is. introduced to fluorinator $\mathrm{B}$, as stated in Section 4.4.5.4.

4.5.5.5 Production of Purified $\mathrm{PuF}_{6}$. $\mathrm{PuF}_{4}$ deposited on alumina in $\mathrm{TD}-1$ is fluorinated at $500^{\circ} \mathrm{C}$. The product is condensed at $-80^{\circ} \mathrm{C}$ in $\mathrm{CT}-3$; and fluorine is recycled to the fluid bed for reuse. The refluorination step is similar to the reaction in fluorinator B except that the fission product and uranium content of. TD- 1 is very low. The chemistry and rates of reaction discussed in Section 4.4 .5 are also pertinent for fluorinations in TD- 1 .

Reuse of alumina for several cycles of decomposition-refluorination is envisioned since fission-product buildup and degradation of alumina should be small. Depending on the characteristics of the bed material, alumina from TD- 1 is periodically discharged to waste.

The product condensed in $\mathrm{CT}-3$ is additionally decontaminated by transferring only part of the $\mathrm{PuF}_{6}$ to the converter. Approximately $90 \%$ of the CT-3 contents is vaporized; the remaining $10 \%$ is recycled to the operating thermal decomposer. Based on the relative volatilities of the fission products listed in Table 4.19, the expected decontamination of $\mathrm{PuF}_{6}$ from 
selected fission products is that shown in Table 4.22. Decontamination from $\mathrm{RuF}_{5}$ by a DF of $\sim 20.00$ enhances the prospects of producing an adequately purified $\mathrm{PuF}_{6}$ product as feed for the converter. The return of part of the $\mathrm{PuF}_{6}$ to $\mathrm{TD}-1^{\prime}$ permits effective staging of $\mathrm{PuF}_{6}$ decontamination by recycle.

TABLE 4.22. Purification of $\mathrm{PuF}_{6}$ by Vaporization from $\mathrm{CT}-3$ at $80^{\circ} \mathrm{C}$

\begin{tabular}{llcrc}
\hline Compound & \multicolumn{1}{c}{$\alpha^{\mathrm{a}}$} & $\%$ Volatilized & Decontamination Factorb \\
\hline $\mathrm{PuF}_{6}$ & 1.00 & 90 & - \\
$\mathrm{UF}_{6}$ & 1.40 & 96 & $\sim 1$ \\
$\mathrm{NpF}_{6}$ & 1.26 & 94.5 & $\sim 1$ \\
$\mathrm{NbF}_{5}$ & 0.0025 & 0.58 & 170 \\
$\mathrm{RuF}_{5}$ & 0.00016 & 0.038 & 2630 \\
$\mathrm{SbF}_{5}$ & 0.057 & 12.3 & 8 \\
\hline
\end{tabular}

${ }^{\text {a }}$ Relative volatility at $80^{\circ} \mathrm{C}$ compared to the volatility of $\mathrm{PuF}_{6}$. ${ }^{\mathrm{b}} \mathrm{DF}=100 / \%$ volatilized.

\subsubsection{Solid Waste Handling}

Two solid-waste streams are produced in this part of the process, i.e., the alumina bed material from TD-l and the spent LiF from the LiF-i sorber. Neither of these waste streams represents a large fission-product (or heat) load, and both streams should be readily handled in containers used for other solid wastes. The frequency of discharge of the alumina bed from TD-1 is difficult to predict and would be determined on the basis of operability of the decomposer and recovery of $\mathrm{PuF}_{6}$ by refluorination. This alumina could be added to stream 20W (waste from fluorinator $B$ ) without significant changes in waste-handling procedures.

Similarly, LiF from LiF-1 would be discarded when the fission product (ruthenium) inventory exceeds a preset level determined by heat load or operability. These solids should pose no special problems when handled similarly to high-level wastes such as stream $20 \mathrm{~W}$.

\section{$4.6 \underline{\mathrm{UF}_{6} \text { Purification }}$}

\subsubsection{Outline of Process Steps}

This portion of the process is concerned with the production of refined $U_{6}$. The input to the process is the plutonium-free $U_{6} F_{6}$ stream from trap LiF-1 (see Section 4.5.1). The bulk of the impurities in this stream are removed by continuous fractional distillation, using two columns in series. The $\mathrm{UF}_{6}$ passes next through selective sorption traps for TcF 6 and $\mathrm{NpF}_{6}$ removal. The refined $\mathrm{UF}_{6}$ stream is split, a portion being fed to 
the converter for the preparation of new oxide core fuel, the remainder being cold-trapped and packaged for shipment off site. The equipment flowsheet for this portion of the process is shown.in schematic form in Fig. 4.15. Key streams are numbered for later reference.

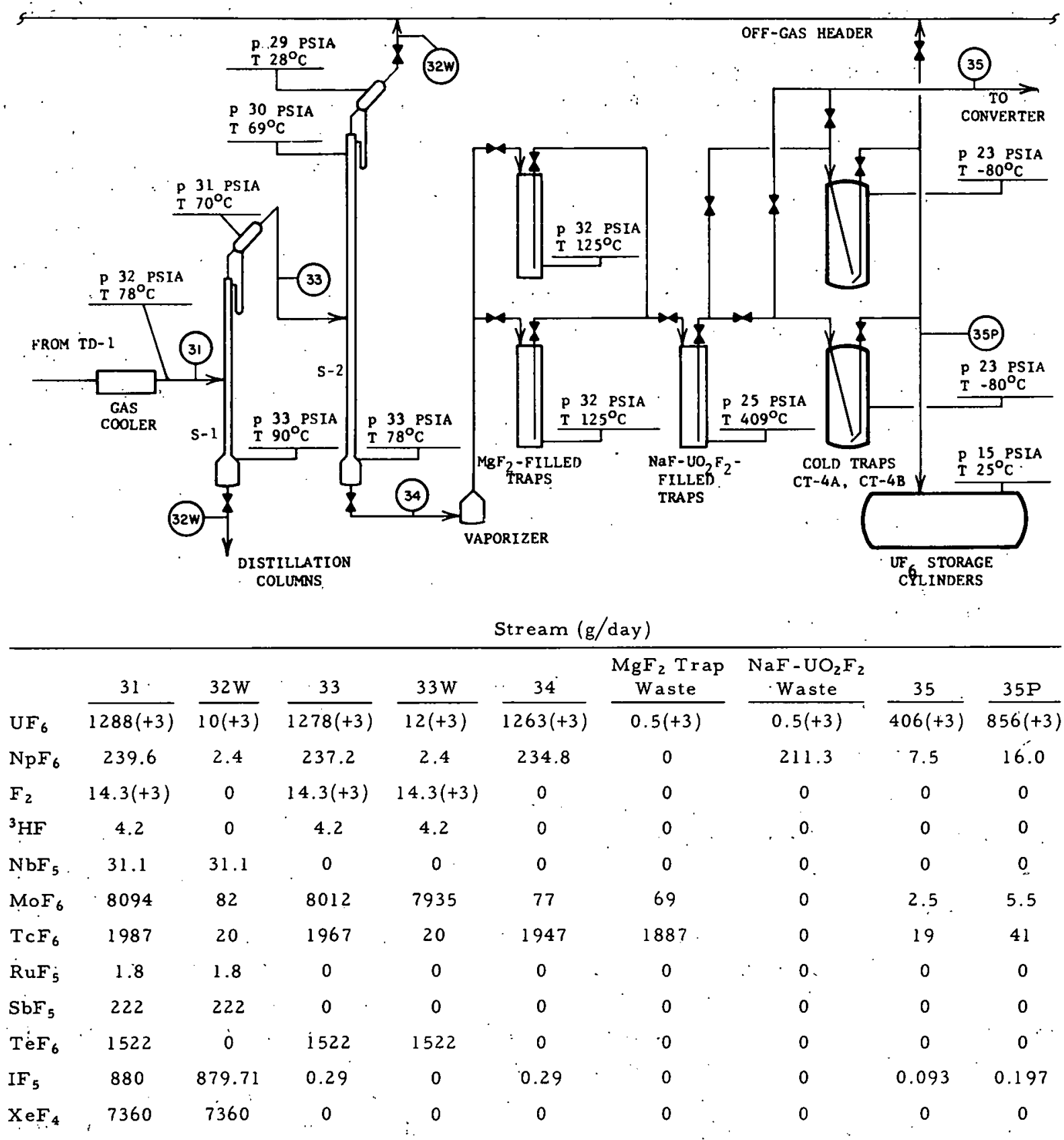

Fig. 4.15. Schematic Diagram of $\mathrm{UF}_{6}$ Purification System

Waste streams are represented by still S-1 bottoms, the overheads from still S-2, and the sorption trap contents or washings from these traps. The still bottoms and overheads are treated in the off-gas treatment plant (see Section 4.8). Treatment of the other wastes is discussed briefly below. 


\subsubsection{Design of Equipment for $\mathrm{UF}_{6}$ Purification}

4.6.2.1 The Distillation Units. The considerable literature regarding $\mathrm{UF}_{6}$ distillation and the commercial-scale operation of a $\mathrm{UF}_{6}$ distillation facility has made $U_{6}$ purification by distillation a well-proven technological operation. Experience considered pertinent to the requirements of the reference process are highlighted next. Work at Brookhaven National Laboratory ${ }^{108}$ showed that feeds of $\mathrm{UF}_{6}-\mathrm{BrF}_{3}$ containing tracer quantities of volatile fission products could be treated in a two-column system to effect high decontamination. In the first column, a light (low-boiling) fraction was separated from the $\mathrm{UF}_{6}-\mathrm{BrF}_{3}$, most of the tellurium being removed overhead. In the second column, $\mathrm{UF}_{6}$ overhead was separated from the $\mathrm{Br} \mathrm{F}_{3}$, iodine $\left(\mathrm{IF}_{5}\right)$, and a small amount of a nonvolatile tellurium compound. The overall beta and gamma $\mathrm{DF}^{\prime} \mathrm{s}$ were about $2 \times 10^{5}$ and about $10^{6}$, respectively. The data for tellurium suggest that the bulk of the tellurium was in the form of $\mathrm{TeF}_{6}$, which went overhead in the first column, and that a small amount, a nonvolatile tellurium species not yet identified, went to the bottoms of the second still. The behavior of the iodine suggests its occurrence as $\mathrm{IF}_{5}$.

Later work at Argonne National Laborator ${ }^{109}$ was an investigation of the batch distillation of a solution obtained by dissolution of irradiated uranium slugs in a mixture of liquid $\mathrm{BrF}_{3}-\mathrm{BrF}_{5}$. Overall decontamination of the $\mathrm{UF}_{6}$ product fraction was $1.3 \times 10^{8}$. Separation from tellurium was good (resulting in a DF of $1.4 \times 10^{6}$ ), as was separation from iodine (which gave a $\mathrm{DF}$ of $2.3 \times 10^{5}$ ). From the fission-product distributions found, it was inferred that the tellurium contaminant was present entirely as $\mathrm{TeF}_{6}$ (no low volatility tellurium compound was found) and that the iodine contaminant was present as $\mathrm{IF}_{5}$.

In 1959, plant-scale refining of $\mathrm{UF}_{6}$ by distillation was started by the Allied Chemical Corporation ${ }^{2}$ in a 5000 -ton/yr feed-materials plant. UF 6 was purified in two continuous fractional-distillation columns, the first for removing low-boilers, the second for removing high-boilers. The design of the first column was based upon separation of $\mathrm{MoF}_{6}$, which also assured separation of $\mathrm{UF}_{6}$ from the more volatile $\mathrm{VOF}_{3}$. This column was 18 in. in diameter and $96 \mathrm{ft}$ high with 100 bubble-cap trays. The overheads from this column contained principally $\mathrm{MOF}_{6}$ and $\mathrm{VOF}_{3}$. The bottoms, containing the $\mathrm{UF}_{6}$ and high-boiling compounds, were fed to the second column. The second column used 45 bubble-cap trays to separate the $U_{F}$ as overheads from the high-boiling contaminant, which was apparently an oxyfluoride of molybdenum. The identity of this compound was not firmly established, but the volatility of $\mathrm{UF}_{6}$ relative to this compound was empirically determined to be about 2.16 .

For the purposes of this report, neither an optimized nor a detailed design of a distillation unit was attempted. Rather, calculations were made to size the still columns and to establish the operating conditions for them. 
The calculational approach used here was to examine a binary system. of $\mathrm{UF}_{6}$ and a key fission-product compound having a volatility slightly above or slightly below that of $\mathrm{UF}_{6}$. If the calculations showed that the required separation between $\mathrm{UF}_{6}$ and the key component could be made, complete separation from compounds of higher or lower volatility than these key components was assumed. The separations calculations were based upon the relative volatilities (with respect to $U F_{6}$ ) of the constituents of the still S-l feed (listed in Table 4.23).

T.ABLE 4.23. Quantity and Relative Volatility of Constituents in Feed to Still S-1

\begin{tabular}{lccc}
\hline Constituent & $\begin{array}{c}\text { Quantity, } \\
\text { g/day }\end{array}$ & $\begin{array}{c}\text { Vapor Pressure, } \\
\mathrm{mm} \mathrm{Hg} \text { at } 80^{\circ} \mathrm{C}\end{array}$ & $\begin{array}{c}\text { Volatility Relative } \\
\text { to UF } 6 \text { Volatility }\end{array}$ \\
\hline $\mathrm{TeF}_{6}$ & 1522 & 19650 & 10.70 \\
${ }^{3} \mathrm{HF}$ & 4.2 & 4651 & 2.53 \\
$\mathrm{MoF}_{6}$ & 8093 & 3303 & 1.80 \\
$\mathrm{UF}_{6}$ & $1.288 \times 10^{6}$ & 1840 & 1.00 \\
$\mathrm{NpF}_{6}$ & 240 & 1652 & 0.90 \\
$\mathrm{TcF}_{6}$ & 1987 & 1628 & 0.88 \\
$\mathrm{IF}_{5}$ & 880 & 351 & 0.19 \\
$\mathrm{XeF}_{4}$ & 7360 & 114.8 & 0.062 \\
$\mathrm{SbF}_{5}$ & 222 & 74.6 & 0.040 \\
$\mathrm{NbF}_{5}$ & 31.1 & 3.3 & 0.0018 \\
$\mathrm{RuF}_{5}$ & 1.8 & 0.21 & 0.00011 \\
\hline
\end{tabular}

The effect on distribution and uranium purity of other possible fission-product compounds was also examined; Table 4.24 gives the relative volatilities of these compounds and two key components. An examination of this table in terms of the volatilities of these compounds relative to $\mathrm{UF}_{6}$ shows that $\mathrm{IOF}_{5}$ and $\mathrm{IF}_{7}$, being substantially more volatile than $\mathrm{MoF}_{6}$, would separate completely from the $\mathrm{UF}_{6}$ in the second still and be found in the fluorine waste stream leaving the condenser of still S-2. Similarly, $\mathrm{TcO}_{3} \mathrm{~F}$, $\mathrm{XeF}_{2}, \mathrm{RuOF}_{4}$, and $\mathrm{TcOF}_{4}$, having about the same volatility or being less volatile than $I F_{5}$, would accumulate with $I F_{5}$ in the still S-l bottoms. Finally, $\mathrm{RuF}_{6}$, with a volatility intermediate to the volatilities of the key components $\mathrm{MoF}_{6}$ and $I F_{5}$, seems to present a separation problem. Fortunately, the thermodynamic stability ${ }^{98}$ of this compound is such that it can be expected to decompose to $\mathrm{RuF}_{5}$ and fluorine under the process conditions found in the thermal decomposer and LiF trap immediately upstream from still S-1. To summarize, the formation of compounds other than those shown in Table 4.24 appears to have a negligible effect on $\mathrm{UF}_{6}$ purity, but their formation should affect the overall fission-product distribution. Since the process waste streams are combined, the process would not be affected, whether the iodine was discharged as $I F_{5}$ from still pot S-l or as $I O F_{5}-I F_{7}$ from the overhead 
of still S-2: Also, the formation of $\mathrm{MoOF}_{4}$ and $\mathrm{TcOF}_{4}$ would simplify the': separation scheme by reducing the load on the second still (MoF 6 separation) and on the $\mathrm{MgF}_{2}$ trap ( $\mathrm{TcF}_{6}$ separation).

TABLE 4.24. Relative Volatilities of Selected

Fission-product Compounds

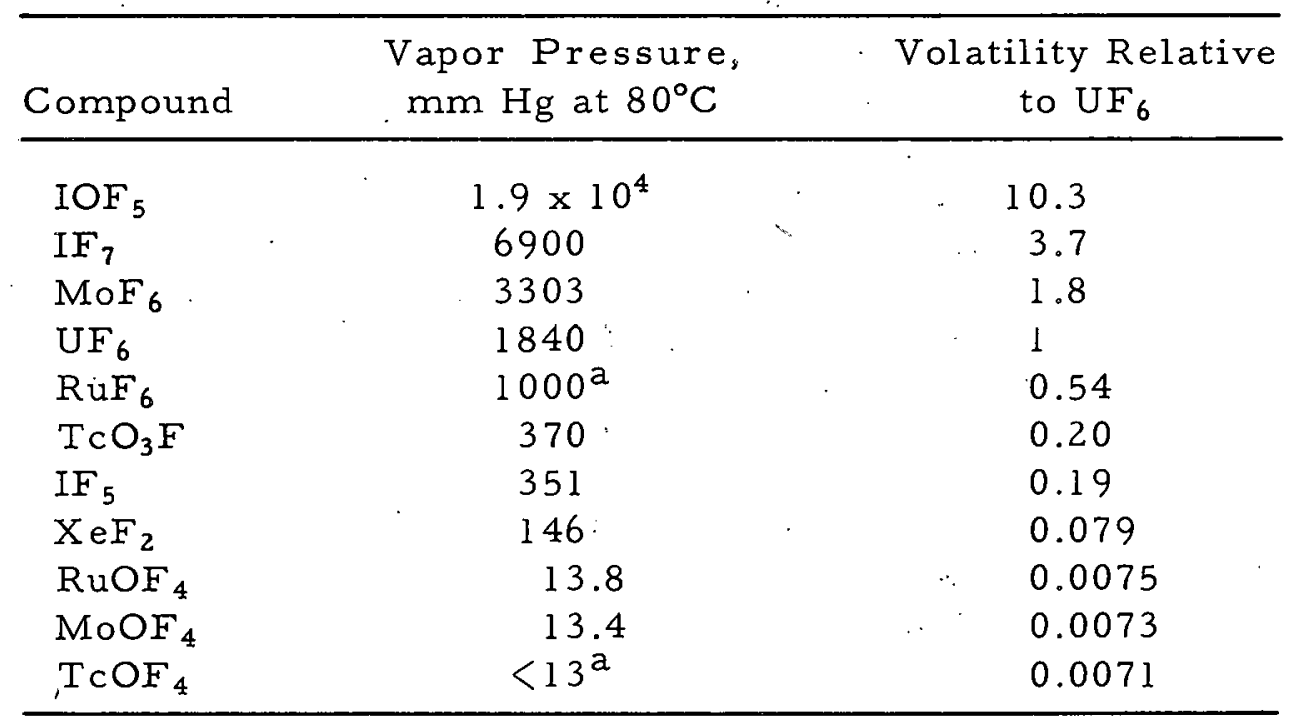

${ }^{a}$ Extrapolated data.

For all fission-product compounds, deviation from ideality was assumed to be small and to have no effect upon distillation column design. Furthermore, it was assumed that the fission-product compounds are completely soluble in $U F_{6}$ and that Raoult's Law is applicable. The effect of the presence of noncondensible fluorine was assumed to be small, since the solubility of fluorine in $\mathrm{UF}_{6}$ is nil at these operating conditions. The effect of the fluorine upon flooding velocity and hence upon column throughput was neglected because the quantity of fluorine represented only about $7 \%$ of the total vapor boilup $r$ ate in the columns.

Column parameters were calculated according to established methods. The minimum number of stages, $N$, required for each column was calculated according to the following equation described by Robinson and Gilliland:

$$
N+1=\frac{\log \left(x^{\prime} / x^{\prime \prime}\right)_{D}\left(x^{\prime \prime} / x^{\prime}\right)_{B}}{\log \alpha_{a v}}
$$

where

$$
\begin{aligned}
& \dot{x}^{\prime}=\text { mol fraction light component, } \\
& x^{\prime \prime}=\text { mol fraction heavy component, }
\end{aligned}
$$




$$
\begin{aligned}
& \left(\mathrm{x}^{\prime} / \mathrm{x}^{\prime \prime}\right)_{\mathrm{D}}=\text { mol ratio overhead, } \\
& \left(\mathrm{x}^{\prime \prime} / \mathrm{x}^{8}\right)_{\mathrm{B}}=\text { mol ratio bottoms }
\end{aligned}
$$

and

$$
\alpha_{\mathrm{av}}=\text { vapor-pressure ratio light-to-heavy component. }
$$

The minimum reflux ratio, $\mathrm{R}_{\mathrm{m}}$, for the first still was calculated. from the following equations:

$$
\frac{R_{m}}{R_{m}+1}=\frac{x_{d}-y_{p}}{x_{f}-x_{p}}
$$

where

$$
\begin{aligned}
\mathrm{y}_{\mathrm{p}}, \mathrm{x}_{\mathrm{p}} & =\text { intersection of } \mathrm{q} \text {-line with equilibrium diagram, } \\
\mathrm{x}_{\mathrm{d}} & =\text { mol fraction } \mathrm{UF}_{6} \text { in the overheads, }
\end{aligned}
$$

and

$$
\begin{aligned}
& x_{f}=\text { mol fraction } U_{6} \text { in the feed; } \\
& y_{p}=x_{p} \frac{q}{q-1}-\frac{x_{f}}{q-1}
\end{aligned}
$$

where.

$$
\begin{aligned}
\mathrm{q}= & \text { heat required to vaporize } 1 \text { mole of feed at the feed-plate } \\
& \text { temperature divided by latent heat of vaporization of the feed; }
\end{aligned}
$$

and

$$
y_{p}=\frac{\alpha x_{p}}{1+x_{p}(\alpha-1)},
$$

where

$$
q=0 \text { for saturated vapor feed. }
$$

The operational reflux ratio $r$ anges from 1.3 to 2 times the minimum in industrial practice: ${ }^{112}$ The reflux ratio value chosen for the calculation of the number of theoretical plates was 1.5 times $\mathrm{R}_{\mathrm{m}}$.

plot of

The number of theoretical plates ${ }^{113}$ required was: estimated from a

$$
\frac{R-R_{m}}{R+1} \text { versus } \frac{S-S_{m}}{S+1}
$$


where

$\mathrm{S}_{\mathrm{m}}=$ minimum theoretical plates at total reflux,

and

$S=$ theoretical plates for the given reflux ratio $R$.

The distillation requirements for still S-l were estimated by calculating the separation of $\mathrm{UF}_{6}$ from $\mathrm{IF}_{5}$, assuming a binary mixture. Table 4.23 gives the quantities and the volatilities of the feed constituents relative to $\mathrm{UF}_{6}$. The volatility of $\mathrm{IF}_{5}$ relative to that of $\mathrm{UF}_{6}$ is 0.19 . Table 4.25 lists the calculated column sizes and design specifications for stills S-1 and S-2.

TABLE 4.25. Size and Design Specifications for Stills S-1 and S-2

\begin{tabular}{lrr}
\hline \multicolumn{1}{c}{ Description } & Still S-1 & Still S-2 \\
\hline Column diameter, & & \\
$\quad$ in. Sch. 40 pipe & 4 & $3 \frac{1}{2}$ \\
Column height, ft & 15 & 25 \\
Minimum reflux ratio & 0.233 & 39 \\
Operating reflux ratio & 0.35 & 58.5 \\
Minimum theoretical plates & & \\
$\quad$ (total reflux) & 9.5 & 12 \\
Number of actual plates & 22 & 172 \\
Boilup rate, mol/hr & 202 & 1000 \\
Column design capacity, & & $15 \mathrm{C}$ \\
kg/(hr)(ft ${ }^{2}$ of UF 6 & 1000 & $\mathrm{~b}$ \\
H.E.T.P., in. & & \\
\hline
\end{tabular}

a Height equivalent to a theoretical plate.

bBased upon the $\mathrm{BrF}_{5}-\mathrm{UF}_{6}$ system. ${ }^{114}$

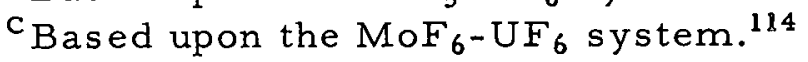

The composition of the bottoms of still S-1 is approximately $47 \% \mathrm{UF}_{6}$, $45 \% \mathrm{XeF}_{4}$, and $5 \% \mathrm{IF}_{5}$. If an operating pressure of about $33 \mathrm{psia}$ is chosen for the still pot, the pot temperature should be about $90^{\circ} \mathrm{C}$. As previously noted, all the fission-product compounds are assumed to be soluble in $\mathrm{UF}_{6}$. Data are lacking for the $\mathrm{XeF}_{4}-\mathrm{UF}_{6}$ system. Should $\mathrm{XeF}_{4}$ prove to be less soluble in $\mathrm{UF}_{6}$ than is necessary to prevent deposition in the still pot, its early removal (possibly by filtration from the liquified $U_{F}$ and $P_{6} F_{6}$ in CT-1 and CT-2) might be desirable.

Fission-product heating must be considered in making a detailed design of the still pot. A daily accumulation in the pot consists of about 6.2 liters of the mixed fluorides containing fission-product compounds that 
generate about $4 \mathrm{~kW}$ (total beta and gamma). If absorption of $100 \%$ of the beta and $20 \%$ of the gamma is assumed, heat generation within the solution will be about $1.28 \mathrm{~kW}$ or about $200 \mathrm{~W} /$ liter of solution. Since about $1.6 \mathrm{~kW}$ are necessary for the required boilup rate, an inventory of 8 liters of solution will provide the necessary process heat; cooling will need to be provided when solution holdup in the still pot for still S-l is in excess of 8 liters. The still pot will also be provided with a heating capability, consistent with good design.

The overheads from still S-I are condensed in a partial condenser operating at $70^{\circ} \mathrm{C}$ and 31 psia. About $38 \%$ of the $\mathrm{UF}_{6}$ is condensed and provides reflux to the still. The condenser duty under these conditions is about $0.6 \mathrm{~kW}$. Since only about $26 \%$ of the overhead $\mathrm{UF}_{6}$ is required as liquid reflux for still $S-1$, the feed to still $S-2$ is mainly saturated vapor plus some liquid $\mathrm{UF}_{6}$. During actual operations, small adjustments in condenser conditions would probably be made to maintain the feed to still S-2 as $100 \%$ saturated vapor.

In still $\mathrm{S}-2, \mathrm{MoF}_{6}$ is separated from $\mathrm{UF}_{6}$ so that the concentration of $\mathrm{MoF}_{6}$ in the $\mathrm{UF}_{6}$ bottoms is $100 \mathrm{ppm}$ and the $\mathrm{UF}_{6}$ loss overhead is less than $1 \%$. Condensed-phase equilibria for the system MoF $6-\mathrm{UF}_{6}$ show complete liquid miscibility at the temperature range of interest for distillation, ${ }^{74}$ suggesting that little or no significant deviations from ideality would be expected. The design parameters for still S-2, based on the equations given above, are presented in Table 4.25.

Table 4.26 lists the quantities of the feed constituents and the relative volatilities of these compounds. The still bottoms are mainly $\mathrm{UF}_{6}$. Setting the operating pressure in the still pot at about 3.3 psia results in a boilup temperature of about $78^{\circ} \mathrm{C}$. Since fission-product heating is nil, the still-pot duty can be fixed at about $1.36 \mathrm{~kW}$ to provide the necessary boilup rate.

TABLE 4.26. Quantity and Relative Volatility of Constituents in Feed to Still S- 2

\begin{tabular}{cccc}
\hline Component & $\begin{array}{c}\text { Quantity, } \\
\text { g/day }\end{array}$ & $\begin{array}{c}\text { Vapor Pressure, } \\
\text { mm Hgat } 80^{\circ} \mathrm{C}\end{array}$ & $\begin{array}{c}\text { Volatility Relative } \\
\text { to UF }\end{array}$ Volatility \\
\hline $\mathrm{TeF}_{6}$ & 1522 & 19650 & 10.7 \\
${ }^{3} \mathrm{HF}$ & 4.2 & 4651 & 2.53 \\
$\mathrm{MoF}_{6}$ & 8012 & 3303 & 1.80 \\
$\mathrm{UF}_{6}$ & $1.278 \times 10^{6}$ & 1840 & 1.00 \\
$\mathrm{NpF}_{6}$ & 237 & 1652 & 0.90 \\
$\mathrm{TcF}_{6}$ & 1967 & 1628 & 0.88 \\
$\mathrm{IF}_{5}$ & 0.29 & 351 & 0.19 \\
\hline
\end{tabular}


The condenser for this still is operated below the solidus for the $\mathrm{MoF}_{6}-\mathrm{UF}_{6}$ overheads at conditions that provide the required $\mathrm{MoF}_{6}$ dragout. The conditions chosen for this case, $28^{\circ} \mathrm{C}$ and 29 psia, result in about $7900 \mathrm{~g}$ of $\mathrm{MoF}_{6}$ and $11,600 \mathrm{~g}$ of $\mathrm{UF}_{6}\left(<1 \%\right.$ of the $\mathrm{UF}_{6}$ input to the still) leaving with the fluorine stream from the top of the condenser. With the condenser

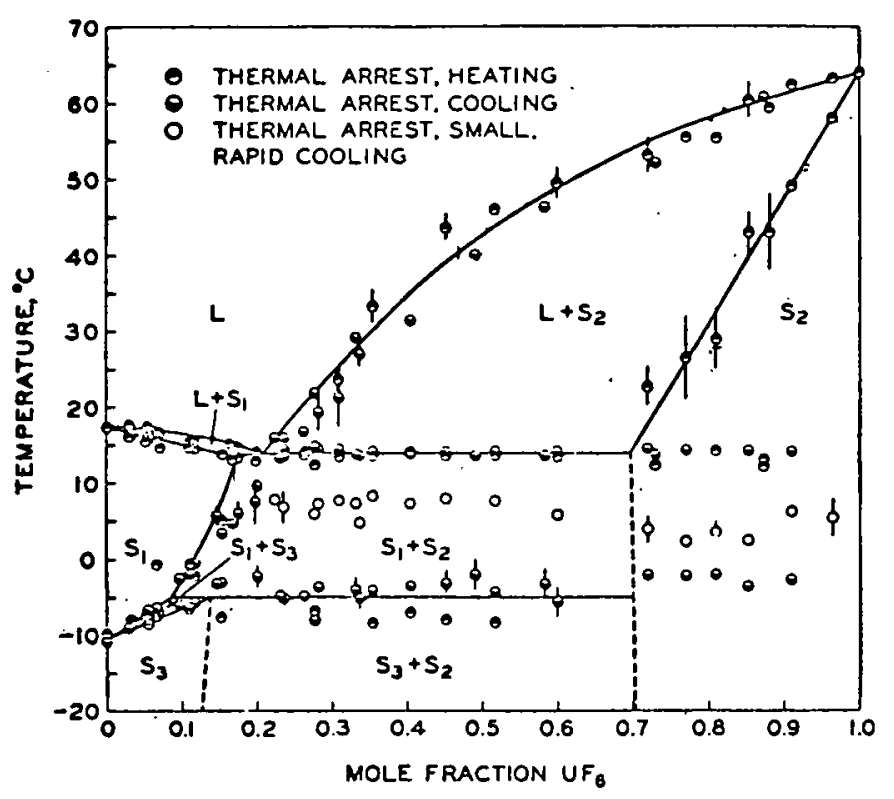

Fig. 4.16. Phase Equilibria in Condensed System $\mathrm{UF}_{6}-\mathrm{MoF}_{6}$ (from p. 13 of Ref. 74) at a low temperature, the relative volatility of $\mathrm{MoF}_{6}$ to $\mathrm{UF}_{6}$ becomes more favorable, 4.5, and provides efficient separation of $\mathrm{MoF}_{6}$ from $\mathrm{UF}_{6}$. This allows use of a shorter column. At equilibrium, the condensate would form a solid solution having the composition. $20 \% \mathrm{MoF}_{6}$ and $80 \% \mathrm{UF}_{6}$ (see Fig. 4.16); however, under the dynamic conditions expected in process operation, liquid ranging in composition from 33 to $80 \% \mathrm{UF}_{6}$ may be present, along with a solid phase ranging in composition from 78 to $97 \% \mathrm{UF}_{6}$. This liquid-solid mixture is heated to about $69^{\circ} \mathrm{C}$ and returned as liquid reflux to the top tray of the still. Actually, two condensers are used batchwise, one on-stream as a collector while the second provides the reflux. Small adjustments in process conditions from those calculated here will compensate for the expected small deviations from ideality and equilibrium. A rough estimate of the condenser duty showed that about $2-\mathrm{kW}$ cooling capacity would be required to provide the necessary reflux to the still.

The $\mathrm{UF}_{6}$ product from still S-2 bottoms (stream 34) is transferred as a liquid to an auxiliary evaporator and then is further purified in the $\mathrm{MgF}_{2}$ and $\mathrm{NaF}-\mathrm{UO}_{2} \mathrm{~F}_{2}$ traps. The finally purified $\mathrm{UF}_{6}$ product is fed to either the converter or cold trap CT-4. When the converter is on the fluoridecleanup part of its cycle and no $\mathrm{UF}_{6}$ is being fed to it, the entire $\mathrm{UF}_{6}$ output from the evaporator is fed to CT-4. In this way, the cyclic operation of the converter does not interfere with the continuity of the distillation operation.

4.6.2.2 The $\mathrm{MgF}_{2}$ Trap. The function of the $\mathrm{MgF}_{2}$ trap is to further decontaminate the $\mathrm{UF}_{6}$ stream from still $\mathrm{S}-2$ by removing technetium. In addition, a large fraction of the residual $\mathrm{MoF}_{6}$ is removed. The flowsheet calculations have been based on $\mathrm{TcF}_{6}$ being a representative product of the fluorination of technetium in the fuel. A review of the literature ${ }^{72}$ suggested that $\mathrm{TcOF}_{4}$ may also be present in the process stream. The vapor pressure 
and chemical properties of $\mathrm{TcOF}_{4}$ are not known, but the vapor pressure of $\mathrm{TcOF}_{4}$ is likely to be less than that of $\mathrm{MoOF}_{4}$ (see Table 4.24). Another technetium compound, $\mathrm{TcO}_{3} \mathrm{~F}$, has been reported and its physical properties characterized. It is included in the present discussion for completeness although it is not likely to be formed under process conditions. Vapor pressures of technetium fluorides are shown in Table 4.27 .

TABLE 4.27. Vapor Pressures of Uranium Hexafluoride and Selected Technetium Fluorides

\begin{tabular}{lcccr}
\hline & \multicolumn{4}{c}{ Vapor Pressure, mm Hg } \\
\cline { 2 - 5 } Compound & $-180^{\circ} \mathrm{C}$ & $-10^{\circ} \mathrm{C}$ & $15^{\circ} \mathrm{C}$ & $75^{\circ} \mathrm{C}$ \\
\hline $\mathrm{TcF}_{6}$ & $10^{-2}$ & 29.7 & 135.2 & 1412 \\
$\mathrm{TcOF}_{4}{ }^{-2}$ & $<10^{-5}$ & $<0.02$ & $<0.2$ & $<10$ \\
$\mathrm{TcO}_{3} \mathrm{~F}$ & $<10^{-4}$ & 1.4 & 16 & 305 \\
$\mathrm{UF}_{6}$ & $5 \times 10^{-4}$ & 7.44 & 55.6 & 1592 \\
\hline
\end{tabular}

a Based on $\mathrm{MoOF}_{4}$ vapor pressure.

Separation of $\mathrm{TcOF}_{4}$ from the $\mathrm{UF}_{6}$ stream (from fluorinator A) occurs in FP-1 and FP-2, where $\mathrm{TcOF}_{4}$ is expected to condense. Technetium trioxyfluoride $\left(\mathrm{TcO}_{3} \mathrm{~F}\right)$ and $\mathrm{TcF}_{6}$ will collect in $\mathrm{CT}-1$ and $\mathrm{CT}-2$ and be trans ferred to the feed vessel for the thermal decomposer. The single-stage distillation from the decomposer feed vessel will result in most of the $\mathrm{TCF}_{6}$ and $\mathrm{TCO}_{3} \mathrm{~F}$ being passed to the thermal decomposer (and directly to still S-1): the small amount of $\mathrm{TcOF}_{4}$ present in the feed vessel will be moved to still S-l via the processing of the feed vessel heel through trap LiF-1. Although no experimental data are available on the thermal stability of $\mathrm{TcF}_{6}$ and $\mathrm{TcO}_{3} \mathrm{~F}, 99.9 \%$ of these compounds have been assumed to pass through the decomposer to still $\mathrm{S}-1$.

The relative volatilities of $\mathrm{UF}_{6}, \mathrm{TcF}_{6}, \mathrm{TcOF}_{4}$, and $\mathrm{TcO}_{3} \mathrm{~F}$ at $75-80^{\circ} \mathrm{C}$ are such that an adequate separation of $\mathrm{TcO}_{3} \mathrm{~F}$ and $\mathrm{TcOF}_{4}$ from $\mathrm{UF}_{6}$ will be obtained. These technetium compounds will be transferred to waste via the still bottoms from still S-1.

In summary, the bulk of the technetium is expected to form $\mathrm{TcF}_{6}$ and will follow $\mathrm{UF}_{6}$ in the process. If a small amount of $\mathrm{TCOF}_{4}$ is formed, it would be distributed between FP-1 and FP-2 and the bottoms of still S-1. Two $\mathrm{MgF}_{2}$ traps, each trap alternately on stream, will be used in the process flowsheet. Table 4.28 gives the general specifications for the $\mathrm{MgF}_{2}$ traps, based on work by Golliher. ${ }^{115,116}$ Because of the large amounts of $\mathrm{MgF}_{2}$ involved and a desire to minimize the cost of reagent and waste handling, it is proposed to regenerate the $\mathrm{MgF}_{2}$ by washing in situ with water and by drying with hot air. ${ }^{116}$ The small volume of aqueous waste generated can be disposed of as a low-level aqueous waste or it can be evaporated and the solids handled as a solid waste. 
TABLE 4.28. Specifications for $\mathrm{MgF}_{2} \operatorname{Trap}$

\begin{tabular}{ll}
\hline Trap size: & $2 \mathrm{ft}$ diam by $9 \mathrm{ft}$ long \\
Operating temperature: & $125^{\circ} \mathrm{C}$ \\
Operating pressure: & $32 \mathrm{psia}$ \\
Weight of $\mathrm{MgF}_{2}:$ & $664 \mathrm{~kg}$ \\
Loading time: & $96 \mathrm{hr}$ \\
Superficial gas velocity: & $0.012 \mathrm{ft} / \mathrm{sec} \mathrm{(at} \mathrm{operating} \mathrm{conditions)}$ \\
$\%$ of inlet $\mathrm{TcF}_{6}$ removed: & 97 \\
$\%$ of inlet $\mathrm{MoF}_{6}$ removed: & 90
\end{tabular}

4.6.2.3 The $\mathrm{NaF}-\mathrm{UO}_{2} \mathrm{~F}_{2}$ Trap. A multistage $\mathrm{NaF}-\mathrm{UO}_{2} \mathrm{~F}_{2}$ sorption step is employed to remove neptunium from the $U F_{6}$ stream leaving the $\mathrm{MgF}_{2}$ trap. Removal of neptunium from uranium by the use of sorbents such as $\mathrm{NaF}$ and $\mathrm{MgF}_{2}$ has been studied at several laboratories. ${ }^{116-118}$. Screening tests performed at $O R N L^{117}$ and $P$ aducah ${ }^{118}$ show NaF to be superior to $\mathrm{CaF}_{2}, \mathrm{LiF}$ and $\mathrm{MgF}_{2}$ for the sorption of $\mathrm{NpF}_{6}$. Katz and Cathers ${ }^{187}$ propose the separation of $\mathrm{UF}_{6}$ from $\mathrm{NpF}_{6}$ by a scheme which requires the complete sorption of $\mathrm{NpF}_{6}$ and $\mathrm{UF}_{6}$ on $\mathrm{NaF}$, decomposition of the neptunium complex, preferential desorption of $\mathrm{UF}_{6}$, and refluorination and desorption. of the neptunium. A simpler scheme proposed for this separation by Chilenskas and Trevorrow ${ }^{119}$ consists of passing the mixed hexafluoride stream through a composite packed bed of alternate layers of NaF and $\mathrm{UO}_{2} \mathrm{~F}_{2}$. Since the reaction of $\mathrm{NpF}_{6}$ with $\mathrm{NaF}^{118}$ proceeds according to

$$
3 \mathrm{NaF}(\mathrm{s})+\mathrm{NpF}_{6}(\mathrm{~g}) \rightleftharpoons 3 \mathrm{NaF} \cdot \mathrm{NpF}_{5}(\mathrm{~s})+\frac{1}{2} \mathrm{~F}_{2}(\mathrm{~g})
$$

it is necessary to remove the fluorine generated in the first NaF stage by reaction with $\mathrm{UO}_{2} \mathrm{~F}_{2}$ to gain a benefit from multistage contact with $\mathrm{NaF}$.

The reaction of $\mathrm{UO}_{2} \mathrm{~F}_{2}$ with fluorine proceeds according to the equation:

$$
\mathrm{UO}_{2} \mathrm{~F}_{2}+2 \mathrm{~F}_{2} \rightarrow \mathrm{UF}_{6}+\mathrm{O}_{2}
$$

The temperature dependence of the reaction $r$ ate at 1 atm of fluorine is expressed by

$$
\log \operatorname{rate}\left[\mathrm{mg} \mathrm{U} /\left(\mathrm{cm}^{2}\right)(\mathrm{hr})\right]=9.9772-\frac{4232}{\mathrm{~T}\left({ }^{\circ} \mathrm{K}\right)} \cdot{ }^{120}
$$

(The $\mathrm{cm}^{2}$ term refers to the geometric surface area of the solid sample.) Little or no reaction of $\mathrm{UO}_{2} \mathrm{~F}_{2}$ with $\mathrm{UF}_{6}$ is expected. ${ }^{121}$.

Trevorrow. ${ }^{122}$ derived an expression for the removal of $\mathrm{NpF}_{6}$ from a $\mathrm{UF}_{6}$ stream as a function of inlet $\mathrm{NpF}_{6}$ concentration. Figure 4.17 shows 
the results of the calculations* for a range of $\mathrm{NaF}$ bed temperatures from 250 to $409^{\circ} \mathrm{C}$. Table 4.29 shows the calculated results of multistage contacting of a $\mathrm{NpF}_{6}-\mathrm{UF}_{6}$ stream at $1.75 \mathrm{~atm}$ and $409^{\circ} \mathrm{C}$, assuming complete removal of the fluorine by $\mathrm{UO}_{2} \mathrm{~F}_{2}$ between stages of $\mathrm{NaF}$. A temperature of at least $409^{\circ} \mathrm{C}$ is required since the dissociation pressure of $2 \mathrm{NaF} \cdot \mathrm{UF}_{6}$ is 1.75 atm at this temperature. The $\mathrm{UF}_{6}$ pressure needs to be kept slightly below $1.75 \mathrm{~atm}$ to prevent the formation of $2 \mathrm{NaF} \cdot \mathrm{UF}_{6}$. As is shown in Table 4.29 , the use of

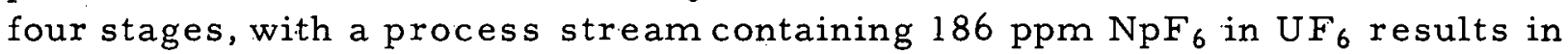
an overall removal of $88 \%$ of the $\mathrm{NpF}_{6}$ and a residual concentration of $21 \mathrm{ppm}$ $\mathrm{NpF}_{6}$ in the product $\mathrm{UF}_{6}$. Additional stages would reduce the outlet concentration of $\mathrm{NpF}_{6}$ although at a progressively lower stage efficiency.

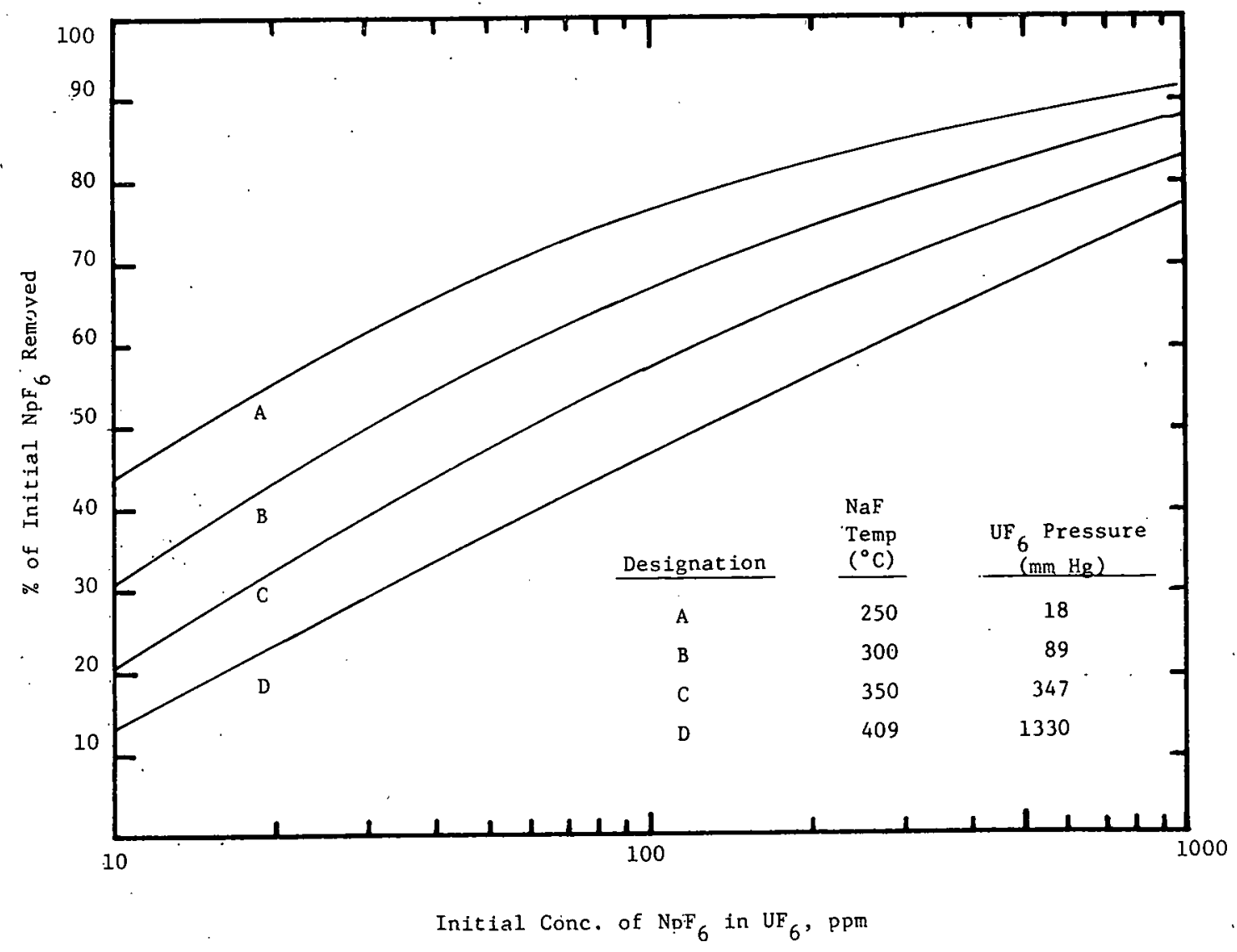

Fig. 4.17. Removal of $\mathrm{NpF}_{6}$ from $\mathrm{UF}_{6}-\mathrm{NpF}_{6}$ Gas Mistures by Reaction with $\mathrm{NaF}$.

TABLE 4.29. Removal of $\mathrm{NpF}_{6}$ from $\mathrm{UF}_{6}-\mathrm{NpF}_{6}$ Gas Mixtures by Multistage Contacting with $\mathrm{NaF}$ at $409^{\circ} \mathrm{C}$

\begin{tabular}{ccccc}
\hline Stage & $\begin{array}{c}\text { Inlet } \mathrm{NpF}_{6} \\
\text { Concentration, ppm }\end{array}$ & $\begin{array}{c}\text { Percent of Inlet } \\
\mathrm{NpF}_{6} \text { Removed }\end{array}$ & $\begin{array}{c}\text { Exit NpF } \\
\text { Cioncentration, ppm }\end{array}$ & $\begin{array}{c}\text { Percent Overall } \\
\text { Removal }\end{array}$ \\
\hline 1 & 186 & 55 & 84 & 5.5 \\
2 & 84 & 44 & 47 & 75 \\
3 & 47 & 35 & 30 & 84 \\
4 & 30 & 29 & 21 & 88 \\
\hline
\end{tabular}

* The removal of $\mathrm{NpF}_{6}$ is a function of the partial pressure of fluorine, but for convenience is expressed in terms of the concentration of $\mathrm{NpF}_{6}$ in $\mathrm{UF}_{6}$ at the $\mathrm{UF}_{6}$ pressures indicated in Fig. 4.17. 
Calculations to size a multistage $\mathrm{NaF}-\mathrm{UO}_{2} \mathrm{~F}_{2}$ process trap that would remove $88 \%$ of the inlet $\mathrm{NpF}_{6}$ resulted in the specifications in Table 4.30 .

Because of the expected long life of the trap (470 days), the overall quantity of waste produced is small. The waste can be handled during any scheduled plant shutdown. The neptunium-loaded $\mathrm{NaF}-\mathrm{UO}_{2} \mathrm{~F}_{2}$ trap can be replaced and either disposed of as a solid waste or sent to an off-site processor for neptunium recovery.

TABLE 4.30. Specifications for Multistage $\mathrm{NaF}-\mathrm{UO}_{2} \mathrm{~F}_{2}$ Trap

\begin{tabular}{|c|c|}
\hline Description & Specification \\
\hline Overall size & $2 \mathrm{ft}$ diam by $9 \mathrm{ft}$ long \\
\hline Feed rate basis & $12 \mathrm{hr}$ on, $12 \mathrm{hr}$ off $\mathrm{a}^{\circ}$ \\
\hline Pressure & $1.75 \mathrm{~atm}$ \\
\hline Temperature & $409^{\circ} \mathrm{C}$ \\
\hline Trap volume & $28.3 \mathrm{ft}^{3}$ \\
\hline Void volume & $\sim 14 \mathrm{ft}^{3}$ \\
\hline $\mathrm{UF}_{6}$ rate & $0.56 \mathrm{cfm}$ at process conditions \\
\hline Number of NaF stages & 4 \\
\hline Length of each $\mathrm{NaF}$ stage & $2 \mathrm{ft} \mathrm{l}$ in. \\
\hline Gas residence time per stage & $6 \mathrm{~min}$ \\
\hline Trap life $(5 \% \text { loading })^{b}$ & 470 days \\
\hline Number of $\mathrm{UO}_{2} \mathrm{~F}_{2}$ stages & 4 \\
\hline Length of each $\mathrm{UO}_{2} \mathrm{~F}_{2}$ stage & 2 in. \\
\hline Residence time per stage & $0.47 \mathrm{~min}$ \\
\hline
\end{tabular}

Intermittent feed for the converter is required.

${ }^{\mathrm{b}}$ Conversion of $5 \%$ of the $\mathrm{NaF}$ to $3 \mathrm{NaF} \cdot \mathrm{NpF}_{5}$.

\subsubsection{Disposition of $\mathrm{UF}_{6}$ Product}

The $\mathrm{UF}_{6}$ leaving the $\mathrm{NaF}-\mathrm{UO}_{2} \mathrm{~F}_{2}$ trap is split into one stream of about $406 \mathrm{~kg} / \mathrm{d}$ ay to the converter and one stream of $856 \mathrm{~kg} /$ day to CT -4 (where it is condensed at about $-80^{\circ} \mathrm{C}$ and separated from about $0.12 \mathrm{scf} /$ day oxygen, which forms as a result of the $\mathrm{F}_{2}+\mathrm{UO}_{2} \mathrm{~F}_{2}$ reaction in the $\mathrm{NaF}-\mathrm{UO}_{2} \mathrm{~F}_{2} \operatorname{trap}$ ). This oxygen is piped to the main off-gas treatment system, where provision is made for oxygen disposal as liquid water. If sufficiently free of activity, the oxygen will be vented. Dual cold traps (CT-4) are provided to permit cyclic operation between cold-trapping and melting of the UF ${ }_{6}$. The liquified $\mathrm{UF}_{6}$ is transferred to steel $\mathrm{UF}_{6}$ storage cylinders and held, pending shipment off site.

\subsubsection{Composition of $\mathrm{UF}_{6}$ Product}

Table 4.31 compares the composition of the refined $U_{6}$ product with the composition of the input stream to still S-l. The overall beta DF* achieved for the purified uranium is $1.6 \times 10^{7}$.

\footnotetext{
$*_{\text {Based on }} 2.1 \times 10^{7}$ beta curies in a daily load of fuel.
} 
TABLE 4.3.1. Composition of $\mathrm{UF}_{6}$ Product

\begin{tabular}{lccc}
\hline Compound & $\begin{array}{c}\mathrm{UF}_{6} \text { to Still S-1, } \\
\mathrm{g} / \text { day }\end{array}$ & $\begin{array}{c}\text { Refined UF } 6 \text { Product, } \\
\mathrm{g} / \text { day }\end{array}$ & Beta Curies/day \\
\hline $\mathrm{UF}_{6}$ & $1.288 \times 10^{6}$ & $1.262 \times 10^{6}$ & - \\
$\mathrm{NpF}_{6}$ & 240 & 23.5 & - \\
$\mathrm{TeF}_{6}$ & 1522 & $\sim 0$ & - \\
$\mathrm{F}_{2}$ & $1.43 \times 10^{4}$ & $\sim 0$ & - \\
${ }^{\mathrm{HF}}$ & 4.2 & $\sim 0$ & - \\
$\mathrm{MoF}_{6}$ & 8094 & 8 & 0.11 \\
$\mathrm{TcF}_{6}$ & 1987 & 60 & 0.39 \\
$\mathrm{IF}_{5}$ & 880 & 0.0029 & 0.78 \\
$\mathrm{XeF}_{4}$ & 7360 & $\sim 0$ & - \\
$\mathrm{SbF}_{5}$ & 222 & $\sim 0$ & - \\
$\mathrm{RuF}_{5}$ & 1.8 & $\sim 0$ & - \\
$\mathrm{NbF}_{5}$ & 31.1 & $\sim 0$ & 1.28 \\
& & & \\
\hline
\end{tabular}

\subsection{Conversion of Mixed Hexafluorides to Oxides}

Dense particulate $\mathrm{PuO}_{2}-\mathrm{UO}_{2}$ product suitable for sintering and refabrication into FBR fuel is withdrawn from the last major processing step in the reference process, conversion. This product, 23 wt $\% \mathrm{PuO}_{2}-\mathrm{UO}_{2}$, is formed in a fluid-bed reactor (a converter): according to the reaction

$$
\mathrm{PuF}_{6}-\mathrm{UF}_{6}(\mathrm{~g})+2 \mathrm{H}_{2} \mathrm{O}(\mathrm{g})+\mathrm{H}_{2}(\mathrm{~g}) \stackrel{650^{\circ} \mathrm{C}}{\longrightarrow} \mathrm{PuO}_{2}-\mathrm{UO}_{2}(\mathrm{~s}):+6 \mathrm{HF}(\mathrm{g}) .
$$

Alternatively, pure $\mathrm{PuF}_{6}$ and $\mathrm{UF}_{6}$ could be converted to their oxides separately. The equipment for separate conversions is not included in the present design conçept.

The main processing units in the converter system (shown in Fig. 4.18) are the fluid-bed reactor for conversion of the hexafluorides to oxide product and a moving-bed reactor containing limestone to remove $\mathrm{HF}$ from the converter off-gas. Table 4.32 gives reactant and product flowrates for the converter system.

\subsubsection{Outline of Process Steps}

The source of feed material for the converter system is decontaminated $\mathrm{P}_{\mathrm{u}} \mathrm{F}_{6}$ from cold trap CT-3 and: decontaminated $\mathrm{U}_{6} \mathrm{~F}_{6}$ from the distillationsorption purification system. The $\mathrm{PuF}_{6}$ and $\mathrm{UF}_{6}$ will be metered and blended in line in the appropriate proportions to give the desired; 23 wt $\% \mathrm{PuO}_{2}-\mathrm{UO}_{2}$ product. Although the stoichiometry of the conversion reaction requires only a single mole of hydrogen and two moles of steam for each mole of the mixed 
oxide, the actual feed to the converter system will be 2.5 moles of steam and 1.5 moles of hydrogen for each mole of the mixed hexafluorides. Excess reagents are used to ensure a high-density product with a minimum amount of residual fluoride. Further reduction in fluoride content of the oxide product requires a cleanup reaction period in which no hexafluorides are fed to the converter but only steam and hydrogen in a $1 / 1$ mole ratio. The process design of the converter system allows semicontinuous operation of the converter, consisting of $\mathrm{l} \mathrm{hr}$ of hexafluoride feed followed by a $\mathrm{l}-\mathrm{hr}$ cleanup period; $34.1 \mathrm{~kg}$ of $\mathrm{PuO}_{2}-\mathrm{UO}_{2}$ product is withdrawn from the converter every $2 \mathrm{hr}$.

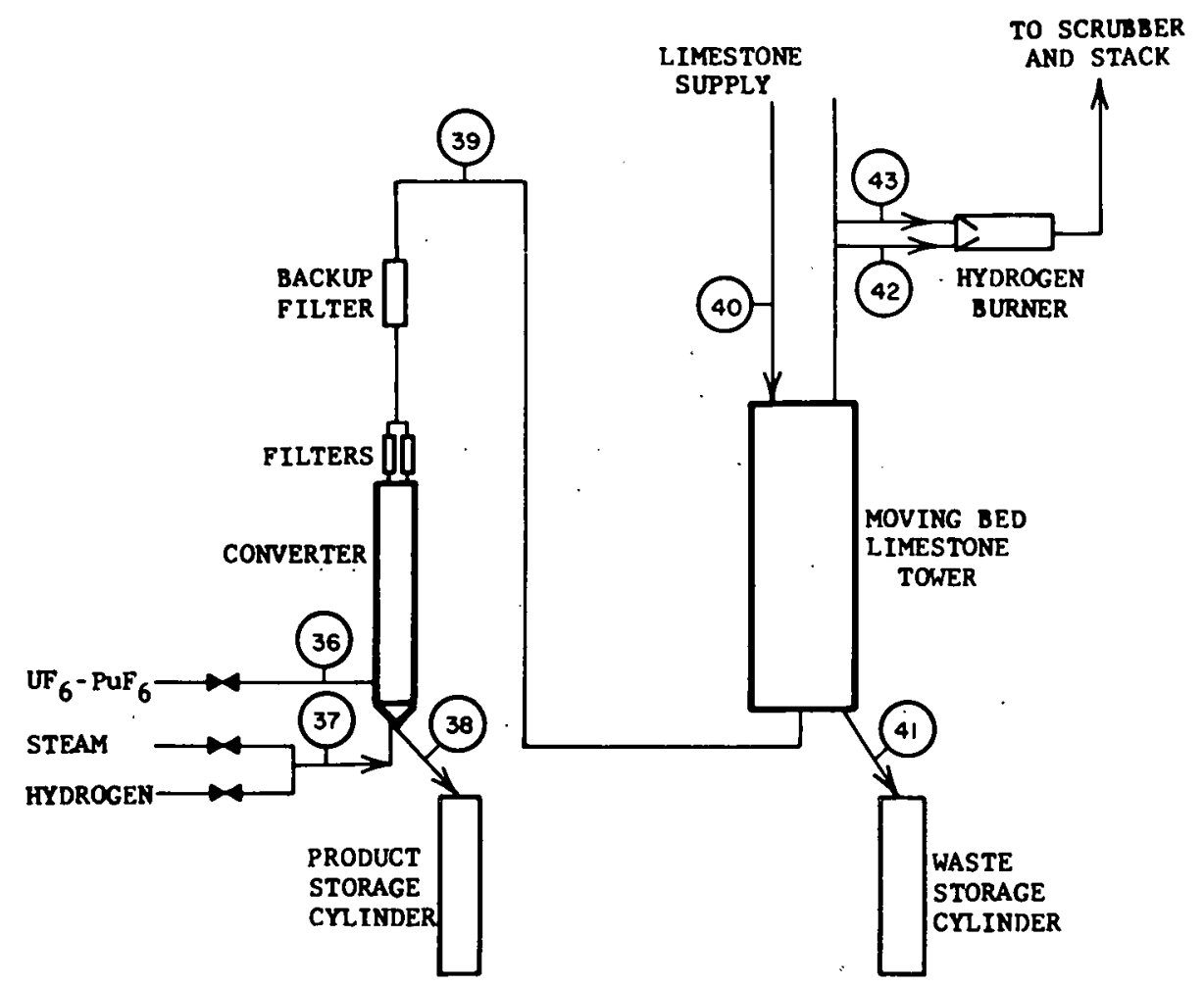

\begin{tabular}{|c|c|c|c|c|c|c|c|c|}
\hline \multicolumn{4}{|c|}{ INPUT } & \multicolumn{3}{|c|}{ WASTE } & \multicolumn{2}{|c|}{ PRODUCT } \\
\hline STREAM NO. & $\begin{array}{c}36 \\
(K G / H R) \\
\end{array}$ & $\begin{array}{c}37 \\
(\mathrm{~K} G / \mathrm{HR}) \\
\end{array}$ & $\begin{array}{c}40 \\
(\mathrm{KG} / \mathrm{HR}) \\
\end{array}$ & & $\begin{array}{r}42 \\
(\mathrm{KG} / \mathrm{HR}) \\
\end{array}$ & $\begin{array}{c}41 \\
(\mathrm{KG} / \mathrm{HR}) \\
\end{array}$ & & $\begin{array}{c}38 \\
(\mathrm{KG} / \mathrm{HR}) \\
\end{array}$ \\
\hline $\mathrm{UF}_{6}-\mathrm{PuF}_{6}$ & 22.2 & .- & -- & STEAM & 2.8 & -- & $\mathrm{UO}_{2}-\mathrm{PuO}_{2}$ & 17.1 \\
\hline STEAM & -- & 5.12 & -- & $\mathrm{H}_{2}$ & 0.32 & -- & & \\
\hline $\mathrm{H}_{2}$ & -- & 0.45 & -- & $\mathrm{CaCO}_{3}$ & -- & 1.6 & & \\
\hline LIMESTONE $\left(\mathrm{CaCO}_{3}\right)$ & -- & -- & 16.5 & $\mathrm{CaF}_{2}$ & -. & 14.8 & & \\
\hline & & & & $\mathrm{CO}_{2}$ & -- & 8.3 & & \\
\hline
\end{tabular}

Fig. 4.18. Schematic Diagram of Equipment for Conversion of Mixed Hexafluorides to Oxide Products 


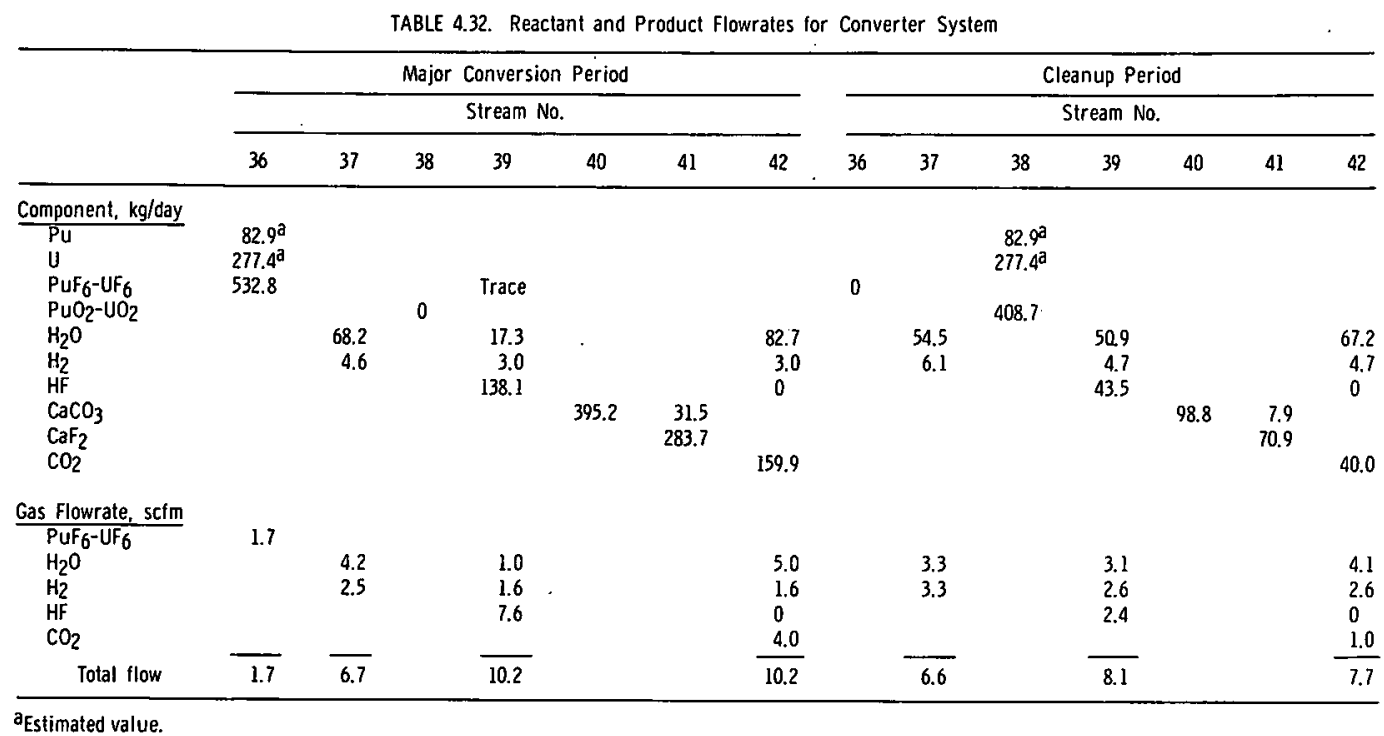

During the hexafluoride feeding period, once-through gas feed is used and the excess reagents (steam and hydrogen) together with the reaction product, hydrofluoric acid $(\mathrm{HF})$, are passed to a moving-bed tower where reaction with limestone removes $H F$ from the gas stream. Excess hydrogen remaining in the gas stream is subsequently burned to water.

During the cleanup period to remove residual fluoride from the deposited layers of oxide, relatively little reactant is used. Once-through gas flow has been selected for this period, although gas recycle is feasible.

The $\mathrm{PuO}_{2}-\mathrm{UO}_{2}$ product is collected in containers appropriately sized and constructed for safe shipment to fuel fabrication facilities. Packaging and shipping of the product, which can be handled by well-known techniques in current use, are not considered to be within the scope of this study.

\subsubsection{Engineering and Instrumentation}

The fluid-bed converter is similar to other processing units in that it is a rectangular parallelepiped $4 \mathrm{in}$. thick, $13.5 \mathrm{in}$. wide, and $7 \mathrm{ft} \mathrm{high}$. The converter is constructed of Inconel and is designed to operate at $650^{\circ} \mathrm{C}$. Because of the tensile strength of Inconel and its small width (13.5 in.), the reactor conforms to the ASTM standards for fixed-pressure vessels at the operating temperature and 2 atm pressure. ${ }^{123}$ The converter is shown schematically in Fig. 4.19.

The converter is operated semicontinuously: A batch of $\mathrm{PuO}_{2}-\mathrm{UO}_{2}$ product $(34.1 \mathrm{~kg})$ is removed every $2 \mathrm{hr}$; the total capacity of the converter is $409 \mathrm{~kg}$ of $\mathrm{PuO}_{2}-\mathrm{UO}_{2}$ product per day. To achieve this production, the converter is operated alternately for $\mathrm{l} \mathrm{hr}$ with mixed hexafluoride-steamhydrogen feed and for $1 \mathrm{hr}$ with steam-hydrogen feed. The inventory of fluid-bed material $\left(\mathrm{PuO}_{2}-\mathrm{UO}_{2}\right)$ ranges from $87.4 \mathrm{~kg}$ at the beginning of a 
$2-\mathrm{hr}$ cycle to $121.5 \mathrm{~kg}$ at the end of the cycle. This inventory corresponds to (1) a static-bed height ranging from $1.5 \mathrm{ft}$ initially to $2.0 \mathrm{ft}$ after $2 \mathrm{hr}$ and (2) a fluid-bed height of approximately $3 \mathrm{ft}$ at all times. At the operating conditions of $650^{\circ} \mathrm{C}$ and $1 \mathrm{~atm}$, the steam-hydrogen reagents will be fed to the reactor at a superficial gas velocity of $1 \mathrm{ft} / \mathrm{sec}$.

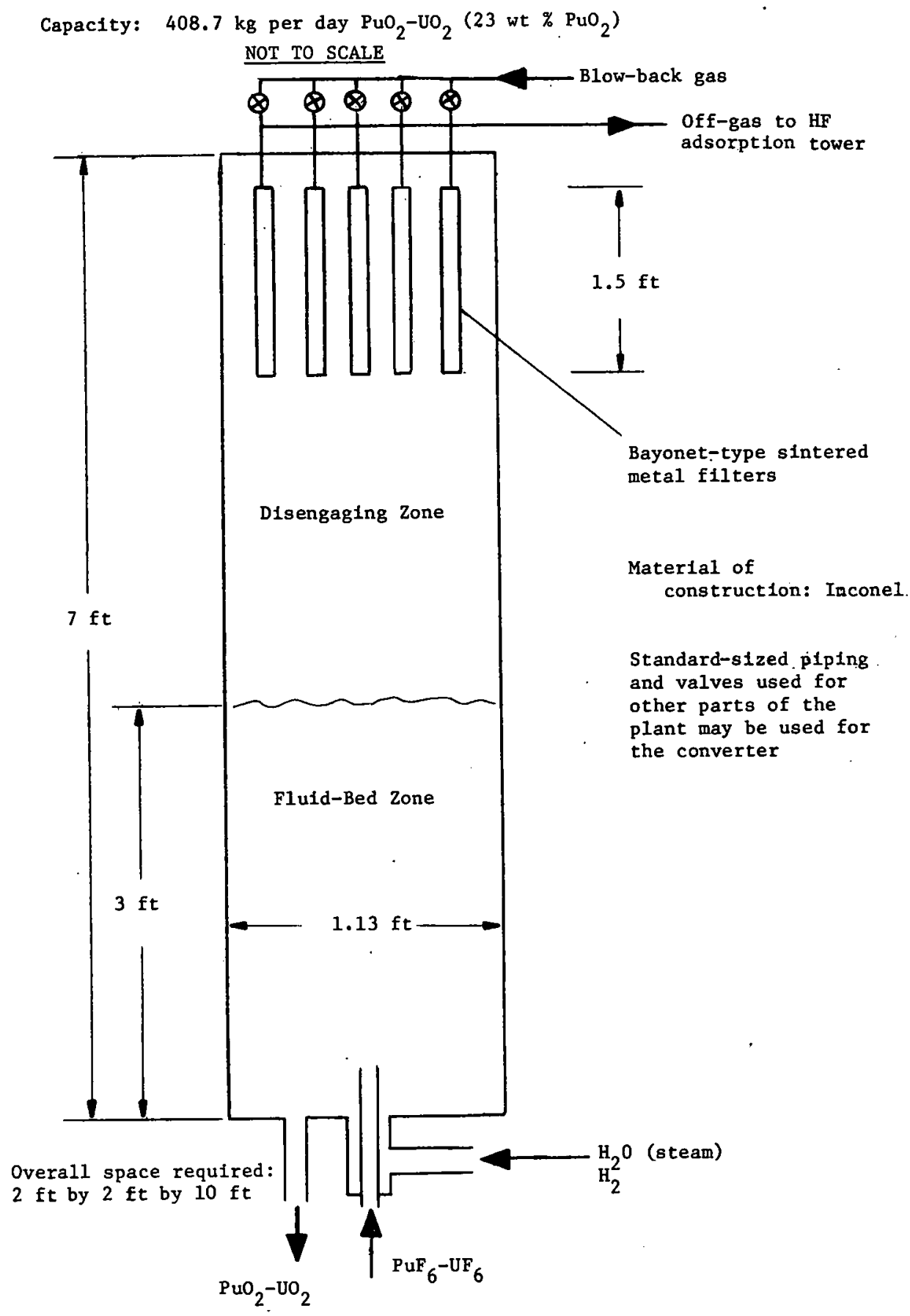

Fig. 4.19. Schematic Diagram of Fluid-bed Converter

As do the uranium and plutonium fluorinators, the fluid-bed converter provides sufficient transport disengaging height above the fluidized bed $(\sim 2.5 \mathrm{ft})$ to remove most of the entrained solids from the gas stream. 
Elutriated fine particles of $\mathrm{PuO}_{2}-\mathrm{UO}_{2}$ will be removed from the converter off-gas by five sintered-metal filters having an average pore size of $10 \mu \mathrm{m}$. Each filter is 1.1 in. thick, $3.0 \mathrm{in}$. wide, and $1 . .5 \mathrm{ft}$ high, so that a total of $3.6 .5 \mathrm{ft}^{2}$ of filter area is available and the forward flowrate of process gas is $2.9 \mathrm{scfm} / \mathrm{ft}^{2}$ filter. Accumulated solids on the filters are returned to the reaction zone by reverse gas flow (or blowback) of each filter every $40 \mathrm{sec}$. Reverse flow of gas at 80 psig is maintained for $0.5 \mathrm{sec}$ so that the blowback. gas flowrate is $2.3 \mathrm{scfm} / \mathrm{ft}^{2}$ filter. The filters are operated at $200^{\circ} \mathrm{C}$ to reduce corrosion to a minimum and to prevent condensation of the steam and $\mathrm{HF}$.

Table 4.33 gives material balances for the conversion of mixed hexafluorides to 23 wt $\% \cdot \mathrm{PuO}_{2}-\mathrm{UO}_{2}$ product. This material balance is drawn around the fluid-bed converter, which uses a feed stream of $532.8 \mathrm{~kg} / \mathrm{day}$ of $\mathrm{UF}_{6}-\mathrm{PuF}_{6}$ to produce $408.7 \mathrm{~kg}$ of $\mathrm{PuO}_{2}-\mathrm{UO}_{2}$ product. As indicated:in Table 4.33 , about $6.6 \%$ of the steam and $23 \%$ of the hydrogen fed to the converter during the cleanup part of the cycle react; therefore, during this period, the converter off-gas may be recycled to the reactor to conserve reagents and to reduce the quantity of waste gas. The converter is operated through 12 complete cycles every $24 \mathrm{hr}$; an average of $34: 1 \mathrm{~kg}$ of product is produced in eich cycle.

TA.BLE 4.33. Material Balance for the Conversion of $\mathrm{PuF}_{6}-\mathrm{UF}_{6}$. to $\mathrm{PuO}_{2}-\mathrm{UO}_{2}$

Production rate: $\quad 408.7 \mathrm{~kg} /$ day 23 wt $\% \mathrm{PuO}_{2}-\mathrm{UO}_{2}$

Product bulk density: $5.5 \mathrm{~g} / \mathrm{cc}$

$\mathrm{PuO}_{2}-\mathrm{UO}_{2}$ fluid bed: $87.4 \mathrm{~kg}$ at start of $2-\mathrm{hr}$ cyclic period;

$121.5 \cdot \mathrm{kg}$ at end of period

\begin{tabular}{|c|c|c|c|c|c|c|c|}
\hline \multirow[b]{2}{*}{ Constituent } & \multicolumn{2}{|c|}{$\begin{array}{l}\text { Major Conversion } \\
\text { Period, kg/day }\end{array}$} & \multicolumn{2}{|c|}{$\begin{array}{c}\text { Cleanup Period, } \\
\mathrm{kg} / \mathrm{day}\end{array}$} & \multicolumn{2}{|c|}{ Total, .kg/day } & \multirow{2}{*}{$\begin{array}{c}\text { Net Gain } \\
\mathrm{kg} / \text { day }\end{array}$} \\
\hline & Input & Output & Input & Output & Input & Output & \\
\hline $\mathrm{PuF}_{6}-\mathrm{UF}_{6}$ & 532.8 & $\sim 0$ & & & 532.8 & $\sim 0$ & -532.8 \\
\hline $\mathrm{PuO}_{2}-\mathrm{UO}_{2}$ & & & & 408.7 & & 408.7 & 408.7 \\
\hline $\mathrm{H}_{2} \mathrm{O}$ & 68.2 & 17.3 & .54 .5 & 50.9 & 122.7 & 68.2 & -54.5 \\
\hline $\mathrm{H}_{2}$ & $4: 6$ & 3.0 & 6.1 & 4.7 & $: 10.7$ & 7.7 & -3.0 \\
\hline $\mathrm{HF}$ & 0 & $1 \cdot 38.1$ & 0 & 43.5 & 0 & 181.6 & 181.6 \\
\hline
\end{tabular}

The material balance in Table 4.33 shows that for each day of operation there is a net consumption of $54.5 \mathrm{~kg}$ of steam and $3.0 \mathrm{~kg}$ of hydrogen and.a net preduction of $181.6 \mathrm{~kg}$ of $\mathrm{HF}$. Off-gas from the converter will consist of all of the HF plus $68.2 \mathrm{~kg}$ of steam per day and $7.7 \mathrm{~kg}$ of hydrogen per day. After removal of $H F$ from the gas stream by reaction with limestone in the moving-bed reactor, the hydrogen will be burned to form $69.3 \mathrm{~kg}$ of $\mathrm{H}_{2} \mathrm{O}$.

All the off-gas from the fluid-bed converter is passed to the movingbed reacitor, which is packed with oolitic limestone particles having a diameter of 0.13 in. This reactor (fabricated of extra-heavy'seamless steel), $3 \mathrm{ft}$ in diameter and l l. $\mathrm{ft}$.high, is shown schematically in Fig. 4.20. The 
diameter was chosen on the basis of pilot-plant development work by Hignett and Siegel ${ }^{124}$ for a TVA demonstration plant. The height of the adsorber unit provides sufficient bed depth and gas residence time for complete adsorption of the HF from the off-gas. The residence time for $H F$ is about 8.2 min during the major conversion period and about $46.3 \mathrm{~min}$ during the cleanup reaction period (based on the volume of feed gas at standard conditions). The operating temperature for the adsorption unit is $100^{\circ} \mathrm{C}$ to prevent condensation of steam and $\mathrm{HF}$.

NOT TO SCALE

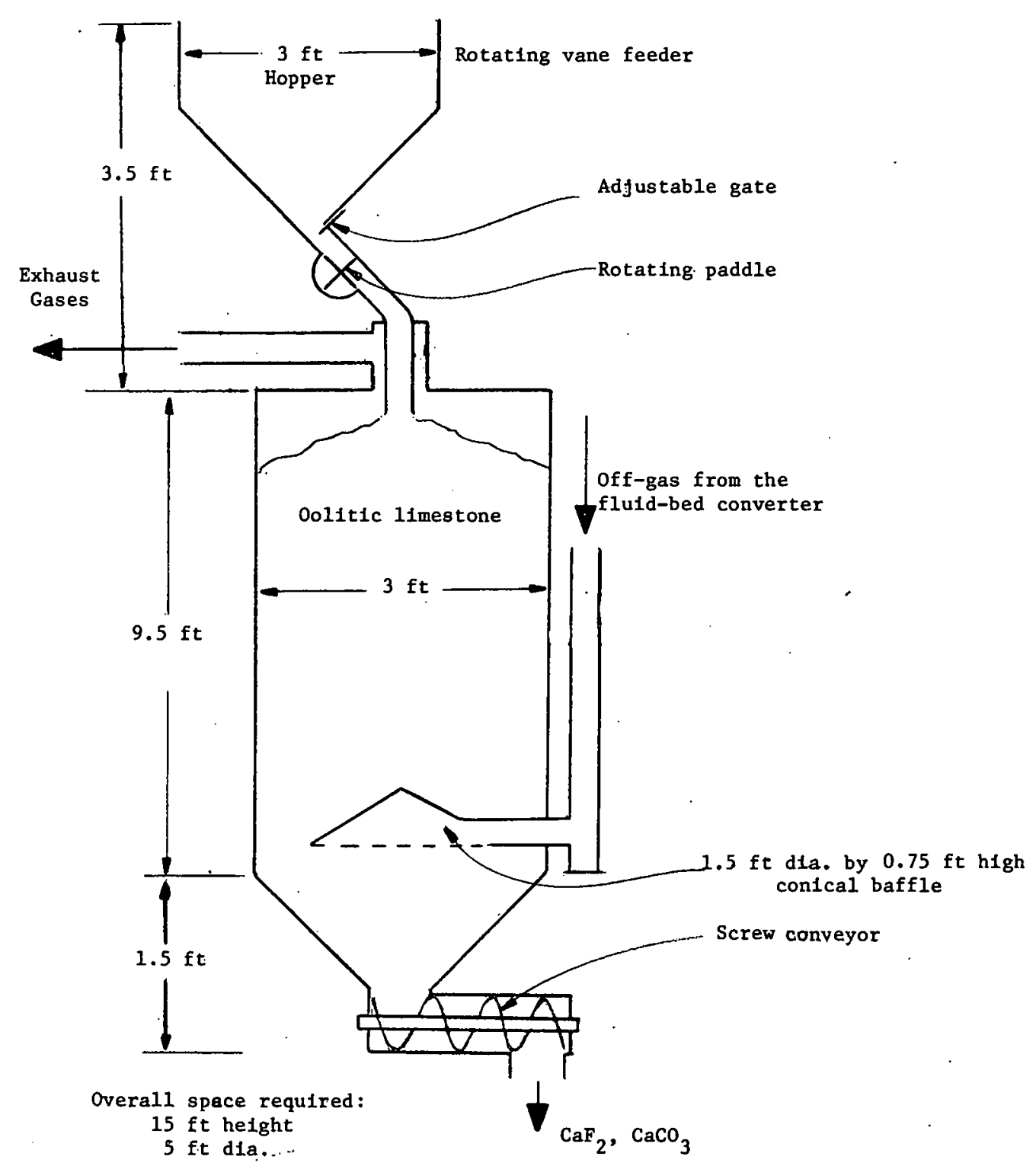

Fig. 4.20. Moving-bed Adsorber for Removing Hydrogen Fluoride from Converter Off-gas

The oolitic limestone consists of agglomerates of small round grains of carbonate of lime; this material is highly reactive, and $92 \%$ of the daily 
input of $494 \mathrm{~kg}$ is chemically utilized for the removal of HF from the offgas. The limestone is fed to the adsorption unit from a 3-ft-diam hopper equipped with a rotating vane feeder, an adjustable gate valve, and a rotating paddle (see Fig: 4.20). The mass of limestone contained in the adsorption unit is $2200 \mathrm{~kg}$.

Table 4.34 gives the material balance for the feed and waste streams to the hydrogen fluoride adsorption unit. The solids input to the unit consists of $494 \mathrm{~kg} / \mathrm{day}$ of oolitic limestone; this input rate is $8 \%$. more than that required to remove $182 \mathrm{~kg} /$ day of $\mathrm{HF}$ fed to the unit during the cyclic major conversion and cleanup periods of operation in the converter. There is a net gain of $81.7 \mathrm{~kg} /$ day steam in the adsorption unit due to the reaction

$$
\mathrm{CaCO}_{3}(\mathrm{~s})+\mathrm{HF}(\mathrm{g}) \rightarrow \mathrm{CaF}_{2}(\mathrm{~s})+\mathrm{H}_{2} \mathrm{O}(\mathrm{g})+\mathrm{CO}_{2}(\mathrm{~g})
$$

This steam, together with steam not used in the conversion reaction, amounts to. $149.9 \mathrm{~kg} / \mathrm{day}$, which is condensed and treated as low-level liquid waste. The volume of liquid waste is $5.3 \mathrm{ft}^{3} /$ day or $40 \mathrm{gal} / \mathrm{day}$. The gaseous lowlevel waste stream consists of $7.7 \mathrm{~kg} /$ day of hydrogen and $199.9 \mathrm{~kg} / \mathrm{day}$ of $\mathrm{CO}_{2}$. The flowrate for the gaseours effluent will average $5.6 \mathrm{scfm}$ during the major conversion periods. The solids waste stream from the adsorption unit consists of $354.6 \mathrm{~kg} /$ day of $\mathrm{CaF}_{2}$ and $39.4 \mathrm{~kg} /$ day of unreacted $\mathrm{CaCO}_{3}$; the storage volume required for this low-level waste is $19.2 \mathrm{ft}^{3} / \mathrm{day}$.

TABLE 4.34. Material Balance for the Hydrogen Fluoride Adsorber

\begin{tabular}{|c|c|c|c|c|c|c|c|}
\hline \multirow[b]{2}{*}{ Constituent } & \multicolumn{2}{|c|}{$\begin{array}{c}\text { Major Conversion } \\
\text { Period, kg/day }\end{array}$} & \multicolumn{2}{|c|}{$\begin{array}{c}\text { Cleanup Period, } \\
\mathrm{kg} / \text { day }\end{array}$} & \multicolumn{2}{|c|}{ Total, kg/day } & \multirow{2}{*}{$\begin{array}{c}\text { Net Gain, } \\
\text { kg/day }\end{array}$} \\
\hline & Input & Output & Input & Output & Input & Output & \\
\hline $\mathrm{H}_{2} \mathrm{O}$ & 17.3 & 82.7 & 50.9 & 67.2 & 68.2 & 149.9 & 81.7 \\
\hline $\mathrm{H}_{2}$. & 3.0 & 3.0 & 4.7 & 4.7 & 7.7 & 7.7 & 0 \\
\hline $\mathrm{HF}$ - & 1.38 .1 & 0 & 43.5 & 0 & 181.6 & 0 & -181.6 \\
\hline $\mathrm{CaCO}_{3}$ & 395.2 & 31.5 & 98.8 & 7.9 & 494.0 & 39.4 & -454.6 \\
\hline $\mathrm{CaF}_{2}$ & 0 & 283.7 & 0 & 70.9 & 0 & 354.6 & 354.6 \\
\hline $\mathrm{CO}_{2}$ & 0 & 159.9 & 0 & $40: 0$ & 0 & 199.9 & 199.9 \\
\hline
\end{tabular}

The instrumentation for the converter and adsorption units includes no instruments of a special nature. Instruments for monitoring temperature, pressure, and reagent flowrates and for analytical applications can be commercial off-the-shelf items.

\subsubsection{Chemistry of Conversion Reactions}

The conversion of mixed hexafluorides of uranium and plutonium to oxide product is predicted upon successful demonstration and development by Knudsen et al., ${ }^{125-127}$ of a fluid-bed process for the conversion of $\mathrm{UF}_{6}$ to $\mathrm{UO}_{2}$. In this process, $\mathrm{UF}_{6}$ is fed with a mixture of steam and hydrogen to a fluidized bed of $\mathrm{UO}_{2}$ product at $650^{\circ} \mathrm{C}$. The initial reaction is very rapid, and a layer of solid oxides and fluorides deposits on the fluid-bed particles. according to the reactions 
$3 \mathrm{UF}_{6}(\mathrm{~g})+8 \mathrm{H}_{2} \mathrm{O}(\mathrm{g})+\mathrm{H}_{2}(\mathrm{~g}) \rightarrow \mathrm{U}_{3} \mathrm{O}_{8}(\mathrm{~s})+18 \mathrm{HF}(\mathrm{g}), \Delta \mathrm{H}_{298}{ }^{\circ} \mathrm{K}=-8 \mathrm{kcal} / \mathrm{mole} ;$

and

$\mathrm{UF}_{6}(\mathrm{~g})+\mathrm{H}_{2}(\mathrm{~g}) \rightarrow \mathrm{UF}_{4}(\mathrm{~s})+2 \mathrm{HF}(\mathrm{g}), \Delta \mathrm{H}_{298^{\circ} \mathrm{K}}=-67.4 \mathrm{kcal} / \mathrm{mole}$.

The fluoride content of the solid product varied ${ }^{125}$ from 0.3 to $1.6 \mathrm{wt} \%$, and the $\mathrm{U}_{3} \mathrm{O}_{8}$ to $\mathrm{UF}_{4}$ ratio was $70 / 30$. Thus reaction of the $\mathrm{UF}_{6}$ produces a product that is not completely reduced and contains an undesirably high fluoride content. Therefore, a cleanup-reaction period during which only steam and hydrogen is fed to the reactor is used (1) to further reduce the product, (2) to further densify the product, and (3) to reduce residual fluoride to acceptable levels $(\sim 250 \mathrm{ppm})$ according to the reactions

$$
\dot{\mathrm{U}}_{3} \mathrm{O}_{8}(\mathrm{~s})+2 \mathrm{H}_{2}(\mathrm{~g}) \rightarrow 3 \mathrm{UO}_{2}(\mathrm{~s})+2 \mathrm{H}_{2} \mathrm{O}(\mathrm{g}) . \Delta \mathrm{H}_{298^{\circ} \mathrm{K}}=-41.1 \mathrm{kcal} / \mathrm{mole} ;
$$

and

$$
\mathrm{UF}_{4}(\mathrm{~s})+2 \mathrm{H}_{2} \mathrm{O}(\mathrm{g}) \rightarrow \mathrm{UO}_{2}(\mathrm{~s})+4 \mathrm{HF}(\mathrm{g}), \quad \Delta \mathrm{H}_{298^{\circ} \mathrm{K}}=44.0 \mathrm{kcal} / \mathrm{mole} .
$$

After the cleanup period, part of the fluid bed equivalent to the quantity of hexafluoride fed during the major conversion period is withdrawn as product. The process worked very well if the major conversion period and the cleanup period were of equal length. Actually, the operating cycle is flexible, and even though alternate $\mathrm{l}-\mathrm{hr}$ periods have been chosen for the operating cycle with $\mathrm{UF}_{6}-\mathrm{PuF}_{6}$, this sequence can be changed, since excellent control over process parameter's (which ensures uniformity of product) is possible in the fluid-bed process. Considerable control over product characteristics such as particle size, density, and residual fluoride content can be exercised through control of the operating cycle, temperature, and reactant ratios. Spheroidal, high-quality $\mathrm{UO}_{2}$ particles with densities up to $9.75 \mathrm{~g} / \mathrm{cc}(89 \% \mathrm{TD})$ have been produced. ${ }^{125}$ Final densification to over $95 \% \mathrm{TD}$ and reduction of fluoride content to $5 \mathrm{ppm}$ were achieved by sintering in hydrogen at about $1600^{\circ} \mathrm{C} .{ }^{125}$

Since the structure and properties of $\mathrm{UF}_{6}$ and $\mathrm{PuF}_{6}$ are similar, a conversion reaction for mixtures of $\mathrm{UF}_{6}-\mathrm{PuF}_{6}$ would probably proceed in a manner similar to that for $\mathrm{UF}_{6}$ alone. For example, the reactions may proceed as follows:

$$
\mathrm{PuF}_{6}-\mathrm{UF}_{6}(\mathrm{~g})+4 \mathrm{H}_{2} \mathrm{O}(\mathrm{g})+2 \mathrm{H}_{2}(\mathrm{~g}) \rightarrow \mathrm{PuO}_{2}-\mathrm{UO}_{2}(\mathrm{~s})+12 \mathrm{HF}(\mathrm{g}),
$$

and

$$
\mathrm{PuF}_{6}-\mathrm{UF}_{6}(\mathrm{~g})+2 \mathrm{H}_{2}(\mathrm{~g}) \rightarrow \mathrm{PuF}_{4}-\mathrm{UF}_{4}(\mathrm{~s})+4 \mathrm{HF}(\mathrm{g})
$$

$\mathrm{U}_{3} \mathrm{O}_{8}$ may form, yielding the intermediate product $\mathrm{PuO}_{2}-\mathrm{U}_{3} \mathrm{O}_{8}$. A cleanup period will be required to further reduce and densify the product 


$$
\mathrm{PuO}_{2}-\mathrm{U}_{3} \mathrm{O}_{8}(\mathrm{~s})+2 \cdot \mathrm{H}_{2}(\mathrm{~g}) \rightarrow \mathrm{PuO}_{2}-3 \mathrm{UO}_{2}(\mathrm{~s})+2 \mathrm{H}_{2} \mathrm{O}(\mathrm{g})
$$

and to reduce residual fluoride to low levels

$$
\mathrm{PuF}_{4}-\mathrm{UF}_{4}(\mathrm{~s})+2 \mathrm{H}_{2} \mathrm{O}(\mathrm{g}) \rightarrow \mathrm{PuO}_{2}-\mathrm{UO}_{2}(\mathrm{~s})+4 \mathrm{HF}(\mathrm{g}) \text {. }
$$

Although no work has been reported on the conversion of such $\mathrm{PuF}_{6}$ $\mathrm{UF}_{6}$ mixtures, Robinson and co-workers ${ }^{128}$. showed the conversion of $\mathrm{PuF}_{6}$ to $\mathrm{PuO}_{2}$ in the presence of $\mathrm{H}_{2} \mathrm{O}$ and hydrogen to be feasible. Also, the hydrogen reduction of $\mathrm{PuF}_{6}$ to $\mathrm{PuF}_{4}$ has been demonstrated in a scrap recovery process at the Dow Rocky Flats Laboratory. Analogous to this, UF 6 was reduced to $\mathrm{UF}_{4}$ with hydrogen at ORGDP. ${ }^{129}$ This reaction is considered pertinent, since the exact mechanism of the overall conversion reaction is not known.

$\mathrm{PuF}_{6}$ is known to be thermally unstable at the temperatures $(650$ $700^{\circ} \mathrm{C}$ ) normally used to convert $\mathrm{UF}_{6}$ to $\mathrm{UO}_{2}$, but we assume that a solid plutonium-uranium material will codeposit and that an acceptable oxide product will be produced by the conversion process, which is the final major processing step in the referenc.e fluoride-volatility process.

An alternative method of converting the $P F_{6}-U F_{6}$ to oxide product could consist of a sequential conversion process, also developed for $U F_{6}$ alone. ${ }^{127}$. In the first step in this process, $U F_{6}$ was reacted with steam at a relatively low temperature of $200^{\circ} \mathrm{C}$ to give a solid $\mathrm{UO}_{2} \mathrm{~F}_{2}$ product near the theoretical density. The $\mathrm{UO}_{2} \mathrm{~F}_{2}$ was then converted to $\mathrm{UO}_{2}$ by reaction with steam and hydrogen at $600^{\circ} \mathrm{C}$. A similar process can be assumed to be practical for $\mathrm{UF}_{6}-\mathrm{PuF}_{6}$ mixtures, if reaction with steam is as sumed to yield a $\mathrm{PuO}_{2} \mathrm{~F}_{2}-\mathrm{UO}_{2} \mathrm{~F}_{2}$ product. This as sumption is supported by the work of Kessie and Ramaswami, ${ }^{130}$ who showed that the gas-phase kinetics for the reactions of $\mathrm{UF}_{6}$ and $\mathrm{PuF}_{6}$ with moisture at ambient conditions were similar.

The proposed development program should first establish the feasibility of the conversion process for $P_{u F}-U F_{6}$ mixtures. A parametric study of variables (e.g., hexafluoride feed rate, reactant ratios, and bed temperature) would provide information on their effect on product particle density, fluoride content, and $\mathrm{PuO}_{2}-\mathrm{UO}_{2}$ homogeneity. In work on the conversion of $\mathrm{UF}_{6}$, the residual fluoride content was about 10.0-300 ppm. Optimization of fluoride removal was not studied, since in subsequent sintering tests at $1650^{\circ} \mathrm{C}$ in hydrogen, the fluoride content was reduced to about $5 \mathrm{ppm}$. The rate of fluoride removal is believed to be a function of particle density, which in turn can be controlled by process variables. Significantly lower sintering temperatures might be possible with an intermediate-density oxide (e.g., 65\% theoretical), which can also be produced. Final densification would be achieved during sintering. 
Most of the fission products associated with the hexafluoride feed before conversion are converted to oxides and remain as trace contaminants in the product. Table 4.35 shows the expected quantities of fission products fed to the converter and in the product oxide. The overall DF at this point in the process is about $7.5 \times 10^{6}$. Tritium as ${ }^{3} \mathrm{HF}$ and possibly $\mathrm{IF}_{5}$ pass from the converter to the limestone adsorption unit with excess reagents. The sorption unit vents to the off-gas treatment system if the residual activity is above the set tolerance; otherwise the sorption unit vents directly to the plant ventilation system.

TABLE 4.35. Fission-product Activities Associated with the Converter Feed and Product Streams and Overall DFa

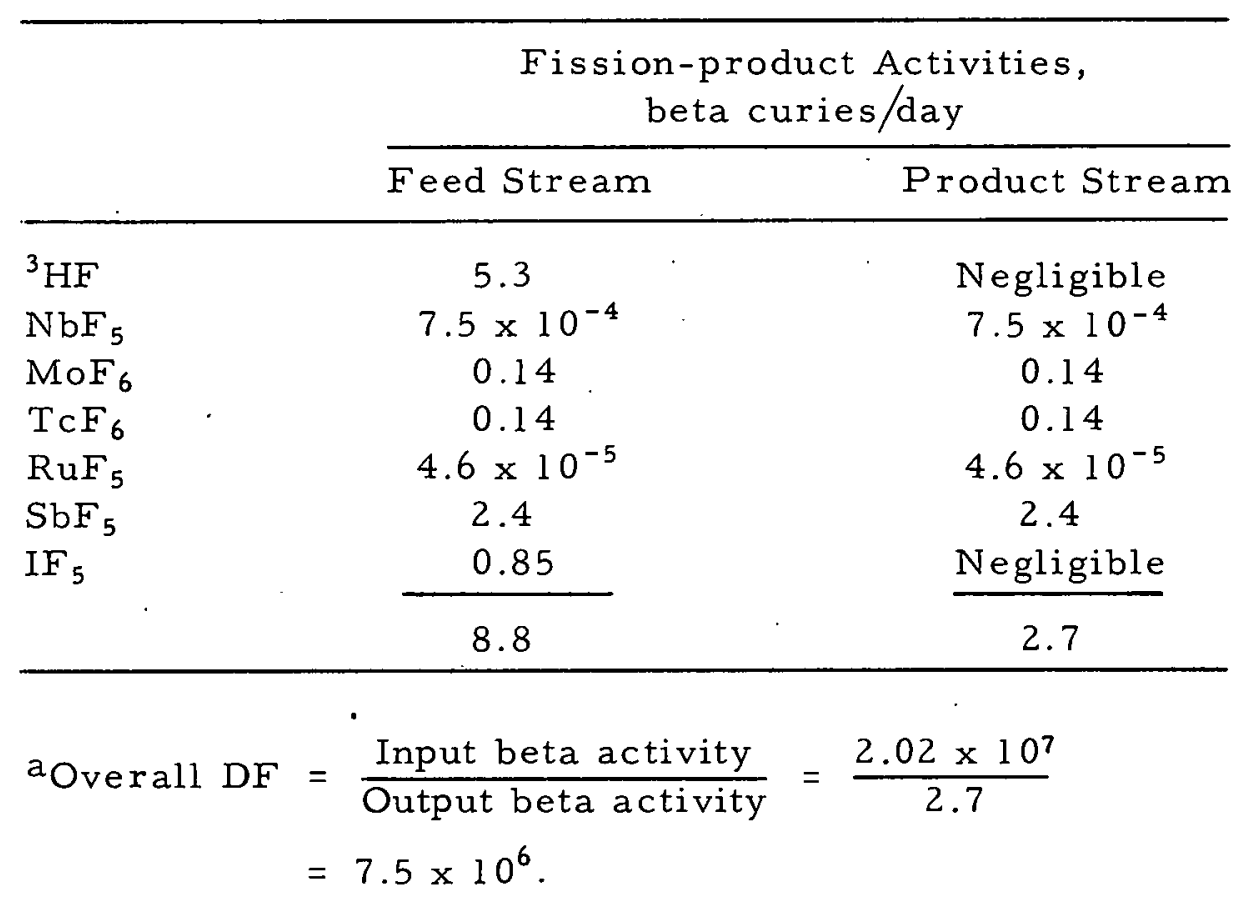

\subsection{4 $\mathrm{PuO}_{2}-\mathrm{UO}_{2}$ Product Packaging}

$\mathrm{PuO}_{2}-\mathrm{UO}_{2}$ product is withdrawn from the converter at a rate of $34.1 \mathrm{~kg}$ per $2-\mathrm{hr}$ cycle or $409 \mathrm{~kg} / \mathrm{day}$. The product is stored in slab-shaped receivers, which are critically safe by geometry, for transport to the fuel fabricators. The product is sampled for accountability and quality-control checks before shipment.

The $\mathrm{PuO}_{2}-\mathrm{UO}_{2}$ product particles will be spheroidal and will be suitable for vibratory compaction into fuel rods, if this is the desired fuelfabrication method. Milling of the product will be necessary if it is desirable to fabricate pellets for use as LMFBR nuclear fuel. Techniques for milling uranium fuels are widely known. Therefore, the milling of $\mathrm{PuO}_{2}-\mathrm{UO}_{2}$ particles-does-not-appear to-be-a-process problem. Further evaluation of the product as to suitability for nuclear fuel will involve physical and chemical tests and ultimately test irradiations. 


\subsection{Gaseous Waste Handling System}

4.8.1 Outline of Process System

A gaseous waste handling system that permits total waste containment is described in this section. Input streams are the sweep gases from the fuel chopper and ball mill (described. in Section 4.2.5), oxygen used in transferring the $\mathrm{RuF}_{5}-\mathrm{NbF}_{5}$ fission-product gas mixture from $F P^{\prime}-1$ and FP-2 to a NaF bed, -off-gas from the fluorinator A recycle gas loop (described in Section 4.3.6), and the distillation column S-1 bottoms and column S-2 overhead. streams (both described in Section. 4.6). The output streams are the sorbents loaded with fission products, water from oxygen disposal (oxygen-hydrogen) reaction, and a xenon-krypton gas mixture. The input streams, the sorbents, and the method of proce'ssing the gaseous wastes are shown schematically in Fig. 4.21. The overhead gas from still S-2 is passed through $\mathrm{NaF}-\mathrm{MgF}_{2}$ to remove ${ }^{3} \mathrm{HF}$ and other fission products before being mixed with the other gaseous wastes and passed through the first activated alumina bed. Here, fluorine and some of the fission-product fluorides are collected by reaction with alumina, and some of the fission-product fluorides are converted to oxides or oxyfluorides or àre decomposed to lower-valence fluorides or to the element and fluorine. Subsequent beds of soda lime, activated alumina, and a Molecular Sieve bed remove most of the remaining fission products from the stream. The oxygen is removed next by reaction with hydrogen and condensation of the water, leaving a xenon-krypton mixture, which is compressed and stored.

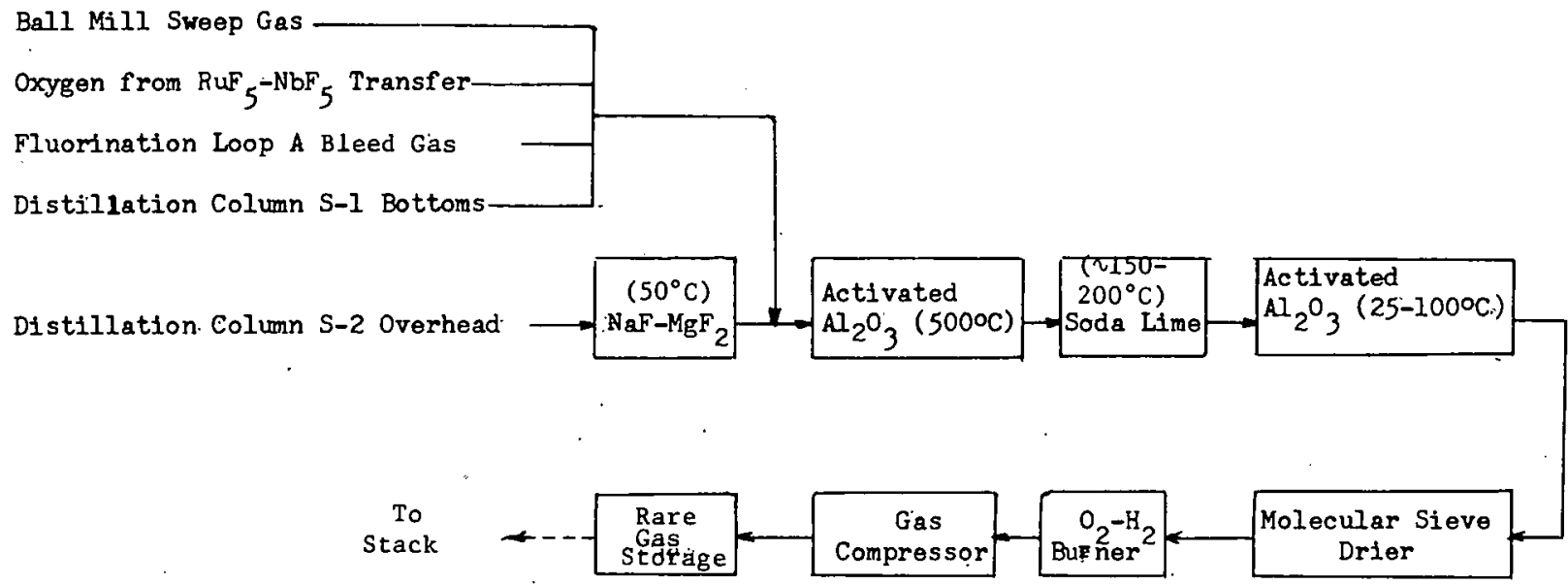

Fig. 4.21. Schematic Diagram of Gaseous Waste Handling System

\subsubsection{Engineering Aspects and Equipment Design}

Pertinent design information and a description are presented for each equipment item in the processing sequence. Equipment sizes are given for all items except the fixed-bed sorbers, which are uniformly $2 \mathrm{ft}$ in diameter and 9. ft tall. 
4.8.2.1 The NaF-MgF ${ }_{2}$ Bed. The overhead gas from distillation column S-2 is passed through $\mathrm{NaF}-\mathrm{MgF}_{2}$ solids (at $\sim 50^{\circ} \mathrm{C}$ ) to remove fluorides of tritium, molybdenum, uranium, and technetium before being combined with other waste streams. Tellurium fluoride and small quantities of the above fission products are not sorbed, but are collected later.

Very little experimental data are available on the capacities of $\mathrm{NaF}$ for fission-product fluorides in fluorine and oxygen gas streams, although the sorption complexes of these compounds have been identified. ${ }^{131}$ Maximum NaF sorption capacities calculated from the complex compositions are considerably higher than the sorption capacities obtained experimentally. For example, sodium fluoride has been loaded to only $5-7 \%$ with niobium when $\mathrm{UF}_{6}$, fluorine, and $\mathrm{NbF}_{5}$ have been recirculated through $\mathrm{NaF},{ }^{132}$ but the niobium content of the complex is $34 \%$. For calculational purposes, a 5 wt $\%$ metal loading of $\mathrm{NaF}$ and other sorbents has been assumed for fissionproduct fluorides. For $\mathrm{UF}_{6}$, more loading data are available and a 20 wt $\%$ metal loading has been assumed. With these criteria, the daily waste volume is $3.74 \mathrm{ft}^{3}$ of $\mathrm{NaF}-\mathrm{MgF}_{2}$, which on a yearly basis (365 days) can be stored in 44 waste-storage cylinders. Fission-product decay heat in the waste is negligible, and the wastes can be shipped to permanent storage immediately.

\subsubsection{The High-temperature Activated-alumina Bed. In this fluid-} ized bed of activated alumina, the fluorine is reacted at $500^{\circ} \mathrm{C}$. Although at this temperature fission-product fluorides may either decompose or form oxides or oxyfluorides, little experimental information is available on the type or extent of the reactions. Therefore, soda lime, low-temperature $\left(25-100^{\circ} \mathrm{C}\right)$ activated alumina, and Molecular Sieve beds are in the process train to collect any fission products not collected by the high-temperature alumina bed. It is expected that $I_{5}$ will be decomposed, the iodine will be sorbed on the soda lime, $\mathrm{XeF}_{4}$ will decompose, and other fission-product fluorides (except possibly $\mathrm{TeF}_{6}$ ) will remain in the $500^{\circ} \mathrm{C}$ alumina bed. The $\mathrm{TeF}_{6}$ will be sorbed in the low-temperature alumina bed. Bed loadings of 5 and $20 \mathrm{wt} \%$ (as metal) have been assumed for the fission-product fluorides and the $\mathrm{UF}_{6}$, respectively. For the conversion of alumina to $\mathrm{AlF}_{3}$ by fluorine, the expected loading is $0.8 \mathrm{~g}$ of fluorine per gram of alumina. ${ }^{133}$ Because of the heat load from the fluorine-alumina reaction and the fission-product decay energy release, a fluid-bed unit with a 10 in. diameter has been chosen rather than a fixed-bed unit. The unit is sized on the basis that oxygen in the feed gas is the fluidizing medium.

The daily volume of alumina waste is $2.52 \mathrm{ft}$, and a waste cylinder is filled every 10.6 days. Filled cylinders must be stored for 3.6 yr before the heat level drops to $2 \mathrm{~W} /$ liter and they can be transferred to a permanent storage site. Thus 124 cylinders are stored at storage equilibrium. The ${ }^{125} \mathrm{Sb}$ fission product is the main heat source after 4 months. Aluminum is added to the alumina. Under these conditions, the aluminum will melt initially, filling most of the void volume and subsequently solidifying. Calculations show a resulting centerline temperature of $144^{\circ} \mathrm{C}$. The addition of aluminum was discussed in Section 4.3 .9 
4.8.2.3 The Soda-lime Bed. The fixed bed. of soda lime sorbs any iodine released from the $500^{\circ} \mathrm{C}$ alumina trap by decomposition of $\mathrm{IF}_{5}$ and possibly some other fission-product compounds not contained by the alumina. The daily volume of waste based on iodine sorption only will be $0.36 \mathrm{ft}^{3}$. Because of the short ${ }^{131}$ I half-life (8.1 days), the heat-generation rate will decay to the level ( $2 \mathrm{~W} /$ liter) desired for permanent storage in less than 43 days.

4.8.2.4... The Low-temperature Activated-alumina Bed. A fixed bed of activated alumina is held at $25-100^{\circ} \mathrm{C}$ to sorb $\mathrm{TeF}_{6}$ that might pass through upstream traps. The design basis for this trap is a loading of $0.074 \mathrm{~g}$ of tellurium per gram of $\mathrm{Al}_{2} \mathrm{O}_{3}$, reported by. Vissers and Steindler. ${ }^{134}$ If all $\mathrm{TeF}_{6}$ entering. the gaseous waste handling facility is assumed to be collected here, the dail.y waste volume will be $0.77 \mathrm{ft}^{3}$. Little heat is released by $\mathrm{TeF}_{6}$ decay, and the alumina can be disposed of immediately.

4.8.2.5 Molecular Sieve Dryer. The fixed-bed Molecular Sieve dryer ensures removal of tritium present in the form of ${ }^{3} \mathrm{H}_{2} \mathrm{O}$ as a result of reaction of ${ }^{3} \mathrm{HF}$ in the $\mathrm{Al}_{2} \mathrm{O}_{3}\left(500^{\circ} \mathrm{C}\right)$. bed. This presumes that some ${ }^{3} \mathrm{HF}$ from the S-2 overhead stream has passed through the $\mathrm{NaF}-\mathrm{MgF} 2$ bed. Also sorbed would be any water released from the high-temperature $\left(500^{\circ} \mathrm{C}\right) \mathrm{Al}_{2} \mathrm{O}_{3}$ and soda-lime beds but not sorbed on the low-temperature. $\left(25-100^{\circ} \mathrm{C}\right) \mathrm{Al}_{2} \mathrm{O}_{3}$ bed. The volume of Molecular Sieve waste is uncertain, but should be relatively small.

4.8.2.6. Oxygen-Hydrogen Reactor. In the oxygen-hydrogen reactor, the oxygen in the mixture of oxygen, xenon, and krypton leaving the Molecular Sieve bed is reacted with hydrogen and condensed as water. About $10 \mathrm{ft}^{3}$ of condensed water would be collected daily. The burner design would be similar to that of oxyhydrogen torches used industrially.

4.8.2.7 Xenon-Krypton Compression and Storage. The gases exițing from the oxygen-hydrogen reactor-are compressed to $10 \mathrm{~atm}$ and stored in a 3-ft-diam, $12 \frac{1}{2}$-ft-long tank. A minimum of 30 days of storage is contemplated to permit decay of the xenon activity. Release of this gas to the ventilation stack will be a function of regulatory policy.

Possibly, on the basis of existing AEC specifications, compression and storage of xenon and krypton may not be done, although this would be contrary to our total containment concept. With no storage, the concentration of xenon released to the environment (calculated using the stack dilution factor of Nuclear Services, Inc. ${ }^{135}$ ) would be below the AEC specification of $3 \mathrm{x} \cdot 10^{-7} \mu \mathrm{Ci} / \mathrm{cc}$. If the more conservative (but more likely in the future) stack dilution factor of ORNL ${ }^{136}$ is used, the xenon environmental concentration would be $11.6 \times 10^{-7} \mu \mathrm{Ci} / \mathrm{cc}$, which is higher than the AEC specification. Storage not only would allow the xenon activity to decay below this value, but also would allow gas release during favorable climatic conditions. Krypton, 
with an activity only about one-thirtieth of the xenon activity at the time the fuel is processed, could be released to the environment without difficulty. After 30 days of storage, krypton and xenon activity levels are about equal.

\subsubsection{Instrumentation}

Fluid-bed sorber instrumentation is similar to that in the fluid-bed units described in Sections 4.3 .5 and 4.4.3. Fixed-bed sorbers are equipped with differential pressure, absolute pressure, and temperature-measuring instruments.

\subsubsection{Material Balance}

Material balances for the gaseous waste handling system are presented in Table 4.36; the numbered streams are those shown in Fig. 4.22. As indicated earlier, some uncertainty exists as to the distribution of the fission products.

\subsubsection{Chemistry of Gaseous Waste Disposal}

Two major types of gaseous waste streams are generated in the process: (1) those streams that represent purposeful disposal of volatile fission-product compounds as exemplified by the residue in still S-1, the overhead fraction from still S-2, and the bleed stream from fluorinator A, and (2) those streams required for disposal of gaseous vehicles such as the

TABLE 4.36. Material Balance for Gaseous Waste Handling System

\begin{tabular}{|c|c|c|c|c|c|c|c|c|c|c|c|c|c|}
\hline & $32 \mathrm{~W}$ & $33 w$ & 36 & 49 & 50 & 51 & 63 & 52 & 53 & 54 & 55 & 56 & 59 \\
\hline \multicolumn{14}{|l|}{ Actinide Compound, g/day } \\
\hline $\begin{array}{l}\mathrm{PuF}_{6} \\
\mathrm{UF}_{6} \\
\mathrm{NpF}_{6}\end{array}$ & $\begin{array}{r}13,000 \\
0\end{array}$ & $\begin{array}{r}12,000 \\
2.4\end{array}$ & $\begin{array}{r}0.03 \\
1 \\
0.005\end{array}$ & & & 0 & $\begin{array}{r}\sim 12,000 \\
2.4\end{array}$ & & $\begin{array}{r}0.03 \\
\sim 13,000\end{array}$ & 0 & 0 & 0 & 0 \\
\hline \multicolumn{14}{|l|}{$\begin{array}{l}\text { Fission-product Elements } \\
\text { or Compounds, g/day }\end{array}$} \\
\hline $\begin{array}{l}\mathrm{NbF}_{5} \\
\mathrm{MoF}_{6} \\
\mathrm{TcF}_{6} \\
\mathrm{RuF}_{5} \\
\mathrm{SbF}_{5} \\
\mathrm{TeF}_{6} \\
\mathrm{IF}_{5} \\
\mathrm{Krypton} \\
\text { Xenon } \\
3_{\mathrm{HF}}\end{array}$ & $\begin{array}{r}31.1 \\
82 \\
20 \\
1.8 \\
222 \\
0 \\
880 \\
0 \\
4,586 \mathrm{~b}\end{array}$ & $\begin{array}{r}0 \\
7.935 \\
20 \\
0 \\
0 \\
1,522 \\
0 \\
0 \\
0 \\
4.2\end{array}$ & $\begin{array}{r}0 \\
1 \\
0.03 \\
0 \\
0.007 \\
93 \\
0.002 \\
133 \\
0 \\
0.04\end{array}$ & . &.$_{0}^{0}$ & $\begin{array}{r}0 \\
0 \\
0 \\
0 \\
0 \\
1,522 \\
0 \\
0 \\
0 \\
0\end{array}$ & 7,935 & & $\begin{array}{r}0 \\
83 \\
20.03 \\
1.8 \\
222 \\
0 \\
0 \\
0 \\
0 \\
0\end{array}$ & $\begin{array}{r}0 \\
0 \\
0 \\
0 \\
0 \\
1.615 \\
880^{\mathrm{a}} \\
133 \\
4.586 \\
0\end{array}$ & $\begin{array}{r}0 \\
0 \\
0 \\
0 \\
0 \\
1,615 \\
0 \\
133 \\
4,586\end{array}$ & $\begin{array}{r}0 \\
0 . \\
0 \\
0 \\
0- \\
0 \\
0 \\
133 \\
4,586\end{array}$ & $\begin{array}{r}0 \\
0 \\
0 \\
0 \\
0 \\
0 \\
0 \\
133 \\
4,586\end{array}$ \\
\hline \multicolumn{14}{|l|}{ Gas Flowrates, scfm } \\
\hline $\begin{array}{l}\mathrm{UF}_{6} \\
\text { Fluorine } \\
\mathrm{O}_{2} \text { sweep gas, ball mill } \\
\mathrm{O}_{2} \text { from fluorination loop } \\
\mathrm{O}_{2} \text { from Ru-Nb transfer } \\
\text { from } \mathrm{CT}-1 \text { and } \mathrm{CT}-2 \text { to } \\
\mathrm{NaF}, 4 \mathrm{hr} / \mathrm{day} \text { only }\end{array}$ & 0.02 & $\begin{array}{r}0.02 \\
0.206\end{array}$ & $\begin{array}{c}\text { Smallc } \\
0.123 \\
\\
2.06\end{array}$ & Smallic & 3.5 & $\begin{array}{r}0 \\
0.206 \\
0\end{array}$ & & & - & $\begin{array}{r}0 \\
0 \\
0 \\
2.06\end{array}$ & 2.06 & 2.06 & 0 \\
\hline$\frac{\text { Miscellaneous }}{\text { Activated } \mathrm{Al}_{2} \mathrm{O}_{3} \mathrm{~kg} / \mathrm{day}}$ & & & & & & & & 71.8 & & & & & \\
\hline
\end{tabular}

aAs iodine.

bAs $\mathrm{XeF}_{4}$.

$C_{\text {Quantity is low, but not specified. }}$ 


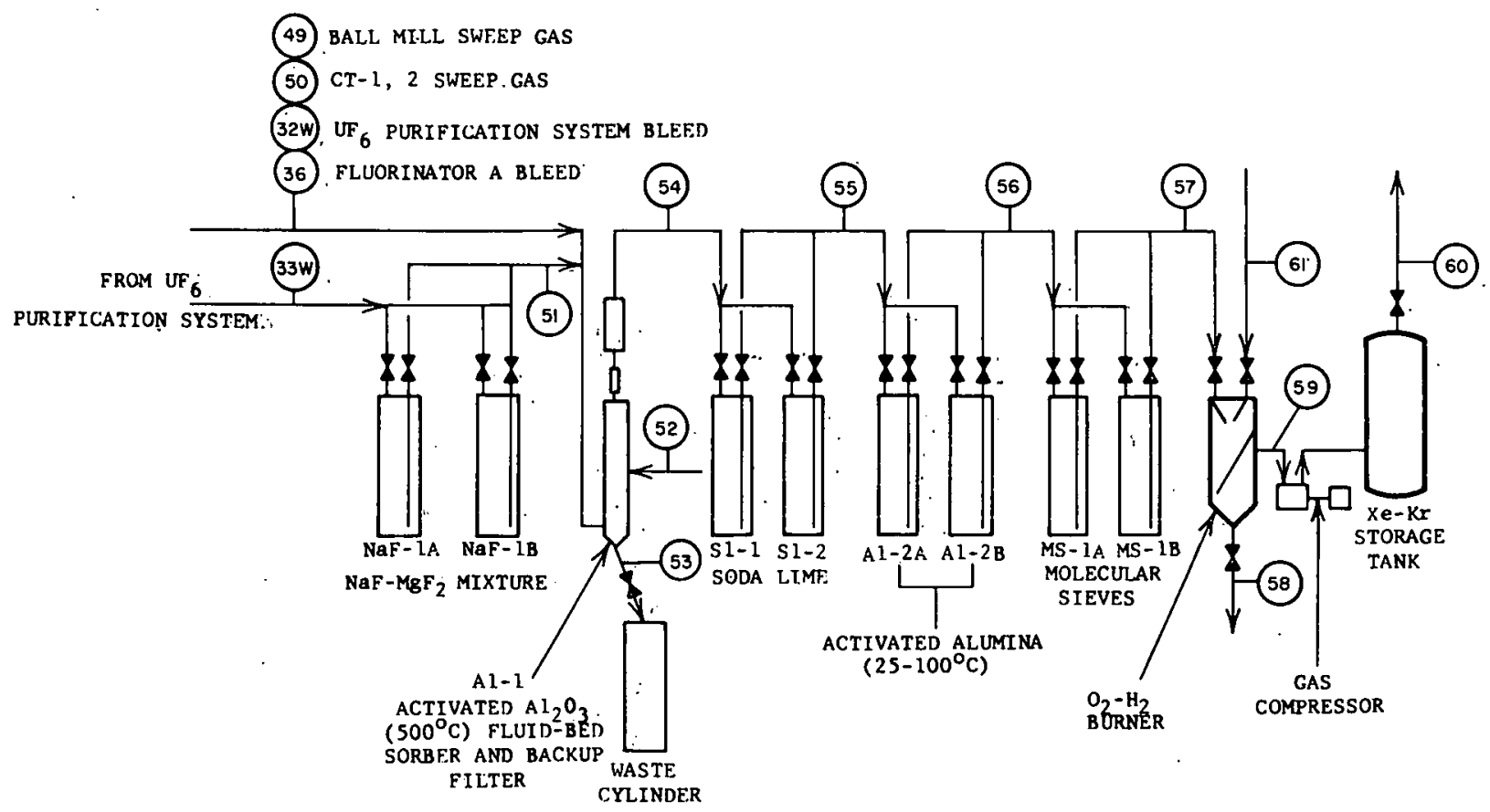

Fig. 4.22. Schematic Diagram of Gaseous Waste Handling System

sweep gas from the ball mill, oxygen used for transfer of fission products. out of FP-1 and FP-2, and excess fluorine from refluorination of $\mathrm{PuF}_{4}$ in T.D-1. Because of similarities in the fission-product content of these streams, a common disposal system is likely to be effective for all waste streams.

4.8.5:1: Fission-product and Uranium Retention by $\mathrm{NaF}-\mathrm{MgF}_{2}$. Only the waste stream (33W) from still S-2 is passed through a heated bed of $\mathrm{NaF}-\mathrm{MgF}_{2}$ before being processed further. The gas stream consists of elemental fluorine from the thermal decomposition of $\mathrm{PuF}_{6}$ (see Section 4.5), $\mathrm{UF}_{6}, \mathrm{MoF}_{6}$, and smaller amounts of $\mathrm{NpF}_{6}, \mathrm{TeF}_{6}, \mathrm{TcF}_{6}$, and ${ }^{3} \mathrm{HF}$. Data ${ }^{137}$ extrapolated from the equilibrium between $\mathrm{HF}$ and $\mathrm{NaF} \cdot \mathrm{HF}$ indicates that $\sim 90 \%$ of the ${ }^{3} \mathrm{HF}$ could be retained in the $\mathrm{NaF}-\mathrm{MgF}_{2}$ trap. Both $\mathrm{UF}_{6}$ and $\mathrm{MoF}_{6}$ are retained on $\mathrm{NaF}^{138}$ the partial pressure of $\mathrm{UF}_{6}$ over the complex $(2 \mathrm{NaF}) \cdot \mathrm{UF}_{6}$ at $50^{\circ} \mathrm{C}$ is about $2 \times 10^{-4} \mathrm{~mm} \mathrm{Hg}$ at equilibrium. The corresponding partial pressure of $\mathrm{MoF}_{6}$ is greater by about a factor of 1000 , which would reduce the uranium content of the gas stream by a factor of $>105$ and reduce the molybdenum content by $\sim 3.5 \times 10^{2}$. Magnesium fluoride would remove additional amounts of $\mathrm{MoF}_{6}$ (see Section 4.6.2.2); the molybdenum content is estimated to be reduced by a factor of $\sim 3 \times 10^{3}$ in this step. Technetium hexafluoride is only partially sorbed by $\mathrm{NaF}$, but $\mathrm{MgF}_{2}$ should remove $97 \%$ or more of the $\mathrm{TcF}_{6}$. No retention of $\mathrm{NpF}_{6}$ on $\mathrm{NaF}$ is assumed because of the high fluorine content of the gas, but $\mathrm{MgF}_{2}$ should remove some $\mathrm{NpF}_{6}$ by sorption. Because of conflicting data in the literature on sorption. of $\mathrm{NpF}_{6}$ b.y. $\mathrm{MgF}_{2}$, this trap is not relied on to reduce the $\mathrm{NpF}_{6}$ level in the off-gas to acceptable levels. No data are available on the reaction of oxyfluorides such 
as $\mathrm{MoOF}_{4}, \mathrm{TcO}_{3} \mathrm{~F}$, and $\mathrm{TcOF}_{4}$ with either $\mathrm{NaF}$ or $\mathrm{MgF}_{2}$, and no interaction is assumed. Tellurium hexafluoride and tellurium oxyfluorides are assumed to be unaffected by $\mathrm{NaF}$ and $\mathrm{MgF}_{2}$.

4.8.5.2 Reaction of Fluorides with Heated Activated Alumina. The gas stream fed to the fluid bed of activated alumina at $500^{\circ} \mathrm{C}$ contains elemental fluorine, krypton, xenon, and iodine (from the head-end), together with $\mathrm{UF}_{6}$, fluorides of $\mathrm{Nb}, \mathrm{Mo}, \mathrm{Tc}, \mathrm{Ru}, \mathrm{Sb}, \mathrm{Te}, \mathrm{I}$, and $\mathrm{Xe}$, and traces of ${ }^{3} \mathrm{HF}$. Little experimental data are available as a guide to the extent of reaction of most of these compounds with alumina. Elemental fluorine and fluorides whose oxides are stable can be expected to react rapidly with heated activated $\mathrm{Al}_{2} \mathrm{O}_{3}$. Thus, uranium, niobium, and antimony should effectively react with and be retained in the bed. Hydrogen fluoride $\left({ }^{3} \mathrm{HF}\right)$ will react at $500^{\circ} \mathrm{C}$, but the tritium will be carried out of the bed as ${ }^{3} \mathrm{H}_{2} \mathrm{O}$. Iodine fluorides are expected to react with activated $\mathrm{Al}_{2} \mathrm{O}_{3}$ to form elemental iodine which volatilizes. Molybdenum and technetium should react with the $\mathrm{Al}_{2} \mathrm{O}_{3}$, but part of the oxides may volatilize from the heated bed. Ruthenium has been shown to react with activated $\mathrm{Al}_{2} \mathrm{O}_{3}$ when present as $\mathrm{RuF}_{5},{ }^{139}$ and retention of ruthenium is expected. The presence of elemental oxygen in the gas stream is not expected to significantly reduce ruthenium retention by the $\mathrm{Al}_{2} \mathrm{O}_{3} .{ }^{140}$ (At $500^{\circ} \mathrm{C}, 3.03 \times 10^{-4} \mathrm{~mm} \mathrm{Hg} \mathrm{RuO}_{4}$ was in equilibrium with $\mathrm{RuO}_{2}$ (s) and $653 \mathrm{~mm} \mathrm{Hg} \mathrm{O}_{2}$,) Mixtures of elemental xenon and fluorine can be expected to react to form $\mathrm{XeF}_{4}$ in parts of the gas-disposal system upstream from the activated alumina fluid-bed reactor, if the system is above $\sim 200^{\circ} \mathrm{C} .^{64}$ On the other hand, xenon fluorides, all of which are volatile, are expected to react rapidly with activated alumina to form elemental xenon and liberate oxygen. The formation of explosive $\mathrm{XeO}_{3}$, usually by hydrolysis of $\mathrm{XeF}_{4}$, appears to be impossible in the alumina bed, since there is no evidence for the existence of this compound above $150^{\circ} \mathrm{C}$ and since most experience indicates that $\mathrm{XeO}_{3}$ is unstable above $50^{\circ} \mathrm{C} .{ }^{141}$ Xenon difluoride does not form $\mathrm{XeO}_{3}$ on hydrolysis. If $\mathrm{XeF}_{4}$ were to pass through the activated alumina bed, subsequent reaction on the heated soda lime would complete the decomposition to elemental xenon.

No information is available on the behavior of fission-product fluoride species other than those mentioned above. Other species such as oxyfluorides are assumed to react completely with activated alumina at $500^{\circ} \mathrm{C}$.

Tellurium hexafluoride may react partially with this activated alumina, but most of the $\mathrm{TeF}_{6}$ is expected to sorb on the low-temperature activated $\mathrm{Al}_{2} \mathrm{O}_{3}$, as discussed in Section 4.8.5.3.

4.8.5.3 Reaction of Fluorides with Soda Lime and Low-temperature Activated Alumina. The gas effluent from the activated-alumina fluid-bed reactor is next passed through a heated $\left(\sim 150-200^{\circ} \mathrm{C}\right)$ packed bed of soda lime. Elemental iodine is expected to be retained in this bed, based on an analogy with the behavior of bromine in the bromine fluoride- $\mathrm{Al}_{2} \mathrm{O}_{3}$-soda lime system. ${ }^{142}$ Unreacted fluorides are expected to be converted to oxides 
or hydroxides and to be retained on the soda-lime bed. Elemental oxygen, xenon and krypton as well as ${ }^{3} \mathrm{H}_{2} \mathrm{O}$ are expected to pass through the packed

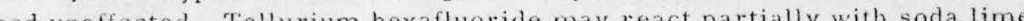
t elevated temperatures, but no significant removat of tellurium from the gas stream is anticipated at this point.

The gas-stream effuent from the soda-lime trap is passed through a bed of activated alumina beld at modest temperatures $\left(25-100^{\circ} \mathrm{C}\right)$. According to Vissers and Steindler, ${ }^{134}$ the $\mathrm{TeF}_{6}$ is sorbed efficiently by alumina. Their results must be confirmed under the conditions of the reference process, with molsture present; their systenu was dry. The anticipated DF of $\sim 10$ meets the requirements (10 CFR 20; see Table 6.12) for discharge of gaseous effluent to the atmosphere.

The treatment of the effluent from the low-temperature activatedatumina trap, which consists of water vapor, oxygen, xenon, and krypton, has been discussed above. Alternative disposal methods for the rare gases include clathrate complex formation for the krypton and storage in solid

form and allowing the xenon to be released after a reasonable decay period.

\subsubsection{Solid Wastes from Gaseous Waste Handling System}

Table 4.37 summarizes the sources of solid wastes accumulated in the processing of gaseous wastes, the daily volume of solid wastes, the yearly cylinder requirements, whether or not aluminum is added to lower the centerline temperature, the time that a cylinder must be stored before heat generation drops to $2 \mathrm{~W} / \mathrm{liter}$ and the number of cylinders that must be temporarily stored on site. Those cylinders for which removal of fission-product decay heat is a problem will be stored in a canal. Other cylinders will be stored in warehouses equipped with suitable monitoring instrumentation.

TABLF 4.37. Solid Wastes trom Gaseous Waste Handing System

\begin{tabular}{|c|c|c|c|c|c|c|c|}
\hline Source & $\begin{array}{c}\text { Daily Waste } \\
\text { volume, } \\
\mathrm{it}^{3}\end{array}$ & $\begin{array}{l}\text { Days of } \\
\text { Operation } \\
\text { betweetn } \\
\text { Cylieder } \\
\text { Changeouls }\end{array}$ & $\begin{array}{l}\text { No. of } \\
\text { cylinders } \\
\text { Retuived } \\
\text { per Yeard }\end{array}$ & $\begin{array}{l}\text { Aluminum } \\
\text { Adtied to } \\
\text { Naste }\end{array}$ & $\begin{array}{l}\text { Temporary } \\
\text { Storagae } \\
\text { rive, } \\
\text { yr }\end{array}$ & $\begin{array}{c}\text { Maximum } \\
\text { Centerline } \\
\text { Iemperature } \\
\text { in Cyinder. } \\
{ }^{\circ} \mathrm{C} \text {. }\end{array}$ & $\begin{array}{l}\text { No. of } \\
\text { Cytinders } \\
\text { at Storage } \\
\text { Equilibrium }\end{array}$ \\
\hline \multirow{4}{*}{ 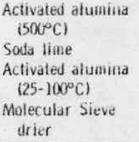 } & & 10.0 & & & & & \\
\hline & 0.36 & 74.3 & 4.91 & No & 0.12 & Low & 1 \\
\hline & 0.78 & 34.5 & 10.6 & № & 0 & Low & 0 \\
\hline & Uncertain & & & & & & \\
\hline
\end{tabular}

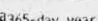




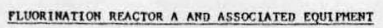
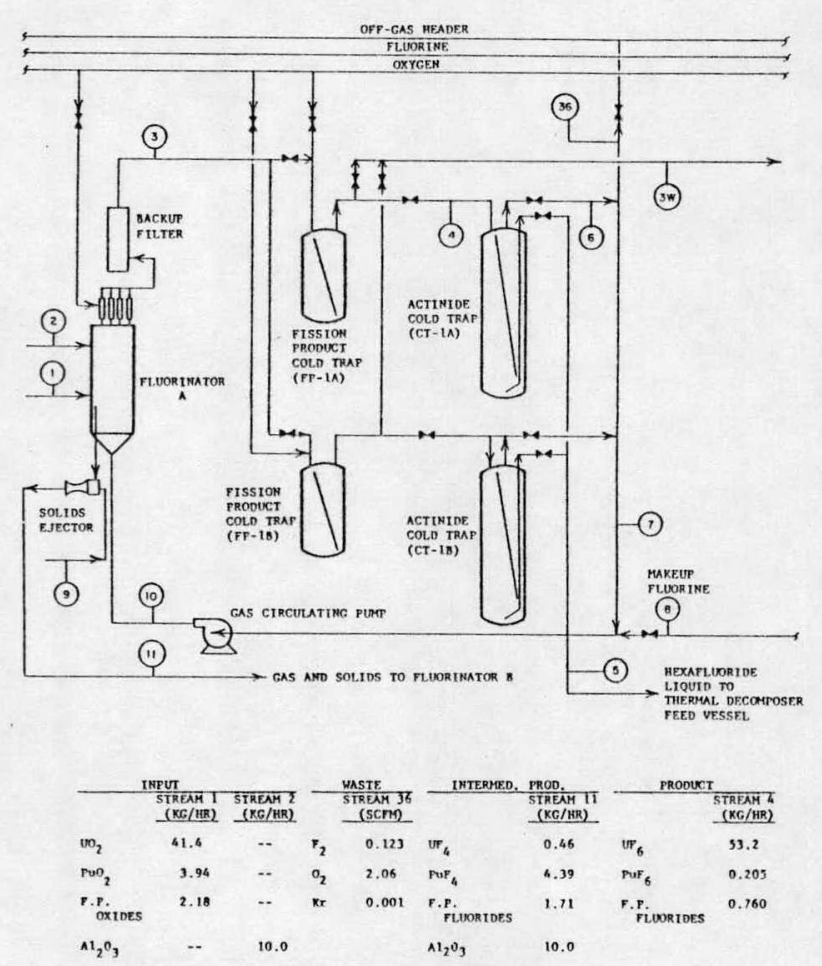

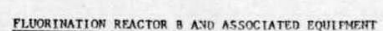

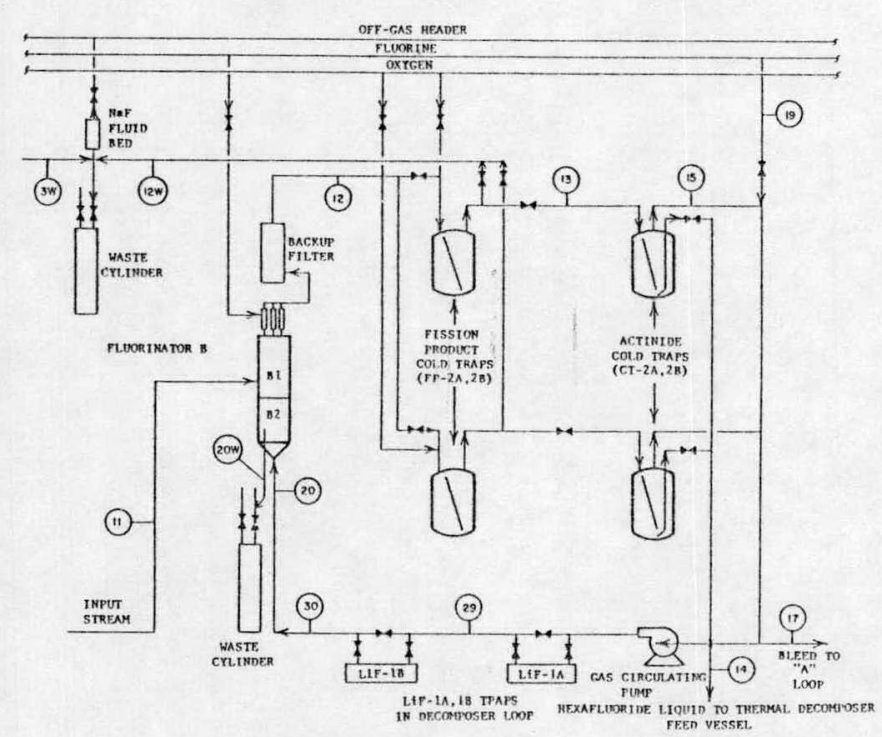

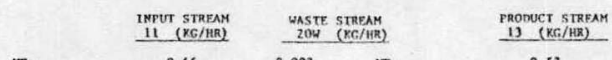

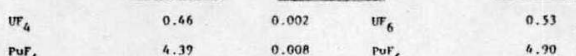

$$
\begin{aligned}
& \begin{array}{lllll}
\text { Pur }_{6} & 4.39 & 0.008 & \text { PuF }_{6} & 4.90 \\
\text { r.P. Fuortips } & 1.71 & 1.71 & \text { F.r. Fuorioes } & 0.083
\end{array} \\
& \mathrm{At}_{2} \mathrm{O}_{3} \quad 10.0 \quad 10.0
\end{aligned}
$$

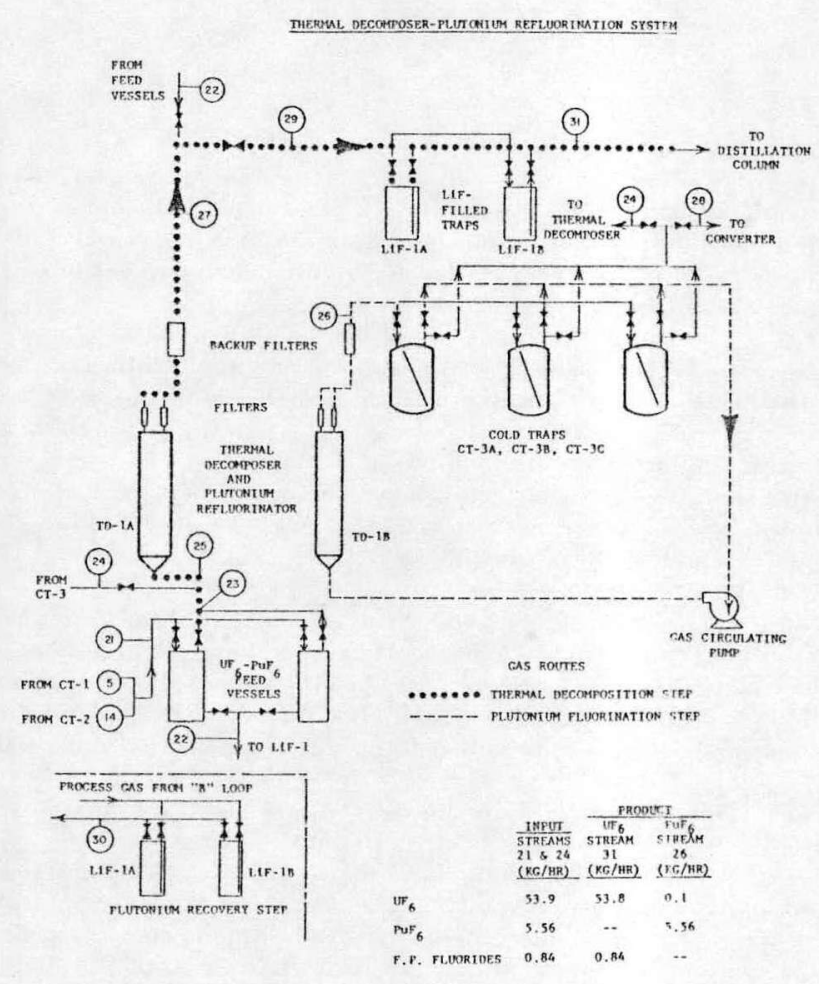


II, FUREFication STSTE

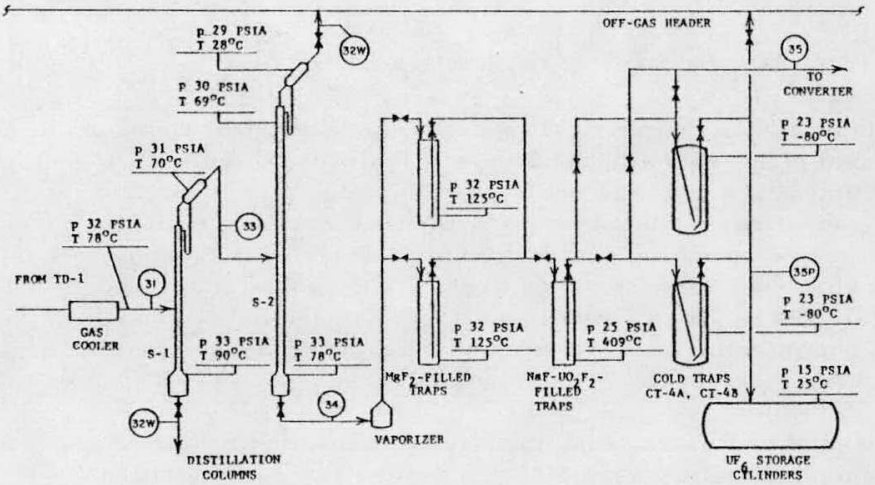

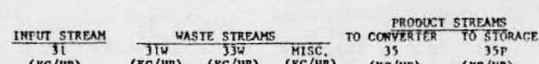

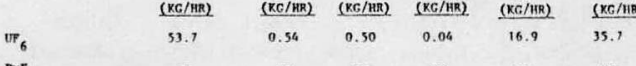

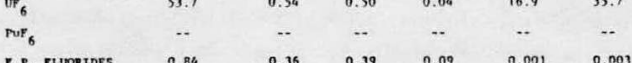

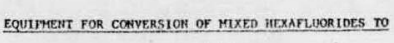
OXIDE Proovects

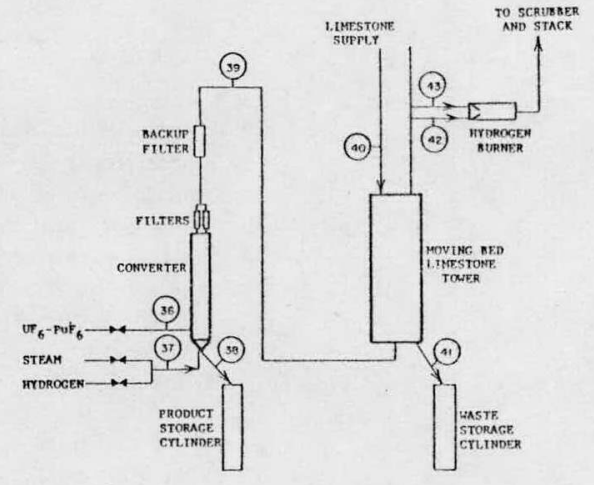

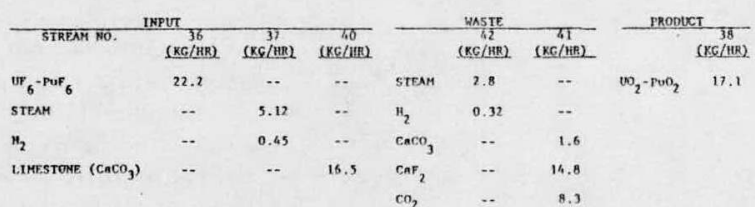

Fig. 4.24. Gomposite of Figs. 4.15, 4.18, and 4.22
GASEOUS WASTE SYSTEM

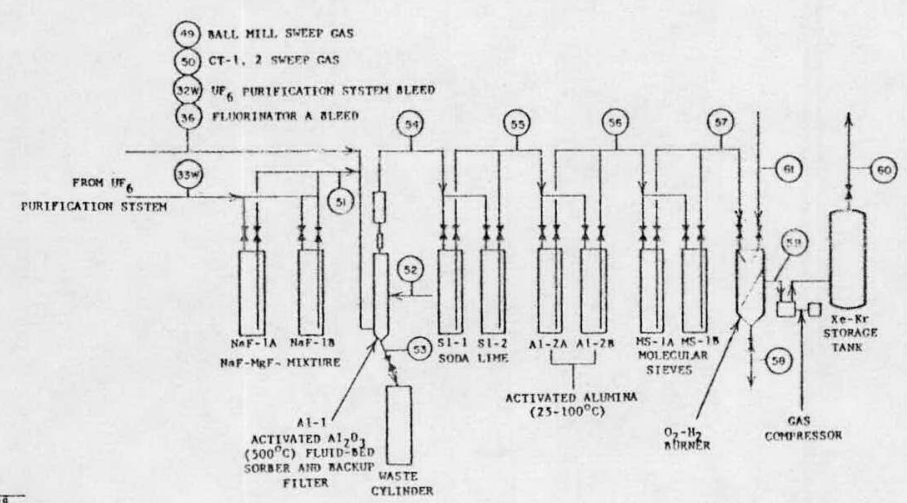


This section describes the physical layout of the conceptual fluoridevolatility reprocessing plant, with emphasis on cell features. Figures 5.1 and 5.2 show a conceptual layout of the main plant building. The main process cell and auxiliary cells are shown, along with other required facilities on the same floor, such as operation control rooms, laboratories, storage areas, the machine shop, and administration areas. The overall building area is approximately 150 by $260 \mathrm{ft}$. Additional facilities are below grade. These include a decontamination cell, a hot-shop area, and a storage pool These include a decontamination cell, a hot-shop area,
for fuel elements awaiting disassembly and processing.

The head-end and processing equipment must be located in heavily shielded cells designed for alpha containment as well as for $\beta-\gamma$ radiation control. Ventilation must be controlled, with flows moving from the least contaminated to the most contaminated sections of the plant. Exhaust will be through one set of high-efficiency filters, charcoal traps, a sand-bed filter, and a final set of high-efficiency filters. A large recirculating caustic scrubber designed to accommodate the total ventilation flow will be located upstream of the first set of air filters. The sand-bed filter serves mainly as an emergency backup device. Ventilation air is finally exhausted through a $100-\mathrm{m}$ stack.

\subsection{Cell Design}

Cell area and volume were based on the following criteria:

a. Nominal 4-ft spacing between vessels for crane and manipulator accessibility and to limit interaction (nuclear criticality safety).

b. Relatively wide aisles, for ease of installation of piping and for movement of large equipment items; aisles may also be used for temporary storage of equipment items.

to service the entire length of the cell.

d. Partitions (thick concrete walls) dividing the main process cell into three areas, considered high-, intermediate-, and low-radiation-level areas.

In addition to a main process cell, two other cells are provided: (1) an argon-atmosphere cell for operations relating to fuel handling when sodium is present, and (2) an air-atmosphere cell for the mechanical headend equipment. Intermediate partitions, which further subdivide the main cell into subcells, may be desirable from the standpoint of maintenance 


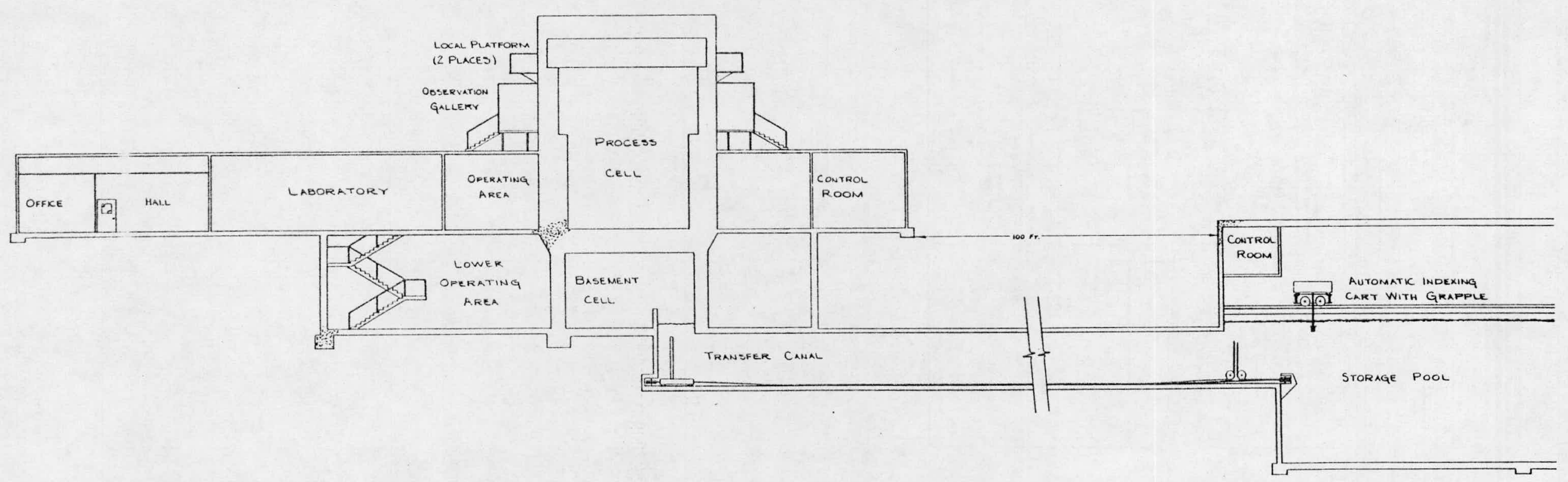

Fig. 5.2. Elevation View of Conceptual LMFBR Fuel-reprocessing Plant 


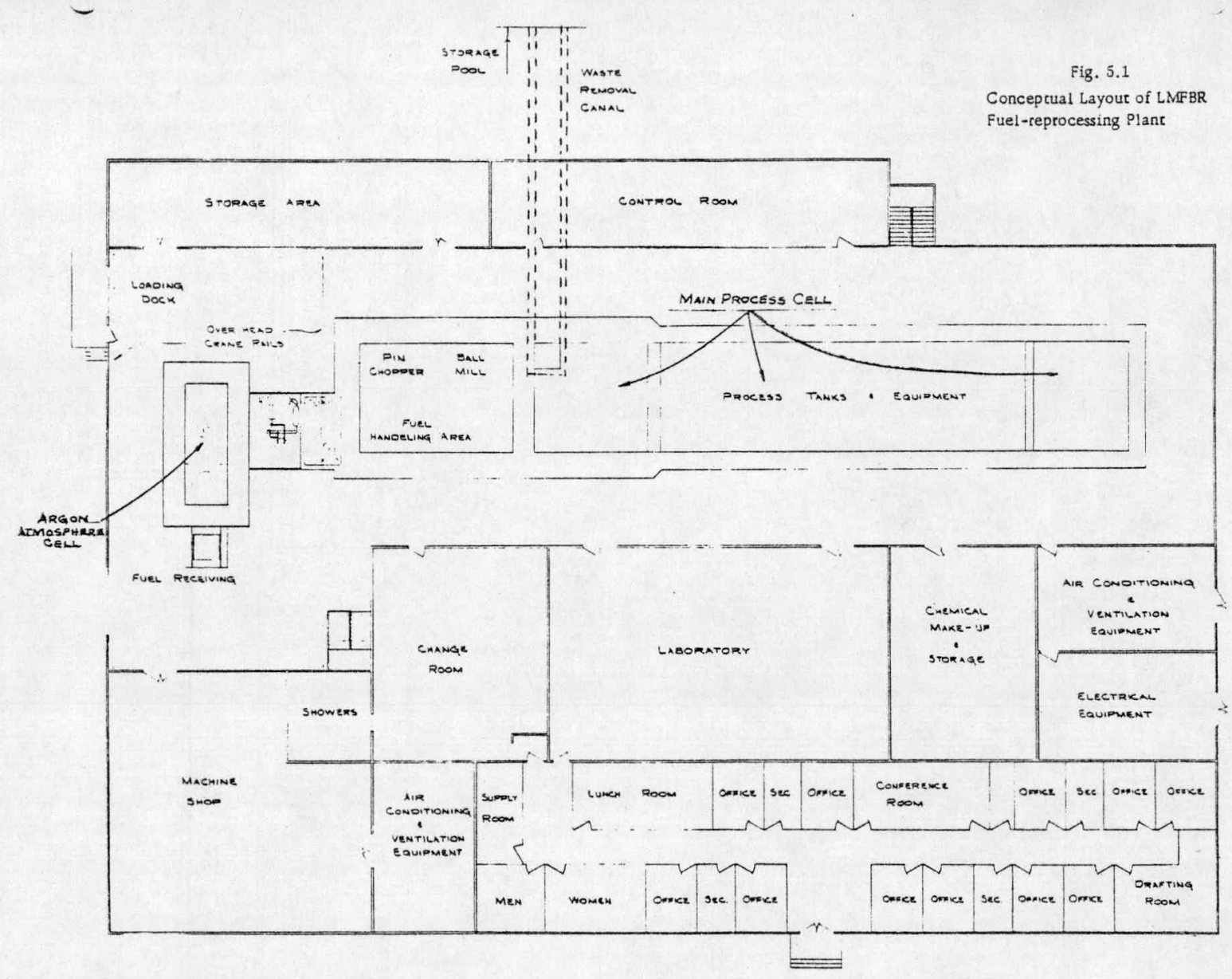


and acc. ssibility, but cell design has not been analyzed to an extent to permit suct delineation. Cell shielding thickness will comply with the regulations te arding personnel exposure.

if the cell configurations reviewed for the present concept, rectangular ce ils and circular (or polygonal) cells are more suitable than canyon or silo-ype cells. The characteristics of the four types of cells are summarizen in Appendix $\mathrm{F}$.

igure 5.3 shows a rectangular cell with the process equipment mounted in two rows (essentially end to end). (Table 5.1 shows the key to the layo it in Fig. 5.3.) The end-to-end configuration should be relatively safe from a criticality standpoint. The inside cell dimensions are $26 \mathrm{ft}$ by about $14 \mathrm{ft}$. Mounting arrangements were not optimized with respect to the spac occupied; therefore any dimensions given should be considered tentativ.

he adjacent mechanical head-end cell and the argon-atmosphere (fuel-re eiving) cell are approximately 26 by $36 \mathrm{ft}$ and 10 by $28 \mathrm{ft}$, respectively. he pool used for underwater storage and for underwater dis assembly of the elements is located below these cells.

TABLE 5.1. Key to Equipment Layout of Fig. 5.3

\section{A, B}

FP-1, F1-2

$\mathrm{CT}-1, \mathrm{C}_{\mathrm{i}}-2, \mathrm{CT}-3, \mathrm{CT}-4$

TD - 1

LiF- 1

A A - 1, A $\leftarrow-2$

SL-1

$\mathrm{NaF}-1$

S-1, S-2

$\mathrm{MgF}_{2}-1$

Converte

Sorber

C-1

$\mathrm{NaF}-\mathrm{UO}_{2}-2$

MS- 1
Fluorination reactors

Fission-product cold traps used with reactors $\mathrm{A}$ and $\mathrm{B}$, respectively. (A, B, and C after a numeral--for example, $1 \mathrm{~A}$ and $1 \mathrm{~B}-\mathrm{-represent}$ parallel traps at a given station.)

$\mathrm{UF}_{6}$ and $\mathrm{PuF}_{6}$ cold traps

The rmal decomposer-refluorination vessel

(dual purpose)

Lithium fluoride traps

Activated-alumina traps

Soda-lime traps

Dryer

NaF trap

Distillation columns

Magnesium fluoride traps

Hexafluoride-to-oxide converter

Hydrogen fluoride disposal

Collection and feed vessels

Sodium fluoride-uranyl fluoride trap

Molecular sieve traps 


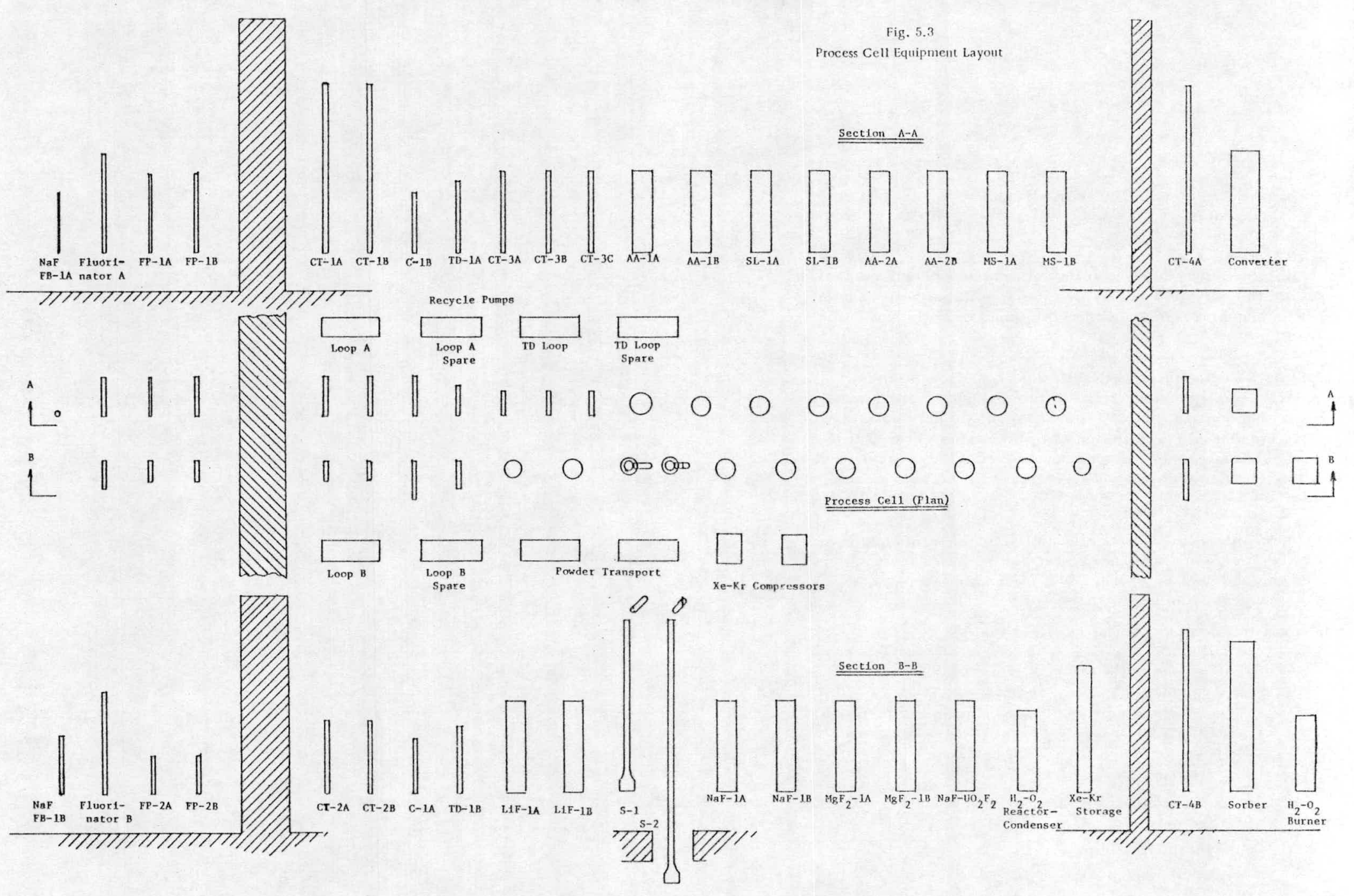


The features of a circular (or polygonal) cell that have made this design desirable for the EBR-II FCF ${ }^{143}$ must be further evaluated in relation to their applicability to the present concept before firm decisions about a cell configuration can be made. A centrally located control room and the technique for bringing power to cranes and manipulators (by way of central posts, rather than from a full-length bus bar as in rectangular cells) appear to be advantages of a circular cell, but these are not key problems in the fluoride-volatility concept. No firm recommendation is made regarding general cell design. Features applicable to either design are discussed next.

\subsection{Cell Features}

\section{2 .1 Cell Height}

The cell height is contingent upon equipment height and the overhead space required for maneuvering manipulators and cranes. With equipment headroom requirements being as great as $15 \mathrm{ft}$ in the reference flowsheet, a free height of $20 \mathrm{ft}$ was selected for the shielded cell proper. An estimated additional $13 \mathrm{ft}$ of cell height is required to accommodate telescoping manipulators and crane movement.

\section{2 .2 Cranes and Manipulators}

A minimum of two overhead cranes and two overhead manipulators ${ }^{144}$ are required, in addition to through-the-wall, master-slave manipulators. Provision must be made for maintenance and repair of the cranes and manipulators. A specially designed blister in the roof of the cell for removing equipment, similar to that used in the EBR-II Fuel Cycle Facility (FCF), might be useful here. This device is essentially a heavy-duty chain hoist with a capacity sufficient to lift crane trolleys and manipulator carriages $(10,000 \mathrm{lb}$ for the EBR-II FCF). Appendix C presents a more detailed description of manipulators and cranes and their capabilities, as gained in the EBR-II FCF.

At work stations in front of shielding windows, sealed master-slave manipulators of the CRL Model A or J type should be provided for performing special operations, maintenance, and repair of parts brought to the work stations by the overhead handling system.

The cranes and manipulators will be common to the process cell and the mechanical head-end cell. Additional units will be required for use in the argon-atmosphere cell and in the basement area.

Reliability of equipment must be high, but even common components such as electrical drives, gear boxes, clutches, limit switches, and electrical sliding contacts fail; these items will be accessible for repair and 
maintenance by remote means. Some parts such as wheels, wheel bearings, and slow-running heavy gearing can be relied on not to fail and will not be remotely repairable. However, remote lubrication of bearings must be provided for. Where necessary, parts to be lubricated will be shielded against high-radiation fields and/or lubricated with radiation-resistant greases and oils.

A desirable feature is that bridge, carriage, and trolley drives be identical and interchangeable. Variable-speed motors are required, either dc or ac. Direct-current motors require fewer leads than ac motors, but both can be used.

\section{2 .3 Windows}

The cells will be provided with the number of shielding windows necessary for routine operations and maintenance.

\subsubsection{Shielding}

The problem of shielding neutron radiation is relatively important and must be considered in the overall design. Heavy concrete shielding will be required for the exterior walls of the argon-atmosphere cell, the head-end area, and most of the process cell area, perhaps a 6 -ft thickness. Considerably less shielding may be acceptable in the region of the converter, since the fuel in this area will have been decontaminated by a factor of $10^{6}$ $10^{7}$.

\subsubsection{Equipment Transfer}

Smaller equipment and supplies can be transferred through small transfer locks in the walls. Two transfer locks will be provided in the floor of the cell to allow transfer to and from the basement decontamination area and hot shop. Doors in the walls capable of admitting large equipment might be provided for use during construction or an emergency, but would not ordinarily be used because they would open to the operating area.

\subsection{Connectors}

The reference plant design depicts a series of process vessels operating in semicontinuous or continuous mode. Piping and electrical connections to these vessels require connectors (a general classification that includes standard flanges) that can be remotely assembled and disassembled to facilitate replacement, repair, or maintenance. Design requirements for connectors and a review of connector types follow.

If possible, connectors will not be used where extreme temperature cycling occurs (e.g., for CT-2, which normally operates between -80 and $80^{\circ} \mathrm{C}$, but will be heated to perhaps $300-500^{\circ} \mathrm{C}$ during cleanup-fluorination periods). Lines and connectors, which are expected to contain only minimal 
deposits of plutonium, will normally be near $100^{\circ} \mathrm{C}$, but may require heating to $300^{\circ} \mathrm{C}$ during cleanup-fluorination periods; pressures will be modest, perhaps 30 psig maximum. Nevertheless, to provide an adequate safety factor, connectors will have to satisfy stringent pressure and temperature cycling and have adequate resistance to corrosion. High radiation levels prevent the use of organic gasket materials (which normally simplify connector problems). This combination of factors makes it necessary to use connectors of all-metal construction, in many cases of nickel or nickel alloys. Gaskets are likely to be of nickel, copper, or aluminum. Lead is useful as gasket material for operation in ambient temperature situations.

The connectors will be handled by manipulators, perhaps of the electromechanical PaR type* (see Appendix G). This will require such features as captive bolts, guide-ins, and special motorized tools for tightening of bolts.

A review of recent development work on remote connectors dis closed that new devices (see Appendix $\mathrm{H}$ ) are being used which hold promise for fluoride-volatility plant application. Among the varieties available are:
a. Swageloks** and other compression-type fittings.
b. Conoseals, ${ }^{+}$a special flange-gasket combination.
c. A yoke-jack screw type for small lines, perhaps to 1 in., used by Fontenay-aux-Roses (FAR) Laboratories, France.
d. Unions with special fittings for motorized tools (a FAR development).
e. Flanges, gaskets, and bolts, fabricated of a combination of materials selected for temperature compensation.
f. The Hanford remote connector. ${ }^{145}$

Because of the experience with a wide variety of connector types, and the advances in manipulator technology, the feasibility of developing suitable remote connectors for fluoride volatility is assured.

\subsection{Valves}

Valves constitute an important process auxiliary, being required in a variety of services at temperatures from ambient to several hundred degrees Centigrade for gases and for regulation and shutoff of solids flow. Many types of valves (bellows-sealed, diaphragm, ball, globe, disc) of

\footnotetext{
* Product of Program and Remote Systems Corporation, St. Paul, Minnesota.

** Product of Crawford Fittings Company, Cleveland, Ohio.

$\dagger$ Product of Aeroquip Company, Marman Division, Los Angeles, California.
} 
appropriate materials (nickel, Monel, Inconel, stainless steel) are available which have seen extensive service in fluoride-volatility applications with radioactive and nonradioactive systems. This does not mean that all valve problems have been solved. Development work may be necessary on valves for particularly rigorous service (for example, for controlling the discharge of highly radioactive particulate alumina and fission-product solids from fluorinator B). Valves for such service should be evaluated for reliability and capability of being maintained. For such applications, alternatives to valves (for example, a pressurized standpipe with a fluidizable sidearm for solids removal) should be sought and evaluated.

To ease the requirements on individual valves, two valves will frequently be used in series, the first often being subjected to more severe service than the second. Frequently, one is for control, and the second is a block or shut-off valve.

\subsection{Fluorine Supply}

Fluorine will be supplied from a centralized facility (either an onsite fluorine plant or liquid fluorine tanks, depending on economics). With improved technology in fluorine cells (i.e., very long cell life and reliability), on-site fluorine production may prove desirable. Single 6000-A cells can produce up to $190 \mathrm{lb}$ of fluorine per day, with a $95 \%$ on-stream time. Cell life before desludging is required, is now $15 \times 10^{6} \mathrm{~A} \mathrm{~h}$ (this represents $2 \frac{1}{2}$ to $3 \mathrm{yr}$ of operation) and is $30 \times 10^{6} \mathrm{~A} \mathrm{~h}$ before the cell needs refurbishing. Estimates of maintenance time periods are $32 \mathrm{hr}$ to desludge (includes $16 \mathrm{hr}$ for nitrogen purge) and $76 \mathrm{hr}$ to refurbish (includes $16 \mathrm{hr}$ for nitrogen purge). The cost of a single cell is approximately $\$ 12,500$.

For the present plant requirements of about $1000 \mathrm{lb}$ of fluorine per day, a 10-cell system would be adequate. Obtaining fluorine in liquidfluorine tank trucks having a capacity of about $5000 \mathrm{lb}$ of liquid fluorine represents a practical alternative. 


\section{ANCILLARY CONSIDERATIONS}

\subsection{Criticality Control}

The design of a volatility plant is quite different from that of an aqueous plant in the engineering approach to nuclear safety since the volatility plant uses nonaqueous, unmoderated process streams. Techniques such as extensive use of dilution of fissile content and incorporation of neutron poisons, used in aqueous processes, tend to be unsuitable. ${ }^{3}$

The approach to criticality control adopted in the present volatility study is to operate with no neutron moderation and with controlled, partial, external reflection of neutrons in order to obtain a low reactivity per unit mass of plutonium in the process system. This concept of criticality control is incorporated in all the geometrical, mechanical, and structural arrangements of process equipment in those sections of the plant where criticality is a significant problem. Instrumental safeguards are also used. Administrative modes of criticality control, such as arbitrary instructions to operators to limit batch sizes, are avoided in this approach. Rather, administrative checks are used for secondary security.

This philosophy of criticality control was guided by the criteria used in the nuclear safety analysis ${ }^{3}$ of the General Electric Midwest Fuel Recovery Plant (MFRP), for which a provisional construction permit has been granted by the Regulatory Branch of the AEC. These criteria are reproduced as Table 6.1.

The present criticality analysis of the process equipment is based directly on calculations ${ }^{146}$ of reactivity made for unmoderated plutoniumbearing material in the configuration of rectangular parallelepipeds or slabs. The principal variables used for the calculation are (1) slab dimensions, (2) effective plutonium density of the process material, and (3) the amount of internal and external reflection involved in the containment of the process material. The criticality handbooks, intended to be consulted primarily for aqueous solutions, were not applicable to the present process design. However, there is an analogy between the present approach and the approach of using "bird-cage" containers for spacing a number of concentrated packages of fissile material in dry storage. Exclusion of water from the fluoride-volatility plant is a key requirement but one that is not in itself an innovation, since exclusion from flooding and exclusion of liquid water from the fluorinator system are basic to both the chemical and nuclear safety of the GE fuel-recovery plant. (For example, see pp. II-4-1, IV-3-2, and V-11-1 of Ref. 3.)

Slab geometry was adopted for the major items of process equipment in the reference plant. However, we do not claim that cylindrical or annular designs could not be used for these cases or that optimum 
TABLE 6.1. Nuclear Safety Criteria (from Ref. 3)

\section{General}

Every reasonable precaution shall be taken to preclude criticality within the fuelrecovery facilities.

\section{Assumed Conditions}

In the establishment of nuclear-safety design parameters, all credible conditions shall be considered and the most reactive foreseeable combination must be assumed. Specified limits must allow for the most reactive conditions that could result from a delay in discovery of piping or equipment failure.

Conditions that can be excluded with minimal administrative control, such as water flooding, may be assumed to be excluded in establishing design parameters. Such assumptions, if made, must be stated as "excluded conditions" in the applicable technical specifications.

Interaction with other sources of fissile material will be considered, assuming the most reactive credible set of conditions involving the amount, volume, and location of the fissile material.

\section{Methods of Analysis}

The specified limits shall be derived, where possible, from experimental data. In the absence of directly applicable experimental measurements, the limits may be based on calculations based on theory, if (1) the calculations can be shown to be valid by comparison with experimental data, and (2) limits of error can be assigned to the results.

Detailed nuclear-safety evaluations for each process system potentially containing fissile material shall be made or reviewed by a qualified specialist in the field before completion of detailed design.

\section{Control Methods}

Favorable geometry shall be the preferred method for preventing criticality.

Where favorable geometry is unreasonably restrictive, administrative controls, such as concentration control or undermoderation, may be used with a margin of safety appropriate for the maximum credible change in conditions. Where practical, instruments or mechanical devices shall be provided to assist operating personnel to measure and control the process within prescribed limits.

The following specific controls are to be considered where applicable:

1. Leakage from geometrically favorable equipment must not be capable of assuming a geometry significantly less favorable.

2. Potential precipitants must be excluded from systems whose nuclear safety is based on homogeneous solutions. materials.

3. Provisions must be made to prevent unsafe accumulations of fissile

4. Transfer of fissile material from favorable to less favorable geometry must not be possible as a consequence of a single error.

\section{Number of Failures}

In the establishment of the nuclear-safety requirements of a system, the minimum number of concurrent, independent failures that could result in criticality must be:

$$
\begin{array}{ll}
\text { Heavily shielded zones } & 2 \\
\text { Lightly shielded zones } & 3 .
\end{array}
$$


dimensions of the slab have been established. The slab concept was used to provide a simple approach that would exemplify the nuclear-safety design of a nonaqueous system. Process vessel construction is conceived as "slab-like" only in a theoretical and approximate way; the actual mechanical design would be expected to use desirable mechanical features such as dished sides, rounded edges and corners, and a sophisticated means of structural support appropriate to the overall plant requirements. The process equipment and ventilation system are considered separately below, followed by a critique section.

Tables 6.2 and 6.3 describe the reference designs of major items of process equipment in terms of internal geometric configuration, fraction of the internal volume occupied by the process material, and quantity of plutonium contained in this process material at the reference conditions. Fluorinators $\mathrm{A}$ and $\mathrm{B}$ are of slab design and are operated continuously. The other major process vessels are of similar slab design, but are operated batchwise (semicontinuously). Of the other vessels (namely, those involved in the headend operations, in uranium purification, and in the handling of final $\mathrm{PuO}_{2}-\mathrm{UO}_{2}$ oxide product), the ball mill is operated continuously and the others are

TABLE 6.2. Reference Data on Fissile Content of Major Process Vessels

\begin{tabular}{lcccccc}
\hline $\begin{array}{c}\text { Process } \\
\text { Vessel }\end{array}$ & $\begin{array}{c}\text { Number } \\
\text { of } \\
\text { Units }\end{array}$ & $\begin{array}{c}\text { Slab } \\
\text { Width, } \\
\text { in. }\end{array}$ & $\begin{array}{c}\text { Slab } \\
\text { Length } \\
\mathrm{ft}\end{array}$ & \multicolumn{2}{c}{$\begin{array}{c}\text { Process } \\
\text { Inventory, kg }\end{array}$} & $\begin{array}{c}\text { Inventory } \\
\text { Volume } \\
\%\end{array}$ \\
\hline Fluorinator A & 1 & 48 & 10 & 4.9 & 45 & 40 \\
Fluorinator B & 1 & 30 & 10 & 0.04 & 4.5 & 60 \\
C T-1 & 2 & 48 & 17 & 430 & 1.7 & 20 \\
C T-2 & 2 & 24 & 7 & 0.4 & 40 & $<20$ \\
C T-3 & 3 & 24 & 8 & $<0.1$ & 42 & $<20$ \\
Feed vessel & 2 & 48 & 5.5 & 430 & 42 & 90 \\
Thermal & 2 & 36 & 10 & 0.9 & 42 & $15-30$ \\
$\quad$ decomposer & 2 & 13.5 & 7 & 78 & 24 & 28 \\
Converter & 1 & & & & & \\
\hline
\end{tabular}

Note: All vessels of slab configuration, nominal 4-in. thickness.

a This is the bulk volume of the normal inventory of process material expressed as a percentage of the total volume of the vessel. Except for the fluorinators, these are batch volumes.

TABLE 6.3. Reference Data on Fissile Content of Miscellaneous Process Vessels

\begin{tabular}{|c|c|c|c|c|c|}
\hline \multirow{2}{*}{$\begin{array}{l}\text { Process } \\
\text { Vessel }\end{array}$} & \multirow{2}{*}{$\begin{array}{c}\text { Number of } \\
\text { Units }\end{array}$} & \multirow{2}{*}{$\begin{array}{l}\text { Dimensions, } \\
\text { in. }\end{array}$} & \multicolumn{2}{|c|}{$\begin{array}{c}\text { Process } \\
\text { Inventory, } \mathrm{kg}\end{array}$} & \multirow{2}{*}{$\begin{array}{c}\text { Inventory } \\
\text { Volume } \\
\%\end{array}$} \\
\hline & & & $\mathrm{U}$ & $\mathrm{Pu}$ & \\
\hline Ball mill & 1 & 18 diam $\times 40$ long (cyl) & 210 & 21 & 25 \\
\hline $\begin{array}{l}\text { Oxide feed } \\
\text { storage hopper }\end{array}$ & 3 & $2 \times 36 \times 120(\mathrm{slab})$ & 292 & 28 & $\sim 90$ \\
\hline $\begin{array}{l}\text { Oxide product } \\
\text { receiver }\end{array}$ & 2 & $4 \times 24 \times 24($ slab $)$ & 139 & 41 & $\approx 90$ \\
\hline
\end{tabular}

a This is the bulk volume of the normal inventory of process material expressed as a percentage of the total volume of the vessel. Except for the fluorinators, these are batch volumes. 
operated on batch cycles. Continuous fluorinators have been emphasized in this discussion because of their key position in the process and because the continuous mode of operation has not been adopted in previous volatility designs.

\subsubsection{General Considerations of Reference Designs}

6.1.1.1 Continuous Fluorination. Although all the vessels are considered critically safe under the stated reference conditions of moderation and reflection (which are maintained as low as practicable), the vessels cannot be considered optimized with respect to the amount of plutonium contained as process inventory. In general, inventories in vessels operated continuously are determined either by the residence time required for chemical conversion or by bulk-volume requirements for heat transfer.

For fluorination in fluorinator $\mathrm{A}$, the residence time is about $12 \mathrm{hr}$ (and the mass of plutonium inventory is directly proportional to this residence time), which is more than twice that required for the uranium fluorination reaction at the reactor temperature of $350^{\circ} \mathrm{C}$. A rather conservative residence time is used to ensure feasibility at as low a fluorination temperature as is practical.

Heat transfer is a major consideration in fluorinator design. At reference conditions, $52 \mathrm{~kW}$ of heat are generated in the fluorination reaction and $28 \mathrm{~kW}$ from fission-product radioactivity. The bed volume needed to provide adequate vessel-wall contact area for heat transfer was compared with the reference bed inventory, and the latter was found to be a factor of two larger than is necessary.

Alternatives in the design of fluorinator $A$ that would allow lower plutonium inventories may be mentioned to illustrate further the issues in designing for criticality control. One alternative would be to divide fluorinator $\mathrm{A}$ into two stages and obtain a criticality benefit by spatial separation; this would divide the heat load approximately in half and would also allow the residence time for each stage to be optimized. Other fluorinating agents, namely, $\mathrm{BrF}_{5}$ or $\mathrm{BrF}_{3}$ vapor in place of fluorine, would allow more rapid fluorination and smaller heats of reaction during the formation of the hexafluorides from oxides. These combined effects might allow reduction by as much as a factor of two in residence time and in inventory. These factors show the potential for improvement and need consideration in scale-up to larger-size plants.

\subsubsection{Batch Units. The reference design of nearly all major} vessels except the primary fluorinators provides for semicontinuous operation, with batch quantities of process materials accumulating on a definite time cycle. The inventories of material listed in Tables 6.2 and 6.3 represent the maximum batch sizes during normal reference operation. The use 
of two (i。e., duplicate) units for CT-1, CT-2, CT-4, the feed vesse1, and the thermal decomposer permits accumulation during a 12-hr (on-stream) period, then discharge during a 12 -hr (off-stream) period; this schedule allows coupling of continuous and semicontinuous processing steps to each other. Such units have an overall 24-hr time cycle of operations; the vessels are emptied completely by the end of each cycle, and a half-day batch is the maximum accumulated in normal operation. Clearly, for any given plant throughput, the batch size in this equipment could be reduced by using more units, each on a shorter time cycle. For some equipment such as CT-1 (which has a batch size of about $650 \mathrm{~kg}$ of hexafluorides), the total batch sizes may be about as large as is practical for 4-in.-thick slabs. The general rule, however, applies; batch inventories may be reduced if additional units are added or, for a given number of processing units of given batch size, the overall throughput may be increased by reducing any portion of the cycle time. If batch units all have the same cycle time, the duty cycle for the units may be synchronized to avoid the need for intermediate holdup vessels. The $2-\mathrm{hr}$ cycle for the single converter differs from the cycles of the other batch vessels, and the still pot of still S-2 (or an auxiliary vessel as indicated in Section 4.6.2.1) acts as the holdup vessel.

Because considerations determining the fissile content of batch equipment differ from those for continuous equipment, the potential of a given process step for continuous operation is a factor in criticality-control design. For example, the fluid-bed thermal decomposer and converter could readily be operated with continuous transport of the solid phase.

Section 4 reviewed the possibility of operating hexafluoride cold traps continuously; no industrial precedent for continuous operation was found. However, use in the reference process of a distillation tower to strip $\mathrm{UF}_{6}$ vapor from a noncondensible gas stream (the gas effluent from the thermal decomposer) is an alternative to using a cold trap. Distillation may readily be performed continuously. Such gas-liquid absorber units can take many forms ${ }^{15,147,148}$ but these possibilities are cited here only as background to general design considerations.

Normal and abnormal operations and means of preventing dangerous accumulations of fissile material are discussed below in connection with criticality analysis of specific items of equipment.

\subsubsection{Source of Data for Criticality Analysis}

Criticality studies related to fluoride-volatility processing (made at Mol, ${ }^{149}$ Belgium, and at the ORGDP ${ }^{150}$ in Oak Ridge, Tenn.) generated results from models that could serve as a basis of nonaqueous criticality analysis. Even so, early calculations did not use realistic configurations--both because realistic LMFBR reprocessing plant designs had not been developed 
and because the relationship of criticality to design is not simple. A small number of calculations ${ }^{146}$ by Merriman of ORGDP (as yet preliminary and unpublished) are the only calculated data considered useful as a guide to the design and analysis of criticality control in fluoride-volatility plants.

In keeping with the method of nuclear-safety analysis described above, the major criticality data used in this analysis are for solid $\mathrm{PuF}_{4}$ in 4-in.-thick slabs with less than full external reflection. These data are summarized in Table 6.4 and Fig. 6.1. It has not been established that other configurations are inferior to slabs or that a 4-in. thickness is optimum, but the 4 -in. slab apparently merits consideration for plants of the size and type selected as the reference design.

TABLE 6.4. Criticality Source Data ${ }^{146}$

$$
\begin{aligned}
& I=4 \text { - by 48-in. slab reactor, alumina (bed) reflector top } \\
& \text { and bottom, l/2-in. nickel wall, } P_{\mathrm{PuF}_{4}}=7 \mathrm{~g} / \mathrm{cc} \\
& \text { (theoretical density, }{ }^{239} \mathrm{Pu} \text { ). } \\
& \text { II }=4 \text { - by } 24-\text { in. slab, remainder as in I (finite-slab } \\
& \text { comparison). } \\
& \text { III = Same as II with } 1 \text {-ft water mist layer all a round and a }
\end{aligned}
$$

\begin{tabular}{|c|c|c|c|c|c|c|c|}
\hline \multirow{2}{*}{$\begin{array}{c}\mathrm{PuF}_{4} \text { Slab } \\
\text { Height, } \\
\text { cm }\end{array}$} & \multirow{2}{*}{$\begin{array}{c}\text { Equivalent } \\
\text { Pu } \\
\text { Inventory, } \\
\text { kg }\end{array}$} & \multicolumn{6}{|c|}{$k_{\text {eff }}$} \\
\hline & & I & II & III & IV & V & VI \\
\hline 12 & 39.5 & 0.768 & 0.744 & 0.763 & 0.800 & 0.813 & - \\
\hline 15 & 49.3 & 0.821 & 0.801 & 0.814 & 0.861 & 0.868 & - \\
\hline 20 & 65.8 & 0.880 & 0.866 & 0.877 & 0.927 & 0.944 & - \\
\hline 30 & 98.7 & 0.960 & 0.935 & 0.956 & 1.000 & 1.034 & - \\
\hline 50 & 164.5 & 1.027 & 0.997 & 1.027 & 1.073 & 1.101 & - \\
\hline 100 & 329.0 & - & - & - & - & - & $0.78^{b}$ \\
\hline
\end{tabular}

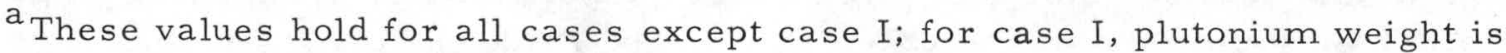
twice the value shown, since the reactor has twice the width of the reactors for the other cases.

bIn Fig. 6.1, a curve was drawn through this point by assuming a constant ratio of masses at $k_{\text {eff }}=0.78$ and 0.90 between cases II and VI. 


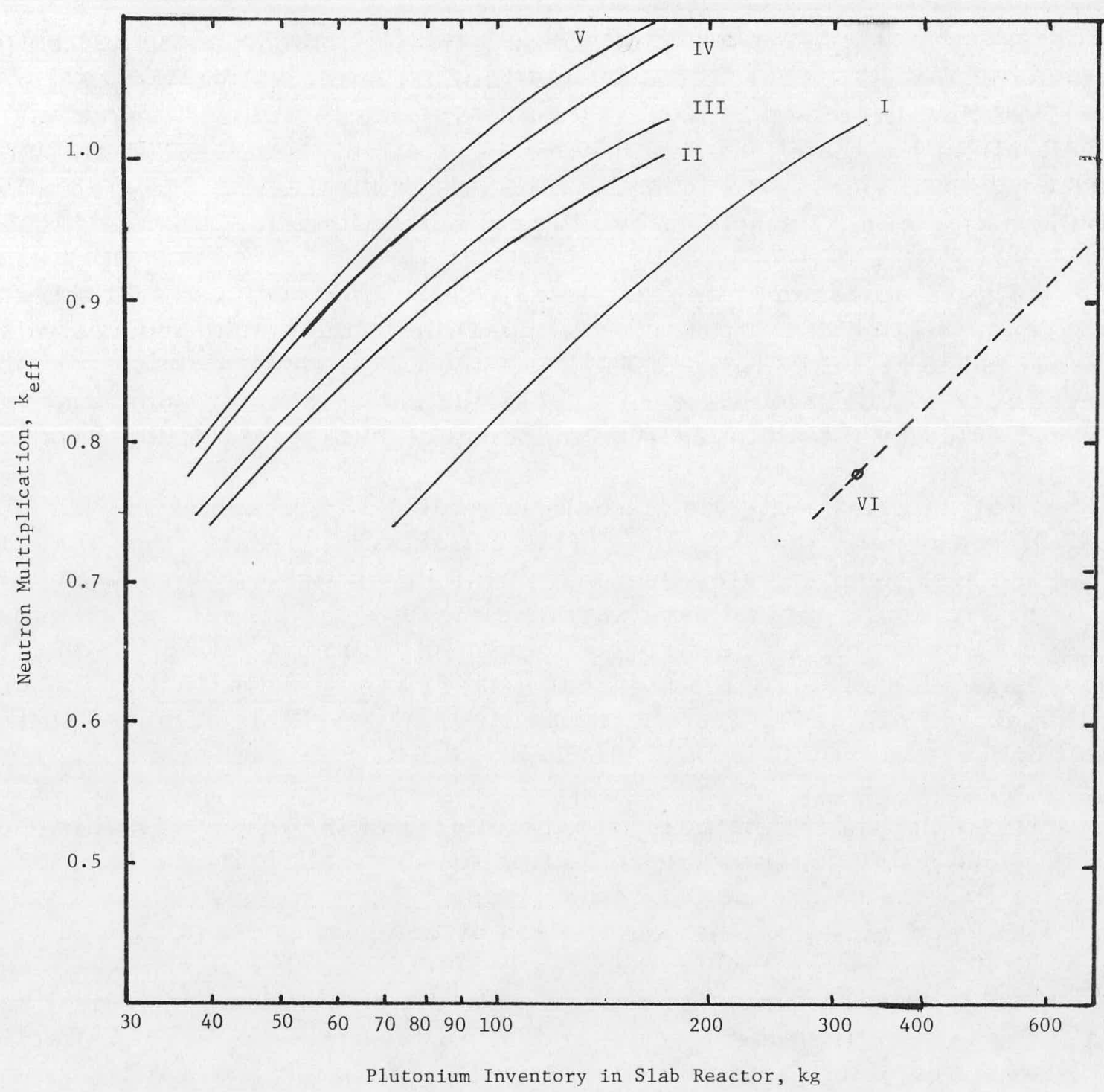

Fig. 6.1. Source Data for Criticality Analysis ${ }^{146}$ for 4 -in.-thick Slabs (see Table 6.4 for key)

The plots in Fig. 6.1 are identified in terms of numbered curves explained in Table 6.4. Plotted is $k_{\text {eff }}$ versus contained plutonium for reference slabs of $\mathrm{PuF}_{4}$. These slab calculations are for 4-in.-thick parallelepipeds of various heights and two reference widths. Curve I is for a 48-in.-wide slab; the others are all for a 24-in. width. There are two $\mathrm{PuF}_{4}$ densities: all numbered curves are for $\mathrm{PuF}_{4}$ at the theoretical maximum density, $7.0 \mathrm{~g} / \mathrm{cm}^{3}$, except curve VI, which is for $\mathrm{PuF}_{4}$ at a density of $5.0 \mathrm{~g} / \mathrm{cm}^{3}$ or $71.5 \%$ of theoretical. The other differences in the $k_{\text {eff }}$ curves are due to different conditions of external neutron reflection at the major (front and back) walls of the slab.

The "slab heights" shown in Table 6.4 are directly related to the mass of the plutonium for a given slab width and density. The slab heights 
for all cases bear the effect of full alumina reflection on the top and bottom surfaces of the slab. The left and right (minor) surfaces (or "edges"), which are the surfaces of smallest area, were not presumed to have external reflection; the effect of the latter is relatively small. The distance between the left and right surfaces is the larger dimension (24 or 48 in。), and the major effect on $k_{e f f}$ is by internal reflection.

The basic assumption for this calculational model was that the maximum concentration of fissile material possible in the actual process would be expected to be in the form of $\mathrm{PuF}_{4}$. In the worst case, a concentrated central zone of $\mathrm{PuF}_{4}$ would extend across the entire reactor width and be fully reflected by the alumina in the upper and lower zones of the reactor.

Full alumina reflection is here considered to be achieved with $30 \mathrm{~cm}$ of $\mathrm{Al}_{2} \mathrm{O}_{3}$ at a density of $2.5 \mathrm{~g} / \mathrm{cm}^{3}$. This reflection is greater than that of water and also much greater than that of $0.5 \mathrm{in}$. of nickel, which causes the major reflection (front and back surfaces) used in the presently calculated exhibits. For example, the strong effect of full alumina reflection on these surfaces is illustrated by the fact that if there is full reflection for an infinite slab of $\mathrm{PuF}_{4}$ at $7.0 \mathrm{~g} / \mathrm{cm}^{3}$, criticality $\left(\mathrm{k}_{\mathrm{eff}}=1.00\right)$ is achieved with a slab thickness of only $0.74 \mathrm{in}^{146}$

In using Fig. 6.1 to interpret the effects of the major variables (dimensions, $\mathrm{PuF}_{4}$ density, and reflection) on criticality, it is convenient to use case $\mathrm{I}$ as the reference for comparisons. The difference in $\mathrm{k}$ eff values for the 48 - and 24-in. widths can be seen by comparing cases I and II. At $k_{\text {eff }}=0.90$, the reactor with the greater width contains about 1.8 times the mass of plutonium than the reactor with the smaller width, indicating that there is very little penalty as a result of the higher internal reflection in the wider column. This fact contributed to the selection of a 48-in. width for the reference fluorination reactor.

External reflection at the major surfaces of the slab is specified as being equivalent to $0.5 \mathrm{in}$. of solid nickel for cases I and II. This reflection is about the minimum achievable for processing equipment. In comparison, a similar slab (case II) with no reflection ${ }^{146}$ could contain $400 \mathrm{~kg}$ of plutonium and have a $k_{\text {eff }}$ of 0.90 ; this is more than five times that for the 0.5 -in. nickel reflection. This would be equivalent to about $720 \mathrm{~kg}$ of plutonium for the 48 -in.-wide slab.

Case III has, in addition to $0.5 \mathrm{in}$. of nickel, a 1 -ft zone on both major surfaces for water spray as part of a cooling system. In addition, reflection by a $60-\mathrm{cm}$ (23.6-in.)-thick wall of concrete was assumed for one side of the column. Case IV, for a $3 / 4$-in. nickel wall, is included to allow comparison for different wall thicknesses. Case V applies to the present reference fluorinator design, which uses forced-air cooling; in this case there is reflection by cooling fins and by an outer sheath, as well as by a 0.5 -in. nickel wall. 
The large effect of density is shown by comparing cases II and VI, which are equivalent except for differing $\mathrm{PuF}_{4}$ densities of 100 and $71.5 \%$ of theoretical, respectively. Case VI is represented by only a single point, but at the calculated $k_{\text {eff }}=0.78$, case VI allows more than five times the mass allowed for case II. So far, realistic analyses of process mechanisms have revealed none that could produce a major zone of $\mathrm{PuF}_{4}$ with a density as high as $5.0 \mathrm{~g} / \mathrm{cm}^{3}$. Nevertheless, the highest possible PuF ${ }_{4}$ density $\left(7.0 \mathrm{~g} / \mathrm{cm}^{3}\right)$ was selected as a reference condition in this criticality analysis as a contribution to the overall safety factor. In addition, dimensional, instrumental, and administrative safeguards are imposed because of the key importance of density and mass control.

Reference criticality models were constructed from the data plotted in Fig. 6.1 for two reference cases, Rl and R2. These two cases are defined below in items 1,2 , and 3 , and the difference between the two cases is defined in item 4 :

1. 4-in. thick by 48-in. wide slab configuration.

2. Full reflection at top and bottom of slab by $30 \mathrm{~cm}$ of alumina at a density of $2.5 \mathrm{~g} / \mathrm{cm}^{3}$.

3. Reflection at sides [ major surfaces front and back by 0.5-in.thick nickel wall plus 0.25 -in.-thick nickel fins and 0.25 -in. outer sheath (case V)].

4. Slabs at two densities, one corresponding to $\mathrm{PuF}_{4}$ at full theoretical density $(\mathrm{R} 1)$ and the other at $71.5 \%$ of theoretical density (R2).

Table 6.5 shows the results for reference cases $R 1$ and $R 2$. These reference cases as described above are plotted in Fig. 6.2 for use in evaluating criticality of the reference fluorinator $A$ and other vessels. This is

TABLE 6.5. Reference Criticality Model Estimated from Source Data Slab dimension: 4 in. thick and $48 \mathrm{in}$. wide.

\begin{tabular}{|c|c|c|c|c|c|c|c|}
\hline \multirow{5}{*}{$\begin{array}{l}\text { Case: } \\
\text { Width, in.: } \\
\text { Density, g/cc: } \\
\text { Other surface }\end{array}$} & \multirow{5}{*}{$\begin{array}{l}\text { causing reflection: } \\
\mathrm{k}_{\text {eff }}\end{array}$} & \multicolumn{6}{|c|}{ Plutonium Mass, kg } \\
\hline & & 1 & II & V & VI & $\mathrm{Rl}^{\mathrm{a}}$ & $\mathrm{R} 2^{\mathrm{b}}$ \\
\hline & & 48 & 24 & 24 & 24 & 48 & 48 \\
\hline & & 7 & 7 & 7 & 5 & 7 & 5 \\
\hline & & - & - & Fins & - & Fins & Fins \\
\hline & 0.75 & 74 & 41 & - & 290 & - & - \\
\hline & 0.8 & 96 & 50 & 37 & 360 & 71 & 511 \\
\hline & 0.85 & 116 & 62 & 45 & 450 & 84 & 610 \\
\hline & 0.9 & 145 & 80 & 55 & 570 & 100 & 705 \\
\hline & 0.95 & 187 & 110 & 67 & - & 114 & - \\
\hline
\end{tabular}

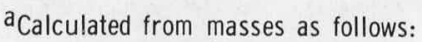
$\mathrm{Rl}=(\mathrm{V})(\mathrm{I}) /(\mathrm{II})$.

${ }^{\mathrm{b}}$ Calculated from masses as follows: $R 2=(R I)(V I) /(I I)$. 


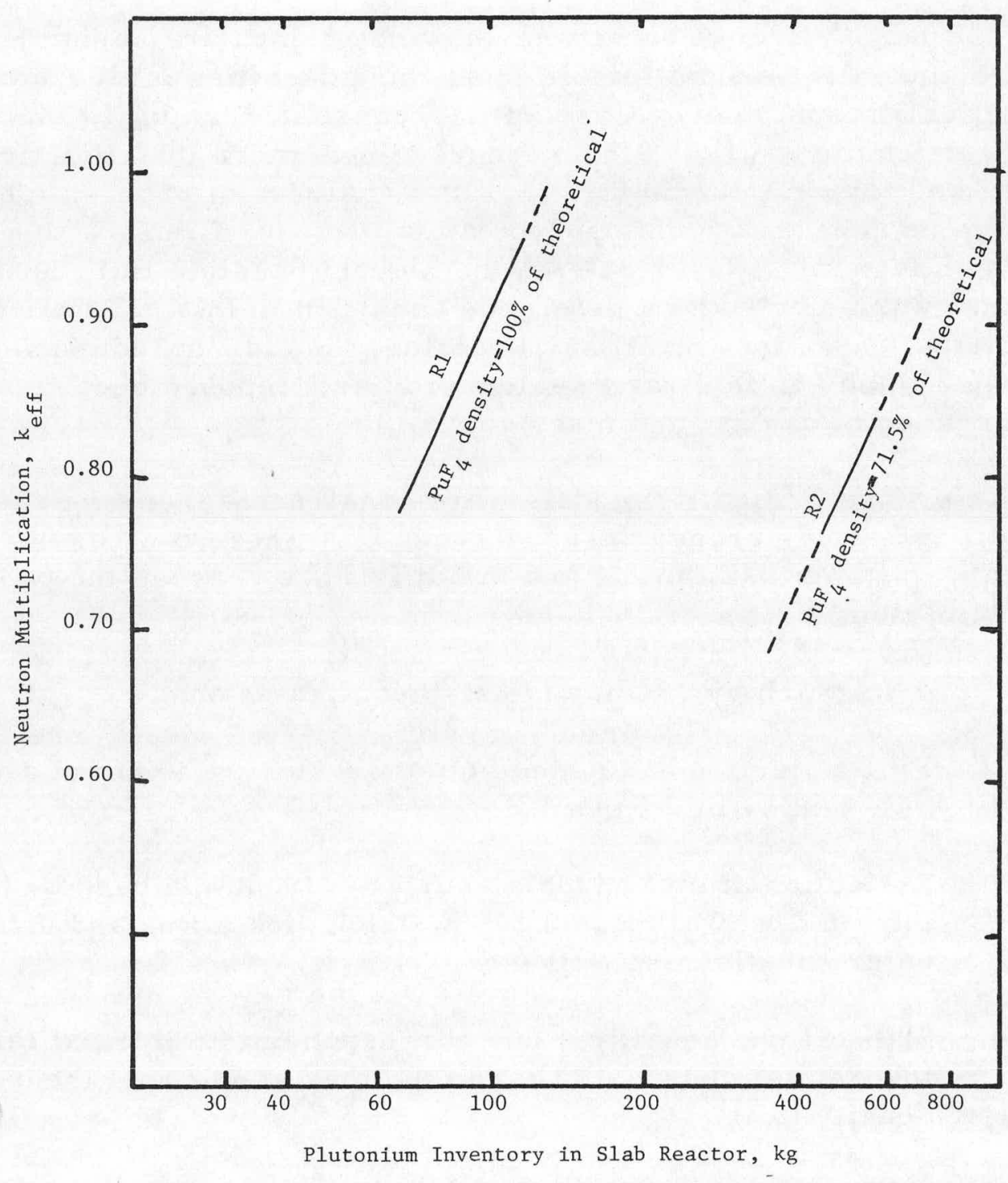

Fig. 6.2. Reference Cases for Criticality Analysis for 4-in. -thick Slabs (see Table 6.5)

the general model for criticality analysis in this study. Where deemed necessary, additional models are included in discussions of particular items of equipment.

\subsubsection{Nuclear-safety Analysis of the Reference Process}

For purposes of nuclear safety, the aim of the slab configuration design is to provide a large surface-to-mass ratio for the contained material with as little external neutron reflection as practical. This aim entails minimizing the neutron-reflecting mass of the vessel wall, insulation, and general structure. Avoidance of both low and high mass-number elements is desirable to minimize reflection. The structure should be designed (1) to prevent any extraneous mass from entering its specified 
volume and thereby changing the neutron-reflection characteristics, and (2) to prevent mechanical distortion of the containment vessel. Although the flowsheet was not designed specifically for slab reactors, the slab design seems satisfactory and does improve heat removal by virtue of higher surface-to-volume ratios.

The safety analysis of all slab vessels is based on a model for plutonium consisting of $\mathrm{a} \mathrm{PuF}_{4}$ slab of reference dimensions for which reactivity $\left(\mathrm{k}_{\mathrm{eff}}\right)$ has been calculated as a function of plutonium content. Nuclear safety is ascertained for selected cases of $\mathrm{PuF}_{4}$ content that are assumed to be representative of normal and credibly abnormal situations.

\subsubsection{Fluorinator A. Fluorinator A is a rectangular parallel-} epiped with inside dimensions $4 \mathrm{in}$. thick, $4 \mathrm{ft}$ wide, and $10 \mathrm{ft}$ high. The upper $6 \mathrm{ft}$ of the vessel provides freeboard and space for exit-gas filters. The cross-sectional area of the vessel is the same from top to bottom. Outside the nickel walls are cooling fins and a jacket for containing the coolant gas stream. Thermal insulation employs low-mass metal sheet or foil. The mechanical design includes enclosure of the slab fluorinator in a cylindrical cage or shell which prevents objects from coming close to the reactor and also serves to stiffen the slab. Process instrumentation and maintenance procedures are not described here, but slab design appears to entail no disadvantages for either.

Some special instrumentation is used to ensure nuclear safety; measured are bed height, density, and weight. More specifically, measurements of plutonium mass, density, and reactivity for $k_{\text {eff }}>0.1$ are needed. Neutron detection seems to be a highly promising technique for detecting plutonium in several applications:

a. Neutrons from $(\alpha, n)$ reactions can indicate plutonium content.

b. Pulsed-neutron multiplication is a possibility.

c. A new (and still very speculative) scheme specially adapted to the slab reactor is a variable-reflector/neutron-detector device. In this scheme, as the external reflection is varied, neutrons self-generated in the fuel show different emission levels because of different degrees of neutron multiplication.

d. A very promising method under development is the delayedneutron monitor, ${ }^{22,151}$ which makes very sensitive determinations of fissile content by measuring the delayed neutrons from fission induced by irradiation of a sample with an external source of thermal neutrons.

The neutron-monitoring methods cited above are expected to allow dependable measurement of the fissile content of any item of equipment. 
Therefore, instrumental interlocks that will prevent the accumulation of more than a predetermined fraction of the normal fissile inventory in a vessel can be applied to ensure nuclear safety.

Plutonium will be present in this system in several forms; the model used in this criticality analysis assumes that $\mathrm{PuF}_{4}$ will be the form with the greatest density. Before fluorination, plutonium will be in the form of $\mathrm{PuO}_{2}$ that cannot be separated from $\mathrm{UO}_{2}$. When the plutonium is fluorinated to $\mathrm{PuF}_{6}$, the density of plutonium is substantially lower than its density in the form of $\mathrm{PuF}_{4}$. No reducing conditions are used that might reduce $\mathrm{PuO}_{2}$ or $\mathrm{PuF}_{4}$ to metal. The maximum (theoretical) density of $\mathrm{PuF}_{4}$ is $7.0 \mathrm{~g} / \mathrm{cm}^{3}$. Although this density value probably cannot be achieved under normal or credibly abnormal conditions, it is used to provide a safety factor for the upper-limit abnormal conditions.

Table 6.6 gives reference operation and design conditions for fluorinator A. From these data, three reference cases are constructed:

Case I. Normal operation: $45.6 \mathrm{~kg}$ of plutonium (as $\mathrm{PuF}_{4}$ ) distributed in a slab 4 in. thick, $48 \mathrm{in.} \mathrm{wide,} \mathrm{and} 48 \mathrm{in.} \mathrm{high} \mathrm{at} \mathrm{an} \mathrm{average} \mathrm{plu-}$ tonium density of $0.30 \mathrm{~g} / \mathrm{cm}^{3}$.

Case II. Overfill case: $114 \mathrm{~kg}$ of plutonium (as $\mathrm{PuF}_{4}$ ) fills fluorinator A completely at the above density. (This case is a hypothetical abnormality in which feed is continued for $20 \mathrm{hr}$ while withdrawal of solids containing $\mathrm{PuF}_{4}$ is blocked.)

TABLE 6.6. Reference Operation and Design Conditions for Fluorinator A

\begin{tabular}{cccc}
\hline Input Flowrate, kg/day & $\begin{array}{c}\text { Core and Axial } \\
\text { Blanket }\end{array}$ & Radial Blanket & Combined Feed \\
\hline Uranium & 40.1 & 474 & 875 \\
Plutonium & 73.9 & 9.6 & 83.5 \\
$\mathrm{Al}_{2} \mathrm{O}_{3}$ & - & - & 240 \\
\hline
\end{tabular}

Normal Inventory

$60.2 \mathrm{~kg}$ of $\mathrm{PuF}_{4}(45.6 \mathrm{~kg}$ of $\mathrm{Pu}), 6.6 \mathrm{~kg}$ of $\mathrm{UF}_{4}, 137 \mathrm{~kg}$ of $\mathrm{Al}_{2} \mathrm{O}_{3}, 18.1 \mathrm{~kg}$ of fission-product fluorides.

\section{Design Parameters}

1. Normal volume of expanded fluid bed: 151 liters.

2. Total volume of vessel: 377 liters.

3. Normal plutonium space density: $0.30 \mathrm{~g} / \mathrm{cm}^{3}$.

4. Normal average bed bulk density: $1.47 \mathrm{~g} / \mathrm{cm}^{3}$.

5. Hypothetical plutonium inventory at "overfill": $114 \mathrm{~kg}$

6. Hypothetical plutonium inventory in pure ${ }^{\mathrm{a}} \mathrm{PuF}_{4}$ slab $\mathrm{b}^{7} \mathrm{in}$. high: $117 \mathrm{~kg}$ of $\mathrm{Pu}$

7. Time to feed excess $71 \mathrm{~kg}$ of plutonium: $20.4 \mathrm{hr}$.

a Pure $\mathrm{PuF}_{4}$ is assumed to have $100 \%$ theoretical density: $7.0 \mathrm{~g} / \mathrm{cm}^{3}(5.31 \mathrm{~g}$ of $\mathrm{Pu}$ per $\left.\mathrm{cm}^{3}\right)$.

${ }^{b_{A}}$ slab 4 in. thick, 48 in. wide, and $7.0 \mathrm{in}$. high in the center of fluorinator $\mathrm{A}$. 
Case III. Upper-limit abnormal case: $114 \mathrm{~kg}$ of plutonium (as $\mathrm{PuF}_{4}$ ) is concentrated as a slab about 7 in. high and extends across the width of the reactor vessel. This slab of $\mathrm{PuF}_{4}$ is centered in the reactor and is subject to full alumina reflection at the top and bottom and partial reflection by the nickel wall and other structural material. The significance of the plutonium density and the reflection will appear later in the discussion of criticality calculations based on this model.

The approach to criticality for $\mathrm{PuF}_{4}$ slabs of the type described above is shown quantitatively in Fig. 6.2, where calculations of neutron multiplication (in terms of $\mathrm{k}_{\text {eff }}$ for reference configuration, plutonium density, and neutron reflection) are plotted against the contained mass of plutonium in the slab. The left-hand curve is for $\mathrm{PuF}_{4}$ at $100 \%$ theoretical density; the right-hand curve (constructed through one point only) indicates roughly the effect of a lower density, $71.5 \%$ of theoretical density. (This lower density is close to, but slightly higher than, the maximum theoretical density of $\mathrm{PuF}_{6}$.)

For the three reference cases, the highest $k_{\text {eff }}$ would be found for the hypothetical consolidation of all plutonium in the form of $\mathrm{PuF}_{4}$ in the center of the reactor. The approach to criticality so indicated may be summarized as follows:

Case I. Normal operation: $\max k_{\text {eff }}<0.1 \quad$ Mass safety factor $>10$ for $100 \% \mathrm{PuF}_{4}$ density.

Case II. Overfill case:

$\max k_{\text {eff }}<0.5 \quad$ Mass safety factor $>10$ for $100 \% \mathrm{PuF}_{4}$ density.

Case III. Upper-limit abnormal

case

$\max k_{\text {eff }}=0.95$ Mass safety factor 1.2 for $100 \% \mathrm{PuF}_{4}$ density.

The plutonium mass that would have to be present in the hypothetical $\mathrm{PuF}_{4}$ slab for $\mathrm{k}_{\text {eff }}$ to be 1 would be about $140 \mathrm{~kg}$ of plutonium at maximum $\mathrm{PuF}_{4}$ density. On the basis of relative mass, the safety factor is about 1.2 for the upper-limit case III. Given a more realistic $\mathrm{PuF}_{4}$ density, the mas safety factor could be increased. The safety factors for cases I (normal) and II (overfill) are both $>10$.

On the basis of the preceding argument and the plot of $\mathrm{k}_{\text {eff }}$ given, the reference operation of fluorinator A apparently is safe. Criticality could occur only if normal preventive measures broke down and simultaneously (1) the normal plutonium inventory was exceeded greatly; (2) abnormally high temperatures and other conditions allowed the $\mathrm{PuF}_{4}$ to consolidate to near-theoretical densities; (3) abnormal disposition of the environment allowed high-neutron-reflection conditions to be realized. 
6.1.3.2 Fluorinator B. Fluorinator B normally has a much smaller inventory of plutonium than does fluorinator A (as shown in Table 6.2). Consequently, the overfill case resulting from stoppage of solids discharge (analogous to that for fluorinator A) would be much less severe and not limiting. Similarly, plutonium consolidation accompanying the overfill case would also not be limiting. The limiting case for fluorinator B would be that based on both overfill and nonfluorination of the $\mathrm{PuF}_{4}$ entering fluorinator B. However, this upper-limit abnormal case would be no worse than the overfill case for fluorinator $A$, since the material entering fluorinator $B$ is the discharge from fluorinator $A$. Also, the total volume and freeboard in fluorinator $B$ are less than in fluorinator $A$; this difference results in greater safety in case of overfill. Total heat generation in fluorinator B is also less than in fluorinator A. Overall, fluorinator B would be safer than fluorinator A.

6.1.3.3 Cold Traps. Hexafluoride cold traps CT-1, CT-2, and CT-3 are of slabconstruction and are operated batchwise. They have the inventories shown in Table 6.2. All normal operations with plutonium hexafluoride (which has a lower theoretical density than $\mathrm{PuF}_{4}$ ) would be safe for the reference slab configuration. Because batch cold traps operate with $80 \%$ or more free space, substantial overfill cases could be hypothesized, although in practice plugging would occur which would prevent further entry of the hexafluoride long before overfilling could be complete. Even the hypothetical $100 \%$ overfill case would not be critical for a density as low as that of the theoretical maximum for $\mathrm{PuF}_{6}$. Nevertheless, $\mathrm{PuF}_{6}$ could decompose to form $\mathrm{PuF}_{4}$ at a rate dependent on temperature and radiation conditions. This $\mathrm{PuF}_{4}$ would have a density less than $100 \%$ of theoretical. It is supposed here that the upper-limit abnormality would be for doublebatching plus decomposition of all $\mathrm{PuF}_{6}$ to $\mathrm{PuF}_{4}$ at $100 \%$ theoretical density. This could result in a $\mathrm{PuF}_{4}$ slab containing a maximum of $84 \mathrm{~kg}$ of plutonium, which is less than the 114-kg plutonium slab in the overfill case for fluorinator $A$. Therefore, the cold traps are considered safe. Actually, double-batching would be prevented instrumentally (e.g., weigh systems are proposed here).

6.1.3.4 Feed Vesse1. The feed vessel for the thermal decomposer normally contains $42 \mathrm{~kg}$ of plutonium in a $\mathrm{PuF}_{6}-\mathrm{UF}_{6}$ batch mixture. Since the freeboard is small, at normal overfill only $46 \mathrm{~kg}$ of plutonium at a low density would be in the vessel, and this is not limiting. As in the cold-trap case, the upper-limit abnormal case would appear to be one in which double-batching (twice the normal plutonium inventory) occurs, as well as complete conversion of $\mathrm{PuF}_{6}$ to $\mathrm{PuF}_{4}$ at maximum theoretical density. Because the feed vessel construction is similar to the slab construction of the fluorinator vessels, this case is considered safe.

6.1.3.5 Thermal Decomposer. The thermal decomposer is considered safe since the upper-limit abnormal case corresponds to the double-batch $\mathrm{PuF}_{4}$ case discussed above for the feed vessel. 
6.1.3.6 Converter. The converter differs from other process vessels in that it operates on a 2 -hr batch cycle and uses steam and hydrogen as gaseous reagents. Although operation at normal temperatures $\left(>500^{\circ} \mathrm{C}\right)$ would preclude condensation and any significant neutron moderation from the steam and hydrogen, consideration was given to internal water-flooding as an abnormal case. Liquid water filling the slab, including the voids of the normal bed in the static condition ( 2 -ft static bed at $5.5 \mathrm{~g} / \mathrm{cm}^{3}, 121.5 \mathrm{~kg}$ of $23 \% \mathrm{PuO}_{2}-\mathrm{UO}_{2}$ mixture containing $24.6 \mathrm{~kg}$ of plutonium), would give a $\mathrm{k}_{\mathrm{eff}}=0.500^{146} \mathrm{Complete}$ overfill (86 $\mathrm{kg}$ of plutonium), followed by consolidation to a plutonium density $\left(5.3 \mathrm{~g} / \mathrm{cm}^{3}\right)$ equivalent to the theoretical density of $\mathrm{PuF}_{4}$, would also be safe, as previously discussed for fluorinator A. Since each batch increment contains about $6 \mathrm{~kg}$ of plutonium, the vessel would be safe if double-batching occurred.

Although very complicated, purely hypothetical cases might be adduced for the converter, dangerous departures from normal operations are multiply preventable by instrumental means.

6.1.3.7 Ball Mill (Head-end). The ball mill mechanically separates oxide fuel from chopped cladding in the plant head-end. The ball mill operates continuously with the normal inventory shown in Table 6.3. Possible chemical reactions, which would cause segregation of plutonium in this vessel, are not deemed credible, nor is water flooding. Only oxygen is present as a possible reagent. No alumina is present, and external neutron reflection is partial, as in fluorinator $A$.

The ball mill proper is a cylinder of 18 -in. diameter with a total volume of 167 liters. For the purposes of the present study, it has not been deemed necessary to make highly detailed equipment designs for the plant head-end. At $80 \%$ of the theoretical density, the mixed feed oxide (core plus blanket, $10 \mathrm{wt} \% \mathrm{PuO}_{2}$ ) would contain $134 \mathrm{~kg}$ of plutonium if the volume of the ball mill was $100 \%$ occupied. This amount of plutonium is almost exactly the critical mass for a homogeneous $\mathrm{PuO}_{2}$-alumina mixture in an 18-in.diam cylinder for full alumina reflection $\left(30 \mathrm{~cm}\right.$ thick at $2.5 \mathrm{~g}$ of $\mathrm{Al}_{2} \mathrm{O}_{3}$ per $\left.\mathrm{cm}^{3}\right)_{0}^{150}$ Because simultaneous realization of these abnormally high values of density, occupancy, and reflection is prevented, the case in which plutonium is uniformly distributed is considered safe, probably by a mass safety factor of four or so. For core fuel only, 20 wt $\% \mathrm{PuO}_{2}$, the unit is considered safe. Models for plutonium segregation and consolidation have not yet been formulated for all hypothetical cases that might be submitted for analysis. However, preferential retention of plutonium and consolidation of this $\mathrm{PuO}_{2}$ at the center of the cylindrical mill (the most unfavorable geometry) does not seem credible at present. The 18-in.-diam ball mill apparently does not constitute a serious problem for design from the criticality standpoint. 
6.1.3.8 Slab-geometry Storage Vessels. The oxide feed hopper and the oxide product receivers are slabvessels (Table 6.3). These vessels contain mixed U-Pu oxide, which has a lower plutonium density than does $\mathrm{PuF}_{4}$, and are safe on the basis of the previous analysis in which partial reflection was assumed. The small freeboard prevents double-batching. The slab for the feed material is thin to aid heat removal.

\subsubsection{Nuclear Safety Analysis of the Ventilation System}

This section presents a criticality safety analysis of the ventilation system. The plant ventilation system is described for reader orientation in following the analysis. The performance required for containment of plutonium and fission products is analyzed in Section 6.2.

6.1.4.1 Disposition of Fissile Material in Ventilation System. In the ventilation system, the performance requirements with respect to criticality are not for the normal process conditions, but for rather wide ranges of abnormal (accident) conditions. The approach used in the design of the ventilation system was to emphasize the safety problems that are distinctive for the volatility process over the full range of realistic possibilities. That is, leaks and ruptures in process equipment were considered capable of introducing $\mathrm{UF}_{6}, \mathrm{PuF}_{6}$, fluorine, and volatile fission-product fluorides into the ventilation system. A combination of water scrubbing and particle filtration can be used to hydrolyze, absorb, and filter most fissile and noxious materials (except inert gases) at the concentrations that might be present in the effluent ventilation air. The design of a criticality safe ventilation system thus becomes a matter of specifying the sizes of the units and determining whether operation is dependable. Figure 6.3 is a schematic diagram of the system.
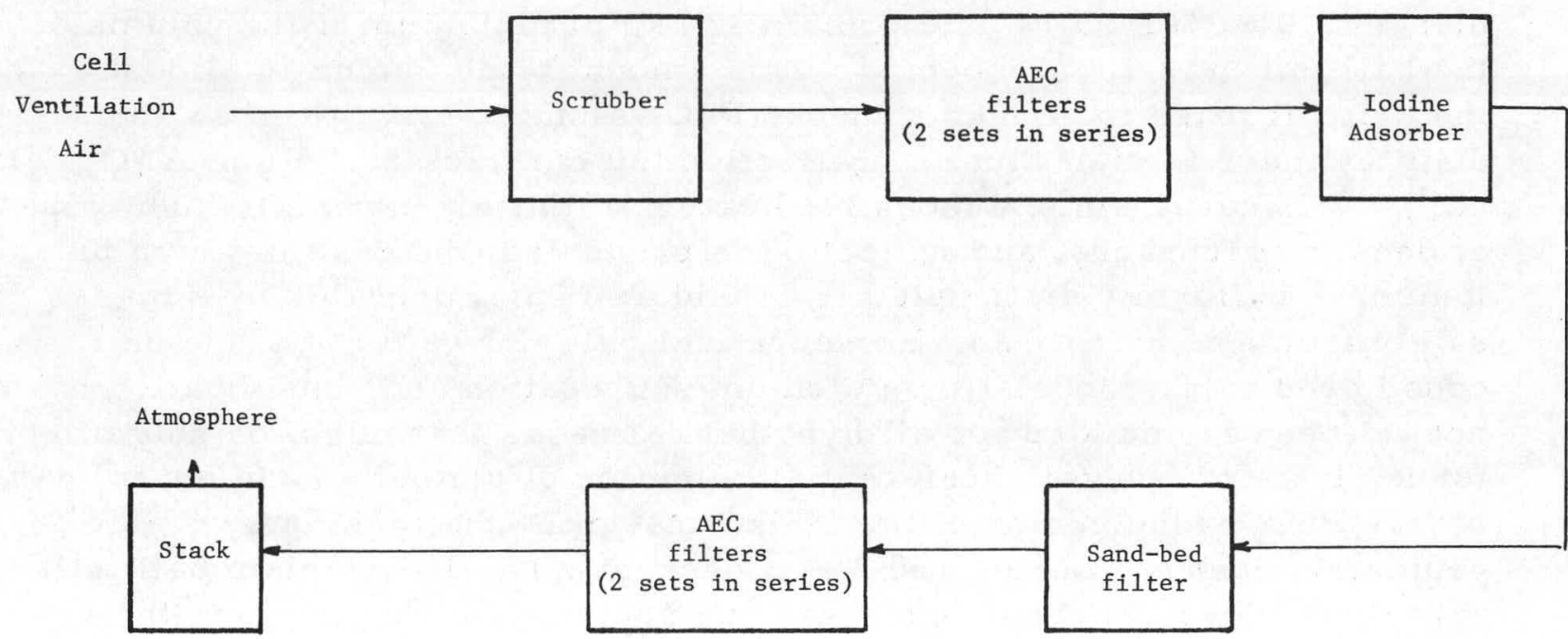

Fig. 6.3. Components of Reference Ventilation System 
The scrubber unit functions as an air humidifier for the vapor-phase hydrolysis of $\mathrm{UF}_{6}$, for $\mathrm{PuF}_{6}$, and for other volatile fluorides, such as $\mathrm{RuF}_{5}$, and $\mathrm{NbF}_{5}$. It also may function as an absorber for dusts and vapors. One product of fluoride hydrolysis is $\mathrm{HF}$, which can be very efficiently absorbed in aqueous solutions. Basic solutions are used in scrubbers to avoid the corrosion by acid solutions. Extensive experience has shown that scrubbers of this general type (see p. 191) are reliable and have desirably low corrosion rates.

The scrubber has the important function of enhancing and safeguarding the operation of filters. The standard AEC filter for particulate materials is susceptible to damage by excessive heat, chemical reagents, condensed water, and also sudden overloading and pressure shocks. The use of a scrubber upstream from the filter minimizes or eliminates such hazards to the filter--specifically hazards from fluorine and reactive fluorides. In the present study it has been assumed that under normal conditions none of the hydrolyzed $\mathrm{UF}_{6}$ or $\mathrm{PuF}_{6}$ is retained in the scrubber, but that these actinides are removed only on the filter. This is not a realistic assumption for large plutonium releases, in which most of the plutonium could be picked up in the scrubber.

The criticality analysis of accidental-release cases cannot readily be made quantitative because of a wide variation of the important variables. The efficiency of scrubbing out the particulate material is a strong function of particle size (the efficiency varying from 5 to 95\%); agglomeration, which varies widely with particle concentration, affects the range of particle size. Particle concentration can vary by several orders of magnitude under the wide range of possible accident conditions. However, under conditions of maximum releases of hexafluorides, the high concentration of particles will favor agglomeration and the scrubber will remove most of the material of large size (particles of size greater than about $10 \mu \mathrm{m}$ ).

The products of hydrolysis of the hexafluorides are $\mathrm{UO}_{2} \mathrm{~F}_{2}$ and $\mathrm{PuO}_{2} \mathrm{~F}_{2}$, which are readily soluble in water solutions up to about $0.1 \underline{\mathrm{M}}$. Since any uranium and plutonium picked up in the scrubber should be dis solved completely in the scrubber solution, it is proposed that a carbonateEDTA-boric acid solution be used in the scrubber to achieve maximum solubility. The carbonate tends to form a complex with uranium and plutonium and to neutralize acid, while the EDTA is an effective complexing agent at a $\mathrm{pH}$ of about 11 . Boron prevents criticality and can be used in solution as a soluble poison, and in the structure (boron steel) as a fixed poison. Some plutonium may be present as $\mathrm{PuF}_{4}$; the solubility of $\mathrm{PuF}_{4}$ in this solution is not known.

As described above, the scrubber prevents rapid rates of collection of solids on the filter, thereby improving the safety of filter operation. The effect of the scrubber and the sand bed, both of which have chemical, heat, 
and pressure-controlling action, is to safeguard the integrity of the AEC filters over a wide range of possible accident conditions, which include fires, the accidental dumping of water into the ventilation system, and perhaps even meteorological incidents such as tornadoes.

The sequence of steps in the reference ventilation system in the event of a release is as follows:

1. Material is released in the process cell.

2. Material is transported in the ventilation gas through ventilation exhaust ducts to the scrubber.

3. Gas stream passes through the scrubber and its demister and exit-gas reheater.

4. Gas stream passes through two sets of AEC filters in series.

5. Gas stream passes through an iodine absorber bed (activated carbon).

6. Gas stream passes through a sand-bed filter.

7. Gas stream passes through another two sets of AEC filters in series as in 4 above.

8. Gas stream passes through the exhaust stack to the atmosphere.

The criticality analysis is based on an estimate of the disposition of plutonium in the ventilation safety system. Plutonium deposition in three areas is considered: the ductwork, the scrubber, and the primary AEC filters (corresponding to items 2,3 , and 4 above).

\subsubsection{Criticality in Air Space of Process Cells and Ducts Leading} to Scrubber. Air entering the cells is assumed to have passed through inlet filters and to be of ambient humidity and temperature; air leaving the cells will have been heated by the process equipment to probably $100-150^{\circ} \mathrm{F}$. It is not proposed to cool or filter this air in the cells or in the ducts. Plutonium released as solid dust would have the usual dust behavior. Plutonium released as $\mathrm{PuF}_{6}$ would be hydrolyzed to an extent controlled by the humidity of the ambient air, and the remainder would evaporate into the air as $\mathrm{PuF}_{6}$ vapor. The hydrolyzed product would be finely divided $\mathrm{PuO}_{2} \mathrm{~F}_{2}$, which in dilute form would not appreciably agglomerate or settle out on surfaces of the cell or ducts. No mechanism for consolidation of plutonium in the process cells or ducts in quantities constituting a criticality hazard appears possible. If equipment is kept water-free and smooth, and welded ductwork is used, there should be no particular difficulty in transferring plutonium to the scrubber. However, a more detailed description and analysis of the system would be required to ensure the selection of an acceptable plant design. 
6.1.4.3 Criticality in Scrubber Unit. Plutonium can enter the scrubber unit as airborne $\mathrm{PuO}_{2} \mathrm{~F}_{2}$ or $\mathrm{PuF}_{6}$ with or without similar uranium compounds. The scrubber is designed to handle a maximum release of $3300 \mathrm{~kg}$ of combined $\mathrm{UF}_{6}+\mathrm{PuF}_{6}$ (as discussed in Section 6.2.1 below). The maximum credible incident involves the release of $300 \mathrm{~kg}$ of $\mathrm{PuF}_{6}$. The most severe criticality case in the scrubber would be based on the assumption that this entire amount of plutonium is deposited in the scrubber anddissolved in the scrubber solution. Plutonium fluoride and uranium fluoride are estimated to be readily soluble up to $0.1 \underline{\mathrm{M}}$ in potassium carbonate solution. A strong complexing agent is included in the scrubber solution (EDTA), and nuclear safety is provided by a fixed poison: boric acid in solution and fixed boron as Pyrex or as boron-steel Raschig rings in liquid-containing portions of the scrubber and associated tanks. The borate ion is a complexing agent for fluoride. The scrubber itself is a spray tower with all internal surfaces washed by the scrubber solution. The demister following the spray section is also washed. Although the details of the poison system can vary widely, a high degree of dependability is needed.

\subsubsection{Criticality in Filter System. Filter loadings of uranium or} plutonium compounds are readily detected by pressure drop measurements. If pressure drop should increase to about 2 in. of $\mathrm{H}_{2} \mathrm{O}$ (for a standard 24-by 24- by 11.5-in. filter unit), the filter would be routinely replaced. If particulate matter penetrated the scrubber (and its demister), the penetrating particles would not be expected to deposit on the ductwork between the scrubber and the filter. Such airborne particles would be expected to distribute with the air to the 30 standard filter units in parallel specified in the reference design. On the other hand, if the particles are susceptible to surface deposition, a fraction of the particles would be picked up by the scrubber and a much smaller amount would appear on the filters.

This section on criticality analysis of filters has considered the maximum filter deposition. Although more realism might be desirable, use of the larger amount of plutonium contributes to the overall safety factor. Table 6.7 gives estimated effects of plutonium deposition on the pressure drop in a standard filter unit.

TABLE 6.7. Estimated Filter Loading Capacity for $\mathrm{PuF}_{6}$ Release

(Filter size: $1000 \mathrm{cfm}$-rated airflow)

$\mathrm{PuF}_{6}$ Release ( $\mathrm{kg}$ of $\mathrm{Pu}$ ) That Gives Indicated

Increases in Pressure Drop at Indicated Percentage of Rated Airflow

\begin{tabular}{ccccc}
\hline $10 \%$ & $20 \%$ & $50 \%$ & $100 \%$ & $\begin{array}{c}\text { in Pressure } \\
\text { Drop, in. } \mathrm{H}_{2} \mathrm{O}\end{array}$ \\
\hline 3.4 & 1.6 & 0.62 & 0.29 & 1 \\
5.4 & 2.6 & 0.98 & 0.47 & 2 \\
8.6 & 4.1 & 1.6 & 0.75 & 4 \\
\hline
\end{tabular}


If the total plant release of uranium and plutonium occurred simultaneously ( $300 \mathrm{~kg}$ of $\mathrm{PuF}_{6}$ and $3000 \mathrm{~kg}$ of $\mathrm{UF}_{6}$ ), about $7 \mathrm{~kg}$ of plutonium and $70 \mathrm{~kg}$ of uranium would be expected to be directly deposited on each parallel filter unit. Since no opportunities for sintering exist, the effective density of the plutonium would be less than $4.0 \mathrm{~g} / \mathrm{cc}$, and batches up to $700 \mathrm{~kg}$ of plutonium might not be critical. However, if there should be a large deposition on the filters, the filters would be completely plugged and would have to be replaced. In practice, the ventilation exhaust air would then be switched to a second bank of (new) filters. to allow continued plant operation. The extreme unlikelihood that particulate would pass through the scrubber at a time when both on-line and standby filter units are plugged (i.e., before the filters could be replaced) is not considered here.

A deposit of $7.0 \mathrm{~kg}$ of plutonium on a plane surface 24 by 24 in. (corresponding to the superficial cross-sectional area of a filter unit) is visualized as $9.05 \mathrm{~kg}$ of $\mathrm{PuO}_{2} \mathrm{~F}_{2}$ (maximum density $=6.57 \mathrm{~g} / \mathrm{cm}^{3}$; minimum volume $=1.42$ liters) deposited as a slab 0.18 in. thick. Since the cake would actually be deposited on a much larger surface area of the convoluted filter, this maximum density/minimum volume slab is used as a "safe" assumption. The maximum plutonium density for this case is

$$
\frac{239}{309}(6.57)=5.07 \mathrm{~g} / \mathrm{cm}^{3}
$$

This maximum density is for the pure (not the hydrated) form of $\mathrm{PuO}_{2} \mathrm{~F}_{2}$. If this is assumed to be the plutonium density, critical thicknesis is indicated by the critical data for water-containing infinite slabs of plutonium-bearing material (shown in Table 6.8). These data indicate the effects of the major variables: plutonium density, reflection, and moderation. However, a somewhat specialized (and in this case, unrealistic) relationship between density and moderation is assumed in Table 6.8; that is, water is assumed to fill the "voids" of the plutonium-bearing structure.

TABLE 6.8. Estimated C ritical Thicknesses of Infinite Slabs of Homogeneous Water-moderated Plutonium $\left({ }^{239} \mathrm{Pu}\right)^{152}$

\begin{tabular}{|c|c|c|c|c|c|}
\hline \multirow[b]{2}{*}{$\begin{array}{l}\text { Plutonium Density, } \\
\qquad \mathrm{g} / \mathrm{cm}^{3}\end{array}$} & \multirow[b]{2}{*}{$\mathrm{H} / \mathrm{Pu}$} & \multicolumn{2}{|c|}{$\begin{array}{c}\text { Water } \\
\text { Reflection }\end{array}$} & \multicolumn{2}{|c|}{$\begin{array}{l}\text { 1/16-in. Stainless } \\
\text { Steel Reflection }\end{array}$} \\
\hline & & $\begin{array}{c}\text { Critical Thickness, } \\
\text { in. }\end{array}$ & $\begin{array}{l}\text { Critical } \mathrm{Pu} \\
\text { Content, }{ }^{\mathrm{a}} \mathrm{kg}\end{array}$ & $\begin{array}{c}\text { Critical Thickness, } \\
\text { in. }\end{array}$ & $\begin{array}{l}\text { Critical } \mathrm{Pu} \\
\text { Content, }{ }^{\mathrm{a}} \mathrm{kg}\end{array}$ \\
\hline 7.0 & 2.5 & 0.92 & 8.7 & 2.5 & 23.6 \\
\hline 6.0 & 3 & 1.02 & 9.6 & 2.7 & 26.4 \\
\hline 5.0 & 4 & 1.1 & 10.4 & 3.0 & 27.3 \\
\hline $4.58^{b}$ & $<4$ & $>1.1$ & $>11$ & $>3.1$ & $>29$ \\
\hline 4.0 & 5 & 1.3 & 12.3 & 3.3 & 31.2 \\
\hline 2.0 & 12 & 1.4 & 13.2 & 3.9 & 36.8 \\
\hline 1.0 & 25 & 1.5 & 14.1 & 4.0 & 37.8 \\
\hline 0.4 & 70 & 1.6 & 15.1 & 4.0 & 37.8 \\
\hline
\end{tabular}

${ }^{\mathrm{a}}$ Calculated for a slab 24 by $24 \mathrm{in.}$ at the density and critical thickness given in this table.

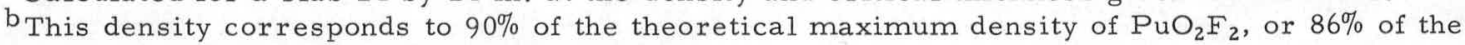
theoretical maximum density of $\mathrm{PuF}_{4}$. 
It is perhaps unexpected that the critical thickness shown in Table 6.8 varies so little for wide variations of plutonium density. Apparently, where the $\mathrm{H} / \mathrm{Pu}$ ratio increases as the plutonium density decreases, there is only a small increase in critical thickness. If $7.0 \mathrm{~kg}$ is taken as the maximum possible plutonium accumulation, the resulting configuration appears to be safe.

\subsubsection{Critique of Reference Concept for Criticality Control}

The critique of criticality control for the reference concept is presented in two parts: the process equipment and the ventilation system. Recommendations for further studies are included.

\subsubsection{Process Equipment. A complete plant design has not been} within the scope of this study, although a conceptual outline of one design has been offered as a reference example for feasibility analysis. Preliminary calculations showed that a separation distance of a foot or so between a fissile accumulation and either a well or another fissile batch can allow large fissile masses to be distributed in a plant. A separation distance of $4 \mathrm{ft}$, which seems safe on the basis of present information, has been adopted in the conceptual plant design. Spatial separation and physical isolation with walls can be achieved by appropriate design, but an economic design has not been prepared.

More calculations and some experimental verification are needed to show (1) the effects of design variables and (2) the uncertainties of the reference approach to criticality control. Slabs of 3- to 8-in. thickness should be examined, and configurations other than slabs should be considered. Design optimization and detailed safety analyses could then be carried out.

A specific analysis (topical report) on mechanisms of plutonium consolidation and sintering is needed. Data reviews by M. J. Steindler (CEN-ANL) were consulted in the present analysis. The best data indicate that $\mathrm{PuF}_{4}$ is stable, with a melting point of $1037^{\circ} \mathrm{C}$. The $\mathrm{PuF}_{4}$ maximum density of $7.0 \mathrm{~g} / \mathrm{cm}^{3}\left(5.3 \mathrm{~g} / \mathrm{cm}^{3}\right.$ of plutonium) seems to be higher than the density of any other possible compound in a nonreducing environment. $\left(\mathrm{PuO}_{2}\right.$ in a solid solution with $\mathrm{UO}_{2}$ is virtually inseparable from $\mathrm{UO}_{2}$.) However, because of the diluting effects of nonfissile isotopes, fluorine, alumina (and other impurities), and voids, plutonium densities greater than $4.0 \mathrm{~g} / \mathrm{cm}^{3}$ are extremely unlikely.

The effect of elevated temperatures on reducing the density (and thereby reducing neutron reactivity) should be considered further. Specific data on thermal expansion of $\mathrm{PuF}_{4}$ are not available, but thermal expansion when the solid temperature is increased to $1000^{\circ} \mathrm{C}$ would be expected to decrease the density approximately a few percent. An even more substantial density decrease may be expected on melting. 
Further analysis of criticality control should consider the consequences of a criticality incident. A high neutron background is considered to minimize energy release in a criticality excursion in cases of rapid rates of insertion of reactivity. However, rates of insertion of reactivity are not expected to be rapid in a continuous processing system.

More attention should be given to criticality as a secondary incident, following other malfunctions or accidents.

Instrumentation should be considered as a means of supplementing geometry in providing adequate safety factors. New instruments to account for fissile material both inside and outside the process equipment are likely to be developed (see Appendix A).

This analysis, though preliminary and incomplete, represents a contribution in its approach to the analysis of geometrically controlled, partially reflected nonaqueous systems.

6.1.5.2 Ventilation System. It is believed that adequate redundancy has been applied to the ventilation safety system and that the required nuclear safety has been achieved, although the design of the ventilation safety system has not been carried to the point of realistic detail, nor has the design of component systems been optimized with respect to the system as a whole. The conceptual design of the reference plant has led to estimates that rather large quantities of fissile and other volatile materials may be released suddenly to the ventilation system in case of an accident. A detailed study of the chemical behavior of plutonium and fission products in the scrubber and other parts of the ventilation system will be needed when the design details of the system are developed. Other plant designs with (a) smaller inventories of fissile and other process materials and (b) segmented ventilation may allow greater nuclear safety.

\subsection{Ventilation System Safety Analysis: Introduction and System Design Concept}

Those aspects of safety pertaining to the release to the atmosphere of any noxious chemical or radioactive effluents depend on the capability and reliability of the ventilation system (shown schematically in Fig. 6.3). Noxious components that are vaporous or airborne are removed from gas streams by various procedures. Reactive chemicals such as fluorine and hydrogen fluoride are neutralized and absorbed adequately in caustic scrubbers. ${ }^{153}$ Radioactive dusts are trapped by filtration on AEC filters. Released uranium and plutonium hexafluoride vapors constitute special cases, but work in this area by Kessie and Ramaswami ${ }^{130}$ presents a method for safe handling of these materials. Their work with $\mathrm{UF}_{6}$ and $\mathrm{PuF}_{6}$ systems showed that hexafluoride vapors released into moist air quickly hydrolyze and are converted to a particulate, airborne solid, which can be filtered efficiently by standard filter systems. 
Volatile fission-product activity falls into several categories of chemical behavior. The major activity is that associated with $\mathrm{RuF}_{5}, \mathrm{NbF}_{5}$, and $\mathrm{SbF}_{5}$. These materials are much less volatile than $\mathrm{PuF}_{6}$, but their removal from a gas stream by hydrolysis and filtration is assumed to be similar to that for $\mathrm{PuF}_{6}$. Compounds such as $\mathrm{MoF}_{6}, \mathrm{TcF}_{6}$, and $\mathrm{TeF}_{6}$ are of similar or higher volatility than $\mathrm{PuF}_{6}$, but $\mathrm{TeF}_{6}$ is somewhat slower to hydrolyze than $\mathrm{PuF}_{6}$, and therefore a special separation technique is used for it.

When gas from a short-cooled fuel is released to the plant ventilation system (for either nuclear power reactors or fuel-reprocessing plants), iodine removal is a serious problem. There are many possible methods for the removal of iodine and its compounds from gas streams. ${ }^{154}$ Iodine combines with small amounts of organic material in normal air or in the plant environment and is converted to $\mathrm{CH}_{3} \mathrm{I}$, which penetrates filters and absorbers that remove elemental iodine. Possibly, the relative scarcity of organic materials in the reference system and the presence of substantial amounts of active fluorides will lessen this difficulty. The process fluorination system would be expected to contain chiefly $\mathrm{IF}_{5}$ and possibly some $\mathrm{IF}_{7}$ and $\mathrm{IOF}_{5}$. The products of hydrolysis of these iodine fluorides in the scrubber would probably be elemental iodine and possibly some $\mathrm{CH}_{3} \mathrm{I}$. Because absorption of iodine in the scrubber solution has not been demonstrated, an additional absorber material for iodine has been tentatively specified in the ventilation system--activated charcoal preloaded with inactive iodine in the form of KI. The KI is needed for effective absorption of $\mathrm{CH}_{3} \mathrm{I}$. Charcoal may be effective for the removal of volatile tellurium compounds.

Xenon is expected to be fluorinated to $\mathrm{XeF}_{4}$ in the process system. This compound has a volatility and hydrolysis behavior similar to that of $\mathrm{PuF}_{6}$, but the product of hydrolysis, the elemental gas, is not removable by filtration. The quantities that would be released in the reference plant are small enough so that apparently no special removal is required.

Tritium will be present as ${ }^{3} \mathrm{HF}$ in the process system and will be efficiently absorbed in the scrubber. The quantities of ${ }^{3} \mathrm{HF}$ that would be accidently released are small enough so that disposal of tritiated water is not believed to be a problem.

The disposition of materials in the plant is as follows:

1. Fluorides less volatile than $\mathrm{UF}_{6}$ and $\mathrm{PuF}_{6}$ will be collected in cold traps FP-1 $(\sim 90 \%)$ and FP-2 ( 10\%). These fluorides include $\mathrm{RuF}_{5}$, $\mathrm{NbF}_{5}$, and $\mathrm{SbF}_{5}$. 
2. Condensible fluorides that have volatilities similar to or higher than $\mathrm{UF}_{6}$ and $\mathrm{PuF}_{6}$ will be collected with $\mathrm{UF}_{6}$ in $\mathrm{CT}-1$ and with $\mathrm{PuF}_{6}$ in $\mathrm{CT}-2$. These include $\mathrm{MoF}_{6}, \mathrm{XeF}_{4}, \mathrm{TcF}_{6}, \mathrm{TeF}_{6}, \mathrm{IF}_{5}, \mathrm{IF}_{7}, \mathrm{IOF}_{5}$, and ${ }^{3} \mathrm{HF}$.

3. Substantial quantities of partially decontaminated $\mathrm{PuF}_{6}$ are present in the feed vessel to the thermal decomposer and of highly decontaminated $\mathrm{PuF}_{6}$ in $\mathrm{CT}-3$.

4. Abnormal operations might result in fission-product and actinide distributions in plant components differing from those outlined above, although the plant inventory would remain the same.

Because the vessels cited all have 12 -hr batch collections, the total plant accumulation of fission products is not more than about 1 day's input and the accumulation of $\mathrm{PuF}_{6}$ is not more than 3 days' input. Rather conservative assumptions were made as reference cases in the subsequent safety analysis.

\subsubsection{Safety Analysis: $\mathrm{PuF}_{6}$ Release}

The mass of plutonium released in the maximum credible accident will be at least as large as the largest single-vessel inventory and might approach plant-inventory levels if vessel isolation is not incorporated in the design. The inventory limits proposed in Table 6.9 show a ratio of plant total inventory to single vessel inventory of only 3 , indicating that a relatively small factor of safety is obtained by vessel isolation. Although present analysis seems to indicate that vessel isolation is not needed, further studies of overall safety (including criticality) may show an advantage of the additional factor of safety obtained by vessel isolation at the inventory levels under consideration.

\section{TABLE 6.9. Plutonium Inventory Limits as Used in Ventilation System Design}

\begin{tabular}{lccc}
\hline & $\mathrm{PuF}_{6}, \mathrm{~kg}$ & $\mathrm{UF}_{6}, \mathrm{~kg}$ & Hydrolyzable Hexafluoride, kg \\
\hline Single Vessel & 100 & 1000 & 1100 \\
Plant Total & 300 & 3000 & 3300 \\
\hline
\end{tabular}

Spray scrubbers using aqueous caustic solution have been widely used for removing volatile fluorides from a gas stream. Packed-bed scrubbers are also well developed, and although they are not adopted here as a reference design, they merit future consideration because of the potential for criticality safety provided by the use of borosilicate glass Raschig rings as a fixed neutron poison in a tower. Humidification capacity is a well-understood phenomenon and can be reliably predicted for a variety of scrubber designs. 
For a relatively high ratio of hexafluoride inventory to process cell air flow, the feed rate of hexafluoride vapor to the scrubber will be limited by saturation-mixing effects with the ventilation air. Table 6.10 gives the effect of the temperature of the cell exhaust air on scrubber design for the extreme case of complete saturation of the air stream with $\mathrm{PuF}_{6}-\mathrm{UF}_{6}$ mixtures. Temperature affects these results primarily by affecting the vapor pressures of the hexafluorides and of water. The cases shown are for the plant as a whole; cell isolation would lower the humidification requirements according to the release rate. The maximum number of transfer units given is approximate.

TABLE 6.10. Air-temperature Effect on Scrubber Design for Air That Is Saturated with Hexafluorides at Selected Constant Temperatures

\begin{tabular}{|c|c|c|c|c|}
\hline Air Temp $\left\{\begin{array}{l}{ }^{\circ} \mathrm{F} \\
{ }^{\circ} \mathrm{C}\end{array}\right.$ & $\begin{array}{l}60 \\
15.55\end{array}$ & $\begin{array}{l}100 \\
37.75\end{array}$ & $\begin{array}{l}140 \\
60.00\end{array}$ & $\begin{array}{l}180 \\
82.2\end{array}$ \\
\hline $\operatorname{Max} \mathrm{P}_{\mathrm{PuF}_{6}}$, Torr & 55.1 & 236 & 708 & $\mathrm{~A}^{\mathrm{a}}$ \\
\hline $\operatorname{Max} P_{U_{6}}$, Torr & 58 & 255 & $A^{a}$ & $\mathrm{~A}^{\mathrm{a}}$ \\
\hline Min wet bulb temp, ${ }^{\circ} \mathrm{F}$ & 38 & 57 & 70 & 81 \\
\hline Min $\mathrm{P}_{\mathrm{H}_{2} \mathrm{O}}$, Torr & 5.82 & 11.9 & 18.8 & 27.1 \\
\hline Scrubber transfer units ${ }^{b}$ & 20 & 42 & $\sim 70^{\mathrm{C}}$ & $\sim 50^{\mathrm{c}}$ \\
\hline
\end{tabular}

${ }^{a}$ One-atmosphere pressure for total exhaust gas; the partial pressures will depend on mixing and the rates of exhaust of cell air.

${ }^{b}$ Relative number of spray stages; see pp. 20-22 of Ref. 130.

${ }^{\mathrm{c}}$ For these high hexafluoride concentrations, the mass transfer is more complicated, and only a rough (conservative) estimate has been made thus far.

Scrubbers ${ }^{155}$ of the type used at ANL can be considered as series and parallel combinations of a modular spray unit of 2 by $2 \mathrm{ft}$ cross section and $4 \mathrm{ft}$ length containing one hollow-cone spray nozzle that impinges on a throat piece of $1-f t$ ID. For a spray-nozzle flowrate of about $10 \mathrm{gal} / \mathrm{min}$ at $100 \mathrm{psi}$ and an air flowrate of $1000 \mathrm{cfm}$, the modular spray unit has a capacity of about one transfer unit. For purposes of the present study, a preliminary estimate of the scrubber design for $30,000 \mathrm{cfm}$ of ventilation air and 40 transfer units is 120 modules, $1200 \mathrm{gal} / \mathrm{min}, 160 \mathrm{ft}$ long with a 120 -sq-ft cross section (e.g., 12 by $10 \mathrm{ft}$ ). After the gas passes through the scrubber section, it flows through a demister for removal of entrained spray droplets from the air flow. The solution inventory would be expected to be about 10,000 gal.

The filter system for hot-cell air discharge is designed so that a minimum of two AEC-type filter banks in series will remain intact after any maximum credible accident. This is achieved by passing the discharge air (after scrubbing) through two AEC filter banks in series, through charcoal traps for iodine trapping, then through a sand-bed filter, and finally through two additional banks of AEC filters in series. In this way the 
consequences of accidents originating either inside or outside the processing cell would be minimized. A properly sized sand-bed filter of the type used at Hanford and Savannah River fuel-reprocessing plants will effectively suppress thermal and pressure surge effects under accident conditions either inside or outside the plant and leave at least two banks of AEC filters intact。

Each AEC filter bank will consist of approximately 30 parallel filter units of 1000 -cfm rating (each is 24 by 24 by 11.5 in.). The sand filter will be approximately 60 by 100 by $10 \mathrm{ft}$ deep.

Calculation of the exposure of the public as a result of a maximum credible release of $\mathrm{PuF}_{6}$ involves several independent factors. These factors, for a range of possible values up to the worst case, are listed in Table 6.11 and discussed below.

1. The mass of plutonium released ranges from the maximum single-vessel inventory up to the total maximum plant inventory. Further evaluation will be required to determine if the worst case is in the noncredible class of incidents.

2. The specific activity range is from one to two times the specific activity range of pure ${ }^{239} \mathrm{Pu}$ and depends on the isotopic content of the plutonium processed. The worst case corresponds to an isotopic content resulting from burnup of about $10 \%$ of the ${ }^{239} \mathrm{Pu}$ in a fast-neutron flux.

3. The filter penetration range includes only the penetration obtained by passage of the gas stream through two intact AEC filters in series under a wide range of release conditions. This gives a factor of safety to the corresponding filtration efficiency. There will probably be significant filtration by the sand-bed filter, but the magnitude of this effect on the performance of a system that includes at least two AEC-type filters in series cannot be determined at present. The values for filter penetration are based on removal by filtration only, and no removal of plutonium from the discharge air in the scrubber is assumed, even though removal in the scrubber will be significant at high hexafluoride concentrations (rapid releases) due to agglomeration and other effects.

4. The stack-dilution factor (see Table 6.11) ranges from the worst case (instantaneous release from a $100-\mathrm{m}$-high stack in a typical flat plains area) to the annual average value. If the duration of stack release for the worst case increased (that is, if duration, instead of being instantaneous, was longer than about $5 \mathrm{~min}$, the approximate gas residence time in the hot cells), the stack-dilution factor for that case would be significantly increased. The estimate of stack-dilution factors given is the result of an extensive literature survey of appropriate meteorological models; the values shown are generally consistent with the results of the safety analyses for the NFS and GE-MFRP processing plants. 
TABLE 6.11. Factors in Calculating Exposure of the Public as a Result of a Maximum Credible Release of $\mathrm{PuF}_{6}$

\begin{tabular}{|c|c|c|}
\hline Factor & Range & Worst Case \\
\hline Plutonium mass, g & $10^{5}$ to $3 \times 10^{5}$ & $3 \times 10^{5}$ \\
\hline Specific activity, $\mathrm{Ci} / \mathrm{g}$ & 0.064 to 0.128 & 0.128 \\
\hline Filter penetration & $10^{-9}$ to $10^{-6}$ & $10^{-6}$ \\
\hline $\begin{array}{l}\text { Stack-dilution factor, } \mathrm{m}^{3} / \mathrm{sec} \\
\quad \text { (reciprocal factor) }\end{array}$ & $5 \times 10^{4}$ to $4 \times 10^{7}$ & $5 \times 10^{4}$ \\
\hline \multicolumn{3}{|l|}{ Exposure } \\
\hline Worst exposure, $(\mathrm{Ci})(\mathrm{sec}) / \mathrm{m}^{3}$ & & $7.7 \times 10^{-7}$ \\
\hline Year average, $\mu \mathrm{Ci} / \mathrm{ml}$ & & $2.4 \times 10^{-14}$ \\
\hline $\begin{array}{l}\text { Percentage of MPC (maximum } \\
\text { permissible concentration) }\end{array}$ & & 40 \\
\hline $\operatorname{MPC}(10 \mathrm{CFR} 20), \mu \mathrm{Ci} / \mathrm{ml}$ & & $6 \times 10^{-14}$ \\
\hline
\end{tabular}

The worst exposure (see Table 6.11) is the product of the "worst case" values of the first three factors divided by the (reciprocal) of the worst stack-dilution factor. Since relatively long-lived plutonium activity is involved, the average annual exposure is more meaningful than the worst exposure. The calculated annual exposure is $40 \%$ of the presently allowed federal standard (10 CFR 20); therefore the indicated overall safety factor is 2.5. For a maximum credible accident, $10 \mathrm{CFR} 20$ is considered safely conservative. The less stringent federal standard, 10 CFR 100 , could possibly be applied on the basis of more exact biological determinations of plutonium exposure.

The above-described method of calculating the level of plutonium release exemplifies how safety factors have been calculated in the basic design of the ventilation system. The overall safety factor is the product of the many factors incorporated in the final calculation. Therefore, the total safety factor is much larger than 2.5 .

\subsubsection{Safety Analysis: Fission-product Release}

Because any volatile fission products released in the reference plant are disposed of similarly to released plutonium hexafluoride and because the methods of removing these constituents from ventilation-exhaust air are similar, the analysis of fission-product release has much in common with the analysis of plutonium hexafluoride release. The principal modification is the addition of an activated carbon absorber for removal of fissionproduct iodine and tellurium. As in the preceding section, emphasis is on technical feasibility rather than optimization. This analysis is made on the assumption that the fission products and the actinide hexafluorides are removed from air independently. This is considered a conservative assumption from the standpoint of the extent of removal of fission products. 
For the reference case, a release was assumed that is equivalent to the radioactivity associated with a one-day input of fission products that are volatile or form volatile fluoride compounds. The factors considered relevant to this analysis were the volatilities of the released species (element or compound) and the effects of individual components of the ventilation equipment train. The behavior of many of the fission-product fluorides is presumed to be similar to the behavior of the actinides in terms of hydrolysis, scrubbing, and filtration.

Table 6.12 lists the radioactivities of the volatile fission products along with the factors needed for calculating exposure to the public. Factors with large uncertainties are placed in brackets and are on the highly conservative side.

TABLE 6.12. Estimated Separation Factors and Calculated Exposures in Unrestricted Areasa

Stack-dilution factor: $5 \times 10^{4} \mathrm{~m}^{3} / \mathrm{sec}$

\begin{tabular}{|c|c|c|c|c|c|c|c|}
\hline Element & $\begin{array}{c}\text { Amount of } \\
\text { Activity, } \\
\text { Ci }\end{array}$ & $\begin{array}{c}\text { Fraction } \\
\text { Vaporized }\end{array}$ & $\begin{array}{c}\text { Scrubber } \\
\text { DF }\end{array}$ & $\begin{array}{c}\text { Filter } \\
\text { DF }\end{array}$ & $\begin{array}{c}\text { Charcoal } \\
\text { DF }\end{array}$ & $\begin{array}{l}\mathrm{MPC}, \mathrm{b} \\
\mu \mathrm{Ci} / \mathrm{ml}\end{array}$ & $\begin{array}{l}\text { Exposure, } \\
\text { MPC-yr }\end{array}$ \\
\hline${ }^{3} \mathrm{H}$ & 2000 & 1 & [1] & 1 & 1 & $2 \times 10^{-7}$ & $6 \times 10^{-3}$ \\
\hline I & $2 \times 10^{5}$ & 1 & [2] & [1] & {$\left[10^{3}\right]$} & $10^{-10}$ & 0.6 \\
\hline Mo & 822 & 1 & 1 & $10^{6}$ & 1 & $3 \times 10^{-8}$ & $2 \times 10^{-8}$ \\
\hline $\mathrm{Nb}$ & $2.4 \times 10^{6}$ & {$[0.1]$} & 1 & $10^{6}$ & 1 & $2 \times 10^{-8}$ & $8 \times 10^{-6}$ \\
\hline $\mathrm{Ru}$ & $6 \times 10^{6}$ & {$[0.1]$} & 1 & $10^{6}$ & 1 & $5 \times 10^{-9}$ & $8 \times 10^{-5}$ \\
\hline $\mathrm{Sb}$ & $8.7 \times 10^{4}$ & {$[0.1]$} & 1 & $10^{6}$ & 1 & $2 \times 10^{-8}$ & $3 \times 10^{-7}$ \\
\hline $\mathrm{Tc}$ & 32.9 & 1 & 1 & $10^{6}$ & 1 & $9 \times 10^{-7}$ & $2 \times 10^{-11}$ \\
\hline $\mathrm{Te}$ & $10^{5}$ & 1 & [1] & [1] & {$\left[10^{2}\right]$} & $6 \times 10^{-9}$ & 0.1 \\
\hline $\mathrm{Xe}$ & $6 \times 10^{4}$ & 1 & 1 & 1 & [1] & $3 \times 10^{-7}$ & 0.1 \\
\hline
\end{tabular}

${ }^{a}$ Refers to the area of the plant site, as described in 10 CFR 20 .

bValues were taken from 10 CFR 20.

${ }^{\mathrm{c}}$ Calculated as:

(Amount of activity)(Fraction vaporized)

$\overline{\left(\text { Scrubber DF)(Filter DF)(Charcoal DF)(Stack-dilution factor)(MPC) } 3.15 \times 10^{7}\right.}$

6.2.2.1 Vaporization. Only a small fraction of the fuel constituents that boil at high temperature $\left(\mathrm{RuF}_{5}\right.$, bp of $272^{\circ} \mathrm{C} ; \mathrm{NbF}_{5}$, bp of $225^{\circ} \mathrm{C} ; \mathrm{SbF}_{5}$, $\mathrm{bp}$ of $150^{\circ} \mathrm{C}$; $\mathrm{XeF}_{4}$, bp of $116^{\circ} \mathrm{C}$ ) will be released to the main ventilation gas stream as a result of vaporization. The bulk of these compounds will probably be hydrolyzed by moisture contained in the cell atmosphere and will remain as solids in the cell. If ruthenium species more volatile than $\mathrm{RuF}_{5}$ (such as $\mathrm{RuF}_{6}$ or $\mathrm{RuOF}_{4}$ ) are present, these would be expected to be retained by hydrolysis-filtration mechanisms which retain other fission products and the actinides.

The $\mathrm{XeF}_{4}$ would decompose to the elemental form upon hydrolysis. The elemental form is the one used in the calculation of exposures in Table 6.12. Only a crude conservative approximation of the fraction vaporized is included in Table 6.12. Design details not fixed at present, such as the process cell temperature, will significantly influence the fraction vaporized. 
6.2.2.2 Scrubber. Tritium will enter the scrubber as the fluoride and be rapidly absorbed and neutralized, but unless provision is made for rapid dumping and replacement of the scrubber solution, the tritium will eventually be lost to the stack as water vapor.

The presence of KI or another complexing agent in the scrubber solution will effect rapid absorption of iodine and its fluorides in the scrubber. Strongly basic or acid solution may cause a loss of iodine from the solution through the formation of HOI or HI, respectively.

The metal fluorides in general will be rapidly hydrolyzed to nonvolatile aerosols in the scrubber gas phase. The particle size may be small enough so that scrubber collection is not significant. The slow hydrolysis of $\mathrm{TeF}_{6}$ will occur primarily in the liquid phase scrubber solution to an extent that has not been determined. Behavior of fission products in another scrubber solution considered (i.e., potassium carbonate-borate solution) is unknown.

6.2.2.3 Filters. Two AEC-type filters in series will give a minimum decontamination factor of $10^{6}$ for nonvolatile aerosols formed by hydrolysis in the scrubber. This value is based on extensive work by Kessie and Ramaswami ${ }^{130}$ with $\mathrm{PuF}_{6}$ releases. The effectiveness of the filters in removing iodine and tellurium compounds is uncertain.

6.2.2.4 Charcoal. The charcoal filters are standard commercial units with 1 -in.-deep beds. They are pleated in a standard frame ( 2 by 2 by $1 \mathrm{ft}$ ) and rated at $1000 \mathrm{cfm}$. They are installed upstream from the sand bed and the final filter and operate on an absorption principle, not as a filter for particulate matter. For clean charcoal preloaded with KI, a decontamination factor greater than $10^{4}$ is likely for the most penetrating high-molecular-weight gas-phase activities $\left(\mathrm{CH}_{3} \mathrm{I}, \mathrm{TeF} 6, \mathrm{Xe}\right)$.* The more conservative decontamination factor values listed in Table 6.12 are based on limited data with aged and loaded charcoal.

6.2.2.5 Stack. The stack-dilution factor of $5 \times 10^{4} \mathrm{~m}^{3} / \mathrm{sec}$ is for a $100-\mathrm{m}$-tall stack with the most unfavorable meteorological conditions.

6.2.2.6 MPC. Table 6.13 summarizes the maximum permissible concentrations (MPC's). The overall average MPC values for elements that contain more than one active isotope of significance were derived from the isotope values and the isotopic fraction, using the following relation for average MPC derived from equations for mixtures in 10 CFR 20, p. 75:

$$
\text { Average } \mathrm{MPC}=1 /\left(\mathrm{C}_{\mathrm{A}} / \mathrm{MPC}_{\mathrm{A}}+\mathrm{C}_{\mathrm{B}} / \mathrm{MPC}_{\mathrm{B}}+\ldots\right) \text {. }
$$

This estimate is based on information discussed at the recent IAEA Symposium on Operating and Developmental Experience in the Treatment of Airborne Radioactive Wastes, SM-110 (Aug 1968). 
These MPC values were used in the calculation of exposures (see Table 6.12). The use of annual average MPC values (MPC-yr) is also based on 10 CFR 20 (p. 66) and the low probability that the hypothesized release will occur.

TABLE 6.13. Maximum Permissible Concentrations of Volatile Fission-product Fluorides in Unrestricted Areas ${ }^{a}$

\begin{tabular}{lccc}
\hline Element & Isotope & Isotopic Fraction & $\begin{array}{c}\text { MPC (Air, Soluble) } \\
\mu \mathrm{Ci} / \mathrm{ml}\end{array}$ \\
\hline $\mathrm{H}$ & 3 & 1.0 & $2 \times 10^{-7}$ \\
$\mathrm{I}$ & Mixture & 1.0 & $10^{-10^{-7}}$ \\
$\mathrm{I}$ & 129 & $2.2 \times 10^{-7}$ & $2 \times 10^{-11}$ \\
$\mathrm{I}$ & 131 & 1.0 & $10^{-10^{-7}}$ \\
$\mathrm{Mo}$ & 99 & 1.0 & $3 \times 10^{-8}$ \\
$\mathrm{Nb}$ & 95 & 1.0 & $2 \times 10^{-8}$ \\
$\mathrm{Ru}$ & Mixture & 1.0 & $5 \times 10^{-9}$ \\
$\mathrm{Ru}$ & 103 & 0.51 & $2 \times 10^{-8}$ \\
$\mathrm{Ru}$ & 106 & 0.49 & $3 \times 10^{-9}$ \\
$\mathrm{Sb}$ & 125 & 1.0 & $2 \times 10^{-8}$ \\
$\mathrm{Tc}$ & Mixture & 1.0 & $9 \times 10^{-7}$ \\
$\mathrm{Tc}$ & $99 \mathrm{~m}$ & 1.0 & $10^{-6}$ \\
$\mathrm{Tc}$ & 99 & $7.7 \times 10^{-3}$ & $7 \times 10^{-8}$ \\
$\mathrm{Te}$ & Mixture & 1.0 & $6 \times 10^{-9}$ \\
$\mathrm{Te}$ & $125 \mathrm{~m}$ & 0.029 & $10^{-8}$ \\
$\mathrm{Te}$ & $127 \mathrm{~m}$ & $1.3 \times 10^{-3}$ & $5 \times 10^{-9}$ \\
$\mathrm{Te}$ & 127 & $3.8 \times 10^{-3}$ & $6 \times 10^{-8}$ \\
$\mathrm{Te}$ & $129 \mathrm{~m}$ & 0.49 & $3 \times 10^{-9}$ \\
$\mathrm{Te}$ & 129 & 0.46 & $2 \times 10^{-7}$ \\
$\mathrm{Te}$ & 132 & 0.019 & $7 \times 10^{-9}$ \\
$\mathrm{Xe}$ & Mixture & 1.0 & $3 \times 10^{-7}$ \\
$\mathrm{Xe}$ & $131 \mathrm{~m}$ & 0.097 & $4 \times 10^{-7}$ \\
$\mathrm{Xe}$ & 133 & 0.90 & $3 \times 10^{-7}$ \\
\hline & & &
\end{tabular}

a Table II, Column 1, 10 CFR 20 (March 20, 1968).

bIsotopic fraction of the given isotope as a weight fraction of the total yield of the fission-product element based on a 500-day fast-neutron irradiation of ${ }^{239} \mathrm{Pu}, 30$-day cooled.

6.2.2.7 Exposure and Conclusions. Exposure, expressed in MPC$\mathrm{yr}$ equivalents, is defined as the maximum value for a given radioactive species expected at a site boundary one-half mile downwind from the stack. The exposures reported in Table 6.12 are calculated values obtained with the tabulated information. The product of the first two factors (amount of activity and fraction vaporized) divided by the other factors (scrubber DF, filter DF, charcoal DF, stack-dilution factor, and MPC), and a units conversion factor $\left(3.15 \times 10^{7} \mathrm{sec} / \mathrm{yr}\right)$ gives the exposure. The sand filter was not considered to decontaminate the gas in this analysis.

Exposure to iodine is the most significant, $60 \%$ of the maximum permissible annual exposure. This does not include the possible increase in exposure due to the grass-cow-milk-child cycle. Further refinement of the system performance to improve iodine removal may be justified, although the overall basis for this analysis is considered conservative. 


\subsubsection{Comments on the Safety Analysis of the Ventilation System}

The engineering and chemical aspects of the ventilation system are highly tentative and incomplete. This is especially true for iodine behavior, although the quantity of iodine releases is uncertain not only for the fluorination process, but also for all reactors and processing plants. The reference conceptual system is probably overdesigned, but until further clarification is achieved, evaluation can only be conjectural. For example, the iodine DF of 2 for the scrubber may be low by a factor of $10^{2}$, and the $\mathrm{CH}_{3} \mathrm{I}$ DF of $10^{3}$ for charcoal is not well established. Increased iodine removal may be obtained by using a 2-in.-deep absorber bed instead of a l-in.-deep standard unit. A system based on the reference design is within the state of the art.

\subsection{Maintenance}

Modes of maintenance ${ }^{156}$ are (1) remote maintenance, in which equipment is designed for installation and replacement by a remotely controlled crane with no need for decontamination prior to replacement or for personnel access to highly radioactive areas, and (2) contact maintenance, in which equipment is decontaminated so that personnel may enter process areas and perform necessary maintenance with essentially conventional techniques and tools.

The choice of which type of maintenance to impose on the reference plant depends on the overall operating schedules. Where only single units exist in the production line, as in the case of the fluorinators ( $\mathrm{A}$ and $\mathrm{B}$ ), the mode of maintenance that will put the unit on-stream the quickest is mandatory. Even if dual units exist (such as cold traps CT-1A and CT-1B), the schedule provides for little downtime, and the time required for maintenance is important. Solutions lie in good reliability, in sufficient flexibility (adequate capacity by overdesign), or in having additional units on standby (which imposes an economic penalty). The greatest benefit would be derived by building in reliability and ruggedness at the outset.

A combination of the two modes of maintenance is proposed for the design of the present reference plant. Because of the high radiation levels, a remote maintenance capability is needed to install and remove equipment in virtually all areas. Since the technology of remote systems, cranes,. manipulators, viewing windows, and advanced optic systems has been rapidly developed, remote maintenance is much less formidable a problem than in years past. The problems of remote maintenance are also moderated by using an efficient equipment layout. Uniform mounting and modular installation are other techniques which should prove useful.

Contact maintenance will be used on equipment that has been sufficiently decontaminated and moved to a contact maintenance area (e.g., a hot shop area with a glovebox arrangement for direct access). A form of 
contact maintenance may also be possible on selected units such as the converter or the still pot of still S-2, since the actinides in these units are highly decontaminated. Specialized equipment such as plastic suits for working in alpha-hazard areas will be required. The neutron levels in these so-called low-level areas may be significant, requiring the use of special shielding by moderating materials to allow direct personnel contact.

Decontamination of equipment that requires maintenance will start with removal of its contents. Generally, a cleanup-fluorination treatment will be used as part of the decontamination procedure. Fluorination should prove successful in decontaminating equipment when the equipment has been exposed only to volatile fluorides (as in the case of cold traps).

Decontamination of the internal surfaces of fluid-bed reactors will be more difficult. The technique of fluidizing fresh beds of alumina in a reactor to abrade the activity layer has been used with some success. Alternatively, more conventional decontamination techniques developed for aqueous process equipment can be used.

Certain operations will be done routinely by remote means. For example, waste-solids receivers will be replaced regularly. Maintenance procedures must also be developed for emergency situations, such as a need to unplug the pneumatic conveyor system. Special tools for rodding and emptying fluid-bed reactors remotely will probably also be needed during the lifetime of the plant.

\subsection{Corrosion of Materials of Construction}

Considerable information has been accumulated regarding the resistance of various materials of construction to halide-containing process gases used in fluoride-volatility processing, both in the U.S. and in Europe. Data on many materials of interest (obtained at Argonne National Laboratory, Oak Ridge Gaseous Diffusion Plant, and Oak Ridge National Laboratory) have been surveyed by Miller and Berry. ${ }^{85}$ This survey, which summarizes the results of both laboratory and pilot-plant scale investigations, suggests that the modest corrosion rates encountered can be readily handled by the use of nickel or nickel-containing alloys. A similar conclusion was drawn from ANL corrosion studies ${ }^{157}$ that studied the effect on nickel of $\mathrm{UF}_{6}$ and selected volatile fission-product fluorides.

The major areas of concern are the corrosion rates expected in (1) fluid-bed reactors $A$ and $B,(2)$ sintered-metal filters, (3) the thermal decomposer (TD-1), (4) the distillation columns, and (5) the converter. Table 6.14 shows the anticipated rates of corrosion for these process items. 
TABLE 6.14. Anticipated Corrosion Rates for Selected

Process Components Made of Nickel

\begin{tabular}{llc}
\hline \multicolumn{1}{c}{ Process Vessel } & \multicolumn{1}{c}{ Process Conditions } & Corrosion Rate, mils/yr \\
\hline Reactor A & $\mathrm{O}_{2}-\mathrm{F}_{2}$ at $350^{\circ} \mathrm{C}$ & 20 \\
Reactor B & $\mathrm{F}_{2}$ at $500-550^{\circ} \mathrm{C}$ & 40 \\
Thermal decomposer & $\mathrm{UF}_{6}-\mathrm{PuF}_{6}$ at $350^{\circ} \mathrm{C}$ & 30 \\
& $\mathrm{~F}_{2}$ at $500^{\circ} \mathrm{C}$ & 40 \\
Converter & $\mathrm{UF}_{6}-\mathrm{PuF}_{6}-\mathrm{H}_{2}-\mathrm{H}_{2} \mathrm{O}$ at $650^{\circ} \mathrm{C}$ & 40 \\
Distillation column & $\mathrm{UF}_{6}$ at $80^{\circ} \mathrm{C}$ & $<1$ \\
\hline
\end{tabular}

Perhaps the most corrosion-sensitive plant components are the porous metal filters used downstream (i.e., above the fluid beds) of the fluid-bed reactors to remove fine particulate solids from the process gas. Corrosion of this component can be minimized by cooling the process gas leaving the fluidized bed to about $125^{\circ} \mathrm{C}$ before filtration. In tests ${ }^{5}$ at Argonne National Laboratory, $\mathrm{PuF}_{4}$ was fluorinated to $\mathrm{PuF}_{6}$ with elemental fluorine using a process cycle in which the filter element was at about $125^{\circ} \mathrm{C}$ with short-term periods at $300^{\circ} \mathrm{C}$. Satisfactory plutonium recovery and apparently adequate filter corrosion resistance resulted. These tests were of short duration, however, and cannot be used to infer the long-term adequacy of the process filter. In other tests, ${ }^{158}$ a porous-metal filter made of matted-nickel fibers and exposed to $20 \%$ fluorine at $315^{\circ} \mathrm{C}$ for $108 \mathrm{hr}$ showed a slight decrease in permeability but no serious chemical attack.

In summary, the large body of existing data from fluoride-volatility experience suggests that modest corrosion rates can be anticipated if nickel and nickel alloys are used as materials of construction. Since the most corrosion-sensitive plant component is apt to be the porous-metal filters, plant design should include the capability of filter replacement on a routine basis. Additional corrosion testing of filter media under the reference process conditions would be desirable.

\subsection{Accountability}

Accountability refers to the procedures used to monitor the locations and quantities of fissile fuel materials in the fuel-processing plant. The accountability method proposed for the present plant uses automatic data processing; input is provided in part by automatic weighing systems. Verification of the input starts with the identification of a particular fuel element after its removal from the shipping cask. Information regarding weight and actinide content will be provided by the fuel manufacturer, and the radiation history of the fuel element also will be known. Fuel elements can best be weighed at the processing plant, if desired, after sodium removal from the exterior of the fuel element while the fuel element is in 
storage in the pool. Individual fuel pins can be weighed after fuel element disassembly, either before or after the pins have been assayed for any sodium logging. After decladding, the weight of the fuel alone is obtained by weighing the fuel storage hopper before the fuel oxide powder is fed to the process.

Sampling of the fuel powder while it is enroute to the first fluorinator (reactor A), followed by chemical analysis of the samples, will provide key information for accountability purposes. This nonhomogeneous powder will be sampled by pulsing small portions of the powder from the pneumatic conveyor line into a secondary vessel. If pulsing is done at regular intervals and if a statistically large number of portions are obtained, the sample will be representative. The material in the secondary vessel will be homogenized and sampled for analysis. This system of sampling will have to be demonstrated and tested in mockup studies.

Weighing of hexafluoride cold traps and the use of neutron survey meters as plutonium monitors will provide additional data for accountability. Necessary information on the plant output will consist of: (1) weight of the converter product, (2) plutonium content of the $\mathrm{PuO}_{2}-\mathrm{UO}_{2}$ product, and (3) the weight and analyses of the excess $U F_{6}$. The plutonium content of waste streams (primarily that discharged from the plutonium fluorinator, reactor $B$, and the cladding hulls from the ball mill) will also be determined. Hopefully, other materials such as LiF sorption traps can be monitored for plutonium content by external means (neutron survey meters) with a go/no-go device, which would indicate when cleanup-fluorination has accomplished its task. Development of a practical accountability method appears feasible.

\subsubsection{Chemical Analyses: Determination of Uranium and Plutonium in Feed and Products}

The analytical procedures that will be used to determine uranium and plutonium in the feed and product streams in this process are basically the same as those now being used for existing aqueous processing plants. A solid sample is weighed, then dissolved in a suitable acid or acid mixture; the solution is next diluted to a known volume and analyzed for the amounts of uranium and plutonium and their isotopic compositions.

The only sample in this process that can be considered unique is the feed. Since the fission-product content and the transplutonium element content of the feed will be significantly higher than for fuels now being processed, special consideration has been given to the problem of dissolving these samples and the choice of methods for analyzing the solutions obtained.

On the basis of existing information, it is anticipated that a mixture of hydrochloric, nitric, and hydrofluoric acids will effect complete solution 
of the uranium and plutonium in the high-burnup samples. However, it will be necessary to establish unequivocally that no acid-insoluble plutoniumfission product compounds have formed in the fuel.

Complete solution of all constituents of the feed will probably not be effected. The fission products (molybdenum, technetium, ruthenium, rhodium, and palladium) are known to precipitate as metallic inclusions within the fuel, and these inclusions are highly resistant to acid attack. Also, some precipitation of fission products may occur after dissolution has been effected. Precipitation of cesium chloropalladinate from solutions of high-burnup fuels has been observed.

Of the various analytical techniques that have been used to determine uranium and plutonium in irradiated fuels, mass-spectrometricisotope dilution (MSID) appears to be best suited to the analysis of the feed for this process. MSID has the advantage of requiring relatively small amounts of uranium and plutonium for the analysis ( 0.1 to $1 \mathrm{mg}$ ). Also, once the spikes $\left({ }^{233} \mathrm{U}\right.$ and $\left.{ }^{242} \mathrm{Pu}\right)$ have been added and isotopic exchange effected, there is no need for quantitative recovery in the chemicalpurification steps. For chemically complex samples such as highly irradiated fuels, the reliability of MSID analytical results is superior to those from any other method of analysis. When properly executed, the relative standard deviation of this method is $\pm 0.2 \%$, with no significant bias.

A relatively large concentration of fission products and transplutonium elements in a feed solution would seriously affect the accuracy of any chemical method of analysis. Each high-precision chemical method (e.g., controlled-potential coulometry) requires complete oxidation (or reduction) to a particular oxidation state, followed by reduction (or oxidation) with a standardized reagent to another oxidation state. Radiolysis within the solution due to the alpha, beta, and gamma activity will seriously interfere with both the oxidation and the reduction processes, and fission products such as molybdenum will be present in sufficient concentrations to interfere chemically in the analysis.

\subsubsection{Determination of Plutonium in Aluminum Oxide Waste Stream}

Two techniques appear worth consideration for the in-line determination of plutonium in the aluminum oxide waste stream: neutron activation and $\mathrm{X}$-ray spectrometry. Both techniques are highly reliable for the determination of plutonium at the 500-ppm level in inactive aluminum oxide. Consideration of the principles of these techniques indicates that they are applicable to a system characterized by high levels of alpha, beta, gamma, and neutron activity. To determine whether neutron activation and X-ray spectrometry could be reduced to practice on this system would require an extensive investigative program. These techniques, as well as discontinuous radiochemical determination of plutonium, are discussed below. 
6.5.2.1 Neutron Activation. One of the most sensitive and specific methods for determining the concentration of fissionable isotopes in a sample is irradiation with thermal neutrons to induce fission, followed by detection of short-lived fission products. For determining plutonium in the aluminum oxide waste stream, a pulsed neutron generator with a thermal neutron flux of $10^{9}$ neutrons $/\left(\mathrm{cm}^{2}\right)(\mathrm{sec})$ would be required. This flux would produce $10^{6}$ fissions per sec per gram of aluminum oxide waste containing $500 \mathrm{ppm}$ of plutonium. Three methods for the detection of short-lived fission products are discussed below: delayed-neutron counting, detection of short-lived noble-gas fission products, and direct gamma counting of fissionproduct gammas.

6.5.2.1.1 Delayed-neutron Counting. ${ }^{22,151}$ The delayed neutrons emitted by some of the short-lived fission products with half-lives of 1-60 sec can be used to detect fission events in inactive samples with a high degree of selectivity. Maximum sensitivity is realized when irradiation, cooling, and counting are closely coupled in time (e.g., l sec for each). Under these conditions, a thermal neutron flux of $10^{9}$ will produce $7 \times 10^{3}$ delayed neutrons per second from $500 \mu \mathrm{g}$ of plutonium. If these delayed neutrons can be counted with an efficiency of $10 \%$ (investigations ${ }^{159}$ at Argonne National Laboratory indicate that this is possible), a count rate of 700 counts/sec could be obtained. Although the neutron background count rate (from the $\alpha, n$ reaction on fluorine-19) will be a factor of 10 higher than that due to delayed neutrons, the increase in count rate of $700 \pm 27$ would be a statistically significant increase over the background count rate, $7000 \pm 84$.

Data from delayed-neutron counting in monitoring ${ }^{235} \mathrm{U}$ in cladding hull waste, shown in Fig. 6.4, indicates applicability to FBR systems.

Neutron counters have the unique operational advantage of being able to perform in high backgrounds of beta and gamma activity.

6.5.2.1.2 Detection of Short-lived Noble-gas Fission Products. Irradiation with thermal neutrons followed by separation and detection of short-lived krypton and xenon fission products is inherently an extremely sensitive and selective method for determining fissionable material in a sample. The general steps of the procedure, as it would be applied to the determination of plutonium in the waste stream, are as follows:

1. Irradiation with thermal neutrons.

2. Removal of krypton and xenon from the sample, and transport of these gases with a helium sweep to a point outside the processing cell.

3. Separation of krypton and xenon from helium by cold trapping.

4. Assaying of the trap by gamma spectroscopy for one or more of the krypton and xenon isotopes. 
BASKETFUL OF HULLS
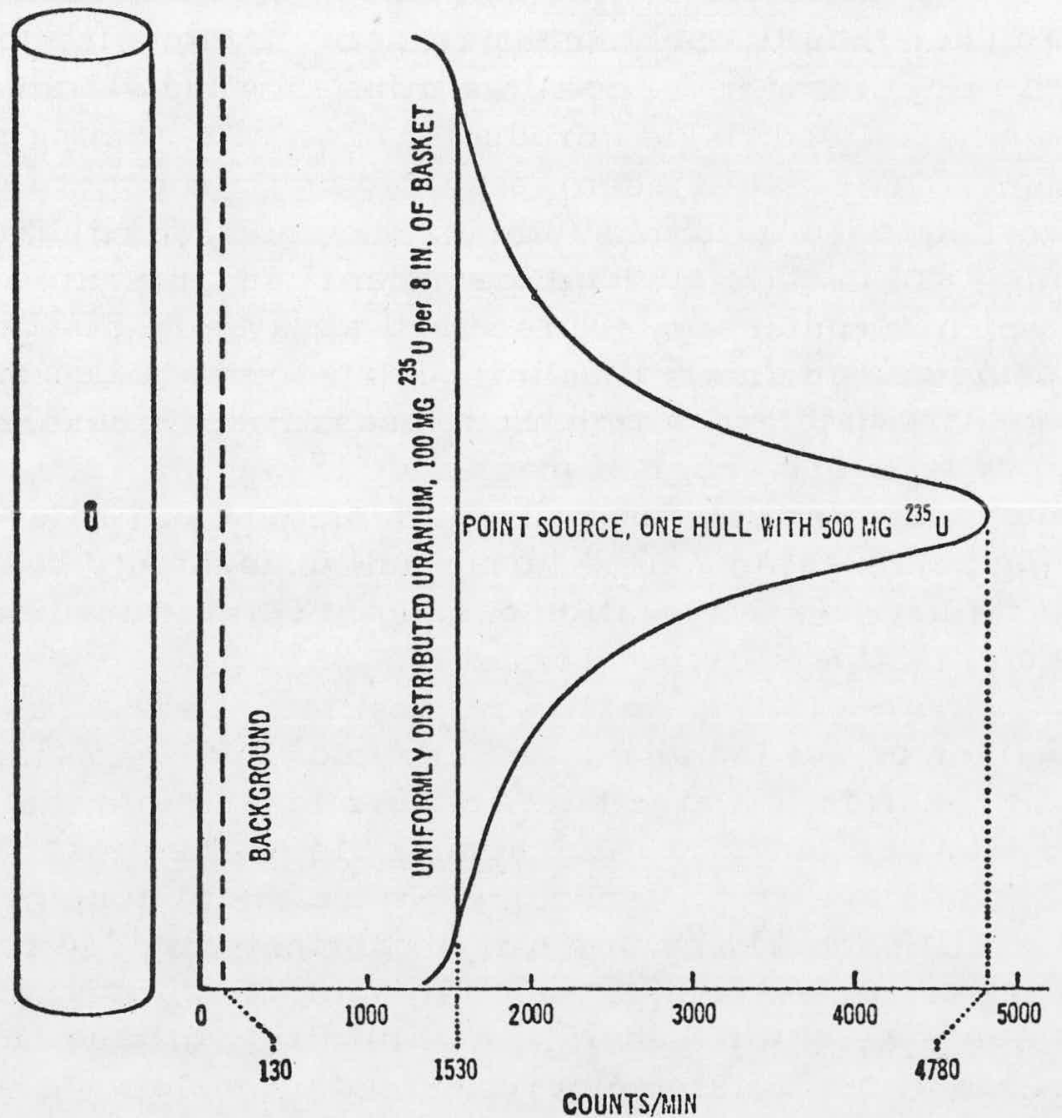

Fig. 6.4. Response of Delayed-neutron Monitor to ${ }^{235} \mathrm{U}$ in Leached Hulls

The tabulation below summarizes the nuclear data and an estimate of the ultimate sensitivity of this method of detecting plutonium. The thermal neutron flux is $10^{9}$, the irradiation times are 10 and $100 \mathrm{sec}$, the separation time (from termination of irradiation to initiation of counting) is $100 \mathrm{sec}$, and the counting time is $100 \mathrm{sec}$.

\begin{tabular}{|c|c|c|c|c|}
\hline \multirow{2}{*}{$\begin{array}{l}\text { Fission } \\
\text { Product }\end{array}$} & \multirow{2}{*}{$\begin{array}{l}\text { Fission } \\
\text { Yield, \% }\end{array}$} & \multirow{2}{*}{$\begin{array}{c}\text { Half-life, } \\
\text { sec }\end{array}$} & \multicolumn{2}{|c|}{ Sensitivity, $\mu \mathrm{g}$} \\
\hline & & & $10 \sec ^{*}$ & $100 \mathrm{sec}^{*}$ \\
\hline Krypton -89 & 1.8 & 200 & 1.0 & 0.1 \\
\hline Krypton-90 & 1.8 & 33 & 1.0 & 0.2 \\
\hline Xenon- 137 & 5.4 & 250 & 0.4 & 0.04 \\
\hline Xenon-139 & 5.6 & 41 & 0.2 & 0.05 \\
\hline
\end{tabular}

Noble-gas fission-product detection is one to two orders of magnitude more sensitive than delayed-neutron detection. The sensitivity advantage arises from a combination of factors: (1) The fission yields of the noble gases are higher than the yields of isotopes, which decay by

*Irradiation time. 
delayed-neutron emission; (2) the gammas-per-decay factors for the noble gases are higher than the neutrons-per-decay factors for the delayedneutron emitters; and (3) the counting efficiency for gammas is higher than for neutrons.

Carrying out a gamma assay for the short-lived noble-gas fission products also has certain obvious operational advantages over carrying out a delayed-neutron assay. The gamma assay would be performed outside the processing cell in an area having a low gamma backg.round; the delayed neutrons must be detected within the processing cell, where the neutron background will be one order of magnitude higher than the signal from the delayed neutrons. Because the neutron detectors will have to be operated in a very high beta-gamma field, there will undoubtedly be problems of component failure due to radiation damage. This, in turn, will necessitate that the equipment be serviced remotely.

Whether or not the short-lived krypton and xenon isotopes will diffuse out of the solids in which they are formed and into the helium sweep gas in a reasonable length of time appears to be the most critical uncertainty for this analytical technique. Since the plutonium in the aluminum oxide waste will probably be in the form of finely divided particles and/or a thin coating on the surface of the aluminum oxide, most of the krypton and xenon atoms (greater than 75\%) will probably diffuse out of these solids shortly (within $1 \mathrm{~min}$ ) after they are formed. Should the retention of krypton and xenon be significant, the method may still be applicable, providing, of course, that the percentage of krypton and xenon released in a fixed time after irradiation is reproducible.

6.5.2.1.3 Direct Gamma Counting of Fission-product Gammas. The possibility of using the very energetic gamma rays emitted by short-lived fission products should also be considered as a technique for detecting the fission events that arise from thermal-neutron irradiation. Rubidium-90, which has a fission yield of $2 \%$ and a half-life of $2.9 \mathrm{~min}$, decays with the emission of $4.3-\mathrm{MeV}$ gamma rays. The highest-energy gamma rays emitted by the long-lived fission products in the waste stream have an energy of 2. $2 \mathrm{MeV}$. It may be possible to interpose sufficient shielding between the irradiated sample and the gamma detector to reduce the number of lowenergy gamma rays impinging on the detector. Consequently, the lowerenergy gamma rays will not pile up and a counting geometry that ensures detection of the limited number of high-energy gammas can be maintained.

6.5.2.2 X-ray Spectrometry. Plutonium in inactive aluminum oxide can be determined by X-ray spectrometry at the 500-ppm level with a high degree of reliability. The steps in the analysis are: the generation of an element's characteristic $\mathrm{X}$ rays (usually by irradiation with an $\mathrm{X}$-ray tube), resolution of the characteristic $X$ rays from the background of scattered incident radiation with an $\mathrm{X}$-ray optical system, and measurement of the intensity of the characteristic $X$ rays with a counter. 
$\mathrm{X}$-ray spectrometry warrants consideration for the determination of plutonium in the aluminum oxide waste stream for several reasons:

1. As stated above, X-ray spectrometry is a highly reliable technique for the determination of plutonium in inactive aluminum oxide.

2. With one exception, which is discussed below, the principal components of an X-ray spectrometer should operate readily in a high radiation field.

3. X-ray spectrometry is used extensively in industry for in-line analysis of streams that are analogous to the aluminum oxide waste stream (e.g., the manufacture of cement).

To determine whether X-ray spectrometry can be applied to the analysis of plutonium in the waste stream, two general problems would have to be considered and experimentally evaluated.

1. The capability of constructing an X-ray spectrometer in which the $\mathrm{X}$-ray detector is adequately shielded from the fission-product gamma activity without an inordinate los in sensitivity.

2. Effect of the high alpha, beta, and gamma activity of the sample on the generation and subsequent resolution of the characteristic $X$ rays.

Since the detectors used to measure the intensity of the characteristic $X$ rays of plutonium have a low but significant efficiency for the detection of the high-energy gamma rays emitted by the fission products, the $\mathrm{X}$-ray spectrometer would have to be designed to shield the detector from these gamma rays. The feasibility of doing this in an X-ray spectrometer arises from the fact that the optical path within the instrument is angular. When a lithium fluoride diffraction crystal is used, the angle between the sample-to-crystal path and the crystal-to-detector path is $155^{\circ} \mathrm{C}$. Since the sample-to detector distance is about 6 in., an adequate amount of shielding apparently could be interposedbetween the sample and the detector. The dis tance between the sample and the detector can be increased if necessary. However, increasing this distance reduces the sensitivity of the instrument.

Superimposed on the spectrum of characteristic $X$ rays and scattered incident radiation from the $\mathrm{X}$-ray tube will be a background of low energy $X$ rays due to (1) the interaction of beta particles with the constituents of the sample (bremsstrahlung), and (2) characteristic plutonium $X$ rays emitted in the decay of ${ }^{242} \mathrm{Cm}$ (the principal alpha emitter in the waste stream). What effects, if any, bremsstrahlung and/or ${ }^{242} \mathrm{Cm}$ decay will have on the analysis will have to be evaluated.

The intensity of the brems strahlung spectrum may be such that the char acteristic plutonium $\mathrm{X}$ rays will be generated from this radiation with sufficient 
intensity to obviate the need for excitation with an X-ray tube. Since the beta activity of the sample will vary with the irradiation and cooling history, the bremsstrahlung spectrum and intensity will vary. However, this variation in excitation radiation could be overcome by the use of an internal standard in the analysis. A knowledge of the burnup of the feed would allow fission-product zirconium to be used for this purpose. The addition of a known amount of thorium oxide to the feed (about $1 \mathrm{~g}$ per kilogram of feed) would allow thorium to be used as the internal standard.

\subsubsection{Discontinuous Radiochemical Determination of Plutonium.} A standard wet chemical determination of plutonium in aluminum oxide would have the advantages of requiring a minimum of analytical development, a minimum of equipment, a very high probability of success, maximum sensitivity, and maximum reliability. The disadvantages of this approach are the time required to execute an analysis (about $30 \mathrm{~min}$ ) and the problem of sampling.

The sample would be leached with a hot mixture of aluminum nitrate and nitric acid; an aliquot of the leach solution would be oxidized with argentic oxide; the plutonium would be extracted into hexone; plutonium would be plated from the hexone; and the plate would be assayed for its alpha activity. The only conditions placed on the analysis are that the sample be weighable (e.g., $10 \mathrm{mg}$ or more) and that it be representative. The only step in the analysis requiring investigation is the leach step. The time required for each step in the analysis is estimated in the following tabulation:

\begin{tabular}{lc} 
Operation & Time, min \\
\cline { 2 - 2 } Weighing & 2 \\
Leaching & 15 \\
Aliquoting & 2 \\
Oxidation & 2 \\
Extraction & 5 \\
Plating & 5 \\
Counting & 1 \\
\multicolumn{1}{c}{ Total } & 32
\end{tabular}

If the leach time can be reduced markedly, the analysis time can be reduced to $20 \mathrm{~min}$. Additionally, the ratio of ${ }^{239} \mathrm{Pu}$ to ${ }^{240} \mathrm{Pu}$ is required to convert the counting data to a weight percent plutonium.

\subsubsection{Determination of Burnup}

Burnup of LMFBR fuels will be determined by analyzing samples of the oxide powder feed for a particular fission product or group of fission products. The samples are analyzed after dissolution in an aqueous medium. 
In the selection of a burnup monitor for a particular nuclear fuel, a number of criteria must be applied: (1) It cannot be an initial constituent of the fuel, (2) it must be retained in the fuel during irradiation, (3) it must have a high fission yield, (4) its yield must be independent of the fissioning nuclide, (5) it must have a low neutron-capture cross section, (6) its yield must be accurately known, and (7) there must be a reliable analytical method available for its determination.

The rare-earth group of fission products meets the above criteria better than any individual fission-product nuclide. Although the fast fission yields of the rare-earth fission products have not been accurately measured, a program is being carried out in the Chemical Engineering Division for this purpose. Within this same program, one analytical method has been developed and another is under development for determining the rare earths in irradiated nuclear fuel. The burnup measurements made using the rare-earth methods will apparently have an accuracy of $\pm 2 \%$ 。 


\section{KEY PROBLEMS}

Key problems or problem areas are recapitulated here. These are problems that appear to have a high degree of uncertainty associated with them for any of the following reasons:
a. Lack of fundamental information.
b. Lack of demonstration experience.
c. Insufficient information to allow a choice to be made among available alternatives.
d. Introduction of a novel idea, heretofore untried.
e. A combination of these (or others).

Although all of the problems discussed are presumed to have solutions because of the overall flexibility of fluoride-volatility processes, some problems are more complex than others and represent a greater challenge. Problems designated key problems should be given priority in a research and development program.

\subsection{Mechanical Separation of Fuel from Cladding}

Although the entire mechanical head-end process represents a design problem of some magnitude, the key portion of this process is considered to be the mechanical separation of fuel from cladding. In the reference process, fuel pins are grouped in bundles of 25 pins and the pins are chopped into short (1/2-to 1-in.) lengths. A rolling operation to split the pins before chopping may be a useful adjunct. The pin sections are fed to a continuous ball mill, which separates the fuel from the cladding, providing it in a powdered form suitable for feeding to the continuous fluid-bed fluorination process; fuel-free hull sections are discharged separately. The uncertainty lies in the lack of experience with such a mill. Two criteria must be met simultaneously:

a. Fuel recovery must be virtually complete (minimal loss of fuel in the discharged hulls).

b. The unit must operate reliably in an enclosure that prevents gaseous fission products from being vented to the main cell ventilation air.

In view of experience with a large chopper at NFS and the small chopper development work at ORNL, fuel chopping is not considered a direct part of this problem. Development of a method for monitoring the discharged: stainless steel hulls for residual fuel is not considered a part of this problem. 


\subsection{Continuous Fluorination}

The concept of continuous fluorination, per se, is considered a proven one, in view of Allied Chemical Corporation's experience with their feedmaterials plant at Metropolis, Illinois. However, a problem of considerable magnitude is to demonstrate the operational goals set forth in this design study. The goals are: satisfactory production rates for $\mathrm{UF}_{6}$ and $\mathrm{PuF}_{6}$, and the necessary separations (separation of uranium from plutonium and separation of each from the alumina-bed material). Particularly, a large economic penalty is associated with discard of plutonium with the waste alumina. Uncertainty about the ability to achieve these goals is due to the unknown chemical reactivity of the FBR fuels. Work with synthetic nonirradiated FBR materials will provide useful data, but confirmatory work with highly irradiated, high-plutonium materials is necessary.

\subsection{Decontamination of $\mathrm{PuF}_{6}$ Stream}

A goal of $10^{6}-10^{7}$ for the decontamination factors has been selected for the uranium and plutonium streams. The primary uncertainty is whether this $D F$ can be achieved in the purification of the $\mathrm{PuF}_{6}$ stream, since final purification of the $\mathrm{UF}_{6}$ stream by fractional distillation is presumed to be a proven method. The proposed method of combining thermal decomposition and simple vaporization (one-stage distillation) to achieve sufficient decontamination of the $\mathrm{PuF}_{6}$ from fission products such as ruthenium, antimony, and niobium has not been studied on FBR systems. In LWR studies, the expected behavior of ruthenium compounds on the basis of thermodynamics differed widely from that observed in actual laboratory tests, making this a key problem in the FBR studies.

\subsection{Preparing an Acceptable $\mathrm{PuO}_{2}-\mathrm{UO}_{2}$ Product}

A fluid-bed conversion process developed earlier for the preparation of $\mathrm{UO}_{2}$ from $\mathrm{UF}_{6}$ is here proposed for the preparation of the final $23 \%$ $\mathrm{PuO}_{2}-\mathrm{UO}_{2}$ product from $\mathrm{UF}_{6}-\mathrm{PuF}_{6}$ mixtures. This process represents the interface between the fuel reprocessor and the fuel fabricator and must produce a product that meets the requirements of the fabricator as to composition ( $\mathrm{O} / \mathrm{M}$ ratio, impurity content), homogeneity (the $\mathrm{U}-\mathrm{Pu}$ distribution specification may be set by the reactor physicists), and density. The uncertainty centers on the fact that the mixed hexafluoride system has not been tested at any scale thus far. An engineering-scale demonstration is needed to establish its feasibility. This should be followed by in-pile performance tests of the oxide product, permitting an overall evaluation of the fluoridevolatility process.

\subsection{Total Containment Concept}

Total containment of the off-gas was not set down as a ground rule for this study, but was added as a goal of the reference process. Thus it 
represents a new concept, the idea of operating a plant without introducing inert gas to the off gas streams. If the goal is reached, the venting of pollutants (fission products or other noxious agents) to the environment would be eliminated in this process. The fission products and noxious chemical agents such as fluorine and HF are converted to stable waste forms, mostly solids, by sorption. Rare fission product gases are compressed and stored.

Retention of key off-gas components, such as iodine, by sorption has been tested. However, uncertainty remains, since not all fission-product compounds formed in the FBR reprocessing scheme have been identified. Another uncertainty is whether a plant can be designed so that only the gases used in the process (such as oxygen and fluorine) are used throughout for purges, pneumatic conveying, etc.

\subsection{Safety}

The preliminary safety analysis for this conceptual plant indicates that both criticality safety and safety related to the accidental release of large quantities of $\mathrm{UF}_{6}, \mathrm{PuF}_{6}$, and fission products have been built in. Criticality safety, however, has been assessed by calculation alone. Experimentation is needed to remove the uncertainty in the present design.

Safety has been achieved by eliminating reflecting and moderating materials and by reactor design (slab geometry); the backup systems are the accountability system (weighing) and monitors (special instrumentation). Water is presumed to be eliminated from key areas. Further work is needed to ensure that criticality safety will meet all the requirements.

The feasibility of containment in the event of major accidents, which release large quantities of hexafluorides and fission products, is based on extrapolation of work by Kessie and Ramaswami. ${ }^{330}$ Safety depends on the hexafluorides being highly reactive (reacting with moisture to form particulate solids) and in part on redundancy of equipment (e.g., dual filter systems). Long-term experience with high-efficiency filters for particulate solids at all AEC sites is the main basis for confidence in this system. The major uncertainty lies in the fact that no large-scale release tests have been performed, even with $U_{6}$. Discussions regarding safety are often philosophical since only rarely are full-scale tests performed. Confidence must be established by experience in which equipment is found to be reliable.

\subsection{Sodium}

The role of sodium in this process is currently an uncertainty, since its behavior in the fluorination process has not been studied. Sodium probably must be eliminated from the feed to the fluorinator on the basis that $\mathrm{NaF}$ has an affinity for $\mathrm{PuF}_{6}$ and that this sorption reaction is irreversible. A head-end that removes sodium must therefore be designed. If sodium cannot be detected in incoming fuel pins or if all fuel pins need to be treated, the head-end will be more complex. The role of sodium remains a potential key problem. 


\section{SUMMARY}

The state of present technology is such that considerable development work and improvement in fuel reprocessing will be required to meet the economic goals of the Liquid Metal Fast Breeder Reactor (LMFBR) program. Because of extensive experience with aqueous reprocessing, there is incentive to adapt this technology to LMFBR fuels, particularly for the short range (i.e., adaptation to existing reprocessing plants or to those that will be built in the near future). However, the present state of aqueous technology is such that its applicability either for the short range or the long range (i.e., adaptation to plants that might be built specifically to reprocess LMFBR fuels) cannot be well assessed. For this reason, in the initial stages of the LFMBR program, both aqueous development work and nonaqueous fluoride-volatility and pyrochemical development work were supported. The decision to provide full support for the development of a single processing scheme was deferred, according to present timetables, until about 1974. The interim development programs were expected to be definitive and to allow a value judgment to be made regarding the final choice of reprocessing method.

The AEC asked the Chemical Engineering Division of Argonne National Laboratory to conduct a study to define the potential of the fluoridevolatility process for application to reprocessing LMFBR fuels. This study was given a high priority to provide a definition of key problem areas and to provide insight into the magnitude of the development task associated with establishing the volatility technology for LMFBR fuels. It was felt that this information could best be provided through the mechanism of process and plant design. Therefore, a conceptual design of a volatility reprocessing plant has been prepared, together with an extensive critique of the process. The uncertainties identified include not only those associated with the unique characteristics of LMFBR fuels but also those inherent in volatility technology, per se.

The following information was to be developed in the study:

1. A process or chemical flowsheet. It was not necessary that the flowsheet be completely proven; however, the process steps should be based on sound principles and must have a high likelihood of being successful.

2. An engineering flowsheet indicating each major piece of equipment, its size, throughput capacity, material of construction, and development status.

3. A conceptual plant design and equipment layout to give an approximation of shielded cell size and shielding thickness, operating maintenance, criticality, safety, accountability, effluent control, etc.

4. A discussion of the uncertainties associated with the flowsheet. This should include a list of major problems, their potential influence on safety or technical feasibility, and their order of importance in relation to the organization and continuation of the development plan. 


\subsection{Ground Rules}

The ground rules for the study were set up in advance and agreed upon by the interested AEC people. This was done to avoid the possibility of selecting ground rules that might bias the results.

It was decided that the study should be based on a central plant serving a regional area, having a capacity for handling the fuel from breeder reactors generating 15,000 $\mathrm{MWe}$, and providing a highly decontaminated product, i.e., a decontamination factor (DF) ranging from $10^{6}$ to $10^{7}$.

The fuel characteristics (specific power, burnup, and composition) were specified in the ground rules. A cooling time of 30 days before processing was specified to maintain low plutonium inventory costs. The fuel selected as a reference was based on an Atomics International preliminary design. Fast reactor fuel designs are not yet firm, but most of the proposed designs are similar.

The plant was to process all the fuel, i.e., core, axial blanket, and radial blanket. The reference process selected in this study is based on this. However, in hindsight, the radial blanket (which is similar to LWR fuel) could probably be processed more cheaply in an LWR fuel reprocessing plant than in one designed specifically for LMFBR fuels.

The plant products were to be decontaminated $\mathrm{UO}_{2}-\mathrm{PuO}_{2}$ powder suitable for refabrication into core fuel, and purified $\mathrm{UF}_{6}$ for shipment off-site and for use in other reactors. Ground rules for waste effluent control were also specified.

\subsection{Process Flowsheet}

A reference process was selected by combining steps that have reasonably sound technical bases according to present knowledge. As the study progressed, numerous potential improvements in the process flowsheet became apparent. However, because of the limited time allowed for completion of the study, most of these alternatives were not included in the basic plant concept. Although the flowsheet chosenfor this study is considered acceptable for evaluation of process feasibility, this flowsheet would probably not be selected for intensive development without modifications.

The main process steps and their basic objectives are:

1. Mechanical head-end; separate the fuel from the cladding.

2. Continuous fluid-bed fluorination; separate first the uranium, then the plutonium as hexafluorides from the bulk of radioactive fission products (Groups I, II, III, and IV) that do not form volatile fluorides. 
3. Thermal decomposition and refluorination; first separate the plutonium as $\mathrm{PuF}_{4}$ from the recombined $\mathrm{UF}_{6}-\mathrm{PuF}_{6}$ products of Step 2, then recover the plutonium as $\mathrm{PuF}_{6}$ for final purification. Thermal decomposition not only provides separation, but also provides substantial decontamination from fission products.

4. Fractional distillation and sorption; purify the $\mathrm{UF}_{6}$.

5. Conversion; convert a $\mathrm{UF}_{6}-\mathrm{PuF}_{6}$ product mixture to a particulate oxide solid for refabrication into core fuel.

It is assumed that the fuel will be transported to the reprocessing plant in sodium-filled containers inside shielded casks. After the fuel is removed from the containers, any sodium remaining on the fuel subas semblies will be removed by controlled oxidation and washing. Details of the mechanical treatment of the fuel are somewhat indefinite at present, since little experimental data are available and fuel designs are not firm. The reference concept involves chopping the fuel pins into short pieces and tumbling the segments in a ball mill to separate the fuel powder from the cladding. Fuel chopping is a well-developed technology, at least for lightwater reactor fuels, but only a very limited amount of experimental work has been done on separation of fuel from chopped segments by ball milling. The latter step requires experimental development.

The fluorination is visualized as a continuous operation using two fluorinators in series. The first fluorinator receives fuel and alumina in powder form and converts the uranium and a small fraction of the plutonium to the hexafluorides by reaction with a fluorine-oxygen mixture at $350^{\circ} \mathrm{C}$ in a fluid bed. The alumina bed (containing $\mathrm{PuF}_{4}$ and fission products) overflows from this reactor into the second reactor, where fluorination of the $\mathrm{PuF}_{4}$ is completed by reaction with concentrated fluorine gas in a fluid bed at temperatures of $500-550^{\circ} \mathrm{C}$. To ensure that the waste alumina bed and fission products discharged from the second reactor would contain a very small amount of plutonium, the second fluorinator would consist of at least two fluid-bed stages arranged so that solids flow countercurrently to the fluorine gas.

The $\mathrm{UF}_{6}$ stream from the first reactor and the $\mathrm{PuF}_{6}$ stream from the second reactor are cooled separately in partial condensers $\left(15^{\circ} \mathrm{C}\right.$ for the $\mathrm{UF}_{6}$ stream and $-10^{\circ} \mathrm{C}$ for the $\mathrm{PuF}_{6}$ stream) to separate the bulk of the volatile ruthenium and niobium pentafluorides. Downstream from these traps, the actinide hexafluorides are separately condensed in traps refrigerated to $-80^{\circ} \mathrm{C}$.

The off-gas stream from each fluorination loop is handled separately, but both are recycled to their respective reactors. Oxygen is a product of the fluorination of the fuel oxides in the first fluorinator, and a fluorine makeup 
stream is provided to maintain favorable fluorination conditions. The second fluorinator operates with recycle of virtually pure fluorine.

A small fraction of the oxygen-fluorine mixture is continuously removed from the off-gas stream of the first fluorinator for treatment in the off-gas treatment system. Because of the high concentrations of fissionproduct iodine, xenon, and krypton in short-cooled LMFBR fuels, the gas treatment system is intended to be capable of virtually complete containment of waste gases. Solid chemical reagents are used to remove fluorine, iodine, and tritium. The oxygen in the gas stream is then converted to water and removed, leaving only the rare fission gases. The latter are compressed and stored indefinitely or released in a controlled manner after partialdecay.

Because a small fraction of the input plutonium may be converted to $\mathrm{PuF}_{6}$ in the first fluorinator and accompany the $\mathrm{UF}_{6}$, the $\mathrm{UF}_{6}$ and $\mathrm{PuF}_{6}$ streams are recombined, and a complete separation of plutonium from uranium is effected in the following step, fluid-bed thermal decomposition. Thermal decomposition of the $\mathrm{PuF}_{6}$ to the nonvolatile tetrafluoride is conducted at about $350^{\circ} \mathrm{C}$. A bed of alumina serves as a base for deposition of the plutonium.

Available data indicate that volatile fission-product fluorides in the uranium-plutonium hexafluoride feed stream to the thermal decomposer will remain with the $\mathrm{UF}_{6}$ stream leaving the thermal decomposer. These fission products will be separated from the $\mathrm{UF}_{6}$ by a combination of chemical absorbers and continuous fractional-distillation columns. Lithium fluoride and sodium fluoride are effective sorbers for fission-product fluorides such as ruthenium pentafluoride, niobium pentafluoride, and antimony pentafluoride; magnesium fluoride is useful for sorption of neptunium fluoride and technetium fluoride. Sorption and distillation are both considered welldeveloped techniques for purification of $\mathrm{UF}_{6}$. The purified $\mathrm{UF}_{6}$ product is split, part being converted to the dioxide along with plutonium and the excess being cold-trapped for subsequent shipment off-site.

The $\mathrm{PuF}_{4}$ in the decomposer is subsequently refluorinated to $\mathrm{PuF}_{6}$ in a fluid-bed operation at $500^{\circ} \mathrm{C}$. Purification of the $\mathrm{PuF}_{6}$ is completed in a final sequence of cold-trapping and evaporation (one-stage distillation) steps. The refined $\mathrm{PuF}_{6}$ vapor represents the plutonium component of the feed to the converter.

Reconversion of the mixed hexafluorides to oxides by reaction of the gaseous mixture of $\mathrm{UF}_{6}-\mathrm{PuF}_{6}$ with steam-hydrogen mixtures has not been studied experimentally, but this operation has been extensively studied and tested for $\mathrm{UF}_{6}$-to- $\mathrm{UO}_{2}$ conversion. $\mathrm{PuF}_{6}$ has been converted to $\mathrm{PuO}_{2}$ separately, improving the likelihood that this process step is feasible. 


\subsection{Process Analysis and Plant Design}

The concept of a continuous fluid-bed fluorination is one developed by Allied Chemical Co. in their feed materials plant at Metropolis, Illinois. The fluorination design criteria for the reference process were, however, based on numerous batch experiments with light-water reactor fuels and a small number of bench-scale experiments with simulated LMFBR fuel. Plutonium losses under $1 \%$ were achieved in this work. The goal in the reference process fluorination step is a loss consistently below $0.5 \%$. More experimental work is needed to verify that this can be achieved.

The choice of continuous operation of the fluorinators and other equipment is important to the economics of the process. One reason for this pertains to the rate of fluorination of plutonium. The rate of fluorination of plutonium is limited by the thermodynamic equilibrium of the fluorination reaction, and to drive the reaction to completion, a large flowrate of recycled fluorine must be used. To complete the fluorination in a practical length of time, the fluorine-to- $\mathrm{PuF}_{6}$ ratio must be as near equilibrium as possible to minimize the total mass flow of fluorine. Plutonium fluorination rates up to $8 \mathrm{~kg} /(\mathrm{hr})\left(\mathrm{ft}^{2}\right)$ have been achieved in some batch experiments, but the rate decreases as the plutonium is depleted from the bed. Therefore, continuous fluorination is considered desirable so that a high fluorination rate be maintained at all times.

It is also interesting to note that the total number of curies of those fission products that form volatile fluorides and those that form nonvolatile fluorides are about equal. This load of volatile radioactivity for shortcooled LMFBR fuels is much larger than that of long-cooled LWR fuel.

Process equipment sizes for the conceptual plant were calculated on the basis of known or estimated reaction rates. A single processing line is used in the conceptual plant; therefore, in most cases only one of each of the major equipment items is required. Many of the auxiliary process vessels and cold traps are installed in duplicate and are operated on a 12-hr batch cycle. This permits uninterrupted operation of the fluorinators, the stills, and the converter.

Removal of heat from the reaction vessels requires careful consideration of their design. Heat loads are most severe in the main fluorination vessels, which have large inventories of fission products, and particularly in the uranium fluorinator, which has a large chemical heat load in addition. Maximum heat fluxes are on the order of $11,000 \mathrm{Btu} /(\mathrm{hr})\left(\mathrm{ft}^{2}\right)$, and calculations show that satisfactory heat removal can be achieved with either air cooling or mist cooling of a finned reactor surface.

A slab design used for the fluorination vessel offers several advantages with regard to the heat problem. It provides a greater surface for 
heat transfer than would a cylindrical vessel of comparable volume and in addition presents a small dimension ( 4 in. thick) across which the heat must be transferred. Thus if fluidization is lost in one of these vessels, heat removal by conduction should prevent any serious consequences due to high temperatures at the center of the vessel.

Overall plant problems such as criticality, accountability, and plant safety in the event of hexafluoride release have been considered in this preliminary evaluation. The approach to criticality control adopted for this volatility plant concept is one that avoids neutron moderation and minimizes neutron reflection to obtain a low reactivity per unit mass of plutonium in the process system. All vessels expected to contain significant quantities of plutonium are of a slab design, which lends itself to safe-byshape geometry. Preliminary criticality calculations by Oak Ridge Gaseous Diffusion Plant (ORGDP) indicate that $100 \mathrm{~kg}$ of plutonium could be safely contained in a 4-in.-thick slab reactor of nickel, 48 in. wide, containing $\mathrm{PuF}_{4}$ at its theoretical density $(7 \mathrm{~g} / \mathrm{cc}$ ) and reflected top and bottom by alumina bed material. The normal operating inventory in the present flowsheet is below $50 \mathrm{~kg}$ of plutonium.

Water is excluded from the reference process, both internally and externally. Other safety factors are also incorporated into plant design (e.g., vessel spacing and arrangement of piping) to prohibit other external reflectors from complicating the criticality problem. In addition, the input of fissile material will be monitored by weighing it, and the inventory of plutonium in the key process vessels (e.g., the fluorinators) will be monitored with nuclear instrumentation. Both procedures represent additional safety factors. An acceptable factor of safety is predicted for both normal and credibly abnormal situations.

Accountability and burnup analyses are accomplished by sampling the fuel before it is fed into the first chemical process stage and by sampling the final waste streams (which establishes loss levels). Weight data obtained during interim storage of the fuel powder before it is fed to the fluorinators also provides input accountability information. Weights and analyses of the final products (the mixed $\mathrm{PuO}_{2}-\mathrm{UO}_{2}$ product of the conversion step) provide the remaining necessary information for accountability.

Waste is disposed by converting all wastes to solid form. The principal high-level wastes are: (1) the alumina waste containing all the nonvolatile fission products and (2) the ruthenium-niobium pentafluoride from the partial condensers. The alumina containing the nonvolatile fission products is discharged to waste storage cylinders. Aluminum shot or coarse powder is added to the waste as it is transferred to the storage cylinder to promote the transfer of heat from the center of the cylinder to the walls and thus lower the centerline temperature. These cylinders are stored under water in a storage canal to permit partial decay of fission products. 
The heat generated by fission-product decay decreases yearly, until after 8 yr the volumetric heat release for the cylinders with the highest heat load has dropped to $2 \mathrm{~W} /$ liter, the maximum value for permanent storage.

The ruthenium-niobium fluorides collected in the partial condensers are removed periodically by warming the condenser and transferring the volatile fluorides in a gas stream to a bed of sodium fluoride where the fission products are sorbed. This NaF is then transferred to storage cylinders like those used for the alumina waste.

About 200 cylinders are required per year, each cylinder being $2 \mathrm{ft}$ in diameter and $9 \mathrm{ft}$ tall. Less than half of these waste containers require interim storage for decay of radioactivity to a level that will permit dry storage.

Considerable design and layout work would be needed to estimate the size of the radiochemical processing cells and the total plant with any appreciable degree of accuracy. This is beyond the scope of the present study, which is only intended to determine process feasibility. Nevertheless, a very preliminary layout of plant equipment was made, and from this, the processing cells and the building appear to by of practical sizes.

Remote maintenance was selected for the most radioactive sections of the plant; semiremote or direct maintenance will be used in other sections. Major repair work will be done in a separate maintenance area located in a sublevel cell equipped with shielding windows and manipulators.

\subsection{Conclusions}

The foregoing conceptual design study of a fluoride-volatility plant shows that the application of fluoride-volatility processing to LMFBR fuels is supported by a substantial body of basic and technological information, which has been generated in reprocessing work on other nuclear fuel materials and in related processes. Among the most pertinent areas of earlier work are:

a. Commercial refining of uranium in the Allied Chemical Corp. plant at Metropolis, Illinois.

b. Extensive development work on fluoride-volatility processing of fully enriched uranium fuels, exemplified by the startup of a hot pilotscale facility in France.

c. Basic and pilot (kilogram)-scale work on the preparation and transport of $\mathrm{PuF}_{6}$. The results of this work are now finding application in the design of a prototype facility for recovering plutonium scrap and recycle material, planned for installation in 1969 at the AEC-owned Dow Rocky Flats Laboratory.

d. Plant-scale experience with the fluid-bed calcination of radioactive waste solutions at the Idaho Nuclear Corp. plant. 
A future source of relevant information is represented by four fluidbed processes--calcination of $\mathrm{UNH}$ to $\mathrm{UO}_{3}$, fluorination of $\mathrm{UO}_{3}$ to $\mathrm{UF}_{6}$, calcination of wastes, and disposal of fluorine--planned for installation by General Electric in their Midwest Fuel Recovery Plant (the Aquafluor Process). Decontamination of $\mathrm{UF}_{6}$ by fractional distillation and sorption techniques is also planned in this facility. This operation will represent the first commercial venture in irradiated-fuel reprocessing that uses these processes.

Existing information, coupled with several innovative design features, provided the basis for the design of a reference process and a reference plant design for LMFBR fuel reprocessing. The reference process shows a high potential for handling highly radioactive, short-cooled fuel, as well as considerable flexibility in processing feed materials with a wide range of fissile material concentrations. The conceptual plant has a practical size, comparable to existing plants that process LWR fuels. With optimization, a substantially improved process should be expected.

The problems associated with the unique features of LMFBR fuels, namely, high plutonium content, high heat load, and high fission-product content, can be accommodated by appropriate design. In the reference process, continuous, slab-shaped fluorination reactors are used. The continuous system minimizes plutonium inventory and permits operating conditions that promote high plutonium throughput. The slab shape eases the heat-removal problem (provides higher wall area-to-bed volume ratios) and provides safe-by-shape geometry. The high fission-product content is accommodated by using a "total containment" concept. The volatile wastes are converted to a solid waste form, while rare gases are separated, compressed, and stored.

The process appears feasible, most of the steps having reasonably sound bases in current technology. The techniques employed--continuous fluid-bed fluorination, hexafluoride cold trapping, fractional distillation, and pneumatic conveying of solids--are basically the same as those used in the earlier work cited above. It is in their application to highly radioactive, high-plutonium fuel that uncertainty arises.

An analysis (critique) of the reference process has defined a number of key problems, which are summarized briefly below.

1. Mechanical decladding of fuel should be studied because of possible difficulties from the high rate of heat generation. Also, it may be difficult to ensure that all fuel oxide has been removed from the fuel hulls by the conceptual ball-milling procedure; supplementary cleanup of hulls may be required.

2. Continuous fluorination will require the development of reliable solids-feeding devices and unique equipment such as slab-shapedfluorinators 
and dual-stage reaction vessels. Plutonium losses in the alumina waste from the fluorination steps must be low.

3. Further development and testing are needed to ensure that plutonium decontamination will meet requirements.

4. The preparation, of mixed fuel oxides by direct fluid-bed conversion of the mixed hexafluorides should be studied on an engineering scale since work to date has been on conversion of $\mathrm{UF}_{6}$ to $\mathrm{UO}_{2}$ and $\mathrm{PuF}_{6}$ to $\mathrm{PuO}_{2}$ separately.

5. Total containment of process gases, although not an essential requirement, is a highly desirable goal. This concept needs development.

6. Further work is needed to ensure that criticality safety and containment of $\mathrm{PuF}_{6}$ will meet all requirements.

7. The role of sodium in the process and its potential effect on plutonium losses will require additional study, since it is known that sodium fluoride forms complexes with $\mathrm{PuF}_{6}$, causing plutonium to be irreversibly sorbed.

Although the key problems have been defined by analysis of one reference process that has not been optimized, the problems are representative of those existing in some alternative volatility flowsheets, which use fluorine alone. These other flowsheets were examined only very qualitatively, time not permitting a more complete study (which is recommended). Of the areas requiring work defined by the conceptual plant-design study, some involve the investigation and confirmation of concepts that are already partially developed but not fully proven. Work on these problems would represent the first stage of a development program on the fluoride-volatility process.

The technique of developing a reference process design and a reference plant concept, without consideration of economics or optimization, has been successful in assessing the applicability of fluoride volatility to LMFBR fuel reprocessing. Further use of this technique should be considered in evaluating the potential of alternative processes (e.g., separate processing of core and blanket, or hybrid processes) and in evaluating the progress of R\&D work. With this kind of ongoing study, the point in time when economic considerations should be given attention can be readily determined. 


\title{
APPENDIX A
}

\author{
Possible Methods for Monitoring Plutonium Buildup*
}

Instrumentation requirements for monitoring plutonium quantity in large fluoride-volatility processing plants can be partitioned into three broad areas or categories:

\section{Category 1. Criticality Control}

From a safety viewpoint, one must be capable of detecting any approach to criticality (for any vessel or subunit in the processing-plant system).

\section{Category 2. Coagulation Detection}

The ability should exist to determine any possible lumping, hangup or concentration of plutonium in any pipe or subsystem.

\section{Category 3. Fuel Inventory}

This aspect (which is obviously related to the Safeguards Program ${ }^{160}$ ) implies instrumentation assistance for (subcritical) fuel inventory.

\section{Noise Measurements}

The application of noise techniques to processing-plant subsystems could provide a measurement of subcriticality (Category 1). This could be done by cross-correlating the outputs of two detectors and, from the noise spectrum or cross-correlation function (which are Fourier transforms of each other), determining the prompt-fission-chain decay constant. This constant yields an indication of the subcriticality.

A number of factors might limit the applicability of noise techniques. The measured decay constant is equal to the prompt-neutron lifetime divided by the prompt subcriticality. Therefore, to deduce the prompt or delayed subcriticality, it is necessary to know either the prompt-neutron lifetime or the decay constant at delayed critical. These quantities may not be easy to obtain for a processing vessel that is not intended to operate at critical. Furthermore, changes in active material configuration (e.g., by coagulation) may change the prompt-neutron lifetime and so may change the correspondence between the observed decay constant and the deduced reactivity. These matters can be explored to some extent by appropriate nuclear calculations.

The commonly conceived method ${ }^{161,162}$ for measurements with noise is to select two frequencies in the noise spectrum with filters and read the

\footnotetext{
* Prepared by R. Gold and associates of ANL Reactor Physics Division (1968).
} 
ratio of the spectral densities at these frequencies, which is related to the decay constant. For unmoderated systems, such as this proposed processing plant contains, a better method would be the use of a wired-program, digital-polarity cross correlator based on a stored-program computer method already developed. ${ }^{163,164}$ Here the correlation could be measured between one detector signal undelayed and the other delayed by transmission through a shift register chain. The ratio of the correlations at two values of lag could serve as a measure of the decay constant.

For such systems, experience has shown that the best type of detector is a plastic scintillator viewed by a photomultiplier. Such a detector has good sensitivity and flat frequency response in the range of interest. A scintillator volume of $10-100 \mathrm{~cm}^{3}$ is appropriate. The detectors could be mounted on the outside of the vessel to be monitored. The gamma sensitivity of such detectors is not a problem, since the prompt component adds to the desired signal, while the delayed component adds only slightly to the uncorrelated background, which is averaged out by the technique.

\section{Coincidence Correlation with Fission Neutrons}

A detection system for both Categories 1 and 3 would use neutron detectors of high gamma-rejection capability and high efficiency. Such a system could consist of a cylindrical annulus surrounding a subunit of the processing plant, such as a reaction vessel. (Separate units could surround the pipes.) Each annulus would consist of a heavy metal shield and a moderator matrix in which a number of neutron detectors would be implanted. An example of such a system is a lead oxide matrix a few feet thick, with $\mathrm{BF}_{3}$ counters dispersed radially and longitudinally. Lead oxide is suggested because it is rather inexpensive, has the necessary gamma-attenuation capabilities, and provides, through the oxygen, a sufficient degree of moderation to slow neutrons down to a velocity that will provide a higher intrinsic efficiency for the $\mathrm{BF}_{3}$ counters. In addition, lead and oxygen would not contribute to an excessive photoproduction of neutrons. Carbon would probably also be suitable as a moderator substitute, although it is not much better than oxygen in this respect. $\mathrm{BF}_{3}$ counters are advisable because of their relatively good efficiency, consistent with a high gamma-rejection capability. If gamma levels through the lead oxide filter remained high, spark chambers could be substituted. (See below.)

The neutron efficiency for such a lead oxide matrix $\mathrm{BF}_{3}$ detector system could lie in the range of $1-10 \%$. Different alternatives for data processing exist. (One such method, noise measurement, is discussed above in Section 1 of this appendix.) Although count rates from each detector-when a multiplicity of detectors is provided for--are not likely to be excessive under the worst conditions, the problem of extracting maximum intelligence may be difficult, despite the availability of integrated circuit logic modules. 
Some of the information derivable would be total neutron rate, timedependent neutron rate, correlated neutron pairs, and delayed-neutron emission. Correlations in neutron pairs and delayed-neutron emission are unique features of neutron multiplicity in emission from spontaneous fission and induced fission. In this respect, it is important to note the dominance of ${ }^{242} \mathrm{Cm}$ in the spontaneous fission neutron background (see Table A.l) as opposed to the criticality hazard arising from induced fission in plutonium. This clearly defines the prompt and delayed radiative properties of fission in ${ }^{239} \mathrm{Pu}$ and ${ }^{242} \mathrm{Cm}$ as an area for further concentrated work. ${ }^{160}$

TABLE A.1. Spontaneous Fission and Alpha Emitters for a 500-kg Spent Core Section ${ }^{\mathrm{a}}$

\begin{tabular}{|c|c|c|c|c|c|c|c|c|}
\hline & $\begin{array}{l}\text { Spontaneous } \\
\text { Fission, } \\
\text { SF/(sec)(g) }\end{array}$ & $\begin{array}{l}\text { Alpha } \\
\text { Decay, } \\
\text { a/(sec)(g) }\end{array}$ & Half-life & $\begin{array}{l}\text { Relative } \\
\text { Weight }\end{array}$ & $\begin{array}{l}\text { Spontaneous } \\
\text { Fission, } \\
\text { n/sec }\end{array}$ & $\begin{array}{l}\text { Alpha } \\
\text { Decay, } \\
\text { a/sec }\end{array}$ & $\begin{array}{c}(a, n), b \\
n / s e c\end{array}$ & $\begin{array}{c}\text { Fission } \\
\text { Product, } \\
\gamma / \mathrm{sec}\end{array}$ \\
\hline 1. Fission & & & & & & & & 20 \\
\hline Products (FP) & & & & $14.0 \mathrm{~kg}$ & & & & $10^{20}$ \\
\hline 2. $232 \mathrm{U}$ & & & & $0.21 \mathrm{mg}$ & & & & \\
\hline 3. ${ }^{237} \mathrm{U}$ & & & 7 days & $1.0 \mathrm{~kg}$ & & & & \\
\hline 4. $238 \mathrm{U}$ & & & & $49.3 \mathrm{~kg}$ & & & & \\
\hline 5. ${ }^{239} \mathrm{U}$ & & & & $0.54 \mathrm{~g}$ & r & & & \\
\hline 6. ${ }^{236} \mathrm{~Np}$ & & & $22 \mathrm{hr}$ & $11.4 \mathrm{~g}$ & & & & \\
\hline 7. ${ }^{237} \mathrm{~Np}$ & & $2.5 \times 10^{4}$ & $10^{6} \mathrm{yr}$ & $92.1 \mathrm{~g}$ & & $2 \times 10^{6}$ & & \\
\hline 8. ${ }^{238} \mathrm{~Np}$ & & & 2 days & $45.9 \mathrm{mg}$ & & & & \\
\hline 9. ${ }^{239} \mathrm{~Np}$ & & & 2 days & $82.5 \mathrm{~g}$ & & & & \\
\hline 10. ${ }^{236} \mathrm{pu}$ & & $2 \times 10^{13}$ & $3 \mathrm{yr}$ & $1.3 \mathrm{mg}$ & & $2 \times 10^{10}$ & & \\
\hline 11. ${ }^{238} \mathrm{pu}$ & & $5 \times 10^{11}$ & $90 \mathrm{yr}$ & $8.5 \mathrm{~g}$ & & $4 \times 10^{12}$ & & \\
\hline 12. ${ }^{239} \mathrm{Pu}$ & & $2 \times 10^{9}$ & $10^{4} \mathrm{yr}$ & $29 \mathrm{~kg}$ & & $6 \times 10^{13}$ & & \\
\hline 13. $240 \mathrm{pu}$ & $5 \times 10^{2}$ & $10^{10}$ & $10^{4} \mathrm{yr}$ & $3.9 \mathrm{~kg}$ & $6 \times 10^{6}$ & $4 \times 10^{13}$ & & \\
\hline 14. ${ }^{241} \mathrm{Pu}$ & & & $13 \mathrm{yr}$ & $1.5 \mathrm{~kg}$ & & & & \\
\hline 15. ${ }^{242 p u}$ & $10^{3}$ & $10^{8}$ & & $0.72 \mathrm{~kg}$ & $2 \times 10^{6}$ & $10^{11}$ & & \\
\hline 16. ${ }^{243} \mathrm{pu}$ & & & & $28.7 \mathrm{mg}$ & & & & \\
\hline 17. ${ }^{241} \mathrm{Am}$ & & $10^{11}$ & $500 \mathrm{yr}$ & $0.128 \mathrm{~kg}$ & & $10^{13}$ & & \\
\hline 18. ${ }^{242} \mathrm{Am}$ & & & $150 \mathrm{yr}$ & $45 \mathrm{mg}$ & & . & & \\
\hline 19. ${ }^{243} \mathrm{Am}$ & & $7 \times 10^{9}$ & & $56.7 \mathrm{mg}$ & & $4 \times 10^{11}$ & & \\
\hline 20. ${ }^{244} \mathrm{Am}$ & & & $1 / 2 \mathrm{hr}$ & $7.3 \mathrm{mg}$ & & & & \\
\hline 21. ${ }^{242} \mathrm{Cm}$ & $10^{7}$ & $1.4 \times 10^{14}$ & 160 days & $11.5 \mathrm{~g}$ & $4 \times 10^{8}$ & $1.5 \times 10^{15}$ & & \\
\hline 22. ${ }^{243} \mathrm{Cm}$ & & $2 \times 10^{12}$ & $28 \mathrm{yr}$ & $0.17 \mathrm{~g}$ & & $3 \times 10^{11}$ & & \\
\hline 23. ${ }^{244} \mathrm{Cm}$ & $4 \times 10^{6}$ & $3 \times 10^{12}$ & $18 \mathrm{yr}$ & $3.7 \mathrm{~g}$ & $5 \times 10^{7}$ & $10^{13}$ & & \\
\hline Total & & & & & $\sim 5 \times 10^{8}$ & $\sim 2 \times 10^{15}$ & $\sim 2 \times 10^{10}$ & $\sim 10^{20}$ \\
\hline
\end{tabular}

a LMFBR Task Force work on fuel cycle done by Atomics International.

busing a yield of $10^{-5}$ neutrons per alpha for ${ }^{19} \mathrm{~F}$.

The possibility of correlation analysis in place of discrete digital pulse analysis should also be investigated. The cost of such a method is likely to be considerably less than digital alternatives. The rather high efficiency of the $\mathrm{BF}_{3}$ detectors improves the possibility of extracting useful and timely information by use of correlation methods.

\section{Spatial Dependence of the Fundamental Mode}

The geometric shape of the processing-plant reaction vessels will characterize the fundamental-mode shape of the neutron-intensity 
distribution (for the critical system). For example, cylindrical vessels imply that the critical-neutron spatial distributions will follow a cosine behavior axially and a $J_{0}$ behavior radially. As a consequence, continuous neutron-intensity monitoring in the axial and radial directions can reveal when criticality is being approached. If the spatial distribution of neutrons should ever approach these fundamental shapes, a clear warning of an increased reactivity would be obtained.

Only the shape (and not the intensity) of the spatial neutron distribution is important in this regard. To this end, the observed space distribution in any relevant variable can be unit-normalized and then expanded in the appropriate eigensolutions pertinent to that variable. If the set $\left\{a_{n}\right\}$ represents the Fourier coefficients corresponding to this eigenexpansion, then the quantities $\left\{\left|a_{n}\right|^{2}\right\}$ represent the probability of the system occupying a state described by the nth eigenfunction. In these terms, criticality is approached if $\left|a_{1}\right|^{2} \rightarrow 1$ and $\left|a_{n}\right|^{2} \rightarrow 0, n>1$. Examination of the time dependence of these Fourier coefficients $\left\{a_{n}(t)\right\}$ will then reveal any approach to criticality.

Diffusion-theory calculations have been run with the $\mathrm{MACH}-1$ code $\mathrm{e}^{165}$ for a typical cylindrical reaction vessel containing $120 \mathrm{~kg}$ of average spent reactor material (Table A.1) plus alumina. This calculation reveals that such a subsystem will possess an effective multiplication of about $1-2 \%$ due mostly to ${ }^{239} \mathrm{Pu}(\sim 6.5 \mathrm{~kg})$. In this state, the axial distribution is practically constant for all energy groups. Moreover, the $1-2 \%$ multiplication implies that fission neutrons to the extent of only $1-2 \%$ of the $(\alpha, n)$ source neutrons will be present.

This is an important result from the viewpoint of Category 2, since it implies that the $(\alpha, n)$ reaction neutrons provide a flux that may be useful in the estimation of plutonium concentrations (for subcritical reaction vessels). Thus an axial mapping of this flux over a (subcritical) reaction vessel would show strong dependence upon ${ }^{239} \mathrm{Pu}$ concentration and reveal spatial irregularities in this concentration.

A device that may be useful in this respect is a long thin detector, which, when immersed in a neutron flux, indicates the spatial distribution of neutrons along the length of the detector. Such a device could be used as a probe, either alongside a reaction vessel or laid along a duct, where it would possibly uncover patches of adhering fissionable material. The device must be absolutely insensitive to gamma radiation.

A spark location chamber, now under development, may be used as such a probe. One chamber now being tested has an active length of $1 \mathrm{~m}$ and a diameter of 1 in. Incident neutrons interact with a fissionable layer (which may respond to thermal neutrons or else to fast neutrons) facing a spark gap. The spark gap is between a long anode resistance wire of 0.004-in. diameter and a circular groove in the cathode, which is kept at 
$3 \mathrm{keV}$. The wire is stretched along the groove. Fission fragments emitted in the proper direction trigger a spark. The spark current divides according to the resistance of the wire; hence output pulses have heights proportional to the spark location. These pulses must usually be strongly attenuated ( $800-V$-high pulses have been measured) before shaping to accommodate subsequent multichannel analyzing equipment ("raw" pulses rise in $10 \mathrm{nsec}$ and decay in $40 \mathrm{nsec}$ ). This detector is entirely unaffected by noise and responds to photons only through photofission (which can be calibrated for). It can run at $100^{\circ} \mathrm{C}$, since it operates best with air at normal pressure. Spatial resolution is currently about $2 \mathrm{~mm}$ with respect to location of a fission event. In contrast with radioautographic techniques, a spark chamber can be permanently emplaced and remotely operated, and it delivers a neutron spectrum within a few minutes. This device is limited only in maximum count rate, which should not exceed a few hundred per second (a limitation that may be pushed upward in the near future).

\section{Threshold Detectors}

The degree of subcriticality in a given subsystem of the plutonium processing plant may be monitored, at least in principle, using activation detectors. In addition to neutrons produced by, fission, neutrons will be produced by various $(\alpha, n)$ reactions. Probably the most important of these reactions to consider is the ${ }^{19} \mathrm{~F}(\alpha, n)^{22} \mathrm{Na}$ process. Alpha particles from the decay of ${ }^{239} \mathrm{Pu}$ have an energy of $5.1 \mathrm{MeV}$, so that the $(\alpha, n)$ reaction on fluorine will produce neutrons having a maximum energy of about $4 \mathrm{MeV}$. Since ${ }^{239} \mathrm{Pu}$ fission neutrons have a continuous energy distribution with an average energy of about $2.27 \mathrm{MeV}$, many fission neutrons possess energies well above the $4-\mathrm{MeV}$ limit of the $(\alpha, \mathrm{n})$ reaction neutrons. Consequently, monitoring fast energetic neutrons above and below this $4-\mathrm{MeV}$ limit will be of value in estimating the ratio of fission neutrons to source neutrons. In this regard, one can use energy discrimination against $(\alpha, n)$ and photoproduced neutrons and thereby attempt to measure any unusual changes in fission rate directly.

For example, suppose two neutron activation detectors are available, one with a threshold above $4 \mathrm{MeV}$ and the other below $4 \mathrm{MeV}$. The first detector will be activated only by the high-energy portion of the fissionneutron spectrum; the second detector will be activated by both fission and $(\alpha, n)$ neutrons. The absorption rates for the two detectors (of atom densities $\mathrm{N}_{1}$ and $\mathrm{N}_{2}$ ) are given by, respectively

$$
\mathrm{R}_{\mathrm{a}_{1}}=\mathrm{N}_{1} \int_{\mathrm{E}_{\mathrm{th} \mathrm{h}_{1}}}^{\infty} \sigma_{\mathrm{a}_{1}}(\mathrm{E}) \phi_{\mathrm{f}}(\mathrm{E}) \mathrm{dE} \quad \text { (fission neutron only) }
$$


and

$R_{a_{2}}=N_{2} \int_{E_{t_{h_{2}}}}^{\infty} \sigma_{a_{2}}(E)\left[\phi_{f}(E)+\phi_{\alpha, n}(E)\right] d E \quad$ (fission and $(\alpha, n)$ neutrons),

where $E_{t h}$ and $E_{t h_{2}}$ are the energy thresholds of the two reactions $\sigma_{a_{1}}$ and $\sigma_{\mathrm{a}_{2}}$, respectively.

The ratio of the two absorption rates is given by

$$
R=\frac{R_{a_{2}}}{R_{a_{1}}}=C+\frac{N_{2} \int_{E_{t h_{2}}}^{E(\alpha, n) \max } \sigma_{a_{2}}(E) \phi_{\alpha, n}(E) d E}{N_{1} \int_{E_{t_{1}}}^{\infty} \sigma_{a_{1}}(E) \phi_{f}(E) d E} .
$$

As the neutron multiplication of the system increases, the activation ratio $R$ must decrease toward the limiting value $C$. Thus, a measurement of the ratio of the saturated activities of two suitably chosen detectors, one sensitive to fission neutrons only and the other sensitive to both $(\alpha, n)$ and fission neutrons, gives a measure of the effective multiplication constant, $\mathrm{k}_{\mathrm{eff}}$, of the system. Table A.2 lists some possibilities for such activation detectors.

TABLE A.2. Activation Threshold Detectors

\begin{tabular}{|c|c|c|c|c|}
\hline & Reaction & $\begin{array}{c}\text { Threshold } \\
\text { Energy, } \\
\text { MeV }\end{array}$ & Half-life & $\begin{array}{c}\text { Natural } \\
\text { Abundance, } \\
\%\end{array}$ \\
\hline 1. & ${ }^{24} \mathrm{Mg}(\mathrm{n}, \mathrm{p}){ }^{24} \mathrm{Na}$ & 5.0 & $15 \mathrm{~h}$ & 78.60 \\
\hline 2. & ${ }^{27} \mathrm{Al}(\mathrm{n}, \alpha){ }^{24} \mathrm{Na}$ & 5.0 & $15 \mathrm{~h}$ & 100.00 \\
\hline 3. & ${ }^{27} \mathrm{Al}(\mathrm{n}, \mathrm{p}){ }^{27} \mathrm{Mg}$ & 2.7 & $9.5 \mathrm{~m}$ & 100.00 \\
\hline 4. & ${ }^{28} \mathrm{Si}(\mathrm{n}, \mathrm{p}){ }^{28} \mathrm{Al}$ & 5.0 & $2.3 \mathrm{~m}$ & 92.18 \\
\hline 5. & ${ }^{31} \mathrm{P}(\mathrm{n}, \mathrm{p}){ }^{31} \mathrm{Si}$ & 1.8 & $2.6 \mathrm{~h}$ & 100.00 \\
\hline 6. & ${ }^{32} \mathrm{~S}(\mathrm{n}, \mathrm{p}){ }^{32} \mathrm{P}$ & 1.8 & $14.3 \mathrm{~d}$ & 95.0 \\
\hline 7. & ${ }^{56} \mathrm{Fe}(\mathrm{n}, \mathrm{p}){ }^{56} \mathrm{Mn}$ & 4.0 & $2.6 \mathrm{~h}$ & 91.68 \\
\hline 8. & ${ }^{115} \operatorname{In}\left(n, n^{\prime}\right)^{115 m} \operatorname{In}$ & 0.3 & $4.5 \mathrm{~h}$ & 95.0 \\
\hline 9. & ${ }^{232} \mathrm{Th}(\mathrm{n}, \mathrm{f}) \mathrm{FP}$ & 1.1 & - & 100.00 \\
\hline 10 & ${ }^{238} \mathrm{U}(\mathrm{n}, \mathrm{f}) \mathrm{FP}$ & 0.6 & - & 99.28 \\
\hline
\end{tabular}


Figures A.1-A.10 show the detailed cross sections for these ten reactions. From considerations such as cross section, half-life, and overall sensitivity, the most favorable reactions for $R_{a_{1}}$ appear to be ${ }^{28} \mathrm{Si}(\mathrm{n}, \mathrm{p})^{28} \mathrm{Al}$ or ${ }^{56} \mathrm{Fe}(\mathrm{n}, \mathrm{p}){ }^{56} \mathrm{Mn}$. For $\mathrm{R}_{\mathrm{a}_{2}}$, the reactions ${ }^{31} \mathrm{P}(\mathrm{n}, \mathrm{p}){ }^{31} \mathrm{Si}$, ${ }^{115} \mathrm{In}\left(\mathrm{n}, \mathrm{n}^{\prime}\right)^{115 \mathrm{~m}} \mathrm{In}$, or the ${ }^{232} \mathrm{Th}(\mathrm{n}, \mathrm{f}) \mathrm{FP}$ seem most applicable. Each of these reaction products, except possibly for ${ }^{232} \mathrm{Th}(\mathrm{n}, \mathrm{f}) \mathrm{FP}$, can easily be counted by beta and/or gamma counting. The ${ }^{232} \mathrm{Th}(\mathrm{n}, \mathrm{f})$ reaction could be monitored with fissiontrack recorders. ${ }^{167}$

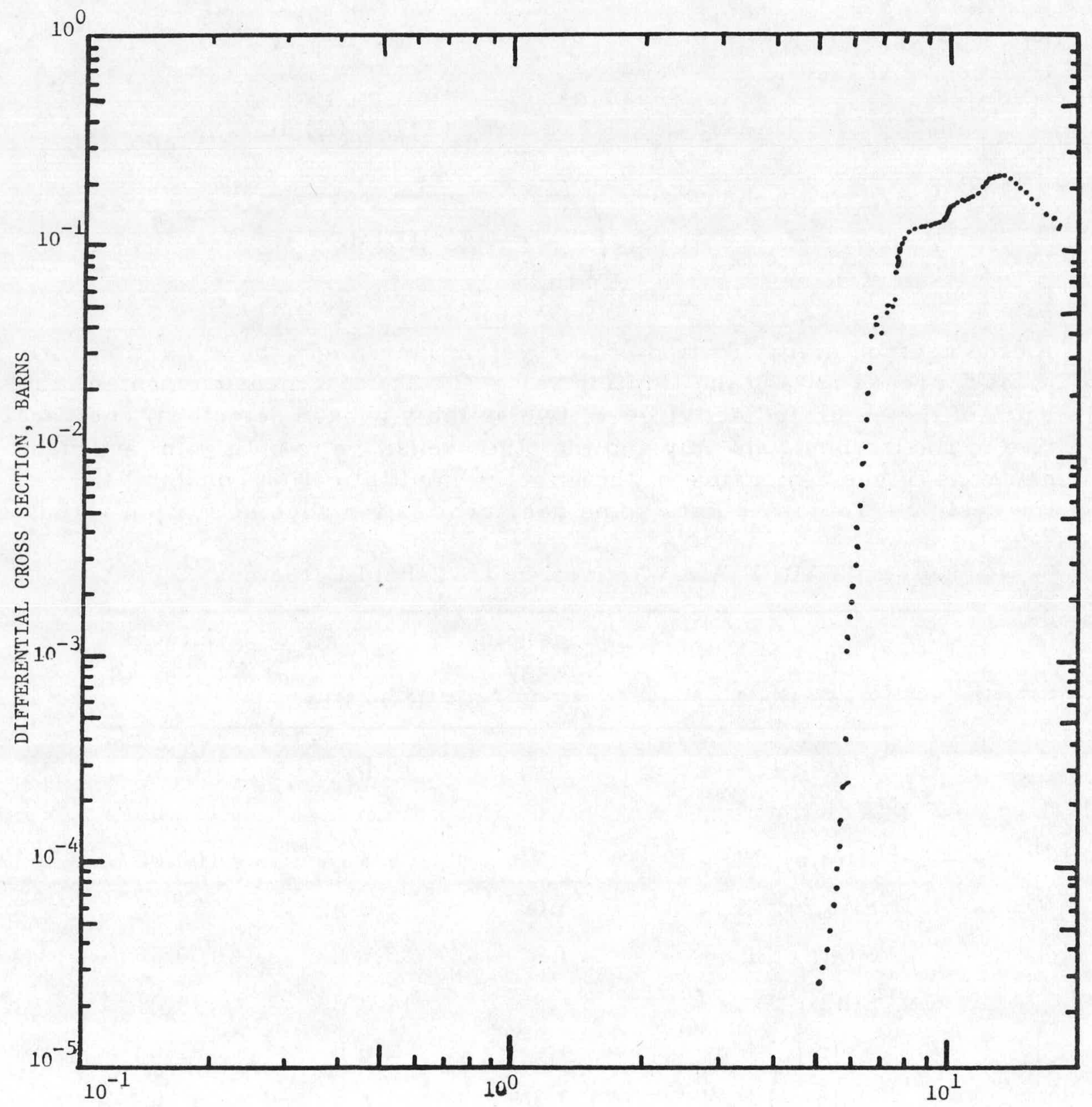

NEUTRON ENERGY, MeV

Fig. A.1. Differential Cross Section for ${ }^{24} \mathrm{Mg}(\mathrm{n}, \mathrm{p}){ }^{24} \mathrm{Na}$ Reaction 


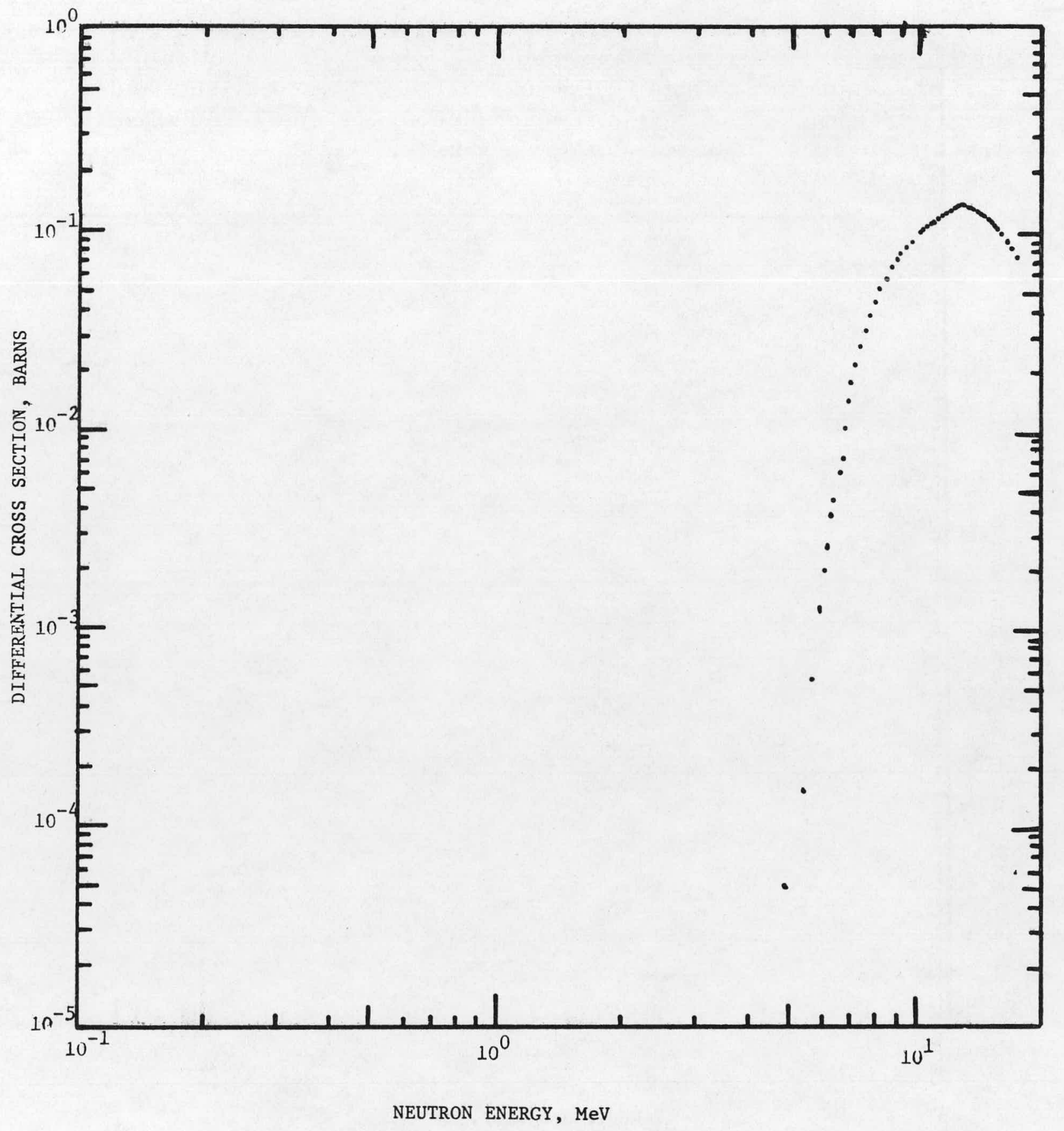

Fig. A.2. Differential Cross Section for ${ }^{27} \mathrm{Al}(\mathrm{n}, \alpha)^{24} \mathrm{Na}$ Reaction 


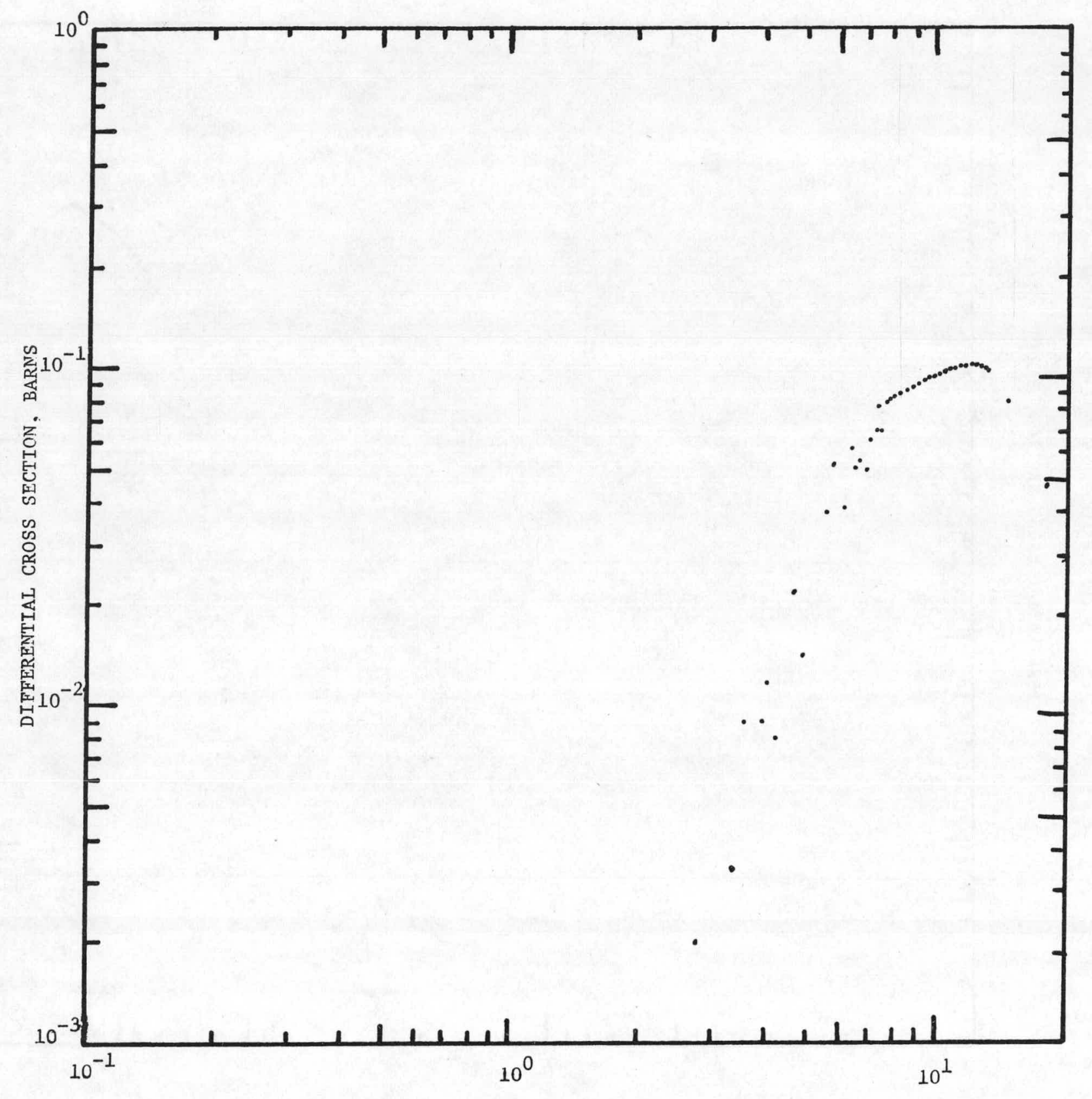

NEUTRON ENERGY, MeV

Fig. A.3. Differential Cross Section for ${ }^{27} \mathrm{Al}(\mathrm{n}, \mathrm{p})^{27} \mathrm{Mg}$ Reaction 


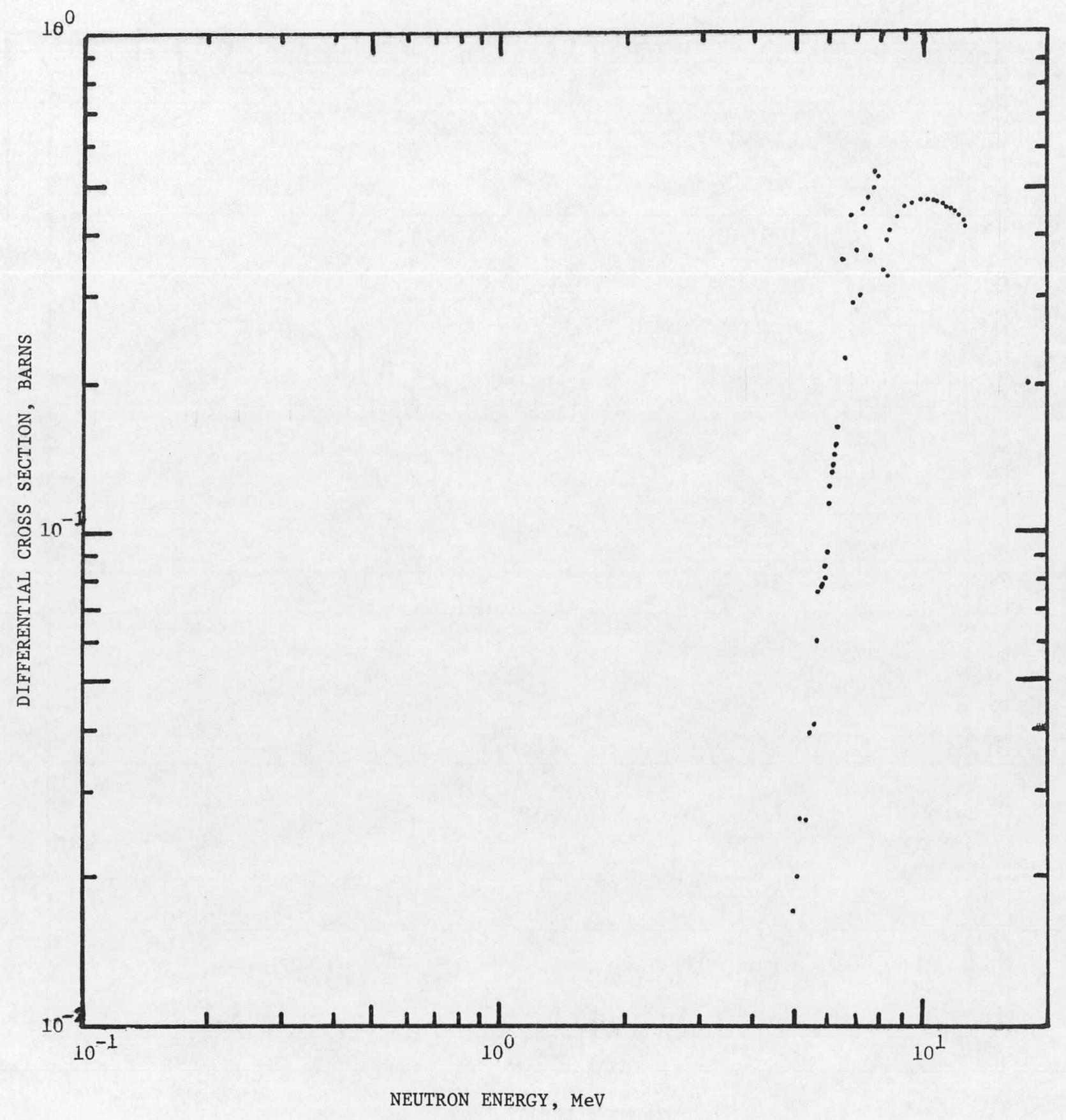

Fig. A.4. Differential Cross Section for ${ }^{28} \mathrm{Si}(\mathrm{n}, \mathrm{p})^{28} \mathrm{Al}$ Reaction 


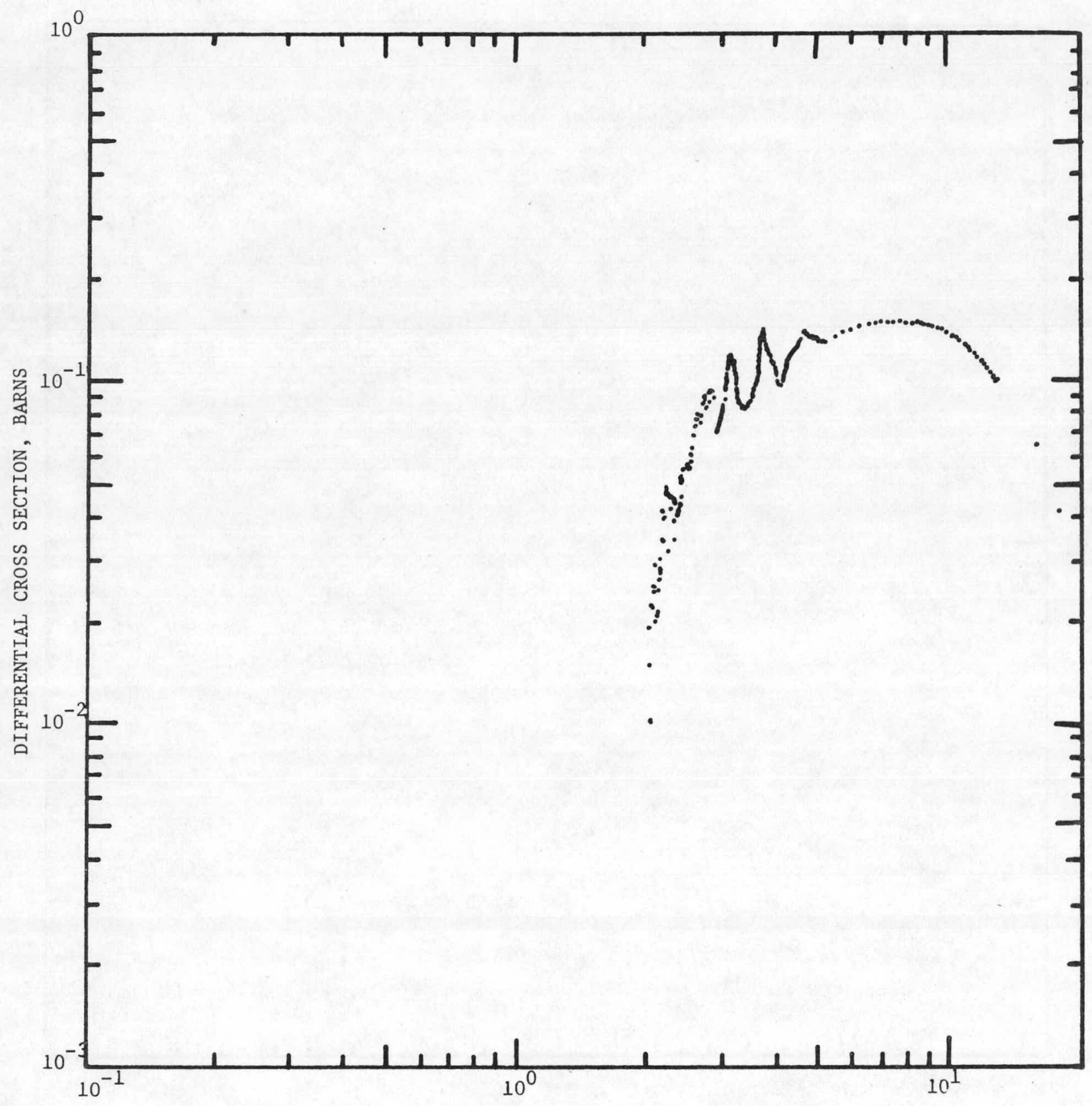

NEUTRON ENERGY, MeV

Fig. A.5. Differential Cross Section for ${ }^{31} \mathrm{P}(\mathrm{n}, \mathrm{p})^{31}$ Si Reaction 


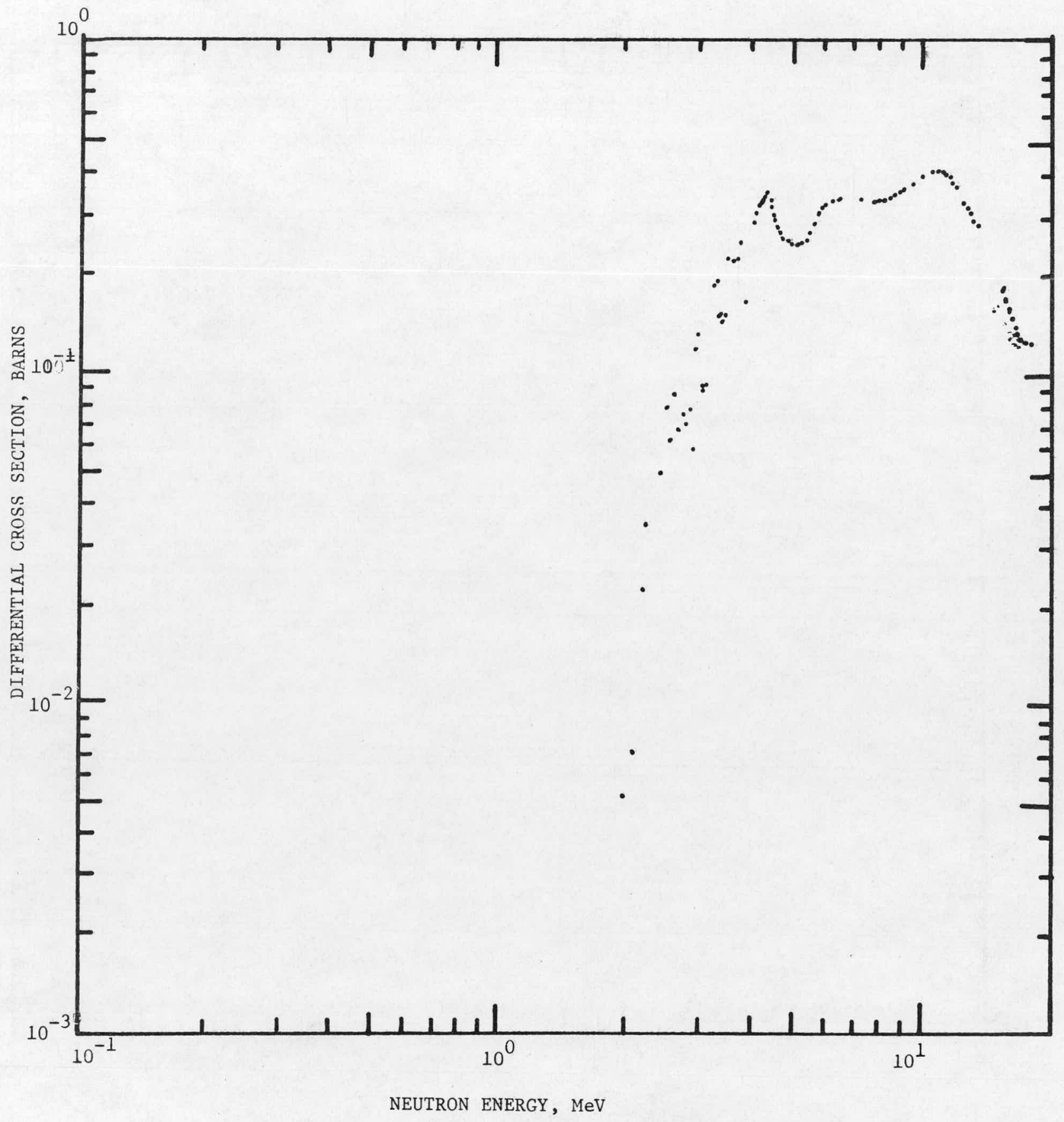

Fig. A.6. Differential Cross Section for ${ }^{32} S(n, p)^{32} p$ Reaction 


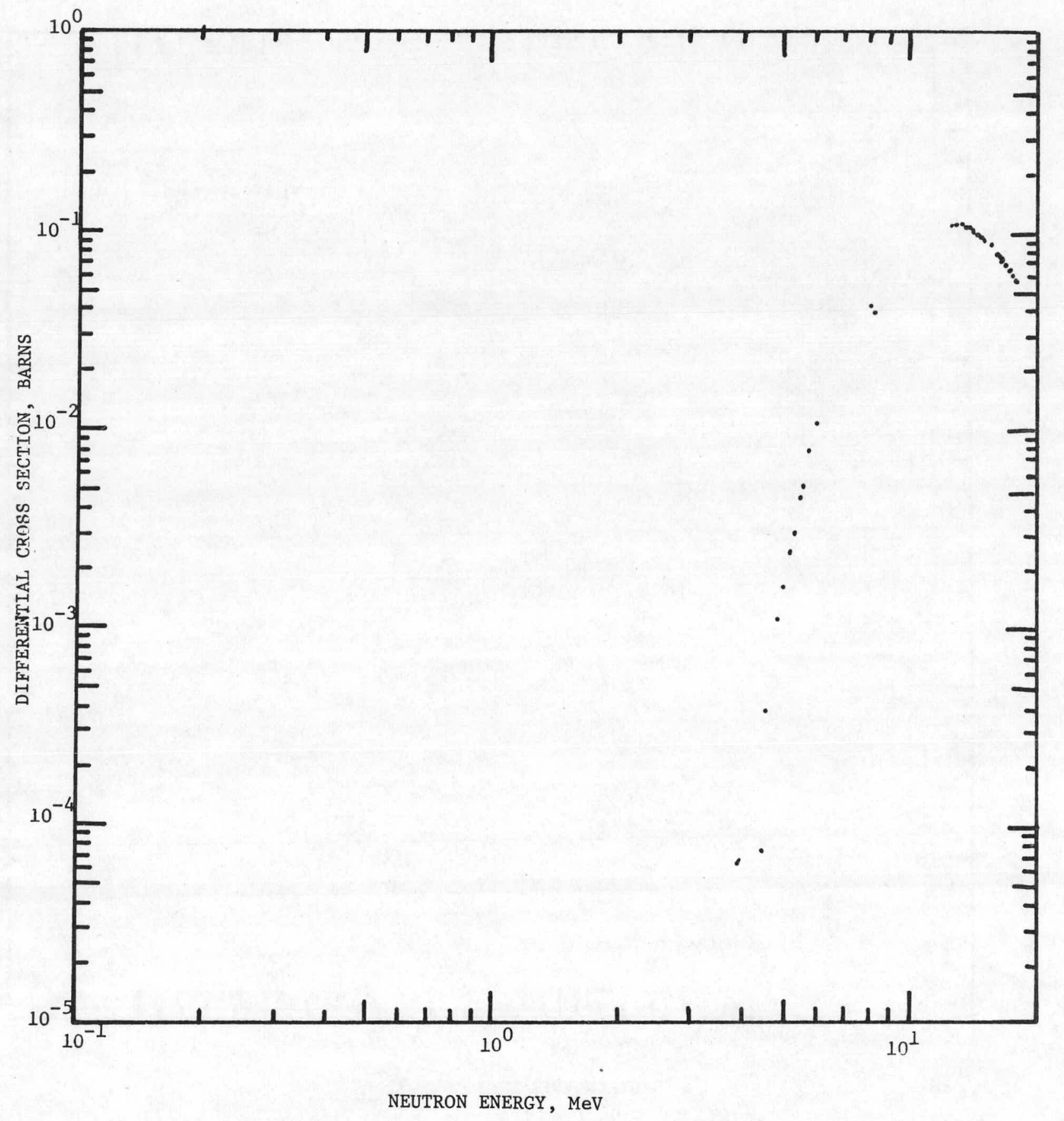

Fig. A.7. Differential Cross Section for ${ }^{56} \mathrm{Fe}(\mathrm{n}, \mathrm{p})^{56} \mathrm{Mn}$ Reaction 


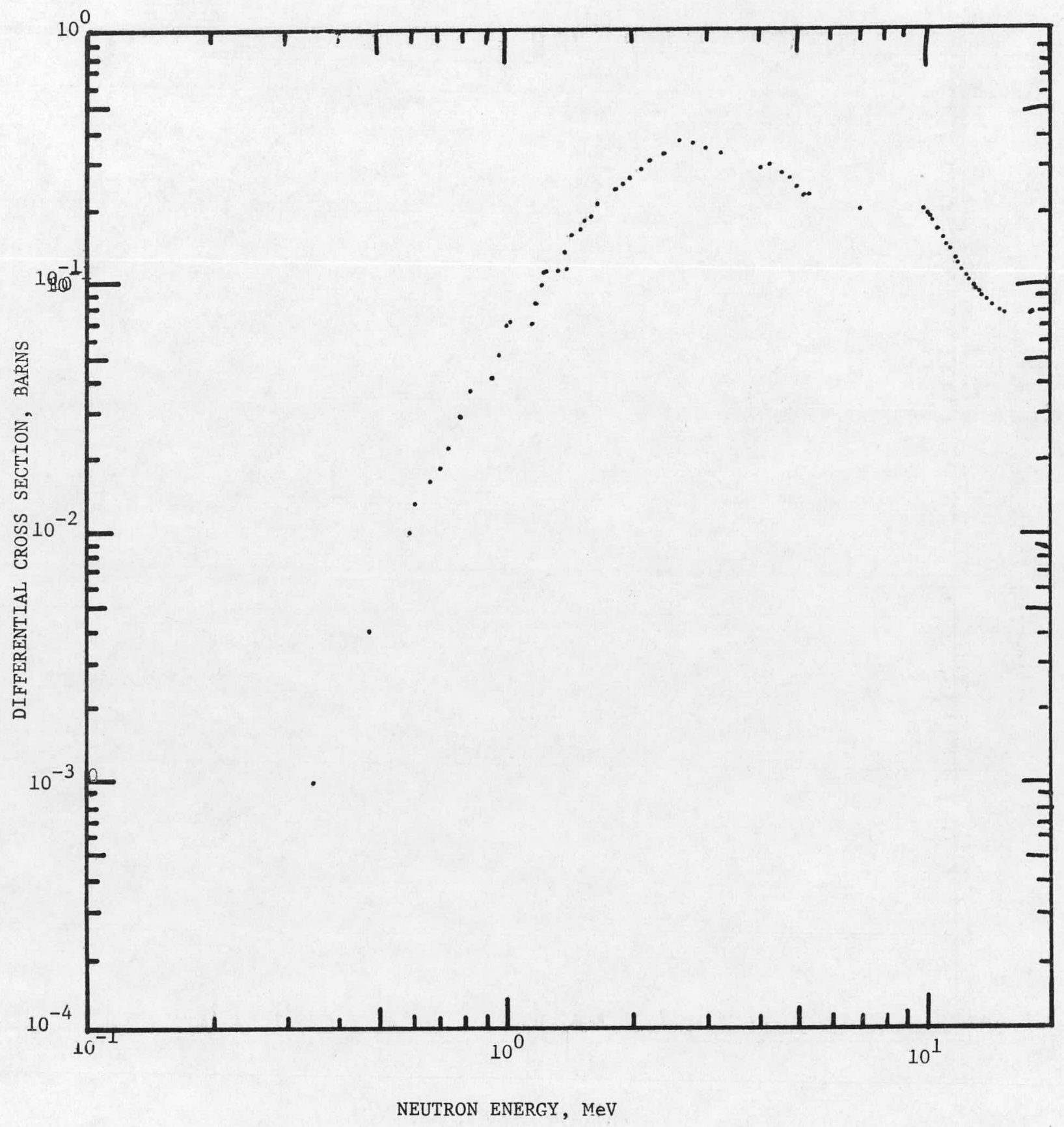

Fig. A.8. Differential Cross Section for ${ }^{115} \operatorname{In}\left(n, n^{n}\right)^{115} m_{\text {In Reaction }}$ 


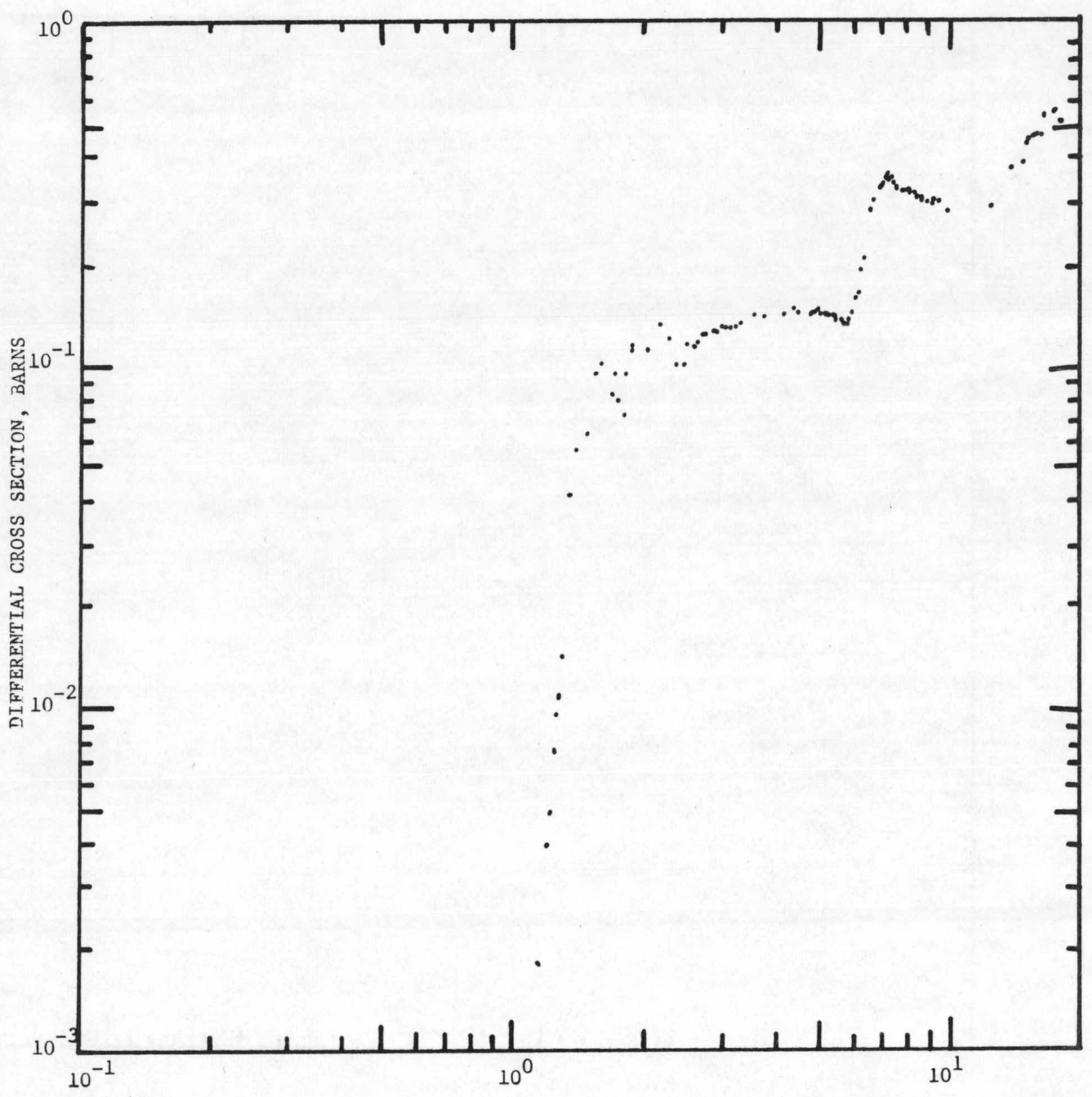

NEUTRON ENERGY, MeV

Fig. A.9. Differential Cross Section for ${ }^{232} \mathrm{Th}(\mathrm{n}, \mathrm{f}) \mathrm{FP}$ Reaction 


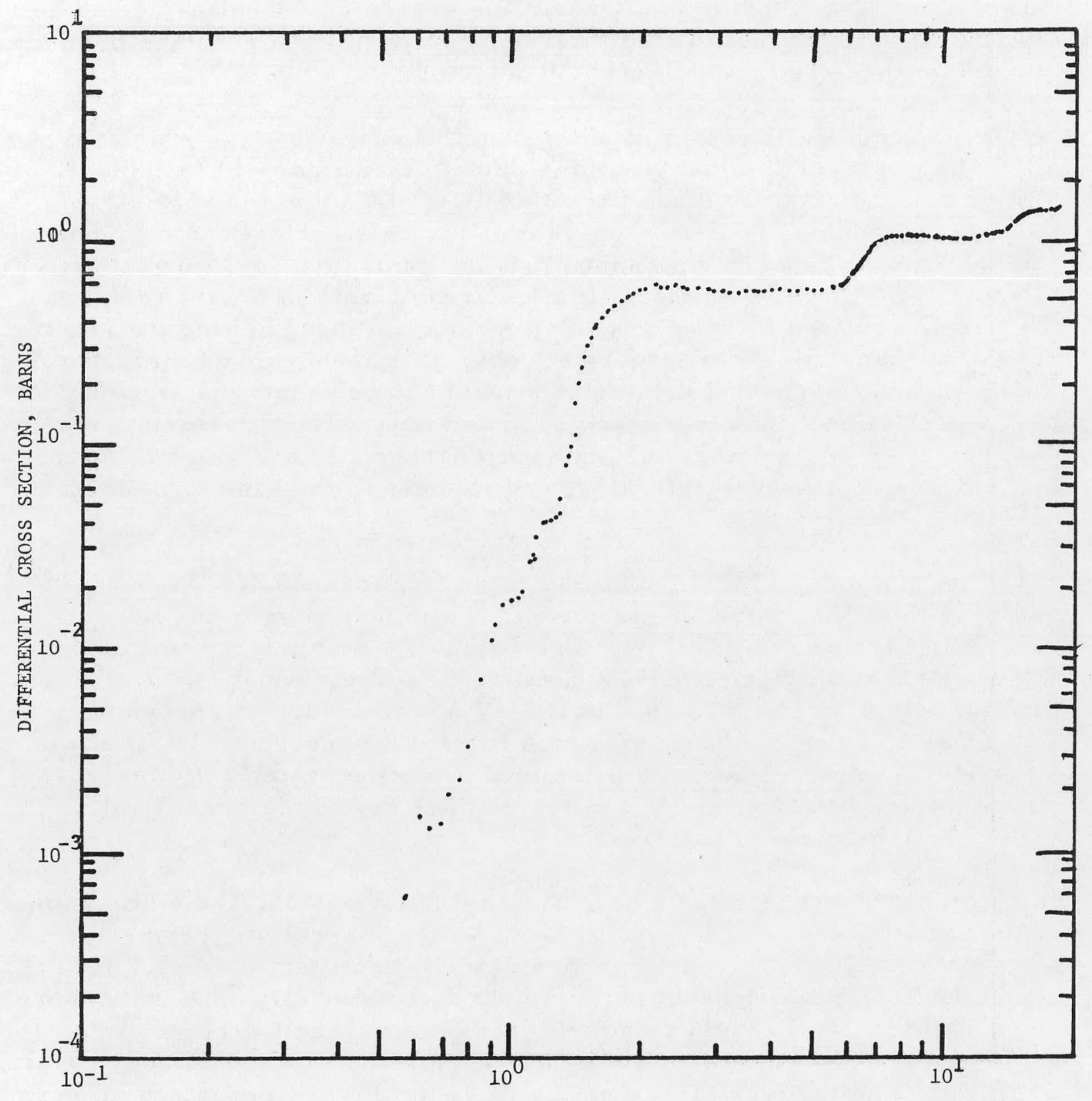

NEUTRON ENERGY, MEV

Fig. A.10. Differential Cross Section for $238 \mathrm{U}(\mathrm{n} ; \mathrm{f}) \mathrm{FP}$ Reaction 
To apply this technique, an experimental calibration procedure would have to be developed for determining the ratio $R=R_{a_{2}} / R_{a_{1}}$ as a function of keff. Moreover, a highly desirable degree of redundancy could be attained by carrying out this calibration procedure for a sufficient number of pairs of these activation threshold detectors.

In general, detectors of other than the activation type which will allow the practical application of this principle are not easy to achieve, since all such detectors must discriminate also against the very strong local gamma flux and possibly operate in adverse thermal environments. For that reason, a two-step method may be applicable, involving an activity of short half-life and low cost. If this activity exists in the form of a gas, it can be circulated through coils or a mantle arranged around the reactor vessel, perhaps in several separate loops. It is then pumped through a detector station (or several detector stations) and released to a large holdup tank, which allows complete decay of the activity. The detector station can thus be set up in a shielded low-radiation background and a favorable thermal environment as well, allowing ready access to the equipment at all times.

A suitable activity that meets these requirements is ${ }^{16} \mathrm{~N}$, since it can be obtained from fast-neutron reactions in both oxygen and fluorine, i.e., ${ }^{16} \mathrm{O}(\mathrm{n}, \mathrm{p})^{16} \mathrm{~N}$ and ${ }^{19} \mathrm{~F}(\mathrm{n}, \alpha)^{16} \mathrm{~N}$. The ${ }^{16} \mathrm{O}(\mathrm{n}, \mathrm{p})^{16} \mathrm{~N}$ reaction can furnish the $\mathrm{R}_{\mathrm{a}_{1}}$ reaction rate, since it possesses a $10.4-\mathrm{MeV}$ threshold. Fluorine, on the other hand, reacts at as low as $3 \mathrm{MeV}$ and therefore can provide $\mathrm{R}_{\mathrm{a}_{2}}$. Since both of these reactions give rise to the same product, ${ }^{16} \mathrm{~N}$, they can be directly compared by using a common detection system. However, this advantage can be offset in certain applications due to the low activation cross sections of these two reactions.

The ${ }^{16} \mathrm{~N}$ activity has a half-life slightly over $7 \mathrm{sec}$ and emits some of the hardest beta rays known (10 MeV, $4 \mathrm{MeV}$ ) as well as three gammas near $6 \mathrm{MeV}$. All these radiations are readily identified, even in a background of other radiations, by pulse-height discrimination. The beta energy is so high that it will yield relatively large amounts of Cherenkov light, for example, in a gas Cherenkov radiator. This device has the unique property of allowing one to discriminate entirely against lower-energy radiation by gas pressure (through which the index of refraction, and hence the Cherenkov threshold, is determined). A Cherenkov gas detector can thus be directly immersed in a neutron flux if this should turn out to have some advantage. This two-gas method with remote detection can also be suitably carried out with scintillation crystals of 3 -in. size or larger. Which detection system can best accomplish the objective of determining unusual increases in the ${ }^{16} \mathrm{~N}$ activity from the oxygen reaction (due to the fission neutron population), in comparison with the ${ }^{16} \mathrm{~N}$ activity from the fluorine reaction (due to the $(\alpha, n)$ background neutron population), is a subject that requires extensive investigation. 


\section{APPENDIX B}

\section{Process-gas Circulation}

The fluorination process gas consists of fluorine and oxygen and presents the problem that no hydrocarbon or carbon lubricants or seals can be used in mechanical devices used for its circulation. Another difficulty is that the quantity of gas to be circulated is small, while the pressure required is relatively large (34 cfm and 10-20 psi differential pressure). This makes it difficult to use centrifugal turbo-compressors. Furthermore, the process gas must be absolutely confined, not only because of its reactive nature but also to control the traces of plutonium hexafluoride contained in the circulating gas. Devices that have possible application are discussed below. These include

1. Diaphragm compressor

2. Peripheral compressor

3. Piston compressor

4. Centrifugal compressor

5. Bellows compressor

6. Injection circulation

1. Diaphragm Compressor

The diaphragm gas compressor was selected for the referenceplant design because it is the only commercial machine that requires no gas purges. This is in support of the total containment concept suggested for the reference plant. The compressor consists of a motor driving a reciprocating piston, which is connected hydraulically to a diaphragm. This diaphragm is in turn connected hydraulically to a second diaphragm, which, when pulsed, moves the process gas. The liquid between the piston and first diaphragm is a hydrocarbon lubricant, and the liquid between the two diaphragms is a fluorocarbon resistant to fluorine. Each diaphragm (of stainless steel, nickel, or other metal) is bolted between two heads, each with a cavity shaped in such a manner that the diaphragm, in flexing back and forth, is bent smoothly without sudden kinks or bends. A diagonal cross section through the axis of the cavity reveals a configuration like that of a bow. The heads are rigid and are bolted together with very high torque (30003300 in. $-1 b$ for $3 / 4$-in. bolts).

This type of compressor is in many respects. ideal for circulating the subject process gas. It is gastight, has no pistons or piston rods to seal, and is available in nickel, Monel, or stainless steel. Drawbacks are its high weight (which makes it hard to handle) and the uncertain lifetime of the diaphragms. 
In the USA, the Lapp Process. Equipment. Division of Lapp Insulator Comp., Inc, built large diaphragm heads until recently. They have eliminated these large compressors from their production and concentrate now on smaller compressors. However, Pressure Products Industries, Inc., at Hatboro, Pa., makes diaphragm compressors large enough to handle our requirements. Their model No.5290, which has a.36-in.-diam head and a 29-in.diam cavity, should be capable of pumping. $34 \mathrm{cfm}$ at about 320 strokes per minute. The head is $7 \frac{1}{2}$ in. thick and weighs about $2000 \mathrm{lb}$. The cost. of a stainless steel machine will be roughly $\$ 12,000$. A $20-\mathrm{hp}$. motor will be required.

Societe H. Corblin, Paris, France, makes large-diaphragm compressors. ORGDP ${ }^{168}$ has tested one that has a 26-in。-diam diaphragm and has a capacity, at 200 strokes per minute, of 11 scfm at a suction pressure of 14.7. psia and a discharge pressure of 30 psia. It is driven by a 5-hp motor. This machine operated $1400 \mathrm{hr}$ without failure, $60 \%$ of the time, compressing fluorine. All parts in contact with the process gas were nickel.

A complete compressor installation.will conșist of a motor driving a.reciprocating piston and two diaphragm heads. Failure of a diaphragm can be detected and repaired before the fluorine does any damage. Double diaphragms can also be furnished.

\section{Peripheral Compressor}

The ORGDP K-25 plant is developing a machine ${ }^{169}$ that functions on the same principles as the turbine pump. It consists of a disk with short, radial vanes on the perimeter, running. in a housing that forms an annular chamber around the vanes. It can handle $60 \mathrm{cfm}$ at $11,000 \mathrm{rpm}$ with a compression ratio of 2 to 1 . On February 10, 1967, the prototype had operated more than. $2400 \mathrm{hr}$, including. $2016 \mathrm{hr}$ on.fluorine plus nitrogen. It depends. on close-clearance shaft seals and helium purging. for protection of the bearings. Inleakage to process gas has been as little as 0.1 scfm for a 2-psi pressure drop across the seal. This amount of inleakage may be acceptable to the reference process. A problem of reverse seal leakage exists when the compressor is stopped, but leakage can be prevented by using a pressurized secondary around the shaft. The present machine has a 10 -in. impeller diameter and provides two stages. Power requirement is about $6 \mathrm{~kW}$. Overall, the machine is compact. From the viewpoint of maintenance and repairs, this type of compressor looks acceptable:

\section{Piston Compressor}

In France, SRTI (Societe De Recherches Techniques. Et Industrielles) builds piston pumps. for the circulation of fluorine. They have two types, the dry and the gastight type. 
The first (type PM51) is a one-cylinder reciprocating machine. Its maximum capacity-is 1800 liters per hour. $(1 \mathrm{cfm})$, and its compression ratio is 2 to 1 or 3 to l. FAR* has obtained a capacity of 1200 liters per hour for a compression ratio of 1.2 to $l$ and a capacity of 500 . liters per hour for a ratio of 2 to 1 . It is designed for pressures between 0.1 and $2 \mathrm{~kg} / \mathrm{cm}^{2}$.

This compressor has a complicated sealing system involving stainless steel bellows and a rubber membrane for sealing the cylinder from the mechanical driving parts. The piston is $80 \mathrm{~mm}$ in diameter and is sealed with glass or metal-reinforced $\mathrm{Kel} / \mathrm{F}$. The stroke is only 5 to $7 \mathrm{~mm}$, depending on the desired compression ratio. The speed is up to $1500 \mathrm{rpm}$. The valves are free disks, $35 \mathrm{~mm}$ in diameter and $0.2 \mathrm{~mm}$ thick, with a stroke of $0.6 \mathrm{~mm}$ for the inlet and $0.7 \mathrm{~mm}$ for the outlet. The dead space is $0.55 \mathrm{~mm}$. A $1.5-\mathrm{hp}$ motor is used.

This compressor has circulated $\mathrm{C} 1 \mathrm{~F}_{3}$ for $600 \mathrm{hr}$ without noticeable damage. During this time, the piston ring was replaced. The ring and the bellows are easily replaced.

This compressor is unusual in having a very short stroke relative to the piston diameter. This results. in a low piston speed, which probably is necessary to avoid burning up (or overheating) the Teflon piston ring. Of course, a low piston speed could also be obtained with a longer stroke and lower rpm. However, the stainless steel bellows and rubber membrane, which seal the cylinder from the mechanical driving parts and from the outside atmosphere, probably dictate this short stroke. The short stroke, in turn, necessitates the large-diameter piston and light valve disks.

The capacity, of this compressor is too small for the plant under study. Presumably, a larger compressor could be built using the same principles.

The other SRTI compressor (type PRB 12.65) has five stages. The first stage is a wobbling disk. One side of this disk pumps gas, and the other side drives five pistons in their individual cylinders. The capacity is $25 \mathrm{~m}^{3} / \mathrm{hr}(14.7 \mathrm{cfm})$ at suction conditions. The compression ratio is $10^{5}$ at zero output. Power requirement is $0.55 \mathrm{~kW}$ at $1500 . \mathrm{rpm}$. The wobbling disk has a $240-\mathrm{mm}$ diameter. The five cylinders have the following diameters:

Two low-pressure cylinders: $50 \mathrm{~mm}$ One medium-pressure cylinder: $50 \mathrm{~mm}$ One medium-pressure cylinder: $35 \mathrm{~mm}$ One high-pressure cylinder: $35 \mathrm{~mm}$

* French atomic energy installation at Fontenay-aux-Roses, France. 
The stroke is 19.6. $\mathrm{mm}$ for all the pistons.

The pistons are sealed by means of narrow clearances and labyrinth seals. No elastomers are used. The compressor is sealed helium-leaktight (with metallic bellows). The data given. indicate that this machine is for vacuum service, but it might be adapted to process-gas circulation service.

Standard, commercially available piston compressors cannot be used for this.service (fluorine plus oxygen) because the compressors.are not absolutely gastight and the oil used for lubrication of the piston and piston rings would react with the process gas. Dry piston compressors using graphite piston rings. cannot be used because the graphite would react with the gas.

\section{Centrifugal Compressor}

Recently, the Sundstrand-Denver Division of the Sundstrand Corporation developed a high-speed centrifugal compressor having a range of 10 $2000 \mathrm{cfm}$ and a compression ratio of 2.2 for air and 3.4 for propane. The speed range is 3600 to $33,900 \mathrm{rpm}$. For small capacities, the compressor consists of an impeller having eight radial vanes running. in a housing with a narrow slit outlet perpendicular to the axis of the impeller. This slit outlet is formed.like an expansion nozzle so that high-speed gas entering the slit slows down and builds up.pressure as the velocity head is changed to a pressure head. The design is referred to as "single-point emission:"

This type of compressor appears to differ from the above-described peripheral compressor in that close clearances are not required except at the shaft seals. The problem of shaft sealing is identical for the two types. The centrifugal type is probably superior. if higher compression is required. Efficiency and performance curves might differ, but these are not so important for the subject service. Since sealing of the shaft is the major problem, the type of machine with the lowest speed for the required performance should be preferred. This might well be the peripheral compressor.

\section{Bellows Compressor}

The above-mentioned compressors have all been built and operated in various services. The bellows compressor is a speculative type related to the diaphragm compressor but without the diaphragm compressor's demand for high accuracy in machining, high speed, and high weight.

Probably, metallic bellows of stainless steel, Monel, or nickel can be built with enough travel to handle the relatively. low volume and pressure required. For example, bellows having a $15 \frac{1}{2}-$ in. OD, a $10 \frac{1}{2}-$ in. ID, and a 0.018 -in. wall thickness can be obtained commercially. The convolutions would be of the neșted design, welded together. Twenty-four such 
convolutions would have a total traverse (difference between collapsed length and fully expanded length) of, about 6 in. With a dummy piston to fill the dead space at the end of the compression stroke, such a cylinder could deliver $34 \mathrm{cfm}$ at 100 strokes per minute. However, because of the depth of the convolutions ( $2 \frac{1}{2}$ in.) and the thin wall ( 0.018 in.), the bellows can only withstand a difference of about 3-psi pressure between the inside and outside of the bellows. To get around this problem, the bellows could be operated by a liquid or gas on the outside so that the pressure differential would become negligible. One could, for example, have a conventional reciprocating piston move a fluid in and out of an enclosure in which the bellows is located. The travel could be automatically controlled.

6. Injection Circulation

Fluorine gas could be circulated, using a liquid or gas as propellant in the air injector, in the same manner that steam is used to pump out condensers in a steam power plant. At Fontenay-aux-Roses, for example, $\mathrm{Kel}-\mathrm{F}$ oil was.used to circulate the fluorine in this manner. However, although the oil was cooled, the vapor pressure of the oil was excessive, oil was entrained with the fluorine, and the method was abandoned.

The injector principle could probably be used with a condensible fluid, because then the driving circuit would consist of a small pump pumping the condensed fluid into an evaporator, eliminating a compressor altogether. The amount of fluorine circulated would probably equal the amount of driving gas. The major part of the energy required for circulation is provided by adding heat at the evaporator. Figure B.l is a flow diagram of such a concept.

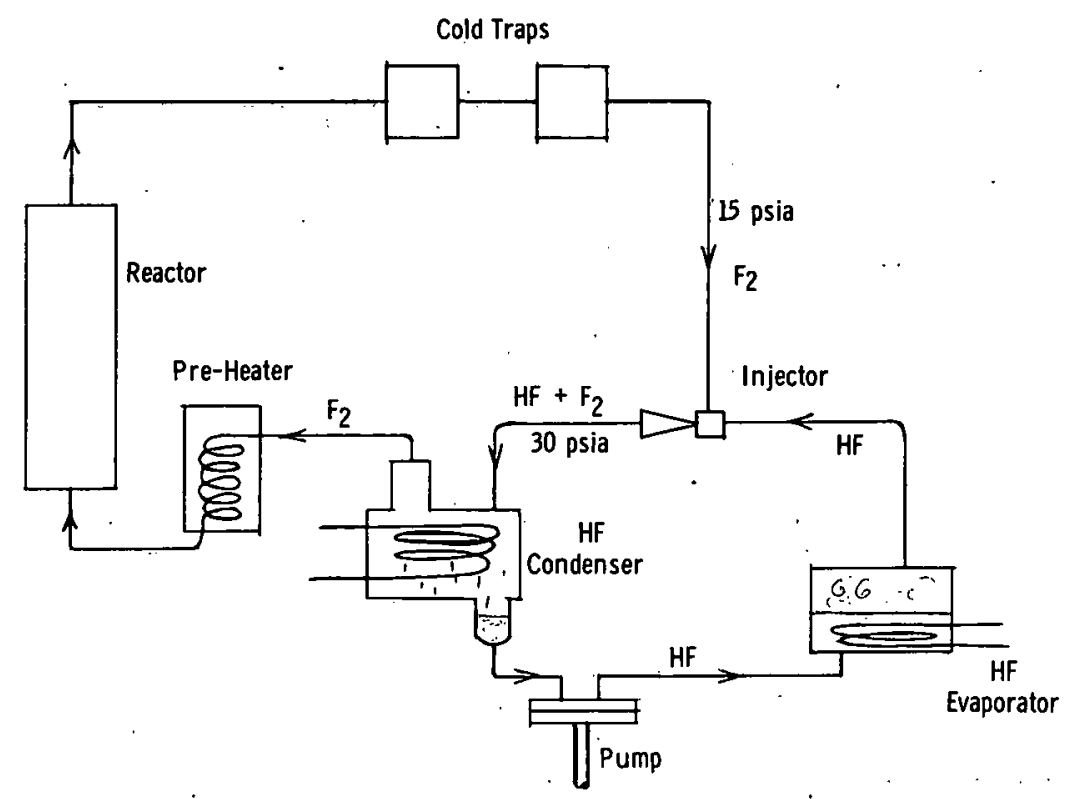

Fig. B.1. Fluorine Circulation by Injection 


\section{APPENDIX C} $\frac{\text { Properties of Oxides and Fluorides }}{\text { of Actinide Elements }}$

1. Uranium
a. $\underline{\mathrm{UO}_{2}}$ M.p.: $2800^{\circ} \mathrm{C}$
B.p.: N.A.*
Vapor
pressure: $\quad\left(1600-2800^{\circ} \mathrm{K}\right) \log \mathrm{P}_{\mathrm{mm}}=-33115 / \mathrm{T}-$
$4.026 \log \mathrm{T}+25.686$
Structure: fcc, $a_{0}=5.468 \AA, \rho_{\text {calc }}=10.97 \mathrm{~g} / \mathrm{cm}^{3}$
$\therefore \mathrm{G}_{\mathrm{f}}^{\circ}$
$\mathrm{kcal} / \mathrm{mole}^{170}$
$-\Delta \mathrm{H}_{\mathrm{f}, 298}^{\circ}=259 \mathrm{kcal} / \mathrm{mole}$

$\begin{array}{ll}246.08 & 298^{\circ} \mathrm{K} \\ 234.0 & 600^{\circ} \mathrm{K} \\ 222.0 & 900^{\circ} \mathrm{K}\end{array}$
b. $\mathrm{UF}_{4} \quad$ M.p.: $1036^{\circ} \mathrm{C}$.
B.p.: $1456^{\circ} \mathrm{C}$
Vapor
pressure: ${ }^{171}$ liquid $\left(1018-1302^{\circ} \mathrm{C}\right) \log \mathrm{P}_{\mathrm{mm}}=-16840 / \mathrm{T}-$
.7.549 $\log \mathrm{T}+37.086$;
solid $\left(740-860^{\circ} \mathrm{C}\right) \log P_{m m}=-20058 / T-$
$7.05 \log \mathrm{T}+38.011$
Structure: monoclinic, $a_{0}=12.79 \AA, b_{0}=10.72 \AA$,
$\mathrm{c}_{0}=8.39 \AA, \alpha=126^{\circ} 10 ! ; \rho_{\text {calc }}=6.70 \mathrm{~g} / \mathrm{cm}^{3}$

$\begin{array}{cc}\begin{array}{c}-\Delta \mathrm{G}_{\mathrm{f}}^{\circ}, \\ \mathrm{kcal} / \mathrm{mole}^{170}\end{array} & \\ 428.4 & 298^{\circ} \mathrm{K} \\ 408.1 & 600^{\circ} \mathrm{K} \\ 387.8 & 900^{\circ} \mathrm{K}\end{array}$
c. $\mathrm{UF}_{6} \quad$ M.p.: $64.05^{\circ} \mathrm{C}$
B.p.: $\quad 56.54^{\circ} \mathrm{C}$

* Not available. 
Vapor

pressure: $\quad$ solid $\left(0-64^{\circ} \mathrm{C}\right) \log \mathrm{P}_{\mathrm{mm}}=6.38363+$

$0.0075377 \mathrm{t}-942.76(\mathrm{t}+183.416)$;

liquid $\left(64-116^{\circ} \mathrm{C}\right) \log \mathrm{P}_{\mathrm{mm}}=6.99464-$

$1126.288 /(t+221.963)$

Structure: ${ }^{172}$ orthorhombic, $a_{0}=9.916 \AA, b_{0}=8.960 \AA$, $\mathrm{c}_{0}=5.245 \AA, \rho_{\text {calc }}=5.02 \mathrm{~g} / \mathrm{cm}^{3}$

$-\Delta \mathrm{G}_{f}^{\circ}$

$\mathrm{kcal} / \mathrm{mole}$ $-\Delta \mathrm{H}_{\mathrm{f}, 298}^{\mathrm{o}}=510.77 \mathrm{kcal} / \mathrm{mole} \mathrm{e}^{173}$

$490.79^{173} \quad 298^{\circ} \mathrm{K}$

$477.8 \quad 600^{\circ} \mathrm{K}$

$448.7 \quad 900^{\circ} \mathrm{K}$.

d. $\underline{\mathrm{UF}_{5}} \quad$ M.p.: $348^{\circ} \mathrm{C}$

B.p.: N.A.

Vapor

pressure: ${ }^{174}$ solid, $\log \mathrm{P}_{\mathrm{mm}}=-800 \mathrm{l} / \mathrm{T}+13.994$

liquid, $\log \mathrm{P}_{\mathrm{mm}}=-5388 / \mathrm{T}+9.819$

Structure: $(\alpha)$ tetragonal, $a_{0}=6.525 \AA, c_{0}=4.472 \AA$, $\rho_{\text {calc }}=5.8 \mathrm{I} \mathrm{g} / \mathrm{cm}^{3}$

( $\beta$ ) tetragonal, $\mathrm{a}_{0}=11.473 \AA, \mathrm{c}_{0}=5.209 \AA$, $\rho_{\text {calc }}=6.45 \mathrm{~g} / \mathrm{cm}^{3}$

$$
-\Delta \mathrm{G}_{\mathrm{f}}^{\circ}, \quad-\Delta \mathrm{H}_{\mathrm{f}, 298, \alpha}^{\circ}=483.7 \mathrm{kcal} / \mathrm{mole}
$$

$\mathrm{kcal} / \mathrm{mole}$

(a) $458.2 \quad 298^{\circ} \mathrm{K}$

N.A. $\quad 600^{\circ} \mathrm{K}$

N.A. $\quad 900^{\circ} \mathrm{K}$

$\beta-\alpha$ transition $125^{\circ} \mathrm{C}$

Disproportionation: $\quad 3 \alpha \mathrm{UF}_{5} \rightleftharpoons \mathrm{U}_{2} \mathrm{~F}_{9}+\mathrm{UF}_{6}(\mathrm{~g})\left(100-200^{\circ} \mathrm{C}\right) \log \mathrm{P}_{\mathrm{mm}}=$ $-2942 / T+7.634$

e. $\underline{\mathrm{UO}_{2} \mathrm{~F}_{2}}$ M.p.: (decomposes)'

B.p.: N.A.

Vapor

pressure: N.A.

Structure: rhombohedral, $\mathrm{a}_{0}=5.755 \AA, \alpha=42^{\circ} 47$ !,

$$
\rho_{\text {calc }}=6.37 \mathrm{~g} / \mathrm{cm}^{3}
$$




$$
\begin{aligned}
& -\Delta G_{f}^{0} \\
& \mathrm{kcal} / \mathrm{mole} \\
& 371 \quad 298^{\circ} \mathrm{K} \\
& 359 \cdot 600^{\circ} \mathrm{K} \\
& 331 \quad 900^{\circ} \mathrm{K} \\
& -\Delta \mathrm{H}_{\mathrm{f}, 305}^{\mathrm{o}}=391.4 \mathrm{kcal} / \mathrm{mole} \mathrm{e}^{175}
\end{aligned}
$$

2. Neptunium
a. $\mathrm{NpO}_{2} \quad$ M.p.: N.A.
B.p.: N.A.
Vapor
pressure: N.A.
Structure: cubic, $a_{0}=5.45 \AA, \rho_{\text {calc }}=11.11 \mathrm{~g} / \mathrm{cm}^{3}$

b. $\mathrm{NpF}_{3} \quad$ M.p.: N.A.

B.p.: N.A.

Vapor pressure: N.A.

Structure: hexagonal, $a_{0}=4.108 \AA, c_{0}=7.273 \AA$, $\rho_{\text {calc }}=9.12 \mathrm{~g} / \mathrm{cm}^{3}$

$-\triangle G_{f}^{\circ}$

$\mathrm{kcal} / \mathrm{mole}$

$-\Delta \mathrm{H}_{\mathrm{f}, 298}^{\circ}=360 \mathrm{kcal} / \mathrm{mole}$

$\begin{array}{ll}342 & 298^{\circ} \mathrm{K} \\ \text { N.A. } & 600^{\circ} \mathrm{K} \\ \text { N.A. } & 900^{\circ} \mathrm{K}\end{array}$

C: $\mathrm{NpF}_{4} \quad$ M.p.: N.A.

B.p.: N.A.

Vapor

pressure: N.A.

Structure: monoclinic, $a_{0}=12.70 \AA, b_{0}=10.64 \AA$,

$$
c_{0}=8.41 \AA, \alpha=126^{\circ} 10^{\prime}, \rho_{\text {calc }}=6.8 \mathrm{~g} / \mathrm{cm}^{3}
$$




\begin{tabular}{|c|c|}
\hline $\begin{array}{c}-\Delta \mathrm{G}_{\mathrm{f}}^{\circ}, \\
\mathrm{kcal} / \mathrm{mole}\end{array}$ & \\
\hline 406 & $298^{\circ} \mathrm{K}$ \\
\hline N.A. & $600^{\circ} \mathrm{K}$ \\
\hline N.A. & $900^{\circ} \mathrm{K}$ \\
\hline
\end{tabular}

$$
-\Delta \mathrm{H}_{\mathrm{f}, 298}^{\circ}=428 \mathrm{kcal} / \mathrm{mole}
$$

d. $\mathrm{NpF}_{6} \quad$ M.p.: $54.4^{\circ} \mathrm{C}$

B.p.: $55.2^{\circ} \mathrm{C}$

Vapor

pressure: $\quad$ solid $\left(0-54.4^{\circ} \mathrm{C}\right) \log \mathrm{P}_{\mathrm{mm}}=-2982 / \mathrm{T}=$

$2.699 \log \mathrm{T}+18.4813$;

liquid $\left(54.4-77^{\circ} \mathrm{C}\right) \log \mathrm{P}_{\mathrm{mm}}=-1913 / \mathrm{T}$ -

$2.347 \log T+14.6125$

Structure: $:^{172}$ orthorhombic, $\mathrm{a}_{0}=9.909 \AA, \mathrm{b}_{0}=8.997 \AA$, $c_{0}=5.202 \AA, \rho_{\text {calc }}=5.03 \mathrm{~g} / \mathrm{cm}^{3}$

$-\Delta G_{f}^{\circ}$

$\mathrm{kcal} / \mathrm{mole}$ $-\Delta \mathrm{H}_{\mathrm{f}, 298}^{\circ}=463 \mathrm{kcal} / \mathrm{mole} \mathrm{e}^{178}$

$\begin{array}{ll}376 * & 298^{\circ} \mathrm{K} \\ \text { N.A. } & 600^{\circ} \mathrm{K} \\ \text { N.A. } & 900^{\circ} \mathrm{K}\end{array}$

e. $\mathrm{NpO}_{2} \mathrm{~F}_{2}$ M.p.: N.A.

B.p.: N.A.

Vapor

pressure: N.A.

Structure: rhombohedral, $a_{0}=5.795 \AA, \alpha=42^{\circ} 16^{\prime}$,

$$
\rho_{\text {calc }}=6.38 \mathrm{~g} / \mathrm{cm}^{3}
$$

$-\Delta \mathrm{G}_{\mathrm{f}}^{\circ}$

$\underline{\mathrm{kcal} / \mathrm{mole}}$

$$
-\triangle H_{f, 298^{-}}^{\circ} \text { N.A. }
$$

$\begin{array}{ll}\text { N.A. } & 298^{\circ} \mathrm{K} \\ \text { N.A. } & 600^{\circ} \mathrm{K} \\ \text { N.A. } & 900^{\circ} \mathrm{K}\end{array}$

3. Plutonium ${ }^{179}$

a. $\mathrm{PuO}_{2} \quad$ M.p.: $2280^{\circ} \mathrm{C}$ (decomposes)

B.p.: N.A.

Vapor

pressure: N.A.

*Estimated. 
Structure: $\quad$ fcc, $a_{0}=5.3960 \AA, \quad \rho_{\text {calc }}=11.46 \mathrm{~g} / \mathrm{cm}^{3}$ $-\Delta G_{f}^{\circ}$

$\mathrm{kcal} / \mathrm{mole}$ $-\Delta \mathrm{H}_{\mathrm{f}, 298}^{\circ}=252.9 \mathrm{kcal} / \mathrm{mole}$

$\begin{array}{lr}240.4 & 298^{\circ} \mathrm{K} \\ 227.7 & 600^{\circ} \mathrm{K} \\ 215.4 & 900^{\circ} \mathrm{K}\end{array}$

b. PuF $_{3}$ M.p.: $1425^{\circ} \mathrm{C}$

B.p.: $200^{\circ} \mathrm{C}^{180}$

Vapor pressure: $\quad\left(1200-1600^{\circ} \mathrm{K}\right) \log \mathrm{P}_{\mathrm{mm}}=-24917 / \mathrm{T}-$ $7.5513 \mathrm{~T}+38.920$

$\left(1243-1475^{\circ} \mathrm{K}\right)^{181} \log \mathrm{P}_{\mathrm{mm}}=-20734 / \mathrm{T}+9.288$

$\begin{array}{cc}\begin{array}{c}-\Delta \mathrm{G}_{\mathrm{f}}^{\circ}, \\ \mathrm{kcal} / \mathrm{mole}^{61}\end{array} & \\ 353.4 & 298^{\circ} \mathrm{K} \\ 335.7 & 600^{\circ} \mathrm{K} \\ 318.3 & 900^{\circ} \mathrm{K}\end{array}$

c. $\mathrm{PuF}_{4} \quad$ M.p.: $1037^{\circ} \mathrm{C}$

B.p.: N.A.

Vapor

pressure: $\quad\left(700-1200^{\circ} \mathrm{C}\right) \log \mathrm{P}_{\mathrm{mm}}=-10040 / \mathrm{T}+5.58$

Structure: monoclinic, $a_{0}=12.62 \AA, b_{0}=10.57 \AA$, $c_{0}=8.28 \AA, \beta=126^{\circ} 10^{\prime}, \rho_{\text {calc }}=7.0 \mathrm{~g} / \mathrm{cm}^{3}$

$-\Delta G_{f}^{\circ}$

$\mathrm{kcal} / \mathrm{mole}$

$-\Delta \mathrm{H}_{\mathrm{f}, 298}^{\circ}=4.4 \mathrm{kcal} / \mathrm{mole}^{61}$

$\begin{array}{ll}393.1 & 298^{\circ} \mathrm{K} \\ 371.8 & 600^{\circ} \mathrm{K} \\ 351.0 & 900^{\circ} \mathrm{K}\end{array}$

d. $\underline{\mathrm{PuF}_{6}} \quad$ M.p.: $51.59^{\circ} \mathrm{C}$

B.p.: $62.16^{\circ} \mathrm{C}$

Vapor

pressure: $\quad$ solid $\left(0-51.59^{\circ} \mathrm{C}\right) \log \mathrm{P}_{\mathrm{mm}}=-2095 / \mathrm{T}+$ $3.4990 \log \mathrm{T}+0.39024$;

liquid $\left(51.59-71.17^{\circ} \mathrm{C}\right) \log \mathrm{P}_{\mathrm{mm}}=-1807.5 / \mathrm{T}-$ $1.5340 \log . T+12.14545$ 


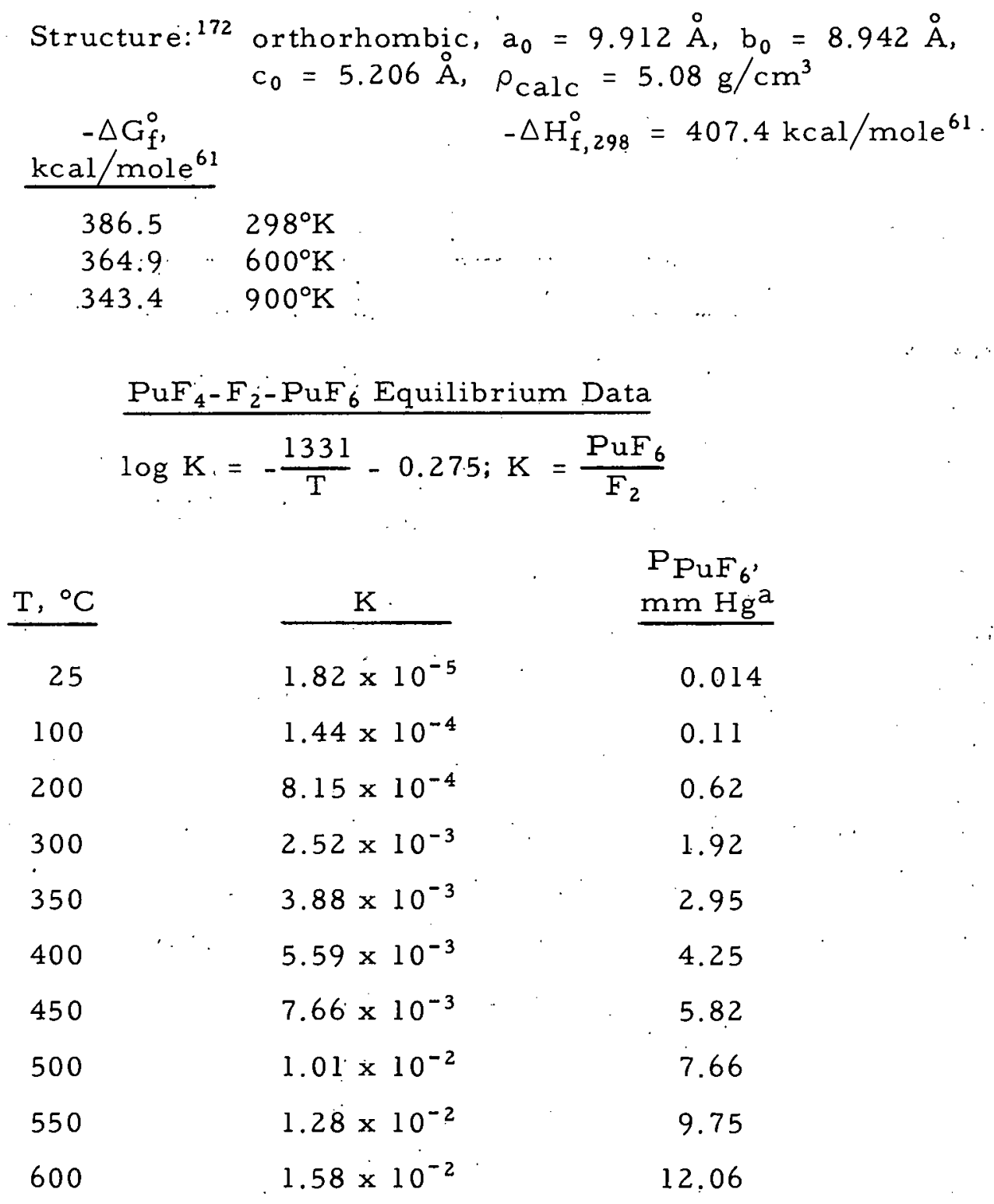

a Pressure of $\mathrm{PuF}_{6}$ in equilibrium with $\mathrm{l}$ atm fluorine and solid $\mathrm{PuF}_{4}$. 


\begin{tabular}{|c|c|c|c|c|c|c|}
\hline & ${ }^{236} \mathrm{Pu}$ & ${ }^{238} \mathrm{Pu}$ & ${ }^{239} \mathrm{Pu}$ & ${ }^{240} \mathrm{Pu}$ & ${ }^{241} \mathrm{Pu}$ & ${ }^{242} \mathrm{Pu}$ \\
\hline Half-life, yr & 2.85 & 86.4 & 24360 & 6580 & 13.2 & $3.79 \times 10^{5}$ \\
\hline Decay & $\alpha$ & $\alpha$ & $\alpha \therefore$ & $\dot{\alpha}$ & $\beta$ & $\alpha$ \\
\hline $\mathrm{E}, \mathrm{MeV}$ & $\begin{array}{l}5.763(69 \%) \\
5.716(31 \%)\end{array}$ & $\begin{array}{l}5.495(72 \%) \\
5.452(28 \%)\end{array}$ & $\begin{array}{l}5.147(72.5 \%) \\
5.134(16.8 \%)\end{array}$ & $\begin{array}{l}5.162(76 \%) \\
5.118(24 \%)\end{array}$ & 0.0208 & $\begin{array}{l}4.898(76 \%) \\
4.853(24 \%)\end{array}$ \\
\hline & - & - & $5.096(10.7 \%)$ & - & - & - \\
\hline $\mathrm{g} / \mathrm{Ci}$ & $1.87 \times 10^{-3}$ & $5.7 \times 10^{-2}$ & 0.162 & 4.39 & $8.8 \times 10^{-3}$ & 0.0255 \\
\hline Half-life, yr & - & - & - & - & $5.72 \times 10^{5}$ & - \\
\hline Decay & - & - & - & - & $\alpha$ & - \\
\hline $\mathrm{E}, \mathrm{MeV}$ & - & - & - & - & $\begin{array}{l}4.893(75 \%) \\
4.848(25 \%)\end{array}$ & - \\
\hline Daughter product & ${ }^{232} \mathrm{U}$ & ${ }^{234} \mathrm{U}$ & ${ }^{235} \mathrm{U}$ & ${ }^{236} \mathrm{U}$ & ${ }^{241} \mathrm{Am} /{ }^{237} \mathrm{U}$ & ${ }^{238} \mathrm{U}$ \\
\hline S.F. half-life, yr & $3.5 \times 10^{9}$ & $4.3 \times 10^{10}$ & $5.5 \times 10^{15}$ & $1.22 \times 10^{11}$ & - & $6.8 \times 10^{10}$ \\
\hline$n_{f} / \sec -g$ & $3.7 \times 10^{4}$ & $3.4 \times 10^{3}$ & 0.03 & $1.02 \times 10^{3}$ & - & $1.7 \times 10^{3}$ \\
\hline $\mathrm{E}_{\gamma}, \mathrm{MeV}$ & 0.047 & 0.0435 & 0.037 & 0.04528 & 0.145 & 0.045 \\
\hline & 0.110 & 0.0998 & 0.052 & - & - & - \\
\hline$\cdot$ & 0.165 & 0.1531 & 0.120 & - & - & - \\
\hline & - & 0.203 & 0.207 & - & - & - \\
\hline 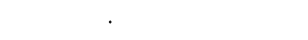 & - & 0.776 & 0.34 & - & - & - \\
\hline & - & $0: 810$ & 0.38 & - & - & - \\
\hline & - & 0.875 & 0.42 & - & - & - \\
\hline $\begin{array}{l}\sigma_{f},(2200 \mathrm{~m} / \mathrm{sec}) \\
\text { (barns) }\end{array}$ & - & 16.8 & . 754 & 0.03 & 1030 & $<0.2$ \\
\hline$\sigma_{f},(1 \mathrm{MeV})$ (barns) & - & - & 1.8 & 1.7 & 1.8 & 1.4 \\
\hline
\end{tabular}




\section{APPENDIX D}

Vapor Prëssures of Volatile Fluorides

(in $\mathrm{mm} \mathrm{Hg}$ )

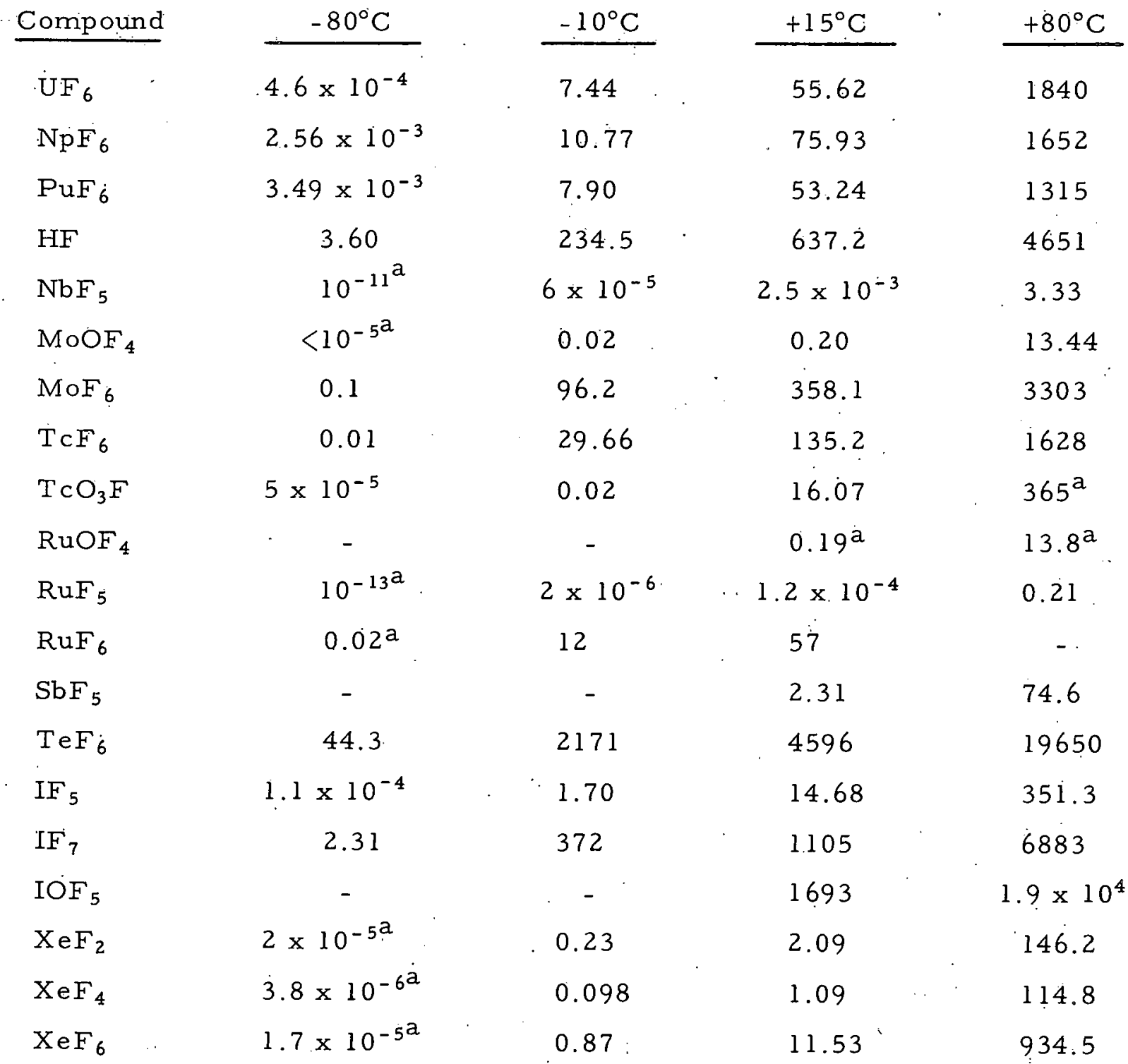

astimated values. 


\section{APPENDIX E}

\section{Calculation of Centerline Temperatures in Waste Pots}

The equation for calculating the centerline temperature of cylindrical waste storage pots is

$$
\int_{0}^{\mathrm{d} / 2} \frac{\mathrm{q} \pi \mathrm{x}^{2} \mathrm{dx}}{2 \pi \mathrm{x}}=-\int_{\mathrm{T}_{\mathrm{C}}}^{\mathrm{T}_{\mathrm{w}}} k \cdot \mathrm{dT}
$$

or

$$
\frac{\mathrm{qd}^{2}}{16}=k\left(\mathrm{~T}_{\mathrm{c}}-\mathrm{T}_{\mathrm{w}}\right)
$$

Rearranging to solve for $T_{C}$ produces

$$
T_{c}=\frac{q^{2}}{16 k}+T_{w}
$$

where

$$
\mathrm{q}=\text { heat dissipation rate, Btu } /(\mathrm{hr})\left(\mathrm{ft}^{3}\right) \text {, }
$$

$\mathrm{x}$ or $\mathrm{d}=$ cylinder diameter, $\mathrm{ft}$,

$$
\begin{aligned}
\mathrm{T} & =\text { temperature, }{ }^{\circ} \mathrm{F}, \\
\mathrm{k} & =\text { thermal conductivity, Btu } /(\mathrm{hr})(\mathrm{ft})\left({ }^{\circ} \mathrm{F}\right), \\
\mathrm{T}_{\mathrm{C}} & =\text { centerline temperature, }{ }^{\circ} \mathrm{F},
\end{aligned}
$$

and

$$
\mathrm{T}_{\mathrm{w}}=\text { cylinder wall temperature, }{ }^{\circ} \mathrm{F} \text {. }
$$

The following assumptions were used:

1. Heat transfer is by conduction to the surface of the container.

2. Heat transfer is in a radial direction only.

3. Heat transfer to water in the storage canal is by nucleate boiling with a negligible temperature drop at the surface of the container.

The centerline temperature for a slab can be calculated from

$$
T_{c}=\frac{q W^{2}}{8 k}+T_{w}
$$

where $W$ is the thickness of the slab. 
Centerline temperatures for cylinders and slabs have been calculated for values of the following parameters:

$$
\begin{aligned}
\mathrm{k}= & 0.25 \mathrm{Btu} /(\mathrm{hr})(\mathrm{ft})\left({ }^{\circ} \mathrm{F}\right) \text { (thermal conductivity ; of activated } \\
& \text { alumina) }
\end{aligned}
$$

and

$$
\begin{aligned}
\mathrm{k}= & 60 \mathrm{Btu} /(\mathrm{hr})(\mathrm{ft})\left({ }^{\circ} \mathrm{F}\right) \text { (thermal conductivity of activated } \\
& \text { alumina-aluminum mixture) } \\
\mathrm{q}= & 10,000 \text { to } 1,000,000 \mathrm{Btu} /(\mathrm{hr})\left(\mathrm{ft}^{3}\right)
\end{aligned}
$$

$\mathrm{d}$ or $\mathrm{W}=0.1$ to $10 \mathrm{ft}$,

$$
\mathrm{T}_{\mathrm{w}}=257^{\circ} \mathrm{F}\left(125^{\circ} \mathrm{C}\right) \text {. }
$$

The calculated data are plotted in Figs, E.1-E.4. 


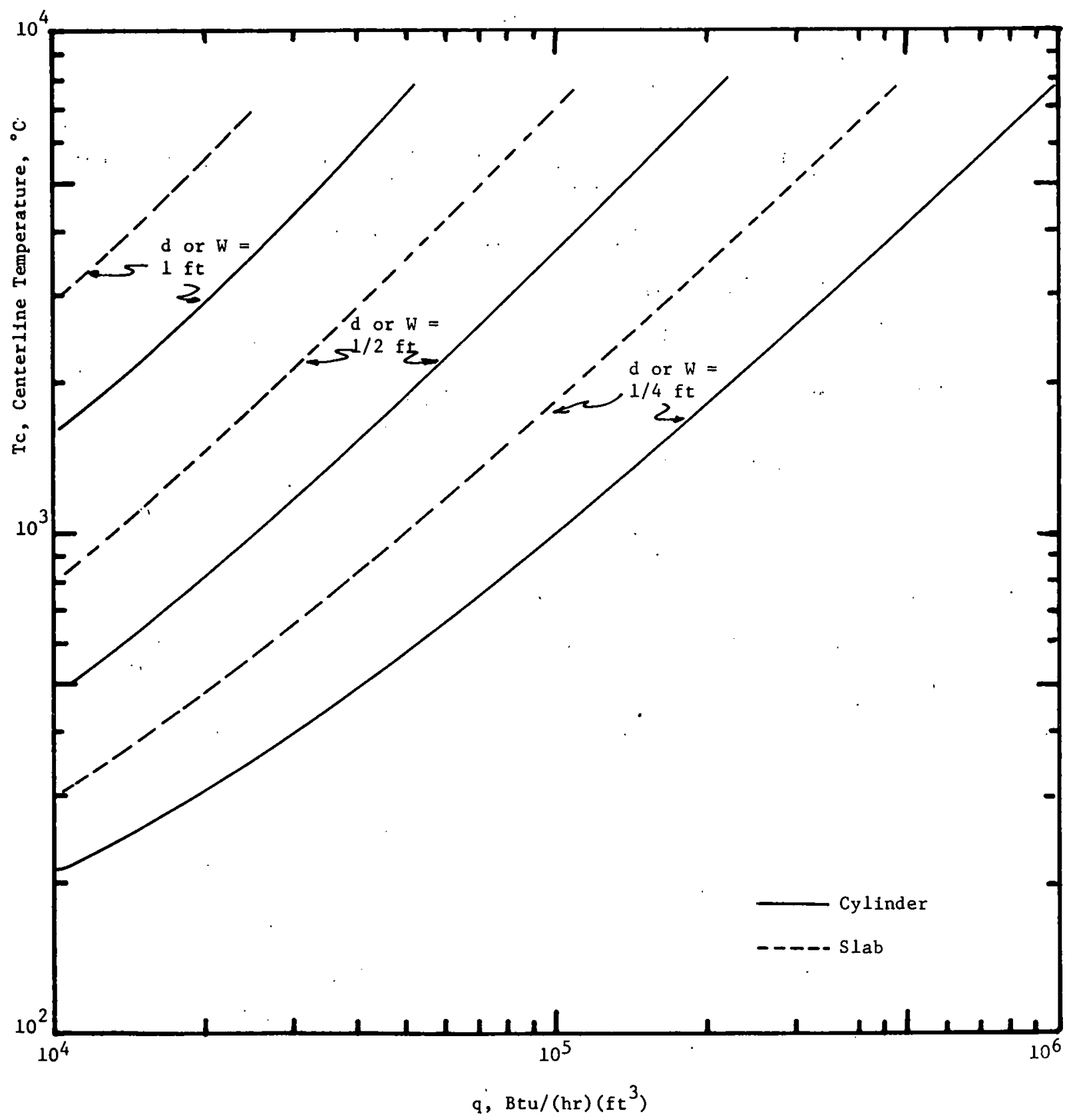

Fig. E.1. Centerline Temperatures for Cylinders and Slabs Filled with Activated Alumina; $\mathrm{q}$ vs $\mathrm{T}_{\mathrm{C}} ; \mathrm{k}=0.25 \mathrm{Btu} /(\mathrm{hr})(\mathrm{ft})\left({ }^{\circ} \mathrm{F}\right) ; \mathrm{T}_{\mathrm{W}}=125^{\circ} \mathrm{C}$ 


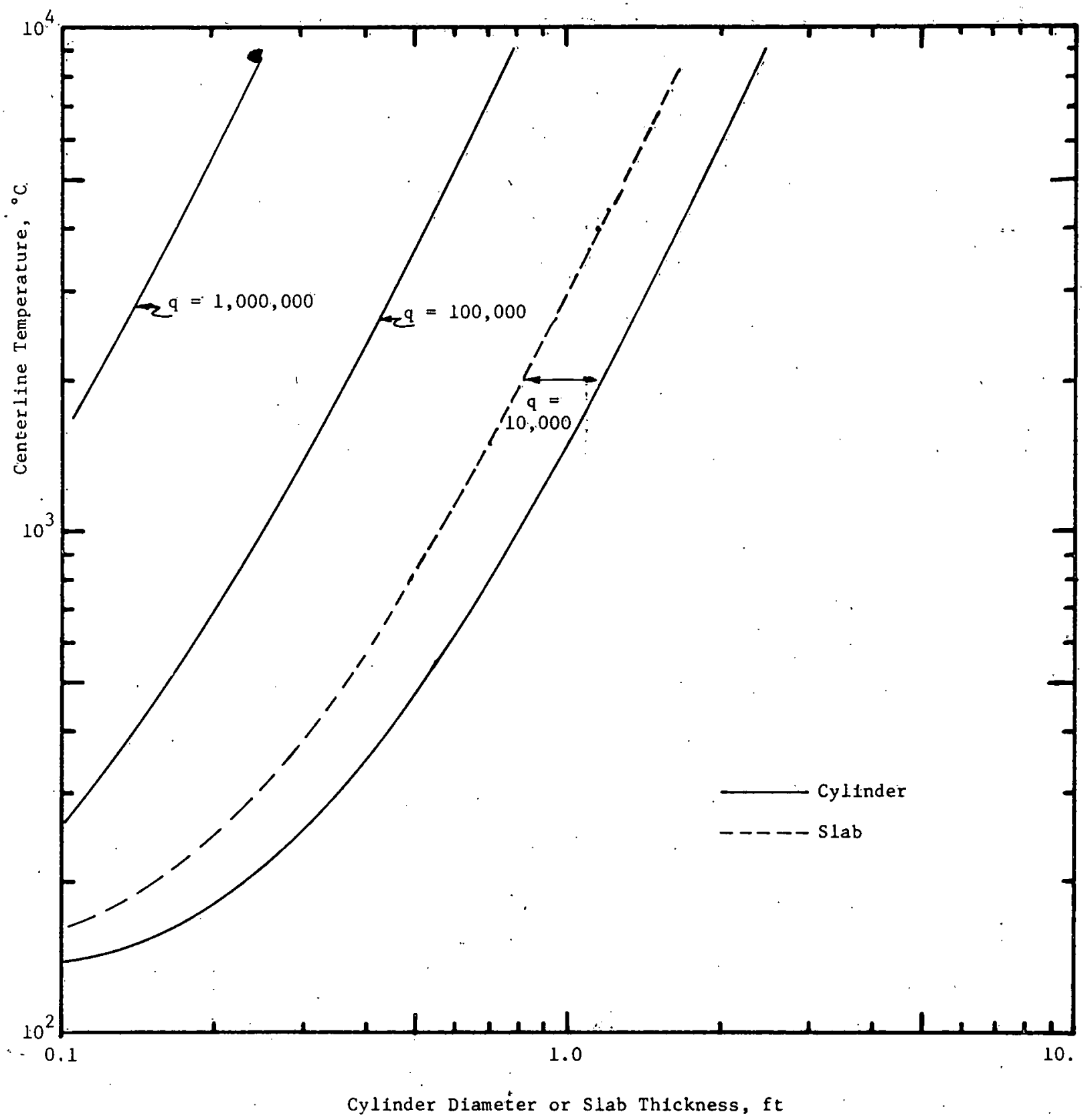

Fig. E.2. Centerline Temperatures for Cylinders and Slabs Filled with Activated Alumina; $d$ or $W$ vs $T_{C} ; k=0.25 \mathrm{Btu} /(\mathrm{hr})(\mathrm{ft})\left({ }^{\circ} \mathrm{F}\right) ; \mathrm{T}_{\mathrm{W}}=125^{\circ} \mathrm{C}$ 


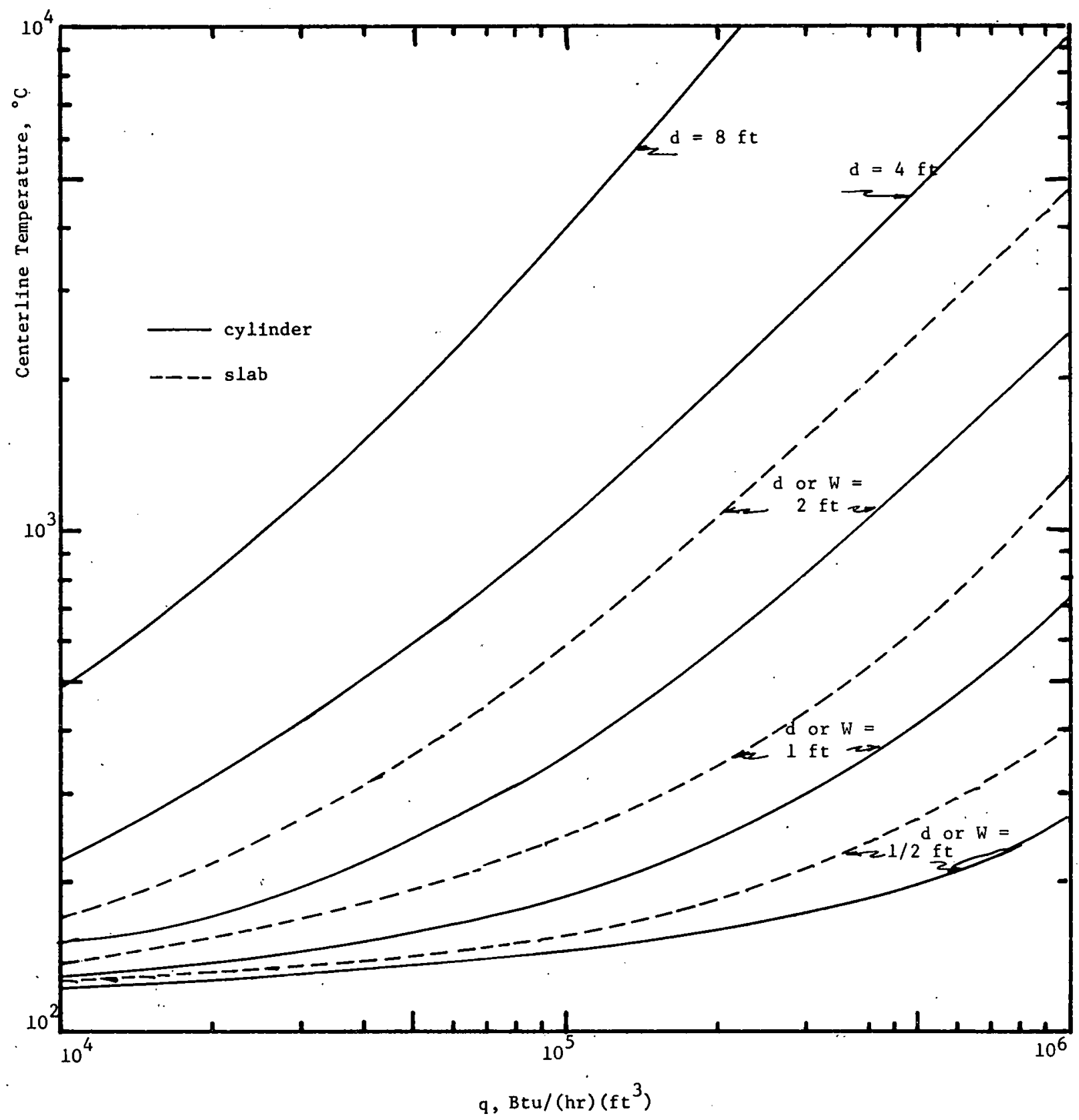

Fig. E.3. Centerline Temperatures for Cylinders and Slabs Filled with $40 \%$ Aluminum $60 \%$ Alumina; $\mathrm{q}$ vs $\mathrm{T}_{\mathrm{C}} ; \mathrm{k}=60 \mathrm{Btu} /(\mathrm{hr})(\mathrm{ft})\left({ }^{\circ} \mathrm{F}\right) ; \mathrm{T}_{\mathrm{W}}=125^{\circ} \mathrm{C}$ 


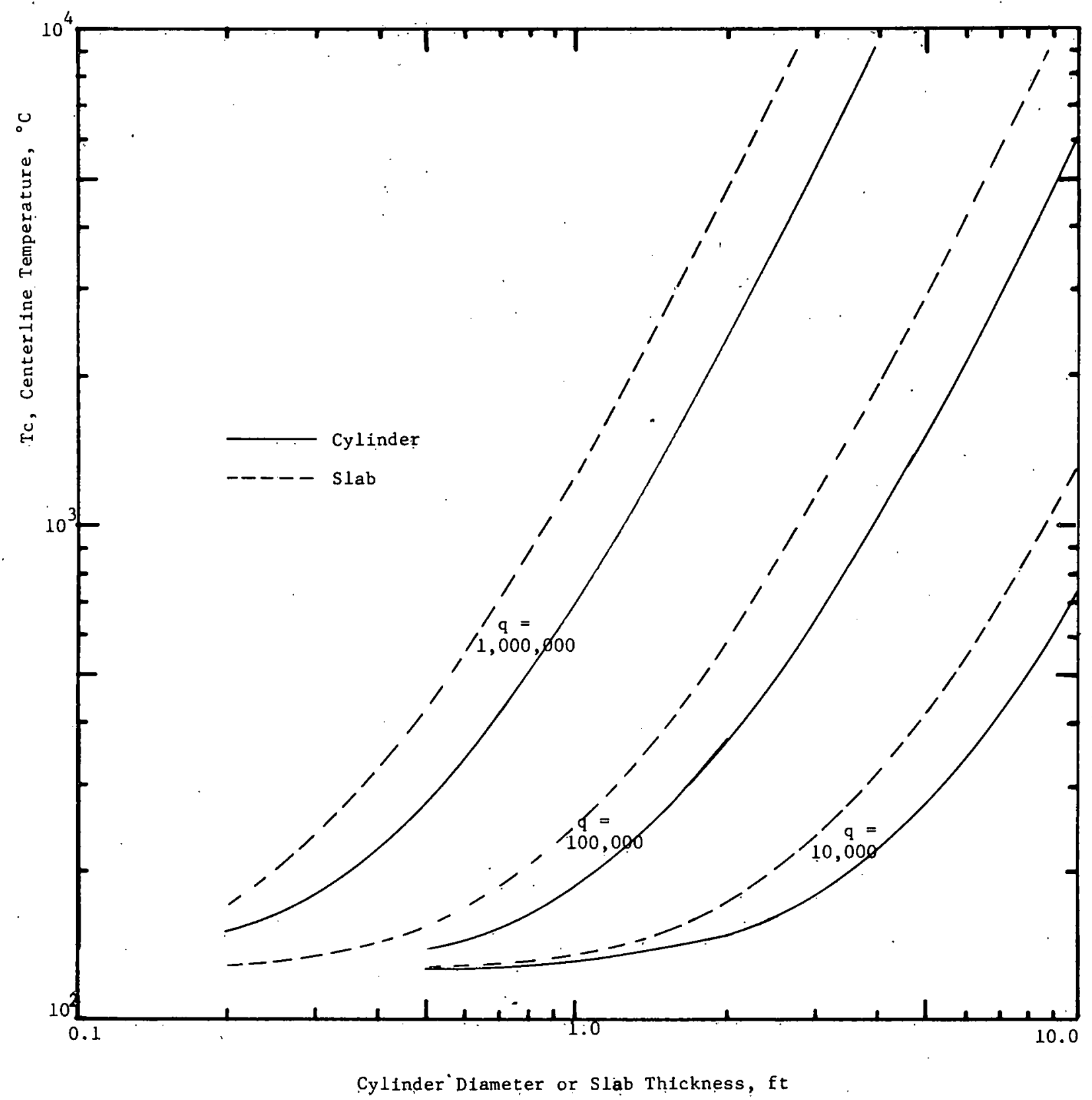

Fig. E.4. Centerline Temperatures for Cylinders and Slabs Filled with $40 \%$ Aluminum$60 \%$ Alumina; $\mathrm{d}$ or $\mathrm{W}$ vs $\mathrm{T}_{\mathrm{C}} ; \mathrm{k}=60 \mathrm{Btu} /(\mathrm{hr})(\mathrm{ft})\left({ }^{\circ} \mathrm{F}\right) ; \mathrm{T}_{\mathrm{W}}=125^{\circ} \mathrm{C}$ 


\section{APPENDIX F}

\section{Cell Design}

This appendix describes the major features of the four shielded-cell designs used in radioactive fuel-processing applications.

\section{Canyon-type Cell}

The canyon-type cell has been used at Hanford. Briefly, it consists of a number of underground cells located.in the floor of a long, narrow room (the canyon), which has a high ceiling. An overhead crane straddles one of the walls in the big. room; the operator's cab is on the side of the wall outside the canyon, thus the wall shields the operator. The cab has additional shielding and is ventilated. Each underground cell has a shielding cover divided into sections which can be handled by the crane (i.e., removed or replaced). No viewing windows are provided; all manipulations are viewed through a large periscope on the crane or with a TV system.

The individual cells are provided with precision-located guide pins and pipe connections for process and service piping. Process vessels, pumps, piping, etc. are prefabricated to narrow tolerances and arranged so that they can be remotely, installed or removed using the overhead crane.

The crane is accessible for direct maintenance when all of the underground cells are covered with the shielding cover. Personnel can enter the canyon dressed in air-breathing suits or with Scott Air Paks.

\section{Rectangular Cell}

The rectangular cell has windows for direct viewing of the process equipment and is fitted with cranes and manipulators for handling, repair, and maintenance. Cranes and manipulators allow greater speed and variety of operations. Precision location of equipment is not required as in the canyon-type cell. Shielding windows, though expensive, permit several operators to function.simultaneously. This.is an advantage when a process operation is not entirely automated and requires human assistance.

Provisions are made for repair and maintenance of cranes and manipulators (for example, by making crane trolleys, manipulator carriages, and bridge drives remotely replaceable). Failed.units are generally moved to a separate repair area where they are decontaminated.

3. Circular or Polygonal Cell

The circular or polygonal cell has windows for direct viewing of the process equipment and is equipped.with cranes and manipulators for 
handling, repair, and maintenance, as in the rectangular cell. It differs from the rectangular cell in being round or many-sided. This design lends. itself to numerous variations. For example, the polygonal cell in the EBR-II Fuel Cycle Facility (FCF) ${ }^{143,144}$ has central posts (one hanging from the ceiling and one supported on the floor), around which crane and manipulator bridges can pivot, covering the entire $360^{\circ}$ circle. The cranes are provided with power through sliprings around the central post. The manipulators (requiring more leads than do the cranes) are powered through cables hanging down through the hollow center post. Alternatively, the manipulators could be powered through cables coming up through the lower central post. In the center of the cell, there is a shielded control and observation room with eight shielding windows. The roof of this central control room supports the lower central post and is a.partly, shielded. low-radiation-level area, where manipulator carriages can be stored when not in use. The outer peripheral wall of the EBR-II FCF cell contains 14 shielding windows and one periscope. The net effect is that equipment and operations can be observed from many different angles, which makes up for lack of depth perception from any one window. For the reference plant, only two manipulators are needed (the EBR-II FCF has six). It might therefore be possible to use sliprings. instead of cables in the reference plant. One central post could be used, which would support the roof of the cell.

Another variation would be to have no central pillar, but instead an overhead crane spanning the entire cell. The crane bridge could be rotated by means of replaceable drive units driving the bridge wheels, or the bridge could be connected by a hollow, vertical shaft (through the center of the roof) to a drive unit located on the roof and accessible for direct maintenance by personnel. The tube would be fastened to the bridge and contain cables for power to the bus bars on the bridge. The crane trolley would travel the entire length of the bridge.

Material and equipment transfer into and out of the cell would be through a transfer lock in the center of the cell floor. One periscope in the ceiling could survey the entire cell.

Another variation would be a shielded center observation chamber, which could rotate and perhaps telescope up and down. Through one shielding window, an operator could survey the entire cell. Additional shielding of individual, highly radioactive equipment might be required.

Yet another variation would be a control room below the central portion of the cell. Periscopes through the floor would enable operators to observe the equipment in the cell and to operate cranes and manipulators. The periscopes could be of an available commercial design, or large mirrors combined with suitable optics could be used for observation. The mirrors inside the cell would be of metal so that they would be radiation-resistant. 
A horizontal shielding window in the cell floor would be needed. Since this window would be protected from direct radiation, it could be relatively thin, e.g., $2 \mathrm{ft}$ thick. This arrangement would result in better light trans mission than would be obtained with shielding windows in the wall of the cell. Large mirrors. would give the operators.a large field of view so that observing the operations would be like looking through a window. The increase in distance to the objects caused by the use of mirrors could be compensated for by suitable optical assistance. Lack of depth perception could be made up for by training two periscopes on the same object. With this design, an operator would always be inacomfortable position for operation of cranes and manipulators. Only a few shielding windows would be required in the outer cell wall, which would have the same thickness around the entire periphery. Radial shielding partitions would be used only for partial shielding of very high radiation level equipment.

The circular design provides a considerable advantage over the rectangular cell design since, if a crane or manipulator is blocked by another crane or manipulator, it can be rotated around a central post and reach.its objective from the other side of the obstruction. The distance an object must be transported.is reduced.in a circular cell, particularly. if there is a central transfer port. If a bridge becomes immobile, it will not block one part of the cell from access by the other bridge.

At Hanford Works many years ago, it was suggested that a circular, remote plant design would be more economical than the rectangular design and apparently would give maximum structural and piping economy and possibly extreme flexibility. ${ }^{182}$

4. Vertical or "Silo"-type Cell.

Equipment that is very tall, such as distillation columns, might be installed in relatively. narrow, tall cells having several levels of shielding windows and with manipulators arranged to travel on vertical bridges mov-. ing along the walls. For the fluoride-volatility plant, this concept could be of interest, since equipment items could be placed one above the other so that the flow of the fuel oxide and alumina-powder would be by gravity from one vessel to another and finally out to waste or storage. Conveyors would not be necessary.

From the operator's viewpoint, such an arrangement might not be attractive, since he would have to move from floor to floor to supervise the equipment. The overhead crane would have a relatively. short travel in such a cell, and this simplify the problem of providing power and control cables or bus baṛs. 


\section{APPENDIX G}

Manipulators and Cranes

The overhead manipulators are of the electromechanical type. Several companies and organizations have been engaged in the fabrication of these machines, but for this study it will suffice to consider three kinds that have been prominent in hot cell facilities.

\section{Argonne-designed General Mills-fabricated Manipulator}

Manipulators ${ }^{143,144}$ in the EBR-II Fuel Cycle Facility have five motions: bridge and carriage travel, telescoping arm, arm rotation, and grip. This type of manipulator has all drive motors located at bridge level and remotely replaceable. No motors or electrical cables.or gearboxes are exposed to radiation. These manipulators are more radiation-resistant than any of the other manipulators available.

This manipulator is unique in many respects. It occupies little space, yet because of the weight of the lead shielding the carriage weighs more than $8000 \mathrm{lb}$ and provides a very stable platform for the telescoping arm. The arm has a downward pushing force of $150 \mathrm{lb}$. It can push 100 . lb horizontally. in any direction and could easily be modified to push with a 500-lb force. Its lifting capacity is $1000 \mathrm{lb}$, which could be readily changed to $2000 \mathrm{lb}$. The tube rotation is good for $100 \mathrm{ft}-1 \mathrm{~b}$ torque at $6 \mathrm{rpm}$. Electrical pickup brushes are replaceable; all drive motors are replaceable just by lifting, with no bolts to loosen or tighten. Without assistance from other devices, the manipulator is capable of picking up an articulated arm and attaching it to the end of the telescoping arm, as well as connecting it electrically to its own power and control system, where provisions already have been made to accommodate the additional functions.

\section{PaR Electromechanical Manipulator}

The PaR electromechanical manipulator is manufactured by

Programmed and Remote Systems Corporation, St. Paul, Minnesota. Several models are available. They have articulated arms, which can be attached at the end of telescoping tubes. All motors are located in the shoulder and the forearm of the manipulators. They are, therefore, more sensitive to radiation than the manipulator described in Section 1 above.

\section{ANL Model E-4 Electric Master-Slave Manipulator}

The ANL Model E-4 electric master-slave manipulator is now available from Central Research Laboratories, Inc. (CRL), Red Wing, Minnesota. This is a versatile machine that can be arranged for $\mathrm{TV}$ operation so that the master arm stays at one spot while the slave roams the cell. It is also 
rugged, compared to mechanical through-the-wall manipulators. Drawbacks are its high cost and complexity, which make it a relatively high-maintenance item. It requires many. leads (over 100. for a pair of arms), which must be carried in flexible, rubber-insulated cables that are quite sensitive to radiation. The expected lifetime is $10^{8} \mathrm{rad}$ accumulated dose, after which the cable insulation breaks. when flexed. When not in use, these manipulators should be kept outside the high-radiation-level cells. The manipulators have telescoping tubes to provide adequate vertical coverage. For good stability, only a few tube sections should be used. For example, one fixed and two telescoping sections, each 10 ft long, would be satisfactory. With an. 18-in. overlap, a travel of $17 \mathrm{ft}$ would be obtained.

The workload should be analyzed to determine whether there is a need for sophisticated and expensive master-slave manipulators, which allow the operator to "feel" the objects handled by the manipulator. An alternative to high efficiency (speed, feel, versatility, etc.). is doing the work with more conventional (and cheaper) electromechanical manipulators. For example, at the ATTILA installation in France, special, relatively, inexpen-: sive, motorized tools (mostly for tightening. bolts) have been constructed to be used by electromechanical manipulators. In other words, in a production plant, where all operations are predictable, very sophisticated manipulators should not be necessary; since special operations can be provided for by the construction of special, but comparatively cheap tools and devices. 


\section{APPENDIX H}

\section{Connectors for Radioactive Plants}

1. New Remote Connectors at Fontenay-aux-Roses, France

Remotely operable connectors for gas service are in use in the ATTILA facility, a fluoride-volatility pilot plant for processing radioactive materials at Fontenay-aux-Roses, France. Also, unique electrical power tools have been designed for making connections. Sketches of some of these devices included in this section are intended primarily to describe the principles involved.

One type of connector (shown in Fig. H.l) for small lines uses a yoke and a jack screw to press the pipe ends together. A motorized tool is used to turn the screw. One of the pipes to be connected is straight, and the other is provided with a short $90^{\circ}$ elbow. The jack screw bears down on the back of this elbow.

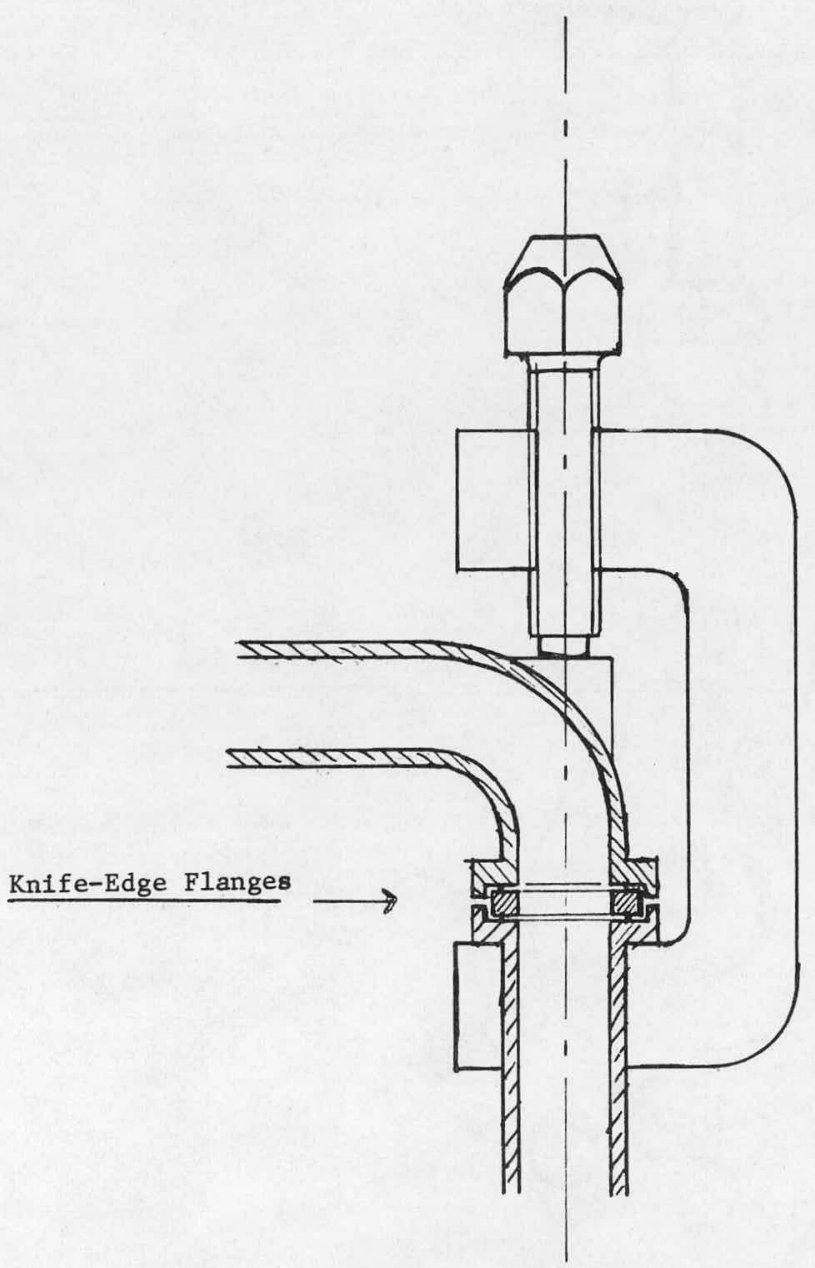

Fig. H.1. Angular Pipe Connector Used at Fontenay -aux-Roses
Another type is referred to as the LeChaton type. This type is like a union with spokes on the part that is free to turn (as shown in Fig. H.2). The spokes have spherical knobs on their free ends, and a motorized tool with a capstan wheel engages the spokes and tightens the "union" (see Fig. H.3). This connector is useful only for pipes up to 1 -in. diameter. Beyond that, the obtainable joint pressure is insufficient to ensure tightness.

The third type is for lines with diameters greater than 1 in. This is a flanged connector with four bolts (as shown in Fig. H.4). Again, a motorized tool is used for tightening the joint (see Fig. H.5). This tool has two motors that drive two sockets mounted on a fork, so that two diametrically opposite bolts can be tightened at the same time. First, two of the bolts are snugged up, then the other two, after which additional tightening is done in several steps to provide equal torque on the bolts. A 


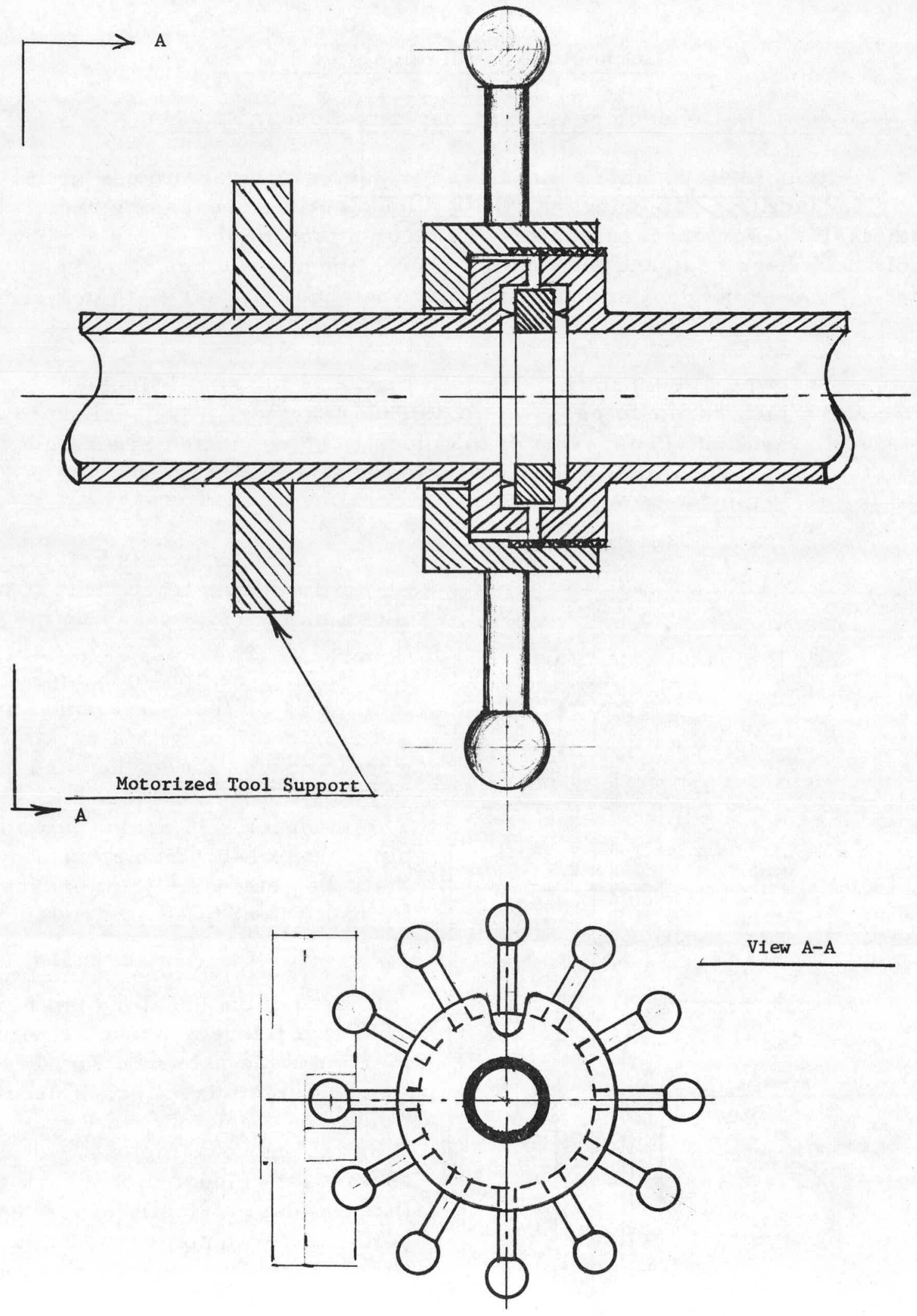

Fig. H.2. "LeChaton" Connector 

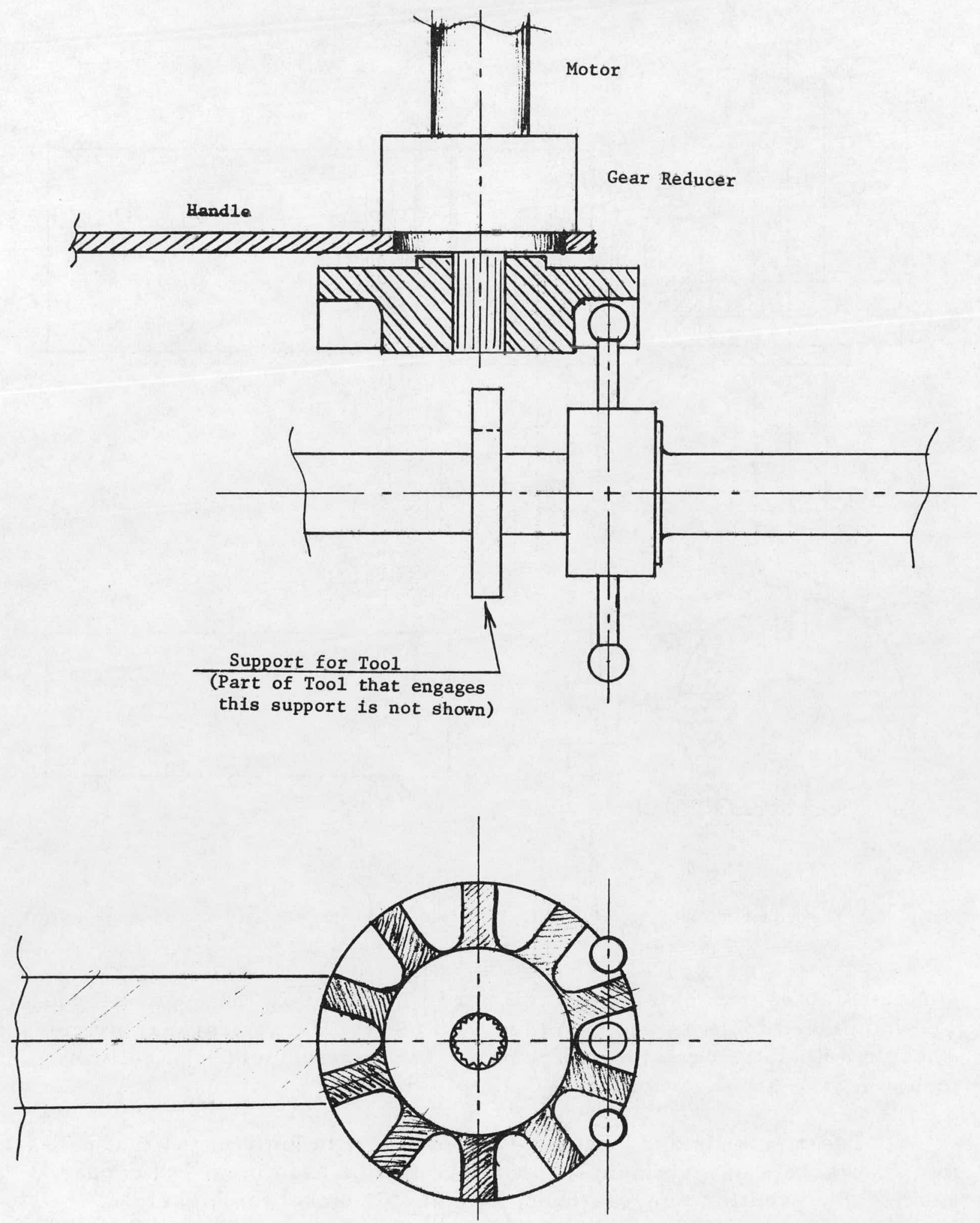

Fig. H.3. Motorized Capstan Drive for LeChaton Connector 


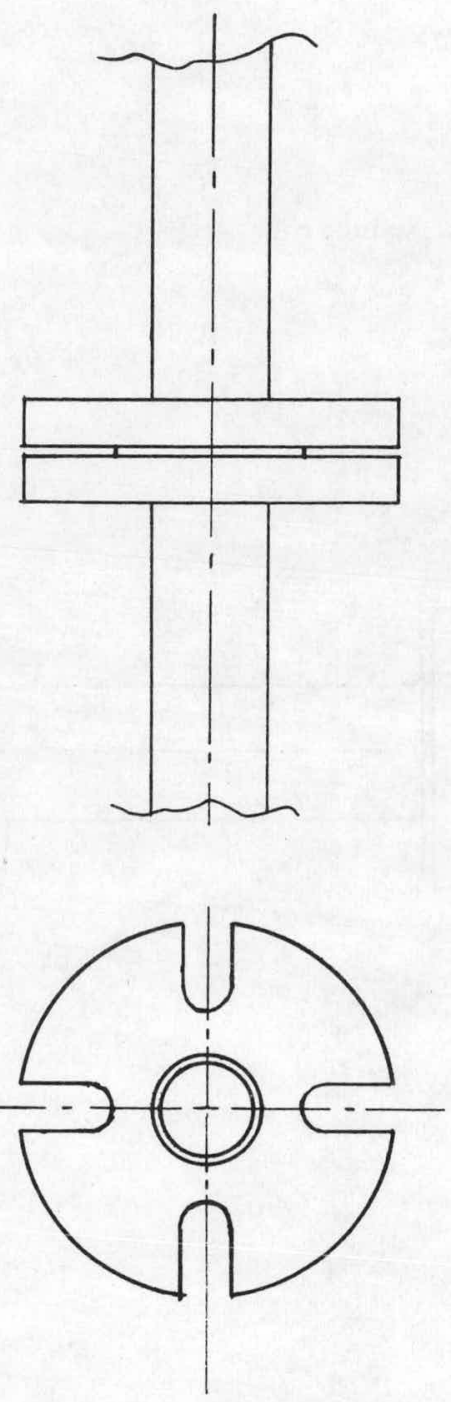

Fig. H.4. Flanged Joint Used at Fontenay-aux-Roses
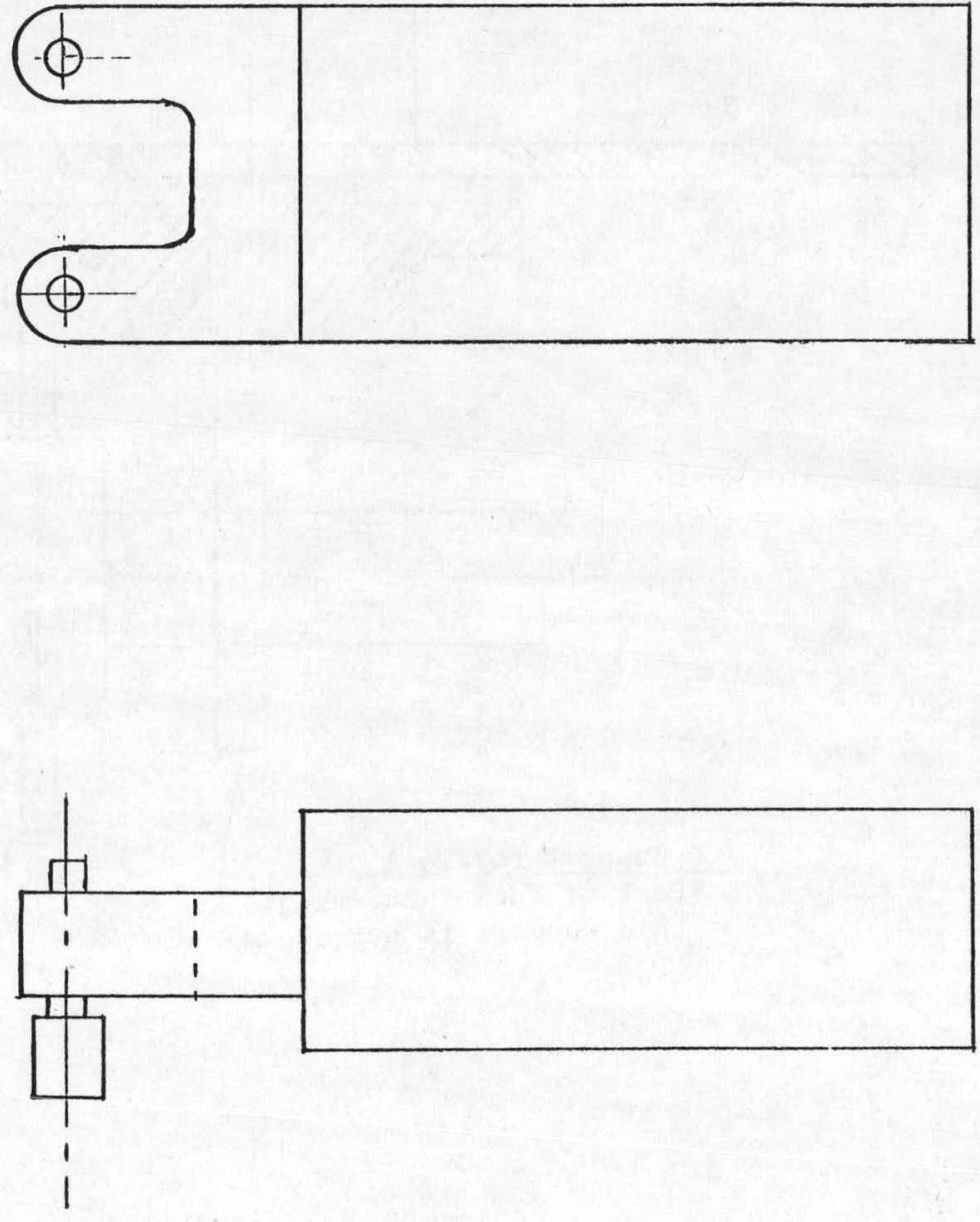

Fig. H.5. Motorized Bolt Torquer Used at Fontenay-aux-Roses

portable control box outside the cell permits control of the applied torque. The motorized tools are manipulated with electromechanical manipulators. These manipulators can move a portable TV camera inside the cell for close viewing of the operations.

The pipe ends and flanges are provided with knife edges that press into flat gaskets of aluminum, copper, or nickel. Aluminum and copper gaskets are used for temperatures up to $250^{\circ} \mathrm{C}$, nickel for higher temperatures.

In CLOVIS,* small-scale equipment can readily be connected and disconnected to test concepts for fluoride-volatility processing. This work

*A test facility at Fontenay-aux-Roses, France. 
is done in walk-in hoods, and all connections have standard flanges with four small bolts, which are directly accessible.

2. Other Connectors and Experience

\section{a. Flanges}

Development of a suitable flange for fluoride-volatility application was the subject of a study at K-25. ${ }^{183}$ Duranickel flanges with two concentric, matching ring projections on each face and a flat nickel gasket were assembled in a 4-in. pipe mockup section and subjected to temperature cycling. The flanges were held together with a temperaturecompensating clamp.* After 12 cycles from 100 to $540^{\circ} \mathrm{C}$, a small leak developed. An Inconel flange and a copper ring-joint gasket, bolted together with carbon-steel bolts and nuts, developed leaks after six cycles between room temperature and $400^{\circ} \mathrm{C} .{ }^{184}$ These results suggest that standard systems could be used under steady temperature conditions. Various other combinations of gaskets and bolting were to be tested, but further work on the program was cancelled due to program changes.

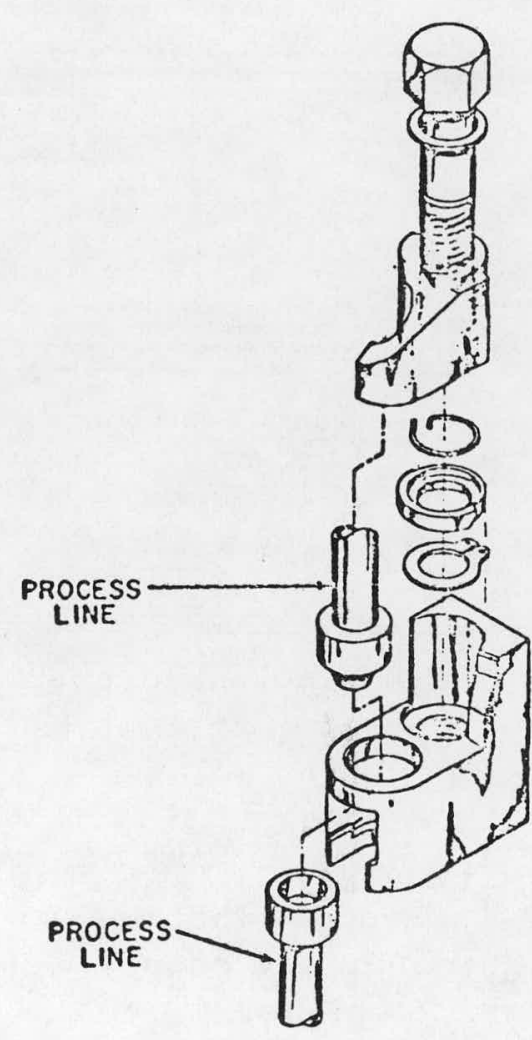

Fig. H.6. TRU Disconnect Clamp and Ferrules 186 b. O-ring Seal

A wide-temperature-range metal O-ring seal is described by Atoji. ${ }^{185}$ This seal uses several sharp concentric ring projections biting into a flat gasket of aluminum confined in a groove. The concentric ring projections on the opposite sides of the gasket are staggered. Because of the sharp rings, the compression required is much less than for a conventional smooth-face seal, so that a screwed union-type seal can be used. This seal remained vacuumtight during repeated thermal cycling between 573 and $4^{\circ} \mathrm{K}$.

\section{c. Other Connectors}

A tapered compression-type connector ${ }^{186}$ is in use at the ORNL TRU facility (see Fig. H.6). Requirements were (1) that assembly be by remote means, (2) that the connector not contain an organic gasket, and (3) that the connector prove reliable under repeated operation. Sizes up to $3 / 4$ in. for tubing and $1 / 2$ in. for pipe are used. Overall, the facility has 3000 of these connectors.

\footnotetext{
* Product of D.S.D. Company, Hamden, Connecticut.
} 
Swagelok* tube fittings are available for tubing up to $1-$ in. OD. They can be reused many times. The Cajon Company** makes Ultra-High vacuum couplings, Type VCR, which have the advantage of not requiring axial clearance for disassembly or assembly. These might be difficult to handle remotely, however.

Conoseals, $†$ a special flange-gasket combination, are made in a wide variety of sizes and materials and may prove suitable for fluoridevolatility applications, but testing is required. Another type offered is the Grayloctt pipe connector, which also appears to be applicable to remote systems.

\footnotetext{
* Product of Crawford Fittings Co., Cleveland, Ohio.

**Cajon Company, Cleveland, Ohio.

† Manufactured by Aeroquip Corporation, Marman Division, Los Angeles, California. †† Gray Tool Co., Houston, Texas.
} 


\section{ACKNOW LEDGEMENTS}

This report represents the combined effort of the staff members of the Chemical Engineering Division. Volatility Section and other ANL experienced personnel, as well as staff members at other AEC laboratories. Assistance is gratefully acknowledged from:

a. R. L. Jarry, E. Rudzitis, L. E. Trevorrow, and J. W. Simmons of ANL-CEN Fluoride Volatility Section.

b. R. Merriman and J. H. Pashley of ORGDP; K-25 Plant.

c. R. Gold and his group from ANL Reactor Physics Division.

d. L. Koppel, consultant to ANL-CEN from Purdue University.

e. O. Heady and others from the DOW Rocky Elats Laboratory. 


\section{REFERENCES}

1. Liquid Metal Fast Breeder Reactor Program Plan, Vol. 8, Fuel Recycle, WASH-1108, p. 8-5.

2. W. C. Ruch et $a Z_{0}$, Production of Pure Uranium Hexafluoride from Ore Concentrates, Chem。Eng。Progr。Symp.Ser.56;.28 (1960).

3. Docket 50-268, Design and Analysis of the Midwest Fuel Recovery Plant.

4. A. A. Jonke, Reprocessing of Nuclear Fuels by Processes Based on Volatilization, Fractional Distillation, and Selective Adsorption, At. Energy Rev。3, 1, IAEA (1965); see also issues of Reactor Fuel Processing and Power Reactor Technology and Reactor Fuel Processing, Quarterly Technical Progress Reviews subsequent to 1965. This periodical is now titled Reactor and Fuel-processing Technology.

5. No Mo Levitz, G. J. Vogel, E. L. Car1s, D. E. Grosvenor, W. A. Murphy, B。 J。 Kullen, and D。J。 Raue, Engineering DeveZopment of Fluid-bed Fluoride Volatility Processes. Part 15. Material Balance Demonstrations, Production Rates, and Fluorine Utilizations in Fluorination of Kilogram Quantities of $\mathrm{PuF}_{4}$ to $\mathrm{PuF}_{6}$ with. Elemental Fluorine in a Fluid-bed Reactor, ANL-7468 (July 1968).

6. R. L. Standifer, A Fluidized-bed Fluoride Volatility Pilot Plant for Plutonium Purification, presented at AIChE Meeting, New Orleans, March 16-20, 1969.

7. Reactor Fue1-Process。 Technol。11(1),68, Ref。1-13 (Winter 1967-68).

8. ANL-1000 MWe LMFBR (Liquid Metal Fast Breeder Reactor), FolZow-on Study Task 1 Report, Vols。 I and II, AI-AEC-12765 (May 1968).

9. Nucl。News 11(7), 41 (July 1968)。.

10. K。A. Varteressian, Argonne National Laboratory, private communication (1968).

11. LMFBR Task Force work on fuel cycle done by Atomics International.

12. S. M. Walas, Reaction Kinetics for Chemical Engineers, p. 82, McGrawHil1, N.Y. (1959)。

13. Centre d'Etude de $1^{8}$ Energie Nucleaire, Reprocessing of Irradiated Fuels, Quarterly Report No. 32, January 1 to March 31, 1968.

14. G. Alfke and G. Gaertner, Solids Mixing in Gas-fluidized Beds with a Continuous Feed of Solids, German Report. BMwF-FBK-66-34 (Nov 1966); see: NSA 21, 17774 (1967)。

15. S。 H. Smiley, D。C. Brater, C。C。Littlefield, and J。H. Pashley, Quantitative Recovery of Uranium Hexafluoride from a Process Gas Stream, Ind Eng。Chem。51(2), 191-196 (1959)。

16. D。I. Dunthorn, The Design of Batch Desublimers, K-L-6220 (Sept 1968).

17. J. A. Patterson; Condensation of Sublimable Material, U.S. Patent $2,583,013$, Jan。22, 1952 (to Standard 0il Development Coo), Chem。. Abstr。46, 3336c (1952)。

18. Wo Ko Lewis, Recovering Vapors of Sublimable Materials, U.S. Patent 2,607,440, Aug. 18, 1952 (to Standard Oil Development Co.), Chem. Abstr. 47, 9c (1953)。 
19. R. M. Young and M. J. Raymond, British Report BR604 (1945).

20. C. B. Beck, T。 D。 Canby, and I. Zonis, Fluidized Condenser, DT-123, Oak Ridge Gaseous Diffusion Plant (1952).

21. J。 C. Bresee and R. P. Larson, A Continuous Cold Trap for Fluoride Volatility Processing of Uronizm, Ind. Eng. Chem。49(9), 1348-54 (1959)。

22. J.E. Strain et al., The Design and Evaluation of a Delayed Neutron Leached-hulZ Monitor, ORNL-4135 (1968).

23. $\mathrm{T}_{0} \mathrm{C}$. Cameron and $\mathrm{H}_{0} \mathrm{M}_{\circ} \mathrm{McCa}$ 11, Jro, Development and Evaluation of Prototype Remote-controlzed Sodium-bonding and Bond-inspection. Processes for EBR-II Fuel Cycle Facility, ANL-6724 (May 1963).

24. R。Gold, Reactor Physics Division, Argonne National Laboratory, private communication (Aug 1968)。

25. B. C. Finney et $a Z_{0}, A$ Conceptual Design and a Cost Estimate of an Onsite Facility for Cleaning, Disassembling, and Canning Short-cooled LMFBR Fuel, ORNL-TM-2050 (May 1968)。

26. J。E。A。 Graae, Argonne National Laboratory, private communication (Dec 1968)。

27. J. J. Katz and E。 Rabinowitch, The Chemistry of Uranium, National Nuclear Energy Series, Div。VIII, Vol. 5, p. 266, Dover Publications, Inc., New York (1951).

28. J。 S。 Boegli and R. G. Deissler, Measured Effective Thermal Conductivity of Uranium Oxide Powder in Various Gases and Gas Mixtures, NACA-RM-E54L10 ( $\mathrm{Lec} 。 10,1954$ ).

29. David Swift, Intern。 J。 Heat Mass Transfer 9, 1069-1074 (1966)。

30. D. E. White, Metallurgy Division, Argonne National Laboratory, unpublished data (1968).

31. C. L。 Bendixsen and G. E. Lohse, Experience with Nonmechanical Solids Flow Control Devices in the Waste Calcining Facility, presented at Symposium on Storage, Flow, and Handling of Solids, Boston, Oct. 20-23, 1968.

32. $\mathrm{M}_{0} \mathrm{M}_{0}$ Hendrickson and $\mathrm{J} 。 \mathrm{~K}_{0}$ Green (Eds.), Research and Development Progroms Executed for the Division of Reactor Deveiopment, Quarterly Progress Report, January-March 1963, HW-78118 (April 1963).

33. J. E. Bodine, J. Guon, and R. J. Sullivan, Second Cycle Airox Reprocessing and Pellet Refabricating of Highly Irradiated Uranium Dioxide, NAASR-11375 (Aug 1965)。

34. L. J. Anastasia, J. D. Gabor, and W. J。 Mecham, Engineering Development of Fluid-bed Fluoride Volatility Processes. Part 3. Fluid-bed Fluorination of Uranium Dioxide Fuel Pellets, ANL-6898 (Aug 1965).

35. I。 E。 Knudsen and N。Mo Levitz, U。S. Patent 3,343,926 (Sept 1967).

36. $K_{0}$ Ono and $W_{0} J_{0}$ McGonnagle, Pulsed Eddy Current Instrument for Measuring Sodium Levels of EBR-II Fuel. Rods, ANL-6278 (July 1961).

37. T. C. Cameron, Argonne National Laboratory, private communication (Aug 1968). 
38. L。 J。 Anastasia, P. G. Alfredson, M。 J。 Steindler, G. W. Redding, J. G. Riha, and M. Haas, Laboratory Investigations in Support of Fluidbed Fluoride Volatility Processes. Part XVI. The Fluorination of $\mathrm{UO}_{2}-$ $\mathrm{PuO}_{2}$-Fission-product Oxide Pellets with Fluorine in a 2-inch-dianeter Fluid-bed Reactor, ANL-7372 (Dec 1967).

39. E。 Carls, Argonne National Laboratory, private communication (June 1968).

40. R. L. Jarry, Argonne National Laboratory, private communication (June 1968)。

41. D. J. Gunn, The Chemical Engineer, P。CE-157 (June 1968).

42. D。R。Richardson, Chem。Eng。68(9), 83-89 (May 1, 1961).

43. J。 D。 Gabor, Argonne National Laboratory, private communication (Sept 1968).

44. J。C.Petrie and D.E。Black, Chem. Eng. Prog。Symp. Ser。62, No. 67, 64 (1966).

45. J. C. Petrie and D. E. Black, Development of Air Distributor Caps for a Fluidized Bed, IDO-14629 (1964)。

46. F. A. Zenz and $N_{0} A_{0}$. Weil, AIChE J 4, 472-479 (1958).

47. J。 M。 Andrews, Ind. Eng。Chem. 52, 85-88 (1960)。

48. A. M. Amitin, I。 G。 Martyushin, and D。A. Gurevich, Dust Entrainment in the Converter Space above a Fluidized Catalyst Bed, see CA 68, 116006q (1968).

49. E. L. Carls and N. M. Levitz, Blowback of Sintered Metal Filters: $A$ Review of Tests and Operating Experience, ANL-7392 (Jan 1968).

50. H. J. Stoever, Applied Heat Transmission, McGraw-Hil1, N.Y., pp. 117 and 129 (1941).

51. M。 Jakob and G。A。 Hawkins, Elements of Heat Transfer, John Wiley and Sons, NoYo, p. 139 (1967).

52. C. O. Bennett and Jo E。 Meyers, Momentum, Heat and Mass Transfer, McGraw-Hill, NoJ。, p. 340 (1962)。

53. H. O. Smith, Argonne National Laboratory, private communication (Aug 1968)。

54. Orv Heady, Dow Rocky Flats Laboratory, private communication (1968).

55. G。E。 Lohse, B。M。 Legler, and B。S。Hales, Tripartite Chemical Engineering Conference, Montreal, Canada (Sept 1968).

56. J。F。Frantz, Chem。Eng。69(19), 175 (Sept。17, 1962).

57. D。H. Templeton et al。, J.Am。Chem. Soc. 85, 242 (1963).

58. M. Jakob, Heat Transfer, Vol。1, John Wiley and Sons, New York, p. 246 (1949).

59. W. H. McAdams, Heat Transmission, McGraw-Hill, New York, p. 49 (1954).

60. M. Rand and 0. Kubaschewski, Thermochemical Properties of $U$ Compounds, Oliver and Boyd (1963); J。 Settle, H. Feder, and Wo Hubbard, JANAF

Thermochemical Tables, J. Phys. Chem。67, 1892 (1963). 
61. F。 L。 Oetting, Chem。Rev.67, 261 (1967)。

62. M. J. Steindler, Laboratory Investigations in Support of Fluid-bed Fluoride Volatility Processes. Part II. The Properties of Plutonizm Hexafluoride, ANL-6753 (Aug 1963)。

63. Lo Anastasia, Argonne National Laboratory, unpublished data (1968).

64. C. F. Weaver, Kinetics of Formation of Xenon Fluorides, UCRL-17169 (1966)。

65. R. C. Vogel, Chemical Engineering Division Semiannual Report, JulyDecember 1964, ANL-6925, pp. 139-141 (May 1965).

66. C. B. Bartlett et alo, Fluidized-Bed Reprocessing of Stainless Steel Clad $\mathrm{UO}_{2}$ Power Reactor Fuels, BNL-968 (Nov 1965).

67. Oak Ridge National Laboratory, Chemical Technology Division Annual Progress Report for Period Ending May 31, 1966, ORNL-3945, p. 48 (Sept 1966).

68. Ro L。 Jarry, A。 V。 Hariharan, J。 Fischer, Mo Jo Steindler, J. J. Stockbar, T。 D。 Baker, $W_{0} H_{0}$ Gunther, and G. W。 Redding, Laboratory Investigations in Support of Fluid-bed Fluoride Volatility Processes. Part IX. The Fluid-bed Fluorination of Plutonium-containing Simulated Oxidic Nuclear. Fuel in a 1-1/2-inch-dicmeter Reactor, ANL-7077 (Dec 1965).

69. A。 A. Chilenskas, Argonne National Laboratory, unpublished data (Nov 1967)。

70. A. A. Chilenskas, Fluidized-Bed Fluoride Volatility Processing of Irradiated $\mathrm{UO}_{2}$ Fuels, Nucl. App1. 5, 11 (1968).

71. R. L. Jarry, Argonne National Laboratory, unpublished data (1968).

72. E. Rudzitis, Argonne National Laboratory, private communication (1968)。

73. L。E. Trevorrow et $a Z_{0}$, Inorg. Chem。6, 1060 (1967).

74. L。E.Trevorrow, M。 J。 Steindler, D。V。 Steid1, and J。T。 Savage, Laboratory Investigations in Support of Fluid-bed Fluoride Volatility Processes. Part XIII. Condensed-phase Equilibria in the System Molybdenum Hexafluoride-Uranium Hexafluoride, ANL-7240 (Aug 1966).

75. J. Jo Reilly et al, Fluidized Bed Reprocessing. of Graphite Matrix Nuclear Fuel, Ind. Eng. Chem。5(1), 51-59 (Jan 1966).

76. R。 P. Wagner, W. A. Shinn, J. Fischer, and M。 Jo Steindler, Laboratory Investigations in Support of Fluid-bed Fluoride Volatility Processes. Part VII. The Decomposition of Gaseous Plutonium Hexafluoride by Alpha Radiation, ANL-7013 (May 1965)。

77. M. Jo Steindler, D。 V. Steidl, and J. Fischer, Laboratory Investigations in Support of Fluid-bed Fluoride Volatility Processes. Part V. The Radiation Chemistry of Plutonium Hexafluoride, ANL-6812 (Dec 1963).

78. M。 Jo Steindler, D。 V. Steidl, and Jo Fischer, The Decomposition of PuF 6 by Gomma Radiation, J. Inorg. Nucl。Chem。26, 1869 (1964)。

79. C。 M. Lederer, J。M。Hollander, and I. Perbman, Table of Isotopes, 6 th Ed., J。Wiley and Sons, New York (1967)。 
80. Jo 0. Blomeke, Nuclear Properties of $U^{235}$ Fission Products, ORNL-1783 (1955)。

81. Mo Kyle, Argonne National Laboratory, unpublished work (Aug 1968)。

82." Jo Io Stevens, An Economic Evaluation of ULtimate Disposal of Liquid Radioactive Wastes by the Fluidized Bed Calcination Process, IDO-14595, p. 10 (Oct。30; 1962)。

83. $R_{\circ}$ H。 Overcashier, D。B。Todd, and R。G。 olney, AIChE J 5, 54-60 (1959)。

84. Jo Do Gabor, Argonne National Laboratory, private communication (Aug 1968)。

85. P.D.Miller and W. E。 Berry, A Survey of Corrosion of the Filuidized Bed Volatility Process, BMI-X-362 (Nov. 5, 1965).

86。 E。Rudzitis, E。H.Van Deventer, and W。 Hubbard, J。Chem。Eng. Data 12, 133 (1967)。

87. A. J. Edwards et al, J。 Chem. Soc。(A) 1968, 2503.

88. A. J. Edwards et al。, Chem. Comm。1967, 462.

89. R。 L. Bradshaw et alo, Evaluation of UZtimate Disposal Methods for Liquid and Solid Radioactive Wastes. VI. Disposal of Solid Wastes in Salt Formations, ORNL-3358 Rev。(March 1969).

90. L。 E。 Trevorrow and $M_{0} J_{0}$ Steindler, Laboratory Investigations in Support of Fluid-bed Fluoride Volatility Processes. Part XV. Estimation of Rates of Thermal Decomposition of Plutonium Hexafluoride in Processs Streoms, ANL-7347 (1967)。

91. R。 Co Vogel, Chemical Engineering Division Semiannual Report, JanuaryJune 1966, ANL-7225, po 106 (Nov 1966).

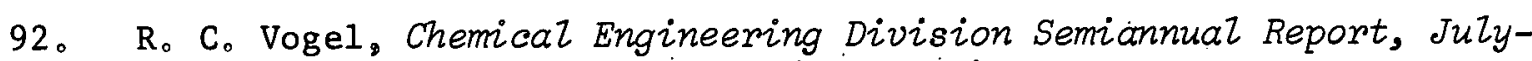
December 1967, ANL-7425, p. 76 (May 1968).

93. L。E. Trevorrow et al, Advan。 Chem。'Series 71, 308 (1967).

94. G. P。 Rutledge, R。 L. Jarry, and Wo Davis, J。 Phys. Chem. 57, 541 (1953).

95. L。E。 Trevorrow, Argonne National Laboratory, unpublished results.

96. R。 $\mathrm{C}$. Vogel, Chemical Engineering Division Research Highlights, May 1966-April 1967, ANL-7350。

97. R. L. Jarry, Argonne National Laboratory, unpublished results (Dec 1966).

97a. M。 Schmeisser and $\mathrm{K}$. Brandle, Advances in Inorganic and Radiochemistry, Volo.5, p。 75, Academic Press, N.Y. (1963)。

98. H. H. Claassen et alo, J. Am。Chem. Soc. 83, 2390 (1961)。

99. $R_{0}$ L。 Jarry, Argonne National Laboratory, unpublished results (Aug 1965)。

100。 N。 M。 Levitz, Argonne National Laboratory, unpublished results (1968)。 
101. M. J. Nichols, PhD Thesis, Durham University (1958)。

102. P. A. G。 O'Hare, The Thermodynomic Properties of Some Chatcogen Fluorides, ANL-7315 (July 1968).

103. P. A. G. O'Hare, private communication, Argonne National Laboratory.

104. S. Katz and G. I. Cathers, Nuc1. Appl。5, 5-10 (July 1968)。

105. L。E. Trevorrow and J. Riha, Argonne National Laboratory, unpublished results (1968)。

106. R. L. Jarry, Argonne National Laboratory, unpublished results. (1968).

107. Paducah Plant Laboratory Progress Report, January-June 1967, KY-L-437, p. 12 (Oct. 10, 1967)。

108. W. R. Page et al., A Continuous Flow Pizot Plant for the Separation of Bromine-Fluorine Compounds and Light End Fission Product Fluorides from $U F_{6}, \mathrm{BNL}-174$ (March 1952)。

109. Wo J. Mecham et al., Decontanination of Irradiated Uranium by a Fluoride Volatility Process, Chem。 Engr. Progr. 53, 2 (Feb 1957).

110. C. S. Robinson and E。 R。 Gilliland, Elements of Fractional Distillation, 4 th Edition, McGraw-Hill Co., Inc。, p. 175 (1950).

111. R。 J。 Hengstebeck, Distillation, pp.93-94, Reinhold Publishing Corp. (1961)。

112. Robinșon and Gilliland, op. cit., p. 130.

113. J. H。 Perry, Chemical Engineers' Hädbook, 3rd Ed。, p. 662, McGraw-Hil1 Co., Inc。(1950).

114. R. O. Ivins, The DistizZation of Uranizon Hexafluoride and Bromine Pentafluoride in a 0.5-inch-dianeter Packed Column, ANL-6362 (1962)。

115. W. R. Golliher, Process for Separation and Recovery of Volatile Fluoride Impurities from Uranium Hexafluoride Containing the Same, U.S. Patent 3,165,376 (Jan。12, 1965).

116. W. R. Golliher et al., Separation of Technetizm-99 from Uranizm Hexafluoride, TID-18290 (1960)。

117. S. Katz and G. I. Cathers, A Gas Sorption-Desorption Method for Separating the Hexafluorides of Neptunium and Uranium, Nucl. Appl. 5, 206210 (Oct 1968).

118. L. E。 Trevorrow, $\dot{T}_{0} \mathrm{~J}$. Gerding, and $\mathrm{M}_{0} \mathrm{~J}$ 。 Steindler, Inorg. Chem。?, 2226 (1968)。

119. A. Chilenskas and L. E. Trevorrow, Argonne National Laboratory, private communication (Sept 1968).

120. S. Lawroski, Chemical Engineering Division Sumary Report, October, November, December, 1958, ANL-5959, p. 22 (March 1959).

121. M。 Jo Steindler, Argonne National Laboratory, private communication (Aug 1968)。

122. L。E. Trevorrow, Argonne National Laboratory, unpublished work (Aug 1968). 
123. H. O. Smith, Argonne National Laboratory, private communication (Oct 1968).

124. T. P. Hignett and M. R. Siegel, Recovery of Fluorine from Stack Gases, Ind. Eng. Chem。 41, 2593 (1949).

125. I. E。 Knudsen, N。 M. Levitz, and A. A. Jonke, Engineering Development of Fluid-bed Fluoride Volatility Processes. Part 6. Preparation of Dense Uranium Dioxide from Uranium Hexafluoride in a Fluidized Bed, ANL-6902 (Dec 1964).

126. I. E。 Knudsen, H. E. Hootman, and NoMo Levitz, A Fluid-bed Process for the Direct Conversion of Uranium Hexafluoride to Uranium Dioxide, ANL-6606 (Feb 1963)。

127. I. E. Knudsen, N. M. Levitz, and S. Lawroski, Preliminary Report on Conversion of Uranium Hexafluoride to Uranium Dioxide in a One-step Fluid-bed Process, ANL-6023 (Aug 1959)。

128. W. Co Robinson, Jro, and $\mathrm{W}_{0} \mathrm{R}_{0}$ Martin, A Feasibility Study of the Conversion of $\mathrm{PuF}_{6}$ to $\mathrm{PuO}_{2}$ by Chemical Vapor Deposition, ORNL-TM-2306 (Aug 1968)。

129. S. H. Smiley and D. C. Brater, Progress in Nuclear Energy, Series III, Process Chemistry, Vol。2, p。177, Pergamon Press, New York (1958)。

130. R. W. Kessie and D. Ramaswami, Removal of Plutonium Hexafluoride from Cel2 Exhaust Air by Hydrolysis and Fiztration, ANL-7066 (Dec 1965).

131. V. N. Prusakov, V。K。Ezhov, O。G。Lebedev, and V. K. Popov, Some Aspects of Nuclear Fuel Processing by Fluorination Method, presented at the $36 \mathrm{th}$ International Congress on Industrial Chemistry, Brussels (Sept. 10-21, 1966).

132. M. J. Stephenson, J。 R。 Merriman, and H。 L。Kaufman, Removal of Impurities from Uranium Hexafluoride by Selective Sorption Techniques, Progress Report for 1966, K-1713 (Ju1y 17, 1967)。

133. J. T. Holmes, L。B.Koppe1, and A。 A。 Jonke, Fluidized-bed Disposal of Fiuorine, Ind。Eng. Chem,, Process, Design Develop.6(4), 408-413 (Oct 1967).

134. D. R. Vissers and M. J. Steindler, Removal of TeF from Gaseous Systems by Solids Reagents, Ind. Eng. Chem。Proc。 Des. Develop. 7(9), 496-502 (Oct 1968).

135. Nuclear Fuels Services, Inc., Spent Fuel Processing Plant--Safety Analysis, AEC Docket. 50-201, Vol。1 (Oct 1962).

136. Wo E. Unger et al,, On-site. Fuel Reprocessing and Recycle Plant-design Study, ORNL-3959 (April 1967).

137. J. Fischer, J. Am. Chem。Soc。79, 6363 (1957)。

138. S。Katz, Inorg. Chem。3, 1598 (1964).

139. R. L. Jarry, Argonne National Laboratory, unpublished work (1968).

140. B. D. Penman and $R_{0} R_{0}$ Hammer, The Ruthenium Dioxide-Oxygen-Ruthenium Tetroxide Equilibrium, IN-1013 (1968)。 
141. S. M. Williamson and CoW. Koch, Nobite Gas Compounds, H. H. Hyman, ed., University of Chịcago Preș, p。158 (1963); S。R。Gunn, ibid., po 149; R: Bo. Smịth, ibido, p. 126 .

142. R. C. Voge1, Chemical Engineering Division Semiannual Report, JanuaryJune 1965, ANL-7055, p。116 (Oct 1965). See also A. A. Chilenskas, Nucl。Appl。5, 11 (1968); R。 J。Flowers et al., The Removal of Bromine and Iodine from Helium Purge of an HTGC Reactor, Part 2, AERE-C/M-354 (Aug 1958); and.W. E。 Browing, Jr。, Nucl。Safety 1(3), 44 (March 1960)。

143. G. J. Bernstein et al., "Design for a Remotely Operated Facility for High Temperature Processing of Spent Reactor Fuel," Proceedings of the Sixth Conference on Hot Laboratories and Equipment, pp. 39-53.(1958).

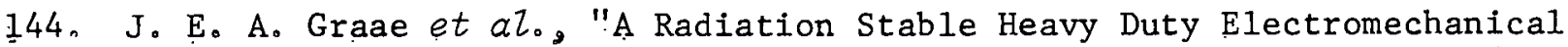
Manipulator," Proceedings of. the Eighth Conference on Hot Laboratories and Equipment, pp. 239-251 (1960).

145. S. M. Stoller and R. B. Richards (Eds.), Reactor Handbook, 2nd Ed., Vol. II, Fuel Reprocessing, Chapter 17, Interscience Publishers, Inc., New York (1961)。

146. Jn R。 Merriman, Oak Ridge Gașeous Diffusion Plant, unpublished data (1968)。

147. M. Levenson, V。 G。 Trice, Jr., and W. J. Mecham, Comparative Cost Study of the Processing of Oxide, Carbide, and Metal Fast-breeder-reactor Fuels by Aqueous, Volatility, and Pyrochemical Methods, ANL-7137 (May 1966)。

148. C.E. Guthrie, Fluidized Bed Volatility-process Design for BrF $F_{5}$ Fluorination and $U F_{6}$ Recovery, ORNL-TM-1206 (July 28, 1965).

149. L. Fouarge, CEN Laboratories, Mol, Belgium, private communication (1968).

150. K. E. Habiger and D. L. Breton, Nuclear Safety Studies for Low Enrichment Fluoride Volatility Fuel Reprocessing Plants, K-1734 (Sept 1968).

151. E. L. Nicholson et al., "Recent Developments in Thorium Fue1 Processing," in Proceedings of Second International Thorium Fuel Cycle Symposium, Gatlinburg, Tennessee (May 3-6, 1966)。

152. AEC Division of Technical Information, Critical Dimensions of Systems Containing ${ }^{235} \mathrm{U},{ }^{239} \mathrm{Pu}$, and ${ }^{233} \mathrm{U}$, TID-7028, p. 38 (June 1964).

153. R. Co Liimatainen and W. J. Mecham, Removal of Halogens, Carbon Dioxide, and Aerosols from Air in a Spray Tower, ANL-5429 (Feb。28, 1955).

154: D。V。 Steid1 and M. J. Steindler, private communication (Jan 1969).

155. G. J. Vogel, E. L. Carls, and W. J。 Mecham, Engineering Development of Fluid-bed Fluoride Volatility Processes. Part 5. Description of a Pilot-scale Facility for Uranium Dioxide-Plutonium Dioxide Processing Studies, ANL-6901 (Dec 1964):

156. W. Ho Farrow, Jro, Radiochemical Separations Plant Study, Part II. Design and Cost Estimates, DP-566 (March 1961)。 
157. W: Ho Gunther and $M_{0}$ J. Steindler, Laboratory Investigations in Support of Fluid-bed Fluoride Volatility Processes. Part XIV. The Corrosion of Nickel and Nickel Alloys by Fluorine, Uranium Hexafluoride, and Selected Volatile Fission Product Fluorides at 500 $\mathrm{C}$, ANL-7241 (Dec 1966).

158. S. H. Smiley et $a Z_{0}$, ORGDP Fuel Reprocessing Studies Summary Progress Report, January-June 1966, K-1691 (Jan。18, 1967).

159. W. A. Shinn and M. J. Sțeindler, Laboratory Investigations in Support of Fluid-bed Fluoride Volatility Processes. Part XVIII. Neutron Counting as an Analytical Method for Plutonium Fluorides, ANL-7402 (Apri1. 1968).

160. A. De Volpi, Argonne National Laboratory, private communication (May 16, 1968)。

161. Wo Seifritz and D. Stegemann, An On-Zine Reactivity Meter Using the Two-detector Cross-correlation Technique for Shutdown Reactivity Measurements, Trans. Am。Nuc1. Soc.10, 283 (1967)。

162. Do P。 Roux and R. C. Kryter, Two-detector Cross-correlation for On-line Shutdown Margin Measurements in Power Reactors, Trans. Am. Nucl. Soc. 10, 284 (1967)。

163. C. E. Cohn, Fast-Reactor Noise Analysis with an On-line Digital Computer, Trans.Am。Nucl. Soc。10, 285 (1967)。

164. Co E. Cohn, "Reactor-noise Studies with an On-1ine Digital Computer," U.S.-Japan Seminar on Reactor Noise Analysis, Paper No. 14 (Sept 1968).

165. Do A. Meneley, L. Co Kvitek, and D. M. O'Shea, MACH 1, A One-dimensional Diffusion-theory Package, ANL-7223 (June 1966)。

166. K. G. Porges, W. Wo Managan, and W. Co Kaiser, Spatially Continuous Neutron Flux Plotting with Spark Chambers, Paper B-15, Second Conference on Neutron Cross Sections and Technology, March 4-7, 1968, Washington, D。C。

167. R. Gold, R。 J。 Armani, and J。 Ho Roberts, Absolute Fission Rate Measurements with Solid State Track Recorders, Nuc1. Sci. Eng. 34 (Oct 1968)。

168. Mo Jo Stephenson, The Corblin Compressor, K-L-2585 (Oct. 25, 1967).

169. M。 Jo Stephenson, L。W. Anderson, and P. S. Cates, Application of the Peripheral Compressor to the Fluoride Volatility Process, K-1751 (1969).

170. $\mathrm{M}_{\circ} \mathrm{H}_{\circ}$ Rand and $\mathrm{O}_{\circ}$ Kubaschewski, The Thermochemical Properties of Uranium Compounds, Oliver and Boyd, London (1963)。

171。 S。 Langer and F. F。 Blankenship, J. Inorg. Nucl. Chem。14, 26 (1960).

172. R. C. Vogel, Chemical Engineering Division Semiannual Report, JanuaryJune 1964, ANL-6900 (Aug 1964)。

173. J。L。Settle, H。M. Feder, and W。 No Hubbard, Jo Phys。Chem。67, 1892 (1963)。

174. A。S。Wolf, J。C。 Posey, and K。E。Rapp, Inorg。Chem. 4, 751. (1965).

175. M。 M。 Popov et $a Z_{0}$, Soviet J. Inorg. Chem。2, 9 (1957)。 Uncorrected for errors $\Delta \mathrm{H}_{\mathrm{f}}^{\circ}$ of. $\mathrm{HF}(\mathrm{aq} \cdot)$. 
176. E. J. Hubert and C. E. Holley, Jr。, Jo Chem。 Eng. Data. 13, 545 (1968).

177. J. Coughlin, Bu11.542, U.S。. Bureau of Mines (1954).

178. G. T. Seaborg and J. J. Katz, Actinide EZements, NNES IV-14A, McGrawHill Co., Inc. (1954)。

179. Plutonium Handbook, O.J.Wick, ed., Gordon and Breach, New York (1967)。

180。 M. H. Rand, Atomic Energy Review 4, Special Issue No. 1 (1966)。

181. R. A. Vent, J。Am。Chem. Soc.90, 5657 (1968)。

182. Proceedings of the Second United Nations Conference on the Peaceful Uses of Atomic Energy, 1958, Vol: 17., p. 528.

183. S. H. Smiley, ORGDP Fuel Reprocessing Studies, Progress Report for Period Ending December 31, 1966, K-L-1780, Part 18 (Feb。10, 1967)。

184. R. G. Nicol, "Engineering and Maintenance Problems in a Fuel Processing. Pilot Plant Using the Volatility Method," Proceedings of 14th Conference on Remote Systems Technology, p. 163 (1966).

185. Masao Atoji, Wide Temperature Range Metal O-ring Seal, Rev. Sci. Inst. 37 (8), 1086-7 (1966).

186. F. L. Peishel et al., "Philosophy of Chemical Processing Equipment Design and Installation in the Transuranium Processing Plant," Proceedings of the 14th Conference on Remote Systems Technology, p. 231 (1966). 
or hydroxides and to be retained on the soda-lime bed. Elemental oxygen, xenon, and krypton as well as ${ }^{3} \mathrm{H}_{2} \mathrm{O}$ are expected to pass through the packed bed unaffected. Tellurium hexafluoride may react partially with soda lime at elevated temperatures, but no significant removal of tellurium from the gas stream is anticipated at this point.

The gas-stream effluent from the soda-lime trap is passed through a bed of activated alumina held at modest temperatures $\left(25-100^{\circ} \mathrm{C}\right)$. According to Vissers and Steindler, ${ }^{134}$ the $\mathrm{TeF}_{6}$ is sorbed efficiently by alumina. Their results must be confirmed under the conditions of the reference process, with moisture present; their system was dry. The anticipated DF of $\sim 10^{4}$ meets the requirements ( 10 CFR 20; see Table 6.12) for discharge of gaseous effluent to the atmosphere.

The treatment of the effluent from the low-temperature activatedalumina trap, which consists of water vapor, oxygen, xenon, and krypton, has been discussed above. Alternative disposal methods for the rare gases include clathrate complex formation for the krypton and storage in solid form and allowing the xenon to be released after a reasonable decay period.

\subsubsection{Solid Wastes from Gaseous Waste Handling System}

Table 4.37 summarizes the sources of solid wastes accumulated in the processing of gaseous wastes, the daily volume of solid wastes, the yearly cylinder requirements, whether or not aluminum is added to lower the centerline temperature, the time that a cylinder must be stored before heat generation drops to $2 \mathrm{~W} /$ liter, and the number of cylinders that must be temporarily stored on site. Those cylinders for which removal of fission-product decay heat is a problem will be stored in a canal. Other fission-product decay heat is a problem will be stored in canal. Other cylinders will be stored in warehouses equipped with instrumentation.

TABLE 4.37. Solid Wastes from Gaseous Waste Handling System

\begin{tabular}{|c|c|c|c|c|c|c|c|}
\hline Source & $\begin{array}{c}\text { Daily Waste } \\
\text { Volume, } \\
\mathrm{ft}^{3}\end{array}$ & $\begin{array}{c}\text { Days of } \\
\text { Operation } \\
\text { between } \\
\text { Cylinder } \\
\text { Changeouts } \\
\end{array}$ & $\begin{array}{c}\text { No. of } \\
\text { cylinders } \\
\text { Required } \\
\text { per Yeara }\end{array}$ & $\begin{array}{c}\text { Aluminum } \\
\text { Added to } \\
\text { Waste }\end{array}$ & $\begin{array}{c}\text { Temporary } \\
\text { Storage } \\
\text { Time, } \\
\text { yr }\end{array}$ & $\begin{array}{c}\text { Maximum } \\
\text { Centerline } \\
\text { Temperature } \\
\text { in Cylinder, } \\
\text { oc } \\
\end{array}$ & $\begin{array}{c}\text { No. of } \\
\text { Cylinders } \\
\text { at Storage } \\
\text { Equilibrium }\end{array}$ \\
\hline \multirow{2}{*}{$\begin{array}{l}\text { Activated alumina } \\
\left(500^{\circ} \mathrm{C}\right) \\
\text { Soda lime } \\
\text { Activated alumina } \\
\left(25-100^{\circ} \mathrm{C}\right) \\
\text { Molecular Sieve } \\
\text { drier }\end{array}$} & $\begin{array}{l}2.52 \\
0.36\end{array}$ & $\begin{array}{l}10.6 \\
74.3\end{array}$ & $\begin{array}{c}34.4 \\
4.91\end{array}$ & $\begin{array}{l}\text { Yes } \\
\text { No }\end{array}$ & $\begin{array}{l}3.6 \\
0.12\end{array}$ & $\begin{array}{l}144 \\
\text { Low }\end{array}$ & $\begin{array}{r}124 \\
1\end{array}$ \\
\hline & $\begin{array}{c}0.78 \\
\text { Uncertain }\end{array}$ & 34.5 & 10.6 & № & 0 & Low & 0 \\
\hline
\end{tabular}

a365-day year. 
ELUORTAATION REACTOR A AND ASSOCIATED EQUUPMEENT

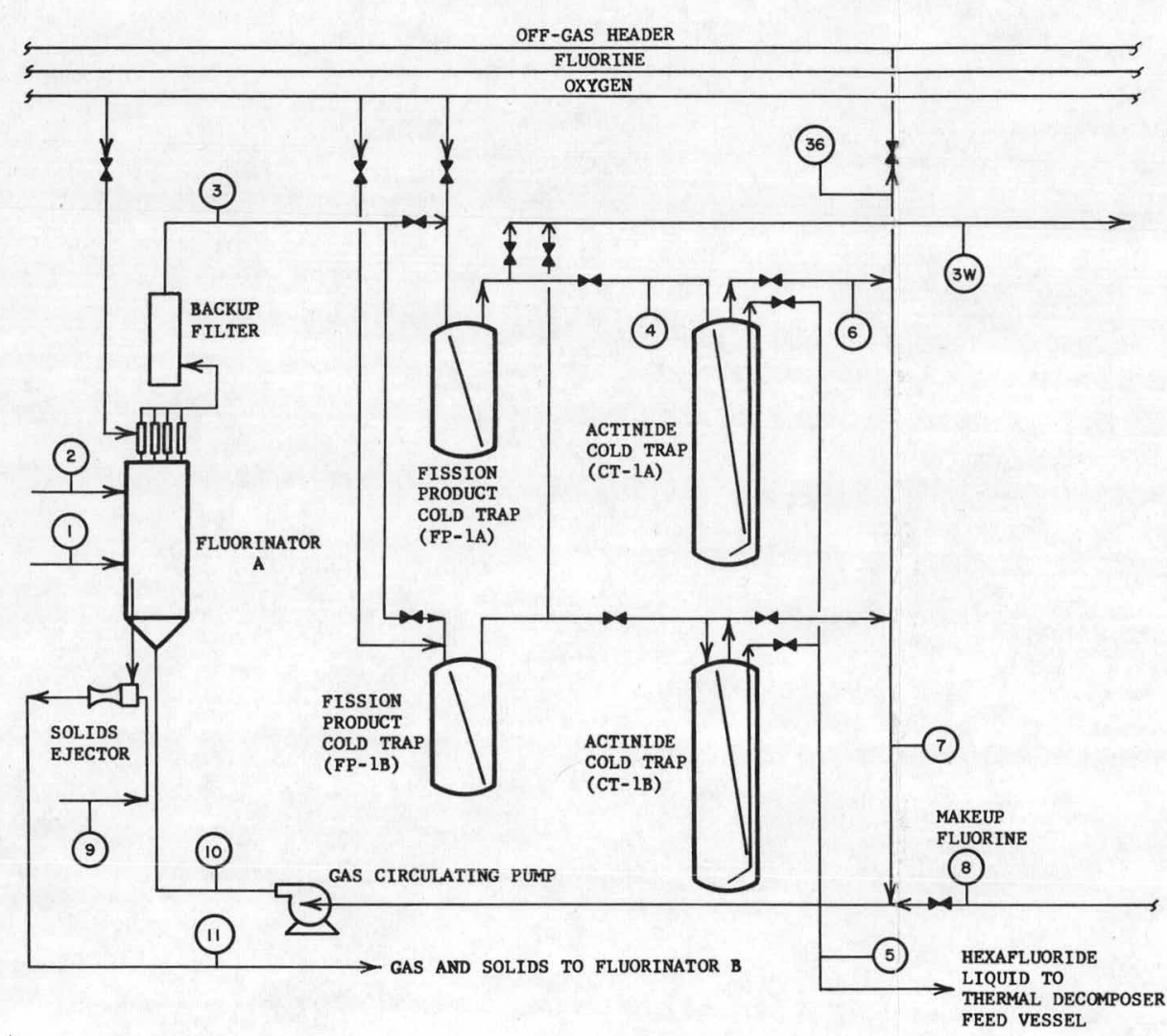

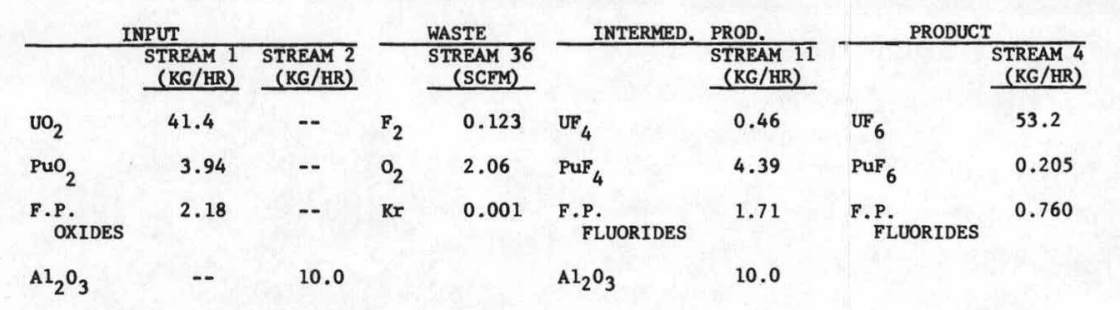

PLUORINATTON REACTOR B AND ASSOCTATED EQUUPYMENT

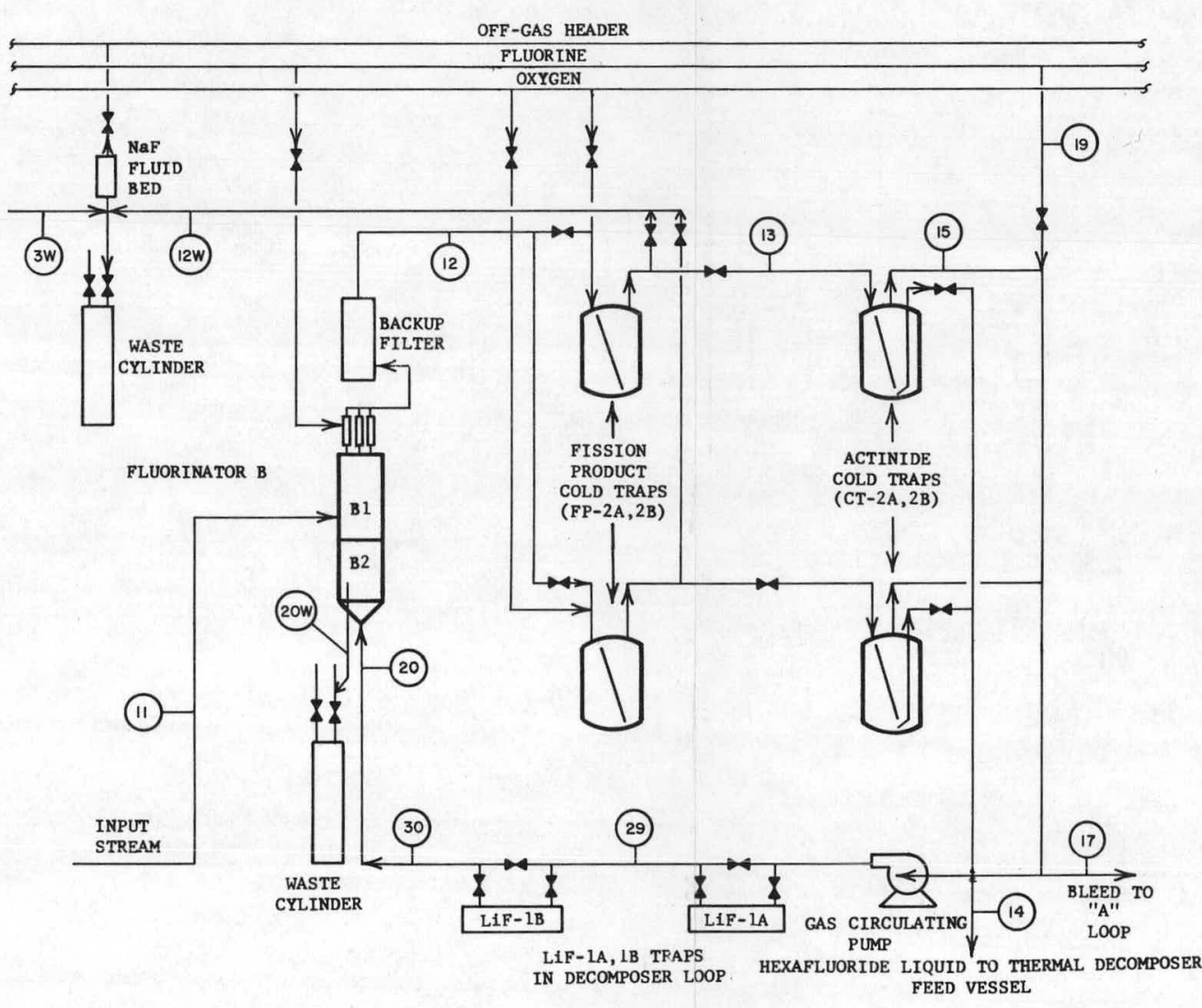

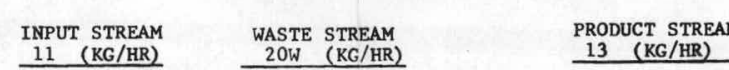

$$
\begin{aligned}
& \begin{array}{lllll}
\text { UF }_{4} & 0.46 & 0.002 & \mathrm{UF}_{6} & 0.53 \\
\text { PuF }_{4} & 4.39 & 0.008 & \text { PuF }_{6} & 4.90 \\
\text { F.P. FUURIDES } & 1.71 & 1.71 & \text { F.P. FLUORDDES } & 0.083
\end{array} \\
& \mathrm{Al}_{2} \mathrm{O}_{3} \quad 10.0
\end{aligned}
$$
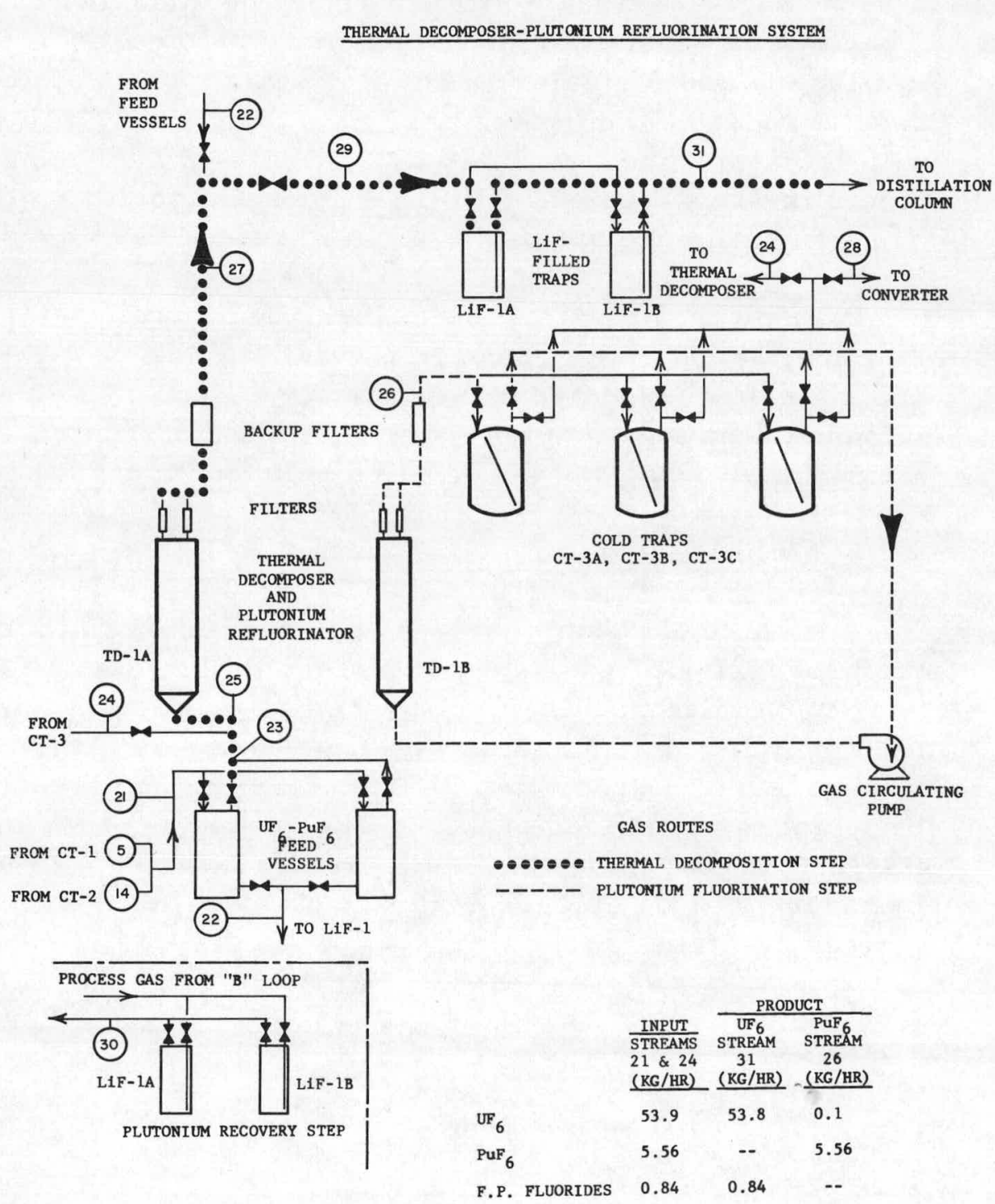
UE ${ }_{6}$ PURIFICATION SYSTEM

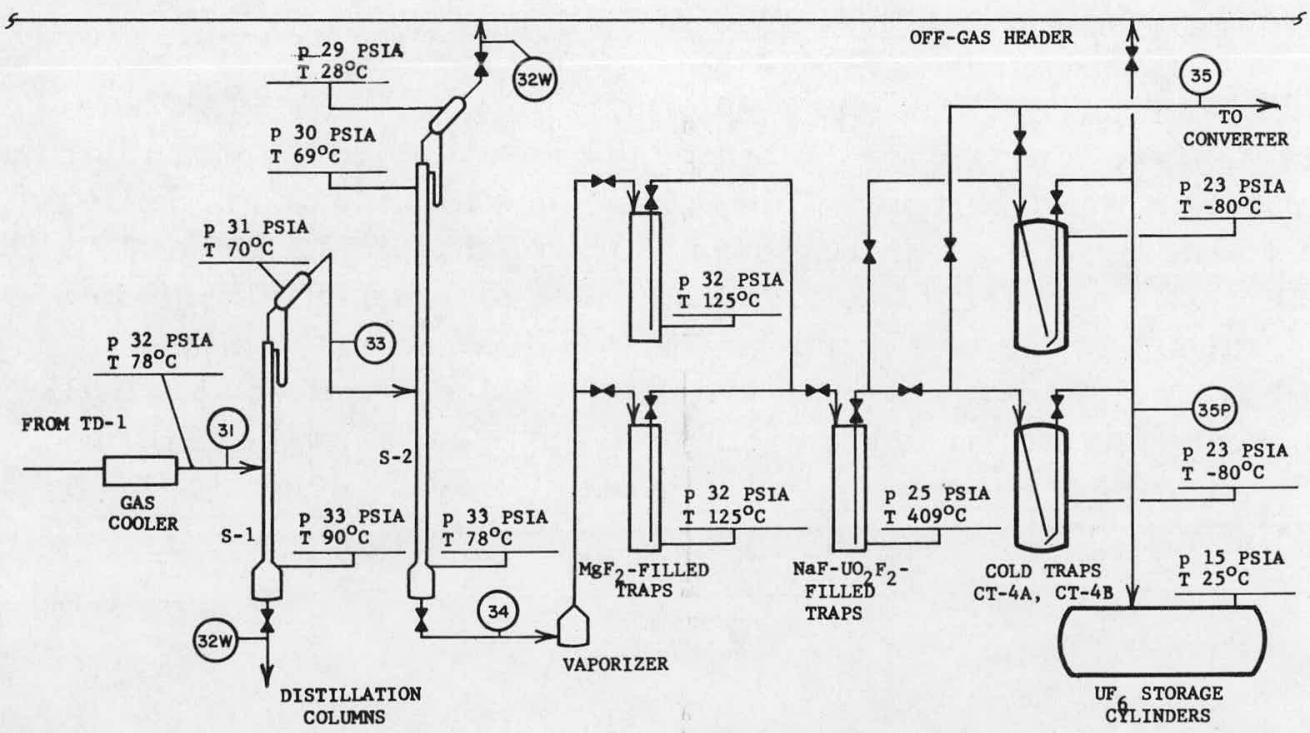

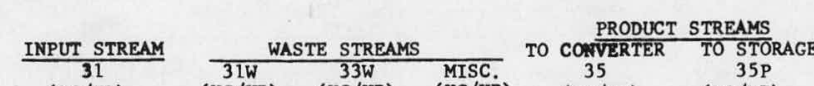

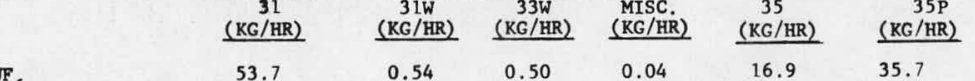

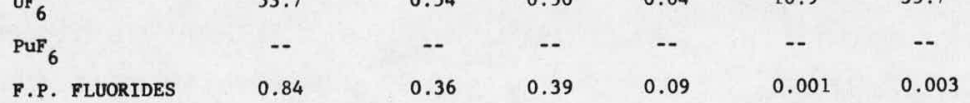

EQUTPMENT POR CONVERSTON OF MIXED HEXAFLUORIDES TO OXIDE PRODUCTS

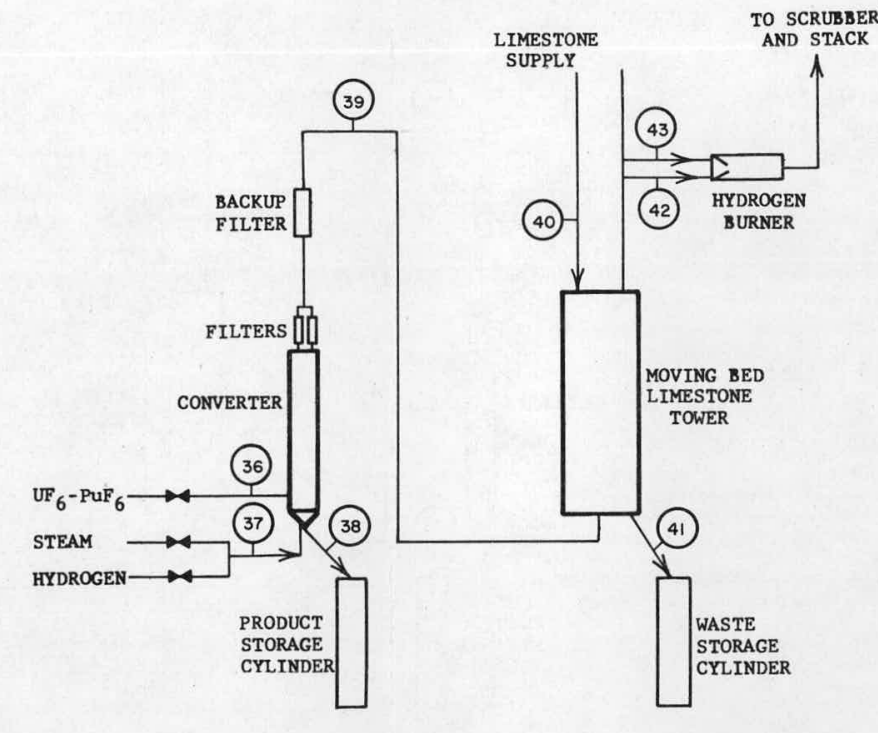

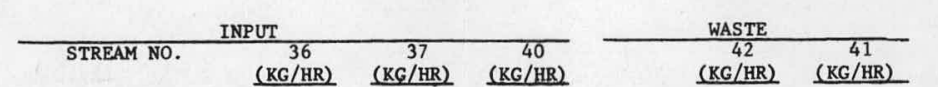

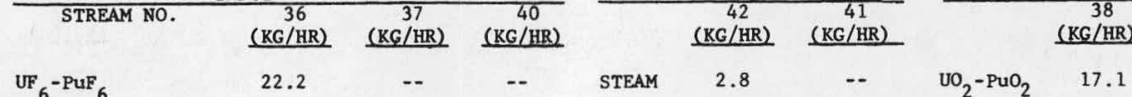

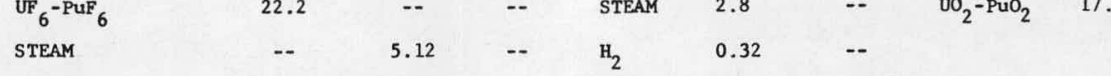

$\mathrm{H}_{2}$
GASBOUS WASTR SYSTRE

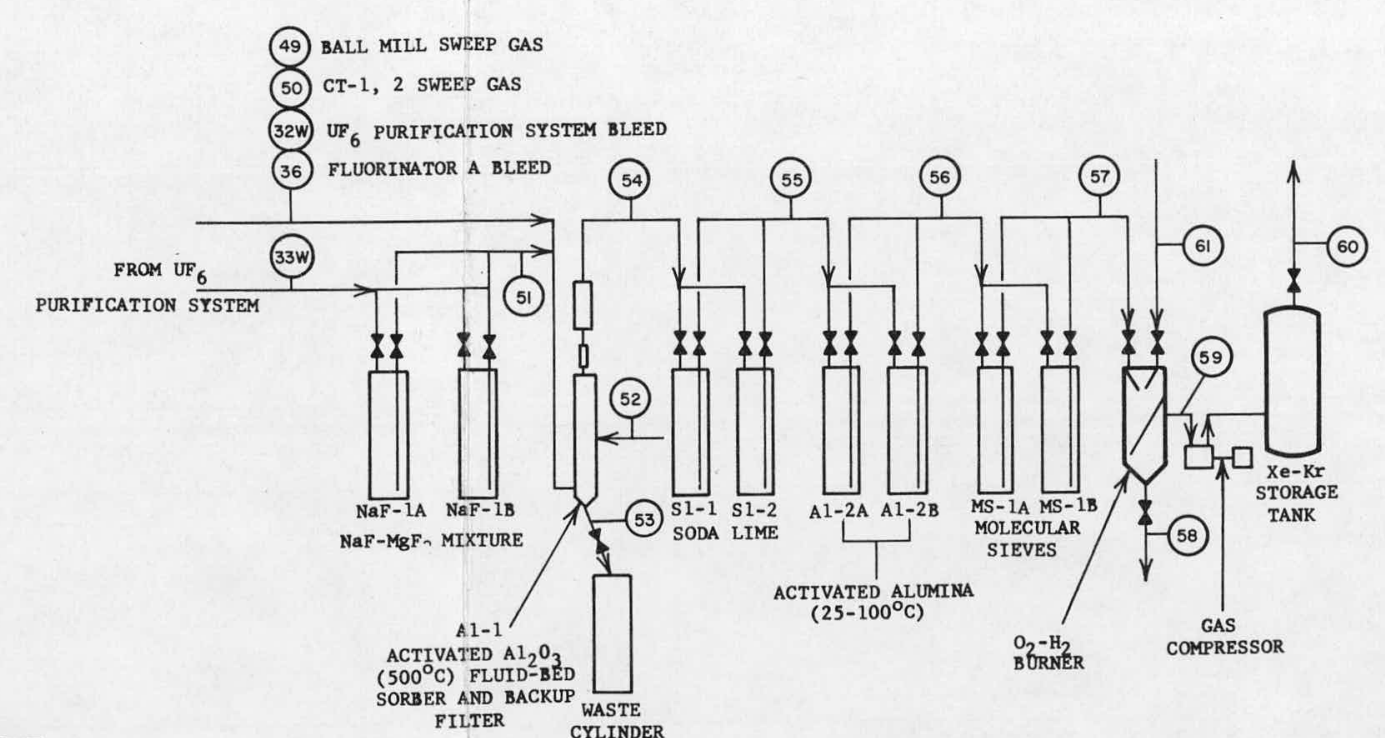

Fig. 4.24. Composite of Figs. 4.15, 4.18, and 4.22 
This section describes the physical layout of the conceptual fluoridevolatility reprocessing plant, with emphasis on cell features. Figures 5.1 and 5.2 show a conceptual layout of the main plant building. The main process cell and auxiliary cells are shown, along with other required facilities on the same floor, such as operation control rooms, laboratories, storage on the she floor, such as opering area is approximately 150 by $260 \mathrm{ft}$. Additional facilities are below grade. The se include a decontamination cell, a hot-shop area, and a storage pool for fuel elements awaiting disassembly and processing.

The head-end and processing equipment must be located in heavily shielded cells designed for alpha containment as well as for $\beta-\gamma$ radiation control. Ventilation must be controlled, with flows moving from the least contaminated to the most contaminated sections of the plant. Exhaust will be through one set of high-efficiency filters, charcoal traps, a sand-bed filter, and a final set of high-efficiency filters. A large recirculating caustic scrubber designed to accommodate the total ventilation flow wil be located upstream of the first set of air filters. The sand-bed filter serves mainly as an emergency backup device. Ventilation air is finally exhausted through a $100-\mathrm{m}$ stack.

\subsection{Cell Design}

Cell area and volume were based on the following criteria:

a. Nominal 4-ft spacing between vessels for crane and manipulator accessibility and to limit interaction (nuclear criticality safety).

b. Relatively wide aisles, for ease of installation of piping and for movement of large equipment items; aisles may also be used for temporary storage of equipment items.

c. Uniform cell height to enable cranes to service the entire length of the cell.

d. Partitions (thick concrete walls) dividing the main process cell into three areas, considered high-, intermediate-, and low-radiation-level areas.

In addition to a main process cell, two other cells are provided: (1) an argon-atmosphere cell for operations relating to fuel handling when sodium is present, and (2) an air-atmosphere cell for the mechanical headend equipment. Intermediate partitions, which further subdivide the main cell into subcells, may be desirable from the standpoint of maintenance 


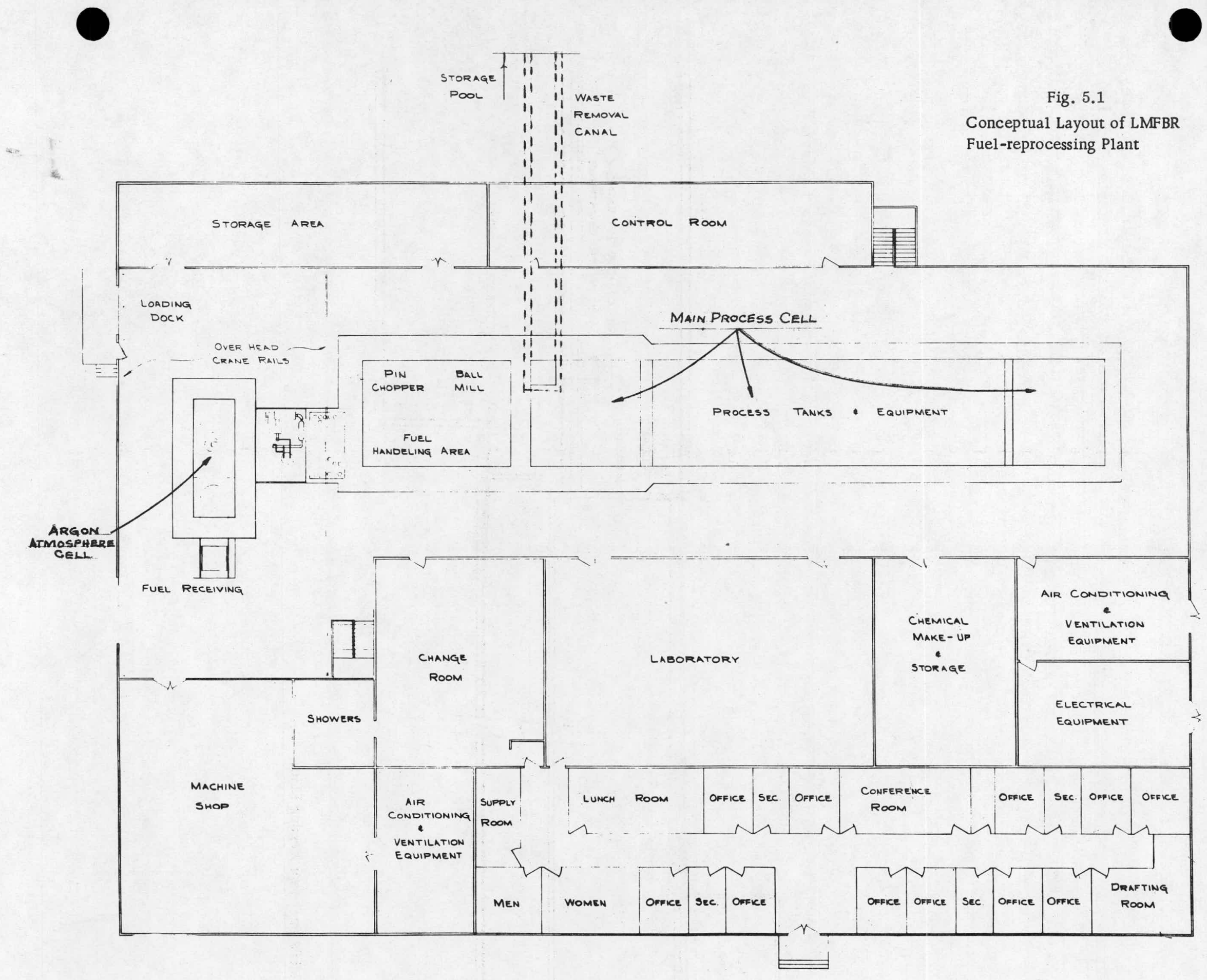




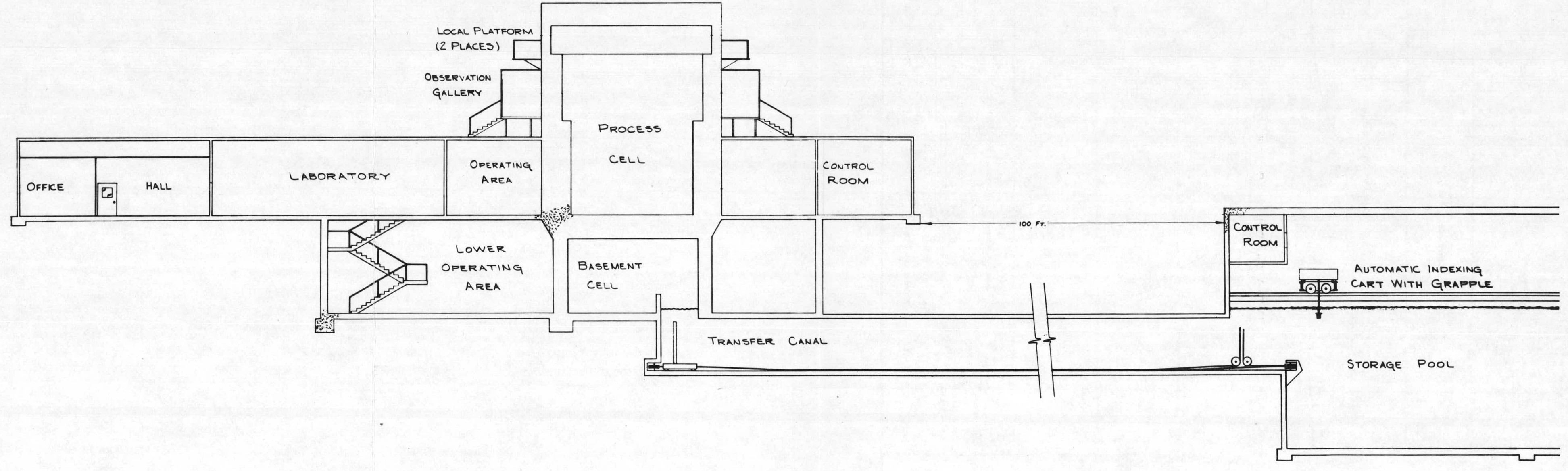

Fig. 5.2. Elevation View of Conceptual LMFBR Fuel-reprocessing Plant 
and accessibility, but cell design has not been analyzed to an extent to permit such delineation. Cell shielding thickness will comply with the regulations regarding personnel exposure.

Of the cell configurations reviewed for the present concept, rectangular cells and circular (or polygonal) cells are more suitable than canyon or silo-type cells. The characteristics of the four types of cells are summarized in Appendix F.

Figure 5.3 shows a rectangular cell with the process equipment mounted in two rows (essentially end to end). (Table 5.1 shows the key to the layout in Fig. 5.3.) The end-to-end configuration should be relatively safe from a criticality standpoint. The inside cell dimensions are $26 \mathrm{ft}$ by about $144 \mathrm{ft}$. Mounting arrangements were not optimized with respect to the space occupied; therefore any dimensions given should be considered tentative.

The adjacent mechanical head-end cell and the argon-atmosphere (fuel-receiving) cell are approximately 26 by $36 \mathrm{ft}$ and 10 by $28 \mathrm{ft}$, respectively. The pool used for underwater storage and for underwater disassembly of the elements is located below these cells.

TABLE 5.1. Key to Equipment Layout of Fig. 5.3

\begin{tabular}{ll}
\hline A, B & Fluorination reactors \\
FP-1, FP-2 & Fission-product cold traps used with reactors A and B, \\
& respectively. (A, B, and C after a numeral--for exam- \\
ple, $1 \mathrm{~A}$ and $1 \mathrm{~B}--$-represent parallel traps at a given \\
station.)
\end{tabular}

CT-1, CT-2, CT-3, CT-4 UF 6 and PuF $_{6}$ cold traps

TD-1

Thermal decomposer-refluorination vessel

(dual purpose)

LiF-1

Lithium fluoride traps

AA-1, AA-2

SL- 1

Activated-alumina traps

DR

Soda-lime traps

$\mathrm{NaF}-1$

S-1, S-2

$\mathrm{MgF}_{2-1}$

Converter

Sorber

Dryer

$\mathrm{NaF}$ trap

Distillation columns

Magnesium fluoride traps

Hexafluoride-to-oxide converter

Hydrogen fluoride disposal

C- 1

Collection and feed vessels

$\mathrm{NaF}-\mathrm{UO}_{2} \mathrm{~F}_{2}$

Sodium fluoride-uranyl fluoride trap

MS - 1

Molecular sieve traps 


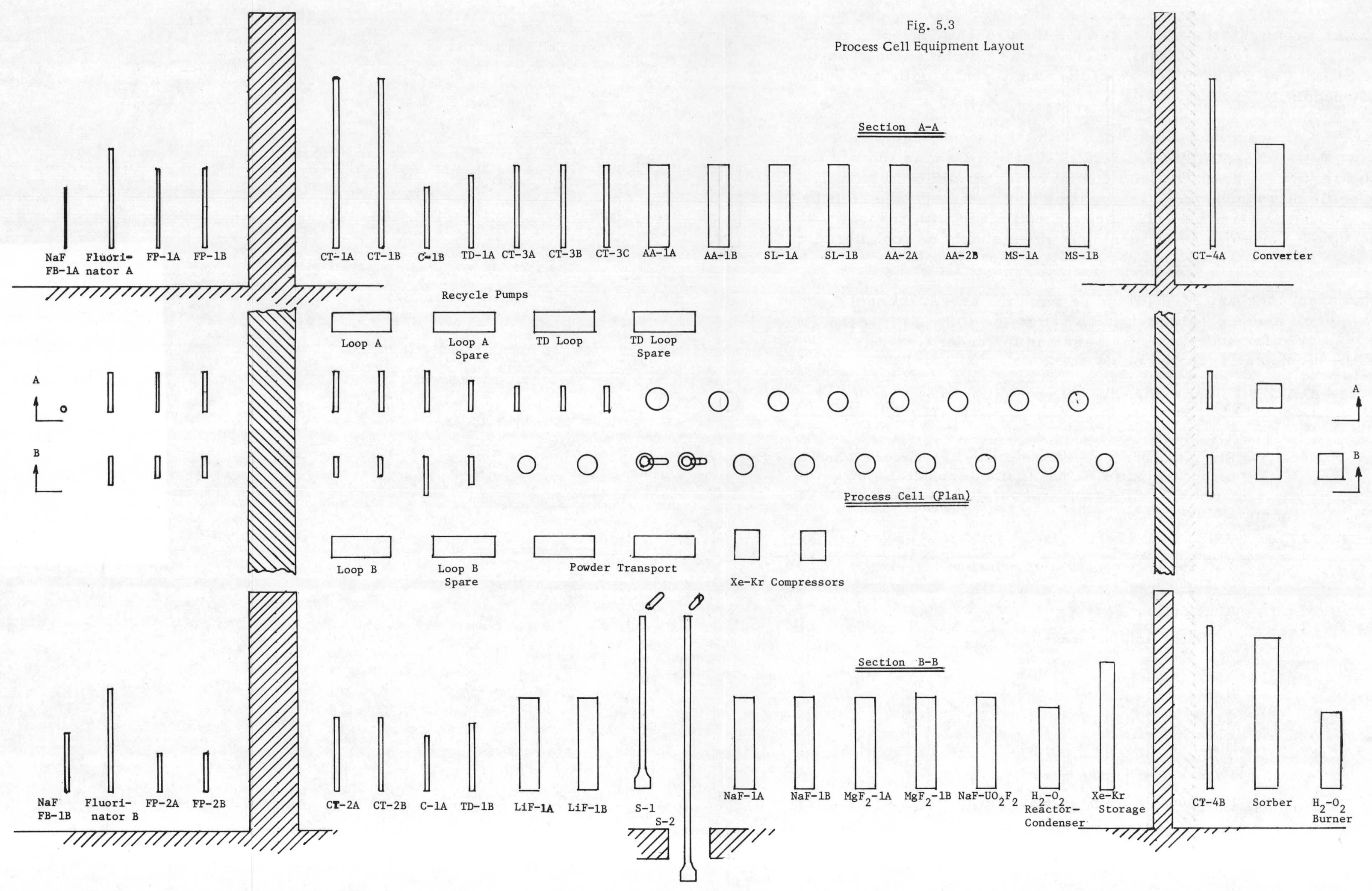




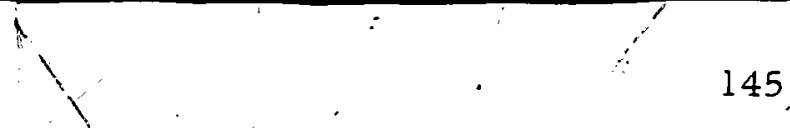

input of $494 \mathrm{~kg}$ is chemically utilized for the removal of HF from the offgas. The limestone is fed to the adsorption unit from a 3-ft-diam hopper equipped with a rotating vane feeder, an adjustable gate valve, and a rotating paddle (see Fig. 4.20). The mass of limestone ccptained.in the adsorption unit is $2200 \mathrm{~kg}$.

Table 4.34 gives the material balance for the feec and waste streams to the hydrogen fluoride adsorption unit. The solids input to the unit consists of $494 \mathrm{~kg} /$ day of oolitic limestone; this input rate is $8 \%$ more than that required to remove $182 \mathrm{~kg} / \mathrm{day}$ of $\mathrm{HF}$ fed to the unit during the cyclic major conversion and cleanup periods of operation in the converter. There is a net gain of $81.7 \mathrm{~kg} /$ day steam in the adsorption unit due to the reaction

$$
\mathrm{CaCO}_{3}(\mathrm{~s})+\mathrm{HF}(\mathrm{g}) \rightarrow \mathrm{CaF}_{2}(\mathrm{~s})+\mathrm{H}_{2} \mathrm{O}(\mathrm{g})+\mathrm{CO}_{2}(\mathrm{~g})
$$

This steam, together with steam not used in the conversion reaction, amounts to $149.9 \mathrm{~kg} / \mathrm{day}$, which is condensed and treated as low-level liquid waste. The volume of liquid waste is $5.3 \mathrm{ft}^{3} /$ day or $40 \mathrm{gal} / \mathrm{day}$. The gaseous lowlevel waste stream consists of $7.7 \mathrm{~kg} / \mathrm{day}$ of hydrogen and $199.9 \mathrm{~kg} / \mathrm{day}$ of $\mathrm{CO}_{2}$. The flowrate for the gaseous effluent will average $5.6 \mathrm{scfm}$ during major conversion periods. The solids waste stream from the adsorption unit consists of $354.6 \mathrm{~kg} /$ day of $\mathrm{CaF}_{2}$ and $39.4 \mathrm{~kg} /$ day of unreacted $\mathrm{CaCO}_{3}$; the storage volume required for this low-level waste is $19.2 \mathrm{ft}^{3} /$ day.

TABLE 4.34. Material Balance for the Hydrogen Fluoride Adsorber

\begin{tabular}{|c|c|c|c|c|c|c|c|}
\hline \multirow[b]{2}{*}{ Constituent } & \multicolumn{2}{|c|}{$\begin{array}{c}\text { Major Conversion } \\
\text { Period, kg/day } \\
\end{array}$} & \multicolumn{2}{|c|}{$\begin{array}{c}\text { Cleanup Period, } \\
\mathrm{kg} / \text { day } \\
\end{array}$} & \multicolumn{2}{|c|}{ Total, kg/day } & \multirow{2}{*}{$\begin{array}{l}\text { Net Gain, } \\
\mathrm{kg} / \text { day }\end{array}$} \\
\hline & Input & Output & Input & Output & Input & Output & \\
\hline $\mathrm{H}_{2} \mathrm{O}$ & 17.3 & 82.7 & 50.9 & 67.2 & 68.2 & 149.9 & 81.7 \\
\hline $\mathrm{H}_{2}$ & 3.0 & 3.0 & 4.7 & 4.7 & 7.7 & 7.7 & 0 \\
\hline $\mathrm{HF} \quad{ }^{\circ}$ & 1.38 .1 & 0 & 43.5 & 0 & 181.6 & 0 & -181.6 \\
\hline $\mathrm{CaCO}_{3}$ & 395.2 & 31.5 & 98.8 & 7.9 & 494.0 & 39.4 & -454.6 \\
\hline $\mathrm{CaF}_{2}$ & 0 & 283.7 & 0 & 70.9 & 0 & 354.6 & 354.6 \\
\hline $\mathrm{CO}_{2}$ & 0 & 159.9 & 0 & $40: 0$ & 0 & 199.9 & 199.9 \\
\hline
\end{tabular}

The instrumentation for the converter and adsorption units includes no instruments of a special nature. Instruments for monitoring temperature, pressure, and reagent flowrates and for analytical applications can be commercial off-the-shelf items.

\subsubsection{Chemistry of Conversion Reactions}

The conversion of mixed hexafluorides of uranium and plutonium to oxide product is predicted upon successful demonstration and development by Knudsen et al., ${ }^{125-127}$ of a fluid-bed process for the conversion of $\mathrm{UF}_{6}$ to $\mathrm{UO}_{2}$. In this process, $\mathrm{UF}_{6}$ is fed with a mixture of steam and hydrogen to a fluidized bed of $\mathrm{UO}_{2}$ product at $650^{\circ} \mathrm{C}$. The initial reaction is very rapid, and a layer of solid oxides and fluorides deposits on the fluid-bed particles according to the reactions 
$3 \mathrm{UF}_{6}(\mathrm{~g})+8 \mathrm{H}_{2} \mathrm{O}(\mathrm{g})+\mathrm{H}_{2}(\mathrm{~g}) \rightarrow \mathrm{U}_{3} \mathrm{O}_{8}(\mathrm{~s})+18 \mathrm{HF}(\mathrm{g}), \Delta \mathrm{H}_{298^{\circ} \mathrm{K}}=-8 \mathrm{kcal} / \mathrm{mole}$

and

$\mathrm{UF}_{6}(\mathrm{~g})+\mathrm{H}_{2}(\mathrm{~g}) \rightarrow \mathrm{UF}_{4}(\mathrm{~s})+2 \mathrm{HF}(\mathrm{g}), \Delta \mathrm{H}_{298^{\circ} \mathrm{K}}=-67.4 \mathrm{kcal} / \mathrm{mole}$.

The fluoride content of the solid product varied ${ }^{125}$ from 0.3 to $1.6 \mathrm{wt} \%$, and the $\mathrm{U}_{3} \mathrm{O}_{8}$ to $\mathrm{UF}_{4}$ ratio was $70 / 30$. Thus reaction of the $U F_{6}$ produces a product that is not completely reduced and contains an undesirably high fluoride content. Therefore, a cleanup-reaction period during which only steam and hydrogen is fed to the reactor is used (1) to further reduce the product, (2) to further densify the product, and (3) to reduce residual fluoride to acceptable levels $(-250 \mathrm{ppm})$ according to the reactions

$$
\mathrm{U}_{3} \mathrm{O}_{8}(\mathrm{~s})+2 \mathrm{H}_{2}(\mathrm{~g}) \rightarrow 3 \mathrm{UO}_{2}(\mathrm{~s})+2 \mathrm{H}_{2} \mathrm{O}(\mathrm{g}), \Delta \mathrm{H}_{298}{ }^{\circ} \mathrm{K}=-41.1 \mathrm{kcal} / \mathrm{mole} ;
$$

and

$$
\mathrm{UF}_{4}(\mathrm{~s})+2 \mathrm{H}_{2} \mathrm{O}(\mathrm{g}) \rightarrow \mathrm{UO}_{2}(\mathrm{~s})+4 \mathrm{HF}(\mathrm{g}), \quad \Delta \mathrm{H}_{298^{\circ} \mathrm{K}}=44.0 \mathrm{kcal} / \mathrm{mole} .
$$

After the cleanup period, part of the fluid bed equivalent to the quantity of hexafluoride fed during the major conversion period is withdrawn as product: The process worked very well if the major conversion period and the cleanup period were of equal length. Actually, the operating cycle is flexible, and even though alternate $1-h r$ periods have been chosen for the operating cycle with $\mathrm{UF}_{6}-\mathrm{PuF}_{6}$, this sequence can be changed, since excellent control over process parameters (which ensures uniformity of product) is possible in the fluid-bed process. Considerable control over product characteristics such as particle size, density, and residual fluoride content can be exercised through control of the operating cycle, temperature, and reactant ratios. Spheroidal, high-quality $\mathrm{UO}_{2}$ particles with densities up to $9.75 \mathrm{~g} / \mathrm{cc}$ ( $89 . \%$ TD) have been produced. ${ }^{125}$ Final densification to over $95 \%$ TD and reduction of fluoride content to 5 ppm were achieved by sintering in hydrogen at about $1600^{\circ} \mathrm{C} .{ }^{125}$

Since the structure and properties of $U F_{6}$ and $P_{u F_{6}}$ are similar, a conversion reaction for mixtures of $U_{6}-P_{4 F_{6}}$ would probably proceed in a manner similar to that for $\mathrm{UF}_{6}$ alone. For example, the reactions may proceed as follows:

$$
\mathrm{PuF}_{6}-\mathrm{UF}_{6}(\mathrm{~g})+4 \mathrm{H}_{2} \mathrm{O}(\mathrm{g})+2 \mathrm{H}_{2}(\mathrm{~g}) \rightarrow \mathrm{PuO}_{2}-\mathrm{UO}_{2}(\mathrm{~s})+12 \mathrm{HF}(\mathrm{g})
$$

and

$$
\mathrm{PuF}_{6}-\mathrm{UF}_{6}(\mathrm{~g})+2 \mathrm{H}_{2}(\mathrm{~g}) \rightarrow \mathrm{PuF}_{4}-\mathrm{UF}_{4}(\mathrm{~s})+4 \mathrm{HF}(\mathrm{g})
$$

$\mathrm{U}_{3} \mathrm{O}_{8}$ may form, yielding the intermediate product $\mathrm{PuO}_{2}-\mathrm{U}_{3} \dot{\mathrm{O}}_{8}$. A cleanup period will be required to further reduce and densify the product 
$3 \mathrm{UF}_{6}(\mathrm{~g})+8 \mathrm{H}_{2} \mathrm{O}(\mathrm{g})+\mathrm{H}_{2}(\mathrm{~g}) \rightarrow \mathrm{T}_{3} \mathrm{O}_{8}(\mathrm{~s})+18 \mathrm{HF}(\mathrm{g}), \Delta \mathrm{H}_{298}{ }^{\circ} \mathrm{K}=-8 \mathrm{kcal} / \mathrm{mole} ;$

and

$U F_{6}(\mathrm{~g})+\mathrm{H}_{2}(\mathrm{~g}) \rightarrow \mathrm{UF} \mathrm{F}_{4}(\mathrm{~s})+2 \mathrm{HF}(\mathrm{g}), \Delta \mathrm{H}_{298^{\circ} \mathrm{K}}=-67.4 \mathrm{kcal} / \mathrm{mole}$.

The fluoride content of the solid product varied ${ }^{125}$ from 0.3 to 1.6 wt $\%$, and the $U_{3} O_{8}$ to $U F_{4}$ ratio was $70 / 30$. Thus reaction of the $U F_{6}$ produces a product that is not completely reduced and contains an undesirably high fluoride content. Therefore, a cleanup-reaction period during which only steam and hydrogen is fed to the reactor is used (1) to further reduce the product, (2) to further densify the product, and (3) to reduce residual fluoride to acceptable levels $(\sim 250 \mathrm{ppm})$ according to the reactions

$$
\mathrm{U}_{3} \mathrm{O}_{8}(\mathrm{~s})+2 \mathrm{H}_{2}(\mathrm{~g}) \rightarrow 3 \mathrm{UO}_{2}(\mathrm{~s})+2 \mathrm{H}_{2} \mathrm{O}(\mathrm{g}), \Delta \mathrm{H}_{298^{\circ} \mathrm{K}}=-41.1 \mathrm{kcal} / \mathrm{mole} ;
$$

and

$$
\mathrm{UF}_{4}(\mathrm{~s})+2 \mathrm{H}_{2} \mathrm{O}(\mathrm{g}) \rightarrow \mathrm{UO}_{2}(\mathrm{~s})+4 \mathrm{HF}(\mathrm{g}), \quad \Delta \mathrm{H}_{298^{\circ} \mathrm{K}}=44.0 \mathrm{kcal} / \mathrm{mole} .
$$

After the cleanup period, part of the fluid bed equivalent to the quantity of hexafluoride fed during the major conversion period is withdrawn as product. The process worked very well if the major conversion period and the cleanup period were of equal length. Actually, the operating cycle is flexible, and even though alternate $1-\mathrm{hr}$ periods have been chosen for the operating cycle with $\mathrm{UF}_{6}-\mathrm{PuF}_{6}$, this sequence can be changed, since excellent control over process parameters (which ensures uniformity of product) is possible in the fluid-bed process. Considerable control over product characteristics such as particle size, density, and residual fluoride content can be exercised through control of the operating cycle, temperature, and reactant ratios. Spheroidal, high-quality $\mathrm{UO}_{2}$ particles with densities up to $9.75 \mathrm{~g} / \mathrm{cc}(89 \% \mathrm{TD})$ have been produced. ${ }^{125}$ Final densification to over $95 \% \mathrm{TD}$ and reduction of fluoride content to 5 ppm were achieved by sintering in hydrogen at about $1600^{\circ} \mathrm{C} .{ }^{125}$

Since the structure and properties of $\mathrm{UF}_{6}$ and $P u F_{6}$ are similar, a conversion reaction for mixtures of $U F_{6}-P_{u F_{6}}$ would probably proceed in a manner similar to that for $\mathrm{UF}_{6}$ alone. For example, the reactions may proceed as follows:

$$
\mathrm{PuF}_{6}-\mathrm{UF}_{6}(\mathrm{~g})+4 \mathrm{H}_{2} \mathrm{O}(\mathrm{g})+2 \mathrm{H}_{2}(\mathrm{~g}) \rightarrow \mathrm{PuO}_{2}-\mathrm{UO}_{2}(\mathrm{~s})+12 \mathrm{HF}(\mathrm{g}),
$$

and

$$
\mathrm{PuF}_{6}-\mathrm{UF}_{6}(\mathrm{~g})+2 \mathrm{H}_{2}(\mathrm{~g}) \rightarrow \mathrm{PuF}_{4}-\mathrm{UF}_{4}(\mathrm{~s})+4 \mathrm{HF}(\mathrm{g})
$$

$\mathrm{U}_{3} \mathrm{O}_{8}$ may form, yielding the intermediate product $\mathrm{PuO}_{2}-\mathrm{U}_{3} \mathrm{O}_{8}$. A cleanup period will be required to further reduce and densify the product 
input of $494 \mathrm{~kg}$ is chemically utilized for the removal of HF from the offgas. The limestone is fed to the adsorption unit from a 3-ft-diam hopper equipped with a rotating vane feeder, an adjustable gate valve, and a rotating paddle (see Fig. 4.20). The mass of limestone ccntained in the adsorption unit is $2200 \mathrm{~kg}$.

Table 4.34 gives the material balance for the feec and waste streams to the hydrogen fluoride adsorption unit. The solids input to the unit consists of $494 \mathrm{~kg} / \mathrm{day}$ of oolitic limestone; this input rate is $8 \%$ more than that required to remove $182 \mathrm{~kg} / \mathrm{day}$ of $\mathrm{HF}$ fed to the unit during the cyclic major conversion and cleanup periods of operation in the converter. There is a net gain of $81.7 \mathrm{~kg} /$ day steam in the adsorption unit due to the reaction

$$
\mathrm{CaCO}_{3}(\mathrm{~s})+\mathrm{HF}(\mathrm{g}) \rightarrow \mathrm{CaF}_{2}(\mathrm{~s})+\mathrm{H}_{2} \mathrm{O}(\mathrm{g})+\mathrm{CO}_{2}(\mathrm{~g})
$$

This steam, together with steam not used in the conversion reaction, amounts to $149.9 \mathrm{~kg} / \mathrm{day}$, which is condensed and treated as low-level liquid waste. The volume of liquid waste is $5.3 \mathrm{ft}^{3} / \mathrm{day}$ or $40 \mathrm{gal} / \mathrm{day}$. The gaseous lowlevel waste stream consists of $7.7 \mathrm{~kg} / \mathrm{day}$ of hydrogen and $199.9 \mathrm{~kg} / \mathrm{day}$ of $\mathrm{CO}_{2}$. The flowrate for the gaseous effluent will average $5.6 \mathrm{scfm}$ during the major conversion periods. The solids waste stream from the adsorption unit consists of $354.6 \mathrm{~kg} /$ day of $\mathrm{CaF}_{2}$ and $39.4 \mathrm{~kg} /$ day of unreacted $\mathrm{CaCO}_{3}$; the storage volume required for this low-level waste is $19.2 \mathrm{ft}^{3} / \mathrm{day}$.

TABLE 4.34. Material Balance for the Hydrogen Fluoride Adsorber

\begin{tabular}{|c|c|c|c|c|c|c|c|}
\hline \multirow[b]{2}{*}{ Constituent } & \multicolumn{2}{|c|}{$\begin{array}{c}\text { Major Conversion } \\
\text { Period, kg/day }\end{array}$} & \multicolumn{2}{|c|}{$\begin{array}{c}\text { Cleanup Period, } \\
\mathrm{kg} / \text { day }\end{array}$} & \multicolumn{2}{|c|}{ Total, $\mathrm{kg} /$ day } & \multirow{2}{*}{$\begin{array}{l}\text { Net Gain, } \\
\text { kg/day }\end{array}$} \\
\hline & Input & Output & Input & Output & Input & Output & \\
\hline $\mathrm{H}_{2} \mathrm{O}$ & 17.3 & 82.7 & 50.9 & 67.2 & 68.2 & 149.9 & 81.7 \\
\hline $\mathrm{H}_{2}$ & 3.0 & 3.0 & 4.7 & 4.7 & 7.7 & 7.7 & 0 \\
\hline $\mathrm{HF}$ - & 138.1 & 0 & 43.5 & 0 & 181.6 & 0 & -181.6 \\
\hline $\mathrm{CaCO}_{3}$ & 395.2 & 31.5 & 98.8 & 7.9 & 494.0 & 39.4 & -454.6 \\
\hline $\mathrm{CaF}_{2}$ & 0 & 283.7 & 0 & 70.9 & 0 & 354.6 & 354.6 \\
\hline $\mathrm{CO}_{2}$ & 0 & 159.9 & 0 & $40: 0$ & 0 & 1.99 .9 & 199.9 \\
\hline
\end{tabular}

The instrumentation for the converter and adsorption units includes no instruments of a special nature. Instruments for monitoring temperature, pressure, and reagent flowrates and for analytical applications can be commercial off-the-shelf items.

\subsubsection{Chemistry of Conversion Reactions}

The conversion of mixed hexafluorides of uranium and plutonium to oxide product is predicted upon successful demonstration and development by Knudsen et al. ${ }^{125-127}$ of a fluid-bed process for the conversion of UF 6 to $\mathrm{UO}_{2}$. In this process, $\mathrm{UF}_{6}$ is fed with a mixture of steam and hydrogen to a fluidized bed of $\mathrm{UO}_{2}$ product at $650^{\circ} \mathrm{C}$. The initial reaction is very rapid, and a layer of solid oxides and fluorides deposits on the fluid-bed particles according to the reactions 
$3 \mathrm{UF}_{6}(\mathrm{~g})+8 \mathrm{H}_{2} \mathrm{O}(\mathrm{g})+\mathrm{H}_{2}(\mathrm{~g}) \rightarrow \mathrm{U}_{3}^{\top} \mathrm{O}_{8}(\mathrm{~s})+18 \mathrm{HF}(\mathrm{g}), \Delta \mathrm{H}_{298^{\circ} \mathrm{K}}=-8 \mathrm{kcal} / \mathrm{mole} ;$

and

$\mathrm{UF}_{6}(\mathrm{~g})+\mathrm{H}_{2}(\mathrm{~g}) \rightarrow \mathrm{UF}_{4}(\mathrm{~s})+2 \mathrm{HF}(\mathrm{g}), \Delta \mathrm{H}_{298^{\circ} \mathrm{K}}=-67.4 \mathrm{kcal} / \mathrm{mole}$.

The fluoride content of the solid product varied ${ }^{125}$ from 0.3 to $1.6 \mathrm{wt} \%$, and the $\mathrm{U}_{3} \mathrm{O}_{8}$ to $\mathrm{UF}_{4}$ ratio was $70 / 30$. Thus reaction of the $\mathrm{UF}_{6}$ produces a product that is not completely reduced and contains an undesirably high fluoride content. Therefore, a cleanup-reaction period during which only steam and hydrogen is fed to the reactor is used (1) to further reduce the product, (2) to further densify the product, and (3) to reduce residual fluoride to acceptable levels $(-250 \mathrm{ppm})$ according to the reactions

$$
\mathrm{U}_{3} \mathrm{O}_{8}(\mathrm{~s})+2 \mathrm{H}_{2}(\mathrm{~g}) \rightarrow 3 \mathrm{UO}_{2}(\mathrm{~s})+2 \mathrm{H}_{2} \mathrm{O}(\mathrm{g}), \Delta \mathrm{H}_{298^{\circ} \mathrm{K}}=-41.1 \mathrm{kcal} / \mathrm{mole} ;
$$

and

$$
\mathrm{UF}_{4}(\mathrm{~s})+2 \mathrm{H}_{2} \mathrm{O}(\mathrm{g}) \rightarrow \mathrm{UO}_{2}(\mathrm{~s})+4 \mathrm{HF}(\mathrm{g}), \quad \Delta \mathrm{H}_{298^{\circ} \mathrm{K}}=44.0 \mathrm{kcal} / \mathrm{mole} .
$$

After the cleanup period, part of the fluid bed equivalent to the quantity of hexafluoride fed during the major conversion period is withdrawn as product. The process worked very well if the major conversion period and the cleanup period were of equal length. Actually, the operating cycle is flexible, and even though alternate $1-\mathrm{hr}$ periods have been chosen for the operating cycle with $U F_{6}-P_{u} F_{6}$, this sequence can be changed, since excellent control over process parameters (which ensures uniformity of product) is possible in the fluid-bed process. Considerable control over product characteristics such as particle size, density, and residual fluoride content can be exercised through control of the operating cycle, temperature, and reactant ratios. Spheroidal, high-quality $\mathrm{UO}_{2}$ particles with densities up to $9.75 \mathrm{~g} / \mathrm{cc}(89 \% \mathrm{TD})$ have been produced. ${ }^{125}$ Final densification to over $95 \%$ TD and reduction of fluoride content to 5 ppm were achieved by sintering in hydrogen at about $1600^{\circ} \mathrm{C} .{ }^{125}$

Since the structure and properties of $\mathrm{UF}_{6}$ and $\mathrm{PuF}_{6}$ are similar, a conversion reaction for mixtures of $U F_{6}-P_{u F}$ would probably proceed in $a$ manner similar to that for $\mathrm{UF}_{6}$ alone. For example, the reactions may proceed as follows:

$$
\mathrm{PuF}_{6}-\mathrm{UF}_{6}(\mathrm{~g})+4 \mathrm{H}_{2} \mathrm{O}(\mathrm{g})+2 \mathrm{H}_{2}(\mathrm{~g}) \rightarrow \mathrm{PuO}_{2}-\mathrm{UO}_{2}(\mathrm{~s})+12 \mathrm{HF}(\mathrm{g})
$$

and

$$
\mathrm{PuF}_{6}-\mathrm{UF}_{6}(\mathrm{~g})+2 \mathrm{H}_{2}(\mathrm{~g}) \rightarrow \mathrm{PuF}_{4}-\mathrm{UF}_{4}(\mathrm{~s})+4 \mathrm{HF}(\mathrm{g})
$$

$\mathrm{U}_{3} \mathrm{O}_{8}$ may form, yielding the intermediate product $\mathrm{PuO}_{2}-\mathrm{U}_{3} \mathrm{O}_{8}$. A cleanup period will be required to further reduce and densify the product 
input of $494 \mathrm{~kg}$ is chemically utilized for the removal of HF from the offgas. The limestone is fed to the adsorption unit from a 3-ft-diam hopper equipped with a rotating vane feeder, an adjustable gate valve, and a rotating paddle (see Fig. 4.20). The mass of limestone ccntained in the adsorption unit is $2200 \mathrm{~kg}$.

Table 4.34 gives the material balance for the feec and waste streams to the hydrogen fluoride adsorption unit. The solids input to the unit consists of $494 \mathrm{~kg} /$ day of oolitic limestone; this input rate is $8 \%$ more than that required to remove $182 \mathrm{~kg} /$ day of $H F$ fed to the unit during the cyclic major conversion and cleanup periods of operation in the converter. There is a net gain of $81.7 \mathrm{~kg} /$ day steam in the adsorption unit due to the reaction

$$
\mathrm{CaCO}_{3}(\mathrm{~s})+\mathrm{HF}(\mathrm{g}) \rightarrow \mathrm{CaF}_{2}(\mathrm{~s})+\mathrm{H}_{2} \mathrm{O}(\mathrm{g})+\mathrm{CO}_{2}(\mathrm{~g})
$$

This steam, together with steam not used in the conversion reaction, amounts to $149.9 \mathrm{~kg} / \mathrm{day}$, which is condensed and treated as low-level liquid waste. The volume of liquid waste is $5.3 \mathrm{ft}^{3} /$ day or $40 \mathrm{gal} / \mathrm{day}$. The gaseous lowlevel waste stream consists of $7.7 \mathrm{~kg} /$ day of hydrogen and $199.9 \mathrm{~kg} / \mathrm{day}$ of. $\mathrm{CO}_{2}$. The flowrate for the gaseous effluent will average $5.6 \mathrm{scfm}$ durin $\sigma^{\prime}$ the major conversion periods. The solids waste stream from the adsorption unit consists of $354.6 \mathrm{~kg} /$ day of $\mathrm{CaF}_{2}$ and $39.4 \mathrm{~kg} /$ day of unreacted $\mathrm{CaCO}_{3}$; the storage volume required for this low-level waste is $19.2 \mathrm{ft}^{3} / \mathrm{day}$.

TABLE 4.34. Material Balance for the Hydrogen Fluoride Adsorber

\begin{tabular}{|c|c|c|c|c|c|c|c|}
\hline \multirow[b]{2}{*}{ Constituent } & \multicolumn{2}{|c|}{$\begin{array}{c}\text { Major Conversion } \\
\text { Period, kg/day } \\
\end{array}$} & \multicolumn{2}{|c|}{$\begin{array}{c}\text { Cleanup Period, } \\
\mathrm{kg} / \text { day }\end{array}$} & \multicolumn{2}{|c|}{ Total, kg/day } & \multirow{2}{*}{$\begin{array}{l}\text { Net Gain, } \\
\text { kg/day }\end{array}$} \\
\hline & Input & Output & Input & Output & Input & Output & \\
\hline $\mathrm{H}_{2} \mathrm{O}$ & 17.3 & 82.7 & 50.9 & 67.2 & 68.2 & 149.9 & 81.7 \\
\hline $\mathrm{H}_{2}$ & 3.0 & 3.0 & 4.7 & 4.7 & 7.7 & 7.7 & 0 \\
\hline $\mathrm{HF}$ - & 138.1 & 0 & 43.5 & 0 & 181.6 & 0 & -181.6 \\
\hline $\mathrm{CaCO}_{3}$ & 395.2 & 31.5 & 98.8 & 7.9 & 494.0 & 39.4 & -454.6 \\
\hline $\mathrm{CaF}_{2}$ & 0 & 283.7 & 0 & 70.9 & 0 & 354.6 & 354.6 \\
\hline $\mathrm{CO}_{2}$ & 0 & 159.9 & 0 & $40: 0$ & 0 & 1.99 .9 & 199.9 \\
\hline
\end{tabular}

The instrumentation for the converter and adsorption units includes no instruments of a special nature. Instruments for monitoring temperature, pressure, and reagent flowrates and for analytical applications can be commercial off-the-shelf items.

\subsubsection{Chemistry of Conversion Reactions}

The conversion of mixed hexafluorides of uranium and plutonium to oxide product is predicted upon successful demonstration and development by Knudsen et al. ${ }^{125-127}$ of a fluid-bed process for the conversion of $U F_{6}$ to $\mathrm{UO}_{2}$. In this process, $\mathrm{UF}_{6}$ is fed with a mixture of steam and hydrogen to a fluidized bed of $\mathrm{UO}_{2}$ product at $650^{\circ} \mathrm{C}$. The initial reaction is very rapid, and a layer of solid oxides and fluorides deposits on the fluid-bed particles according to the reactions 